\title{
Katalog der Fundorte
}

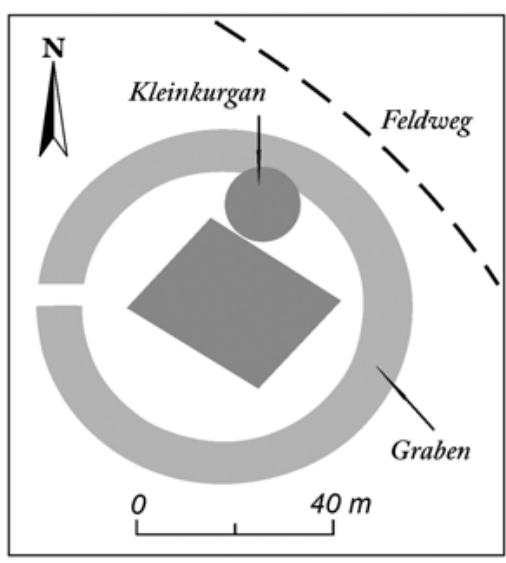

Abb. 106 | Skizze des Kurgans 5 km südwestlichvom Dorf Žalauly

Kurgan - 5 km südwestlich vom Dorf Žalauly [FEZ] (Abb. Io6; Karte 3 Nr. 61): ALT I858 m N43 02.982 E79 04.217; Gebiet Almaty (kasach. Алматы облысы), Rajymbekskij rajon (kasach. Райымбек ауданы).

Der Großkurgan befindet sich an der nordwestlichen Kante des Hochplateaus Kegen (kasach. Кеген), an der Südseite des Bergrückens Kuluktau (kasach. Қулықтау). Der Grabhügel wurde auf einer Riedelkante erbaut, die sich auf dem rechten, nordwestlichen Ufer des Flusses Kegen (kasach. Кеген) erstreckt. Der Kurgan liegt I78 km ostsüdöstlich von der Stadt Almaty (kasach. Алматы), I3 $\mathrm{km}$ westnordwestlich vom Dorf Kegen und $5 \mathrm{~km}$ südwestlich vom Dorf Žalauly (kasach. Жалаулы) entfernt.

$200 \mathrm{~m}$ südöstlich und Io० m nordwestlich vom Großkurgan liegen zwei Kleinkurganketten, jeweils eine Kette in jede Himmelsrichtung. Jede dieser Kleinkurganketten zählt fünf Kurgane, deren Höhe zwischen o,I $\mathrm{m}$ und 0,5 $\mathrm{m}$ beträgt. Die Durchmesser schwanken zwischen 6 und Io m. Aufgrund der geringen Größe der Kurgane wurden die Ketten der Kleinkurgane nicht aufgenommen.

Kurgancharakteristik:

Kurgan I (Abb. I07)

Seitenlänge 26-30 m; Dm Kreisgraben 73 m; 33 m Lage: $\mathrm{N}_{43} 02.982$ E79 04.2I7

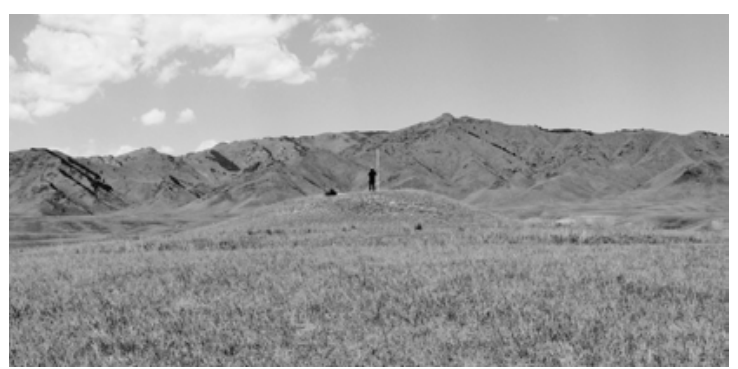

Abb. 107| Kurgan I. Blick von S

Abhänge: keine Merkmale

Weitere Konstruktionen: In einem Abstand von II-I3 m um den Kurgan herum wurde ein Kreisgraben von bis zu Io $\mathrm{m}$ Breite und I $\mathrm{m}$ Tiefe angelegt; exakt an der Westseite bricht der Graben ab. Diesen Bereich kann man als einen Eingang von $5 \mathrm{~m}$ Breite interpretieren.
Der Graben umgibt eine Art runde Plattform, auf der der Kurgan steht. Im Nordbereich der Plattform, leicht nach Osten versetzt, unmittelbar am Rand der Kurganaufschüttung, befindet sich ein Kleinkurgan.

Zustand: in der Mitte ein Raubtrichter; Der Aushub des Raubtrichters überdeckte die östliche Seitenkante der Kurganaufschüttung.

Sonstiges: Die Ecken des Kurgans sind nach den vier Haupthimmelsrichtungen ausgerichtet. An den Seitenkanten der pyramidenförmigen Kurganaufschüttung sind die Steine der Kurgankrepis sichtbar. An der Oberfläche liegen einzelne mittelgroße Steine $(35 \times 15 \mathrm{~cm})$ der Kurganabdeckung.

\section{Kleinkurgan}

Dm I4 m; H I,2 m

Lage: N43 02.996 E79 04.214

Form: abgerundet, plattformähnlich mit abgeflachter Kuppe

Abhänge: drei steile, der südlich gelegene flacher Zustand: in der Mitte ein Raubtrichter

Sonstiges: auf der Oberfläche mittelgroße $(\mathrm{ab} 60 \times 40$ $\times$ Iо $\mathrm{cm}$ ) und kleine $($ Iо $\times 8 \times 5 \mathrm{~cm}$ ) Steine der Kurganabdeckung 


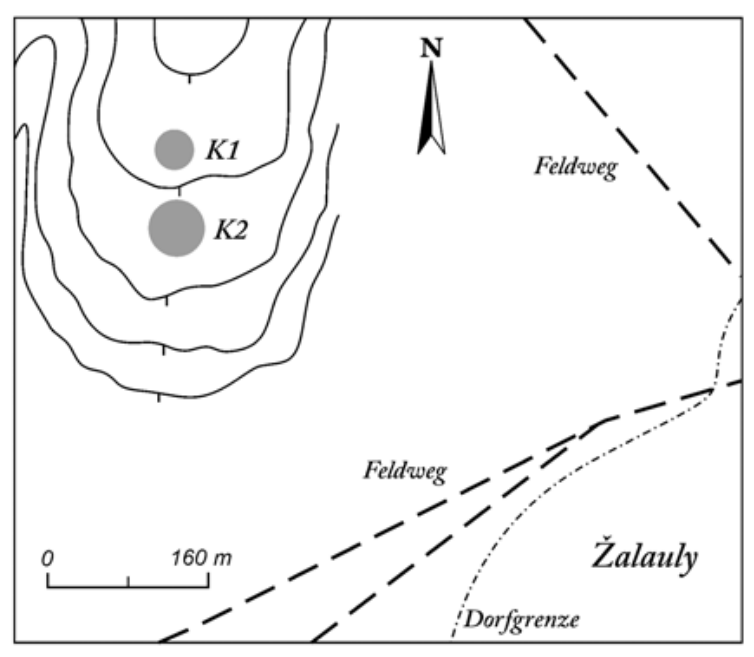

Abb. 108 | Lageskizze der zwei Kurgane $400 \mathrm{~m}$ westlich vom Dorf Žalauly
Zwei Kurgane - $400 \mathrm{~m}$ westlich vom Dorf Žalauly [FEZ] (Abb. ıо8; Karte 3 Nr. 64): ALT I855 m N43 04.063 E79 06.456; Gebiet Almaty (kasach. Алматы облысы), Rajymbekskij rajon (kasach. Райымбек ауданы); Ausmaß N-S Iı $8 \times$ O-W 60 m.

An der nordwestlichen Grenze des Hochplateaus Kegen (kasach. Кеген), an der Südseite des Bergrückens Kuluktau (kasach. Қулықтау), auf einer Riedelkante, die sich auf dem rechten, nördlichen Ufer des Flusses Kegen (kasach. Кеген) befindet, stehen zwei Großkurgane. Die Kurgane liegen $179,5 \mathrm{~km}$ ostsüdöstlich von der Stadt Almaty (kasach. Алматы) entfernt, II $\mathrm{km}$ nordwestlich vom Dorf Kegen und $400 \mathrm{~m}$ westsüdwestlich vom Dorf Žalauly (kasach. Жалаулы).

Die Kurgane bildeten eine $\mathrm{N}-\mathrm{S}$ ausgerichtete Achse. Von der Kurganmitte aus gemessen beträgt der Abstand zwischen den Kurganen 8I m. Beide

Kurgane haben drei steile und einen (immer südlichen) sanften Abhang. Es wurden keine besonderen architektonischen Merkmale an der Oberfläche festgestellt.

Ioo m nordwestlich von Kurgan I befinden sich zwei Kleinkurgane (Dm 20 m und I5 m; H o,2 m und $0,3 \mathrm{~m}$ ), die komplett überpflügt wurden. Aufgrund der geringen Größe wurden die Kleinkurgane nicht aufgenommen.

Aufgrund der Lage im Gelände, der Struktur und äußeren Erscheinungsform können beide Kurgane der sakischen Periode der Früheisenzeit zugeordnet werden.

Kurgancharakteristik:

Kurgan I

Dm 3I m; H 3 m

Lage: N43 04.I06 E79 06.452

Form: abgerundet, plattformähnlich mit abgeflachter

Kuppe

Abhänge: drei steile, südlicher sanft

Zustand: mehrere Raubtrichter auf der Oberfläche

Sonstiges: keine Steine an der Oberfläche

\author{
Kurgan 2 \\ Dm 50 m; H 6 m \\ Lage: N43 04.063 E79 06.456 \\ Form: abgerundet, plattformähnlich mit abgeflachter \\ Kuppe \\ Abhänge: drei steile, südlicher sanft \\ Zustand: mehrere Raubtrichter auf der Oberfläche; Auf \\ der Kurgankuppe befindet sich eine rechteckige Senke \\ von $2 \times 2 \mathrm{~m}$ Größe, bis zu o,3 $\mathrm{m}$ Tiefe, in der sich die \\ Überreste einer Konstruktion aus Beton befinden. \\ Sonstiges: keine Steine an der Oberfläche
}

Lit.: Bajpakov/Gorjačev 2007, 6I.

Ergänzung

Direkt im Dorf Žalauly fanden Schüler im Frühling I988 einen Schatzfund (N43 04.026 E79 07.IO०). Er umfasste 649 Gegenstände aus Gold und ging als „Schatzfund von Žalauly“ (Abb. Io9) in die Fachliteratur ein (Samašev 2007, I64). Es handelte sich dabei um Fundstücke, die wahrscheinlich aus mehreren beraubten Kurganen stammen. Der Schatzfund setzte sich aus mehreren Schmuckstücken (z.B. Zierröhrchen [Abb. I09,I]) und Trachtbestandteilen (z. B. Gürtelaufsätze (Abb. I09,4), einem Pektorale [Abb. I09,3]), sowie aus Beschlägen (Abb. I09,6) und Zierplättchen (Abb. I09,5) im skytho-sibirischen Tierstiel (Abb. I09,2) zusammen (Samašev 2007, I64; Samašev u.a. 2007, 98-99). 

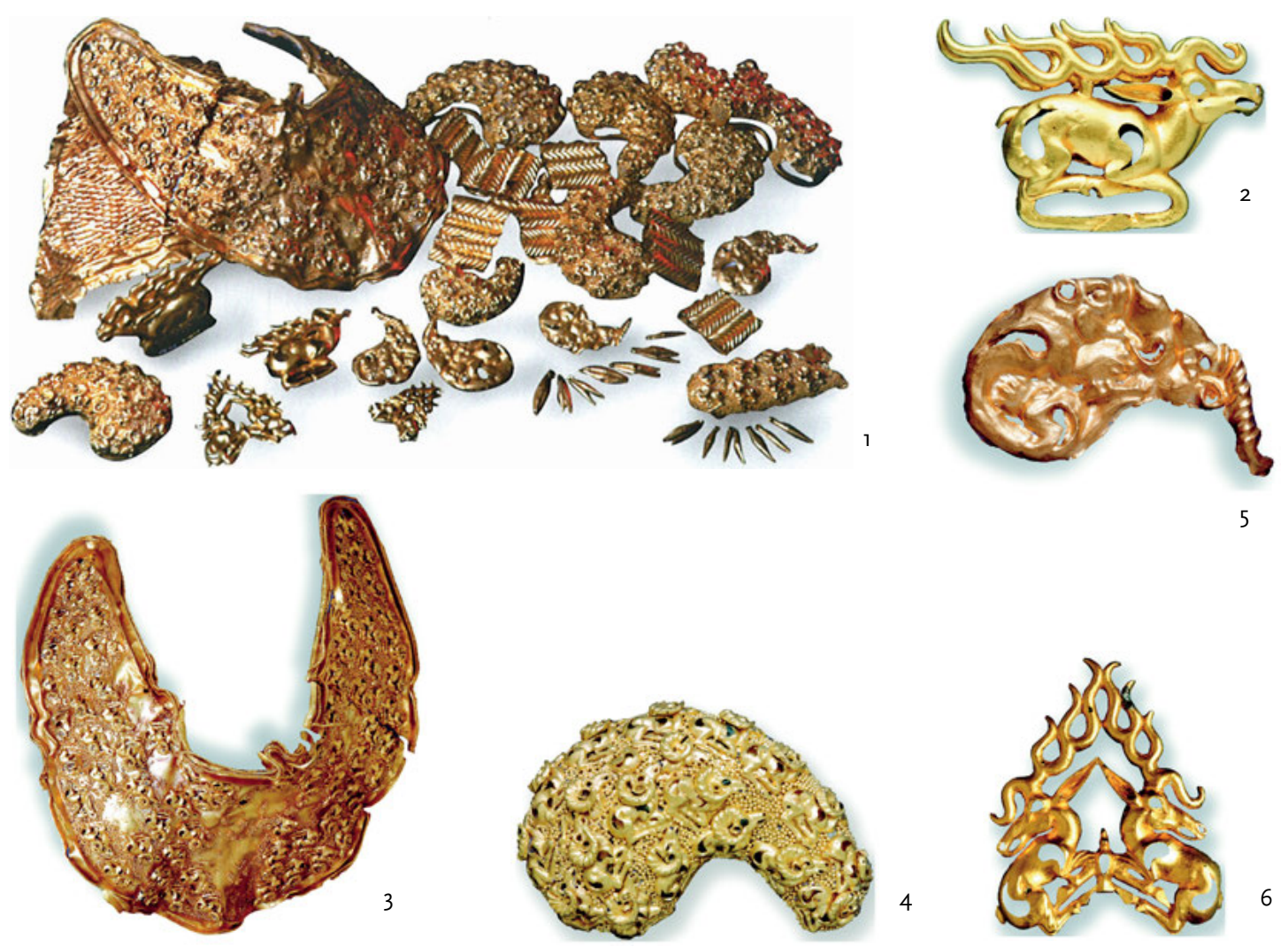

Abb. 109 | „Schatzfund von Žalauly“ (I Samašev 2007, I64, Abb. 2; 2-6 Foto Z. Samašev)

Obwohl es unklar bleiben wird, aus welchen Kurganen diese Stücke entnommen wurden, besteht die Möglichkeit, dass sie aus der Umgebung des Dorfes Žalauly stammen. Das lässt erahnen, was die Kurgane der sakischen Elite auf dem Hochplateau Kegen bewahren. Zudem ermöglichen diese Gegenstände einen chronologischen Rahmen für die Kurgane der sakischen Elite zu ziehen. Es handelte sich hier um Objekte, die sowohl der „klassischen“ sakischen Zeit (5.-3. Jh. v. Chr.) zugeordnet werden können (Samašev 2007, I64; Samašev u.a. 2007, 98-99) als auch um Gegenstände, die eher für die frühe sakische Zeit typisch sind (Samašev 2007, I64; Samašev u.a. 2007, I6-I8). Davon zeugt z. B. ein goldener Beschlag mit zwei antithetisch angeordneten Hirschen, deren Geweihe zusammenlaufen. Das Stück hat Ähnlichkeit mit einem Objekt aus der Nekropole Čilikty-2 (Ostkasachstan), Kurgan I (Samašev u.a. 2004b, I46-I49; Samašev u.a. 2007, 24-3I). Der Kurgan I von Čilikty-2 wurde in das 7. Jh. v. Chr. datiert (Samašev 2007, I65).

Auf diese Weise gewann man durch einen Zufallsfund die Möglichkeit, die elitären sakischen Kurgane um das Dorf Žalauly und mindestens die großen Kurgane der Nordhälfte des Plateaus Kegen in eine Zeitspanne vom 7. bis 3. Jh. v. Chr. zu datieren. 
Drei Kurgane - 7 km westlich vom Dorf Saty [FEZ] (Abb. IIO-III; Karte 3 Nr. 43): ALT I 548 m N43 03.2I3 E78 ı9.407; Gebiet Almaty (kasach. Алматы облысы), Rajymbekskij rajon (kasach. Райымбек ауданы); Ausmaß N-S I9I × O-W 75 m.

Im Tal des Flusses Čilik (kasach. Шелек), das zwischen den Bergketten Transili- (kasach. Iле) und Kungej-Alatau (kasach. Күнгей Алатауы) liegt, nördlich vom Uročišče Kurmekty (kasach. Күрметі) und südlich vom Gebirgsrücken Akšolak (kasach. Ақшолақ), am rechten, südlichen Ufer des Čilik, befinden sich drei Kurgane. Die Kurgane liegen II7 km ostsüdöstlich von der Stadt Almaty (kasach. Алматы) und $7 \mathrm{~km}$ westsüdwestlich vom Dorf Saty (kasach. Саты) entfernt.

Die Kurgane stehen in einer N-S ausgerichteten Reihe und haben drei steile und einen (immer südlichen) sanften Abhang. Der Durchmesser schwankt zwischen $30 \mathrm{~m}$ und 5I m, die Höhe zwischen $2 \mathrm{~m}$ und 5,3 m. Es wurden keine besonderen architektonischen Merkmale an der Oberfläche festgestellt.

Da die Kurgane sich auf einem Acker befinden, ist die gesamte Kurganperipherie zerstört.

Anhand der Lage im Gelände, der Struktur und der äußeren Erscheinungsform können die Kurgane der sakischen Periode der Früheisenzeit zugeordnet werden.

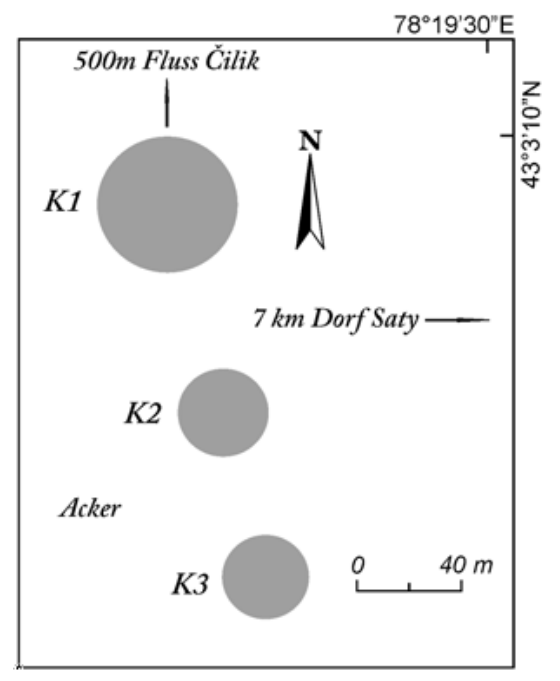

Abb. 110| Lageplan der drei Kurgane 7 km westlich vom Dorf Saty

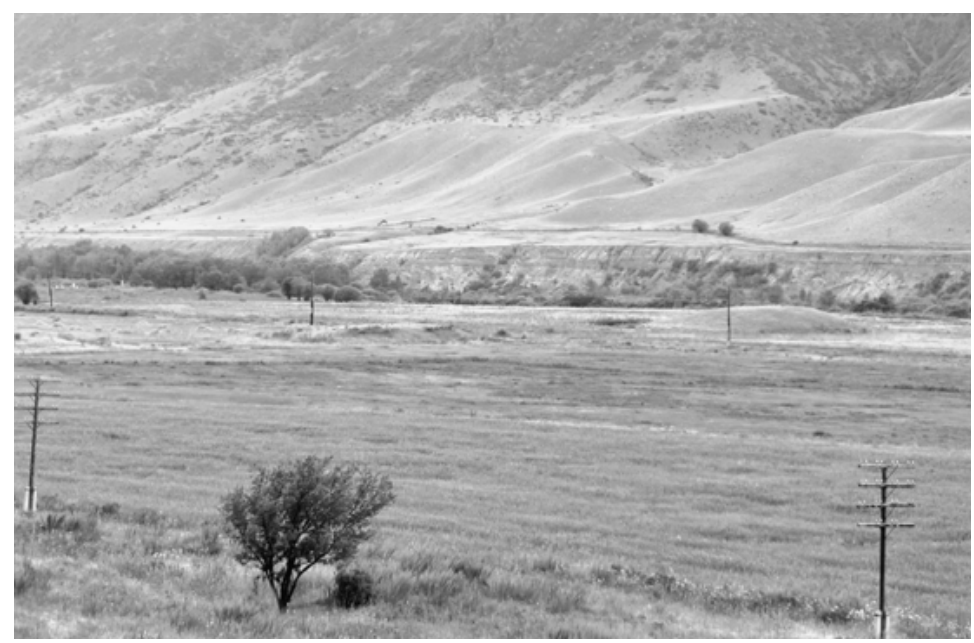

Abb. 11 | Drei Kurgane 7 km westlich vom Dorf Saty. Blick von SO

Kurgancharakteristik:

Kurgan I

Dm 5I m; H 5,3 m

Lage: N43 03.213 E78 I9.407

Form: abgerundet, plattformähnlich mit abgeflachter Kuppe

Abhänge: drei steile, südlicher sanft

Zustand: in der Mitte ein Raubtrichter

Sonstiges: einzelne mittelgroße Steine $(\mathrm{ab} 40 \times 20 \times$ I5 $\mathrm{cm}$ ) an der Oberfläche

\section{Kurgan 2}

Dm 32 m; H 3 m

Lage: N43 03.I69 E78 I9.422

Form: abgerundet, plattformähnlich mit abgeflachter Kuppe
Abhänge: drei steile, südlicher sanft

Zustand: in der Mitte ein Raubtrichter

Sonstiges: einzelne mittelgroße Steine $(\mathrm{ab} 40 \times 20 \times$ $\mathrm{I} 5 \mathrm{~cm}$ ) an der Oberfläche

\section{Kurgan 3}

Dm 30 m; H 2 m

Lage: N43 03.133 E78 I9.433

Form: abgerundet, plattformähnlich mit abgeflachter Kuppe

Abhänge: drei steile, südlicher sanft

Zustand: in der Mitte und in der Südhälfte jeweils ein Raubtrichter

Sonstiges: einzelne große $(\mathrm{ab} 70 \times 50 \times 30 \mathrm{~cm})$ und mittelgroße Steine (ab $40 \times 20 \times 10 \mathrm{~cm})$ an der Oberfläche 
Forschungsgeschichte und Bemerkungen

Zum ersten Mal wurden die Kurgane durch die Archäologische Expedition der Staatlichen Pädagogischen Universität „Abaj“ (Alma-Ata) unter der Leitung von Dr. A. Mar'jašev entdeckt. Die Expedition führte im Auftrag des Staatlichen Kulturkomitees der Akademie der Wissenschaften und des Denkmalpflegeamtes der Kasachischen SSR im Jahre I99I eine Bestandsaufnahme der archäologischen Bodendenkmäler im Kegenskij rajon ${ }^{80}{ }^{8}$ des Gebietes Almaty durch (Mar'jašev/Gorjačev I99I, 25).

Eine zweite Besichtigung der Kurgane fand 2005 statt, als das Turgen-Forschungsteam der Almaty Survey-Expedition (APAЭ) unter der Leitung von A. Gorjačev eine Revision der archäologischen Bodendenkmäler im Rajymbekskij rajon des Gebietes Almaty durchführte (Bajpakov u.a. 2006, I29).

Bei beiden Begehungen wurden Beschreibungen der Kurgane und des Geländes gemacht. Allerdings wurden damals Maße von $26 \mathrm{~m}$ bis $52 \mathrm{~m}$ Durchmesser und o,6 m; I,o $\mathrm{m}$ und I, $5 \mathrm{~m}$ Höhe angegeben. Die Fotos zeigen, dass die Kurgane wesentlich höher sind (Gesamtlänge der benutzten Messlatte: $3 \mathrm{~m}$ ).

Lit.: Bajpakov u.a. 2006, I29; Mar'jašev/Gorjačev I99I, 25.

Gräberfeld Aksaj-9 [FEZ] (Abb. II2-II3; Karte 3 Nr. 56): ALT I427 m N43 II.28I E79 05.609; Gebiet Almaty (kasach. Алматы облысы), Rajymbekskij rajon (kasach. Райымбек ауданы); Ausmaß N-S $940 \times$ O-W I40 m.

Die Nekropole Aksaj-9 liegt auf der Ebene zwischen dem Čaryn Canyon (kasach. Шарын) und am nördlichen Fuß des Bergrückens Kuluktau (kasach. Қулықтау). Der Fundort befindet sich I77 km östlich der Stadt Almaty (kasach. Алматы), 3,7 km südwestlich des Dorfes Aksaj (kasach. Ақсай) und 7,3 km nordöstlich des Dorfes Uzynbulak (kasach. Ұзынбұлақ), auf einem Riedel, der sich von Süden nach Norden neigt. Östlich und westlich vom Riedel aus verlaufen zwei Schluchten, in denen periodisch-saisonale Bäche fließen. Die gesamte Nekropole zählt 30 mittelgroße und kleine Kurgane. Die Kurgane bilden zwei N-S verlaufende Ketten, wobei die südwestliche Kette nur aus

580 Heute wurde der Kegenskij rajon in den Rajymbekskij rajon eingegliedert.

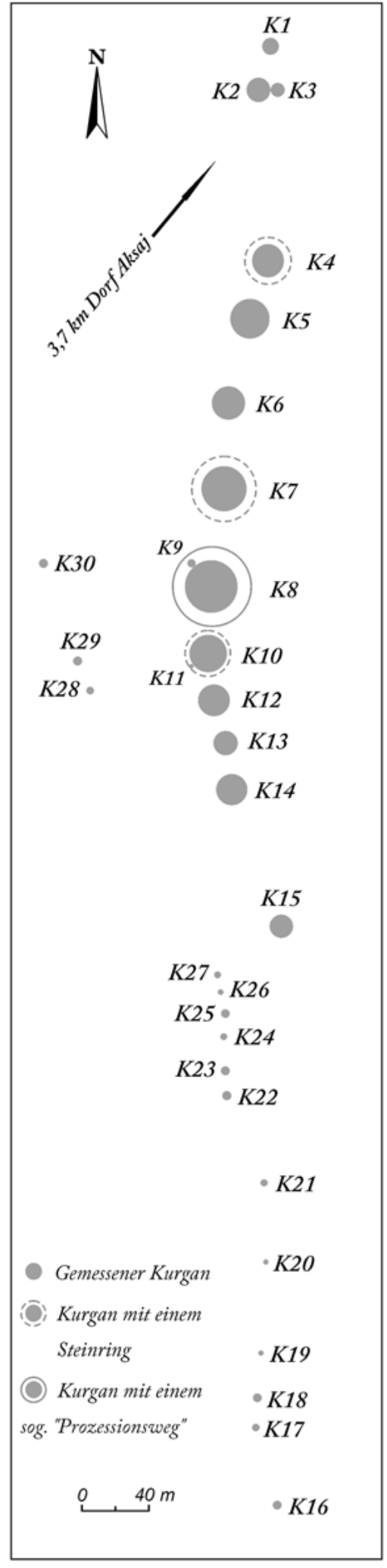

Abb. 112 |

Plan des Gräberfeldes Aksaj-9 
Kleinkurganen besteht. Die größeren Kurgane befinden sich in der Nordhälfte der Nekropole und die kleineren in der Südhälfte. Die Nordostkette besteht nur aus mittelgroßen Kurganen. Die größten Kurgane der Kette wurden fast in deren Zentrum errichtet. Um den größten Kurgan der Nekropole wurde ein umlaufender sog. Prozessionsweg (?) gebaut. Die äußere Markierung dieses Weges wurde durch große, rötliche, senkrecht aufgestellte Steine angezeigt. Zwischen dem Kurganrand und dem sog. Prozessionsweg, im nordwestlichen Sektor der Konstruktion, befindet sich ein Kleinkurgan. Nördlich und südlich von diesem „Großkurgan“ stehen zwei Kurgane, jeweils einer pro Himmelsrichtung, mit Steinkreisen. Der vierte Kurgan in nördlicher Richtung weist ebenso einen Steinkreis auf. Weitere architektonische Merkmale wurden auf der Nekropole nicht festgestellt.

Der Durchmesser der Kurgane schwankt zwischen 3 m und 3I $\mathrm{m}$ (5I $\mathrm{m}$ mit dazugehörenden Steinkonstruktionen). Die Höhe variiert von o,I m bis zu 3 m. Sechs Kurgane des Gräberfeldes weisen einen Raubtrichter auf. Bei I7 Kleinkurganen wurde die gesamte Fläche überpflügt. Die Kurganaufschüttung eines Kurgans ist überpflügt und weist ebenfalls einen Raubtrichter auf. Bei sechs weiteren Kurganen konnten keine Raubtrichter bzw. Senken festgestellt werden. Zehn Kurgane haben drei steile und einen (immer südlichen) sanften Abhang. Bei den restlichen 20 Kurganen konnten keine besonderen Merkmale an den Abhängen aufgrund des mehrmaligen Überpflügens und der geringen Größe bestimmt werden.

Anhand der Lage im Gelände, der Struktur und der äußeren Erscheinungsform können alle Kurgane des Gräberfeldes der sakischen Periode der Früheisenzeit zugeordnet werden.

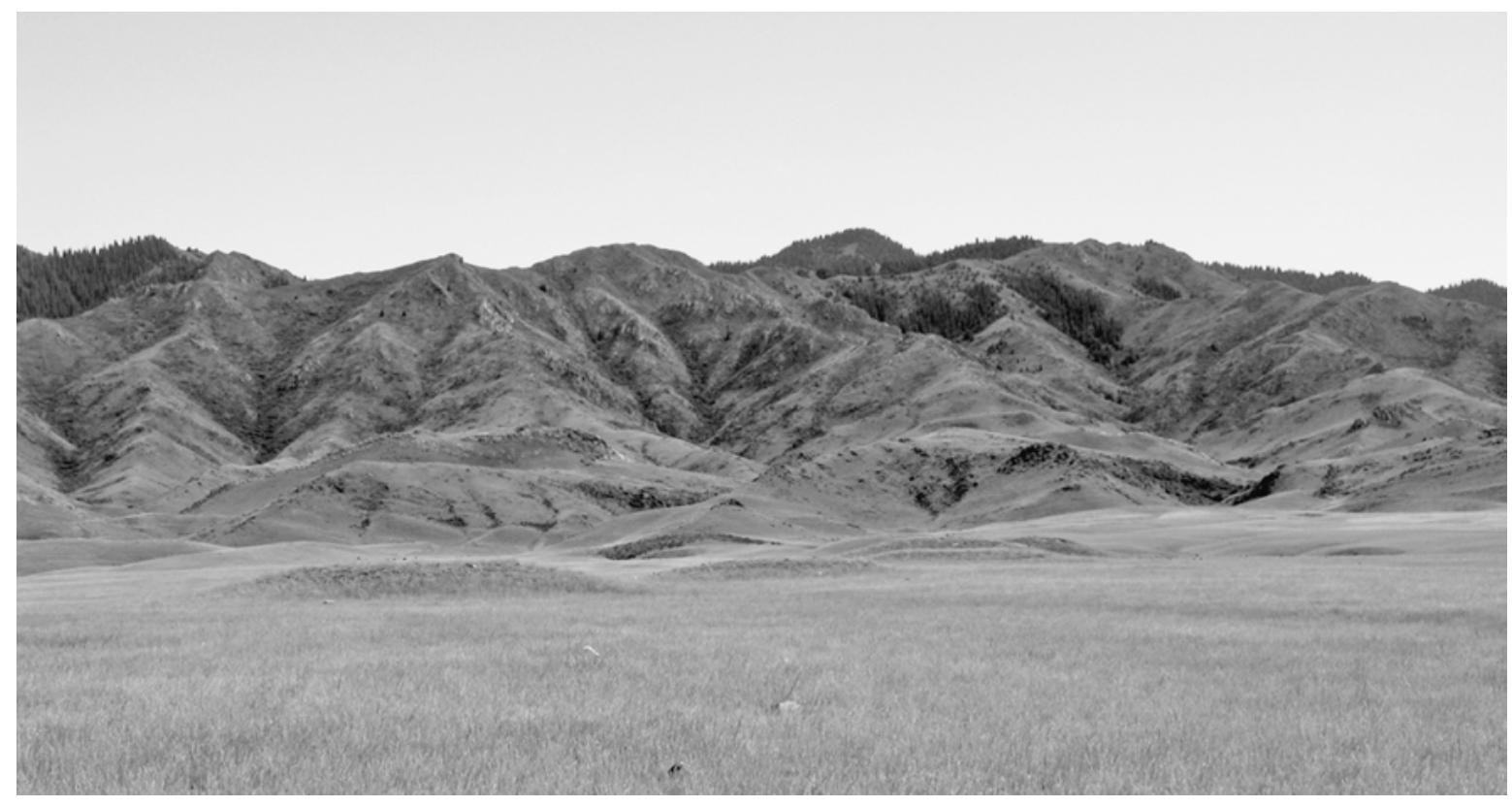

Abb. 113 | Gräberfeld Aksaj-9. Nordöstliche Kurgankette. Blick von N

Kurgancharakteristik:

Nordöstliche Kurgankette

Kurgan I (Kleinkurgan)

Dm io m; H o,2 m

Lage: N43 II.468 E79 05.650; der nördlichste Kurgan der Kette
Form: abgerundete Erhebung

Abhänge: keine Merkmale

Zustand: der Kurgan wurde überpflügt

Sonstiges: an der Oberfläche mittelgroße $(\mathrm{ab} 40 \times 25 \times$ Io $\mathrm{cm}$ ) Steine der Kurganaufschüttung 
Kurgan 2 (Kleinkurgan)

Dm I4 m; H o,4 m

Lage: N43 II.452 E79 05.648

Form: abgerundete Erhebung

Abhänge: keine Merkmale

Zustand: in der Mitte ein Raubtrichter; der Kurgan wurde überpflügt

Sonstiges: an der Oberfläche mittelgroße $(\mathrm{ab} 40 \times 30 \times$ $20 \mathrm{~cm}$ ) Steine der Kurganaufschüttung

Kurgan 3 (Kleinkurgan)

Dm 8 m; H o,I m

Lage: N43 II.452 E79 05.650

Form: abgerundete Erhebung

Abhänge: keine Merkmale

Zustand: der Kurgan wurde mehrmals überpflügt

Sonstiges: an der Oberfläche mittelgroße $(\mathrm{ab} 40 \times 20 \times$ Io $\mathrm{cm}$ ) Steine der Kurganaufschüttung

Kurgan 4 (Abb. II4)

Dm 2I m; Dm Steinkreis 32 m; H I,5 m

Lage: N43 II.393 E79 05.644

Form: abgerundet, plattformähnlich mit abgeflachter Kuppe

Abhänge: drei steile, südlicher sanft

Weitere Konstruktionen: Um den Kurgan, in einem Abstand von 5,5 $\mathrm{m}$ vom Rand des Kurgans, verläuft ein Steinkreis, der aus mittelgroßen rötlichen Steinen (ab $50 \times 40 \times 30 \mathrm{~cm}$ ) gebaut worden war.

Zustand: kein Trichter, keine Mulde

Sonstiges: gesamte Oberfläche mit mittelgroßen Steinen $(\mathrm{ab} 30 \times 10 \times 5 \mathrm{~cm})$ bedeckt

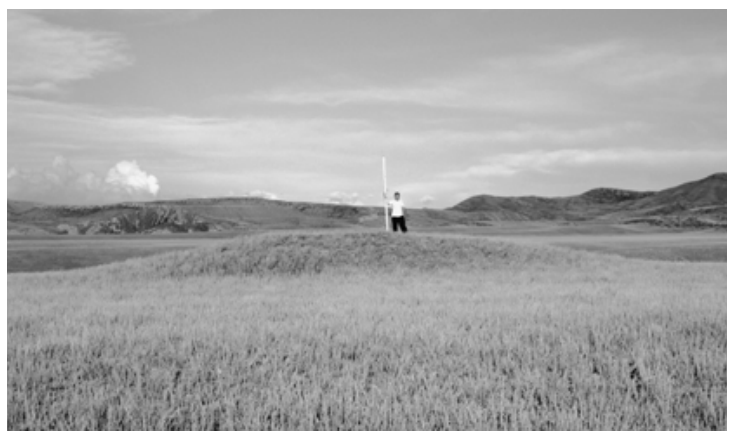

Abb. 114| Kurgan 4. Blick von W

\section{Kurgan 5}

Dm 23 m; H I m

Lage: N43 II.372 E79 05.633

Form: niedrig, abgerundet, plattformähnlich mit abgeflachter Kuppe

Abhänge: drei steile, südlicher sanft

Zustand: kein Raubtrichter, keine Mulde

Sonstiges: gesamte Oberfläche mit mittelgroßen Steinen $(\mathrm{ab} 40 \times 20 \times 10 \mathrm{~cm})$ bedeckt

\section{Kurgan 6}

Dm 22 m; H I m

Lage: N43 II.344 E79 05.622

Form: niedrig, abgerundet, plattformähnlich mit abgeflachter Kuppe

Abhänge: drei steile, südlicher sanft

Zustand: kein Raubtrichter, keine Senke

Sonstiges: gesamte Oberfläche mit mittelgroßen Steinen $(\mathrm{ab} 40 \times 30 \times 20 \mathrm{~cm})$ bedeckt

\section{Kurgan 7}

Dm 28 m; Dm Steinkreis 44 m; H 2,2 m

Lage: N43 II.3I5 E79 05.6I8

Form: abgerundet, plattformähnlich mit abgeflachter Kuppe

Abhänge: drei steile, südlicher sanft

Weitere Konstruktionen: Um den Kurgan herum, in einem Abstand von $8 \mathrm{~m}$ vom Rand des Kurgans aus, verläuft ein Steinkreis, der aus mittelgroßen, rötlichen Steinen $(\mathrm{ab} 40 \times 30 \times 20 \mathrm{~cm})$ gebaut wurde.

Zustand: kein Trichter, keine Senke

Sonstiges: gesamte Oberfläche mit mittelgroßen Steinen $(\mathrm{ab} 40 \times 20 \times 10 \mathrm{~cm})$ bedeckt

Kurgan 8 (Abb. II5)

Dm 3I m; Dm sog. Prozessionsweg $52 \mathrm{~m} ; \mathrm{H}_{3} \mathrm{~m}$

Lage: N43 II.28I E79 05.609

Form: abgerundet, plattformähnlich mit abgeflachter Kuppe

Abhänge: drei steile, südlicher sanft

Weitere Konstruktionen: Der Kurgan ist von einem I $m$ breiten sog. Prozessionsweg (?) umgeben, der in 9-Io m Entfernung vom Rand des Kurgans verläuft. Er wird durch große, senkrecht aufgestellte, rötliche Steine $(\mathrm{ab} 50 \times 40 \times 30 \mathrm{~cm})$ begrenzt. Zwischen dem Kurgan und dem sog. Prozessionsweg, im nordwestlichen Sektor, befindet sich ein Kleinkurgan (K9).

Zustand: kein Raubtrichter, keine Senke; jedoch liegt auf der Nordhälfte des Kurgans ein Aushub

Sonstiges: Die Oberfläche ist zum Teil mit mittelgroßen Steinen ( $\mathrm{ab} 40 \times 25 \times$ IO $\mathrm{cm}$ ) bedeckt; K8 ist der größte Kurgan der Nekropole

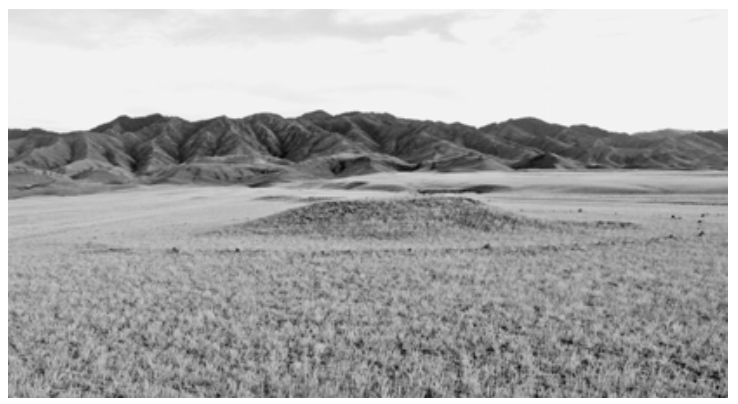

Abb. 115 | Kurgan 8. Blick vom K7, von N 
Kurgan 9 (Kleinkurgan)

Dm 5 m; H o,I m

Lage: N43 II.29I E79 05.596; in der NW-Peripherie von K8

Form: abgerundete, steinerne Erhebung

Abhänge: keine Merkmale

Zustand: in der Mitte eine Seke

Sonstiges: Die Erhebung besteht aus großen $(60 \times 40 \times$ $30 \mathrm{~cm})$ und mittelgroßen Steinen $(20 \times 15 \times 10 \mathrm{~cm})$

\section{Kurgan Io}

Dm 22 m; Dm Steinkreis 29 m; H I,5 m

Lage: N43 II.258 E79 05.606

Form: abgerundet, plattformähnlich mit abgeflachter Kuppe

Abhänge: drei steile, südlicher sanft

Weitere Konstruktionen: Um den Kurgan herum, in einem Abstand von 3,5 m vom Rand des Kurgans, verläuft ein Steinkreis, der aus mittelgroßen, rötlichen Steinen $(\mathrm{ab} 30 \times 20 \times 10 \mathrm{~cm})$ gebaut wurde. Zwischen dem Kurgan und dem sog. Prozessionsweg im südwestlichen Bereich befindet sich ein Kleinkurgan (KII). Zustand: in der Mitte eine Senke

Sonstiges: gesamte Oberfläche mit mittelgroßen Steinen $(\mathrm{ab} 40 \times 20 \times$ Io $\mathrm{cm})$ bedeckt

Kurgan II (Kleinkurgan)

Dm 3 m; H o, I m

Lage: N43 II.254 E79 05.600; in der SW-Peripherie des KIO

Form: abgerundete, steinerne Erhebung

Abhänge: keine Merkmale

Zustand: keine Senke

Sonstiges: Die Erhebung besteht aus mittelgroßen (40 $\times 30 \times 20 \mathrm{~cm})$ und kleinen Steinen $($ I 5 X IO $\times 5 \mathrm{~cm})$

\section{Kurgan I2}

Dm is m; H I, 5 m

Lage: N43 II.24I E79 05.608

Form: abgerundet, plattformähnlich mit abgeflachter Kuppe

Abhänge: drei steile, südlicher sanft

Zustand: in der Mitte ein Raubtrichter

Sonstiges: gesamte Oberfläche mit mittelgroßen Steinen $(\mathrm{ab} 40 \times 20 \times 10 \mathrm{~cm})$ bedeckt

Kurgan I3 (Kleinkurgan)

Dm I4 m; H I m

Lage: N43 II.226 E79 05.6I2

Form: abgerundet, plattformähnlich mit abgeflachter Kuppe

Abhänge: drei steile, südlicher sanft

Zustand: in der Mitte ein Raubtrichter

Sonstiges: gesamte Oberfläche mit großen $(60 \times 40$ $20 \mathrm{~cm})$ und mittelgroßen Steinen $(\mathrm{ab} 40 \times 20 \times 10 \mathrm{~cm})$ bedeckt
Kurgan I4 (Kleinkurgan)

Dm I9 m; H I,5 m

Lage: N43 II.2I0 E79 05.6I5

Form: niedrig, abgerundet, plattformähnlich mit abge-

flachter Kuppe

Abhänge: drei steile, südlicher sanft

Zustand: in der Mitte ein Raubtrichter

Sonstiges: gesamte Oberfläche mit mittelgroßen Steinen $(\mathrm{ab} 50 \times 40 \times 20 \mathrm{~cm})$ bedeckt

Kurgan I5 (Kleinkurgan)

Dm I4 m; H o,7 m

Lage: N43 II.I62 E79 05.635; südlichster Kurgan der Kette

Form: niedrig, abgerundet, plattformähnlich mit abgeflachter Kuppe

Abhänge: drei steile, südlicher sanft

Zustand: in der Mitte ein Raubtrichter

Sonstiges: gesamte Oberfläche mit mittelgroßen Steinen $(\mathrm{ab} 40 \times 30 \times 20 \mathrm{~cm})$ bedeckt

Südwestliche Kurgankette

$$
\begin{aligned}
& \text { Kurgane 16-27 } \\
& \text { Dm 3-5 m; H O,I-O,2 m } \\
& \text { Lage: KI6 N43 I0.966 E79 05.6I9 } \\
& \text { KI7 N43 I0.992 E79 05.6I2 } \\
& \text { Ki8 N43 ir.00I E79 05.6I3 } \\
& \text { Ki9 N43 II.0I6 E79 05.6I6 } \\
& \text { K2O N43 II.046 E79 05.620 } \\
& \text { K2I N43 II.073 E79 05.62I } \\
& \text { K22 N43 II.IO4 E79 05.605 } \\
& \text { K23 N43 II.II3 E79 } 05.605 \\
& \text { K24 N43 II.I25 E79 05.605 } \\
& \text { K25 N43 II.I33 E79 05.606 } \\
& \text { K26 N43 II.I40 E79 05.605 } \\
& \text { K27 N43 II.I46 E79 05.604 }
\end{aligned}
$$

Form: niedrige, abgerundete Erhebungen

Abhänge: An keinem der Kurgane konnten besonderen Merkmale festgestellt werden

Zustand: Alle Kurgane sind überpflügt

Sonstiges: gesamte Oberflächen aller Kurgane mit mittelgroßen Steinen bedeckt

Kurgane 28-30

Dm 3-5 m; H o,2-0,4 m

Lage: K28 N43 II.247 E79 05.550

K29 N43 II.257 E79 05.545

K30 N43 II.292 E79 05.53I

Form: niedrige, abgerundete Erhebungen

Abhänge: An keinem der Kurgane konnten besonderen Merkmale festgestellt werden

Zustand: Alle Kurgane sind überpflügt

Sonstiges: gesamte Oberflächen aller Kurgane mit mittelgroßen Steinen bedeckt 
Forschungsgeschichte und Bemerkungen

Das Gräberfeld Aksaj-9 wurde im Laufe einer Revision der archäologischen Bodendenkmäler im Rajymbekskij rajon des Gebietes Almaty im Jahre 2005 vom Turgen-Forschungsteam der Almaty SurveyExpedition (APAЭ) unter der Leitung von A. Gorjačev entdeckt (Bajpakov u.a. 2006, 26I). Es wurden eine Beschreibung und ein topographischer Plan der Nekropole hergestellt. Jedoch wurden nur die I5 Kurgane der Nordhälfte der Nekropole aufgenommen. Noch I5 weiter südlich gelegene Kleinkurgane wurden nicht erwähnt.

Lit.: Bajpakov u.a. 2006, 26I-262.

Gräberfeld Akšoky-4 [FEZ] (Abb. II6-II7; Karte 3 Nr. 58): ALT i9o m N43 OI.324 E78 54.489; Gebiet Almaty (kasach. Алматы облысы), Rajymbekskij rajon (kasach. Райымбек ауданы); Ausmaß N-S 6оo $\times \mathrm{O}-\mathrm{W} 500 \mathrm{~m}$.

Die Nekropole befindet sich in der Nordhälfte vom Uročišče Akšoky (kasach. Ақшоқы), am Fuße der Südwestseite des Bergrückens Kuluktau (kasach. Қулықтау), auf einem Riedel, der von Nordosten nach Südwesten geneigt verläuft, am rechten, westlichen Ufer des Flusses Šybyšy (kasach. Шыбышы). Die Kurgane stehen I64 km ostsüdöstlich der Stadt Almaty (kasach. Алматы), 26 km westlich vom Dorf Kegen (kasach. Кеген), I7,5 km westsüdwestlich vom Dorf Žalauly (kasach. Жалаулы) und 3,6 km südsüdwestlich vom Dorf Šybyšy (kasach. Шыбышы).

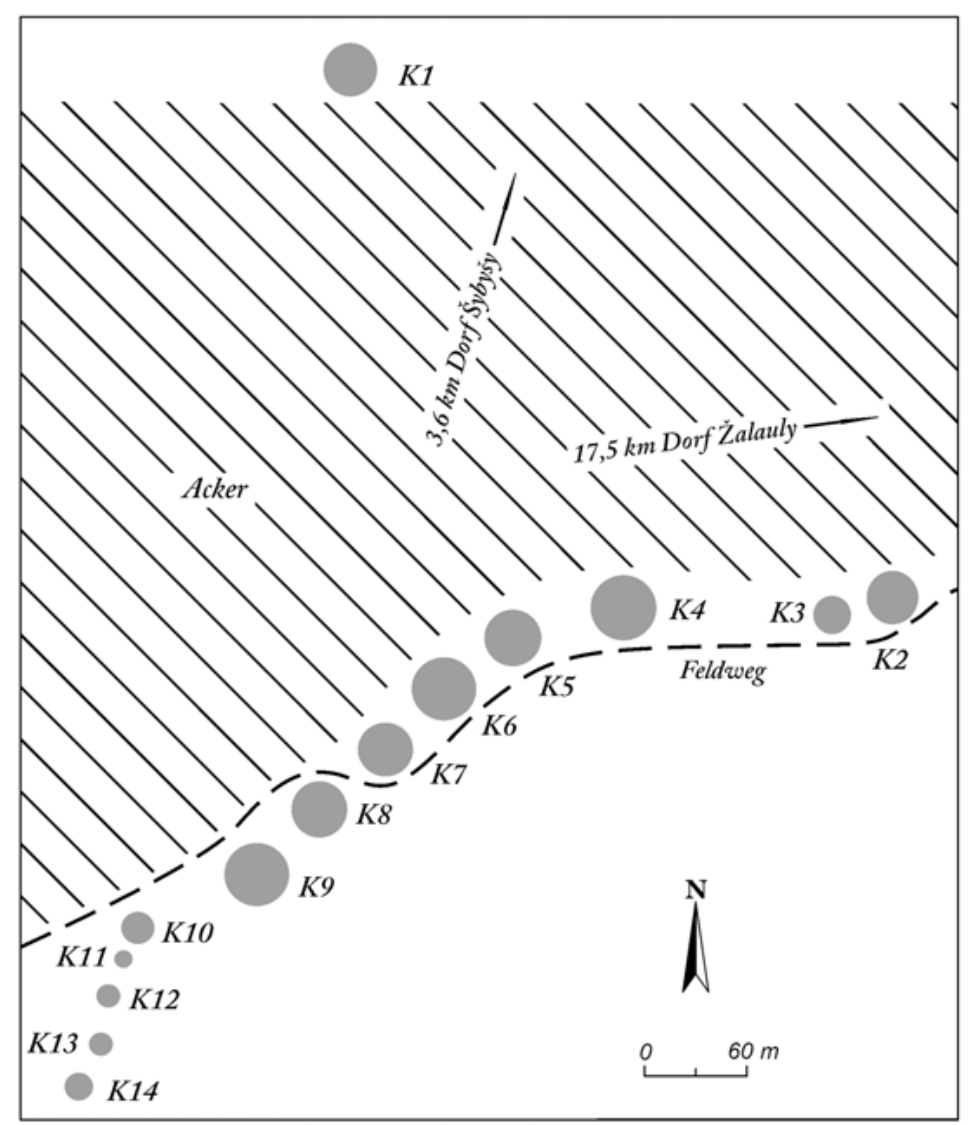

Abb. 116 | Plan des Gräberfeldes Akšoky-4 
Das Gräberfeld besteht aus zwei NO-SW-ausgerichteten Ketten, die den Riedelverlauf wiederholen und einem alleinstehenden Kurgan (KI), der 320 m nördlich der restlichen Kurgane steht. Insgesamt befinden sich auf der Nekropole I4 Kurgane. Die östlich gelegene Kette besteht aus großen und mittelgroßen Kurganen. Auf der westlich gelegenen Kurganreihe wurden lediglich Kleinkurgane festgestellt. Da sich zwischen den Ketten und dem alleinstehenden Kurgan ein Acker befindet, wurde die Peripherie der Kurgane zerstört.

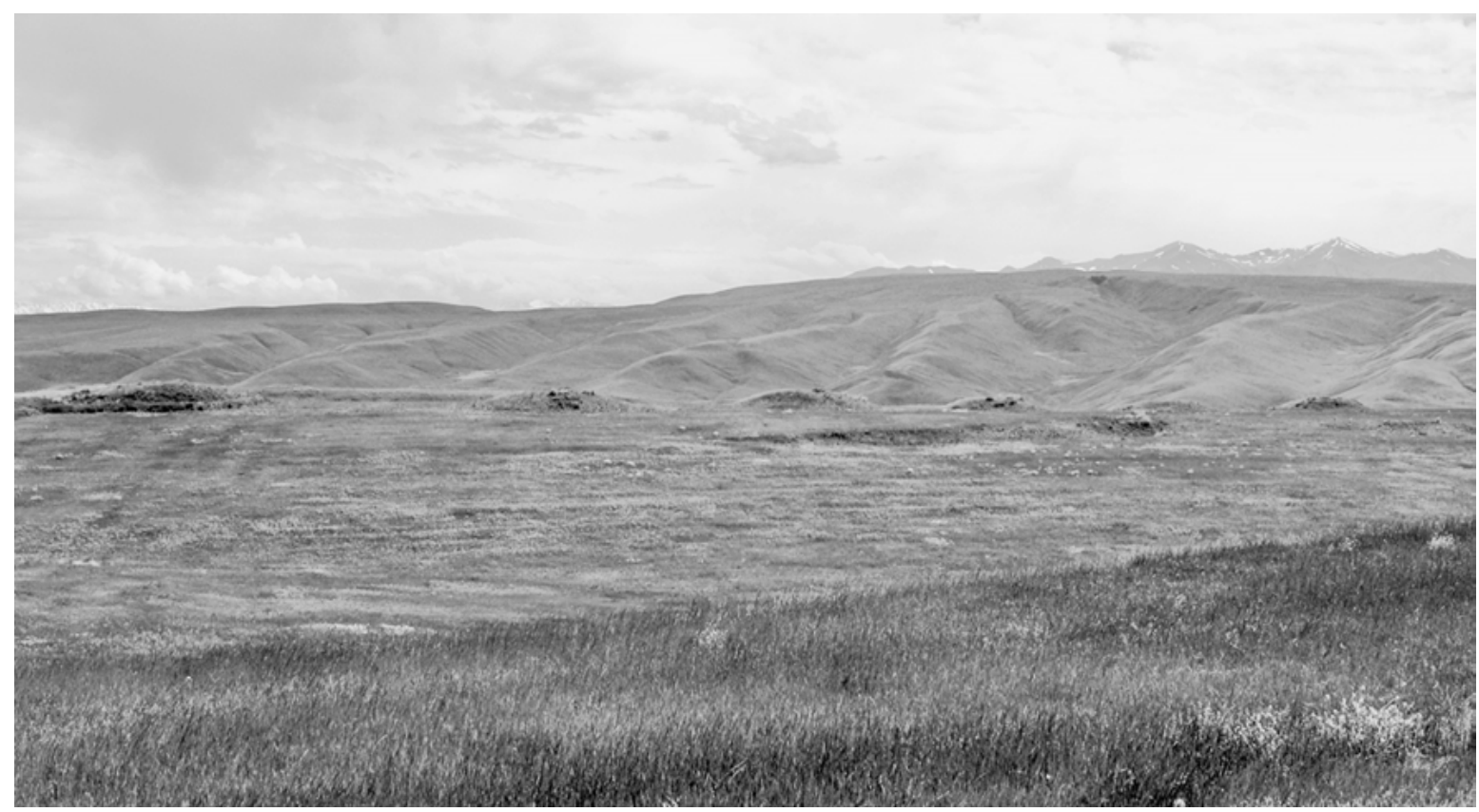

Abb. 117 | Das Gräberfeld Akšoky-4. Blick von NW

Alle Kurgane haben drei steile und einen (immer südlichen) sanften Abhang. Der Durchmesser der Kurgane schwankt zwischen II $\mathrm{m}$ und $37 \mathrm{~m}$, die Höhe zwischen I $\mathrm{m}$ und $5 \mathrm{~m}$. Alle mittelgroßen Kurgane des Gräberfeldes weisen einen oder mehrere Raubtrichter auf. Es wurden keine besonderen architektonischen Merkmale an der Oberfläche festgestellt.

Anhand der Lage im Gelände, der Struktur und der äußeren Erscheinungsform können alle Kurgane des Gräberfeldes der sakischen Periode der Früheisenzeit zugeordnet werden.

Kurgancharakteristik:

Kurgan I

Dm 3I m; H 3 m

Lage: N43 OI.500 E78 54.374; der nördlichste, separate Kurgan

Form: abgerundet, plattformähnlich mit abgeflachter Kuppe

Abhänge: drei steile, südlicher sanft

Zustand: in der Mitte ein Raubtrichter

Sonstiges: An der Oberfläche liegen mittelgroße Steine der Kurganaufschüttung (ab $45 \times 30 \times$ Io $\mathrm{cm}$ ); auf der Kurgankuppe liegen große Steine $(\mathrm{ab} \mathrm{I} 30 \times 60 \times 20 \mathrm{~cm})$
Östliche Kurgankette

\section{Kurgan 2}

Dm 29 m; H 2,3 m

Lage: N43 OI.322 E78 54.6II

Form: abgerundet, plattformähnlich mit abgeflachter Kuppe

Abhänge: drei steile, südlicher sanft

Zustand: in der Mitte ein Raubtrichter

Sonstiges: fast keine Steine auf der Oberfläche

Kurgan 3

Dm 2I m; H 3 m

Lage: N43 OI.3I8 E78 54.58I 
Form: abgerundet, plattformähnlich mit abgeflachter Kuppe

Abhänge: drei steile, südlicher sanft

Zustand: in der Mitte ein Raubtrichter; im Westteil der Kurgankuppe ein Betonpfosten

Sonstiges: keine Steine auf der Oberfläche

\section{Kurgan 4}

Dm 37 m; H 4 m

Lage: N43 oI.324 E78 54.489

Form: abgerundet, plattformähnlich mit abgeflachter Kuppe

Abhänge: drei steile, südlicher sanft

Zustand: in der Mitte ein Raubtrichter; die Südost- und Nordsektoren sind durch moderne Technikeingriffe stark beschädigt

Sonstiges: keine Steine auf der Oberfläche

\section{Kurgan 5}

Dm 32 m; H 4 m

Lage: N43 OI.3I8 E78 54.440

Form: abgerundet, plattformähnlich mit abgeflachter Kuppe

Abhänge: drei steile, südlicher sanft

Zustand: in der Mitte ein Raubtrichter

Sonstiges: keine Steine auf der Oberfläche

\section{Kurgan 6}

Dm 35 m; H 5 m

Lage: N43 oI.299 E78 54.4IO

Form: abgerundet, plattformähnlich mit abgeflachter Kuppe

Abhänge: drei steile, südlicher sanft

Zustand: in der Mitte und im nordwestlichen Bereich jeweils ein Raubtrichter

Sonstiges: keine Steine auf der Oberfläche

\section{Kurgan 7}

Dm 30 m; H 3 m

Lage: N43 OI.289 E78 54.382

Form: abgerundet, plattformähnlich mit abgeflachter Kuppe

Abhänge: drei steile, südlicher sanft

Zustand: in der Mitte ein Raubtrichter

Sonstiges: keine Steine auf der Oberfläche

\section{Kurgan 8}

Dm $28 \mathrm{~m} ; \mathrm{H} 3 \mathrm{~m}$

Lage: N43 OI.263 E78 54.358

Form: abgerundet, plattformähnlich mit abgeflachter Kuppe

Abhänge: drei steile, südlicher sanft

Zustand: in der Mitte ein Raubtrichter

Sonstiges: keine Steine auf der Oberfläche

\section{Kurgan 9}

Dm 35 m; H 3 m

Lage: N43 OI.243 E78 54.329

Form: abgerundet, plattformähnlich mit abgeflachter Kuppe

Abhänge: drei steile, südlicher sanft

Zustand: in der Mitte ein Raubtrichter

Sonstiges: keine Steine auf der Oberfläche

Westliche Kurgankette

\section{Kurgan Io}

Dm I8 m; H 2 m

Lage: N43 OI.227 E78 54.276

Form: abgerundet, plattformähnlich mit abgeflachter Kuppe

Abhänge: drei steile, südlicher sanft

Zustand: in der Mitte ein Raubtrichter

Sonstiges: keine Steine auf der Oberfläche

Kurgan II (Kleinkurgan)

Dm II m; H I m

Lage: N43 OI.2I7 E78 54.269

Form: abgerundete Erdaufschüttung mit abgeflachter

Kuppe

Abhänge: drei steile, südlicher sanft

Zustand: keine Senke

Sonstiges: keine Steine auf der Oberfläche

Kurgan I2 (Kleinkurgan)

Dm I4 m; H I, 5 m

Lage: N43 OI.207 E78 54.263

Form: abgerundete Erdaufschüttung mit abgeflachter

Kuppe

Abhänge: drei steile, südlicher sanft

Zustand: keine Senke

Sonstiges: keine Steine auf der Oberfläche

Kurgan I3 (Kleinkurgan)

Dm I4 m; H I,2 m

Lage: N43 OI.I9I E78 54.260

Form: abgerundete Erdaufschüttung mit abgeflachter Kuppe

Abhänge: drei steile, südlicher sanft

Zustand: keine Senke

Sonstiges: keine Steine auf der Oberfläche

Kurgan I4 (Kleinkurgan)

Dm I6 m; H I, 5 m

Lage: N43 OI.I80 E78 54.247

Form: abgerundete Erdaufschüttung mit abgeflachter Kuppe

Abhänge: drei steile, südlicher sanft

Zustand: keine Senke

Sonstiges: keine Steine auf der Oberfläche

Lit.: Bajpakov u.a. 2006, 23I, 235. 
Gräberfeld Aktasty-3 [FEZ und frühtürkische Periode] (Abb. II8-II9; Karte 3 Nr. 74): ALT 2054 m N43 oI.I60 E79 24.2г3; Gebiet Almaty (kasach. Алматы облысы), Rajymbekskij rajon (kasach. Райымбек ауданы); Ausmaß N-S 310 × O-W 200 m.

Die Nekropole befindet sich an der Ostgrenze des Hochplateaus Kegen (kasach. Кеген), an der Südseite der Temirlik-Berge (kasach. Темирлик), am südwestlichen Fuß des Berges Aktasty (kasach. Ақтасты), nordnordöstlich einer kleinen allein stehenden Felskuppe, am linken, östlichen Ufer des Flusses Aktasty (kasach. Ақтасты). Die Kurgane stehen 204 km ostsüdöstlich von der Stadt Almaty (kasach. Алматы), І4,7 km östlich vom Dorf Kegen (kasach. Кеген) und I km nördlich vom Dorf Aktasty (kasach. Ақтасты) entfernt.

Das Gräberfeld besteht aus 45 mittelgroßen und kleinen Kurganen, die fünf N-S verlaufende Ketten mit leichter östlicher Abweichung bilden. Nur die östlichste Kette besteht aus mittelgroßen Kurganen. Die anderen, westlich gelegenen Ketten weisen nur Kleinkurgane der früheisenzeitlichen sakischen Periode und quadratische Umfriedungen der frühtürkischen Periode auf. Die frühtürkischen Kurgane wurden an die Kettenenden bzw. zwischen die sakischen Kurgane gebaut.

Um einen Kurgan ( $\mathrm{K}_{4}$ nach der Arbeitsnummerierung) der östlichsten Kette herum, der der größte Kurgan des Gräberfeldes ist, wurde, ein umlaufender sog. Prozessionsweg (?) erbaut. Die äußere Markierung dieses Weges wurde durch große, rötliche, senkrecht angeordnete Steine gekennzeichnet. Um vier weitere Kurgane dieser Kette, die nördlich und südlich vom K4 errichtet worden wa-

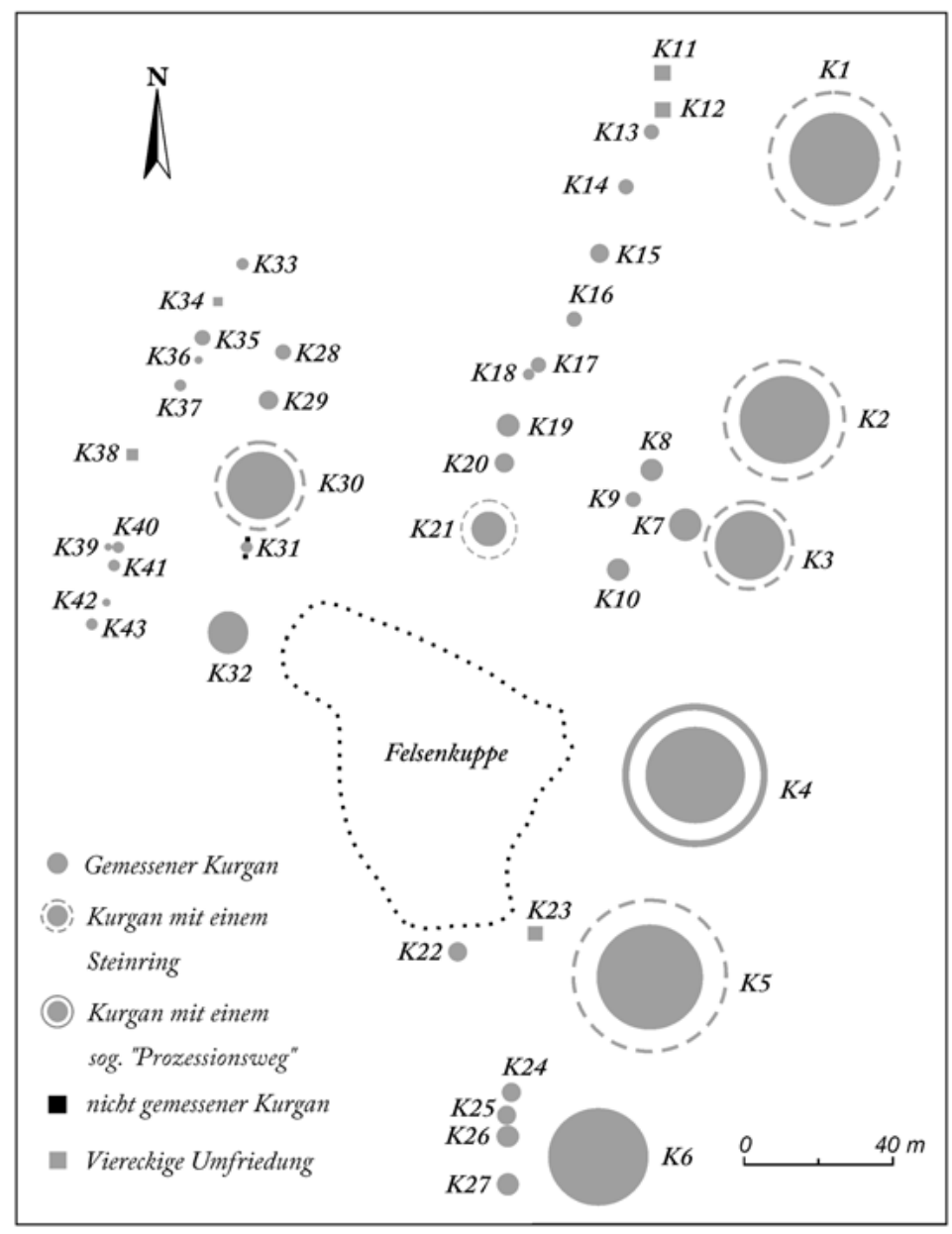

Abb. 118 | Plan des Gräberfeldes Aktasty-3 
ren, wurden Steinkreise festgestellt. Der südlichste Kurgan der mittleren Kette, der gleichzeitig auch der Größte der Kette ist, sowie der größte Kurgan der zweiten westlichen Kette, der sich in deren Mitte befindet, weisen ebenso Steinkreise auf.

Weitere architektonische Merkmale wurden auf der Nekropole nicht festgestellt.

Alle größeren Kurgane (sechs Konstruktionen der ersten östlichen Kette) haben drei steile und einen sanften (immer gen Süden abfallenden) Abhang. Der Durchmesser der Kurgane schwankte zwischen $2 \mathrm{~m}$ und $28 \mathrm{~m}$ (insgesamt $42 \mathrm{~m}$ zusammen mit den Steinkonstruktionen), die Höhen zwischen O,I $\mathrm{m}$ und 2,5 m. Fast alle mittelgroßen Kurgane des Gräberfeldes wiesen einen Raubtrichter auf. Eine Ausnahme stellte der erste nördlichste Kurgan der ersten östlichen Kette (KI nach der Arbeitsnummerierung) dar, da dort keine Senke bzw. kein Raubtrichter gesichtet wurde.

Anhand der Struktur und der äußeren Erscheinungsform konnten die Kurgane der Nekropole der sakischen Periode der Früheisenzeit und der frühtürkischen Periode des frühen Mittelalters zugeordnet werden.

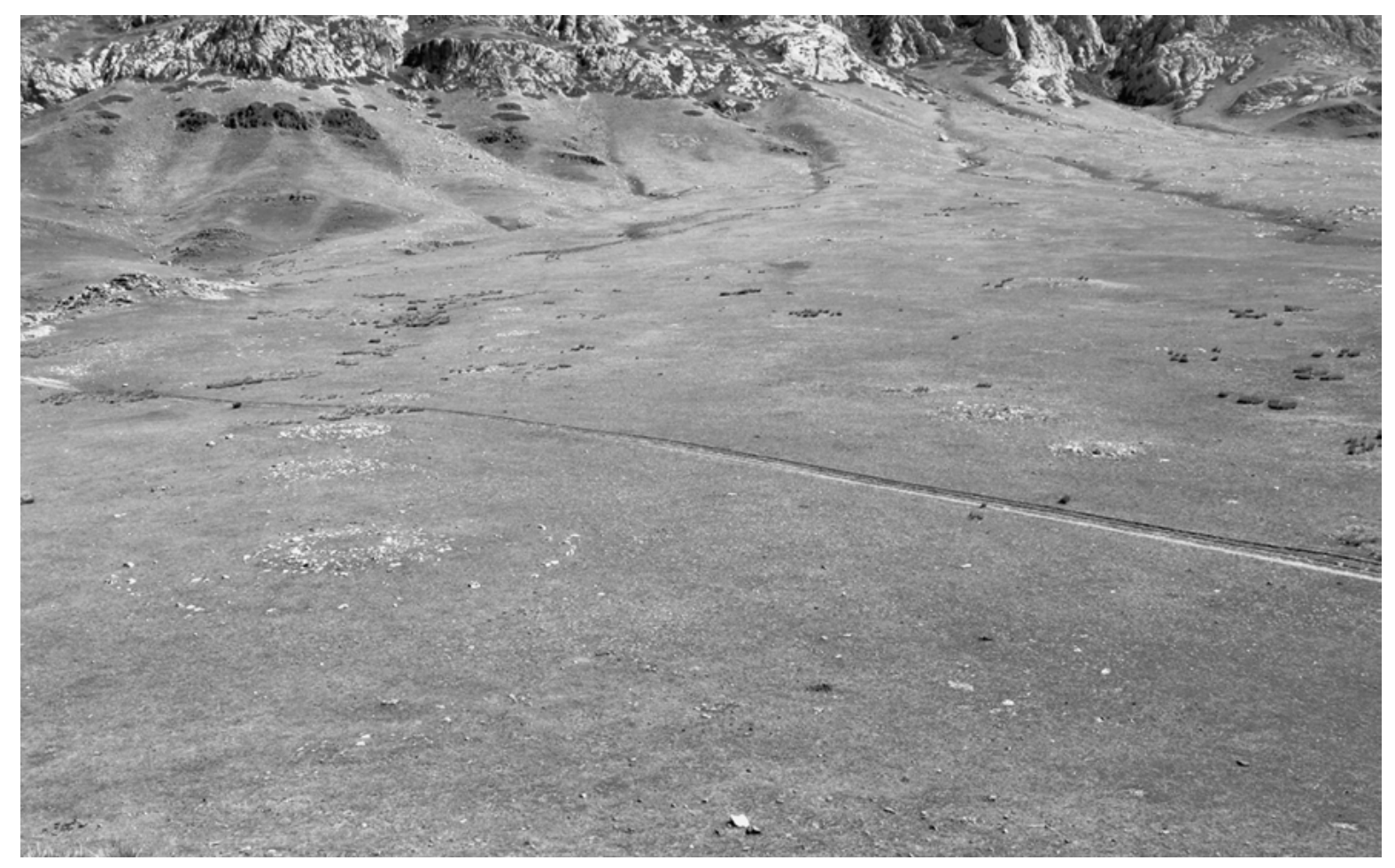

Abb. 119 | Das Gräberfeld Aktasty-3. Blick von S

Kurgancharakteristik:

Erste östliche Kurgankette

\section{Kurgan I}

Dm 25 m; Dm Steinkreis 36 m; H I, 5 m

Lage: N43 OI.I60 E79 24.2I3; der nördlichste Kurgan der Kette

Form: abgerundet, plattformähnlich mit abgeflachter Kuppe

Abhänge: drei steile, südlicher sanft
Weitere Konstruktionen: Um den Kurgan herum verläuft, in einem Abstand von 5,5 m vom Rand, ein Steinkreis, der aus mittelgroßen rötlichen Steinen (ab $50 \times$ $40 \times 30 \mathrm{~cm}$ ) gebaut wurde

Zustand: kein Trichter, keine Senke; Der Steinkreis ist nur in der Nordhälfte der Kurganperipherie erhalten. Sonstiges: gesamte Oberfläche mit mittelgroßen Steinen $(\mathrm{ab} 30 \times \mathrm{IO} \times 5 \mathrm{~cm})$ bedeckt 


\section{Kurgan 2}

Dm 24 m; Dm Steinkreis 3I m; H 2 m

Lage: N43 OI.I2I E79 24.198

Form: abgerundet, plattformähnlich mit abgeflachter Kuppe

Abhänge: drei steile, südlicher sanft

Weitere Konstruktionen: Um den Kurgan herum verläuft, in einem Abstand von 3,5 m vom Rand, ein Steinkreis, der aus mittelgroßen Steinen $(\mathrm{ab} 50 \times 40 \times 30 \mathrm{~cm})$ gebaut wurde

Zustand: in der Mitte eine Senke; Der Steinkreis ist nur in der Nordhälfte der Kurganperipherie erhalten.

Sonstiges: gesamte Oberfläche mit mittelgroßen Steinen $(\mathrm{ab} 30 \times \mathrm{IO} \times 5 \mathrm{~cm}$ bis zum Schotter) bedeckt

\section{Kurgan 3}

Dm I8 m; Dm Steinkreis 24 m; H I m

Lage: N43 OI.IOI E79 24.I87

Form: niedrig, abgerundet, plattformähnlich mit abgeflachter Kuppe

Abhänge: drei steile, südlicher sanft

Weitere Konstruktionen: Um den Kurgan herum verläuft, in einem Abstand von 3, o m vom Rand, ein Steinkreis, der aus mittelgroßen Steinen $(\mathrm{ab} 50 \times 40 \times 30 \mathrm{~cm})$ gebaut wurde

Zustand: in der Mitte eine Senke; Der Steinkreis ist nur in der Westhälfte der Kurganperipherie erhalten.

Sonstiges: gesamte Oberfläche mit mittelgroßen Steinen ( $\mathrm{ab} 30 \times$ Io $\times 5 \mathrm{~cm}$ bis zum Schotter) bedeckt

Kurgan 4 (Abb. I2o)

Dm 25 m; Dm sog. Prozessionsweg 39 m; H 2,5 m

Lage: N43 OI.070 E79 24.I74

Form: abgerundet, plattformähnlich mit abgeflachter Kuppe

Abhänge: drei steile, südlicher sanft

Weitere Konstruktionen: 6-7 m vom Rand des Kurgans entfernt liegt umlaufend ein sog. Prozessionsweg von 0,5-0,7 m Breite; Dieser wird durch große, senkrecht angeordnete, rötliche Steine $(\mathrm{ab} 50 \times 40 \times 30 \mathrm{~cm})$ begrenzt. Zwischen dem Kurgan und dem sog. Prozessionsweg, also im nördlichen Bereich, befinden sich fünf rechteckige Vertiefungen ${ }^{8}{ }^{8}$

Zustand: in der Nordhälfte ein Raubtrichter

Sonstiges: Die Oberfläche ist mit mittelgroßen Steinen (ab $60 \times 40 \times 20 \mathrm{~cm}$ bis zum Schotter) bedeckt. $\mathrm{K}_{4}$ ist der größte Kurgan der Nekropole.

\section{Kurgan 5}

Dm 28 m; Dm Steinkreis 42 m; H I, 5 m

Lage: N43 OI.042 E79 24.I60

Form: abgerundet, plattformähnlich mit abgeflachter Kuppe

Abhänge: drei steile, südlicher sanft

58I Eine genaue Differenzierung ist ohne Ausgrabung unmöglich.

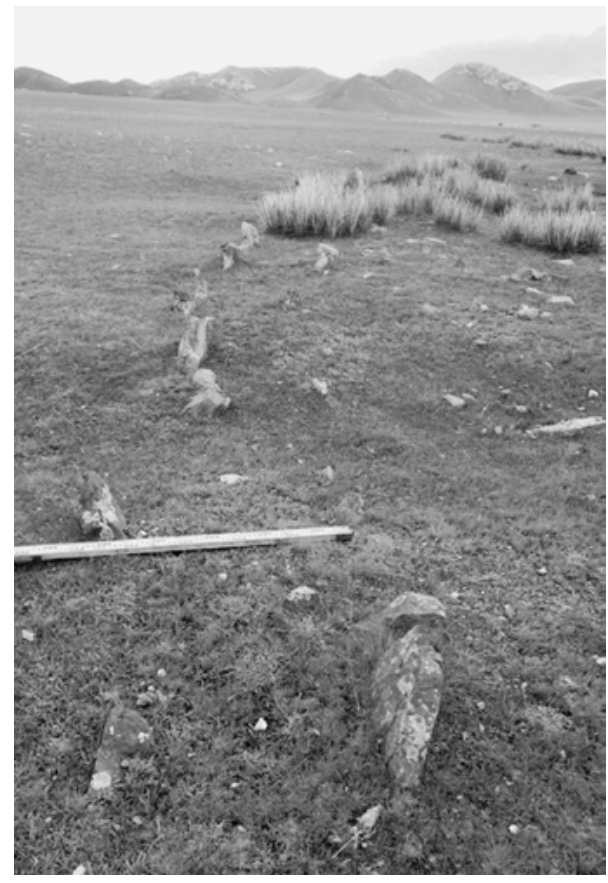

Abb. $120 \mid$ Kurgan 4. Nordbereich des sog.

Prozessionsweges. Blick von W

Weitere Konstruktionen: Um den Kurgan herum verläuft, in einem Abstand von $7 \mathrm{~m}$ vom Rand, ein Steinkreis, der aus mittelgroßen Steinen (ab $50 \times 40 \times 30 \mathrm{~cm})$ gebaut wurde

Zustand: in der Mitte ein Raubtrichter; der Steinkreis ist nur zum Teil erhalten

Sonstiges: gesamte Oberfläche mit mittelgroßen Steinen ( $\mathrm{ab} 50 \times 30 \times 10 \mathrm{~cm}$ bis zum Schotter) bedeckt

\section{Kurgan 6}

Dm 25 m; H I m

Lage: N43 OI.oI7 E79 24.I47; der südlichste Kurgan der Kette

Form: niedrig, abgerundet, plattformähnlich mit abgeflachter Kuppe

Abhänge: drei steile, südlicher sanft

Zustand: in der Mitte ein Raubtrichter

Sonstiges: Der Randbereich des Kurgans ist mit mittelgroßen Steinen (ab $30 \times 20 \times$ IO cm) bedeckt; die Kurgankuppe ist kahl

Zweite östliche Kurgankette

Kurgan 7 (Kleinkurgan)

Dm $9 \mathrm{~m} ; \mathrm{H} \circ, 2 \mathrm{~m}$

Lage: N43 OI.IO7 E79 24.I76; N einer einzeln stehenden Felskuppe

Form: abgerundete Steinanhäufung

Abhänge: keine Merkmale

Zustand: kein Trichter, keine Senke 
Kurgan 8 (Kleinkurgan)

Dm 6 m; H o,2 m

Lage: N43 OI.II6 E79 24.I56; N einer einzeln stehenden Felskuppe; nördlichster Kurgan der Kette

Form: abgerundete Steinanhäufung

Abhänge: keine Merkmale

Zustand: kein Trichter, keine Senke

Kurgan 9 (Kleinkurgan)

Dm 4 m; H o,I m

Lage: N43 OI.II2 E79 24.I52; N einer einzeln stehenden Felskuppe

Form: abgerundete Steinanhäufung

Abhänge: keine Merkmale

Zustand: kein Trichter, keine Senke

Kurgan ıo (Kleinkurgan)

Dm 6 m; $\mathrm{H} \circ, 2 \mathrm{~m}$

Lage: N43 OI.IO2 E79 24.I48; N einer einzeln stehenden Felskuppe

Form: abgerundete Steinanhäufung

Abhänge: keine Merkmale

Zustand: kein Trichter, keine Senke

Kurgan 22 (Kleinkurgan)

Dm $5 \mathrm{~m}$; H o, $3 \mathrm{~m}$

Lage: N43 OI.047 E79 24.I25; S einer einzeln stehenden Felskuppe

Form: abgerundete Steinanhäufung

Abhänge: keine Merkmale

Zustand: kein Trichter, keine Senke

Kurgan 23 (Kleinkurgan)

Maß $2 \times 2 \mathrm{~m}$; $\mathrm{H}$ O,I $\mathrm{m}$

Lage: N43 OI.049 E79 24.I40; S einer einzeln stehenden Felskuppe

Form: quadratische Umfriedung

Zustand: kein Trichter, keine Senke

Sonstiges: Die Seiten der Umfriedung sind an den vier Haupthimmelsrichtungen orientiert.

Bemerkung: frühtürkische Periode

Kurgan 24 (Kleinkurgan)

Dm 5 m; H o, I m

Lage: N43 OI.026 E79 24.I2I; S einer einzeln stehenden Felskuppe

Form: abgerundete Steinanhäufung

Abhänge: keine Merkmale

Zustand: kein Trichter, keine Senke

Kurgan 25 (Kleinkurgan)

Dm 5 m; H o,I m

Lage: N43 OI.020 E79 24.I2I; S einer einzeln stehenden Felskuppe

Form: abgerundete Steinanhäufung

Abhänge: keine Merkmale

Zustand: kein Trichter, keine Senke
Kurgan 26 (Kleinkurgan)

Dm 6 m; H o,I m

Lage: N43 OI.020 E79 24.I2I; S einer einzeln stehenden Felskuppe

Form: abgerundete Steinanhäufung

Abhänge: keine Merkmale

Zustand: kein Trichter, keine Senke

Kurgan 27 (Kleinkurgan)

Dm 6 m; H o,I m

Lage: N43 OI.oI3 E79 24.II9; S einer einzeln stehenden Felskuppe; südlichster Kurgan der Kette

Form: abgerundete Steinanhäufung

Abhänge: keine Merkmale

Zustand: kein Trichter, keine Senke

Mittlere Kurgankette

Kurgan II (Kleinkurgan)

Maß $4 \times 4$ m; H o,I m

Lage: N43 OI.I74 E79 24.I62; nördlichster Kurgan der Kette

Form: quadratische Umfriedung

Zustand: kein Trichter, keine Senke

Sonstiges: Die Seiten der Umfriedung sind an den vier Haupthimmelsrichtungen orientiert.

Bemerkung: frühtürkische Periode

Kurgan I2 (Kleinkurgan)

Maß $4 \times 4$ m; H o,I m

Lage: N43 OI.I69 E79 24.I62

Form: quadratische Umfriedung

Zustand: kein Trichter, keine Senke

Sonstiges: Die Seiten der Umfriedung sind an die vier Haupthimmelsrichtungen orientiert.

Bemerkung: frühtürkische Periode

Kurgan I3 (Kleinkurgan)

Dm 4 m; H o,2 m

Lage: N43 OI.I66 E79 24.I59

Form: abgerundete Steinanhäufung

Abhänge: keine Merkmale

Zustand: kein Trichter, keine Senke

Kurgan I4 (Kleinkurgan)

Dm $4 \mathrm{~m} ; \mathrm{H}$ o,2 $\mathrm{m}$

Lage: N43 OI.I58 E79 24.I54

Form: abgerundete Steinanhäufung

Abhänge: keine Merkmale

Zustand: kein Trichter, keine Senke

Kurgan I5 (Kleinkurgan)

Dm 5 m; H o,I m

Lage: N43 OI.I48 E79 24.I48

Form: abgerundete Steinanhäufung

Abhänge: keine Merkmale

Zustand: kein Trichter, keine Senke 
Kurgan i6 (Kleinkurgan)

Dm 4 m; H o,2 m

Lage: N43 OI.I39 E79 24.I42

Form: abgerundete Steinanhäufung

Abhänge: keine Merkmale

Zustand: kein Trichter, keine Senke

Kurgan I7 (Kleinkurgan)

Dm 4 m; H o,2 m

Lage: N43 OI.I32 E79 24.I34

Form: abgerundete Steinanhäufung

Abhänge: keine Merkmale

Zustand: kein Trichter, keine Senke

Kurgan I8 (Kleinkurgan)

Dm 3 m; H o,I m

Lage: N43 OI.I3I E79 24.I33

Form: abgerundete Steinanhäufung

Abhänge: keine Merkmale

Zustand: kein Trichter, keine Senke

Kurgan I9 (Kleinkurgan)

Dm 6 m; H o,2 m

Lage: N43 OI.I24 E79 24.I28

Form: abgerundete Steinanhäufung

Abhänge: keine Merkmale

Zustand: kein Trichter, keine Senke

Kurgan 20 (Kleinkurgan)

Dm 5 m; H o,2 $\mathrm{m}$

Lage: N43 OI.II8 E79 24.I27

Form: abgerundete Steinanhäufung

Abhänge: keine Merkmale

Zustand: kein Trichter, keine Senke

Kurgan 2I (Kleinkurgan)

Dm 9 m; Dm Steinkreis I5 m; H o,3 m

Lage: N43 OI.III E79 24.I25; der südlichste Kurgan der Kette

Form: abgerundete Steinanhäufung

Abhänge: keine Merkmale

Weitere Konstruktionen: Um den Kurgan herum verläuft, in einem Abstand von $3 \mathrm{~m}$ vom Rand, ein Steinkreis, der aus mittelgroßen Steinen $(\mathrm{ab} 50 \times 40 \times 30 \mathrm{~cm})$ gebaut wurde.

Zustand: kein Trichter, keine Senke; Steinkreis nur zum Teil erhalten

Sonstiges: größter Kurgan der Kette

Zweite westliche Kurgankette

Kurgan 28 (Kleinkurgan)

Dm $4 \mathrm{~m}$; H o,I m

Lage: N43 OI.I36 E79 24.084; nördlichster Kurgan der Kette

Form: abgerundete Steinanhäufung

Abhänge: keine Merkmale

Zustand: kein Trichter, keine Senke
Kurgan 29 (Kleinkurgan)

Dm 5 m; H O,I m

Lage: N43 OI.I29 E79 24.080

Form: abgerundete Steinanhäufung

Abhänge: keine Merkmale

Zustand: kein Trichter, keine Senke

Kurgan 30 (Kleinkurgan)

Dm I8 m; Dm Steinkreis 34 m; H o,5 m

Lage: N43 OI.I20 E79 24.08I

Form: abgerundete Steinanhäufung

Abhänge: keine Merkmale

Weitere Konstruktionen: Um den Kurgan herum verläuft, in einem Abstand von $8 \mathrm{~m}$ vom Rand, ein Steinkreis, der aus mittelgroßen Steinen $(\mathrm{ab} 50 \times 40 \times 30 \mathrm{~cm})$ gebaut wurde.

Zustand: kein Trichter, keine Senke; Steinkreis nur zum Teil erhalten

Sonstiges: größter Kurgan der Kette

Kurgan 3I (Kleinkurgan)

Dm 3 m; H o, I m

Lage: N43 OI.IO8 E79 24.074

Form: abgerundete Steinanhäufung

Abhänge: keine Merkmale

Weitere Konstruktionen: Direkt nördlich und südlich direkt an den Kurgan anschließend befinden sich je eine quadratische, I $\times$ I $m$ große Umfriedung. Die Seiten beider Umfriedungen sind an den vier Haupthimmelsrichtungen orientiert und könnten in der frühtürkischen Periode errichtet worden sein

Zustand: kein Trichter, keine Senke

Kurgan 32 (Kleinkurgan)

Dm II $\mathrm{m} ; \mathrm{H} \circ, 2 \mathrm{~m}$

Lage: N43 oI.096 E79 24.070; südlichster Kurgan der Kette

Form: abgerundete Steinanhäufung

Abhänge: keine Merkmale

Zustand: kein Trichter, keine Senke

Erste westliche Kurgankette

Kurgan 33 (Kleinkurgan)

Dm 3 m; H o,I m

Lage: N43 OI.I50 E79 24.077

Form: abgerundete Steinanhäufung

Abhänge: keine Merkmale

Zustand: kein Trichter, keine Senke

Kurgan 34 (Kleinkurgan)

$\mathrm{Maß} 2 \times 2 \mathrm{~m} ; \mathrm{H}$ O,I $\mathrm{m}$

Lage: N43 OI.I44 E79 24.07I

Form: quadratische Umfriedung

Zustand: kein Trichter, keine Senke

Sonstiges: Die Seiten der Umfriedung sind an den vier Haupthimmelsrichtungen orientiert

Bemerkung: frühtürkische Periode 
Kurgan 35 (Kleinkurgan)

Dm 4 m; H o, I m

Lage: N43 OI.I39 E79 24.067

Form: abgerundete Steinanhäufung

Abhänge: keine Merkmale

Zustand: kein Trichter, keine Senke

Kurgan 36 (Kleinkurgan)

$\mathrm{Maß}$ I, $5 \times$ I, 5 m; H o,I m

Lage: N43 OI.I36 E79 24.067

Form: quadratische Umfriedung

Zustand: kein Trichter, keine Senke

Sonstiges: Die Seiten der Umfriedung sind an den vier

Haupthimmelsrichtungen orientiert

Bemerkung: frühtürkische Periode

Kurgan 37 (Kleinkurgan)

Dm 3 m; H o, I m

Lage: N43 OI.I32 E79 24.063

Form: abgerundete Steinanhäufung

Abhänge: keine Merkmale

Zustand: kein Trichter, keine Senke

Kurgan 38 (Kleinkurgan)

Maß $3 \times 3$ m; H o, I m

Lage: N43 OI.I22 E79 24.052

Form: quadratische Umfriedung

Zustand: kein Trichter, keine Senke

Sonstiges: Die Seiten der Umfriedung sind an den vier

Haupthimmelsrichtungen orientiert.

Bemerkung: frühtürkische Periode

\author{
Kurgan 39 (Kleinkurgan) \\ Dm 2 m; H o,I m \\ Lage: N43 OI.IO9 E79 24.047 \\ Form: abgerundete Steinanhäufung \\ Abhänge: keine Merkmale \\ Zustand: kein Trichter, keine Senke
}

Kurgan 40 (Kleinkurgan)

Dm 3 m; H o,I m

Lage: N43 OI.IO9 E79 24.048

Form: abgerundete Steinanhäufung

Abhänge: keine Merkmale

Zustand: kein Trichter, keine Senke

Kurgan 4I (Kleinkurgan)

Dm 3 m; H o, I m

Lage: N43 OI.IO7 E79 24.047

Form: abgerundete Steinanhäufung

Abhänge: keine Merkmale

Zustand: kein Trichter, keine Senke

Kurgan 42 (Kleinkurgan)

Dm 2 m; H o, I m

Lage: N43 OI.IOI E79 24.046

Form: abgerundete Steinanhäufung

Abhänge: keine Merkmale

Zustand: kein Trichter, keine Senke

Kurgan 43 (Kleinkurgan)

Dm 3 m; H o, I m

Lage: N43 or.o98 E79 24.043

Form: abgerundete Steinanhäufung

Abhänge: keine Merkmale

Zustand: kein Trichter, keine Senke

Forschungsgeschichte und Bemerkungen

Das Gräberfeld Aktasty-3 wurde in den I96oer Jahren von der Archäologischen Siebenstromland-Expedition entdeckt. Im Jahre 2006 wurde der Fundort im Laufe einer Revision der archäologischen Bodendenkmäler im Rajymbekskij rajon des Gebietes Almaty vom Turgen-Forschungsteam der Almaty Survey-Expedition (APAЭ) unter der Leitung von A. Gorjačev erneut untersucht (Bajpakov/Gorjačev 2007, I52-I53). Es wurden eine Beschreibung und ein topographischer Plan der Nekropole hergestellt. Jedoch wurde nur die Osthälfte der Nekropole, also I4 Kurgane, aufgenommen. Weitere 3I westlich gelegene Kleinkurgane wurden nicht erwähnt.

Lit.: Bajpakov/Gorjačev 2007, I5-153.

Gräberfeld Asy Saga [FEZ] (Abb. I2I-I22; Karte 3 Nr. 29): ALT 840 m N43 29.978 E78 20.274; Gebiet Almaty (kasach. Алматы облысы), Enbekšikazachskij rajon (kasach. Еңбекшіқазақ ауданы); Ausmaß $\mathrm{N}-\mathrm{S} \mathrm{I}, 4 \times \mathrm{O}-\mathrm{W}$ o, $5 \mathrm{~km}$.

Beim Dorf Kyzylšaryk (kasach. Қызыл шарық), са. I4 km südsüdöstlich vom Dorf Čilik (kasach. Шелек) entfernt, auf dem linken, westlichen Ufer des Asy (kasach. Aсы) gelegen, befindet sich die Nekropole Asy Saga. Alle Kurgane weisen dort drei steile und einen (immer nach Süden abfallenden) sanften Abhang auf. Die Nekropole besteht nur aus sechs Großkurganen, die eine N-S - Achse bilden. Der 
Durchmesser der Kurgane schwankt zwischen $40 \mathrm{~m}$ und $149 \mathrm{~m}$ (mit dem sog. Prozessionsweg $252 \mathrm{~m}$ ), die Höhen betragen zwischen 2,5 $\mathrm{m}$ und ca. 2I m. Alle Kurgane weisen unterschiedliche architektonische Merkmale auf.
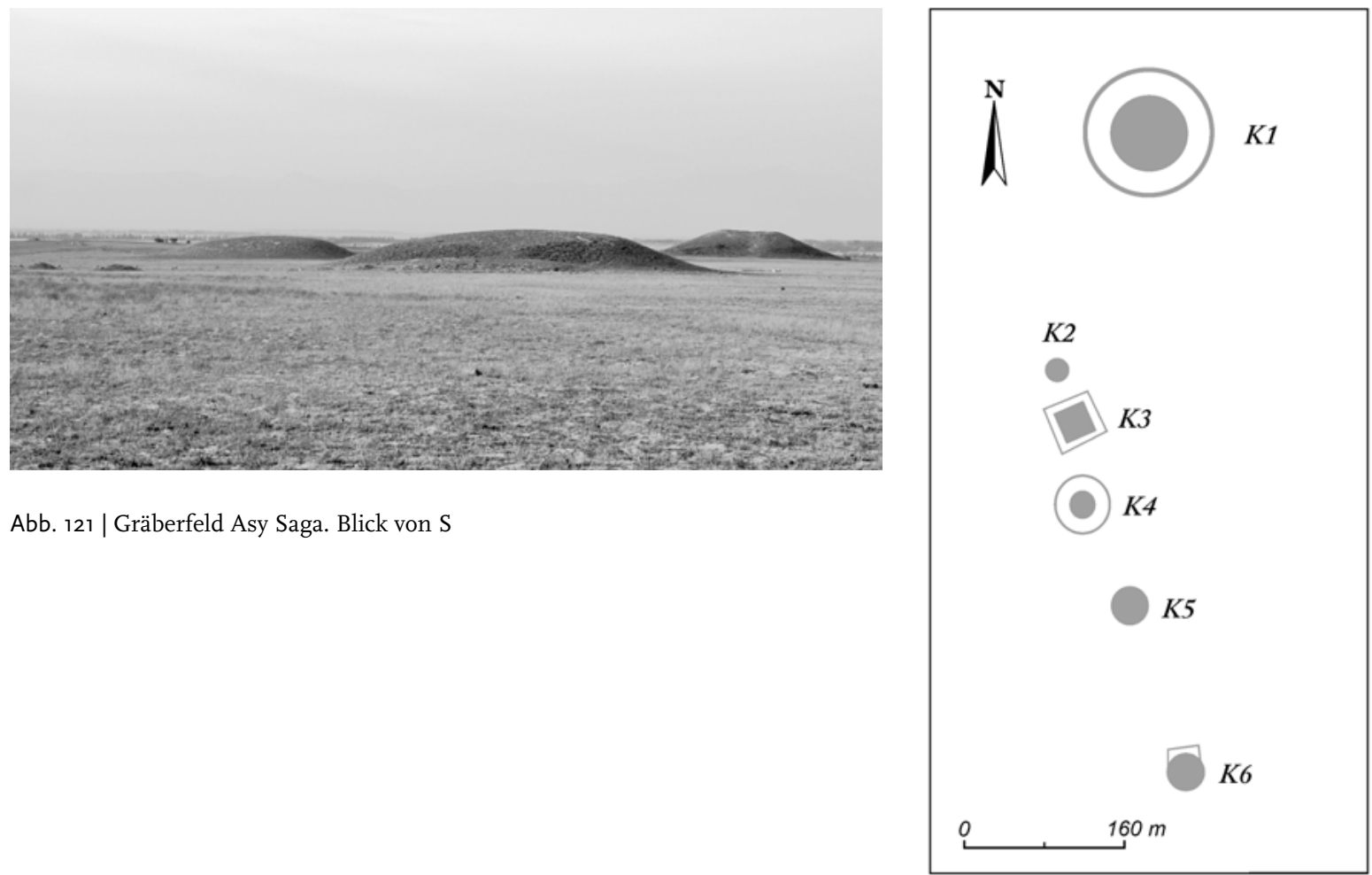

Abb. 121 | Gräberfeld Asy Saga. Blick von S

Abb. 122 | Plan des Gräberfeldes Asy Saga

Anhand der Lage im Gelände, der Struktur und der äußeren Erscheinungsform können alle Kurgane des Gräberfeldes der sakischen Periode der Früheisenzeit zugeordnet werden.

Kurgancharakteristik:

Kurgan I (Abb. I23,I)

Dm I49 m; Dm mit dem sog. Prozessionsweg 252 m; H 2 I $\mathrm{m}$

Lage: N43 30.300 E78 20.432;

KI ist der nördlichste Kurgan der Kette und wurde nordöstlich, separiert von den übrigen Hügeln der Nekropole angelegt.

Form: abgerundet, plattformähnlich mit abgeflachter Kuppe

Abhänge: drei steile, südlicher sanft

Weitere Konstruktionen: $47-48$ m vom Rand des Kurgans entfernt liegt ein umlaufender sog. Prozessionsweg, dessen Breite $5 \mathrm{~m}$ beträgt (Abb. 123,2). Dieser wird durch große Steine $(\mathrm{ab} 60 \times 40 \times 30 \mathrm{~cm})$ begrenzt, während in seinem Inneren gestampfter Steinschutt liegt. Zwischen dem Kurgan und dem sog. Prozessionsweg befinden sich 2I kleine steinerne Konstruktionen.

Zustand: in der Mitte und im nördlichen Bereich zwei Raubtrichter
Sonstiges: gesamte Oberfläche mit mittelgroßen Steinen bedeckt

Kurgan 2 (Abb. I23,3)

Dm $40 \mathrm{~m} ; \mathrm{H}_{3} \mathrm{~m}$

Lage: N43 30.054 E78 20.26I

Form: abgerundet, plattformähnlich mit abgeflachter Kuppe

Abhänge: drei steile, südlicher sanft

Zustand: in der Mitte ein Raubtrichter

Sonstiges: einzelne mittelgroße Steine der Kurganabdeckung an der Oberfläche

Kurgan 3 (Abb. I23,4)

L (Seite) 56 m; L (Seite des sog. Prozessionsweges) 95 $\mathrm{m} ; \mathrm{H} 4 \mathrm{~m}$

Lage: N43 $30.000 \mathrm{E} 78$ 20.286

Form: viereckig, pyramidenähnlich mit abgeflachter Kuppe 

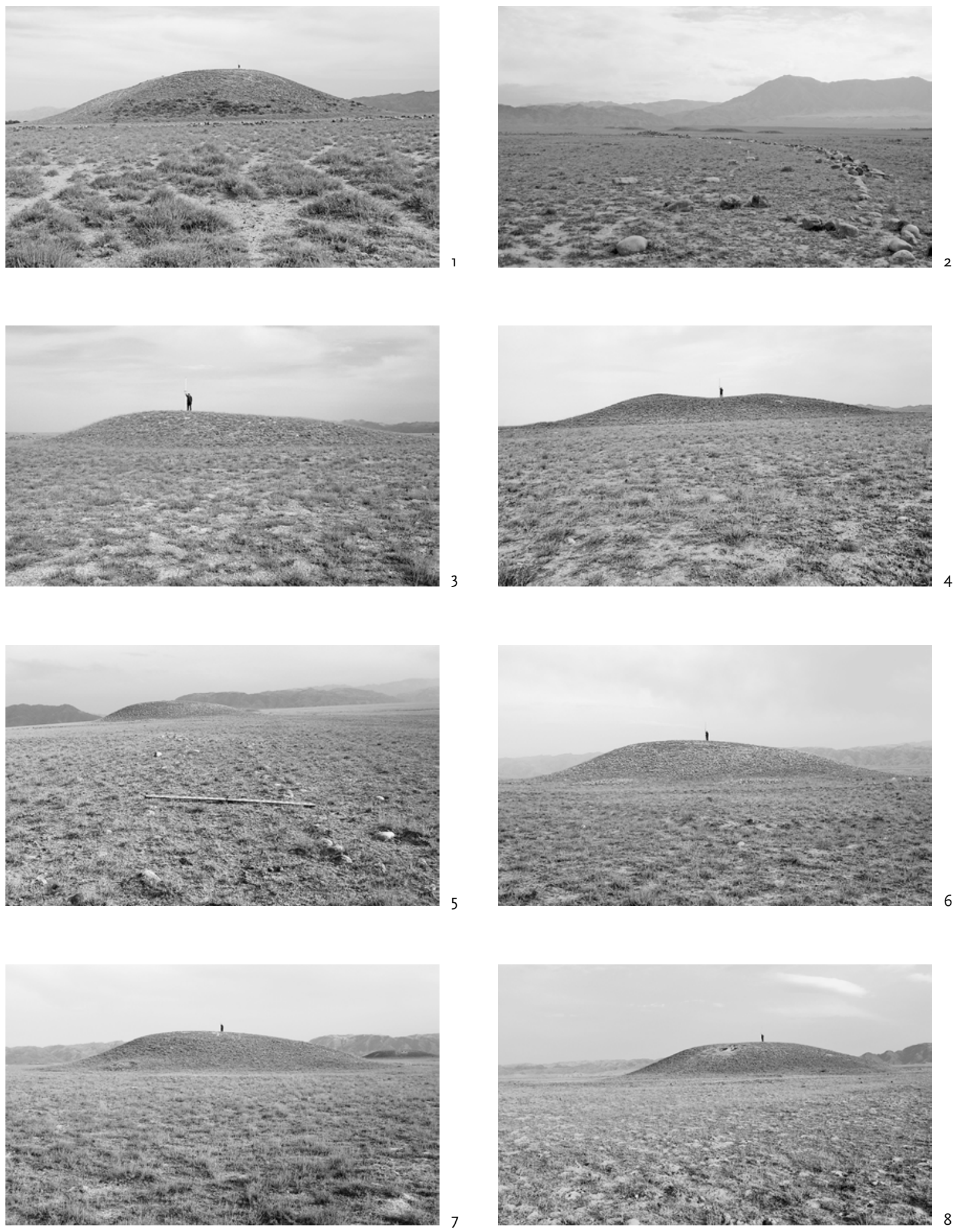

Abb. 123 | Gräberfeld Asy Saga; I. Kurgan I, Blick von W; 2. Sog. Prozessionsweg, Südwestbereich, Blick von N; 3. Kurgan 2, Blick von W; 4. Kurgan 3, Blick von W; 5. Sog. Prozessionsweg, Westseite, Blick von N; 6. Kurgan 4, Blick von WNW; 7. Kurgan 5, Blick von NW; 8. Kurgan 6, Blick von WNW 
Abhänge: drei steile, südlicher sanft

Weitere Konstruktionen: In einem Abstand von ca. I7 m zum Kurgan liegt umlaufend ein sog. Prozessionsweg, dessen Breite 2,5 m misst (Abb. I23,5). Prinzipiell ist er jenem von Kurgan I sehr ähnlich, weist allerdings eine viereckige Form auf. Der Zustand des „Weges“ ist nicht an allen Seiten gleich: während er an der westlichen und nördlichen Seite sehr gut erhalten ist, ist er an der östlichen und südlichen Seite fast vollständig zerstört. Dort sind nur einzelne Fragmente und in einer Linie liegende große Steine erhalten.

Zustand: in der Mitte ein Raubtrichter

Sonstiges: Die Seiten des Kurgans sind grob an den vier Haupthimmelsrichtungen orientiert. Die gesamte Oberfläche ist mit absichtlich zerschlagenen und gesplitterten rötlichen Steinen bedeckt. Im Fußbereich der nordwestlichen Ecke des Grabhügels sind Steine von der Kurgankrepis sichtbar; im Fußbereich der Nordseite liegt ein kleiner Steinwall.

Kurgan 4 (Abb. I23,6)

Dm 62 m; Dm mit dem sog. Prozessionsweg 106 m; H $5 \mathrm{~m}$

Lage: N43 29.905 E78 20.3I2

Form: abgerundet, plattformähnlich mit abgeflachter Kuppe

Abhänge: drei steile, südsüdwestlicher sanft

Weitere Konstruktionen: $20 \mathrm{~m}$ vom Kurgan entfernt liegt ein $2 \mathrm{~m}$ breiter umlaufender sog. Prozessionsweg, dessen Erhaltungszustand zum Teil schlecht ist. Zwischen dem Kurgan und dem sog. Prozessionsweg befinden sich im nordnordwestlichen Bereich vier kleine steinerne Konstruktionen, die als Kleinkurgane interpretiert werden können.

Zustand: In der Mitte des Kurgans befindet sich eine leichte Absenkung, die von einer Beraubung des Grabhügels stammen könnte.

Sonstiges: an der Oberfläche kleine und mittelgroße, weiße Steine der Kurganabdeckung; Hügelkuppe dagegen fundfrei

Kurgan 5 (Abb. I23,7)

Dm 72 m; H 6 m

Lage: N43 29.790 E78 20.379

Form: abgerundet, plattformähnlich mit abgeflachter Kuppe

Abhänge: drei steile, südwestlicher sanft

Zustand: in der Mitte keine Spuren einer Absenkung Sonstiges: mittelgroße Steine der Kurganaufschüttung an der Oberfläche; außer auf der abgeflachten Kurgankuppe

Kurgan 6 (Abb. 123,8 )

Dm 68 m; H 5 m

Lage: N43 29.6I7 E78 20.426

Form: abgerundet, plattformähnlich mit abgeflachter Kuppe

Abhänge: drei steile, südsüdwestlicher sanft

Weitere Konstruktionen: An der Nordseite des Kurgans wurde eine Art „Vorsprung“ aus Erde und Steinschutt gebaut (B $22 \mathrm{~m}, \mathrm{~L} 52 \mathrm{~m}, \mathrm{H} \circ, 4-0,5 \mathrm{~m}$ ).

Zustand: in der Mitte leichte Senke (Raubtrichter?)

Sonstiges: Die Oberfläche des Kurgans, mit Ausnahme der abgeflachten Kuppe, ist mit kleinen und mittelgroßen Steinen bedeckt.

\section{Forschungsgeschichte}

Im Jahre I992 wurde die Nekropole im Rahmen der Zusammenstellung der Studie „Denkmäkler der Geschichte und Kultur der Republik Kasachstan“ und der Passportisierung der archäologischen Bodendenkmäler in Almaty- und Taldy-Kurgan-Gebieten, von V. A. Grošev und A. N. Mar’jašev (Archäologisches Institut Almaty) untersucht und beschrieben. Allerdings wurden Kurgan I und die restlichen Kurgane als zwei unterschiedliche Fundorte beschrieben (Grošev/Mar’jašev I992, I3).

Kurgan I bezeichnete man als alleinstehenden Kurgan Kajrat I (russ. Кайрат I) und die restlichen Kurgane als Gräberfeld Kajrat II (russ. Кайрат II).

Eine Lageskizze oder ein Gräberfeldplan wurden nicht angefertigt.

Lit.: Gass 2011a, 65-7, Fig. 3, I4-2; Gass 2011b, 2I2-215, Abb. 5-8, I0-I4; Gass (im Druck); Grošev/Mar’jašev I992, I3; Nagler 2009, 408, Abb. 76; Nagler u.a. 2010, 49-54; Samašev u.a. 2009, 350-352.

Gräberfeld am Stausee Bartogaj [FEZ] (Abb. ı24; Karte 3 Nr. 39): ALT ıo80 m N43 22.137 E78 30.898; Gebiet Almaty (kasach. Алматы облысы), Enbekšikazachskij rajon (kasach. Еңбекшіқазақ ауданы); Ausmaß N-S 2,8 $\times$ O-W o, $58 \mathrm{~km}$.

Die Nekropole liegt ca. I2 8 km östlich von der Stadt Almaty (kasach. Алматы) und 34 km südöstlich des Dorfes Čilik (kasach. Шелек) entfernt, direkt am Ostufer des Stausees Bartogaj und südlich der Serektas Berge. Das Gräberfeld besteht aus zwei Kurganketten. Die Südkette liegt im Becken des Stau- 


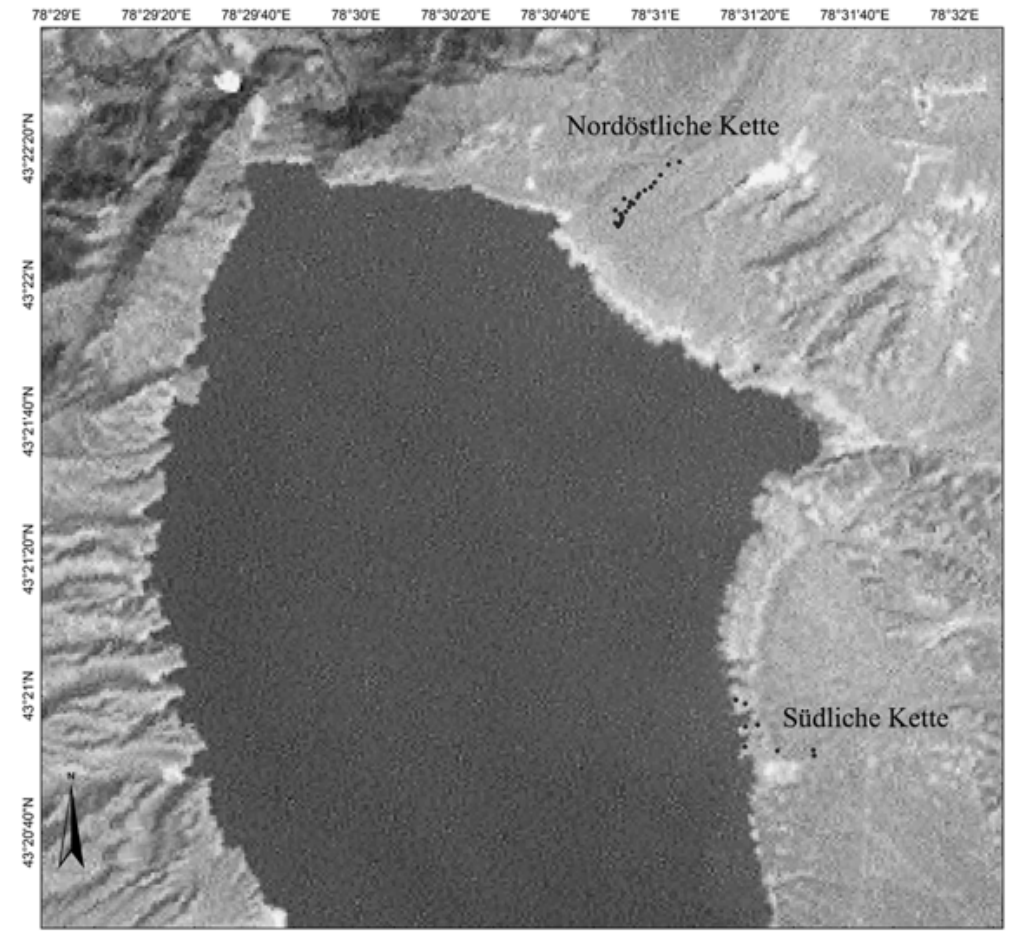

Abb. 124 | Gräberfeld am Bartogaj Stausee

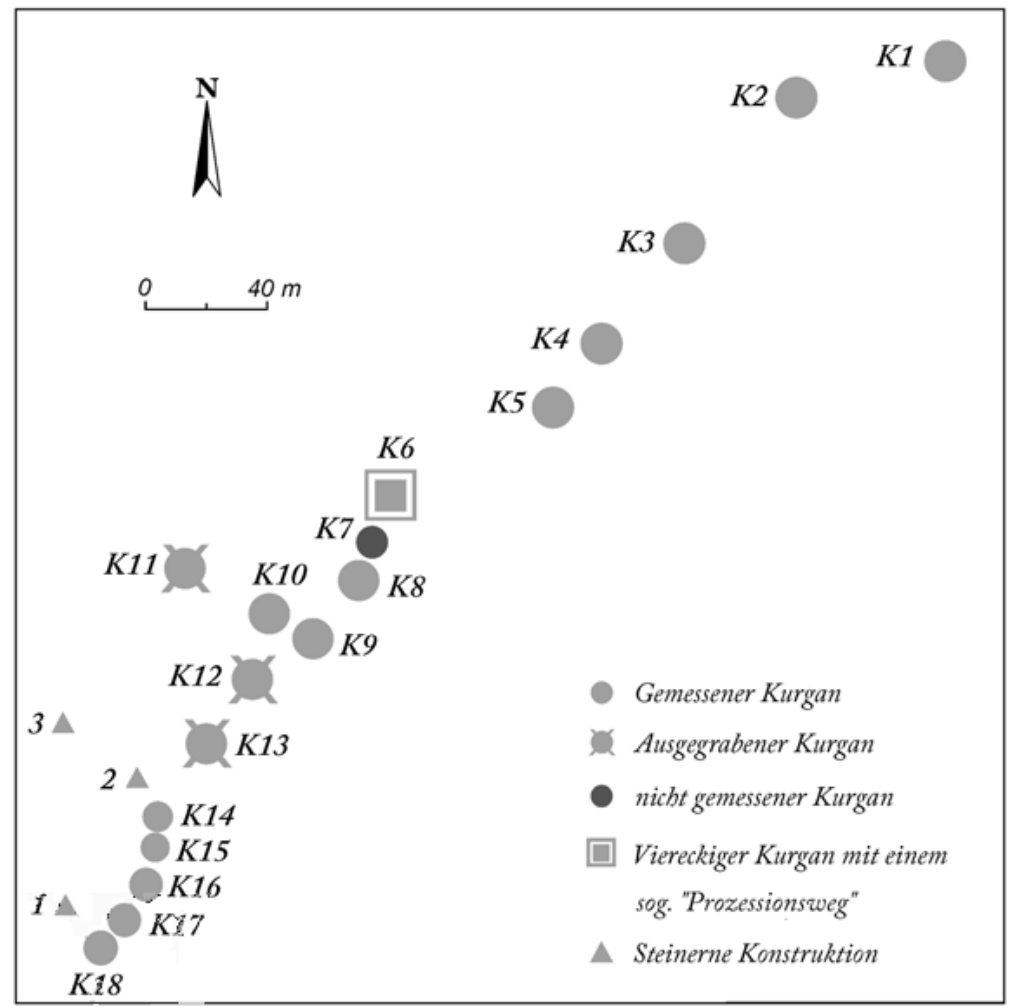

Abb. 125 | Gräberfeld am Stausee Bartogaj, nordöstliche Kurgankette 
sees und wird in den Frühlings- und Sommermonaten von Wasser überflutet. Die Nordkette wurde im Herbst 2008 untersucht. Am Ufer befanden sich ca. I9 Kurgane, die drei O-W ausgerichtete Reihen darstellten. Der Durchmesser der Kurgane schwankte zwischen Io $\mathrm{m}$ und 20 m, die Höhe reichte bis zu o,4 m. Der Erhaltungszustand der Kurgane war von „schlecht“ bis „sehr schlecht“, da die Kurgane durch die ständig wechselnde Wasserhöhe stark gestört wurden. Die nordöstliche Kurgankette (Abb. I25) befindet sich ca. 300 m nördlich von der nordöstlichen Uferkante des Stausees. Die NO-SW ausgerichtete Kette besteht aus I8 Kurganen, von denen drei ausgegraben wurden ${ }^{82}$, und drei einzelnen Bestattungen in Steinkisten (?). Die Kurgane erreichen im Durchschnitt einen Durchmesser von Io $\mathrm{m}$ bis I8-20 $\mathrm{m}$ und haben eine Höhe ca. 0,2-0,7 m. Der in der Mitte der Kette befindliche Kurgan Nr. 6583 weist eine viereckige Form auf. Um den Kurgan herum verläuft ein sog. Prozessionsweg, dessen äußere Form den Umriss des Kurgans wiederholt. Im Vergleich zur südlichen Kurgankette sind hier die Kurgane besser erhalten.

Anhand der Struktur und der äußeren Erscheinungsform können die Kurgane des Gräberfeldes der sakischen Periode der Früheisenzeit zugeordnet werden.

Charakteristik der Kurgane der nordöstlichen Kette:

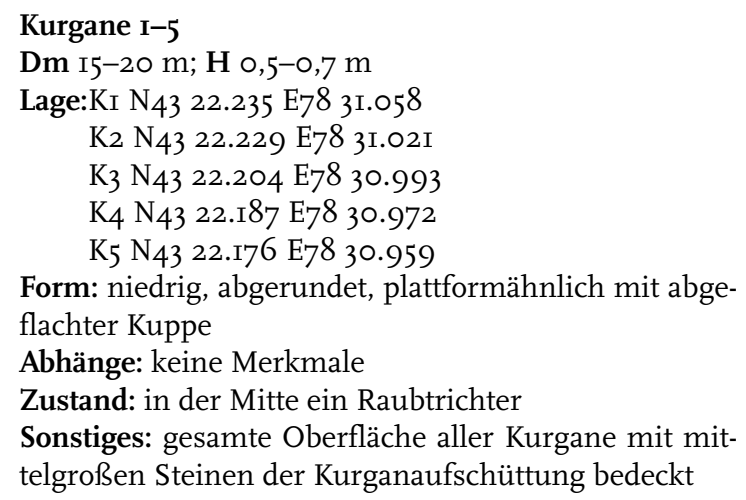

Form: niedrig, abgerundet, plattformähnlich mit abgeflachter Kuppe

Abhänge: keine Merkmale

Zustand: in der Mitte ein Raubtrichter

Sonstiges: gesamte Oberfläche aller Kurgane mit mittelgroßen Steinen der Kurganaufschüttung bedeckt

\begin{abstract}
Kurgan 6 (Abb. I26,I)
Seitenlänge $20 \mathrm{~m} ; \mathrm{H} 0,7 \mathrm{~m}$

Lage: N43 22.I60 E78 30.9I9

Form: viereckig mit abgeflachter Kuppe

Abhänge: keine Merkmale

Weitere Konstruktionen: ca. 7-9 m vom Rand des Kurgans entfernt liegt ein ebenso viereckiger sog. Prozessionsweg, dessen Breite I,O-I,5 $\mathrm{m}$ beträgt. Er wird durch mittelgroße Steine $(\mathrm{ab} 40 \times 30 \times 20 \mathrm{~cm})$ begrenzt.

Zustand: in der Mitte ein Raubtrichter

Sonstiges: Die Seiten des Kurgan, sowie des sog. Prozessionsweges sind an den vier Haupthimmelsrichtungen orientiert; gesamte Oberfläche mit mittelgroßen Steinen bedeckt
\end{abstract}
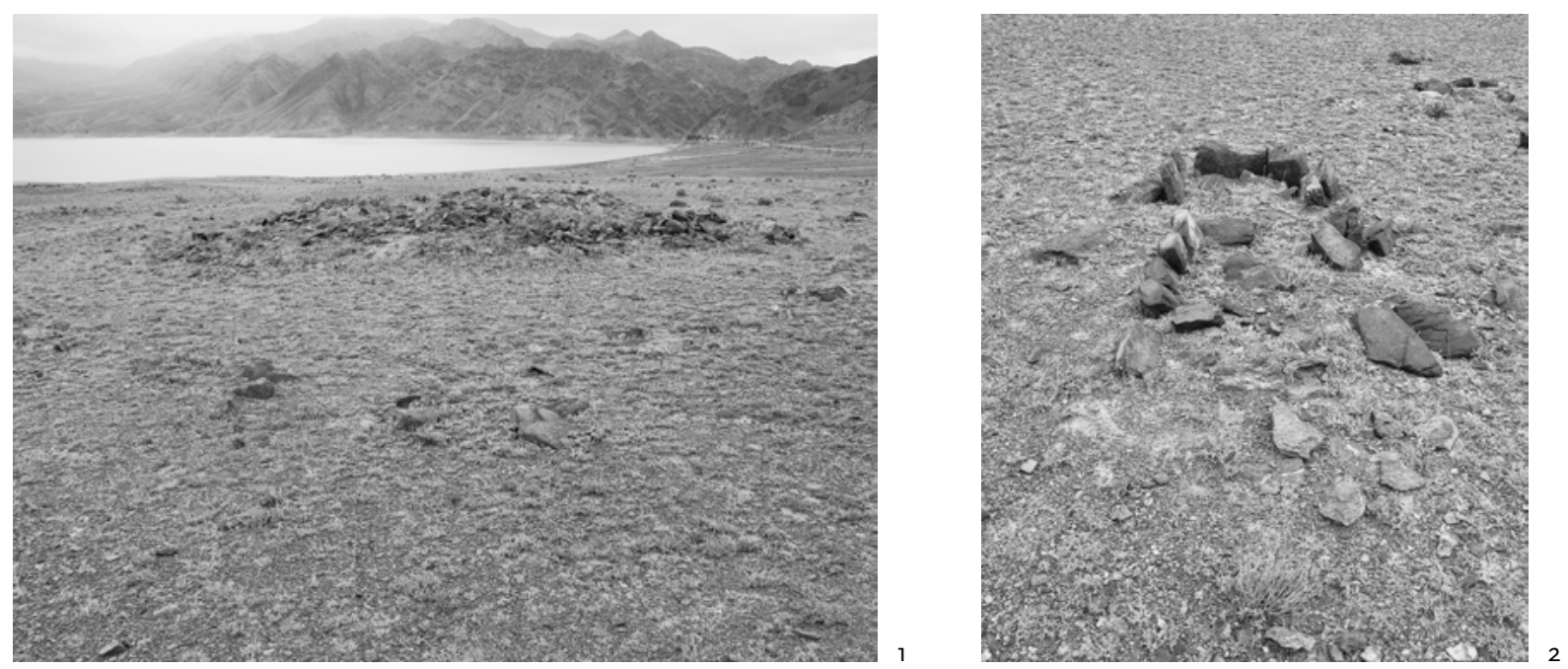

Abb. 126 | Gräberfeld am Stausee Bartogaj; r. Kurgan 6, Blick von NO; 2. Kiste 2, Blick von W

582 Wann und von wem ist nicht festzustellen.

583 Nach unserer Arbeitsnummerierung. 
Kurgane 7-IO und $14-18$

Dm IO-I8 m; H ०,2-0,5 m

Lage: $\mathrm{K}_{7}$ - nicht gemessen

K8 N43 22.I47 E78 30.910

K9 N43 22.I37 E78 30.898

Kio N43 22.I42 E78 30.888

KI4 N43 22.I06 E78 30.859

KI5 N43 22.IOI E78 30.858

KI6 N43 22.095 E78 30.855

KI7 N43 22.089 E78 30.850

KI8 N43 22.083 E78 30.844

Form: niedrig, abgerundet, plattformähnlich mit abge-

flachter Kuppe bis zu rundlichen Steinanhäufungen

Abhänge: keine Merkmale

Zustand: in der Mitte ein Raubtrichter

Sonstiges: gesamte Oberfläche aller Kurgane mit kleinen und mittelgroßen Steinen der Kurganaufschüttung bedeckt

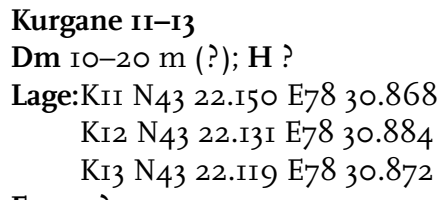

Abhänge: ?

Zustand: Anstelle der Kurgane befinden sich hier Gruben. Anhand der erweiterten Absenkungen in der Mitte des Grubenbodens und der offensichtlich geputzten Grubenwände sowie anhand des nahegelegenen Abraumhaufens konnte festgestellt werden, dass diese
Befunde ausgegraben, aber nicht rekultiviert worden sind. Von wem und wann sie ausgegraben wurden, konnte nicht geklärt werden $5^{84}$.

\section{Steinkiste I}

L ? m; B ? $\mathrm{m}$

Lage: N43 22.091 E78 30.837

Form: rechteckige, aus senkrecht stehenden Steinplatten gebaute Steinkiste

Ausrichtung: WSW-ONO

Sonstiges: Um die Kiste herum liegen große $(60 \times 40 \times$ $30 \mathrm{~cm}$ ) Steine

Steinkiste 2 (Abb. I26,2)

L ? $\mathrm{m} ; \mathbf{B}$ ? $\mathrm{m}$

Lage: N43 22.II4 E78 30.854

Form: rechteckige, aus senkrecht stehenden Steinplatten gebaute Steinkiste

Ausrichtung: W-O

Steinkiste 3

L ? $\mathrm{m} ; \mathbf{B}$ ? $\mathrm{m}$

Lage: N43 22.I25 E78 30.837

Form: rechteckige, aus senkrecht stehenden Steinplatten gebaute Steinkiste

Ausrichtung: N-S

Sonstiges: Die Steinkiste ist mit einer rundlichen Steinanhäufung (mittelgroße Steine) überdeckt; trotz dieser Bauart konnten die senkrecht stehenden Steinplatten der Kiste gut erkannt werden.

\section{Ergänzung}

9,9 km nordöstlich von der Nekropole entfernt wurde ein Gräberfeld, das aus Kleinkurganen bestand, festgestellt. Ein Kurgan wies einen doppelten Steinkreis (sog. Prozessionsweg?) (Nr. I) auf. Dieser Kurgan war der größte und stand südlich und abseits von den restlichen Kleinkurganen.

Ein zweites ähnliches Gräberfeld befand sich 6,5 km von der Nekropole am Stausee Bartogaj entfernt. Dieses Gräberfeld wies auch einen größeren Kurgan mit doppeltem Steinkreis (sog. Prozessionsweg?) (Nr. 2) auf. Er lag ebenso südlich und abseits von den restlichen Kleinkurganen.

Kurgan (Nr. I; Abb. I27,I)

Dm 24 m; Dm äußere Grenze des doppelten Steinkreises (sog. Prozessionsweges?) $42 \mathrm{~m} ; \mathrm{H} 0,7 \mathrm{~m}$

Lage: N43 25.242 E78 37.I58

Form: abgerundet, plattformähnlich mit abgeflachter Kuppe

Abhänge: drei steile, südlicher sanft

Weitere Konstruktionen: $8 \mathrm{~m}$ vom Rand des Hügels entfernt liegt ein umlaufender doppelter Steinring, dessen Breite I m misst (Abb. I27,2). Dieser wird durch mittelgroße gesplitterte Steine, die senkrecht eingestellt worden sind, begrenzt; evtl. handelte es sich hier um einen sog. Prozessionsweg.
Zustand: auf der Kurgankuppe keine Senke

Sonstiges: ganze Oberfläche ist mit gesplitterten rötlichen mittelgroßen Steinen bedeckt

Kurgan (Nr. 2; Abb. I27,3)

Dm 20 m; Dm äußere Grenze des doppelten Steinkreises (sog. Prozessionsweges?) $40 \mathrm{~m} ; \mathrm{H} \mathrm{I,O-I,2} \mathrm{m}$

Lage: N43 23.876 E78 35.286

Form: abgerundet mit abgeflachter Kuppe

Abhänge: drei steile, südlicher sanft

Weitere Konstruktionen: 9 m vom Rand des Hügels entfernt liegt ein umlaufender doppelter Steinring, dessen Breite I m umfasst. Dieser wird durch mittelgroße,

584 Im Archiv des Archäologischen Institutes Almaty gab es keinen Bericht zu dieser Grabung. 

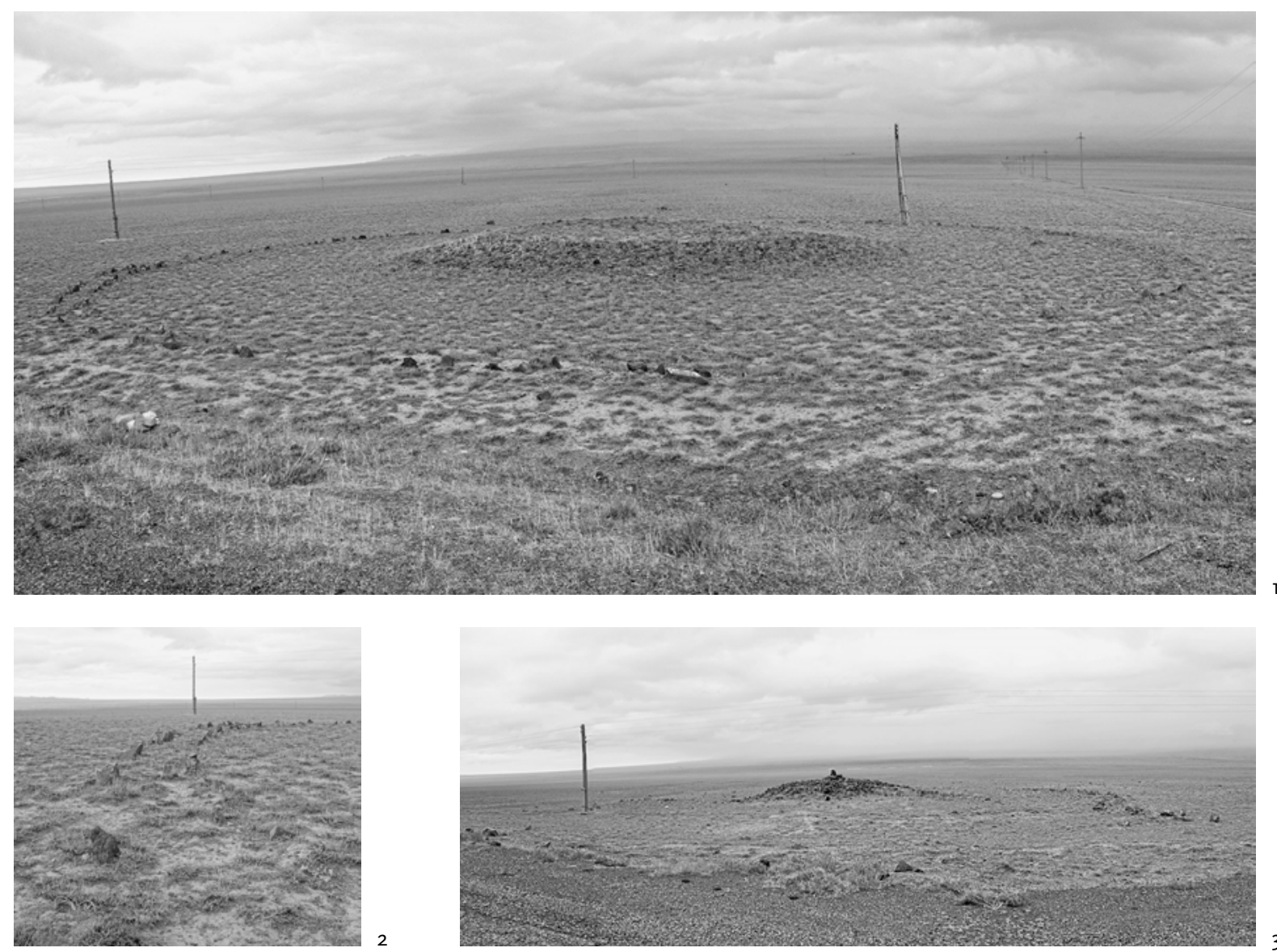

Abb. 127 | Umgebung vom Gräberfeld am Stausee Bartogaj. Kurgane (Nr. I und Nr. 2), Blick von N; I. Kurgan (Nr. I); 2. Kurgan (Nr. I), Doppelring/ sog. Prozessionsweg (?), Ostsektor; 3. Kurgan (Nr. 2)

gesplitterte Steine, die senkrecht aufgestellt worden sind, begrenzt; evtl. handelte es sich hier um einen sog. Prozessionsweg
Zustand: auf der Kurgankuppe keine Senke Sonstiges: gesamte Oberfläche mit mittelgroßen Steinen bedeckt

Gräberfeld Bes Tobe [FEZ] (Abb. I28; Karte 3 Nr. 22): ALT 660 m N43 30.582 E77 49.513; Gebiet Almaty (kasach. Алматы облысы), Enbekšikazachskij rajon (kasach. Еңбекшіқазақ ауданы); Ausmaß N-S $2,9 \times \mathrm{O}-\mathrm{W} 0,5 \mathrm{~km}$.

Das Gräberfeld Bes Tobe befindet sich in einer flachen Ebene nördlich der Bergkette Transili-Alatau (kasach. Іле Алатауы), 77 km nordöstlich von der Stadt Almaty, 4 km nordöstlich vom Dorf Aščbulak (kasach. Ащыбулак) und 5,5 km südwestlich vom Dorf Teskensu (kasach. Тескенсу) entfernt. Die Nekropole wurde auf dem linken, westlichen Kiikpaj-Ufer (kasach. Кийкпай) angelegt. Das Gräberfeld zählt heute insgesamt 47 große und kleine Kurgane, die eine N-S Achse bilden und sich zu drei Ketten formieren. Die westliche Kette (K7-K40) besteht nur aus Kleinkurganen. Die mittelgroßen und großen Kurgane bilden die östliche (KI-K6) und die nördliche (K4I-K47) Kette (Abb. I29).

Fast alle Kurgane weisen einen oder mehrere Raubtrichter auf. Der Durchmesser der Kurgane liegt zwischen $8 \mathrm{~m}$ und 8I $\mathrm{m}$, die Höhe zwischen o,3 $\mathrm{m}$ und $6 \mathrm{~m}$. Die Kurgane sind im Gelände meist durch mittelgroße Steine $(\mathrm{ab} 30 \times 20 \times 15 \mathrm{~cm})$ an der Oberfläche gekennzeichnet. 3I Kurgane haben drei steile 


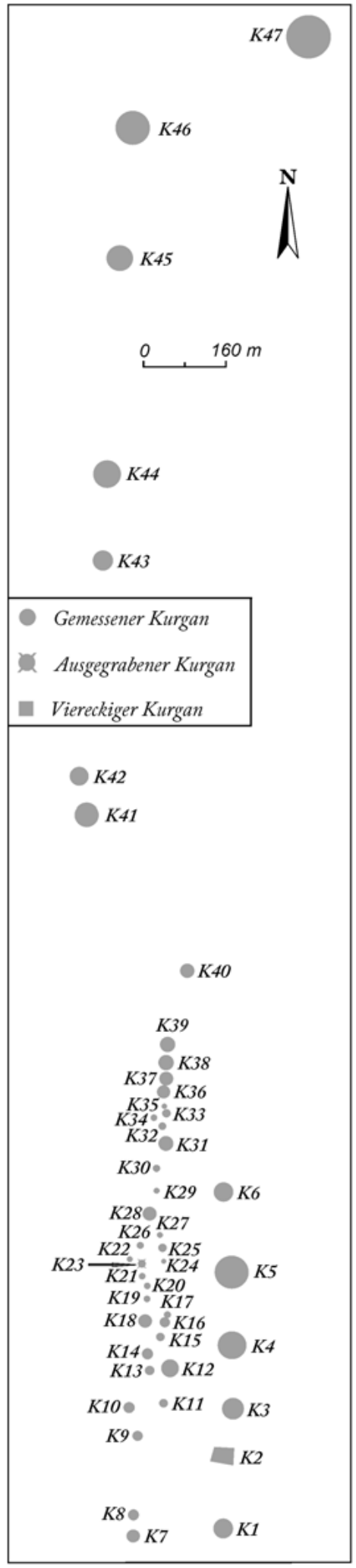

Abb. 128 | Plan des Gräberfeldes Bes Tobe

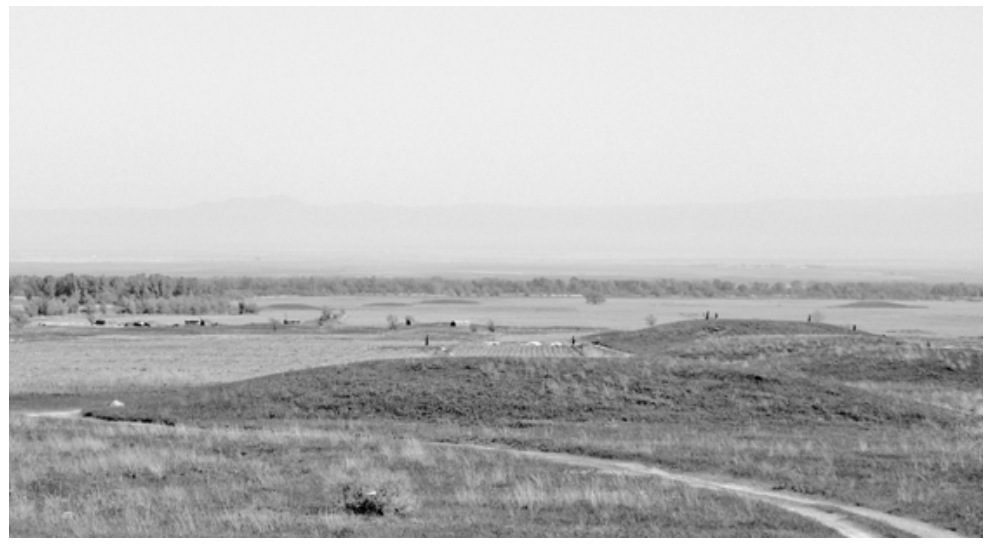

Abb. 129 | Gräberfeld Bes Tobe. Übersichtsfoto. Östliche Kette, im Hintergrund nördliche Kurgankette. Blick von S

und einen (immer südlich abfallenden) sanften Abhang. Ein Kurgan weist eine viereckige, pyramidenähnliche Form mit abgeflachter Kuppe auf. Trotz der pyramidenförmigen Konstruktion hat dieser Kurgan auch einen sanften südlichen Abhang. Bei I3 Kurganen konnten aufgrund der geringen Größe und bei drei Kurganen aufgrund des schlechten Erhaltungszustandes gar keine Merkmale der Aufschüttung festgestellt werden.

Das gesamte Gräberfeld grenzt an modernes Ackergebiet. Fast alle Kurgane der nördlichen Kette befinden sich direkt auf dem Acker, so dass die Peripherie der Kurgane vollständig zerstört ist.

Anhand der geographischen Lage, der Struktur und der äußeren Erscheinungsform können alle Kurgane des Gräberfeldes der sakischen Periode der Früheisenzeit zugeordnet werden.

Kurgancharakteristik:

Östliche Kette

\section{Kurgan I}

Dm 37 m; H 3 m

Lage: N43 30.229 E77 49.497; südlichster Kurgan der östlichen Kette Form: abgerundet, plattformähnlich mit abgeflachter Kuppe Abhänge: drei steile, südlicher sanft

Zustand: an der Oberfläche drei Raubtrichter; Peripherie des Kurgans durch Acker beschädigt

Sonstiges: keine Steine an der Oberfläche

Kurgan 2 (Abb. I3o)

Seitenlänge $33 \mathrm{~m} ; \mathrm{H}_{3} \mathrm{~m}$

Lage: N43 30.306 E77 49.499

Form: viereckig, pyramidenähnlich mit abgeflachter Kuppe

Abhänge: drei steile, südlicher sanft

Zustand: kein Raubtrichter; Der Fußbereich des Kurgans an der Ostseite ist durch einen Bewässerungskanal gestört; die Westseite des Fußbereiches ist durch einen Feldweg beschädigt 


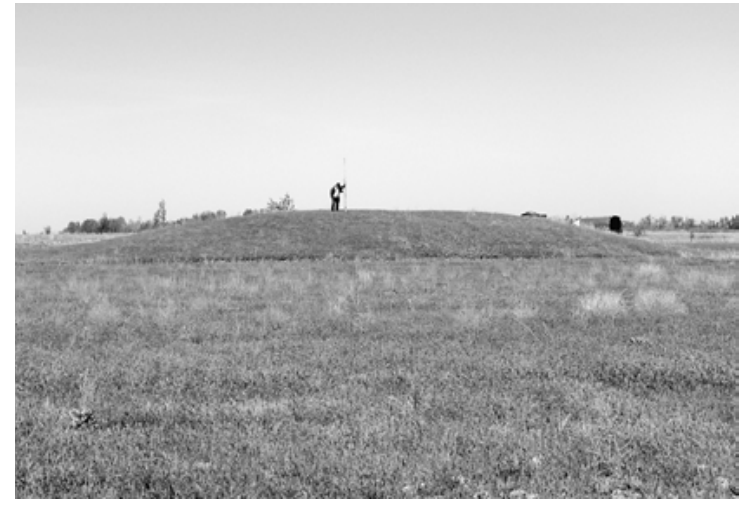

Abb. $130 \mid$ Kurgan 2. Blick von O

Sonstiges: Oberfläche mit einzelnen mittelgroßen Steinen $(\mathrm{ab} 20 \times$ I5 $\times$ IO $\mathrm{cm})$ bedeckt; am Kurganrand liegen größere Steine $(\mathrm{ab} 70 \times 60 \times 50 \mathrm{~cm})$

\section{Kurgan 3}

Dm $40 \mathrm{~m} ; \mathrm{H}_{4} \mathrm{~m}$

Lage: N43 30.356 E77 49.518

Form: abgerundet, plattformähnlich mit abgeflachter Kuppe

Abhänge: drei steile, südlicher sanft

Zustand: in der Mitte leichte Senke durch einen Raubtrichter; nordwestnördlicher Randbereich durch einen Feldweg stark beschädigt

Sonstiges: keine Steine an der Oberfläche

\section{Kurgan 4}

Dm $52 \mathrm{~m} ; \mathrm{H}_{4} \mathrm{~m}$

Lage: N43 30.42I E77 49.5I9

Form: abgerundet, plattformähnlich mit abgeflachter Kuppe

Abhänge: drei steile, südlicher sanft

Zustand: in der Mitte ein Raubtrichter; westlicher Randbereich des Kurgans durch einen Feldweg beschädigt; Peripherie durch den Pflug zerstört

Sonstiges: keine Steine an der Oberfläche

\section{Kurgan 5}

Dm 57 m; H 5 m

Lage: N43 30.499 E77 49.522

Form: abgerundet, plattformähnlich mit abgeflachter Kuppe

Abhänge: drei steile, südlicher sanft

Zustand: auf der Oberfläche fünf Raubtrichter; Westlicher Randbereich des Kurgans ist durch einen Feldweg beschädigt. Peripherie durch Acker zerstört Sonstiges: keine Steine an der Oberfläche

\section{Kurgan 6}

Dm 3I m; H 2 m

Lage: N43 30.582 E77 49.513; der nördlichste Kurgan der Ostkette
Form: abgerundet, plattformähnlich mit abgeflachter Kuppe

Abhänge: drei steile, südlicher sanft

Zustand: kein Raubtrichter; westlicher und nördlicher Randbereich durch den Acker zerstört

Sonstiges: kleinster Kurgan der Kette; an der Oberfläche mittelgroße und kleine Steine $(30 \times 20 \times 15 \mathrm{~cm})$

Westliche Kette

Kurgan 7 (Kleinkurgan)

Dm $24 \mathrm{~m} ; \mathrm{H}$ 0,5-0,7 m

Lage: N43 30.226 E77 49.368; südlichster Kurgan der westlichen Kette

Form: klein, abgerundet, plattformähnlich mit abgeflachter Kuppe

Abhänge: drei steile, südlicher sanft

Zustand: kein Raubtrichter

Sonstiges: keine Steine an der Oberfläche

Kurgan 8 (Kleinkurgan)

Dm 20 m; H O,5 m

Lage: N43 30.248 E77 49.370

Form: abgerundete Erhebung

Abhänge: drei steile, südlicher sanft

Zustand: gesamter Kurgan ist überpflügt

Sonstiges: an der Oberfläche einige mittelgroße Steine $(30 \times 20 \times 15 \mathrm{~cm})$

Kurgan 9 (Kleinkurgan)

Dm I8 m; H I $\mathrm{m}$

Lage: N43 30.330 E77 49.379

Form: abgerundete Erhebung

Abhänge: keine Merkmale

Zustand: ganzer Kurgan ist überpflügt

Sonstiges: an der Oberfläche einige kleine Steine (I5 $\times$ IO $\times 5 \mathrm{~cm}$ )

Kurgan ıo (Kleinkurgan)

Dm 20 m; H I m

Lage: N43 30.360 E77 49.368

Form: abgerundete Erhebung

Abhänge: drei steile, südlicher sanft

Zustand: kein Raubtrichter; Randbereich des Kurgans überpflügt

Sonstiges: an der Oberfläche kleine Steine $(15 \times$ Io $\times$ $5 \mathrm{~cm}$ )

Kurgan II (Kleinkurgan)

Dm I6 m; H o,5 m

Lage: N43 30.363 E77 49.4I8

Form: abgerundete Erhebung

Abhänge: drei steile, südlicher sanft

Zustand: gesamter Kurgan ist überpflügt

Sonstiges: keine Steine an der Oberfläche

\section{Kurgan 12}

Dm 27 m; H 3 m

Lage: N43 30.399 E77 49.429 
Form: abgerundet, plattformähnlich mit abgeflachter Kuppe

Abhänge: drei steile, südlicher sanft

Zustand: in der Mitte ein Raubtrichter

Sonstiges: keine Steine an der Oberfläche

Kurgan I3 (Kleinkurgan)

Dm I8 m; H I m

Lage: N43 30.398 E77 49.400

Form: abgerundete Erhebung

Abhänge: drei steile, südlicher sanft

Zustand: die Westhälfte ist überpflügt

Sonstiges: an der Oberfläche mittelgroße und kleine

Steine $(30 \times 20 \times 10 \mathrm{~cm})$

Kurgan I4 (Kleinkurgan)

Dm 20 m; H I m

Lage: N43 30.4I5 E77 49.398

Form: abgerundete Erhebung

Abhänge: drei steile, südlicher sanft

Zustand: kein Raubtrichter

Sonstiges: keine Steine an der Oberfläche

Kurgan I5 (Kleinkurgan)

Dm i6 m; H o,5 m

Lage: N43 30.433 E77 49.4I7

Form: abgerundete Erhebung

Abhänge: keine Merkmale

Zustand: gesamter Kurgan ist überpflügt

Sonstiges: keine Steine an der Oberfläche

Kurgan I6 (Kleinkurgan)

Dm I8 m; H o,5-0,8 m

Lage: N43 30.448 E77 49.424

Form: abgerundete Erhebung

Abhänge: drei steile, südlicher sanft

Zustand: kein Raubtrichter

Sonstiges: einzelne kleine Steine $(20 \times$ Io $\times 8 \mathrm{~cm})$ an der Oberfläche

Kurgan I7 (Kleinkurgan)

Dm I4 m; H o, 5 m

Lage: N43 30.453 E77 49.427

Form: abgerundete Erhebung

Abhänge: drei steile, südlicher sanft

Zustand: kein Raubtrichter

Sonstiges: einzelne kleine Steine $(15 \times 10 \times 5 \mathrm{~cm})$ an der Oberfläche

Kurgan I8 (Kleinkurgan)

Dm 24 m; H I, 5 m

Lage: N43 30.450 E77 49.395

Form: abgerundete Erhebung

Abhänge: drei steile, südlicher sanft

Zustand: kein Raubtrichter; der westliche Fußbereich des Kurgans ist durch einen Feldweg beschädigt

Sonstiges: keine Steine an der Oberfläche
Kurgan I9 (Kleinkurgan)

Dm I4 m; H o, 3 m

Lage: N43 30.473 E77 49.400

Form: kleiner, fast flacher Kurgan

Abhänge: keine Merkmale

Zustand: kein Raubtrichter

Sonstiges: keine Steine an der Oberfläche

Kurgan 20 (Kleinkurgan)

Dm I4 m; H o, 3 m

Lage: N43 30.487 E77 49.400

Form: kleiner, fast flacher Kurgan

Abhänge: keine Merkmale

Zustand: kein Raubtrichter

Sonstiges: keine Steine an der Oberfläche

Kurgan 2I (Kleinkurgan)

Dm 14 m; H o, 3 m

Lage: N43 30.497 E77 49.394

Form: kleiner, fast flacher Kurgan

Abhänge: keine Merkmale

Zustand: kein Raubtrichter

Sonstiges: an der Oberfläche liegen einige mittelgroße und kleine Steine $(30 \times 20 \times 10 \mathrm{~cm})$

Kurgan 22 (Kleinkurgan)

Dm I2 m; H o,4 m

Lage: N43 30.5I5 E77 49.377

Form: abgerundete Erhebung

Abhänge: drei steile, südlicher sanft

Zustand: kein Raubtrichter

Sonstiges: an der Westseite des Kurgans einzelne mittelgroße Steine $(20 \times$ I $5 \times$ IO $\mathrm{cm})$

Kurgan 23 (Kleinkurgan)

Dm (ursprünglich) 8 m; H unbekannt

Lage: N43 30.506 E77 49.397

Form: unbekannt

Abhänge: ?

Zustand: Der Kurgan wurde bereits ausgegraben (wann und von wem ist nicht bekannt), bzw. zerstört. Im mittleren Bereich befindet sich offene Grabgrube; die Grabungsfläche ist weder konserviert noch rekultiviert. Der Abraum liegt westlich und östlich der Grabgrube Sonstiges: Im Archiv des Archäologischen Institutes, Almaty gibt es keinen Bericht zu dieser Grabung

Kurgan 24 (Kleinkurgan)

Dm 8 m; H o,3 m

Lage: N43 30.5II E77 49.425

Form: kleiner, fast flacher Kurgan

Abhänge: keine Merkmale

Zustand: kein Raubtrichter

Sonstiges: an der Oberfläche einige mittelgroße und kleine Steine $(\mathrm{ab} 30 \times 15 \times 8 \mathrm{~cm})$

Kurgan 25 (Kleinkurgan)

Dm i6 m; H o, 5 m

Lage: N43 30.526 E77 49.424 
Form: abgerundete Erhebung

Abhänge: drei steile, südlicher sanft

Zustand: kein Raubtrichter

Sonstiges: keine Steine an der Oberfläche

Kurgan 26 (Kleinkurgan)

Dm I4 m; H o,3 m

Lage: N43 30.529 E77 49.392

Form: kleiner, fast flacher Kurgan

Abhänge: keine Merkmale

Zustand: kein Raubtrichter

Sonstiges: an der Oberfläche einige mittelgroße und kleine Steine $(\mathrm{ab} 30 \times 20 \times 10 \mathrm{~cm})$

Kurgan 27 (Kleinkurgan)

Dm Io m; H o, 3 m

Lage: N43 30.540 E77 49.42I

Form: kleiner, fast flacher Kurgan

Abhänge: keine Merkmale

Zustand: kein Raubtrichter; Der östliche Randbereich des Kurgans ist durch einen Bewässerungskanal zerstört

Sonstiges: keine Steine an der Oberfläche

Kurgan 28 (Kleinkurgan)

Dm 24 m; H I, 5 m

Lage: N43 30.562 E77 49.407

Form: abgerundete Erhebung

Abhänge: drei steile, südlicher sanft

Zustand: kein Raubtrichter

Sonstiges: keine Steine an der Oberfläche

Kurgan 29 (Kleinkurgan)

Dm Io m; H o,3 m

Lage: N43 30.586 E77 49.4I9

Form: abgerundete Erhebung

Abhänge: keine Merkmale

Zustand: gesamter Kurgan wurde überpflügt

Sonstiges: an der Oberfläche mittelgroße Steine $(25 \times$ $20 \times 10 \mathrm{~cm}$ )

Kurgan 30 (Kleinkurgan)

Dm I4 m; H o,4 m

Lage: N43 30.6I0 E77 49.4I9

Form: abgerundete, flache Erhebung

Abhänge: keine Merkmale

Zustand: kein Raubtrichter

Sonstiges: keine Steine an der Oberfläche

Kurgan 3I (Kleinkurgan)

Dm 28 m; H I, 5 m

Lage: N43 30.635 E77 49.435

Form: abgerundete, flache, plattformähnliche Erhebung

Abhänge: drei steile, südlicher sanft

Zustand: in der Mitte ein Raubtrichter

Sonstiges: keine Steine an der Oberfläche
Kurgan 32 (Kleinkurgan)

Dm I4 m; H o,3 m

Lage: N43 30.654 E77 49.430

Form: abgerundete, flache Erhebung

Abhänge: keine Merkmale

Zustand: kein Raubtrichter

Sonstiges: keine Steine an der Oberfläche

Kurgan 33 (Kleinkurgan)

Dm I4 m; H o, 3 m

Lage: N43 30.667 E77 49.436

Form: abgerundete, flache Erhebung

Abhänge: keine Merkmale

Zustand: kein Raubtrichter

Sonstiges: keine Steine an der Oberfläche

Kurgan 34 (Kleinkurgan)

Dm I2 m; H o, 3 m

Lage: N43 30.662 E77 49.4I9

Form: abgerundete, flache Erhebung

Abhänge: keine Merkmale

Zustand: die Westhälfte des Kurgans ist durch Pflugarbeiten zerstört

Sonstiges: keine Steine an der Oberfläche

Kurgan 35 (Kleinkurgan)

Dm Io $\mathrm{m}$; H o, $3 \mathrm{~m}$

Lage: N43 30.674 E77 49.433

Form: abgerundete, flache Erhebung

Abhänge: keine Merkmale

Zustand: kein Raubtrichter

Sonstiges: keine Steine an der Oberfläche

Kurgan 36 (Kleinkurgan)

Dm 25 m; H I m

Lage: N43 30.690 E77 49.434

Form: abgerundete, flache, plattformähnliche Erhebung

Abhänge: drei steile, südlicher sanft

Zustand: in der Mitte eine Senke

Sonstiges: keine Steine an der Oberfläche

Kurgan 37 (Kleinkurgan)

Dm 24 m; H I m

Lage: N43 30.703 E77 49.438

Form: abgerundete, flache, plattformähnliche Erhebung

Abhänge: drei steile, südlicher sanft

Zustand: in der Mitte ein Raubtrichter; Peripherie des Kurgans durch den Acker und einen Feldweg zerstört Sonstiges: keine Steine an der Oberfläche

Kurgan 38 (Kleinkurgan)

Dm 28 m; H I m

Lage: N43 30.720 E77 49.439

Form: abgerundete, flache, plattformähnliche Erhebung

Abhänge: drei steile, südlicher sanft

Zustand: in der Mitte ein Raubtrichter; Peripherie des Kurgans ist durch den Acker zerstört

Sonstiges: keine Steine an der Oberfläche 
Kurgan 39 (Kleinkurgan)

Dm 34 m; H I, 5 m

Lage: N43 30.739 E77 49.44I

Form: abgerundete, flache, plattformähnliche Erhebung

Abhänge: drei steile, südlicher sanft

Zustand: kein Raubtrichter; Südwestseite vom Pflug gestört

Sonstiges: an der Oberfläche einzelne mittelgroße Steine $(30 \times 20 \times 10 \mathrm{~cm})$

Kurgan 40 (Kleinkurgan)

Dm 28 m; H I,O-I, 5 m

Lage: N43 30.8I5 E77 49.473; nördlichster Kurgan der Westkette

Form: abgerundete, flache, plattformähnliche Erhebung

Abhänge: drei steile, südlicher sanft

Zustand: in der Mitte ein Raubtrichter; westliche Peripherie durch den Pflug zerstört

Sonstiges: an der Oberfläche einzelne mittelgroße Steine $(30 \times 15 \times 8 \mathrm{~cm})$

Nördliche Kette

Kurgan 4I

Dm 40 m; H 3 m

Lage: N43 30.98I E77 49.337; südlichster Kurgan der Nordkette

Form: abgerundet, plattformähnlich mit abgeflachter Kuppe

Abhänge: drei steile, südlicher sanft

Zustand: in der Mitte ein Raubtrichter; Peripherie durch den Pflug zerstört

Sonstiges: keine Steine an der Oberfläche

\section{Kurgan 42}

Dm 34 m; H 3 m

Lage: N43 31.02I E77 49.329

Form: abgerundet, plattformähnlich mit abgeflachter Kuppe

Abhänge: drei steile, südlicher sanft

Zustand: die Kurgankuppe scheint planiert zu sein; Peripherie durch den Pflug zerstört

Sonstiges: keine Steine an der Oberfläche

\section{Kurgan 43}

Dm 38 m; H 2 m

Lage: N43 31.247 E77 49.372

Form: abgerundet, plattformähnlich mit abgeflachter Kuppe

Abhänge: drei steile, südlicher sanft

Zustand: in der Mitte ein Raubtrichter; Direkt über dem Kurgan verläuft ein Feldweg. Die westliche Peripherie ist dicht bewaldet, die östliche Peripherie durch den Pflug zerstört

Sonstiges: kleinster Kurgan der Kette; an der Oberfläche einzelne mittelgroße Steine $(30 \times 20 \times 15 \mathrm{~cm})$
Kurgan 44

Dm 5I m; H 4 m

Lage: N43 31.336 E77 49.383

Form: abgerundet, plattformähnlich mit abgeflachter Kuppe

Abhänge: ?

Zustand: in der Mitte ein Raubtrichter; südlicher und nördlicher Abhang des Kurgans sind sehr sanft, Kuppe des Kurgans evtl. planiert; östlicher Kurganrand und die Peripherie durch den Pflug zerstört; westliche Peripherie dicht bewaldet

Sonstiges: an der Oberfläche keine Steine sichtbar

Kurgan 45

Dm 48 m; H 3 m

Lage: N43 3I.562 E77 49.4I2

Form: abgerundet, plattformähnlich mit abgeflachter Kuppe

Abhänge: drei steile, südlicher sanft

Zustand: in der Mitte ein Raubtrichter; Peripherie des Kurgans vollständig überpflügt

Sonstiges: keine Steine an der Oberfläche

Kurgan 46

Dm 6I m; H 4 m

Lage: N43 31.698 E77 49.437

Form: abgerundet, plattformähnlich mit abgeflachter Kuppe

Abhänge: drei steile, südlicher sanft

Zustand: An der nördlichen und südlichen Hälfte des Kurgans ist jeweils ein Raubtrichter zu sehen; die Peripherie ist komplett überpflügt

Sonstiges: keine Steine an der Oberfläche

Kurgan 47 (Abb. I3I)

Dm 8I m; H 6 m

Lage: N43 31.787 E77 49.695

Form: abgerundet, plattformähnlich mit abgeflachter Kuppe

Abhänge: drei steile, südlicher sanft

Zustand: in der Mitte ein Raubtrichter; Peripherie vollständig überpflügt

Sonstiges: keine Steine an der Oberfläche, stattdessen liegen große Steine $(\mathrm{ab} 70 \times 50 \times 30 \mathrm{~cm})$ im Fußbereich des Kurgans (von Traktoren gesammelt)

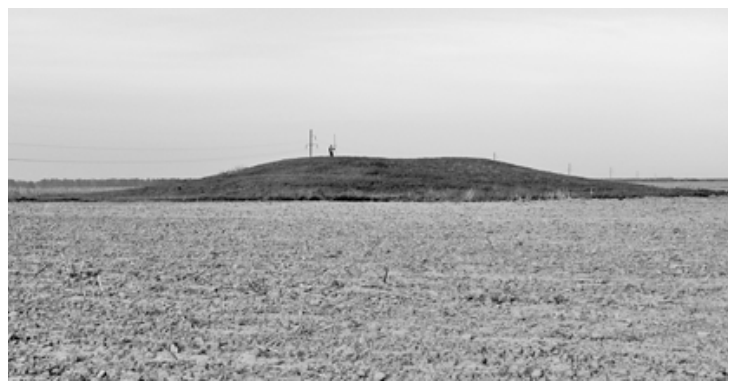

Abb. 131 | Kurgan 47. Blick von W 
Forschungsgeschichte und Bemerkungen

Im Auftrag des Institutes „Kazproektrestavracija“ 585 und des Kulturministeriums der Kasachischen SSR führte I985 die Archäologische Expedition der Kasachischen Pädagogischen Hochschule „Abaj“ unter der Leitung von A. N. Mar’jašev im Rahmen der Bestandsaufnahme und Passportisierung der archäologischen Bodendenkmäler im Gebiet Almaty ein Survey an dem Gräberfeld Bes Tobe durch (Mar'jašev u.a. I986, 2, 29). Es wurden dabei nur die nördlichsten Kurgane der Nekropole erfasst, die nach unserer Nummerierung den Kurganen K43-K47 entsprechen. Eine Lageskizze oder ein Gräberfeldplan wurden nicht angefertigt.

Lit.: Mar’jašev u.a. ı986, 29.

Gräberfeld Bestobe-3 [FEZ] (Abb. I32-I33; Karte 3 Nr. 59): ALT I994 m N43 02.227 E78 58.757; Gebiet Almaty (kasach. Алматы облысы), Rajymbekskij rajon (kasach. Райымбек ауданы); Ausmaß N-S $290 \times$ O-W I90 m.

Die Nekropole befindet sich am Nordwestfuß des Bestobe-Berges (kasach. Бестобе), der sich an der Südseite des Bergrückens Kuluktau (kasach. Қулықтау) erstreckt. Die Kurgane stehen I7o km ostsüdöstlich von der Stadt Almaty (kasach. Алматы), ІІ,7 km südwestlich vom Dorf Žalauly (kasach. Жалаулы), 3,6 km südöstlich vom Dorf Šybyšy (kasach. Шыбышы) und 6 km nördlich vom Dorf Taldy (kasach. Талды) entfernt.

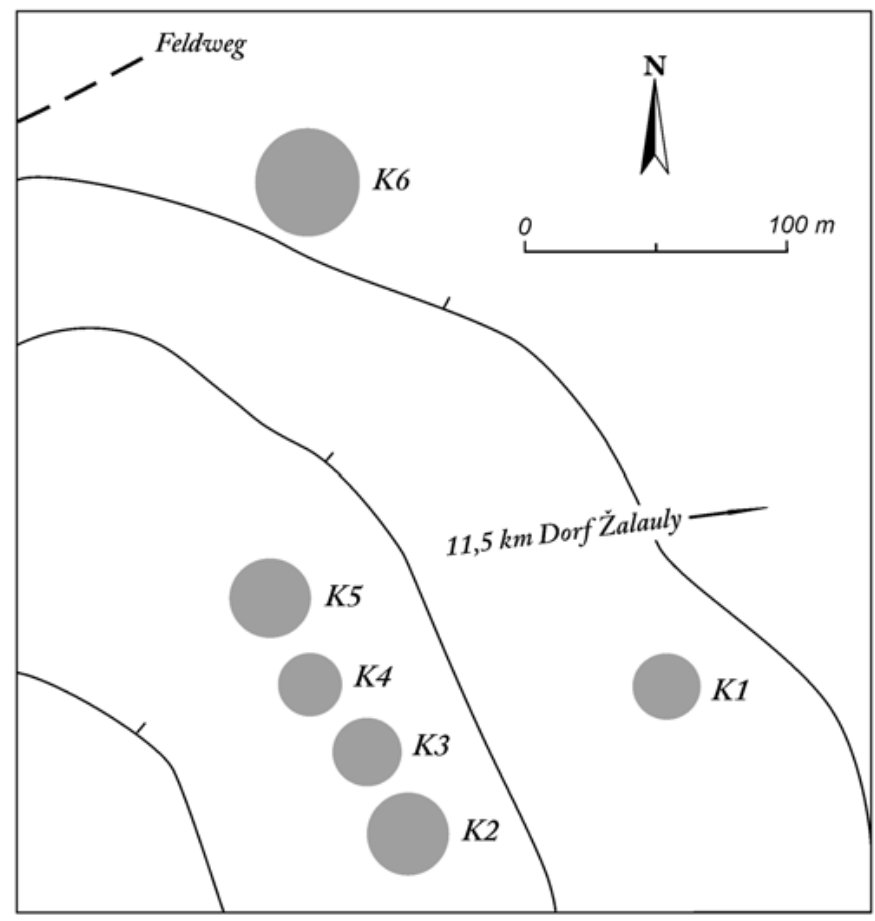

Abb. 132 | Plan des Gräberfeldes Bestobe-3

585 Projektentwicklungsinstitut für Konservierung und Restaurierung der Kulturdenkmäler „Kazproektrestavracija“. 


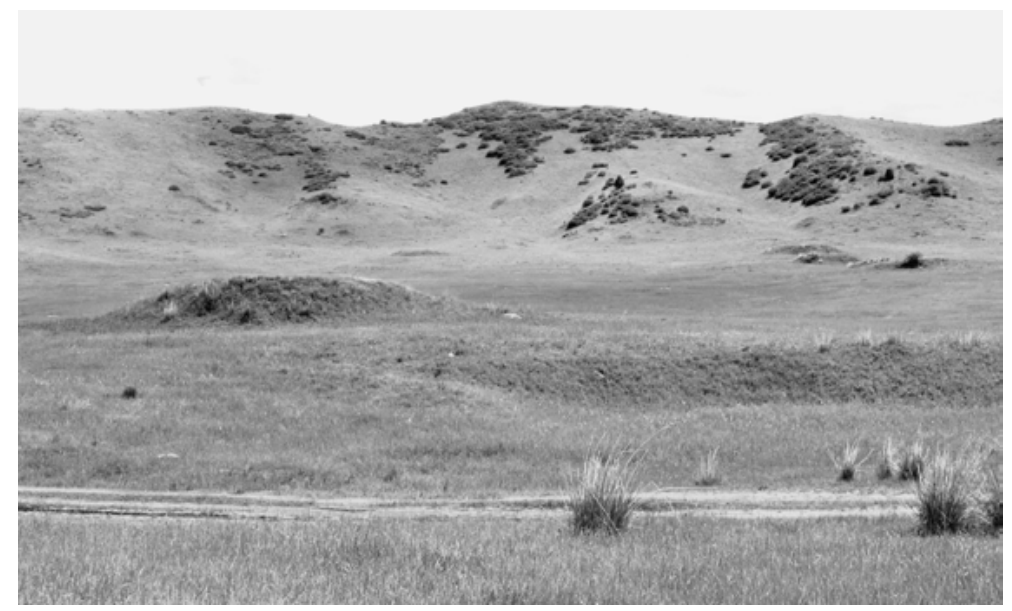

Abb. 133 | Das Gräberfeld Bestobe-3. Blick von NW

Das Gräberfeld besteht aus zwei NW-SO verlaufenden Ketten und zählt sechs Kurgane. In der östlich gelegenen Kette kommen nur zwei Kurgane, die $250 \mathrm{~m}$ voneinander entfernt stehen, zum Vorschein. Der nördliche Kurgan der Kette (K6 nach der Arbeitsnummerierung) ist der größte Kurgan des gesamten Gräberfeldes. Bei der westlich gelegenen Kette werden vier eng aneinander gebaute Kurgane beobachtet.

Alle Kurgane haben drei steile und einen (immer gen Süden abfallenden) sanften Abhang. Der Durchmesser der Kurgane schwankt zwischen $24 \mathrm{~m}$ und $38 \mathrm{~m}$, die Höhe zwischen $2 \mathrm{~m}$ und $4 \mathrm{~m}$. Alle Kurgane des Gräberfeldes weisen einen Raubtrichter auf. Es wurden keine besonderen architektonischen Merkmale an der Oberfläche festgestellt.

Anhand der Struktur und der äußeren Erscheinungsform können alle Kurgane des Gräberfeldes der sakischen Periode der Früheisenzeit zugeordnet werden.

Kurgancharakteristik:

Östliche Kurgankette

\section{Kurgan I}

Dm 24 m; H 3 m

Lage: N43 02.II7 E78 58.863

Form: abgerundet, plattformähnlich mit abgeflachter Kuppe

Abhänge: drei steile, südlicher sanft

Zustand: in der Mitte ein Raubtrichter

Sonstiges: einzelne große Steine (ab 100 ×60 ×30 cm) an der Oberfläche

Kurgan 6 (Abb. I34,I)

Dm 38 m; H 4 m

Lage: N43 02.227 E78 58.757

Form: abgerundet, plattformähnlich mit abgeflachter Kuppe

Abhänge: drei steile, südlicher sanft

Zustand: in der Mitte ein Raubtrichter

Sonstiges: einzelne mittelgroße Steine $(\mathrm{ab} 50 \times 25 \times$ I5 cm) an der Oberfläche; am Kurganrand drei große
Steine $(\mathrm{ab}$ I30 × $40 \times 40 \mathrm{~cm})$; größter Kurgan des Gräberfeldes

Westliche Kurgankette

Kurgan 2 (Abb. 134,2)

Dm 30 m; H 3,5 m

Lage: N43 02.09० E78 58.788; der südlichste Kurgan der Kette

Form: abgerundet, plattformähnlich mit abgeflachter Kuppe

Abhänge: drei steile, südlicher sanft

Zustand: in der Mitte ein Raubtrichter

Sonstiges: einzelne mittelgroße Steine $(\mathrm{ab} 40 \times$ Io $\times$ Io $\mathrm{cm}$ ) an der Oberfläche

\section{Kurgan 3}

Dm 25 m; H 2,5 m

Lage: N43 02.107 E78 58.774

Form: abgerundet, plattformähnlich mit abgeflachter Kuppe 

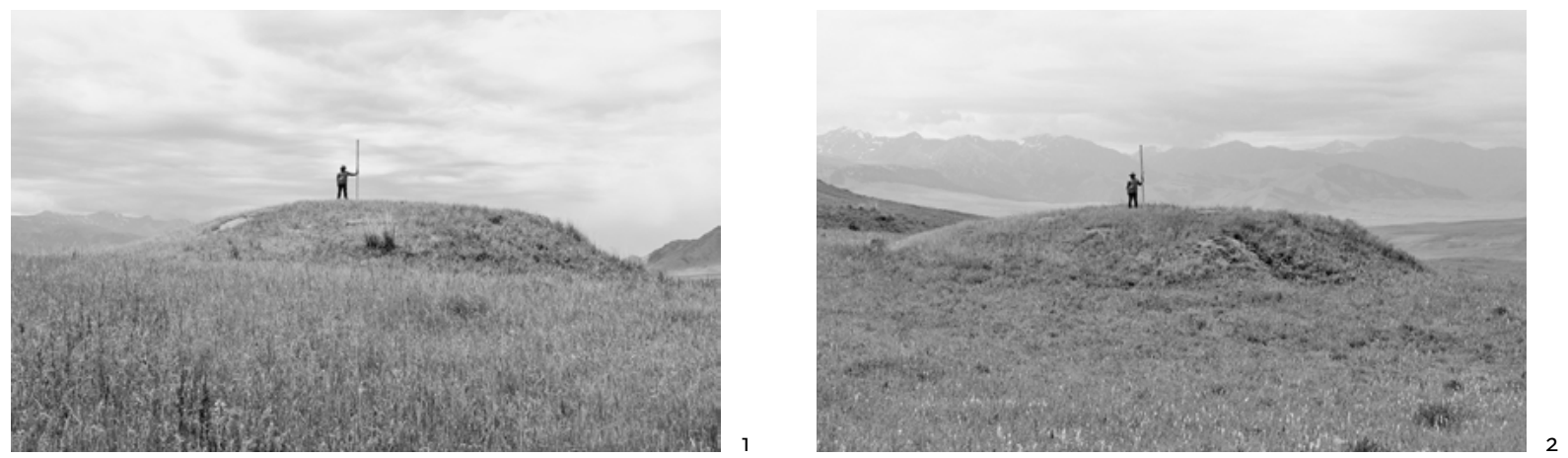

Abb. 134 | Kurgane des Gräberfeldes Bestobe-3. Blick von O; I. Kurgan 6; 2. Kurgan 2

Abhänge: drei steile, südlicher sanft

Zustand: in der Mitte ein Raubtrichter

Sonstiges: einzelne mittelgroße Steine $(\mathrm{ab} 60 \times \mathrm{I} 5 \times$ Io $\mathrm{cm}$ ) an der Oberfläche

\section{Kurgan 4}

Dm 24 m; H 2 m

Lage: N43 02.I22 E78 58.759

Form: abgerundet, plattformähnlich mit abgeflachter

Kuppe

Abhänge: drei steile, südlicher sanft

Zustand: in der Mitte ein Raubtrichter
Sonstiges: einzelne mittelgroße Steine $\left(\right.$ ab $50 \times I_{5} \times$ Io $\mathrm{cm}$ ) an der Oberfläche

\author{
Kurgan 5 \\ Dm 29 m; H 2 m \\ Lage: N43 O2.I4I E78 58.747; der nördlichste Kurgan \\ der Nekropole \\ Form: abgerundet, plattformähnlich mit abgeflachter \\ Kuppe \\ Abhänge: drei steile, südlicher sanft \\ Zustand: in der Mitte ein Raubtrichter \\ Sonstiges: einzelne mittelgroße Steine $\left(\mathrm{ab} 50 \times \mathrm{I}_{5} \times\right.$ \\ Io $\mathrm{cm}$ ) an der Oberfläche
}

Forschungsgeschichte

Das Gräberfeld Bestobe-3 wurde 2006 im Laufe einer Revision der archäologischen Bodendenkmäler im Rajymbekskij rajon des Gebietes Almaty vom Turgen-Forschungsteam der Almaty Survey-Expedition (APAЭ) unter der Leitung von A. Gorjačev entdeckt (Bajpakov/Gorjačev 2007, 77).

Lit.: Bajpakov/Gorjačev 2007, 77 .

Gräberfeld Boroldaj [FEZ] (Abb. I35-I36; Karte 3 Nr. 2): ALT 727 m N43 20.2I7 E76 52.II8; Gebiet Almaty (kasach. Алматы облысы), Stadt Almaty (kasach. Алматы); Ausmaß N-S 3,4 × O-W I,I km.

Die Nekropole Boroldaj befindet sich auf dem gleichnamigen Plateau (kasach. Боролдай), nördlich der Bergkette Transili-Alatau (kasach. Іле Алатауы), zwischen den Flüssen Boroldaj (kasach. Боролдай), der westlich des Plateaus fließt, und Bol'šaja Almatinka (kasach. Үлкен Алматы), der östlich des Plateaus verläuft. Die Oberfläche des Plateaus ist fast eben und hat eine gewisse Neigung von Westen nach Osten, so dass die Westhälfte des Plateaus ca. IO-I5 $\mathrm{m}$ höher als die Osthälfte ist. Das Plateau Boroldaj trennt die Stadt Almaty im Nordwesten und das Dorfes Boraldaj (kasach. Боралдай) im Südosten voneinander territorial.

Die Nekropole besteht aus 52 großen und mittelgroßen Kurganen, die fünf S-N verlaufenden Ketten bilden. Der Durchmesser der Kurgane schwankt zwischen 3 m und I50 m, ihre Höhe zwischen O,I $\mathrm{m}$ und I4,4 m. Fast alle Kurgane haben im Plan eine abgerundete Form. Lediglich Kurgan 49 (nach der Arbeitsnummerierung) ist im Plan oval. I8 Kurgane (35\% der Gesamtzahl der Kurgane) weisen einen oder mehrere Raubtrichter auf. Zehn weitere Kurgane (I9\%) zeigen sowohl keine Senke, als auch 

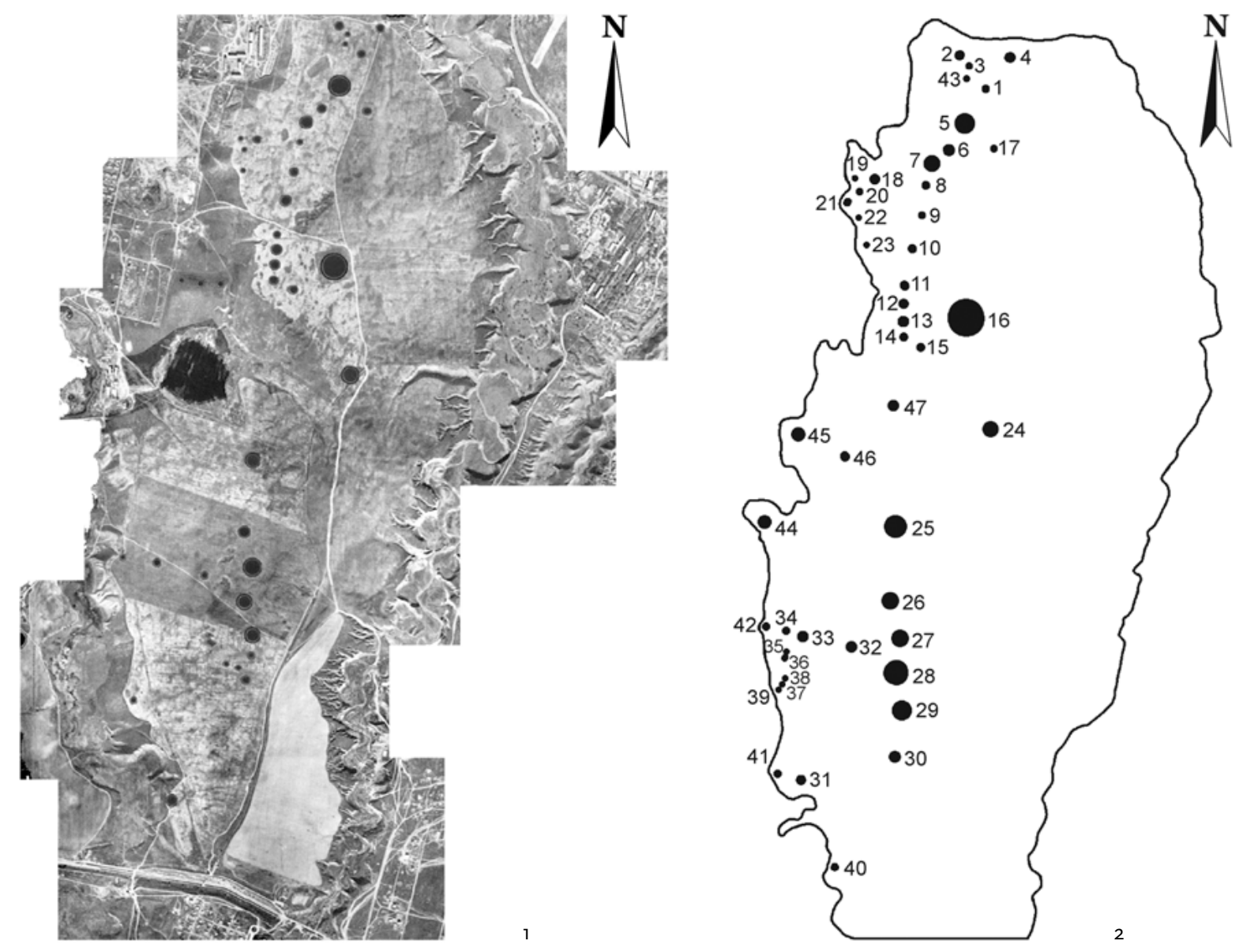

Abb. 135 | Gräberfeld Boroldaj; r. Luftbild (Samašev u.a. 2006, 9); 2. Plan-Schema (Samašev u.a. 2006, 34)

keinen Trichter an der Oberfläche und bei 24 Kurganen (46\%) kann der Zustand der Kurganaufschüttung nicht eindeutig geklärt werden. An drei Seiten besitzen sie steile Abhänge und an der vierten sanfte. In ıo Fällen (ı\%\%) befindet sich der sanfte Abhang im Süden, in fünf Fällen (9\%) exakt im Westen, bei drei Kurganen (6\%) im Südosten, bei jeweils einem Kurgan (2\%) im Südwesten, Nordwesten und Osten. Ein Kurgan zeigt die sanften Abhänge sowohl im Nordosten als auch im Nordwesten. Gar keine besonderen Merkmale der Abhänge weisen I5 Kurgane (29\%) auf und bei weiteren I5 Kurganen konnten keine Merkmale bestimmt werden.

Um drei Kurgane herum wurden die Überreste von Steinkreisen festgestellt. I8 Kurgane sind von je einem Kreisgraben umgeben, jedoch in einem Fall (Kıo) sogar von einem doppelten. Bei einem der Kreisgräben wurden zwei Eingangsbereiche beobachtet. Die Gräben von vier Kurganen sind an einer Stelle unterbrochen. Es handelt sich um die südsüdwestliche (in einem Fall), um die südliche (in einem Fall) und um die westlichen (in zwei Fällen) Seiten. Die Breite der Gräben schwankt zwischen 0,5 m und I, $\circ \mathrm{m}$ und die Tiefe reicht bis zu einem Meter. Wälle treten bei acht Kurganen auf, bei sechs davon wurden sowohl Wälle (Breite bis zu o,5 m) als auch Kreisgräben beobachtet.

Besonders hebt sich der Kurgan I6 von den restlichen Grabhügeln der Nekropole ab. Einerseits ist er der größte Kurgan des Gräberfeldes, andererseits weist der Kurgan ein komplexes Konstruktionsmuster in seiner Peripherie auf. Es sind dabei besonders mehrere Steinkreise, ein Kleinkurgan und eine Stele mit einer Jagdszene hervorzuheben. 


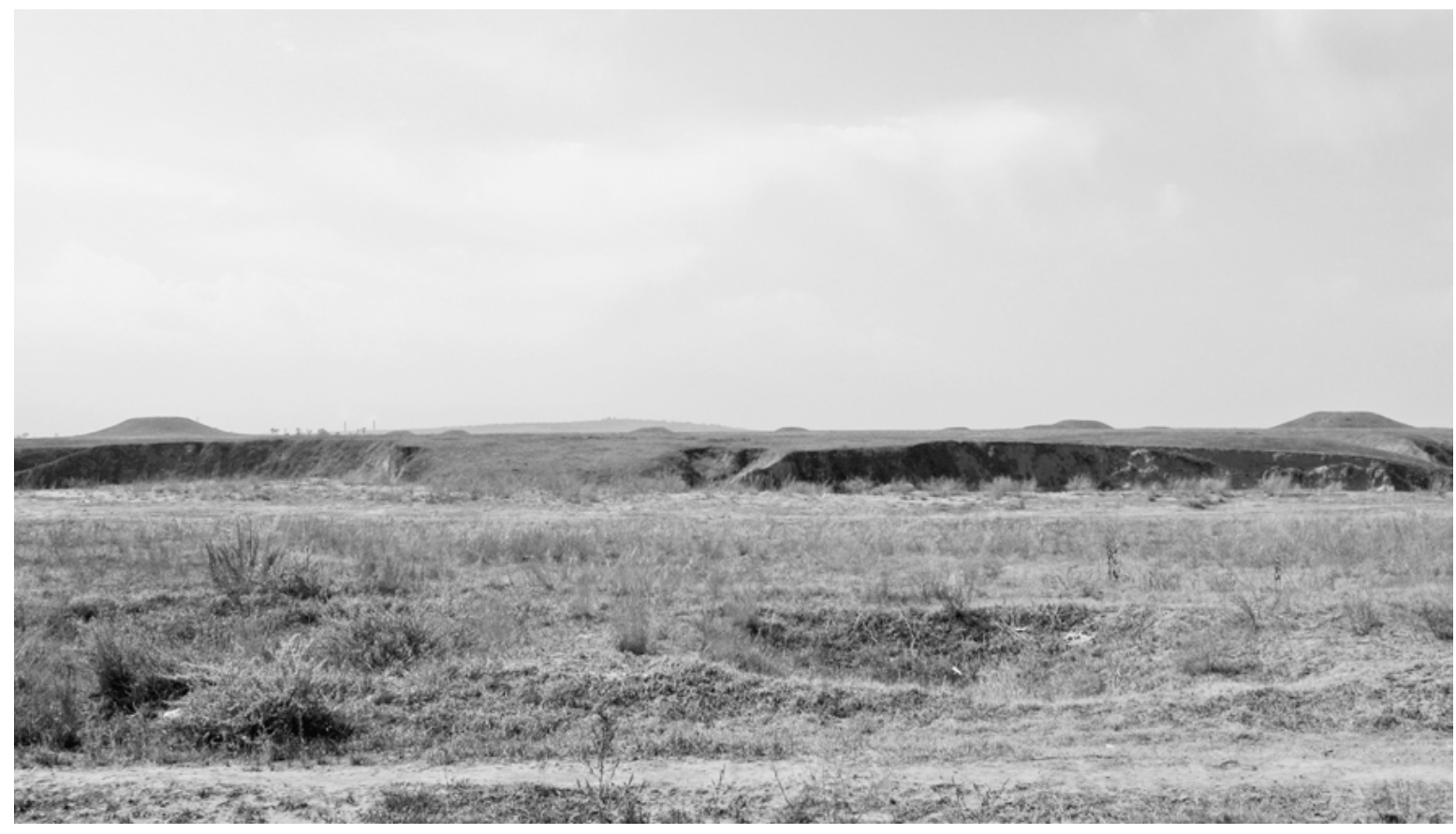

Abb. 136 | Gräberfeld Boroldaj. Nordhälfte. Blick von ONO

Anhand der Lage im Gelände, der Struktur und äußeren Erscheinungsform können alle Kurgane der Nekropole der sakischen Periode der Früheisenzeit zugeordnet werden. Nach Meinung von Samašev u.a. datiert man die Fundstelle in das 6.-3. Jh. v. Chr. (Samašev u.a. 2006, 22).

Kurgancharakteristik:

Da die Nekropole 2005 von den Mitarbeitern des Archäologischen Instituts „A. Ch. Margulan“, Almaty, unter der Leitung von Z. Samašev komplett untersucht und 2006 publiziert wurde, ist die Kurgancharakteristik aus dieser Publikation entnommen (Samašev u.a. 2006, 52-155).

\section{Kurgan I}

Dm 39,7 m; Dm Kreisgraben 4I,7 m; H 3,4 m

Lage: $\mathrm{N}_{43} 20.740 \mathrm{E}_{7} 6$ 52.183

Form: abgerundet, plattformähnlich mit abgeflachter

Kuppe

Abhänge: drei steile, westlicher sanft

Weitere Konstruktionen: am Kurganrand schließt ein ०,7-I,O $\mathrm{m}$ breiter Graben an (Tiefe nicht angegeben) Zustand: westlicher Abhang im Randbereich zum Teil beschädigt

Kurgan 2 (Kleinkurgan)

Dm 29,2 m; H I,2 m

Lage: N43 20.8I5 E76 52.I05

Form: niedrig, abgerundet mit abgeflachter Kuppe Abhänge: drei steile, westlicher sanft

Zustand: Kuppe durch einen Triangulationspunkt beschädigt
Kurgan 3 (Kleinkurgan)

Dm 26,7 m; H o,8 m

Lage: N43 20.79I E76 52.I33

Form: niedrig, abgerundet mit abgeflachter Kuppe

Abhänge: keine Merkmale

Zustand: südlicher und östlicher Kurganrand zerstört

Kurgan 4 (Kleinkurgan)

Dm 37 m; H I m

Lage: N43 20.8Io E76 52.258

Form: niedrig, abgerundet

Abhänge: drei steile, östlicher sanft

Zustand: durch Lehmgrube komplett zerstört

Kurgan 5 (Abb. I37,I)

Dm 83 m; Dm Kreisgraben 85 m; H 9,4 m

Lage: N43 20.66r E76 52.II6

Form: abgerundet, plattformähnlich mit abgeflachter Kuppe

Abhänge: zwei steile, nordöstlicher und südwestlicher sanft 

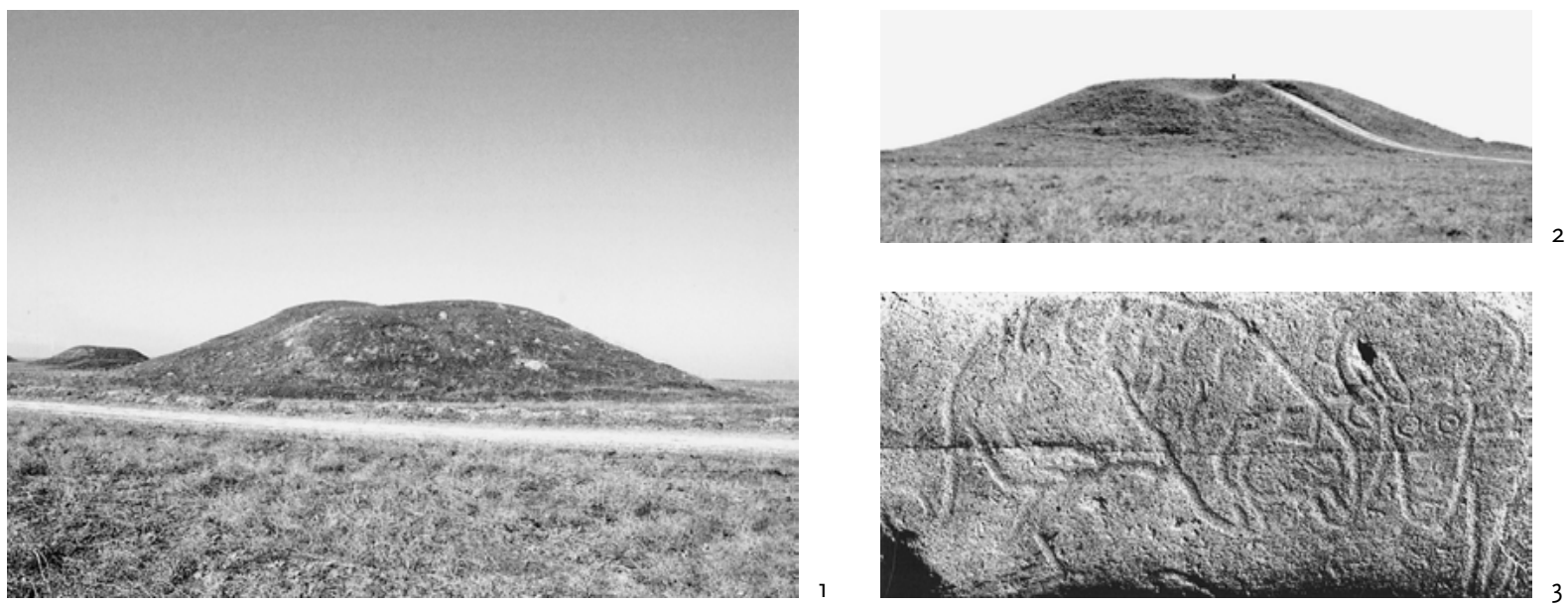

Abb. 137 | Gräberfeld Boroldaj; I. Kurgan 5 (Samašev u.a. 2006, 61): 2. Kurgan I6 (Samašev u.a. 2006, 83); 3. Fragment einer Stele beim Kurgan i6 (Samašev u.a. 2006, 33)

Weitere Konstruktionen: Der Kurganrand ist von einem I,o m breiten Kreisgraben umgeben (Tiefe nicht angegeben), der an der westlichen und südwestlichen Seite abbricht; diese Bereiche kann man als zwei Eingänge interpretieren (Breite nicht angegeben); an die äußere Grabengrenze schließt ein kleiner Wall an (Maße nicht angegeben).

Zustand: in der Mitte ein Raubtrichter; in der Osthälfte Spuren eines Raubtunnels

\section{Kurgan 6}

Dm 36,5 m; H 2,9 m

Lage: N43 20.605 E76 52.067

Form: abgerundet, plattformähnlich mit abgeflachter Kuppe

Abhänge: drei steile, südlicher sanft

Zustand: in der Mitte ein Raubtrichter; an den südlichen und östlichen Seiten Spuren von moderner Lehmgewinnung

\section{Kurgan 7}

Dm 52,5 m; Dm Kreisgraben 54,5 m; H 6,8 m

Lage: N43 20.572 E76 52.0I7

Form: abgerundet, plattformähnlich mit abgeflachter Kuppe

Abhänge: drei steile, nordwestlicher sanft

Weitere Konstruktionen: Der Kurganrand ist von einem 0,5-I, O $\mathrm{m}$ breiten Graben umgeben (Tiefe nicht angegeben), der an der südsüdwestlichen Seite abbricht; diesen Bereich (Breite nicht angegeben) kann man als einen Eingang interpretieren.

Zustand: in der Mitte zwei Raubtrichter; an der Nordseite Spuren von moderner Lehmgewinnung

Kurgan 8 (Kleinkurgan)

Dm $30 \mathrm{~m} ; \mathrm{H} \mathrm{I}, 6 \mathrm{~m}$

Lage: N43 20.522 E76 51.997
Form: abgerundet, plattformähnlich mit abgeflachter Kuppe

Abhänge: drei steile, südlicher sanft

Weitere Konstruktionen: Der Kurganrand ist von einem Kreisgraben umgeben (Breite und Tiefe nicht angegeben), der an der Nordseite nicht erhalten ist; an die äußere Grabengrenze schließt ein kleiner Wall an (Maße nicht angegeben)

Zustand: keine Senke, kein Trichter; an der Südseite des Kurganrandes einige moderne Lehmgewinnungsgruben

\section{Kurgan 9}

Dm 37,8 m; H 4 m

Lage: N43 20.453 E76 51.983

Form: abgerundet, plattformähnlich mit abgeflachter Kuppe

Abhänge: drei steile, südöstlicher sanft

Weitere Konstruktionen: Der Kurganrand wird von einem Kreisgraben umlaufen (Breite und Tiefe nicht angegeben); an die äußere Grabengrenze schließt ein kleiner Wall an (Maße nicht angegeben); beide Konstruktionselemente sind nur an der Osthälfte erhalten. Zustand: keine Senke, kein Trichter; der nördliche Abhang ist im Randbereich abgeschnitten

Sonstiges: Oberfläche mit weißen Kieselsteinen bedeckt; um den Kurgan herum einzelne große weiße Steine

\section{Kurgan Io}

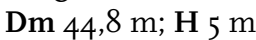

Lage: N43 20.378 E76 51.952

Form: abgerundet, plattformähnlich mit abgeflachter Kuppe

Abhänge: drei steile, südöstlicher sanft

Weitere Konstruktionen: Im Südosten und Südwesten ist der Kurgan von einem Wall umgeben (Breite 0,5 m, 
Höhe nicht angegeben); auf beiden Seiten des Walles verläuft je ein Kreisgraben (Breite I,5 m; Tiefe O,5-I,O m); I5 m südlich vom Kurganrand Konzentration weißer Kieselsteine und größerer Steine - möglicherweise Überreste eines Steinkreises

Zustand: in der Mitte ein Raubtrichter; an der südwestlichen Seite Spuren vom Raubtunnel, die im Raubtrichter münden

Kurgan II (Kleinkurgan)

Dm 30,4 m; H I,2 m

Lage: N43 20.273 E76 51.935

Form: abgerundete, abgeflachte Erhebung

Abhänge: keine Merkmale

Zustand: ?

Sonstiges: einzelne weiße und graue Kieselsteine an der Oberfläche

\section{Kurgan I2}

Dm 42,6 m; H 4,8 m

Lage: N43 20.257 E76 51.926

Form: abgerundet, plattformähnlich mit abgeflachter Kuppe

Abhänge: drei steile, südlicher sanft

Weitere Konstruktionen: am Kurganrand verläuft ein kleiner Wall (Maße nicht angegeben)

Zustand: in der Mitte ein Raubtrichter; an der südlichen Seite Spuren vom Raubtunnel

\section{Kurgan I3}

Dm 43,4 m; H 4,5 m

Lage: N43 20.228 E76 51.922

Form: abgerundet, plattformähnlich mit abgeflachter Kuppe

Abhänge: drei steile, südlicher sanft

Weitere Konstruktionen: Am Kurganrand verläuft ein kleiner Wall (Maße nicht angegeben).

Zustand: am nordnordwestlichen Abhang eine moderne Grube

Sonstiges: westlich vom Kurgan (2,5-3,0 m entfernt) große weiße Steine

\section{Kurgan 14}

Dm 27,4 m; H 3,5 m

Lage: N43 20.192 E76 51.923

Form: abgerundete, abgeflachte Erhebung

Abhänge: drei steile, südlicher sanft

Zustand: ?

Sonstiges: einzelne weiße Kieselsteine an der Oberfläche

\section{Kurgan I5}

Dm 32,5 m; Dm Kreisgraben 34,5 m; H 2,4 m

Lage: N43 20.169 E76 51.98I

Form: abgerundet, plattformähnlich mit abgeflachter Kuppe

Abhänge: keine Merkmale
Weitere Konstruktionen: Am Kurganrand verläuft ein I,O $\mathrm{m}$ breiter Graben (Tiefe nicht angegeben), der an der südlichen Seite abbricht; diesen Bereich (Breite nicht angegeben) kann man als Eingang interpretieren. Zustand: in der Mitte eine moderne Grube; an der Westseite eine Senke

Sonstiges: einzelne weiße Kieselsteine an der Oberfläche; östlich und nordöstlich vom Kurgan einzelne große Steine

Kurgan I6 (Abb. I37,2)

Dm I5O m; H I4,4 m

Lage: N43 20.2I7 E76 52.II8

Form: abgerundet, plattformähnlich mit abgeflachter Kuppe

Abhänge: keine Merkmale

Weitere Konstruktionen: Südlich vom Kurgan befinden sich einige Steinkreise, die eine Breite von I,5-2 $\mathrm{m}$ aufweisen (ihre Anzahl und der Durchmesser sind nicht angegeben). Ebenso südlich, an den Kurganrand angrenzend liegt eine rundliche Steinkonzentration mit einem Durchmesser von 20 m (Kleinkurgan?). Südlich vom Kurgan befindet sich eine Stele aus weißem Stein mit der Darstellung eines liegenden Huftieres (evtl. Schaf), das von einem Tiger angegriffen wird (Abb. 137,3). Nordöstlich vom Kurgan liegt ein Steinkreis, der einen Durchmesser von $6 \mathrm{~m}$ und eine Breite von I $m$ aufweist. $3 \mathrm{~m}$ nördlich vom Kurgan treten einzelne große Steine auf; hinter denen ein Kreisgraben (Maße sind nicht angegeben) festgestellt werden konnte; I50 m südöstlich vom Kurgan liegt eine Reihe aus großen Steinen; 50 m östlich vom Kurgan entfernt, befinden sich einzelne große Steine.

Zustand: in der Mitte ein Raubtrichter; an der Südseite mehrere Gruben; von der Südwestseite führt ein Feldweg auf die Kuppe; Peripherie des Kurgans überpflügt Sonstiges: einzelne grau-blaue Kieselsteine an der Oberfläche

\section{Kurgan $\mathbf{1 7}$}

Dm 36,5 m; H 2,2 m

Lage: N43 20.593 E76 52.205

Form: abgerundet, plattformähnlich mit abgeflachter Kuppe

Abhänge: drei steile, südlicher sanft

Weitere Konstruktionen: den Kurganrand umläuft ein 0,5-0,7 m breiter Kreisgraben (Tiefe nicht angegeben) Zustand: die Kuppe ist durch einen Triangulationspunkt beschädigt

Kurgan I8 (Kleinkurgan)

Dm 3I,6 m; H I,4 m

Lage: N43 20.542 E76 51.840

Form: abgerundete, abgeflachte Erhebung

Abhänge: drei steile, südöstlicher sanft

Weitere Konstruktionen: südlich und südöstlich vom Kurgan kleiner Kreisgraben (Maße nicht angegeben) Zustand: ? 
Kurgan I9 (Kleinkurgan)

Dm 25,3 m; H o,9 m

Lage: N43 20.542 E76 51.785

Form: abgerundete, abgeflachte Erhebung

Abhänge: keine Merkmale

Zustand: ?

Kurgan 20 (Kleinkurgan)

Dm 2I,2 m; H o,5 m

Lage: N43 20.520 E76 5I.8I5

Form: abgerundete Erderhebung

Abhänge: keine Merkmale

Zustand: gesamte Oberfläche überpflügt

Kurgan 2I (Kleinkurgan)

Dm 20 m; H O, 5 m

Lage: N43 20.513 E76 51.800

Form: abgerundete Erderhebung

Abhänge: keine Merkmale

Zustand: gesamte Oberfläche überpflügt

Kurgan 22 (Kleinkurgan)

Dm 2I,5 m; H o,5 m

Lage: N43 20.458 E76 51.793

Form: abgerundete Erderhebung

Abhänge: keine Merkmale

Zustand: gesamte Oberfläche überpflügt

Kurgan 23 (Kleinkurgan)

Dm 2I,5 m; H o,5 m

Lage: N43 20.402 E76 5I.8I5

Form: abgerundete Erderhebung

Abhänge: keine Merkmale

Zustand: gesamte Oberfläche überpflügt

\section{Kurgan 24}

Dm 7I,9 m; Dm Kreisgraben 74 m; H 7,6 m

Lage: N43 I9.598 E76 52.190

Form: abgerundet, plattformähnlich mit abgeflachter Kuppe

Abhänge: drei steile, südlicher sanft

Weitere Konstruktionen: Am Kurganrand verläuft ein I,o $\mathrm{m}$ breiter und o,3 tiefer Kreisgraben; nordwestlich vom Kurgan befinden sich acht große Steine, einer davon trägt Spuren von Steinbearbeitung, so dass er einem Hirschstein ähnelte.

Zustand: in der Mitte ein Raubtrichter; Randbereich der nördlichen und östlichen Abhänge durch einen Graben beschädigt

\section{Kurgan 25}

Dm 83,5 m; H 6 m

Lage: N43 19.748 E76 51.890

Form: abgerundet, plattformähnlich mit abgeflachter Kuppe

Abhänge: drei steile, südwestlicher sanft

Weitere Konstruktionen: Am Kurganrand verläuft ein Kreisgraben (Maße nicht angegeben), der an der süd- lichen Seite abbricht; diesen Bereich (Breite nicht angegeben) kann man als einen Eingang interpretieren. Südöstlich vom Kurgan, $30 \mathrm{~m}$ vom Kurganrand entfernt, zeigt sich ein Steinkreis (Maße nicht angegeben). Zustand: in der Mitte ein Raubtrichter; die Abhänge weisen mehrere kleine Gruben auf; die Peripherie ist überpflügt

Sonstiges: südlich vom Kurgan Konzentration von Kieselsteinen, möglicherweise die Überreste eines überpflügtes Kleinkurgans

Kurgan 26

Dm 5I,5 m; H 4,7 m

Lage: N43 19.570 E76 51.873

Form: abgerundet, plattformähnlich mit abgeflachter Kuppe

Abhänge: drei steile, westlicher sanft

Weitere Konstruktionen: um den Kurgan herum schlecht erhaltene Überreste von einem Kreisgraben und einem Wall

Zustand: in der Mitte ein Raubtrichter; nördlicher Randbereich beschädigt

Sonstiges: an der Oberfläche einzelne weiße Kieselsteine

\section{Kurgan 27}

Dm 67,3 m; H 6,I m

Lage: N43 I9.494 E76 51.90I

Form: abgerundet, plattformähnlich mit abgeflachter Kuppe

Abhänge: drei steile, südlicher sanft

Weitere Konstruktionen: südlich vom Kurgan Steinkreis aus graublauen Kieselsteinen (Maße nicht angegeben)

Zustand: im nordöstlichem Bereich der Kuppe ein Raubtrichter

Sonstiges: an der Oberfläche einzelne weiße Kieselsteine

\section{Kurgan 28}

Dm 46,2 m; H ?586 m

Lage: N43 I9.410 E76 51. 883

Form: abgerundet, plattformähnlich mit abgeflachter Kuppe

Abhänge: drei steile, südlicher sanft

Weitere Konstruktionen: südlich, um den Kurganrand herum, Überreste von einem Kreisgraben und einem Wall (Maße und die Reihenfolge sind nicht angegeben) Zustand: in der Mitte ein moderner Raubschacht; nördlicher Randbereich beschädigt

Sonstiges: an der Oberfläche einzelne weiße Kieselsteinen

586 In der Publikation wurde die Höhe von Io6,3 m für Kurgan 28 angegeben (Samašev u.a. 2006, 106), was jedoch zweifelhaft ist. Es könnte sich hier um einen Tippfehler handeln. 


\section{Kurgan 29}

Dm 69,3 m; H 4,6 m

Lage: N43 I9.323 E76 51.907

Form: abgerundet, plattformähnlich mit abgeflachter Kuppe

Abhänge: ?

Weitere Konstruktionen: am östlichen, südlichen und westlichen Kurganrand einzelne große weiße Steine; 20-30 m südwestlich vom Kurgan entfernt schlecht erhaltene Überreste von einem Steinkreis (?)

Zustand: im nordöstlichen Bereich der Kuppe ein Raubtrichter, zwei weitere Trichter am Nordabhang

Sonstiges: an der Oberfläche weiße Kieselsteine

\section{Kurgan 30}

Dm 33 m; H 3,6 m

Lage: N43 I9.218 E76 51.885

Form: abgerundet, plattformähnlich mit abgeflachter Kuppe

Abhänge: ?

Weitere Konstruktionen: Am südlichen Kurganrand zeigt sich ein o,7-I,o m breiter Kreisgraben (Tiefe nicht angegeben), der in östlicher Richtung den Kurgan umgibt.

Zustand: am südsüdöstlicher Abhang alte Grube

Sonstiges: an der Oberfläche weiße Kieselsteine

Kurgan 3I (Kleinkurgan)

Dm $20 \mathrm{~m} ; \mathrm{H} \mathrm{I}, 5 \mathrm{~m}$

Lage: N43 I9.187 E76 51.523

Form: abgerundete, abgeflachte Erhebung

Abhänge: drei steile, ein sanft (welcher nicht angegeben)

Weitere Konstruktionen: Am südlichen Kurganrand zeigt sich ein 0,7 m breiter Kreisgraben (Tiefe nicht angegeben).

Zustand: gesamte Oberfläche überpflügt

\section{Kurgan 32}

Dm 3I,3 m; H 2 m

Lage: N43 I9.470 E76 5I.750

Form: abgerundet, mit abgeflachter Kuppe

Abhänge: ?

Weitere Konstruktionen: Am Kurganrand verläuft ein Kreisgraben (Maße nicht angegeben), der an der westlichen Seite abbricht; diesen Bereich (Breite nicht angegeben) kann man als einen Eingang interpretieren.

Zustand: ?

Kurgan 33

Dm 34,I m; H 2,5 m

Lage: N43 19.497 E76 51.598

Form: abgerundet, plattformähnlich mit abgeflachter Kuppe

Abhänge: drei steile, westlicher sanft

Weitere Konstruktionen: Am Kurganrand verläuft ein Kreisgraben (Maße nicht angegeben), der an der west- lichen Seite abbricht; diesen Bereich (Breite nicht angegeben) kann man als einen Eingang interpretieren.

Zustand: ?

Kurgan 34 (Kleinkurgan)

Dm 20 m; H I, 8 m

Lage: N43 I9.5I8 E76 5I.478

Form: abgerundet, plattformähnlich mit abgeflachter Kuppe

Abhänge: ?

Zustand: auf den nördlichen und östlichen Abhängen Gruben

Kurgan 35 (Kleinkurgan)

Dm I2 m; H O,5 m

Lage: N43 I9.480 E76 5I.448

Form: abgerundete, abgeflachte Erhebung

Abhänge: drei steile, westlicher sanft

Zustand: ?

Kurgan 36 (Kleinkurgan)

Dm 20 m; H I m

Lage: N43 I9.472 E76 51.442

Form: abgerundete, abgeflachte Erhebung

Abhänge: keine Merkmale

Zustand: ?

Kurgan 37 (Kleinkurgan)

Dm I5 m; H I, 5 m

Lage: N43 I9.392 E76 51.500

Form: abgerundete, abgeflachte Erhebung

Abhänge: keine Merkmale

Zustand: an der Nordseite eine Grube; an der Ostseite ein Graben; über die Westhälfte verläuft ein Feldweg

Kurgan 38 (Kleinkurgan)

Dm I5 m; H I, 5 m

Lage: N43 I9.400 E76 51.498

Form: abgerundete, abgeflachte Erhebung

Abhänge: keine Merkmale

Zustand: an der Ostseite ein Graben

Kurgan 39 (Kleinkurgan)

Dm I5 m; H o, 5 (?) $\mathrm{m}$

Lage: N43 I9.370 E76 51.510

Form: abgerundete, abgeflachte Erhebung

Abhänge: keine Merkmale

Zustand: an der Ostseite ein Graben

Kurgan 40

Dm $40 \mathrm{~m} ; \mathrm{H}_{4} \mathrm{~m}$

Lage: N43 19.042 E76 51.650

Form: abgerundet, plattformähnlich mit abgeflachter Kuppe

Abhänge: drei steile, südlicher sanft

Weitere Konstruktionen: am südlichen Kurganrand Kreisgraben (Maße nicht angegeben) 
Zustand: Kuppe durch einen Triangulationspunkt beschädigt; nördliche und westliche Hälfte durch die Lehmgrube zerstört; über den Randbereich der Osthälfte verläuft ein Feldweg

Sonstiges: Die Aufschlüsse der Lehmgrube zeigen, dass die Kurganaufschüttung aus gelbem sandigem Lehm bestand

Kurgan 4I (Kleinkurgan)

Dm I5 m; H I m

Lage: N43 I9.I43 E76 51.445

Form: abgerundete, abgeflachte Erhebung

Abhänge: keine Merkmale

Zustand: ?

\section{Kurgan 42}

Dm 20 m; H 2 m

Lage: N43 I9.5I7 E76 5I.480

Form: abgerundete, abgeflachte Erhebung

Abhänge: ?

Zustand: in der Nordhälfte eine moderne Grube; in der Osthälfte eine große Senke

Kurgan 43 (Kleinkurgan)

Dm 25,2 m; H I m

Lage: N43 20.740 E76 51.093

Form: abgerundete, abgeflachte Erhebung

Abhänge: ?

Zustand: ?

Kurgan 44 (Kleinkurgan)

Dm 30 m; H I,6 m

Lage: N43 I9.734 E76 51.39I

Form: abgerundete, abgeflachte Erhebung

Abhänge: ?

Zustand: ?

Kurgan 45

Dm 50 m; H 3 m

Lage: N43 20.007 E76 51.652 (Google Earth [20II])

Bemerkung: befindet sich im gesperrten Gebiet, $\mathrm{Zu}$ gang daher unmöglich

\section{Kurgan 46}

Dm 35 m; H 3 m

Lage: N43 I9.967 E76 5I.740 (Google Earth [20II])

Form: abgerundet mit abgeflachter Kuppe

Bemerkung: befindet sich im gesperrten Gebiet, $\mathrm{Zu}-$ gang daher unmöglich
Kurgan 47 (Kleinkurgan)

Dm 20 m; H I m

Lage: N43 20.097 E76 51.883

Form: abgerundete, abgeflachte Erhebung

Abhänge: ?

Zustand: ?

\section{Kurgan 48}

Dm 32 m; H 2 m

Lage: N43 20.I45 E76 51.733

Form: abgerundet, plattformähnlich mit abgeflachter Kuppe

Abhänge: keine Merkmale

Zustand: in der nordwestlichen Hälfte eine Senke

Kurgan 49 (Kleinkurgan)

Dm 20 m; H o,5 m

Lage: N43 20.133 E76 51.700

Form: ovale, abgeflachte Erhebung

Abhänge: ?

Zustand: in der südwestlichen Hälfte eine Senke; im Randbereich des südwestlichen Abhanges eine Lehmgrube

Kurgan 50 (Kleinkurgan)

Dm 25 m; H I, 5 m

Lage: N43 20.133 E76 51.650

Form: abgerundete, abgeflachte Erhebung

Abhänge: ?

Zustand: ?

Kurgan $5 \mathbf{I}$

Dm 5 m; H o, I m

Lage: N43 19.275 E76 51.832

Form: abgerundete Erhebung

Abhänge: ?

Zustand: Kurgan komplett überpflügt

Sonstiges: einzelne mittelgroße und kleine Steine an der Oberfläche

Bemerkung: ursprüngliche Größe unklar

Kurgan 52 (Kleinkurgan)

Dm 3 m; H o, I m

Lage: N43 I9.260 E76 51.868

Form: ?

Abhänge: ?

Zustand: Kurgan komplett überpflügt

Sonstiges: einzelne mittelgroße und kleine Steine an der Oberfläche

Bemerkung: ursprüngliche Größe unklar

Lit.: Samašev u.a. 2005e, 73; Samašev u.a. 2006; Tujakbaeva u.a. I985, ıо. 
Gräberfeld Ereul [FEZ] (Abb. I38-I40; Karte 3 Nr. 69): ALT I988 m N42 48.808 E79 I5.967; Gebiet Almaty (kasach. Алматы облысы), Rajymbekskij rajon (kasach. Райымбек ауданы); Ausmaß N-S 8,6 $\times$ O-W IO,० km.

Auf der Südhälfte des Plateaus Kegen (kasach. Кеген), nahe der kasachisch-kirgisischen Staatsgrenze, auf einer Ebene nördlich der Bergkette Kungej-Alatau (kasach. Күнгей Алатауы) befinden sich fünf Ketten und vier einzelne Kurgane, die zu dem Gräberfeld Ereul gehören. Die Nekropole erstreckt sich über mehrere Kilometer und der Abstand zwischen den einzelnen Kurganketten beträgt I,O-3,5 km. Einige Kurganreihen sind durch kleine Flüsse voneinander getrennt. Trotz der Entfernung und der hydrologischen Trennung konnten die Ketten dem gleichen Fundort zugeordnet werden. Grund dafür ist die Lage in einer Ebene um das Dorf Ereul (kasach. Ереуіл), die im Norden durch das Šol'adyr-Gebirge (kasach. Шольадыр) vom restlichen Plateau Kegen abgetrennt ist und sich im Süden bis zum Fuß der Bergkette Kungej-Alatau erstreckt.

Das Gräberfeld liegt І96,5 km südöstlich der Stadt Almaty (kasach. Алматы), $22 \mathrm{~km}$ südlich des Dorfes Kegen (kasach. Кеген), zwischen den Dörfern Ereul und Mynžylky (kasach. Мыңжылқы), am östlichen Ufer des Flusses Karkara (kasach. Қарқара). Insgesamt wurden hier 35 mittelgroße und große Kurgane festgestellt. Die Grabanlagen messen zwischen $14 \mathrm{~m}$ und $95 \mathrm{~m}$ im Durchmesser und erreichen Höhen zwischen I,5 m und 7,5 m. Fast alle Kurgane des Gräberfeldes weisen Raubtrichter auf und sind durch drei steile und einen sanften Abhang gekennzeichnet. Bei 30 Kurganen befindet sich der sanfte Abhang exakt im Süden, jeweils bei zwei Kurganen im Südosten und im Südsüdosten und ein Kurgan zeigt kein solches Merkmal.

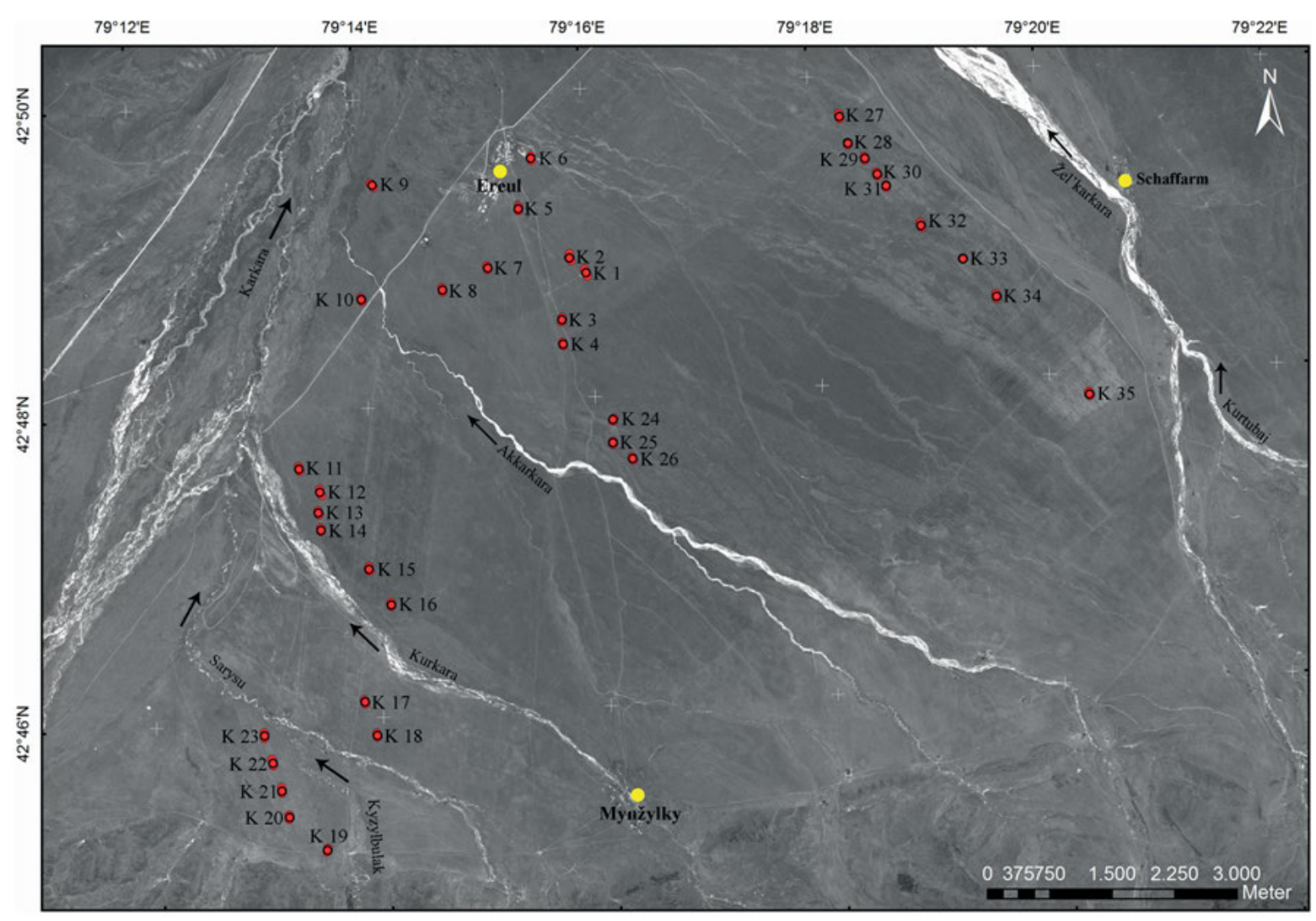

Abb. 138 | Übersichtsplan des Gräberfeldes Ereul (SPOT) 


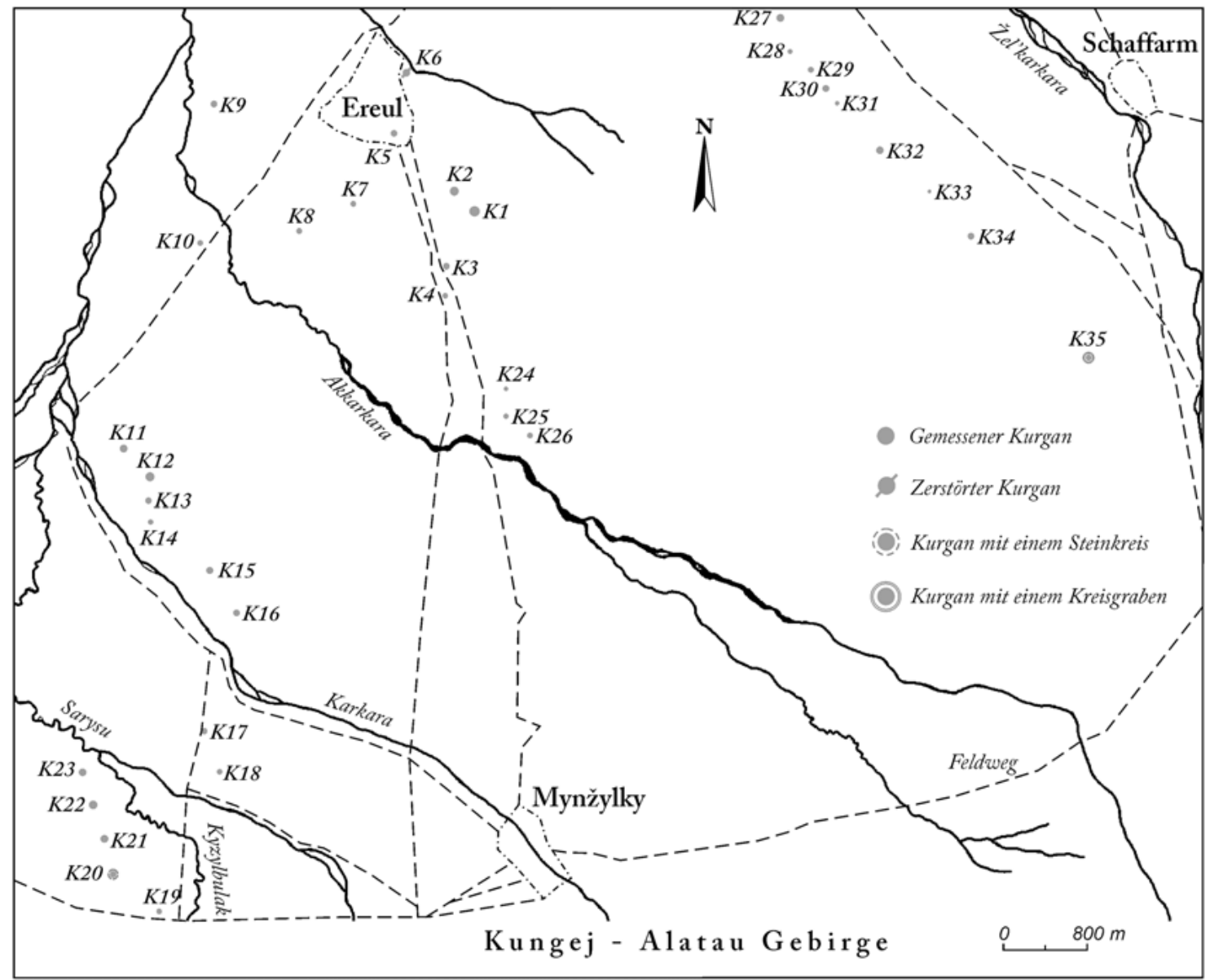

Abb. 139 | Plan des Gräberfeldes Ereul

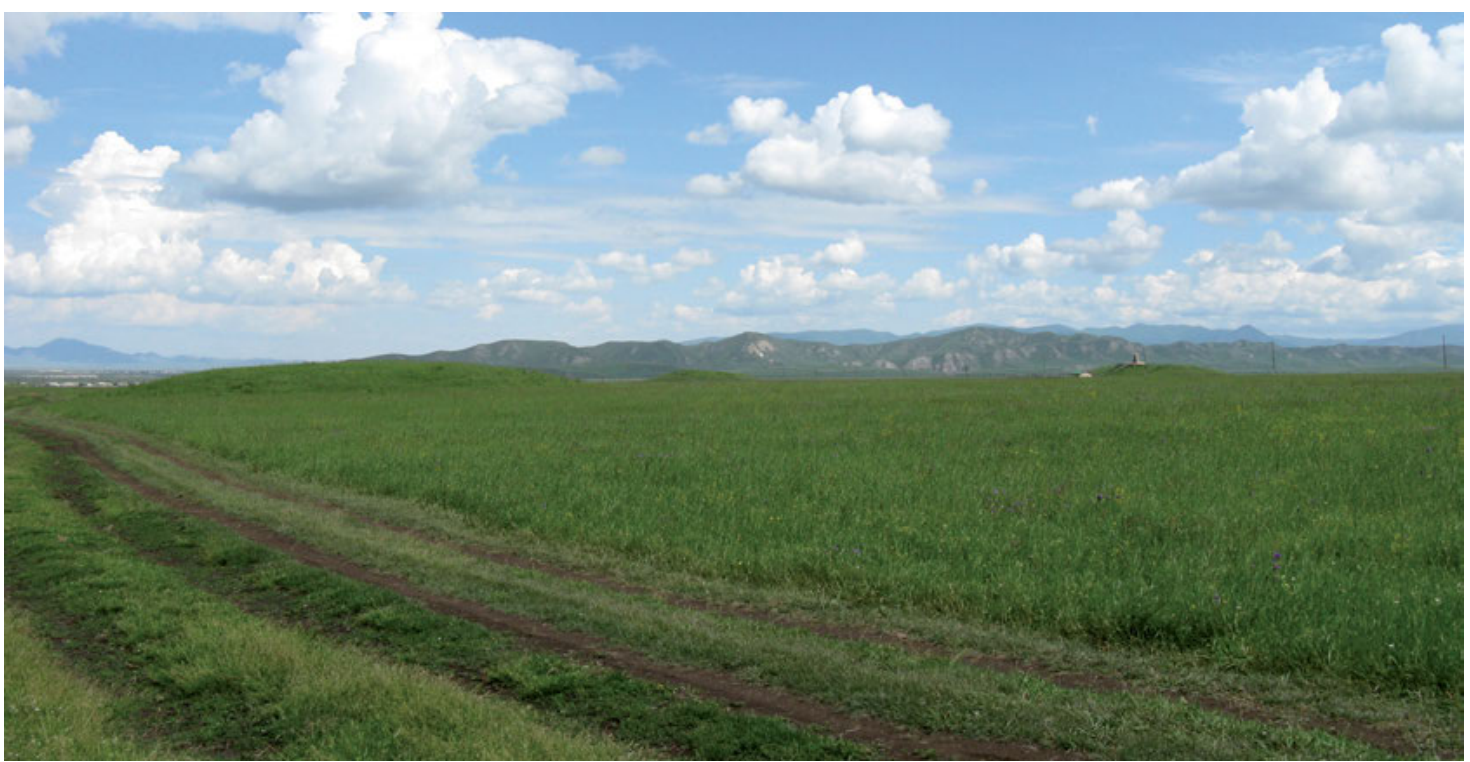

Abb. 140 | Gräberfeld Ereul. Mittlere Kette. Überblick von S 
Die vier alleinstehenden Kurgane (K7-Kio nach der Arbeitsnummerierung) stehen südwestlich vom Dorf Ereul (Abb. I38-I39), an beiden Ufern des Flusses Akkarkara (kasach. Ақ қарқара), der der rechte, östliche Nebenfluss des Flusses Karkara ist.

Die mittlere Kette besteht aus neun Kurganen (KI-K6 und K24-K26) und verläuft in einer Achse von NNW nach SSO (Abb. I38-I39). Die nördlichen Kurgane der Kette stehen im Südteil des Dorfes Ereul auf der rechten, östlichen Seite des Flusses Akkarkara. Die Kurgane sind zum Teil stark beschädigt.

Eine weitere Kette (KII-KIG) besteht aus sechs Kurganen und verläuft von NW nach SO (Abb. I38-I39). Die Kette befindet sich 5,3 km südwestlich vom Dorf Ereul und $4 \mathrm{~km}$ nordwestlich vom Dorf Mynžylky, am rechten, östlichen Ufer des Kurkara-Flusses (kasach. Қурқара).

Nördlich davon wurde eine kleine Kette beobachtet, die nur aus zwei Kurganen (KI7 und KI8) besteht und N-S ausgerichtet ist (Abb. I38-I39). Die Kurgane stehen zwischen den Flüssen Kurkara und Sarysu (kasach. Сарысу), 6,8 km südlich vom Dorf Ereul und 3,2 km westnordwestlich vom Dorf Mynžylky entfernt.

Als Westkette kann die aus fünf Kurganen (KI9-K23) bestehende Kurganenreihe angenommen werden, die am linken, westlichen Ufer des Flusses Kyzylbulak (kasach. Қызылбұлақ) liegt (Abb. I38-I39). Die Kurgane befinden sich $8 \mathrm{~km}$ südsüdwestlich vom Dorf Ereul und $4 \mathrm{~km}$ westlich vom Dorf Mynžylky entfernt. Der zweitsüdlichste Kurgan (K20) weist einen Steinkreis auf.

Die aus neun Kurganen bestehende Ostkette (K27-K35) verläuft in einer NW-SO-Achse (Abb. I38-I39). Sie liegt 5, O km östlich des Dorfes Ereul und 7,7 km nordöstlich des Dorfes Mynžylky am linken, westlichen Flussufer der Žel'karkara (kasach. Жел қарқара) entfernt. Die gesamte Kette befindet sich auf einem Acker und weist, mit Ausnahme des südlichsten Kurgans (K35), keine architektonischen Merkmale auf. In einem Abstand von i9 m um den Kurganrand wurde umlaufend und ununterbrochen (?) ein Kreisgraben angelegt.

Anhand der Landschaftsplatzierung, der Struktur und der äußeren Erscheinungsform können alle Kurgane des Gräberfeldes der sakischen Periode der Früheisenzeit zugeordnet werden.

Kurgancharakteristik:

Mittlere Kurgankette

Kurgan 3

Kurgan I (Abb. I4I,I)

Dm $95 \mathrm{~m} ; \mathrm{H} 7,5 \mathrm{~m}$

Lage: N42 48.808 E79 I5.967

Form: abgerundet, plattformähnlich mit abgeflachter

Kuppe

Abhänge: drei steile, südsüdöstlicher sanft

Zustand: Auf der Kurgankuppe befindet sich ein Ehrenmal für die „Opfern des Aufstandes von I9ı6“, zu dem eine Treppe führt; nördlich vom Ehrenmal steht ein trigonometrischer Mast; in der Mitte, westlich versetzt ein Raubtrichter

Sonstiges: keine Steine an der Oberfläche

\section{Kurgan 2}

Dm 84 m; H 7 m

Lage: N42 48.912 E79 I5.830

Form: abgerundet, plattformähnlich mit abgeflachter Kuppe

Abhänge: drei steile, südöstlicher sanft

Zustand: in der Mitte ein gewaltiger Raubtrichter Sonstiges: keine Steine an der Oberfläche

Dm 53 m; H 4,5 m
Lage: N42 48.512 E79 I5.733

Form: abgerundet, plattformähnlich mit abgeflachter Kuppe

Abhänge: drei steile, südlicher sanft

Zustand: in der Mitte eine Senke

Sonstiges: keine Steine an der Oberfläche

\section{Kurgan 4 \\ Dm 42 m; H 2 m \\ Lage: N42 48.355 E79 I5.730 \\ Form: flache Erhöhung \\ Abhänge: keine Merkmale}

Zustand: kein Raubtrichter, keine Senke; über die Westhälfte des Kurgans verläuft ein alter Feldweg

Sonstiges: keine Steine an der Oberfläche

\section{Kurgan 5}

Dm 57 m; H 5 m

Lage: N42 49.244 E79 I5.397; an südlicher Dorfgrenze von Ereul

Form: abgerundet, plattformähnlich mit abgeflachter Kuppe 

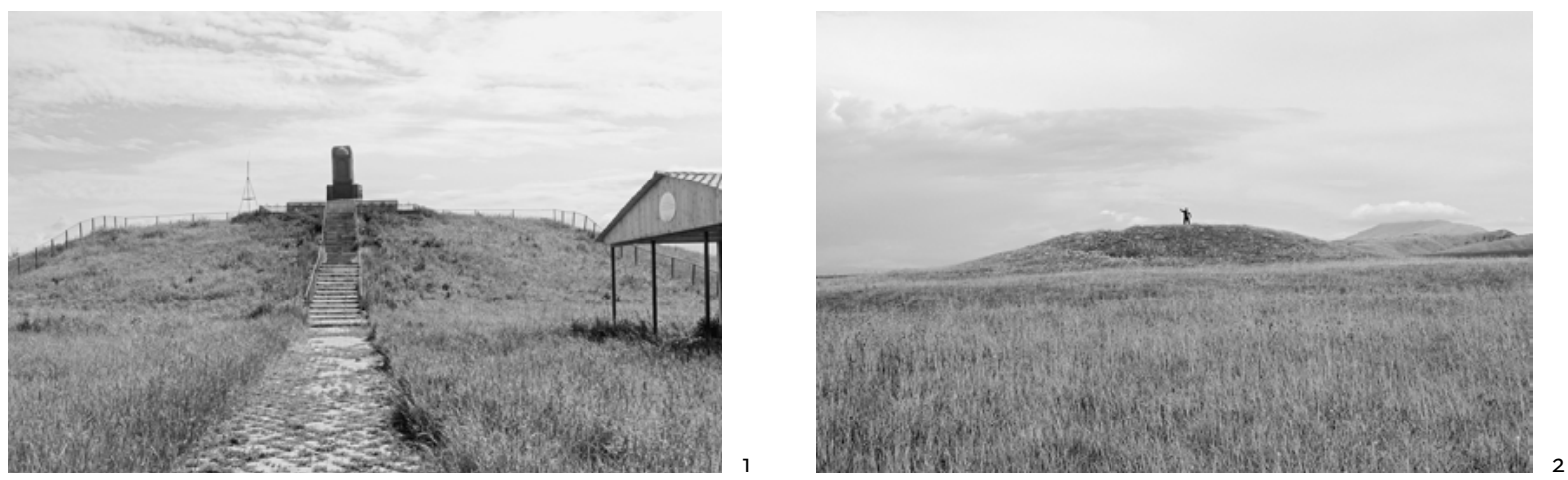

Abb. 141 | Gräberfeld Ereul. Blick von W; I. Bebauter Kurgan I; 2. Kurgan 35

Abhänge: drei steile, südlicher sanft

Zustand: in der Mitte ein Raubtrichter

Sonstiges: keine Steine an der Oberfläche

\section{Kurgan 6}

Dm 6I m; H 3 m (?)

Lage: N42 49.566 E79 15.530; der nördlichste Kurgan der Kette

Form: ?

Abhänge: drei steile, südlicher sanft

Zustand: Durch das gesamte Zentrum des Kurgans verläuft eine I3 $\mathrm{m}$ breite, W-O ausgerichtete Silagegrube, die die ganze Kurganaufschüttung bis zur modernen Oberfläche schneidet.

Sonstiges: keine Steine an der Oberfläche

\section{Kurgan 24}

Dm 35 m; H 5 m

Lage: N42 47.844 E79 I6.I39

Form: abgerundet, plattformähnlich mit abgeflachter Kuppe

Abhänge: drei steile, südlicher sanft

Zustand: in der Mitte ein Raubtrichter

Sonstiges: keine Steine an der Oberfläche

\section{Kurgan 25}

Dm 38 m; H 3 m

Lage: N42 47.699 E79 I6.I28

Form: abgerundet, plattformähnlich mit abgeflachter Kuppe

Abhänge: drei steile, südlicher sanft

Zustand: in der Mitte ein Raubtrichter

Sonstiges: keine Steine an der Oberfläche; auf der Kurgankuppe, südlich der Mitte befindet sich ein trigonometrischer Mast

\section{Kurgan 26}

Dm $45 \mathrm{~m}$; H 2 m

Lage: N42 47.588 E79 I6.292; der südlichste Kurgan der Kette
Form: abgerundet, plattformähnlich mit abgeflachter Kuppe

Abhänge: drei steile, südlicher sanft

Zustand: in der Mitte ein Raubtrichter

Sonstiges: keine Steine an der Oberfläche

Einzeln stehende Kurgane

\section{Kurgan 7}

Dm 47 m; H 4,5 m

Lage: N42 48.87I E79 I5.IOI; rechtes, östliches Ufer der Akkarkara

Form: abgerundet, plattformähnlich mit abgeflachter Kuppe

Abhänge: drei steile, südlicher sanft

Zustand: in der Mitte ein Raubtrichter

Sonstiges: keine Steine an der Oberfläche

Bemerkungen: Zwischen K7 und K8 und nördlich davon verläuft eine $\mathrm{N}-\mathrm{S}$ ausgerichtete Kette, die aus fünf Kleinkurganen besteht (Dm IO-20 m; H O,5-I,O m). Aufgrund ihrer geringen Größe wurden die Kurgane nicht aufgenommen bzw. vermessen.

\section{Kurgan 8}

Dm 5 I m; H 4,5 m

Lage: $\mathrm{N}_{42} 48.742$ E79 I4.695; rechtes, östliches Ufer der Akkarkara

Form: abgerundet, plattformähnlich mit abgeflachter Kuppe

Abhänge: drei steile, südlicher sanft

Zustand: in der Mitte ein Raubtrichter

Sonstiges: keine Steine an der Oberfläche

\section{Kurgan 9}

Dm 6r m; H 4,5 m

Lage: N42 49.44I E79 I4.I26; erste, rechte, östliche Uferterrasse der Akkarkara

Form: abgerundet, plattformähnlich mit abgeflachter Kuppe 
Abhänge: drei steile, südlicher sanft

Zustand: in der Mitte ein Raubtrichter, in der Osthälfte zwei weitere Raubtrichter

Sonstiges: keine Steine an der Oberfläche

\section{Kurgan Io}

Dm 45 m; H 4 m

Lage: N42 48.704 E79 I3.978; linkes, westliches Ufer der Akkarkara

Form: abgerundet, plattformähnlich mit abgeflachter Kuppe

Abhänge: drei steile, südlicher sanft

Zustand: in der Mitte ein Raubtrichter

Sonstiges: keine Steine an der Oberfläche; auf der Kurgankuppe trigonometrischer Mast

Kurgankette auf dem rechten, östlichen Ufer der Kurkara

\section{Kurgan II}

Dm 60 m; H 6 m

Lage: N42 47.628 E79 13.353; der nördlichste Kurgan der Kette

Form: abgerundet, plattformähnlich mit abgeflachter Kuppe

Abhänge: drei steile, südlicher sanft

Zustand: in der Mitte ein Raubtrichter

Sonstiges: keine Steine an der Oberfläche

\section{Kurgan I2}

Dm 80 m; H 6 m

Lage: N42 47.474 E79 I3.532

Form: abgerundet, plattformähnlich mit abgeflachter Kuppe

Abhänge: drei steile, südlicher sanft

Zustand: in der Mitte ein Raubtrichter

Sonstiges: keine Steine an der Oberfläche

\section{Kurgan I3}

Dm 53 m; H 4,5 m

Lage: N42 47.344 E79 I3.5IO

Form: abgerundet, plattformähnlich mit abgeflachter Kuppe

Abhänge: drei steile, südlicher sanft

Zustand: in der Mitte ein Raubtrichter

Sonstiges: keine Steine an der Oberfläche

\section{Kurgan I4}

Dm 4I m; H 3,5 m

Lage: N42 47.234 E79 I3.520

Form: abgerundet, plattformähnlich mit abgeflachter Kuppe

Abhänge: drei steile, südlicher sanft

Zustand: in der Mitte ein Raubtrichter

Sonstiges: keine Steine an der Oberfläche; kleinster Kurgan der Kette

\section{Kurgan I5}

Dm 59 m; H 4,5 m

Lage: N42 46.96I E79 I3.929

Form: abgerundet, plattformähnlich mit abgeflachter Kuppe

Abhänge: drei steile, südlicher sanft

Zustand: in der Mitte eine Senke

Sonstiges: keine Steine an der Oberfläche

\section{Kurgan 16}

Dm 53 m; H 3 m

Lage: N42 46.727 E79 I4.I04; südlichster Kurgan der Kette

Form: abgerundet, plattformähnlich mit abgeflachter Kuppe

Abhänge: drei steile, südlicher sanft

Zustand: in der Mitte eine Senke

Sonstiges: keine Steine an der Oberfläche

Kurgankette zwischen den Flüssen Kurkara und Sarysu

Kurgan I7

Dm 5I m; H 3 m

Lage: N42 46.I05 E79 I3.83I; Nordkurgan

Form: abgerundet, plattformähnlich mit abgeflachter Kuppe

Abhänge: drei steile, südlicher sanft

Zustand: in der Mitte eine Senke

Sonstiges: keine Steine an der Oberfläche

\section{Kurgan $\mathrm{I} 8$}

Dm 44 m; H 3 m

Lage: N42 45.885 E79 13.927; Südkurgan

Form: abgerundet, plattformähnlich mit abgeflachter Kuppe

Abhänge: drei steile, südlicher sanft

Zustand: in der Mitte eine Senke

Sonstiges: keine Steine an der Oberfläche

Westliche Kurgankette

\section{Kurgan I9}

Dm 44 m; H 2,5 m

Lage: N42 45.I56 E79 I3.44I; der südlichste Kurgan der Kette

Form: abgerundet, plattformähnlich mit abgeflachter Kuppe

Abhänge: drei steile, südlicher sanft

Zustand: in der Mitte eine Senke

Sonstiges: keine Steine an der Oberfläche

\section{Kurgan 20}

Dm 5I m; Dm Steinkreis 59 m; H 3 m

Lage: N42 45.38I E79 I3.II8

Form: abgerundet, plattformähnlich mit abgeflachter Kuppe

Abhänge: drei steile, südlicher sanft 
Weitere Konstruktionen: Um den Kurgan herum, in einem Abstand von $4 \mathrm{~m}$ zum Rand des Kurgans, verläuft ein Steinkreis, der aus mittelgroßen Steinen (ab $40 \times 20 \times 10 \mathrm{~cm})$ gebaut worden ist.

Zustand: in der Mitte ein Raubtrichter

Sonstiges: keine Steine an der Oberfläche

\section{Kurgan 2I}

Dm 68 m; H 5 m

Lage: N42 45.558 E79 I3.066

Form: abgerundet, plattformähnlich mit abgeflachter Kuppe

Abhänge: drei steile, südlicher sanft

Zustand: in der Südhälfte ein Raubtrichter

Sonstiges: keine Steine an der Oberfläche

\section{Kurgan 22}

Dm 74 m; H 5,5 m

Lage: N42 45.745 E79 I2.998

Form: abgerundet, plattformähnlich mit abgeflachter Kuppe

Abhänge: drei steile, südlicher sanft

Zustand: in der Mitte ein Raubtrichter

Sonstiges: keine Steine an der Oberfläche

\section{Kurgan 23}

Dm 66 m; H 6 m

Lage: N42 45.9I8 E79 I2.938

Form: abgerundet, plattformähnlich mit abgeflachter Kuppe

Abhänge: drei steile, südlicher sanft

Zustand: in der Mitte Raubtrichter

Sonstiges: keine Steine an der Oberfläche

Bemerkungen: nördlich von K23 ein Kleinkurgan;

Aufgrund seiner geringen Größe wurde der Kurgan nicht aufgenommen bzw. vermessen.

Östliche Kurgankette

\section{Kurgan 27}

Dm 66 m; H 4,5 m

Lage: N42 49.735 E79 I8.259; nördlichster Kurgan der Kette

Form: abgerundet, plattformähnlich mit abgeflachter Kuppe

Abhänge: drei steile, südlicher sanft

Zustand: in der Mitte ein gewaltiger Raubtrichter

Sonstiges: keine Steine an der Oberfläche

\section{Kurgan 28}

Dm 25 m; H 2 m

Lage: N42 49.557 E79 I8.322

Form: abgerundet, plattformähnlich mit abgeflachter Kuppe

Abhänge: drei steile, südlicher sanft

Zustand: in der Mitte ein Raubtrichter

Sonstiges: keine Steine an der Oberfläche
Kurgan 29

Dm 48 m; H 3 m

Lage: N42 49.455 E79 I8.465

Form: abgerundet, plattformähnlich mit abgeflachter Kuppe

Abhänge: drei steile, südlicher sanft

Zustand: in der Mitte eine Senke

Sonstiges: keine Steine an der Oberfläche

\section{Kurgan 30}

Dm 57 m; H 5 m

Lage: N42 49.35I E79 I8.567

Form: abgerundet, plattformähnlich mit abgeflachter

Kuppe

Abhänge: drei steile, südlicher sanft

Zustand: in der Mitte ein Raubtrichter

Sonstiges: keine Steine an der Oberfläche

Kurgan 3I

Dm 34 m; H 3 m

Lage: N42 49.268 E79 I8.642

Form: abgerundet, plattformähnlich mit abgeflachter

Kuppe

Abhänge: drei steile, südsüdöstlicher sanft

Zustand: in der Mitte ein Raubtrichter

Sonstiges: keine Steine an der Oberfläche

\section{Kurgan 32}

Dm ${ }_{3}$ m; H 4 m

Lage: N42 49.004 E79 I8.93I

Form: abgerundet, plattformähnlich mit abgeflachter Kuppe

Abhänge: drei steile, südöstlicher sanft

Zustand: in der Mitte ein Raubtrichter

Sonstiges: keine Steine an der Oberfläche

Kurgan 33 (Kleinkurgan)

Dm I4 m; H I, 5 m

Lage: N42 48.775 E79 I9.279

Form: abgerundet, plattformähnlich mit abgeflachter Kuppe

Abhänge: drei steile, südlicher sanft

Zustand: in der Mitte ein Raubtrichter

Sonstiges: keine Steine an der Oberfläche

\section{Kurgan 34}

Dm 55 m; H 3,5 m

Lage: N42 48.522 E79 I9.563

Form: abgerundet, plattformähnlich mit abgeflachter Kuppe

Abhänge: drei steile, südlicher sanft

Zustand: in der Mitte ein Raubtrichter

Sonstiges: keine Steine an der Oberfläche

Kurgan 35 (Abb. I4I,2)

Dm 54 m; Dm Kreisgraben II4 m; H 4,5 m

Lage: N42 47.858 E79 20.335; südlichster Kurgan der Kette 
Form: abgerundet, plattformähnlich mit abgeflachter Kuppe

Abhänge: drei steile, südlicher sanft

Weitere Konstruktionen: In einem Abstand vom ig $\mathrm{m}$ Kurganrand ist ein durchgehender Kreisgraben bis $\mathrm{zu}$ II $\mathrm{m}$ Breite und I,O-I,5 $\mathrm{m}$ Tiefe angelegt worden.
Zustand: in der Mitte ein gewaltiger Raubtrichter; Der Aushub liegt in der Osthälfte, so dass der Kurgan deformiert und asymmetrisch erscheint.

Sonstiges: gesamte Oberfläche mit mittelgroßen Steinen ( $\mathrm{ab} 40 \times 15 \times 5 \mathrm{~cm}$ bis zu Schottergröße) bedeckt

Forschungsgeschichte und Bemerkungen

Im Jahre 2006 wurden die Kurgane des Gräberfeldes Ereul im Zuge einer Revision der archäologischen Bodendenkmäler im Rajymbekskij rajon des Gebietes Almaty vom Turgen-Forschungsteam der Almaty Survey-Expedition (APAЭ) unter der Leitung von A. Gorjačev zum ersten Mal dokumentiert (Bajpakov/Gorjačev 2007, I77-I78, I80-I92). Es wurden eine Beschreibung und ein topographischer Plan der Kurgane hergestellt. Jedoch wurden nicht alle Kurgane aufgenommen ${ }^{87}$ und die untersuchten Kurgane der Nekropole zu unterschiedlichen Kurganengruppen und sogar Gräberfeldern zugeordnet.

Konkordanzliste der Fundortes88 (Bajpakov/Gorjačev 2007):

FEZ Kurgangruppe an der Südgrenze des Dorfes Ereul ${ }^{89}$ : Bajpakov/Gorjačev 2007, I9०, Abb. I49; ALT 2015 m, N42 48'94,3" E79 I5'37,0"590; *entspricht dem Topoi Survey 2009 - Gf. Ereul KI, K2, K3, K5 und $\mathrm{K} 6$.

FEZ Gf. Ereul-I (russ. Ереул-I): Bajpakov/Gorjačev 2007, I88, Abb. I48; ALT I998 m, N42 48'74,2" E79 I4'70,2"; *entspricht dem Topoi Survey 2009 - Gf. Ereul K7, K8 und einer Kurgankette, die aus Kleinkurganen bestand und sich zwischen $\mathrm{K} 7$ und K8, nördlich davon befand.

FEZ Ein Kurgan 2,2 km südwestlich vom Dorf Ereul: Bajpakov/Gorjačev 2007, I87, Abb. I47; ALT I997 m, N42 48'59,6" E79 I4'I3,4"; *entspricht dem Topoi Survey 2009 - Gf. Ereul Kio.

FEZ Gf. Sarysu-I (russ. Capыcy-I): Bajpakov/Gorjačev 2007, ı83, Abb. I44; ALT 2042 m, N42 46'72,7" E79 I4'II,I"; *entspricht dem Topoi Survey 2009 - Gf. Ereul KII, KI2, Ki3, Ki4, Ki5 und Ki6.

FEZ Zwei Kurgane 2,5 km nordwestlich vom Dorf Mynžylky: Bajpakov/Gorjačev 2007, I82, Abb. I43; ALT 2058 m, N42 45'89,I" E79 13'99,2"; *entspricht dem Topoi Survey 2009 - Gf. Ereul KI7 und Ki8.

FEZ Ein Kurgan 4 km südwestlich vom Dorf Mynžylky: Bajpakov/Gorjačev 2007, I78, Abb. I40; ALT 2070 m, N42 45'16,0" E79 13'44,7"; *entspricht dem Topoi Survey 2009 - Gf. Ereul Kig.

FEZ Kurgangruppe 4,5 km westlich vom Dorf Mynžylky: Bajpakov/Gorjačev 2007, I80, Abb. I4I; ALT 2054 m, N42 45'38,6" E79 I3'II,9"; *entspricht dem Topoi Survey 2009 - Gf. Ereul K20, K2I, K22, K23 und ein Kleinkurgan nördlich vom K23.

FEZ Drei Kurgane 4 km nördlich vom Dorf Mynžylky: Bajpakov/Gorjačev 2007, I75, Abb. I37; ALT 205I m, N42 47'69,9" E79 I6'ı2,3"; *entspricht dem Topoi Survey 2009 - Gf. Ereul K24, K25 und K26.

Lit.: Bajpakov/Gorjačev 2007, I77-I78, I80-I92.

587 Kurgane 4, 9, 27-35 (nach der Arbeitsnummerierung) wurden während der Geländearbeit im Jahr 2006 nicht aufgenommen.

588 Im Sommer 2009 führte auch der Autor in diesem Gebiet in Zusammenarbeit mit dem Archäologischen Institut „A. Ch. Margulans“, Almaty (Z. Samašev, B. Nurmuchanbetov) einen Survey durch, der hier als „Topoi Survey 2009 " bezeichnet wird.
589 KI wurde im Bericht (Bajpakov/Gorjačev 2007, I90) als ein Ehrenmal der Dorfgründung deklariert. Die Entfernung zwischen den Kurganen und ihre geographische Lage wurden fälschlich dokumentiert. Der $290 \mathrm{~m}$ südlich von Kurgan 4 gelegene Kurgan 3 wurde nicht aufgenommen.

590 Grad-Minuten-Sekunden-System. 
Gräberfeld Issyk [FEZ] (Abb. I42-I43; Karte 3 Nr. I4): ALT 835 m N43 23.623 E77 23.797; Gebiet Almaty (kasach. Алматы облысы), Enbekšikazachskij rajon (kasach. Еңбекшіқазақ ауданы); Ausmaß N-S $2,7 \times \mathrm{O}-\mathrm{W} 2,3 \mathrm{~km}$.

Die Nekropole Issyk liegt ca. $40 \mathrm{~km}$ ostnordöstlich der Stadt Almaty (kasach. Алматы) und 6,5 km nordwestlich der Stadt Issyk (kasach. Eciк) am linken, westlichen Ufer des Esik-Flusses (kasach. Eciк). Im Süden verläuft das Transili-Alatau (kasach. Іле Алатауы). Das Gräberfeld wurde durch den in das 5. Jh. v. Chr. zu datierenden sog. „Goldenen Mann“ (kasach. „Алтын адам“/ „Altyn Adam“) bekannt, der im Jahre I970 entdeckt worden ist (Akišev K.A. I978, 5ff.; Parzinger 2004, 55-57; Samašev 2007, I62-I70) und bis zur Entdeckung des Fürstengrabes von Aržan 2 in Tuva (Čugunov u.a. 2003, II3-I62; Cugunov u.a. 2007, 69-82; Cugunov u.a. 2010) als die reichste wissenschaftlich untersuchte früheisenzeitliche Bestattung östlich des Urals galt. Die Nekropole besteht heute aus 52 großen und mittelgroßen Kurganen.

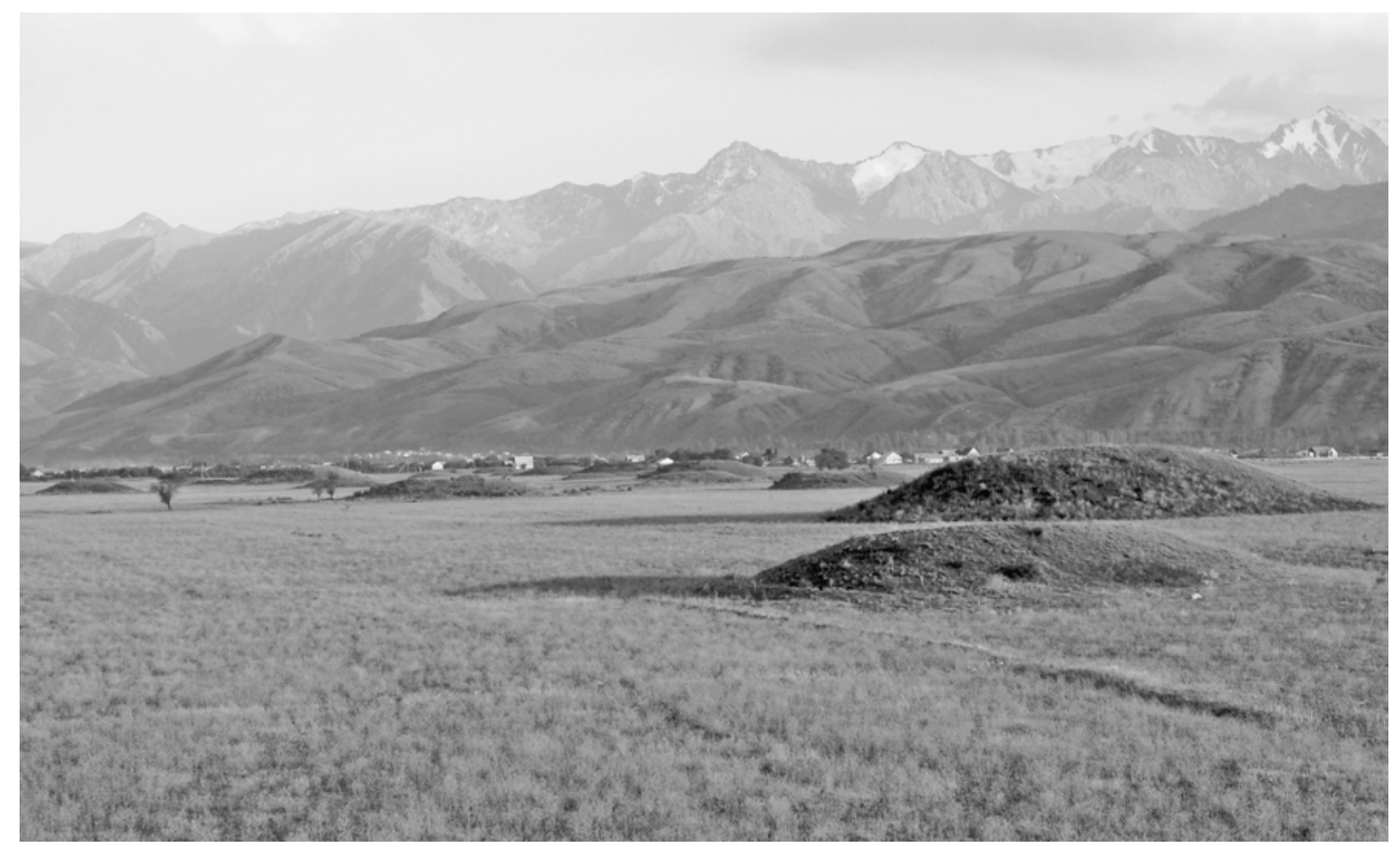

Abb. 142 | Gräberfeld Issyk. Blick von N

Der Durchmesser der Hügel schwankt zwischen I6 m und I45 m, ihre Höhe zwischen $2 \mathrm{~m}$ und $8 \mathrm{~m}$. Das Gräberfeld besteht aus sechs oder sieben Kurganketten, welche von SO nach NW verlaufen. Die genaue Anzahl der Ketten konnte wegen einer Teilbebauung der Nekropole nicht bestimmt werden. Alle Kurgane des Gräberfeldes weisen Raubtrichter auf. Von drei Seiten haben sie steile Abhänge, von der Vierten sanfte. In 29 Fällen haben die Kurgane den sanften Abhang im Südosten, in Io Fällen exakt im Süden, bei drei Kurganen exakt im Osten, bei jeweils einem Kurgan im Nordwesten und im Südwesten, ein Kurgan hat überhaupt keinen sanften Abhang und bei sieben Kurganen konnte aufgrund eines hohen Zerstörungsgrades dieses Merkmal nicht bestimmt werden.

Anhand der Landschaftsplatzierung, der Struktur und der äußeren Erscheinungsform können alle Kurgane des Gräberfeldes der sakischen Periode der Früheisenzeit zugeordnet werden. 


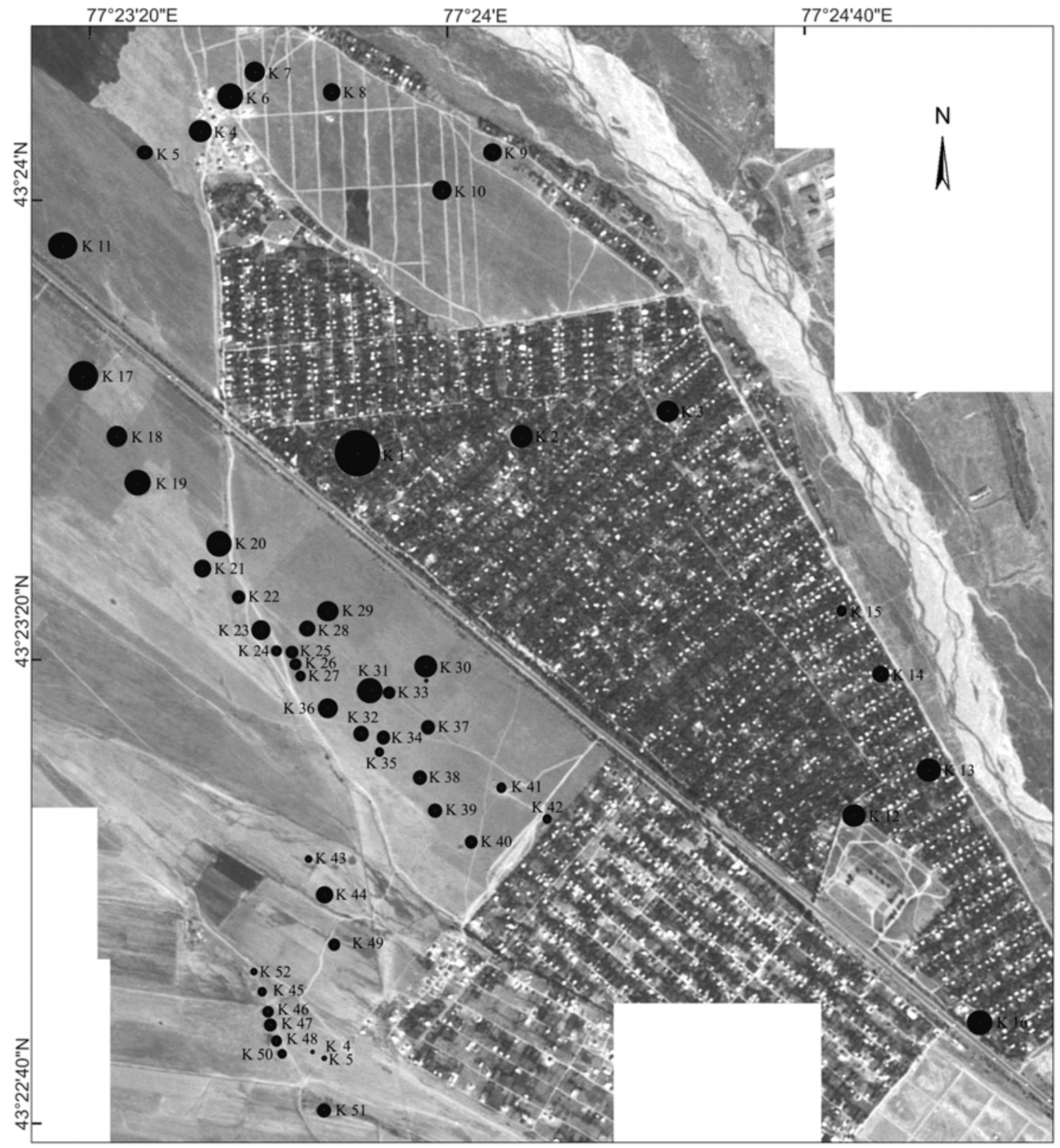

Abb. 143 | Gräberfeldplan Issyk (SPOT)

Kurgancharakteristik:

Kurgan I (Abb. I44,I)

Dm I2I m; H io m

Lage: N43 23.623 E77 23.797

Form: abgerundet, plattformähnlich mit abgeflachter Kuppe

Abhänge: drei steile, östlicher sanft

Zustand: in der Mitte ein gewaltiger Raubtrichter Sonstiges: Kurganrand dicht bebaut

\section{Kurgan 2}

Dm 56 m; H 9 m

Lage: N43 23.639 E77 24.II3

Form: abgerundet, plattformähnlich mit abgeflachter Kuppe

Abhänge: drei steile, südöstlicher sanft

Zustand: in der Mitte ein Raubtrichter

Sonstiges: Kurganrand dicht bebaut und zum Teil zerstört 

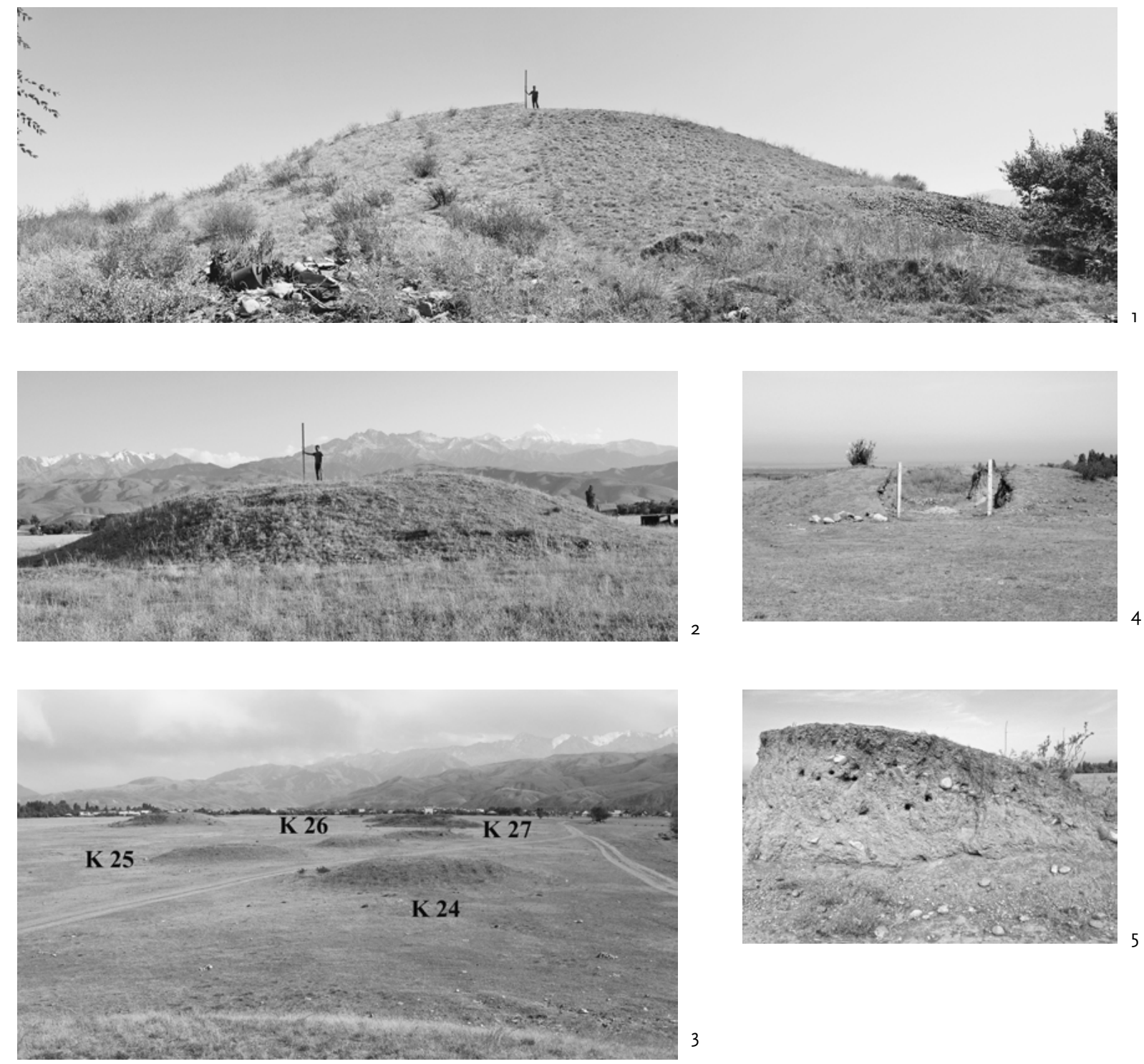

Abb. 144 | Kurgane des Gräberfeldes Issyk; I. Kurgan I, Blick von NW; 2. Kurgan Io. Blick von N; 3. Kleinkurgane 24-27, Blick von N; 4. Kurgan 4I, Blick von S; 5. Kurgan 4I, Nordprofil vom NO-Viertel des Kurgans

\section{Kurgan 3}

Dm 62 m; H 9 m

Lage: N43 23.672 E77 24.402

Form: abgerundet, plattformähnlich mit abgeflachter Kuppe

Abhänge: drei steile, südöstlicher sanft

Zustand: in der Mitte ein Raubtrichter

Sonstiges: einzelne Steine an der Oberfläche;

Kurganrand dicht bebaut und zum Teil zerstört

\section{Kurgan 4}

Dm 57 m; H 4,5 m

Lage: N43 24.092 E77 23.50I
Form: abgerundet, plattformähnlich mit abgeflachter Kuppe

Abhänge: drei steile, östlicher sanft

Zustand: in der Mitte ein Raubtrichter

\section{Kurgan 5}

Dm 40 m; H 3 m

Lage: N43 24.064 E77 23.390

Form: abgerundet, plattformähnlich mit abgeflachter Kuppe

Abhänge: drei steile, südöstlicher sanft Zustand: in der Mitte ein Raubtrichter 


\author{
Kurgan 6 \\ Dm $64 \mathrm{~m} ; \mathrm{H}_{4}, 6 \mathrm{~m}$ \\ Lage: N43 24.I43 E77 23.562 \\ Form: abgerundet, plattformähnlich mit abgeflachter \\ Kuppe \\ Abhänge: drei steile, südöstlicher sanft \\ Zustand: in der Mitte ein Raubtrichter \\ Sonstiges: einzelne Steine an der Oberfläche

\section{Kurgan 7} \\ Dm 54 m; H 6,8 m \\ Lage: N43 24.I76 E77 23.6I4 \\ Form: abgerundet, plattformähnlich mit abgeflachter \\ Kuppe \\ Abhänge: drei steile, südöstlicher sanft \\ Zustand: in der Mitte ein Raubtrichter \\ Sonstiges: einzelne Steine an der Oberfläche
}

\section{Kurgan 8}

Dm 47 m; H 5 m

Lage: N43 24.I43 E77 23.765

Form: abgerundet, plattformähnlich mit abgeflachter Kuppe

Abhänge: drei steile, südöstlicher sanft

Zustand: in der Mitte ein Raubtrichter

Sonstiges: Im Bereich der modernen Pflugspuren, die sich um den Kurgan herum befinden, liegen mittelgroße Steine, die evtl. von einem Steinkreis stammen könnten.

\section{Kurgan 9}

Dm 46 m; H 4 m

Lage: N43 24.049 E77 24.074

Form: abgerundet, plattformähnlich mit abgeflachter Kuppe

Abhänge: drei steile, östlicher sanft

Weitere Konstruktionen: IO-I2 m nördlich und nordwestlich vom Kurganrand entfernt befinden sich drei Kreiskonstruktionen (Erdkonstruktionen: Dm io $\mathrm{m}$, I8 $\mathrm{m}$ und I6 m), die evtl. einen ethnographischen Ursprung haben.

Zustand: in der Mitte zwei Raubtrichter

Sonstiges: gut erhaltene Steinabdeckung

Kurgan io (Abb. I44,2)

Dm 48 m; H 5 m

Lage: N43 23.997 E77 23.972

Form: abgerundet, plattformähnlich mit abgeflachter Kuppe

Abhänge: drei steile, südöstlicher sanft

Zustand: in der Mitte eine Senke (Dm 4-5 m; 0,5 m tief)

Sonstiges: einzelne Steinkonzentrationen an der Oberfläche

\section{Kurgan II}

Dm 69 m; H 6,4 m

Lage: N43 23.935 E77 23.228
Form: abgerundet, plattformähnlich mit abgeflachter Kuppe

Abhänge: drei steile, südöstlicher sanft

Zustand: in der Mitte ein Raubtrichter

Sonstiges: einzelne Steine an der Oberfläche

Kurgan 12

Dm 57 m; H 6 m

Lage: N43 23.090 E77 24.746

Form: abgerundet, plattformähnlich mit abgeflachter Kuppe

Abhänge: drei steile, südöstlicher sanft

Zustand: in der Mitte ein Raubtrichter

Sonstiges: nördliche und westliche Seiten des Kurganrandes durch einen Feldweg und eine Bebauung beschädigt

Kurgan I3

Dm 64 m; H 5 m

Lage: N43 23.I47 E77 24.894

Form: abgerundet, plattformähnlich mit abgeflachter Kuppe

Abhänge: drei steile, südöstlicher sanft

Zustand: in der Mitte ein Raubtrichter

Sonstiges: einzelne Steine an der Oberfläche;

Fußbereich des Kurgans ist durch die Bebauung zerstört

\section{Kurgan 14}

Dm 42 m; H ? m

Lage: N43 23.289 E77 24.80I

Form: ?

Abhänge: ?

Zustand: sehr stark zerstört, auf dem Kurgan läuft ein Feldweg; dicht bebaut

Sonstiges: weißt Spuren der Steinabdeckung auf

\section{Kurgan I5}

Dm ? m; H 3 m

Lage: N43 23.379 E77 24.73I

Form: abgerundet, plattformähnlich mit abgeflachter Kuppe

Abhänge: ?

Zustand: in der Mitte ein Raubtrichter

\section{Kurgan 16}

Dm 65 m; H 7,4 m

Lage: N43 22.783 E77 24.979

Form: abgerundet, plattformähnlich mit abgeflachter Kuppe

Abhänge: ?

Zustand: in der Mitte ein Raubtrichter

Sonstiges: einzelne Steine an der Oberfläche;

Randbereich des Kurgans durch die Bebauung zerstört

\section{Kurgan 17}

Dm 74 m; H 6,7 m

Lage: N43 23.747 E77 23.264 
Form: abgerundet, plattformähnlich mit abgeflachter Kuppe

Abhänge: drei steile, südöstlicher sanft

Zustand: in der Mitte ein Raubtrichter

Sonstiges: einzelne Steinanhäufungen an der Oberfläche

\section{Kurgan 18}

Dm 53 m; H 4 m

Lage: N43 23.658 E77 23.319

Form: abgerundet, plattformähnlich mit abgeflachter Kuppe

Abhänge: drei steile, südöstlicher sanft

Zustand: in der Mitte ein Raubtrichter

Sonstiges: einzelne Steine an der Oberfläche

\section{Kurgan I9}

Dm 65 m; H 6,7 m

Lage: N43 23.592 E77 23.36I

Form: abgerundet, plattformähnlich mit abgeflachter Kuppe

Abhänge: drei steile, südöstlicher sanft

Zustand: in der Mitte ein Raubtrichter

Sonstiges: einzelne Steine an der Oberfläche

\section{Kurgan 20}

Dm 66 m; H 4,5 m

Lage: N43 23.50I E77 23.52I

Form: abgerundet, plattformähnlich mit abgeflachter Kuppe

Abhänge: drei steile, nordwestlicher sanft

Zustand: in der Mitte ein Raubtrichter

Sonstiges: einzelne Steine an der Oberfläche

\section{Kurgan 2I}

Dm 46 m; H 4,5 m

Lage: N43 23.468 E77 23.483

Form: abgerundet, plattformähnlich mit abgeflachter Kuppe

Abhänge: drei steile, südöstlicher sanft

Zustand: in der Mitte ein Raubtrichter

Sonstiges: einzelne Steine an der Oberfläche;

37 m südlich vom Kurgan befinden sich zwei Kleinkurgane

\section{Kurgan 22}

Dm 34 m; H 2,5 m

Lage: N43 23.423 E77 23.549

Form: abgerundet, plattformähnlich mit abgeflachter Kuppe

Abhänge: drei steile, südöstlicher sanft

Zustand: in der Mitte ein Raubtrichter

Sonstiges: einzelne Steine an der Oberfläche;

I2 $\mathrm{m}$ und I9 $\mathrm{m}$ südlich vom Kurgan zwei Kleinkurgane (Dm $8 \mathrm{~m}$ und $\mathrm{I} 4 \mathrm{~m}$ )
Kurgan 23

Dm 5I m; H 6 m

Lage: N43 23.376 E77 23.59I

Form: abgerundet, plattformähnlich mit abgeflachter Kuppe

Abhänge: drei steile, südöstlicher sanft

Zustand: in der Südhälfte zwei Raubtrichter

Kurgan 24 (Kleinkurgan; Abb. I44,3)

Dm $30 \mathrm{~m} ; \mathrm{H}$ ? $\mathrm{m}$

Lage: N43 23.345 E77 23.620

Form: abgerundet, plattformähnlich mit abgeflachter Kuppe

Abhänge: drei steile, südöstlicher sanft

Zustand: in der Mitte eine Senke

Kurgan 25 (Kleinkurgan; Abb. I44,3)

Dm 34 m; H ? m

Lage: N43 23.343 E77 23.650

Form: abgerundet, plattformähnlich mit abgeflachter Kuppe

Abhänge: drei steile, südöstlicher sanft

Zustand: in der Mitte ein Raubtrichter

Kurgan 26 (Kleinkurgan; Abb. I44,3)

Dm $32 \mathrm{~m} ; \mathrm{H}$ ? $\mathrm{m}$

Lage: N43 23.325 E77 23.657

Form: abgerundet, plattformähnlich mit abgeflachter

Kuppe

Abhänge: drei steile, südöstlicher sanft

Zustand: in der Mitte eine Senke

Kurgan 27 (Kleinkurgan; Abb. I44,3)

Dm $30 \mathrm{~m} ; \mathrm{H}$ ? $\mathrm{m}$

Lage: N43 23.308 E77 23.666

Form: abgerundet, plattformähnlich mit abgeflachter Kuppe

Abhänge: drei steile, südöstlicher sanft

Zustand: in der Mitte eine Senke

Kurgan 28

Dm 22 m; H 4 m

Lage: N43 23.377 E77 23.682

Form: abgerundet, plattformähnlich mit abgeflachter Kuppe

Abhänge: drei steile, südöstlicher sanft

Zustand: in der Mitte ein Raubtrichter

Sonstiges: Oberfläche dicht mit Steinen bedeckt

\section{Kurgan 29}

Dm 5I m; H 4 m

Lage: N43 23.400 E77 23.722

Form: abgerundet, plattformähnlich mit abgeflachter Kuppe

Abhänge: drei steile, südöstlicher sanft

Zustand: in der Mitte ein Raubtrichter

Sonstiges: Oberfläche dicht mit Steinen bedeckt;

Randbereich des Kurgans überpflügt 


\author{
Kurgan 30 \\ Dm 58 m; H 5,3 m \\ Lage: N43 23.316 E77 23.9I2 \\ Form: abgerundet, plattformähnlich mit abgeflachter \\ Kuppe \\ Abhänge: drei steile, südöstlicher sanft \\ Zustand: in der Mitte ein Raubtrichter \\ Sonstiges: an der Südseite dicht am Kurgan befindet \\ sich ein Kleinkurgan
}

Kurgan 30 (Kleinkurgan)

Dm I4 m; H o,3 m

Lage: N43 23.300 E77 23.9I2; unmittelbar neben der Südseite von Kurgan 30

Form: kreisförmige Steinanhäufung

Abhänge: keine Merkmale

Kurgan 3I

Dm 66 m; H 6 m

Lage: N43 23.284 E77 23.804

Form: abgerundet, plattformähnlich mit abgeflachter Kuppe

Abhänge: drei steile, südlicher sanft

Zustand: in der Mitte ein Raubtrichter

Sonstiges: ostsüdöstlich vom Kurgan schließt Kleinkurgan 33 unmittelbar an

\section{Kurgan 32}

Dm 39 m; H 4 m

Lage: N43 23.223 E77 23.782

Form: abgerundet, plattformähnlich mit abgeflachter Kuppe

Abhänge: drei steile, südöstlicher sanft

Zustand: in der Mitte ein Raubtrichter

Sonstiges: Steine der Kurganabdeckung an der Oberfläche

Kurgan 33 (Kleinkurgan)

Dm 35 m; H ? m

Lage: N43 23.280 E77 23.838

Form: abgerundet, plattformähnlich mit abgeflachter Kuppe

Abhänge: drei steile, südöstlicher sanft

Zustand: in der Mitte ein Raubtrichter

Sonstiges: Oberfläche dicht mit Steinen bedeckt

Kurgan 34 (Kleinkurgan)

Dm $30 \mathrm{~m} ; \mathrm{H}$ ? $\mathrm{m}$

Lage: N43 23.2I7 E77 23.825

Form: abgerundet, plattformähnlich mit abgeflachter Kuppe

Abhänge: ?

Zustand: in der Mitte ein Raubtrichter

Sonstiges: Oberfläche dicht mit Steinen bedeckt

Kurgan 35 (Kleinkurgan)

Dm 26 m; $H$ ? $\mathrm{m}$

Lage: N43 23.196 E77 23.8I6
Form: abgerundet, plattformähnlich mit abgeflachter Kuppe

Abhänge: drei steile, südöstlicher sanft

Zustand: in der Mitte ein Raubtrichter

Sonstiges: einzelne Steine an der Oberfläche;

Randbereich durch Pflug stark beschädigt

Kurgan 36

Dm 49 m; H 4,4 m

Lage: N43 23.26I E77 23.722

Form: abgerundet, plattformähnlich mit abgeflachter Kuppe

Abhänge: drei steile, südöstlicher sanft

Zustand: in der Mitte ein Raubtrichter

Kurgan 37 (Kleinkurgan)

Dm 33 m; H ? m

Lage: N43 23.229 E77 23.9I3

Form: abgerundet, plattformähnlich mit abgeflachter Kuppe

Abhänge: drei steile, südlicher sanft

Zustand: in der Mitte ein Raubtrichter

Sonstiges: Oberfläche dicht mit Steinen bedeckt

Kurgan 38 (Kleinkurgan)

Dm $30 \mathrm{~m} ; \mathrm{H}$ ? $\mathrm{m}$

Lage: N43 23.I57 E77 23.894

Form: abgerundet, plattformähnlich mit abgeflachter Kuppe

Abhänge: drei steile, südöstlicher sanft

Zustand: in der Mitte ein Raubtrichter, im östlichen Bereich zwei weitere Raubtrichter; Westabhang durch den Pflug zerstört

Sonstiges: einzelne Steine an der Oberfläche

\section{Kurgan 39}

Dm 37 m; H 3 m

Lage: N43 23.IIO E77 23.922

Form: abgerundet, plattformähnlich mit abgeflachter Kuppe

Abhänge: drei steile, südlicher sanft

Zustand: in der Mitte ein Raubtrichter, im nordöstlichen Bereich ein weiterer Raubtrichter

Sonstiges: einzelne Steine an der Oberfläche

\section{Kurgan 40}

Dm 32 m; H 3 m

Lage: N43 23.063 E77 23.99I

Form: abgerundet, plattformähnlich mit abgeflachter Kuppe

Abhänge: drei steile, südlicher sanft

Zustand: Da der Kurgan im Jahre I999 von B. Nurmuchanbetov zum Teil ausgegraben worden ist, führt durch den gesamten Kurgan ein $\mathrm{O}-\mathrm{W}$ angelegter Schnitt, dessen Breite $7 \mathrm{~m}$ misst.

Sonstiges: die Überreste von Nord- und Südprofil zeigen, dass die Kurganaufschüttung aus lehmigem Sand und Kieselsand bestand; die oberste Schicht aber aus 
mittelgroßen Kieselsteinen, die eine Kurganabdeckung bildeten. Kurgankuppe ohne Steine

Bemerkungen: Im Archiv des Archäologischen Institutes, Almaty gibt es keinen Bericht zu dieser Grabung. Kurgan 40 wurde im Bericht von K. Bajpakov (Bajpakov u.a. 2005c, 29, Foto 23) lediglich als ein für die Museifizierung vorbereitetes Objekt illustriert

Kurgan 4I (Abb. I44,4)

Dm 28 m; H 2,5 m

Lage: N43 23.I4O E77 24.054

Form: abgerundet, plattformähnlich

Abhänge: ?

Zustand: Da der Kurgan im Jahre I999 von B. Nurmuchanbetov zum Teil ausgegraben worden ist, führen durch den gesamten Kurgan zwei O-W und N-S ausgerichtete Schnitte, deren Breite jeweils $5 \mathrm{~m}$ beträgt.

Sonstiges: die Überreste der Profile zeigen folgende Vertikalstratigraphie: a) unterste Schicht: Lehm, lehmiger Sand und Kieselsteine, b) Steinpackung, c) ähnliche Schicht, wie „a“ (o,4 $\mathrm{m}$ dick), allerdings nimmt die Mächtigkeit der Schicht zur Mitte des Kurgans ab, d) moderne dunkelbraune bis hellgraue Humusschicht (Abb. I44,5)

Bemerkungen: Im Archiv des Archäologischen Institutes in Almaty gibt es keinen Bericht zu dieser Grabung. Kurgan 4I wurde im Bericht von K. Bajpakov (Bajpakov u.a. 2005c, 30, Foto 24) lediglich als ein für die Museifizierung vorbereitetes Objekt illustriert

\section{Kurgan 42}

Dm 25 m; H 2 m

Lage: N43 23.093 E77 24.I42

Form: abgerundet, plattformähnlich mit abgeflachter Kuppe?

Abhänge: ?

Zustand: Da der Kurgan im Jahre I999 von B. Nurmuchanbetov zum Teil ausgegraben worden ist, fehlt die gesamte Südhälfte

Bemerkung: Im Archiv des Archäologischen Institutes in Almaty gibt es keinen Bericht zu dieser Grabung

\section{Kurgan 43}

Dm 40 m; H 2,5 m

Lage: N43 22.994 E77 23.70I

Form: abgerundet, plattformähnlich mit abgeflachter Kuppe

Abhänge: drei steile, südlicher sanft

Zustand: in der Mitte keine Senke

Sonstiges: einzelne Steine an der Oberfläche

Kurgan 44 (Kleinkurgan)

Dm 20 m; H ? m

Lage: N43 23.046 E77 23.670

Form: abgerundete Erhebung

Abhänge: keine Merkmale

Zustand: in der Mitte ein Raubtrichter

Sonstiges: an der Oberfläche keine Steine
Kurgan 45 (Kleinkurgan)

Dm 26 m; H I, 5 m

Lage: N43 22.858 E77 23.572

Form: abgerundet, plattformähnlich mit abgeflachter Kuppe

Abhänge: drei steile, südlicher sanft

Zustand: in der Mitte ein Raubtrichter

Sonstiges: an der Oberfläche keine Steine

Kurgan 46

Dm 30 m; H 2 m

Lage: N43 22.829 E77 23.583

Form: abgerundet, plattformähnlich mit abgeflachter

Kuppe

Abhänge: drei steile, südlicher sanft

Zustand: in der Mitte ein Raubtrichter

Sonstiges: an der Oberfläche keine Steine

\section{Kurgan 47}

Dm 35 m; H 3 m

Lage: N43 22.809 E77 23.587

Form: abgerundet, plattformähnlich mit abgeflachter

Kuppe

Abhänge: drei steile, südlicher sanft

Zustand: in der Mitte ein Raubtrichter

Sonstiges: an der Oberfläche keine Steine; der südliche und südwestliche Abhang sind durch den Pflug stark beschädigt

Kurgan 48

Dm $30 \mathrm{~m} ; \mathrm{H} \mathrm{2,5} \mathrm{m}$

Lage: N43 22.786 E77 23.598

Form: abgerundet, plattformähnlich mit abgeflachter

Kuppe

Abhänge: drei steile, südlicher sanft

Zustand: in der Mitte ein Raubtrichter

Sonstiges: an der Oberfläche keine Steine

Kurgan 49 (Kleinkurgan)

Dm 30 m; H I, 5 m

Lage: N43 22.922 E77 23.7I6

Form: abgerundete Erhebung

Abhänge: ?

Zustand: in der Mitte ein Raubtrichter

Sonstiges: einzelne Steine an der Oberfläche

Kurgan 50 (Kleinkurgan)

Dm 26 m; H I, 5 m

Lage: N43 22.768 E77 23.608

Form: abgerundete Erhebung

Abhänge: drei steile, südlicher sanft

Zustand: in der Mitte ein Raubtrichter

Sonstiges: an der Oberfläche keine Steine

Kurgan $5 \mathbf{I}$

Dm 34 m; H 3 m

Lage: N43 22.686 E77 23.687

Form: abgerundet, plattformähnlich 
Abhänge: drei steile, südwestlicher sanft

Zustand: Entlang der O-W Achse verläuft durch die Mitte des Kurgans eine Störung, deren Breite 3-4 m misst, evtl. durch einen Bagger entstanden

Sonstiges: einzelne Steine an der Oberfläche

\author{
Kurgan 52 (Kleinkurgan) \\ Dm 20 m; H I m \\ Lage: N43 22.886 E77 23.557 \\ Form: abgerundete Erhebung \\ Abhänge: drei steile, südlicher sanft \\ Zustand: in der Mitte ein Raubtrichter \\ Sonstiges: einzelne Steine an der Oberfläche
}

Forschungsgeschichte

Im Jahre I960 wurden auf dem Gräberfeld Issyk 2I (35591) Kleinkurgane ausgegraben. Die Untersuchungen wurden durch ein Forschungsteam der archäologischen Siebenstromland-Expedition unter der Leitung von A. Čarikov durchgeführt. Die untersuchten Kurgane befanden sich entlang des linken Esik-Ufers und in der Nähe der großen Kurgane der Nekropole. Die genaue Lage der Kleinkurgane wurde nicht angegeben. Es handelte sich um Kurgane mit einem Durchmesser zwischen 4,5 $\mathrm{m}$ und Io $\mathrm{m}$ und einer Höhe von o, I $\mathrm{m}$ bis zu o,4 m. Alle Kurgane wiesen eine Senke, die in der Regel frei von Steinen war, auf.

Auflistung der untersuchten Kurgane (Čarikov I960):

Kurgan I

Dm $8 \mathrm{~m} ; \mathbf{H}$ o,2 $\mathrm{m}$

Lage: am linken Ufer des Flusses Esik

Form: abgerundete Erhebung

Zustand: in der Mitte eine Senke

Befund: - ovale Grabgrube in der Mitte

- Ausrichtung: O-W

- Maße: $2,5 \times$ I,2 × I, 6 m592

Funde: Zahnfragment eines Kindes

Kurgan 2

Dm Io m; H o,4 m

Lage: am linken Ufer des Flusses Esik, 25 m SW von KI entfernt

Form: abgerundete Erhebung

Zustand: in der Mitte eine Senke

Befund: - ovale Grabgrube in der Mitte

- Ausrichtung: O-W

- Maße: 2,8 × I,3 × I,6 m

Funde: Tierknochen (Schlüsselbein?), Wandscherbe

\section{Kurgan 3}

Dm 5 m; H o, I m

Lage: II $\mathrm{m} \mathrm{N}$ von einem großen Kurgan entfernt

Form: abgerundete Steinaufschüttung, der mittlerer

Bereich ist frei von Steinen

Zustand: in der Mitte eine Senke

Befund: - rechteckige Grabgrube in der Mitte

- Ausrichtung: N-S

- Maße: I, 8 × I,O × I,I m

- Funde: keine

59I Laut der Nummerierung wurden 35 Kleinkurgane ausgegraben, allerdings sind im Feldtagebuch nur 2I Kurgane erwähnt.

\section{Kurgan 4}

Dm 5,7 m; H o,4 m

Lage: $400 \mathrm{~m} \mathrm{NW}$ von KI und K2, $150 \mathrm{~m}$ vom linken Ufer des Flusses Esik entfernt

Form: abgerundete Steinaufschüttung (aus Kieselsteinen gebaut)

Zustand: ?

Befund: - keine Grabgrube - Gedenkstätte ?

Funde: keine

\section{Kurgan 7}

Dm 5 m; H o,2 $\mathrm{m}$

Lage: schloss direkt W an K8 an

Form: abgerundete Steinaufschüttung, der mittlerer Bereich ist frei von Steinen

Zustand: ?

Befund: - rechteckige Grabgrube in der Mitte

- Ausrichtung: N-S

Funde: keine

$$
\text { - Maße: } 2,0 \times 0,9 \times 1,0 \mathrm{~m}
$$

Kurgan 8

Dm $9 \mathrm{~m} ; \mathrm{H} \circ, 3 \mathrm{~m}$

Lage: $50 \mathrm{~m}$ NO von einem großen Kurgan entfernt

Form: abgerundete Steinaufschüttung aus Kieselsteinen Zustand: beraubt

Befund: - rechteckige Grabgrube im SO-Bereich des Kurgans

- Ausrichtung: N-S

- Maße: 2,5 × I,O × I,O m

Funde: Menschenknochen (fragmentarisch erhalten), Holzkohle

592 Hier und im Folgenden wurde die Tiefe der Grabgrube vom antiken Laufhorizont aus gemessen. 


\section{Kurgan 9}

Dm 6 m; B 4,5 m; H o,3 m

Lage: Io $\mathrm{m} \mathrm{NW}$ von einem der großen Kurgane entfernt

Form: ovale, NO-SW orientierte Erhebung

Zustand: beraubt

Befund: - rechteckige Grabgrube im SW-Bereich des Kurgans (Grab I)

- Ausrichtung: NW-SO

- Maße: I,9 × 0,8 × I,4 m

- rechteckige Grabgrube im NO-Bereich des Kurgans (Grab 2)

- Ausrichtung: NW-SO

- Maße: I,7 × 0,8 × I,0 m

* Die Grabgruben befanden sich parallel zu einander. Funde: keine

\section{Kurgan 12}

Dm 6,5 m; H o,3 m

Lage: II m NO von einem der großen Kurgane entfernt Form: abgerundete Erhebung aus Seinen

Zustand: in S-Bereich des Kurgans eine Senke $(0,8 \times$ I,I $\mathrm{m}$ ) ohne Steine

Befund: - rechteckige Grabgrube im S-Bereich des Kurgans

- Ausrichtung: N-S

Funde: keine

- Maße: I, $8 \times 0,8 \times 0,8 \mathrm{~m}$

\section{Kurgan I3}

Dm 6 m; H o,2 m

Lage: $15 \mathrm{~m}$ WNW von einem der großen Kurgane entfernt

Form: abgerundete Erhebung aus Steinen, in der Mitte keine Steine

Zustand: ?

Befund: - rechteckige Grabgrube im W-Bereich des Kurgans

- Ausrichtung: O-W

- Maße: I,9 × I,O × I,I m

Funde: keine

\section{Kurgan 15}

Dm 5 m; H o,2 m

Lage: $25 \mathrm{~m}$ östlich von einem großen Kurgan entfernt Form: abgerundete Erhebung (aus Kieselsteine)

Abhänge: drei steile, südlicher sanft

Zustand: beraubt

Befund: - runde Grabgrube im W-Bereich des Kurgans (Grab I)

- Dm I,8 m; Tiefe I,2 m

- rechteckige Grabgrube im O-Bereich des Kurgans (Grab 2)

- Ausrichtung: N-S

- Maße: 2,0 × 0,9 × I,3 m

Funde: keine

\section{Kurgan I6}

Dm 5,5 m; H o, I m

Lage: $35 \mathrm{~m}$ ONO von einem der großen Kurgane entfernt

Form: abgerundete steinerne Erhebung

Zustand: ?

Befund: - ovale Grabgrube im S-Bereich des Kurgans - Ausrichtung: N-S

$$
\text { - Maße: 2,3 × I,2 × I,2 m }
$$

Funde: keine

\section{Kurgan I7}

Dm 4,5 m; H o,2 m

Lage: 16 m östlich von einem der großen Kurgane entfernt

Form: abgerundete Erhebung aus Steinen

Zustand: in der Mitte eine I, $0 \times$ I, $5 \mathrm{~m}$ große Senke

Befund: - rechteckige Grabgrube im W-Bereich des Kurgans

- Ausrichtung: NW-SO

- Maße: I,9 × I,O × I,3 m

Funde: keine

\section{Kurgan I8}

Dm 6 m; H o,2 m

Lage: $23 \mathrm{~m}$ östlich von einem der großen Kurgane entfernt

Form: abgerundete Erhebung aus Steinen

Zustand: ?

Befund: - rechteckige Grabgrube in der Mitte des Kurgans

- Ausrichtung: N-S

- Maße: 2,O × I,O × I,5 m

Funde: keine

\section{Kurgan I9}

Dm ? m; H o,I m

Lage: $\mathrm{I} 6 \mathrm{~m}$ W von einem der großen Kurgane entfernt, schloss im SW-Bereich an Ki3 an

Form: abgerundete Erhebung aus Steinen, in der Mitte keine Steine

Zustand: ?

Befund: - rechteckige Grabgrube in der Mitte des Kurgans

- Ausrichtung: NW-SO

- Maße: 2,4 × I,O × I,O m

Funde: keine

Kurgan 20

Dm 5,5 m; H o,05 m

Lage: II $\mathrm{m}$ östlich von einem großen Kurgan entfernt Form: Flachkurgan, im Kreis angeordnete Steine

Zustand: in der Mitte eine Senke

Befund: - rechteckige Grabgrube im O-Bereich des Kurgans

- Ausrichtung: N-S

Funde: keine 
Kurgan 25

Dm 8 m; H o,4 m

Lage: $10 \mathrm{~m}$ W von einem großen Kurgan entfernt

Form: abgerundete Erhebung, z.T. aus Kieselsteinen

Abhänge: drei steile, südlicher sanft

Zustand: in der Mitte eine ovale, 3, $0 \times$ 2,0 m große, N-S orientierte Senke

Befund: - ovale Grabgrube in der Mitte des Kurgans

- Ausrichtung: N-S

- Maße: 2,4 × I,I × I,2 m

Funde: keine

\section{Kurgan 27}

Dm 5 m; H o,I m

Lage: 26 m SO von einem großen Kurgan entfernt

Form: abgerundete steinerne Erhebung

Zustand: in der Mitte eine Senke, keine Steine

Befund: - rechteckige Grabgrube im SW-Bereich des Kurgans

- Ausrichtung: NW-SO

Funde: keine

$$
\text { - Maße: I,7 × I,I × I,I m }
$$

\section{Kurgan 29}

Dm 5 m; H o,I m

Lage: dicht neben $\mathrm{K}_{3} \mathrm{O}$, am S-Rand eines der großen Kurgane

Form: abgerundete Erhebung, die Kurganaufschüttung geht fließend in die Aufschüttung von K3o über

Zustand: ?

Befund: - rechteckige Grabgrube im O-Bereich des Kurgans

- Ausrichtung: NW-SO

Funde: keine

$$
\text { - Maße: 2,2 × I,O × I,I m }
$$

\section{Kurgan 30}

Dm 5 m; H o,I m

Lage: dicht an K29 angeschlossen, am S-Rand eines großen Kurgans

Form: abgerundete Erhebung, die Kurganaufschüttung geht fließend in die Aufschüttung von K29 über Zustand: ?

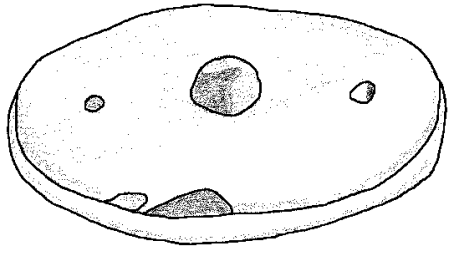

Abb. 145 | Handmühle

(Čarikov i960, 37a)
Befund: - rechteckige Grabgrube im SW-Bereich des Kurgans

- Ausrichtung: NNW-SSO

- Maße: 2,I × 0,8 × I,O m

Funde: keine
Kurgan 3I

Dm ? m; H ? m

Lage: I2 m SW von einem großen Kurgan entfernt

Form: abgerundete Erhebung aus Steinen

Zustand: in der Mitte eine rechteckige Senke mit abgerundeten Ecken, I5 cm tief, 2,2 2 I,2 $\mathrm{m}$ groß, S-N orientiert, ohne Steine

Befund: - rechteckige Grabgrube in der Mitte des Kurgans

- Ausrichtung: NW-SE

- Maße: 2,O × I,O × 0,8 m

Funde: runde steinerne Handmühle (Abb. I45) aus zwei Teilen bestehend (Dm $30 \mathrm{~cm}$; H 6,5 cm; Dm Bohrung $5 \mathrm{~cm}$ )

\section{Kurgan 35}

Dm 5 m; H o, I m

Lage: $35 \mathrm{~m}$ SSO von einem großen Kurgan entfernt

Form: abgerundete steinerne Erhebung

Zustand: in der Mitte eine Senke, keine Steine

Befund: - rechteckige Grabgrube in der Mitte des Kurgans

- Ausrichtung: NW-SO

- Maße: 2,0 × 0,9 × I,2 m

Funde: keine

I969/ 70 wurden von K. Akišev auf der Nekropole fünf Großkurgane ausgegraben. Die untersuchten Kurgane befanden sich im südwestlichen Bereich des Gräberfeldes, welcher heute überbaut ist. Die genaue Lage der Kurgane wurde nicht angegeben. Da drei Kurgane komplett beraubt worden waren, wurden sie nicht weiter erläutert. Im vierten Kurgan fanden sich in einer großen rechteckigen Grabgrube, deren Wände mit großen Kieselsteinen umrandet worden waren, menschliche Überreste. Kurgan Nr. 4 wurde ebenso beraubt. In der Grabgrube lagen auf einer Erhebung aus Erde zwei Skelette, die mit den Köpfen nach Westen orientiert worden sind. Zwischen den Knochen der Verstorbenen befanden sich mehrere kleine goldene Plättchen und eine zepterförmige Haarnadel aus Eisen, die in einem Goldblatt eingewickelt worden war593 (Akišev K.A. 1978, 6). 
In der zweiten Grabkammer des fünften Kurgans wurde eine Bestattung eines sakischen Fürsten, des sog. „Goldenen Mannes von Issyk“ (Abb. I47,I7), entdeckt. „Der Tote trug eine hohe, spitz zulaufende Kopfbedeckung, eine gegürtete Jacke mit langen Ärmeln, eine Hose sowie halbhohe Stiefel. Haube, Jacke und Stiefel bestanden aus rotem Stoff oder waren mit rotem Stoff überzogen sowie mit fast 4000 aufgenähten Goldblechstücken verziert, die verschiedene figurale Muster wiedergeben. Auch Dolch und Schwert aus Eisen wiesen goldene Inkrustationen auf“ (Parzinger 2006, 660). In der Grabkammer befanden sich noch zahlreiche Gefäße, Schöpfkellen und Tabletts aus Holz sowie etliche weitere Behälter aus Ton, Bronze und Silber (Akišev K.A. 1978). Durch diesen Fund wurde das Gräberfeld Issyk bekannt. Der Kurgan selbst wurde später als Kurgan „Issyk“ bezeichnet (Akišev K.A. I97I; Akišev K.A. I974; Akišev K.A. I978; Parzinger 2006, 659-660; Samašev 2007, 166).

Kurgan „Issyk“ (Akišev K.A. I978):

Dm 60 m; H 6 m

Form: abgerundet, plattformähnlich mit abgeflachter Kuppe (Abb. I46,I)

Abhänge: ?

Zustand: im Zentrum ein mächtiger Raubtrichter (Dm I2 $\mathrm{m}$, Tiefe 2,3 $\mathrm{m}$ )

Stratigraphie der Aufschüttung: 3-4 Schichten, Schichten aus Flusskieselsteinen wechselten sich mit einer Schicht aus Schotter und Lehm ab

Befunde: - Zentralgrab - geplündert (nähere Angaben fehlen)

- Südgrab, I5 $\mathrm{m}$ südlich vom Zentralgrab und IO-I2 m nördlich von der Südgrenze des Kurgans

- rechteckige Grabkammer (3,3 × I,9 $\mathrm{m}$ groß und I,3-I,5 $\mathrm{m}$ hoch) war sorgfältig aus Lärchenbalken gezimmert (Abb. I46,2)

Bestattung: - Platzierung: auf dem Holzboden im nördlichen Bereich der Grabkammer (Abb. I46,3)

- Lage: Rückenstrecker

- Ausrichtung: Kopf nach Westen

- Anthropologische Bestimmung: Mann, ca. I6-I8 Jahre alt594

Beigaben: - Im westlichen Bereich der Grabkammer befanden sich Metall- und Tongefäße (insgesamt 25 Expl.);

- Im südlichen Bereich der Grabkammer lagen hölzerne Tabletts und Schöpfkellen (insgesamt I2 Expl.); - Im nördlichen Bereich der Grabkammer, im KopfSchulterbereich des Verstorbenen, befanden sich eine vergoldete Peitsche, ein Pfeil mit goldener Pfeilspitze, Perlen (26 Expl.) und ein Bronzespiegel.

- Dicht am Bestatteten fast 4000 Goldbleche mit verschiedenen figuralen Mustern, darunter ein Ohrring, ein Halsring, zwei Fingerringe, eisernes Schwert und eiserner Dolch mit Goldinkrustationen und ein Silberlöffel

Funde: - Kopfbedeckung (Abb. I46,4)

I. gegossene Statuette eines Argali, Gold, I, $6 \times$ I,9 cm (vgl. Akišev K.A. I978, 24, Abb. I6, Taf. 6)
2. geflügelte Pferdeprotome mit Ziegenhörnern, Holz mit Blattgold verziert, I0,0 × 17,5 cm (2 Expl.) (vgl. Akišev K.A. I978, I8-I9, Abb. 9; 24, Abb. I7)

3. Plättchen in Flügelform, Blattgold, IO, $\times$ I7,5 cm (4 Expl.) (vgl. Akišev K.A. 1978, 24)

4. Plättchen: Panther und Gebirgszug, Blattgold, 5,2 × 7,6 cm (3 Expl.) (vgl. Akišev K.A. I978, 24-25, Abb. I8, Taf. 4)

5. Plättchen in einer Gebirgszugform, Blattgold, 3,7 × 4,7 cm (I Expl.) (vgl. Akišev K.A. I978, 25, Taf. 4)

6. Pantherplättchen, Blattgold, 5,5 ×3,7 cm (2 Expl. gespiegelt) (vgl. Akišev K.A. I978, 25, Abb. I9, Taf. 4)

7. Plättchen in Form eines stilisierten Löwenkopfes, Blattgold, 2,2 × 2,6 cm (6 Expl.) (vgl. Akišev K.A. 1978, 25, Abb. 20, Taf. 2)

8. Pferdeplättchen (Vorderteil eines Pferdes), Blattgold, 6,5 × 5,2 cm (2 Expl. ein Plättchen spiegelt das andere ab) (vgl. Akišev K.A. I978, 25, Abb. 2I, Taf. 5)

9. Bergziegenplättchen, Blattgold, $4,5 \times 2,8 \mathrm{~cm}(5$ Expl.) (vgl. Akišev K.A. 1978, 25-26, Abb. 22, Taf. 5)

Io. Vogelskulptur, Holz und Blattgold, $3,0 \times 3,5 \mathrm{~cm}$ (5 Expl.) (vgl. Akišev K.A. 1978, 25-26, Abb. 23, Taf. 8)

II. Diadem (besteht aus vier Plättchen, zwei linke und zwei rechte Paaren), das mit einem Zickzackmuster geschmückt ist; dieses Muster stellt entweder Bergspitzen oder Pflanzenblätter dar, Blattgold, Dm 22, o cm (I Expl.) (vgl. Akišev K.A. I978, 26, Abb. 24, Taf. I)

I2. Plättchen in Form eines kleinen Flügels, mit roter Farbe bemaltes Blattgold, 8, I × 2,8 cm (2 Expl. gespiegelt) (vgl. Akišev K.A. 1978, 26-27, Abb. 25, Taf. I) 
I3. längliche Plättchen in Flügelform, zum Teil mit roter Farbe bemaltes Blattgold, 26,0-26,8 $\times$ 2,0 cm (4 Expl. je zwei gespiegelt) (vgl. Akišev K.A. I978, 26-27, Abb. 26, Taf. Iо)

I4. figurale Dekorplättchen, Blattgold, $8,0 \times 3,7 \mathrm{~cm}$, $7,5 \times 3,6 \mathrm{~cm}, 6,0 \times 5,2 \mathrm{~cm}, 5,5 \times 4,0 \mathrm{~cm}, 5,0 \times$ 4,0 cm (5 Expl.) (vgl. Akišev K.A. I978, 26-27, Abb. 27, Taf. 9)

I5. kleine figurale Dekorplättchen in einer geometrischen, floralen, schnabel- oder krallenähnlichen Form, Blattgold, 8,0 × 2,6 cm (7 Expl.) (vgl. Akišev K.A. I978, 26, 28, Abb. 28-29, Taf. II)

I6. geometrische Plättchen, Blattgold mit roter und schwarzer Farbe ornamentiert, I7,0-I7,2 $\times$ 2,0 cm (2 Expl.) (vgl. Akišev K.A. I978, 26, 28, Abb. 30, Taf. I2)

I7. pfeilähnlicher Schmuck, Gold, 38,0-40,0 × 2,0 cm (4 Expl.) (vgl. Akišev K.A. I978, 26, 29, Abb. 3I, Taf. 7)

I8. Plättchen in Form einer Bergspitze, Blattgold mit roter Farbe ornamentiert, 7,8 8 I3,3 cm, 7,0 $\times$ I3,0 cm (4 Expl.) (vgl. Akišev K.A. 1978, 26, Taf. 5,8$)$

I9. Miniaturbäume, Golddraht, H 4,5 cm (5 Expl.) (vgl. Akišev K.A. I978, 26, Abb. 23, Taf. 8)

- Jacke mit langen Ärmeln (Abb. I46,5) und halbhohe Stiefel (Abb. I46,6)

I. Plättchen in Form eines stilisierten Tigerkopfes zwischen horizontal gekerbten Leisten, Blattgold, 3,9 × 4,I cm (54 Expl.) (vgl. Akišev K.A. I978, 27, 29, Abb. 32, Taf. I4)

2. Plättchen in Form eines stilisierten Tigerkopfes zwischen vertikal gekerbten Leisten, Blattgold, 3,I × 4,3 cm (59 Expl.) (vgl. Akišev K.A. I978, 27, 29, Abb. 33, Taf. I3)

3. Dreieckplättchen (zwei rechteckig-ovalen Leisten, die miteinander einen spitzen Winkel bilden; zwischen diesen Leisten befindet sich eine Raute), Blattgold, 2,2 × 2, O cm (24II Expl.) (vgl. Akišev K.A. I978, 27, 30, Abb. 34, Taf. I8)

4. rechteckige figurale Plättchen, Blattgold, 2,2 $\times$ 3,8 cm (30 Expl.) (vgl. Akišev K.A. I978, 27, 30, Abb. 35, Taf. I5)

5. zusammengesetztes Blechschild (Knöpfe?), gegossenes Gold und Blattgold, 2,0 × 3,2 cm (3 Expl.) (vgl. Akišev K.A. I978, 27, 30, Abb. 36, Taf. I7)

6. rechteckige Plättchen, Blattgold, unterschiedliche Größen (genaue Angaben fehlen) (488 Expl.) (vgl. Akišev K.A. I978, 27, 33, Abb. 37, Taf. I6)

7. quadratische Plättchen, Blattgold, unterschiedliche Größen (genaue Angaben fehlen) (162 Expl.) (vgl. Akišev K.A. I978, 27, Taf. ı6)

8. runde Plättchen, Blattgold, unterschiedliche Größe (genaue Angaben fehlen) (30 Expl.) (vgl. Akišev K.A. I978, 27, Taf. ı6)
9. gekerbte Zierröhrchen, Blattgold, unterschiedliche Größen (genaue Angaben fehlen) (Iо3 Expl.) (vgl. Akišev K.A. ı978, 27, 33, Abb. 37, Taf. ı6)

ıo. halbmondförmige Plättchen, Blattgold, unterschiedliche Größen (genaue Angaben fehlen) (108 Expl.) (vgl. Akišev K.A. I978, 27, 33, Abb. 37, Taf. ı6)

II. rautenförmige Plättchen, Blattgold, unterschiedliche Größen (genaue Angaben fehlen) (313 Expl.) (vgl. Akišev K.A. I978, 27, 33, Abb. 37, Taf. I6)

I2. Plättchen von unregelmäßiger Form, ohne Maßangaben (74 Expl.) (vgl. Akišev K.A. I978, 28)

I3. runde, flache und fassförmige Karneolperlen, ohne Maßangaben (Io Expl.) (vgl. Akišev K.A. I978, 28)

I4. walzenförmige Perlen aus weißer Paste, ohne Maßangaben (ı6 Expl.) (vgl. Akišev K.A. I978, 28)

- Gürtelsatz (Abb. I46,7)

I. Blechschild in Form eines liegenden Hirsches, Seitenansicht, gegossenes Gold und vier rechteckige Silberösen an der Rückseite, $4,8 \times 8,8 \mathrm{~cm}$ (3 Expl.) (vgl. Akišev K.A. 1978, 28, 33, Abb. 38, Taf. I9)

2. Blechschild in Form eines Hirschkopfes, Flachrelief, Seitenansicht, gegossenes Gold und zwei Silberösen an der Rückseite, 3,I × 4,I cm (I3 Expl.) (vgl. Akišev K.A. I978, 28, 33, Abb. 39, Taf. 2I)

- Waffe

I. Dolch/Akinakes (Abb. I47,I4), Eisen mit Goldeinlagen, L 48,0 cm, B der Klinge $7,7 \mathrm{~cm}$ (I Expl.), lag zwischen den Knochen des linken Armes und dem Körper (vgl. Akišev K.A. I978, I7, 28-29, 34, Abb. 40, Taf. 23-24)

2. Scheidendeckblech (Abb. I47,5), Verzierung des oberen Teiles der Dolchscheide, ein Elch mit zurückgewandtem Kopf in einem bohnenförmigen gekerbten Rahmen, durchbrochener Goldbeschlag, 5,5 × I3,4 cm (I Expl.) (vgl. Akišev K.A. I978, I7-23, 29, Taf. 25)

3. Scheidendeckblech (Abb. I47,6), Verzierung des unteren Teiles der Dolchscheide, ein Pferd mit um $180^{\circ}$ verdrehtem Hinterleib in einem rechteckigen gekerbten Rahmen mit einer abgerundeten und einer spitzen Schmalseite, durchbrochener Goldbeschlag, I5,7 × 4, I cm (I Expl.) (vgl. Akišev K.A. I978, I7-23, 29, 34, Abb. 4I, Taf. 25)

4. Riemenverteiler (Abb. I47,7), „pilzförmig“ im Querschnitt, die untere walzenförmige Hälfte mit vier rechteckigen Öffnungen, die Oberfläche verziert ein Rolltier (Wolf), Gold, 2,8 $\times$ $2,4 \mathrm{~cm}$ (2 Expl.), befanden sich dicht an den Überresten der Dolchscheide (vgl. Akišev K.A. I978, I7, 29-30, 34, Abb. 42, Taf. 26-27) 

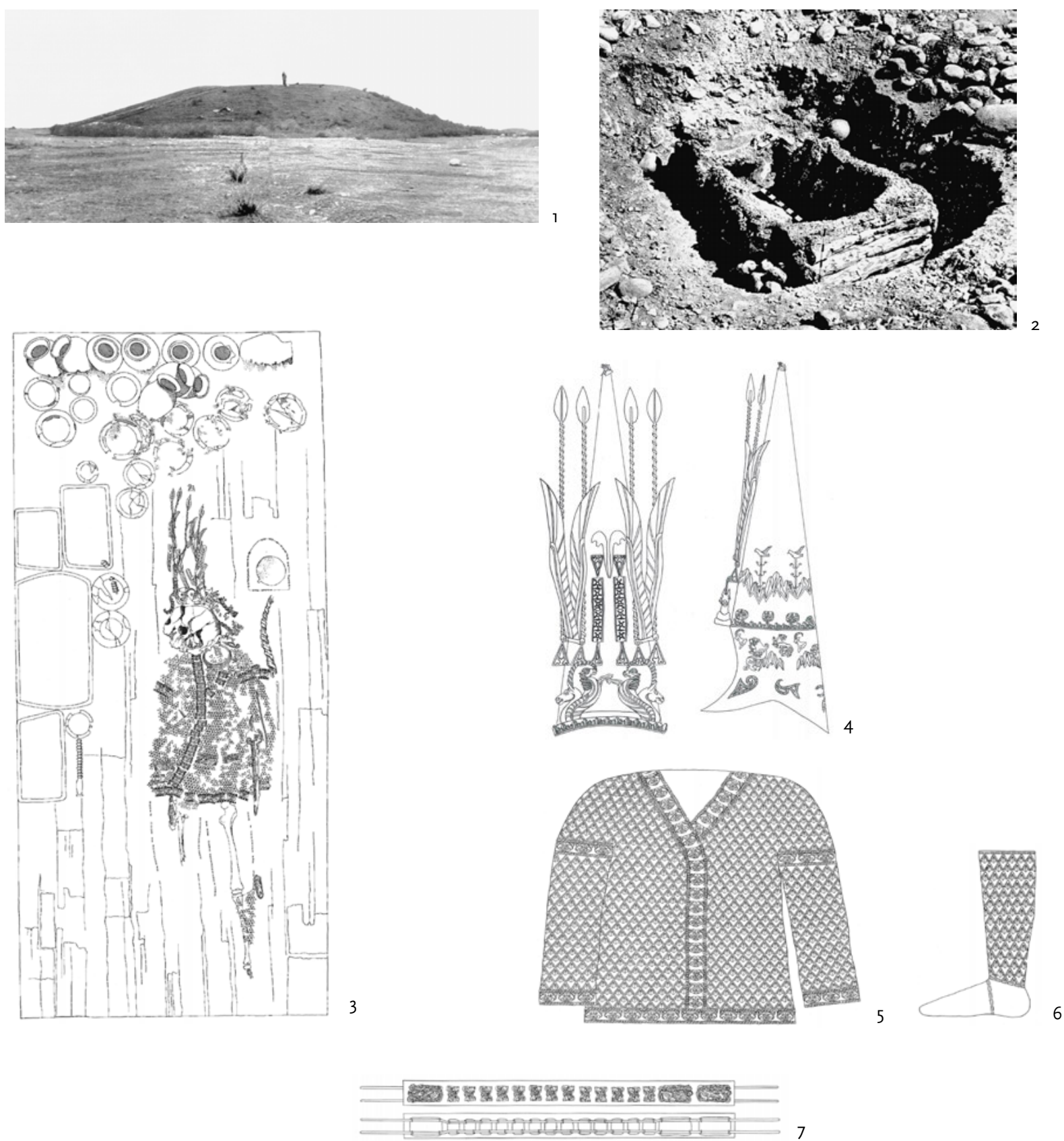

Abb. 146 | Kurgan „Issyk“; I. Kurgan (Akišev K.A. I978, 8-9, Abb. I); 2. Südgrab, Grabkammer (Akišev K.A. I978, II, Abb. 2); 3. Südgrab, Bestattung, Kopf nach Westen (Akišev K.A. 1978, I4, Abb. 5); 4. Hohe, spitz zulaufende Kopfbedeckung, Rekonstruktion (Akišev K.A. 1978, 47, Abb. 62, 63); 5. Jacke mit langen Ärmeln, Rekonstruktion (Akišev K.A. I978, 48, Abb. 64); 6. Halbhohe Stiefel; Rekonstruktion (Akišev K.A. I978, 49, Abb. 67); 7. Gürtelsatz, Rekonstruktion (Akišev K.A. I978, 50, Abb. 68) 

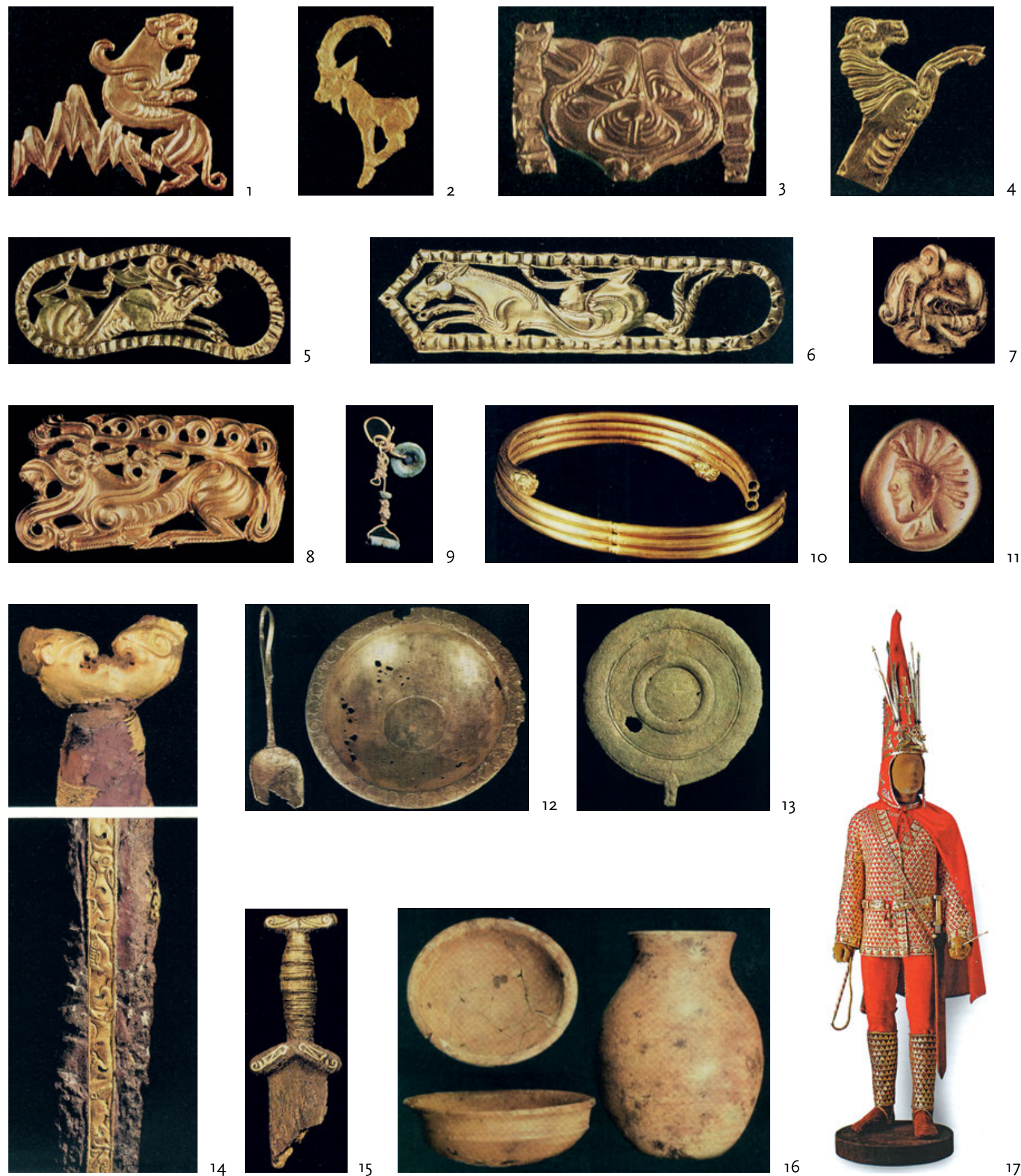

Abb. 147 | Kurgan „Issyk“;

I-7.IO-II Blattgold/Gold, 8 gegossenes Gold mit Silberelementen, 9 Gold mit Türkis, I2 Silber, I3 vergoldete Bronze, I4-I5 Eisen mit Goldanlagen, I6 Ton; I-4 Plättchen (Akišev K.A. I978, Taf. 4-5.13); 5-6 Scheidendeckbleche (Akišev K.A. I978, Taf. 25); 7 Riemenverteiler (Akišev K.A. 1978, Taf. 26-27); 8 Blechschild in Form eines liegenden Hirsches (Akišev K.A. 1978, Taf. I9); 9 Ohrring (Akišev K.A. 1978, Taf. 33); ıo Halsreif (Akišev K.A. I978, Taf. 28-29); I Fingerring (Samašev 2007, Abb. I0); I2 (links) Löffel (Akišev K.A. 1978, Taf. 34); I2 (rechts) große Schale (Akišev K.A. I978, Taf. 34); I3 Spiegel (Akišev K.A. I978, Taf. 33); I4 Dolch (Akišev K.A. I978, Taf. 23-24); I5 Schwert (Akišev K.A. I978, Taf. 24); I6 Keramik (Akišev K.A. I978, Taf. 39); I7 „Goldener Mann von Issyk“, Rekonstruktion von K.A. Akišev (Samašev 2007, I66) 
5. Schwert, fragmentarisch erhalten (Abb. I47,I5), Eisen mit Goldeinlagen, erhaltene L $20,0 \mathrm{~cm}$, B der Klinge 6,9 cm (I Expl.), lag rechts vom Skelett, entlang des rechten Beines (vgl. Akišev K.A. I978, I7, 30, 35, Abb. 43, Taf. 24)

6. Schieber vom Schwertriemen, Gold (3 Expl.), zwei davon sind zylinderförmig und einer ist rund, der größte zylinderförmige Schieber ist verziert, Tigerkopfdarstellung, zwei weitere sind unverziert, I, $8 \times$ I,7 cm, befanden sich neben dem Schwertgriff (vgl. Akišev K.A. I978, I7, 30, 35, Abb. 44, Taf. 6)

- Schmuck, Toilettegerät

I. vierfach gewundener Halsreif mit zwei aufgesetzten Löwenköpfen (Abb. I47,IO), Gold, Dm I3,O cm, befand sich bei den Halswirbeln (vgl. Akišev K.A. I978, I7, 30, 35, Abb. 45, Taf. 28-29)

2. Fingerring mit glatter, ovaler Oberfläche, Gold, $\mathrm{H}$ 2,3 cm, Dm 2,5 cm, kam unter den Bodenbrettern der Grabkammers zum Vorschein (vgl. Akišev K.A. I978, I7, 30, 36, Abb. 46, Taf. 30)

3. Fingerring mit dem Bildnis eines federartig geschmückten menschlichen Kopfes (Abb. I47,II), Gold, H 2,7 cm, Dm 2,5 cm, lag zwischen den Mittelhandknochen der rechten Hand (vgl. Akišev K.A. I978, I7, 30, 36, Abb. 47, Taf. 31; Samašev 2007, I66, Abb. I0)

4. Ohrring mit Anhängern (Abb. I47,9), Gold und vier Türkisperlen, $3, \mathrm{I} \times 2,4 \mathrm{~cm}$, befand sich links des Schädels (vgl. Akišev K.A. I978, I7, 30-3I, 36, Abb. 48, Taf. 33)

5. Spiegel mit Griffdornrest (Abb. I47,I3), Bronze, vergoldet, Dm I2,8 cm, lag links vom Schädel in der Nordhälfte der Grabkammer (vgl. Akišev K.A. I978, 23, 31, 37, Abb. 49, Taf. 33)

6. Reitpeitsche mit Goldblechband umwickeltem Knauf, Holz und Gold, 34,0 × 3,0 cm, befand sich links des Skelettes im Schulterbereich (vgl. Akišev K.A. I978, 23, 31, 37, Abb. 50, Taf. 32)

- Geschirr

I. große Schale mit breitem horizontal ausgestellten Schalenrand (Abb. I47,I2 rechts), der mit 32 Kreisen an der oberen Seite verziert ist; am Boden der Schale ist eine achtblättrige Rosette angenietet, Silber, $\mathrm{H}_{3}, 8 \mathrm{~cm}$, Dm I5,6 cm (vgl. Akišev K.A. I978, 31, 37, Abb. 5I, Taf. 34)

2. kleine Schale mit runenartiger Ritzgravur an der Außenseite (Abb. 53), Silber, H 2,2 cm, Dm $7,7 \mathrm{~cm}$ (vgl. Akišev K.A. I978, 3I, 38, 54-55 Abb. 52, 70-7I Taf. 34)

3. Schale, fragmentarisch erhalten, mit einem Wulst am Rand, Flachboden, Vergoldung an der äußeren Wand (ohne Abb.); Bronze, Ausmaß - nicht angegeben (vgl. Akišev K.A. I978, 3I)

4. Löffel rechteckig mit abgerundeten Ecken, langer, im Querschnitt runder Stiel, dessen Ende zurückgebogen ist und so Hals, Kopf und Schnabel eines Vogels darstellt (Abb. I47,I2 links); Silber, I6,0 × 3,8 cm (vgl. Akišev K.A. I978, 31, 38, Abb. 53, Taf. 34)

In der Grabkammer befanden sich I2 hölzerne Geschirrgegenstände, gut erhalten waren nur drei:

5. Großes Tablett, rechteckig mit einem schmalen Rand, der sich nach oben verjüngt, aus einem Birkenklotz geschnitten, $67,5 \times 37,5 \times 3,0 \mathrm{~cm}$ (vgl. Akišev K.A. I978, 31, Taf. 36)

6. Kleines Tablett, rechteckig mit einem schmalen Rand, der sich nach oben verjüngt, aus einem Birkenklotz geschnitten, 46,0 × 29,0 ×3,0 cm (vgl. Akišev K.A. I978, 31, Taf. 37)

7. Schöpfkelle, Holz, L des Griffes 25,0 cm, Dm 9,5 cm (vgl. Akišev K.A. I978, 3I, 38, Abb. 54, Taf. 37)

Drei weitere ähnliche Griffe von anderen Schöpfkellen lagen auf den Überresten einer hölzernen Schüssel

Sämtliche Keramik aus der Grabkammer war hartgebrannt und scheibengedreht (Abb. I47,I6)

8. Krug mit Flachboden (Io Expl.) I7,0-20,0 $\times$ I2,0-I4,O cm (vgl. Akišev K.A. I978, 3I, Taf. 38-39)

9. Schüssel mit Flachboden (6 Expl.) 6,0-6,5 $\times$ I4,O-I7, o cm (vgl. Akišev K.A. I978, 3I, Taf. 39) Weitere Information fehlt.

Chronologie: - nach Akišev - 5. Jh. v. Chr. (Akišev K.A. I978, 39)

nach Parzinger - 6.-5. Jh. v. Chr. (Parzinger 2006, 660)

Im Jahre I97I wurde auf dem Gräberfeld Issyk ein weiterer Kurgan ausgegraben. Es handelte sich hier um eine Rettungsgrabung, da der südliche Teil des Gräberfeldes dem PMK-704595, auf dessen zukünftigen Gelände dieser Kurgan sich befand, eingegliedert wurde. Die Rettungsgrabung wurde durch die Archäologen des Instituts für Geschichte, Archäologie und Ethnographie der Akademie der Wissenschaften der Sowjetischen Sozialistischen Republik Kasachstan zuerst von B. Nurmuchanbetov und später von A. G. Maksimova durchgeführt596.

„Kurgan beim Dorf Issyk“ (Maksimova I97I): 
Dm 30 m; H 3,0-3,5 m (?)

Lage: südlicher Teil der Nekropole, auf dem PMK-704 Gelände

Form: ?

Zustand: beraubt

Befund: - quadratische Grabgrube im Kurganzentrum

- Ausrichtung: Seiten orientieren sich an den Haupthimmelsrichtungen

- Maße: $5 \times 5 \times$ I m

- Grabwände: mit mittelgroßen Kieselsteinen umgelegt

- Grababdeckung: Holzbalken, fragmentarisch erhalten

- Grabboden: mit großen Kieselsteinen bedeckt, darüber folgte eine Schotterschicht

Bestattung: - zwei Menschenskelette, Skelett 2 lag im Fußbereich des Skelettes I

- Platzierung: entlang der Ostwand der Grabgrube

- Lage: beide Bestatteten - Rückenstrecker

- Ausrichtung: beide Skelette - Kopf nach SW

- Anthropologische Bestimmung: fehlt

Beigaben: - dicke dunkelbraune organische Schicht unter beiden Skeletten, Überreste von einem Filzteppich (?)

Skelett I

- Pfeilspitzen aus Eisen (Lage - nicht angegeben, Expl. - nicht angegeben, Maße - fehlt)
- Eiserne Fragmente von einem Schwert (?) (Lage nicht angegeben, Expl. - nicht angegeben, Maße fehlt)

- Goldblättchen rechteckiger Form (Lage - nicht angegeben, Expl. - nicht angegeben, Maße - fehlt)

- eiserne Haarnadel, vergoldet; Nadelkopf kugelförmig; Verzierung - entweder Krallen oder Schnäbel eines Greifen (Lage - nicht angegeben, Expl. - nicht angegeben, Maße - fehlt)

Skelett 2

- Ein rechteckiges Goldplättchen aus Goldfolie im Kopfbereich (exakte Lage - nicht angegeben, Maße - fehlt)

- eiserne Fragmente von einem Messer (?), rechts vom Beckenknochen (Maße - fehlt)

- drei eiserne rechteckige Plättchen mit Bronzeinkrustation, links vom Beckenknochen (Maße - fehlt)

Funde aus der Grabgrube: drei Gefäße

I. Schüssel; Maße - nicht angegeben; rot, scheibengedreht, feingemagert, außen geglättet

2. Krug; Maße - nicht angegeben; scheibengedreht, feingemagert, außen geglättet, innen Reste von Speisekruste an der Wänden

3. fragmentarisch erhaltenes Gefäß; Form - nicht angegeben; Maße - fehlt; grobgemagert, auf der Innenseite befinden sich Stoffabdrücke

Chronologie: da das Fundmaterial, besonders die Goldplättchen und die Keramik, mehrere Parallelen zu dem Fundmaterial des Kurgans „Issyk“ aufweisen $\rightarrow$ 5. Jh. v. Chr.

Im Rahmen der Rettungsgrabungen im Gebiet Almaty wurde im Jahre 1992 ein am Ufer des Flusses Esik gelegener, stark erodierter Kurgan ausgegraben. Die Rettungsgrabung wurde durch die Firma „Atalyk“ unter der Leitung von B. Nurmuchanbetov durchgeführt.

„Kurgan auf dem Gf. Issyk, I. Stelle“ (Nurmuchanbetov u.a. I992):

Dm I8 m; H 2,2 m

Lage: linkes, westliches Ufer des Esik, an der nordöst-

lichen Grenze der Issyk-Datschen

Form: ?

Zustand: durch die Ufererosion stark beschädigt

Stratigraphie der Aufschüttung: vier Schichten (von oben nach unten) - weitere Angaben fehlen

I. moderne Humusschicht

2. Steinschicht (Kurganpanzer) aus großen Kieselsteinen

3. lehmige Schicht mit Kieselsteinbeimischung

4. Steinschicht
Befund: zu I/3 durch die Ufererosion zerstört

- Platzierung: nicht angegeben

- Form: nicht angegeben

- Ausrichtung: nicht angegeben

- Maße: nicht angegeben

Bestattung: - einzelne Knochen (Brustbereich) eines menschlichen Skelettes

Funde: - Keramikfragmente

- eiserne Fragmente

- Bronzefragmente

*Weitere Angaben zu den Funden fehlen

Chronologie: $6 .-5$. Jh. v. Chr.

Im Jahre 2004 wurden auf der Nekropole im Rahmen des kasachischen staatlichen Programms „Kulturerbe" drei Kurgane erforscht. Dabei handelte es sich sowohl um eine Forschungs- als auch um eine Rettungsgrabung, die die Mitarbeiter des Archäologischen Instituts „A. Ch. Margulan“ aus Almaty durchgeführt hatten. Die Arbeit verlief unter der Leitung von K. Bajpakov und B. Nurmuchanbetov.

Auflistung der untersuchten Kurgane (Bajpakov u.a. 2005c): 
Kurgan № 4 (Kleinkurgan)

Dm II, 8 m; H o,25 m

Lage: N43 22.77I E77 23.667

Form: abgerundete Erhebung aus mittelgroßen ( $15 \times$ $20 \mathrm{~cm}$ ) Kieselsteinen

Zustand: die nördliche und die südliche Seiten des Kurganrandes sind überpflügt

Stratigraphie: von oben nach unten

I. Kieselsteine

2. Humusschicht (Mächtigkeit - nicht angegeben)

3. gelber sandiger Lehm (Mächtigkeit $0,75 \mathrm{~m}$ )

4. gewachsener Boden (in einer Tiefe von I,I m von heutiger Oberfläche)

Befunde: keine

Funde: keine

Kurgan № 5 (Kleinkurgan)

Dm I4,6 m; H o,75 m

Lage: 39 m südöstlich vom Kurgan № 4

N43 22.762 E77 23.690

Form: abgerundet, plattformähnlich mit abgeflachter Kuppe

Abhänge: drei steile, südlicher sanft

Zustand: beraubt

Stratigraphie: von oben nach unten

I. Steinpackung (mittelgroße Kieselsteine) mit Humus (Mächtigkeit O,I-O,7 m)

2. gelber sandiger Lehm (Mächtigkeit o,3 m)

3. gewachsener Boden

Befund: - Grabgrube in der Mitte des Kurgans, rechteckige mit abgerundeten Ecken

- Ausrichtung: O-W

- Maße: 2,9 × I,I × 0,85 m (Tiefe von der heutigen Oberfläche aus gemessen)

Funde: im Ostbereich der Grabgrube

- zwei Holzfragmente

- eine Keramikscherbe
- Menschenknochen (Rippen, Wirbelsäule, Schädelkalotte)

* Nähere Angaben fehlen

\section{Kurgan № 6}

Dm 3I,O m; H 2,2 m

Lage: nördlicher Bereich der Nekropole, linkes westliches Ufer des Esik, auf dem Gelände einer Datsche N43 22.126 E77 26.308

!!! Da die dementsprechenden Koordinaten zu einem Punkt südlich des Gräberfeldes, auf dem rechten, östlichen Esik-Ufer, eigentlich schon in der Stadt-Issyk und nicht zu dem Datschen-Gebiet führen, können sie nicht als richtig angenommen werden.

Form: abgerundet, plattformähnlich mit abgeflachter Kuppe

Abhänge: drei steile, südöstlicher sanft

Zustand: - durch die Ufererosion ist die Nordhälfte des Kurgans zerstört

in der Mitte ein Raubtrichter (I,2 $\mathrm{m}$ tief)

Stratigraphie: von oben nach unten

I. moderne Humusschicht (Mächtigkeit: in der Mitte $0,38 \mathrm{~m}$; am Kurganrand $0,95 \mathrm{~m}$ )

2. Steinpackung (Mächtigkeit: Westbereich o,9 m; Ostbereich $0,4 \mathrm{~m}$ )

3. grauer sandiger Lehm mit Schotterbeimischungen (Mächtigkeit - nicht angegeben)

4. gewachsener Boden

Befund: - Grabgrube in der Mitte des Kurgans, rechteckig mit abgerundeten Ecken

- Ausrichtung: O-W

- Maße: 3,I × 2,4 × I,5 m (die Tiefe vom antiken Laufhorizont gemessen)

Funde: - Holzfragmente

- Einzelne fragmentarisch erhaltene Menschenknochen

* Die Funde lagen in gesamter Grabgrube verstreut.

Lit.: Akišev A.K. I980; Akišev K.A. 1971, 408; Akišev K.A. 1974, 6I-77; Akišev K.A. I978; Archeologičeskaja karta Kazachstana I960, 309-310; Artamonov 1973, 36, 38; Baipakov 2008, 58; Bajpakov 1992, 56; Bajpakov/Bektureeva I998, 2-I4; Bajpakov u.a. I993, I09; Bajpakov u.a. 2005c, 2-3, 6-8, 22-31; Bernštam I938, I9; Bernštam I94Ib, 6, 27; Carikov I96o; Dublickij 1939a, I/93/8I; Gass 20IIa, 6o-6I, Fig. 3, 5-7; Gass 20IIb, 2II-2I2, Abb. 2-4; Gass (im Druck); Livšic I980, 3-I2; Maksimova 197I; Martynov A. 2008, 10; Nagler 2008, 70, 73; Nurmuchanbetov u.a. 1992, 29, 35; Ongar 2008, 22I, 223; Parzinger 2004, 56-58; Parzinger 2006, 659-662; Samašev 2007, I65-167; Samašev u.a. 2004b, Bd. I; Samašev u.a. 2005a, 38, 40, 49, 86-89; Zadneprovskij I992, 77-78; Zagorodnij/Grigor'ev I998, II7-I24. 
Gräberfeld auf dem Plateau Kegen [FEZ] (Abb. I48-I54; Karte 3 Nr. 68): ALT i861 m N42 58.859 E79 I4.90I; Gebiet Almaty (kasach. Алматы облысы), Rajymbekskij rajon (kasach. Райымбек ауданы); Ausmaß N-S I6,2 × O-W i6,6 km.

Auf dem Plateau Kegen befinden sich mehrere Ketten, jedoch nur vier von ihnen bestehen aus Großkurganen und können dem Gräberfeld auf dem Plateau Kegen zugeordnet werden597. Zudem wurden zu der Nekropole zwei allein stehende Großkurgane gezählt. Das Gräberfeld liegt I ९o km ostsüdöstlich von der Stadt Almaty (kasach. Алматы), zwischen den Dörfern Kegen (kasach. Кеген) und Karkara (kasach. Қарқара), auf dem hochgelegenem Bergplateau Kegen, auf beiden Ufern des Flusses Karkara (kasach. Қарқара). Insgesamt wurden hier 39 mittelgroße und große Kurgane festgestellt, wobei zwei davon nicht eingemessen worden sind. Die Grabanlagen messen zwischen $35 \mathrm{~m}$ und $330 \mathrm{~m}$ im Durchmesser und erreichen Höhen zwischen I,5 m und I4,7 m. Fast alle Kurgane des Gräberfeldes weisen Raubtrichter auf. Ebenfalls haben fast alle Kurgane auf dem Plateau drei steile und einen (mit leichten Abweichungen immer südlichen) sanften Abhang. Beim Kurgan 3 liegt der sanfte Abhang im Südwesten.

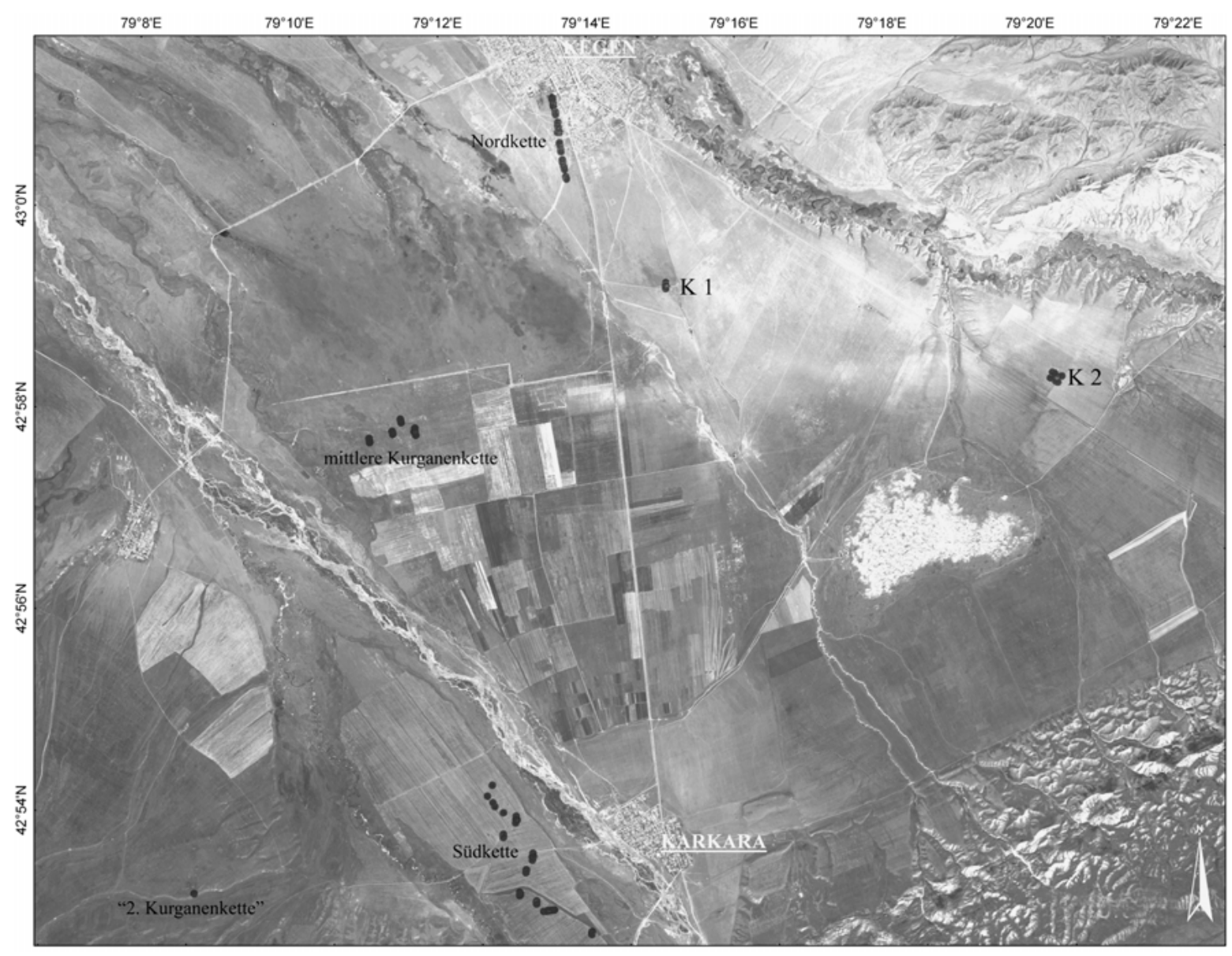

Abb. 148 | Übersicht der Kurganketten auf dem Plateau Kegen (SPOT)

597 Um die Kurganketten besser voneinander unterscheiden zu können, werden sie als Nordkette, mittlere Kette, Südkette und 2. Kurgankette bezeichnet. 
Die zwei alleinstehende Kurgane (KI und K2) wurden separat platziert und weisen eine abweichende Bauweise auf. Kurgan I (Abb. I48) befindet sich 4,6 km südöstlich vom Dorf Kegen, Io $\mathrm{km}$ nordnordöstlich vom Dorf Karkara, I,I6 km östlich von der Bundesstraße Kegen Karkara, zwischen den Flüssen Kegen und Karkara. Da im südöstlichen Bereich des Kurganrandes ein Schäfereinsiedlerhof steht, führt zu dem Kurgan von der Bundesstraße Kegen - Karkara ein Feldweg.

$7,3 \mathrm{~km}$ südöstlich von Kurgan I steht Kurgan 2. Trotz der Entfernung befinden sich beide Kurgane in Sichtweite zueinander. Kurgan 2 (Abb. I48-I49) liegt II km südöstlich vom Dorf

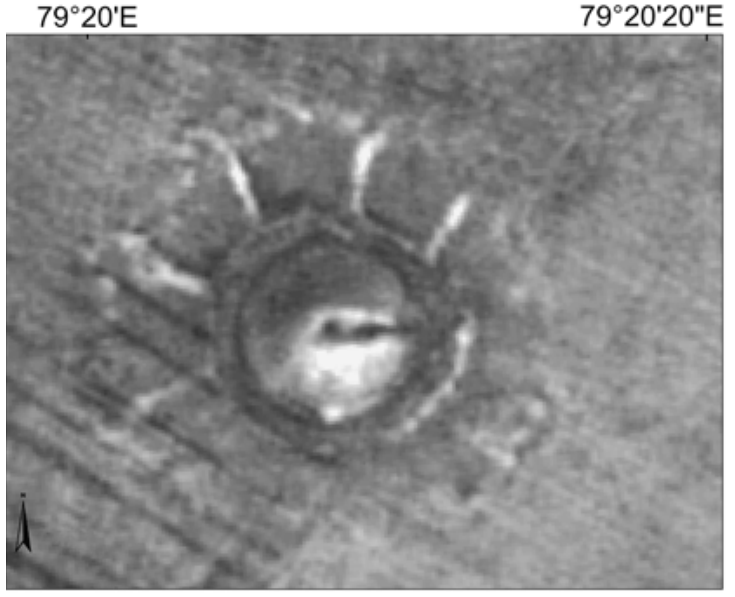

Abb. 149 | Allein stehender Kurgan 2 (SPOT) Kegen, ebenso II km nordöstlich vom Dorf Karkara und $430 \mathrm{~m}$ von der Bundesstraße Kegen Narynkol (kasach. Нарынкол) entfernt, am linken, westlichen Ufer des Flusses Kegen.

Die N-S verlaufende Nordkette (Abb. I48, I50) besteht aus I3 Kurganen und liegt im Südteil des Dorfes Kegen, 200-250 m westlich von der Bundesstraße Kegen - Karkara. Die Kurgane der Kette wurden durch die Bebauung zum Teil stark beschädigt und weisen keine besonderen architektonischen Merkmale auf.

Die O-W (Abb. I48, I5I) verlaufende mittlere Kette besteht aus vier Kurganen und befindet sich $7 \mathrm{~km}$ südwestlich vom Dorf Kegen und 8,7 km nordwestlich vom Dorf Karkara, östlich des Flusses Karkara. Da die Kette auf einem Acker liegt, ist die Peripherie der Kurgane komplett zerstört.

Die aus I6 Kurganen bestehende Südkette (Abb. I48, I53) verläuft in einer NW - SO Achse. Sie liegt 2,2 km westlich des Dorfes Karkara und I5,5 km südlich des Dorfes Kegen am linken, westlichen Karkara-Ufer. Die gesamte Kette befindet sich auf einem Acker und weist keine architektonischen Merkmale, mit Ausnahme des dritten südlichsten Kurgans (K4), auf. Um den Kurgan herum wurde ein Kreisgraben angelegt. An der westlichen und östlichen Seite bricht der Graben ab. Diese Bereiche kann man als zwei Eingänge interpretieren.

Weiter westlich, 8,4 km vom Dorf Karkara und I6,3 km südwestlich vom Dorf Kegen entfernt, auf der westlichen Seite des Flüßes Karkara befindet sich die „2. Kurgankette“ (Abb. I48, I52), die von N nach S verläuft. Die Kette besteht aus vier Großkurganen, die auf einem Acker stehen. Alle Kurgane weisen einen Raubtrichter auf, ihre Peripherie wurde bereits zerstört. Um die Großkurgane herum stehen noch mindestens fünf Kleinkurgane (Dm 6-8 m; H o,I-O,2 m), die überpflügt worden waren. Wegen ihrer geringen Größe und schlechten Erhaltungszustände wurden sie nicht aufgenommen.

Anhand der Landschaftsplatzierung, der Struktur und der äußeren Erscheinungsform können alle Kurgane des Gräberfeldes der sakischen Periode der Früheisenzeit zugeordnet werden. 


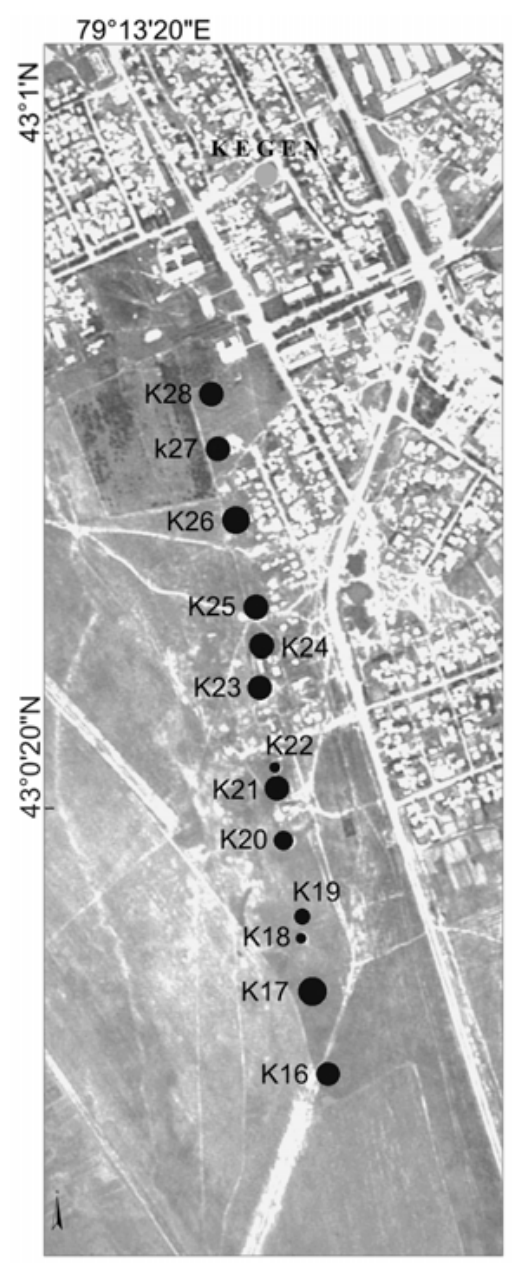

Abb. 150 | Gräberfeld auf dem Plateau Kegen. Nordkette (SPOT)

\section{Kurgancharakteristik:}

Allein stehende Kurgane

Kurgan I (Abb. I55,I-3)

Dm I35 m; H I4,2 m

Lage: N42 58.893 E79 I4.904

Form: abgerundet, pyramidenartig

Abhänge: drei steile, südlicher sanft

Zustand: In der zweiten Hälfte des 20. Jh. wurde direkt am südsüdöstlichen Abhang des Kurgans durch eine Baumaschine ein Weg vom Kurganrand zur Kurgankuppe angelegt; die Kuppe ist nachträglich planiert und beschädigt worden, als ein trigonometrischer Mast und ein Haus auf ihr errichtet wurden (heute ist vom Haus nur das Fundament erhalten). Im nordöstlichen und südlichen Bereich der Kurganaufschüttung befinden sich große Senken (Raubtrichter?); im südöstlichen Be-

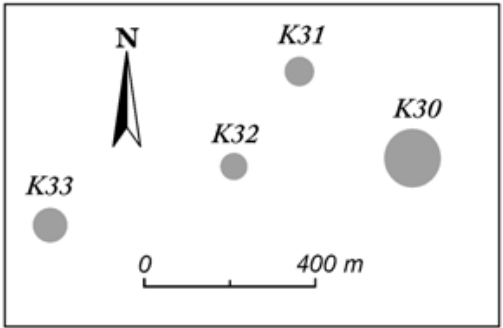

Abb. 151 | Gräberfeld auf dem Plateau Kegen. Mittlere Kurgankette (Plan)

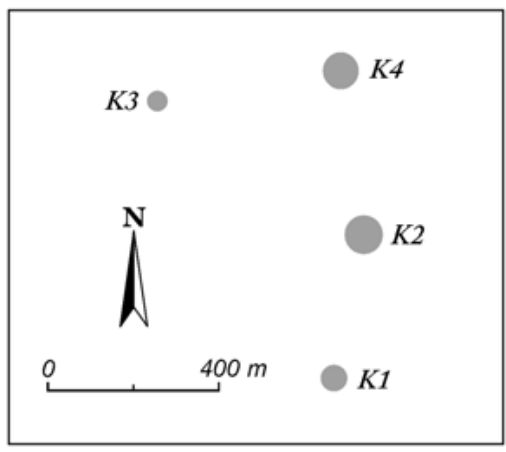

Abb. 152 | Gräberfeld auf dem Plateau Kegen. 2. Kurgankette (Plan) reich des Kurganrandes steht ein Schäfereinsiedlerhof, daher ist die Peripherie des Kurgans dort beschädigt. Entlang der Nordseite des Kurganrandes wurde ein Bewässerungskanal gebaut.

Sonstiges: Dank des durch eine Baumaschine angelegten Weges konnte die Bauweise des Kurgans ganzheitlich nachvollzogen werden. Die Anlage wurde aus gestampften Lehmziegeln $(20 \times 40 \mathrm{~cm}$ bis $20 \times$ IO $\mathrm{cm}$ ) unter Verwendung von Lehm-Mörtel erbaut.

Kurgan 2 (Abb. 77, I56,I-2)

Dm I45 m; Plattform Seitenlänge I64 m; Dm mit Baurampen 330 m; H I3 m (I2 m davon Kurganaufschüttung und ca. I $\mathrm{m}$ Plattform) Lage: N42 57.789 E79 20.IOI 


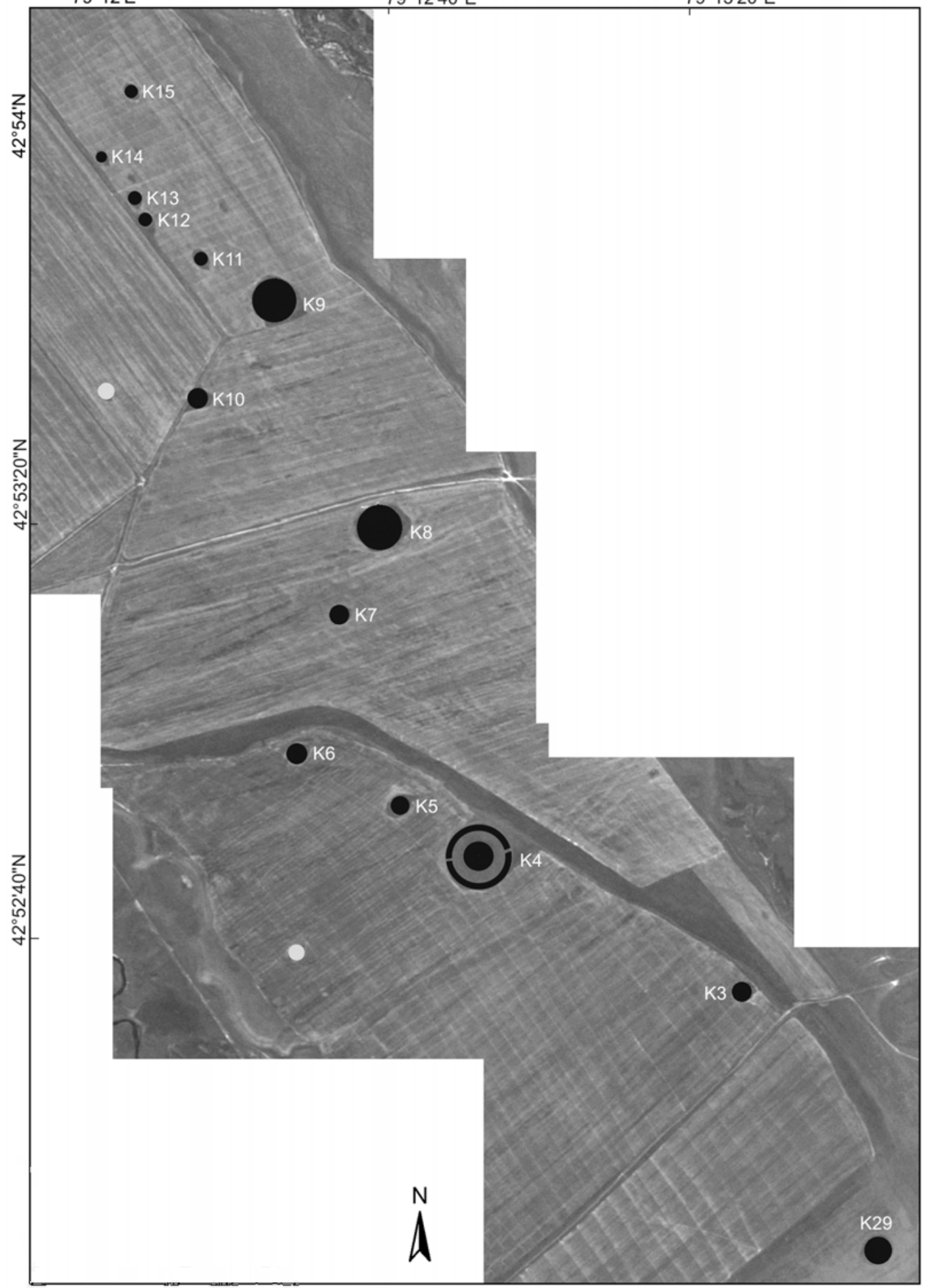

Abb. 153 | Gräberfeld auf dem Plateau Kegen. Südkette (SPOT) 


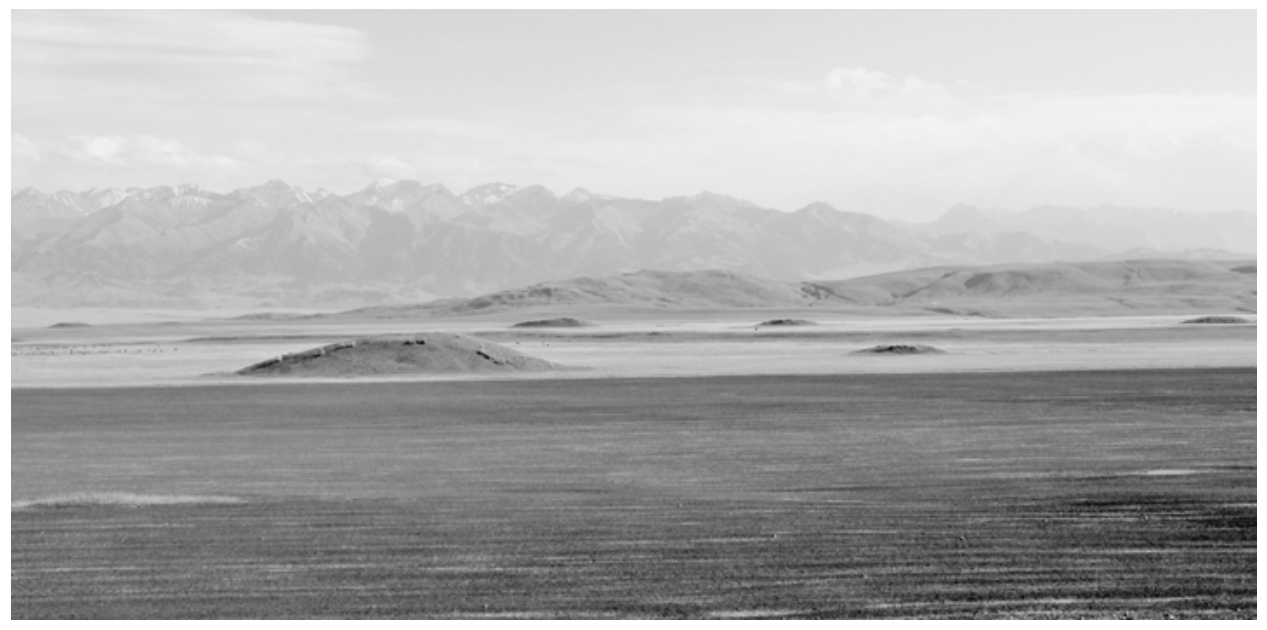

Abb. 154 | Gräberfeld auf dem Plateau Kegen. Südkette. Blick von W
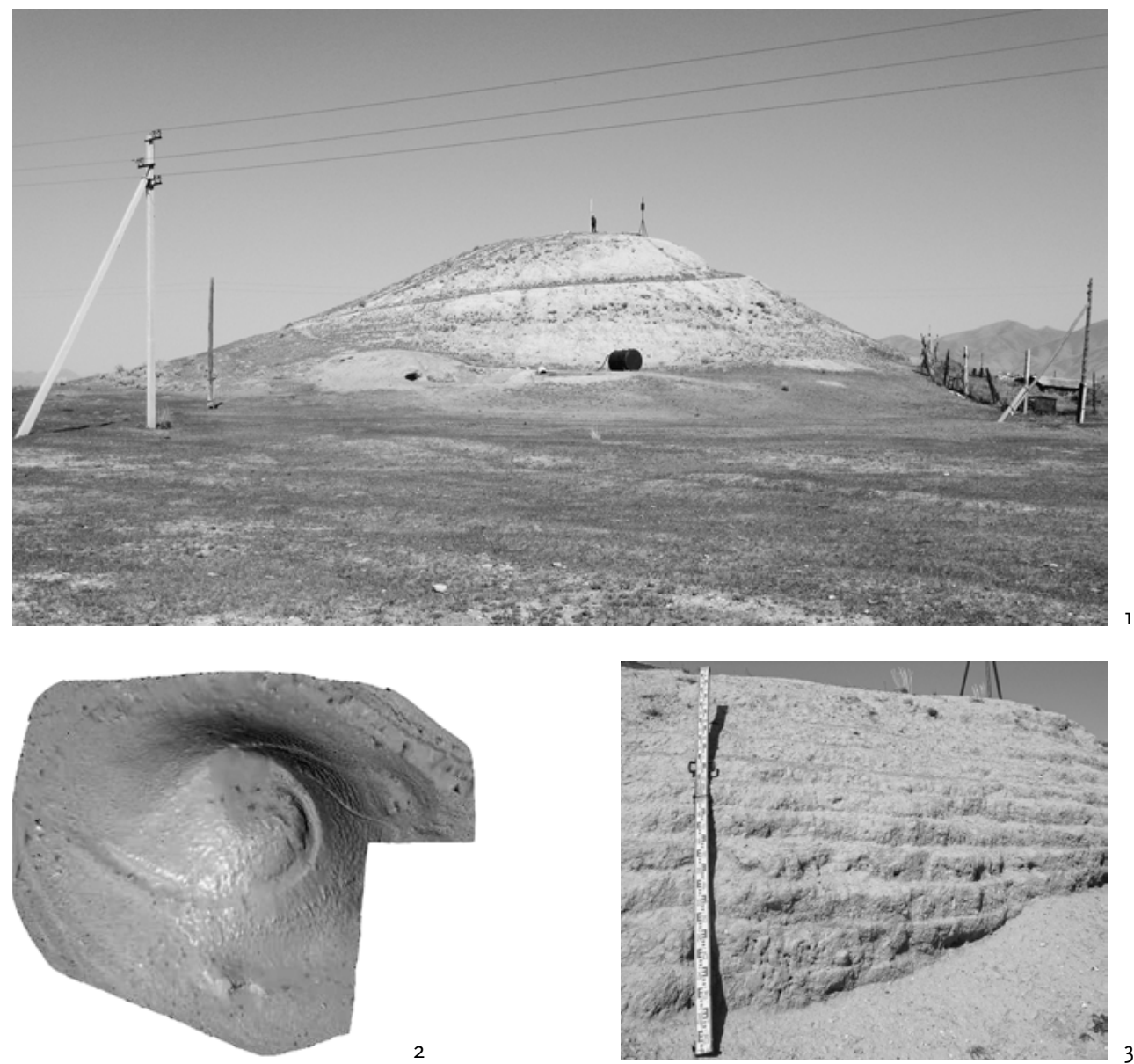

Abb. 155 | Kurgan I des Gräberfeldes auf dem Plateau Kegen; I. Blick von OSO; 2. 3D-Modell, Blick von O (M. Dörre und Ch. Voll)598; 3. Weg auf der Kurganaufschüttung, Lehmziegel

598 Die Beuth-Hochschule für Technik Berlin. 

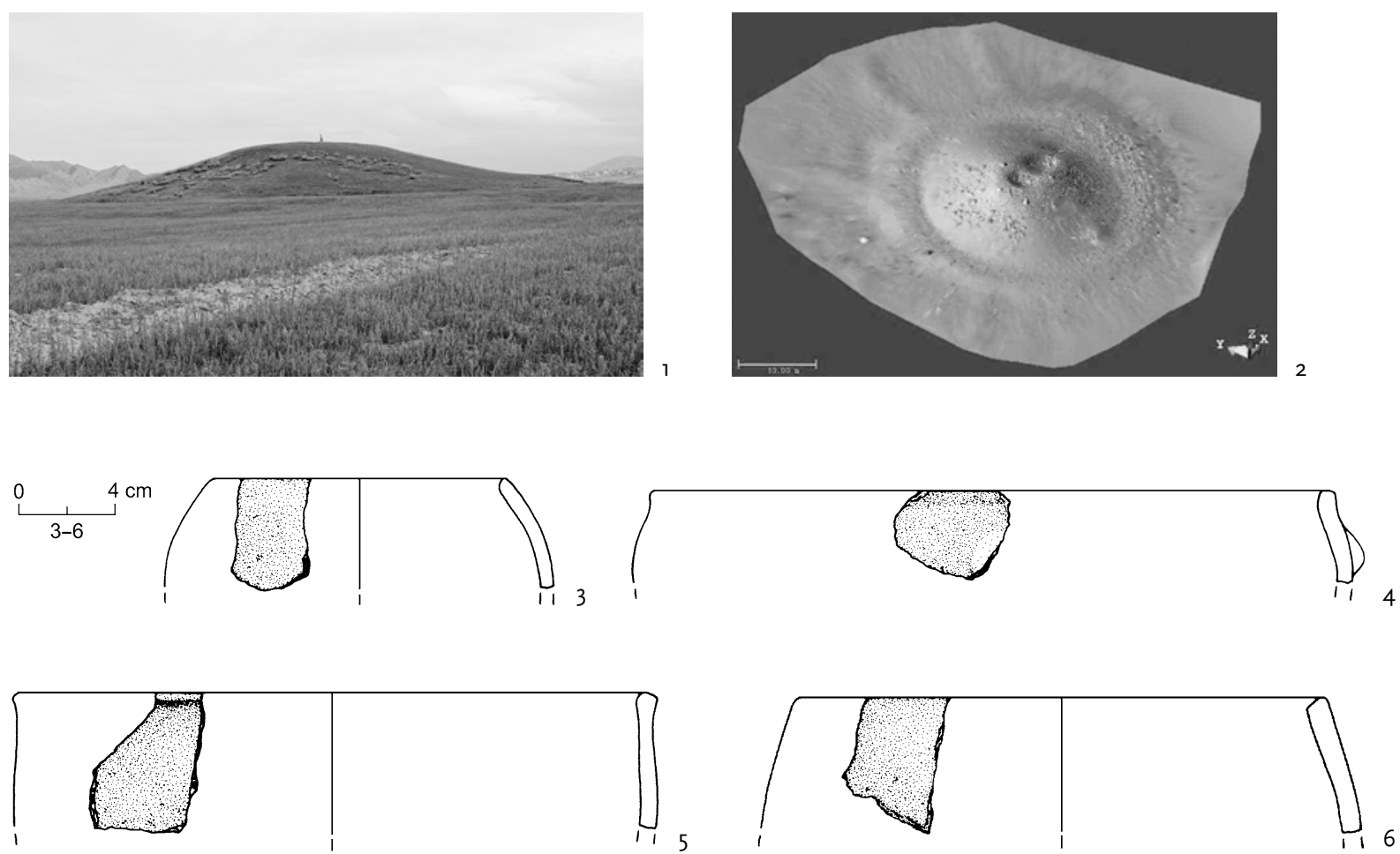

Abb. 156 | Kurgan 2 des Gräberfeldes auf dem Plateau Kegen; I. Blick von W; 2. 3D-Modell, Blick von W (M. Dörre und Ch. Voll); 3-6. Funde von der Fläche I, Schicht 4

Form: abgerundeter Kurgan mit abgeflachter Kuppe auf einer viereckigen Plattform mit abgerundeten, an den vier Haupthimmelsrichtungen ausgerichteten Ecken Abhänge: drei steile, südlicher sanft

Zustand: in der Mitte ein gewaltiger Raubtrichter; die östliche und südöstliche Peripherie des Kurgans ist komplett überpflügt

Sonstiges: Auf der Oberfläche liegen kleine und mittelgroße Steine der Kurganabdeckung; wie die SPOT-Satellitenaufnahmen in einer 2,5 $\mathrm{m}$ Auflösung (Abb. I49) zeigten, wies der Kurgan neben der Plattform noch weitere Konstruktionen auf, welche an der Oberfläche kaum sichtbar sind. Es handelte sich um fünf streifenartige Befunde, die vom nördlichen und westlichen Kurganrand aus strahlenförmig verlaufen (B ca. 6-IO m). In den Zwischenräumen sind Senken erkennbar.

- Im Sommer 2009 wurde diese Konstruktion von der Kasachisch-Deutschen Archäologischen Expedition untersucht. Es handelte sich um eine Konstruktion, die durch Bautätigkeiten bei der Errichtung dieses Kurgans entstanden ist; denn genau an dieser Stelle wurde das Baumaterial für die oberirdische Konstruktion des Baus gewonnen. Die Streifen (Abb. I49), die strahlenförmig vom Kurgan abgehen, sind Reste der Baurampen, welche nach der Errichtung der Konstruktion nicht zugeschüttet bzw. zerstört worden sind599.
- Insgesamt wurden im nordwestlichen Kurganrandbereich drei Flächen freigelegt (Fläche 1 - die längsten Seiten $34 \times 27 \mathrm{~m}$; Flächen 2 und 3-20,5 $\times 2 \mathrm{~m}$ );

- Stratigraphie der Fläche I (von oben nach unten):

I. Mischschicht aus Humus und Lehm (Mächtigkeit bis $0,3 \mathrm{~m}$ )

2. Lehm im südöstlichen Bereich der Fläche (Mächtigkeit bis $0,5 \mathrm{~m}$ )

3. Lehm mit höherem Sand- und Kieselanteil (Mächtigkeit bis o,2 m)

4. „Kulturschicht“ - dunkle, feinsandige Schicht mit Holzkohlenpartikeln in der Nordecke der Fläche (Mächtigkeit bis o,2 m)

5. Sand/Kies - gewachsener Boden

- Stratigraphie der Flächen 2 und 3 (von oben nach unten):

I. Mischschicht aus Humus und Lehm (Mächtigkeit Fläche 2 - bis $0,2 \mathrm{~m}$, Fläche 3 - bis 0,25 m)

2. Lehm (Mächtigkeit Fläche $2-0,3-0,7 \mathrm{~m}$, Fläche 3-0,25 m)

3. Sand/Kies - gewachsener Boden

599 Für die Mitteilung dieser Information möchte ich mich bei Prof. Dr. H. Parzinger, Dr. A. Nagler, Dr. M. Nawroth, PD Dr. Z. Samašev und M.-R. Boroffka bedanken. 
Funde $^{600}$ (Abb. 156,3-6): in der Nordostecke der Fläche I an der Grenze zwischen Schicht I und 2, kam ein oberes Stück eines rechten Schienbeines von Schaf/ Ziege zum Vorschein; in der Senke zwischen den Baurampen (Nordostecke der Fläche I, Schicht 4) befanden sich einige Knochen von Schaf/Ziege, die evtl. einem Tier gehören könnten, ein linkes Schaftstück der Speiche vom Rind, zwei Knochen vom Pferd, und zwar ein rechtes Schaftstück der Speiche und ein linkes Beckenstück (Jungtier), sowie II nicht bestimmbare Tierknochenfragmente (zwei davon waren kalziniert) und Keramikscherben; Keramik: vier Randscherben von verschiedenen Gefäßen grau-braun, leicht sandig, handgemacht

Chronologie: FEZ, sakische Periode;

I4C-Datierung 490-460 BC60I

Südkette

Kurgan 3

Dm 52 m; H 4 m

Lage: N42 52.5IO E79 I3.47I

Form: abgerundet, plattformähnlich mit abgeflachter Kuppe

Abhänge: drei steile, südwestlicher sanft

Zustand: in der Mitte ein Raubtrichter; da der Kurgan auf dem Acker liegt, ist seine Peripherie zerstört

Sonstiges: keine Steine an der Oberfläche

Kurgan 4 (Abb. I57)

Dm 85 m; Dm Kreisgraben I93 m; H 9 m

Lage: N42 52.752 E79 I2.907

Form: abgerundet, plattformähnlich mit abgeflachter Kuppe

Abhänge: drei steile, südlicher sanft

Weitere Konstruktionen: in einem Abstand von 38,5 m vom Kurganrand wurde ein Kreisgraben von bis $\mathrm{zu}$ I5,5 m Breite und 2,0-2,5 m Tiefe angelegt. An der westlichen (leicht nach Süden versetzt) und östlichen (leicht nach Norden versetzt) Seite bricht der Graben $\mathrm{ab}$; diese Bereiche kann man als zwei Eingänge, deren Breite 8-Io m misst, interpretieren.

Zustand: in der Mitte ein Raubtrichter

Sonstiges: keine Steine an der Oberfläche

\section{Kurgan 5}

Dm 53 m; H 4 m

Lage: N42 52.842 E79 I2.745

Form: abgerundet, plattformähnlich mit abgeflachter Kuppe

Abhänge: drei steile, südlicher sanft

Zustand: in der Mitte ein Raubtrichter

Sonstiges: keine Steine an der Oberfläche

600 Archäozoologische Bestimmung von Prof. Dr. rer. nat. Norbert Benecke, Deutsches Archäologisches Institut, Naturwissenschaftliches Referat an der Zentrale, Archäozoologie.

\section{Kurgan 6}

Dm 56 m; H 4,7 m

Lage: N42 52.934 E79 I2.524

Form: abgerundet, plattformähnlich mit abgeflachter Kuppe

Abhänge: drei steile, südlicher sanft

Zustand: in der Mitte ein Raubtrichter

Sonstiges: keine Steine an der Oberfläche

Kurgan 7

Dm 56 m; H 4,6 m

Lage: N42 53.I56 E79 I2.626

Form: abgerundet, plattformähnlich mit abgeflachter Kuppe

Abhänge: drei steile, südlicher sanft

Zustand: in der Mitte ein Raubtrichter

Sonstiges: keine Steine an der Oberfläche

\section{Kurgan 8}

Dm I33 m; H I4,7 m

Lage: N42 53.295 E79 I2.725

Form: abgerundet, plattformähnlich mit abgeflachter Kuppe

Abhänge: drei steile, südlicher sanft

Zustand: in der Mitte ein Raubtrichter; durch östlichen und nordöstlichen Bereich des Kurgans verläuft ein Graben; insgesamt Osthälfte des Kurgans stark beschädigt Sonstiges: keine Steine an der Oberfläche

\section{Kurgan 9}

Dm I2 8 m; H I3,4 m

Lage: N42 53.674 E79 I2.522

Form: abgerundet, plattformähnlich mit abgeflachter Kuppe

Abhänge: drei steile, südlicher sanft

Zustand: in der Mitte ein Raubtrichter, der nach Westen als ein Graben ausläuft

Sonstiges: keine Steine an der Oberfläche

\section{Kurgan Io}

Dm 58 m; H 4 m

Lage: N42 53.5I6 E79 I2.342

Form: abgerundet, plattformähnlich mit abgeflachter Kuppe

Abhänge: drei steile, südlicher sanft

Zustand: in der Mitte ein Raubgraben

Sonstiges: keine Steine an der Oberfläche

\section{Kurgan II}

Dm 55 m; H 2,0-2, 5 m

Lage: N42 53.744 E79 12.359

Form: abgerundet, plattformähnlich mit abgeflachter Kuppe

GoI Nachweise zur Probe finden sich im Appendix I Nr. I3. 

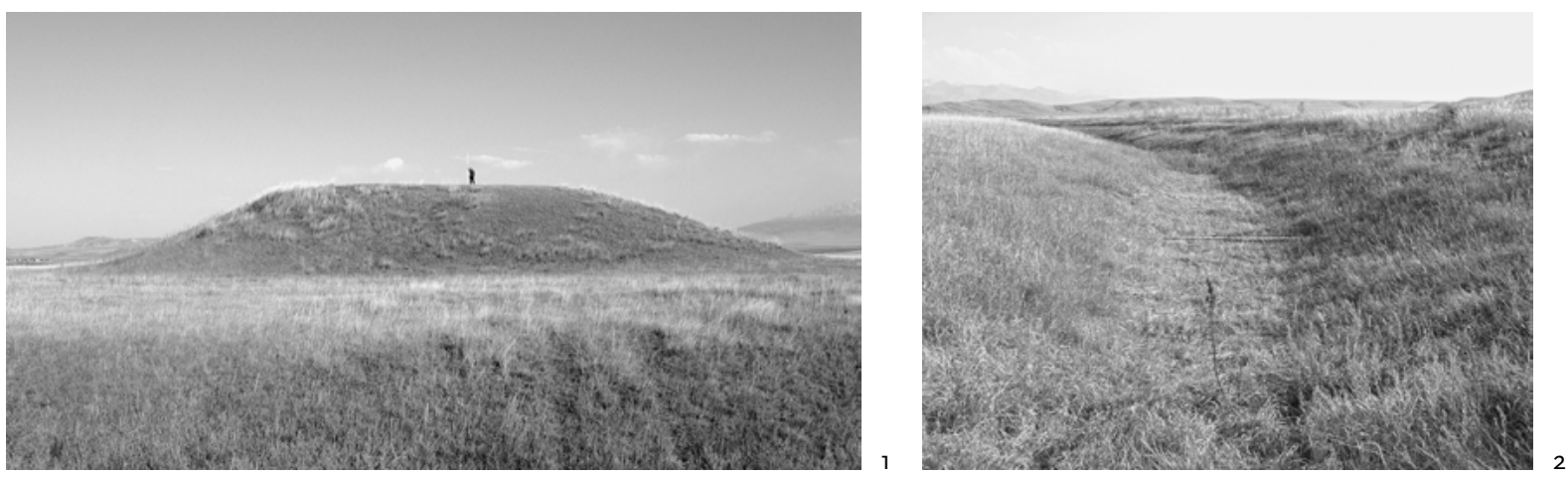

Abb. 157 | Kurgan 4 des Gräberfeldes auf dem Plateau Kegen; I. Blick von W; 2. Kreisgraben um Kurgan, SSW Bereich, Blick von W

Abhänge: drei steile, südlicher sanft

Zustand: in der Mitte eine Senke

Sonstiges: keine Steine an der Oberfläche

\section{Kurgan 12}

Dm $60 \mathrm{~m} ; \mathrm{H} \mathrm{2,5} \mathrm{m}$

Lage: N42 53.810 E79 I2.244

Form: abgerundet, plattformähnlich mit abgeflachter Kuppe

Abhänge: drei steile, südlicher sanft

Zustand: in der Mitte ein Raubtrichter

Sonstiges: keine Steine an der Oberfläche

\section{Kurgan I3}

Dm 50 m; H I, 5 m

Lage: N42 53.849 E79 I2.223

Form: niedrig, abgerundet, plattformähnlich mit abgeflachter Kuppe

Abhänge: drei steile, südlicher sanft

Zustand: in der Mitte eine Senke

Sonstiges: keine Steine an der Oberfläche

\section{Kurgan I4}

Dm 40 m; H I, 5 m

Lage: N42 53.9I7 E79 I2.I54

Form: niedrig, abgerundet, plattformähnlich mit abgeflachter Kuppe

Abhänge: drei steile, südlicher sanft

Zustand: in der Mitte eine Senke

Sonstiges: keine Steine an der Oberfläche

\section{Kurgan 15}

Dm 45 m; H 2 m

Lage: N42 54.023 E79 I2.227; nördlichster Kurgan der Südkette

Form: niedrig, abgerundet, plattformähnlich mit abgeflachter Kuppe

Abhänge: drei steile, südlicher sanft

Zustand: in der Mitte eine Senke

Sonstiges: keine Steine an der Oberfläche
Kurgan 29

Dm 78 m; H 7,5 m

Lage: N42 52.077 E79 I3.743; südlichster Kurgan der Kette

Form: abgerundet, plattformähnlich mit abgeflachter Kuppe

Abhänge: drei steile, südlicher sanft

Zustand: in der Mitte ein gewaltiger Raubtrichter

Sonstiges: keine Steine an der Oberfläche

Nordkette

\section{Kurgan 16}

Dm 46 m; H 3 m

Lage: N43 00.008 E79 I3.630; südlichster Kurgan der Kette

Form: abgerundete Erhebung

Abhänge: drei steile, südlicher sanft

Zustand: in der Mitte eine Senke

Sonstiges: keine Steine an der Oberfläche

\section{Kurgan 17}

Dm 55 m; H 5,7 m

Lage: N43 00.106 E79 I3.6I2

Form: abgerundet, plattformähnlich mit abgeflachter Kuppe

Abhänge: drei steile, südlicher sanft

Zustand: in der Mitte eine Senke

Sonstiges: keine Steine an der Oberfläche

Kurgan I8 (Abb. 5I)

Dm 35 m; H 2 m

Lage: N43 00.I66 E79 I3.595

Form: abgerundet, plattformähnlich mit abgeflachter Kuppe

Abhänge: drei steile, südlicher sanft

Zustand: Der Ostbereich ist durch die Lehmgewinnung von den Kegener Bewohnern fast komplett abgetragen. Sonstiges: keine Steine an der Oberfläche; Das Abtragen der Osthälfte ermöglichte es, die Kurganaufschüttung zu untersuchen. Sie bestand aus Lehm bis sandi- 
gem Lehm; in der Mitte konnte eine Halbkugel aus dunklerem Lehm angedeutet werden.

\section{Kurgan I9}

Dm 40 m; H 2 m

Lage: N43 00.I89 E79 I3.596

Form: niedrig, abgerundet, plattformähnlich mit abgeflachter Kuppe

Abhänge: drei steile, südlicher sanft

Zustand: in der Mitte ein Raubtrichter

Sonstiges: keine Steine an der Oberfläche

\section{Kurgan 20}

Dm $38 \mathrm{~m} ; \mathrm{H} 3 \mathrm{~m}$

Lage: N43 00.28I E79 I3.580

Form: abgerundet, plattformähnlich mit abgeflachter Kuppe

Abhänge: drei steile, südlicher sanft

Zustand: in der Mitte ein Raubtrichter

Sonstiges: keine Steine an der Oberfläche

Kurgan 2I

Dm 44 m; H 4 m

Lage: N43 00.342 E79 I3.573

Form: abgerundet, plattformähnlich mit abgeflachter Kuppe

Abhänge: drei steile, südlicher sanft

Zustand: in der Nordhälfte ein Raubtrichter

Sonstiges: keine Steine an der Oberfläche

\section{Kurgan 22}

Dm $40 \mathrm{~m} ; \mathrm{H} 2 \mathrm{~m}$

Lage: N43 00.362 E79 13.567

Form: niedrig, abgerundet, plattformähnlich mit abgeflachter Kuppe

Abhänge: drei steile, südlicher sanft

Zustand: in der Mitte ein Raubtrichter

Sonstiges: keine Steine an der Oberfläche

\section{Kurgan 23}

Dm $38 \mathrm{~m} ; \mathrm{H} 4,5 \mathrm{~m}$

Lage: N43 00.462 E79 13.559

Form: abgerundet, plattformähnlich mit abgeflachter Kuppe

Abhänge: drei steile, südlicher sanft

Zustand: ehemaliger Raubtrichter mit Beton verfüllt und in der Mitte ein trigonometrischer Mast aufgestellt; südlicher und südwestlicher Kurganrandbereich durch Bewässerungskanal beschädigt; auf dem nördlichen Randbereich liegt ein Grundstück, dadurch ist dieser Bereich und die Kurganperipherie hier beschädigt Sonstiges: keine Steine an der Oberfläche

\section{Kurgan 24}

Dm 45 m; H 4 m

Lage: N43 00.506 E79 I3.560

Form: abgerundet, plattformähnlich mit abgeflachter Kuppe
Abhänge: drei steile, südlicher sanft

Zustand: keine Senke, kein Trichter; der Westbereich ist durch die Lehmgewinnung von den Bewohnern Kegens zerstört

Sonstiges: keine Steine an der Oberfläche

\section{Kurgan 25}

Dm 44 m; H 4 m

Lage: N43 00.553 E79 I3.556

Form: abgerundet, plattformähnlich mit abgeflachter Kuppe

Abhänge: drei steile, südlicher sanft

Zustand: im Nordbereich eine Senkung

Sonstiges: keine Steine an der Oberfläche

Kurgan 26

Dm 52 m; H 5,5 m

Lage: N43 00.653 E79 I3.532

Form: ursprüngliche Form ist unklar

Abhänge: drei steile, südlicher sanft

Zustand: in der Mitte ein Raubtrichter; östlicher Kurganrandbereich bebaut; der westliche Kurganrandbereich durch eine Müllgrube zerstört

Sonstiges: Oberfläche mit Kieselsteinen bedeckt

\section{Kurgan 27}

Dm 44 m; H 3,5 m

Lage: N43 00.737 E79 13.509

Form: abgerundet, plattformähnlich mit abgeflachter Kuppe

Abhänge: drei steile, südlicher sanft

Zustand: kein Raubtrichter, in der Südhälfte des Kurgans liegt ein Aushub

Sonstiges: auf der Oberfläche Kieselsteine

\section{Kurgan 28}

Dm $42 \mathrm{~m} ; \mathrm{H}$ 3,6 m

Lage: N43 00.800 E79 I3.50I; nördlichster Kurgan der Kette

Form: abgerundet, plattformähnlich mit abgeflachter Kuppe

Abhänge: drei steile, südlicher sanft

Zustand: kein Raubtrichter, jedoch liegt im westlichen und nordwestlichen Bereich des Kurgans ein Aushub; die Peripherie des Kurgans ist überpflügt

Sonstiges: keine Steine an der Oberfläche

Mittlere Kurgankette

\section{Kurgan 30}

Dm I32 m; H II,7 m

Lage: N42 57.567 E79 II.422

Form: abgerundet, plattformähnlich mit abgeflachter Kuppe

Abhänge: drei steile, südlicher sanft

Zustand: in der Mitte ein Raubtrichter

Sonstiges: keine Steine an der Oberfläche 


\section{Kurgan 3I}

Dm 65 m; H 3,5 m

Lage: N42 57.682 E79 II.236

Form: abgerundet, plattformähnlich mit abgeflachter

Kuppe

Abhänge: drei steile, südlicher sanft

Zustand: in der Mitte ein Raubtrichter

Sonstiges: keine Steine an der Oberfläche

\section{Kurgan 32}

Dm 38 m; H 4,5 m

Lage: N42 57.567 E79 II.II7

Form: abgerundet, plattformähnlich mit abgeflachter Kuppe

Abhänge: drei steile, südlicher sanft

Zustand: kein Raubtrichter; in der Südhälfte mehrere unklare Senken

Sonstiges: keine Steine an der Oberfläche

\section{Kurgan 33}

Dm 79 m; H 4 m

Lage: N42 57.503 E79 10.799

Form: abgerundet, plattformähnlich mit abgeflachter Kuppe

Abhänge: drei steile, südlicher sanft

Zustand: in der Mitte ein Raubtrichter

Sonstiges: keine Steine an der Oberfläche

2. Kurgankette

2. Kurgankette Kurgan I

Dm 53 m; H 5,3 m

Lage: N42 53.I69 E79 ०8.II8
Form: abgerundet, plattformähnlich mit abgeflachter Kuppe

Abhänge: drei steile, südlicher sanft

Zustand: in der Mitte ein Raubtrichter

Sonstiges: keine Steine an der Oberfläche

2. Kurgankette Kurgan 2

Dm 83 m; H 9 m

Lage: N42 53.346 E79 08.180

Form: abgerundet, plattformähnlich mit abgeflachter Kuppe

Abhänge: drei steile, südlicher sanft

Zustand: in der Mitte ein gewaltiger Raubtrichter

Sonstiges: keine Steine an der Oberfläche

2. Kurgankette Kurgan 3

Dm $40 \mathrm{~m} ; \mathrm{H}_{3} \mathrm{~m}$

Lage: N42 53.525 E79 07.84I

Form: abgerundet, plattformähnlich mit abgeflachter Kuppe

Abhänge: drei steile, südlicher sanft

Zustand: in der Mitte ein Raubtrichter

Sonstiges: keine Steine an der Oberfläche

\section{Kurgankette Kurgan 4}

Dm $80 \mathrm{~m}$; H $9 \mathrm{~m}$

Lage: N42 53.55I E79 08.I54

Form: abgerundet, plattformähnlich mit abgeflachter

Kuppe

Abhänge: drei steile, südlicher sanft

Zustand: in der Mitte ein gewaltiger Raubtrichter

Sonstiges: keine Steine an der Oberfläche

\section{Forschungsgeschichte}

Im Sommer 2009 untersuchte die Kasachisch-Deutsche Archäologische Expedition zwei Großkurgane auf dem Plateau Kegen (KI und K2). Es wurden eine geomagnetische Prospektion und geodätische Aufnahme vorgenommen. Zudem wurde der nordwestliche Randbereich des Kurgans 2 untersucht (siehe Kurgancharakteristik, Kurgan 2).

Lit.: Akišev K.A. 1974, 6I; Bartol'd I966, 77-78; Gass 20IIb, 215-2I6, Abb. I5-2I; Gass (im Druck); Nagler 2009, 408, Abb. 77; Nagler u.a. 2010, 49-54; Otčety otdelov i ekspedicij I979, 33; Turkestan I9I4, I23-I24.

Gräberfeld Kokpijaz [FEZ] (Abb. I58; Karte 3 Nr. 66): ALT I870 m N42 58.I73 E79 02.262; Gebiet Almaty (kasach. Алматы облысы), Rajymbekskij rajon (kasach. Райымбек ауданы); Ausmaß N-S $200 \times \mathrm{O}-\mathrm{W} 50 \mathrm{~m}$.

Die Nekropole befindet sich am nordwestlichen Rand des Hochplateaus Kegen (kasach. Кеген), am linken, westlichen Ufer des Flusses Žinsajbulak (kasach. Жынсайбұлақ), I km südwestlich der Mündungsstelle der Flüsse Žinsajbulak und Žarganak (kasach. Жарганак). Die Kurgane stehen I75 km ostsüdöstlich von der Stadt Almaty (kasach. Алматы), г6 km südwestlich des Dorfes Kegen (kasach. Кеген), I,I km nordwestlich des Dorfes Šyrganak (kasach. Шырғанақ) und I, 8 km südöstlich des Dorfes Karkara (kasach. Қарқара). Das Gräberfeld besteht aus sieben mittelgroßen und kleinen Kurganen, 
die zwei Ketten bilden. Die westlich gelegene und N-S verlaufende Kette weist drei mittelgroße Kurgane auf, wobei der nördlichste Kurgan abseits der beiden weiteren steht. Da die östlich gelegene und von Nordwest nach Südost verlaufende Kette nur aus vier kleinen, flachen Kurganen besteht, wurde sie nicht aufgenommen. Alle mittelgroßen Kurgane haben drei steile und einen (immer südlichen) sanften Abhang. Der Durchmesser der Kurgane schwankt zwischen $24 \mathrm{~m}$ und $33 \mathrm{~m}$, die Höhe zwischen 2,0 m und 3,2 m. Der südlichste mittelgroße Kurgan weist keine Senke bzw. Raubtrichter auf.

Anhand der Lage im Gelände, der Struktur und der äußeren Erscheinungsform können alle Kurgane der Nekropole der sakischen Periode der Früheisenzeit zugeordnet werden.
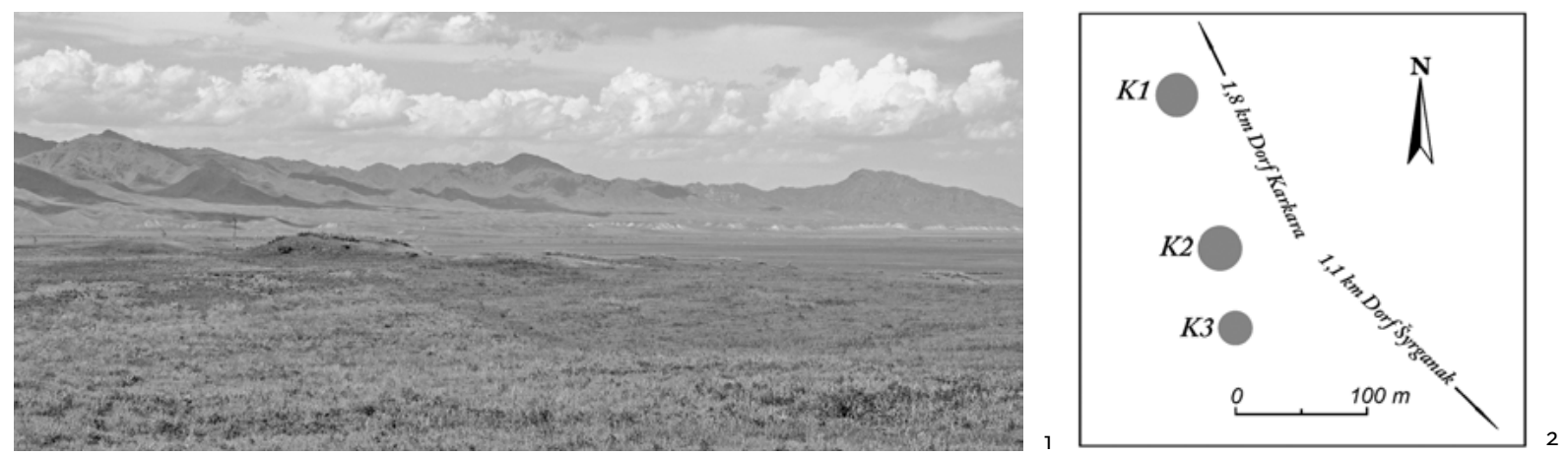

Abb. 158 | Gräberfeld Kokpijaz; I. Blick von SW; 2. Plan der Nekropole

Kurgancharakteristik:

Kurgan I

Dm 33 m; H 2 m

Lage: N42 58.236 E79 02.246; nördlichster Kurgan der Kette

Form: abgerundet, plattformähnlich mit abgeflachter Kuppe

Abhänge: drei steile, südlicher sanft

Zustand: in der Mitte eine Senke

Sonstiges: keine Steine an der Oberfläche

\section{Kurgan 2}

Dm 33 m; H 3,2 m

Lage: N42 58.173 E79 02.262

Form: abgerundet, plattformähnlich mit abgeflachter Kuppe

\begin{abstract}
Abhänge: drei steile, südlicher sanft
Zustand: in der Mitte eine Senke

Sonstiges: keine Steine an der Oberfläche

Bemerkung: größter Kurgan der Nekropole
\end{abstract}

\section{Kurgan 3}

Dm 24 m; H 2 m

Lage: N42 58.I40 E79 02.273; südlichster Kurgan der Kette

Form: abgerundet, plattformähnlich mit abgeflachter Kuppe

Abhänge: drei steile, südlicher sanft

Zustand: keine Senke, kein Raubtrichter

Sonstiges: keine Steine an der Oberfläche

Kurgangruppe Krasnyj Vostok [FEZ] (Abb. I59; Karte 3 Nr. I5): ALT 908 m N43 21.932 E77 22.8І2; Gebiet Almaty (kasach. Алматы облысы), Enbekšikazachskij rajon (kasach. Еңбекшіқазақ ауданы); Ausmaß N-S IO2 × O-W I60 m.

Die Kurgangruppe liegt ca. 43 km nordöstlich der Stadt Almaty (kasach. Алматы), 6,3 km westlich der Stadt Issyk (kasach. Ecik), 2,5 km westlich des Dorfes Rachat (kasach. Рахат) und I,8 km südöstlich des Dorfes Krasnyj Vostok (russ. Красный Восток) am rechten, östlichen Ufer eines Bergflusses ${ }^{6 \circ 2}$. Im Süden verläuft das Transili-Alatau. In unmittelbarer Nähe, 400 m nordöstlich, liegt die Siedlung Krasnyj Vostok. Die Kurgangruppe besteht aus zwei Großkurganen, die eine W-O verlaufende Achse bilden.

602 Der Gebirgsbach hat keinen offiziellen Namen. 


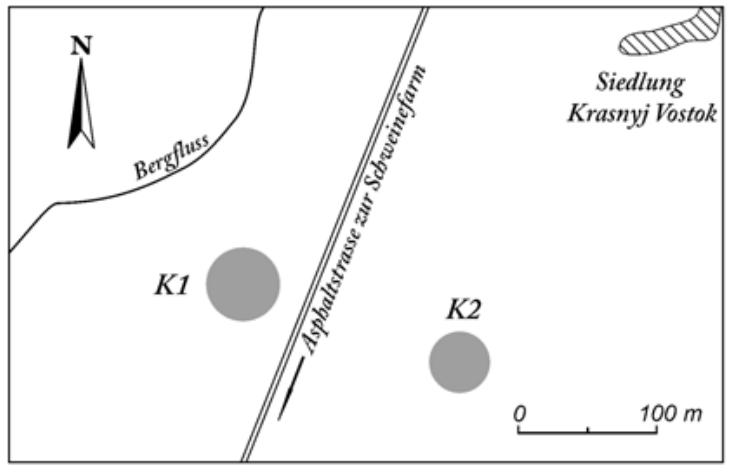

Abb. 159 | Lageskizze der Kurgangruppe Krasnyj Vostok

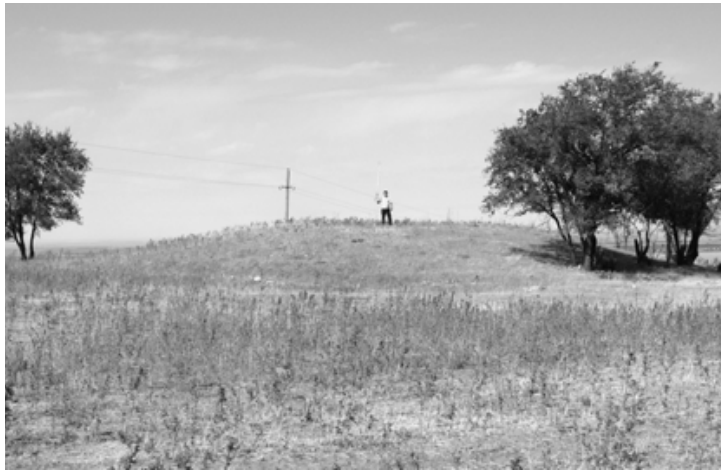

Abb. $160 \mid$ Kurgan I. Blick von SO

Zwischen den Kurganen verläuft eine Asphaltstraße, die vom Dorf Krasnyj Vostok zur Schweinefarm führt. Die Kurgane weisen drei steile und einen (immer südwestlichen) sanften Abhang auf. Beide Kurgane haben jeweils einen Raubtrichter. Es wurden keine besonderen architektonischen Merkmale festgestellt.

Anhand der Landschaftsplatzierung, der Struktur und der äußeren Erscheinungsform können alle Kurgane des Gräberfeldes der sakischen Periode der Früheisenzeit zugeordnet werden.

Kurgancharakteristik:

Kurgan I (Abb. I6o)

Dm 54 m; H 3 m

Lage: N43 21.932 E77 22.8I2

Form: abgerundet, plattformähnlich mit abgeflachter Kuppe

Abhänge: drei steile, südwestlicher sanft

Zustand: in der Mitte ein Raubtrichter

Sonstiges: keine Steine der Kurganaufschüttung an der Oberfläche

\author{
Kurgan 2 \\ Dm 53 m; H 2 m \\ Lage: N43 21.899 E77 22.926 \\ Form: abgerundet, plattformähnlich mit abgeflachter \\ Kuppe \\ Abhänge: drei steile, südwestlicher sanft \\ Zustand: in der Mitte leichte Senke (Raubtrichter?) \\ Sonstiges: an der Oberfläche einzelne große Steine der \\ Kurganaufschüttung
}

Gräberfeld Kyzylšaryk [FEZ] (Karte 3 Nr. 28): ALT 745 m N43 30.942 E78 I7.235; Gebiet Almaty (kasach. Алматы облысы), Enbekšikazachskij rajon (kasach. Еңбекшіқазақ ауданы); Ausmaß N-S 3,7 × $\mathrm{O}-\mathrm{W} 4,4 \mathrm{~km}$.

Die Nekropole besteht aus zwei N-S ausgerichteten Ketten und einem alleinstehenden Kurgan. Sie befindet sich auf der nördlich vom Transili-Alatau (kasach. Іле Алатауы) gelegenen Flachebene, ca. Iг2 $\mathrm{km}$ ostnordöstlich von der Stadt Almaty (kasach. Алматы) und І,9 km südsüdöstlich vom Dorf Kyzylšaryk (kasach. Қызыл шарық) am linken, westlichen Ufer des Asy (kasach. Aсы). Insgesamt wurden auf dem Gräberfeld 37 Klein- und Großkurgane sowie fünf Konstruktionen aus Steinen festgestellt. Der Durchmesser der Hügel schwankt zwischen $6 \mathrm{~m}$ und 6r m (86 m mit sog. Prozessionsweg), ihre Höhe zwischen 0,2 m und 7 m. Fast alle Kurgane des Gräberfeldes weisen Raubtrichter auf. I6 Kurgane haben drei steile und einen sanften Abhang. In I4 Fällen weisen die Kurgane im Süden und in zwei Fällen im Südwesten einen sanften Abhang auf. Vier Kurgane haben gar keine besonderen Merkmale bezüglich der Abhänge und bei acht Kurganen konnte aufgrund eines hohen Zerstörungsgrades keine Neigung bestimmt werden.

Die erste, östlichste Kette (Abb. I6I) besteht aus I3 Kurganen, wobei nur die neun südlichsten gemessen werden konnten, da sich die Kette exakt an der südsüdöstlichen Grenze des Dorfes Kyzylšaryk 

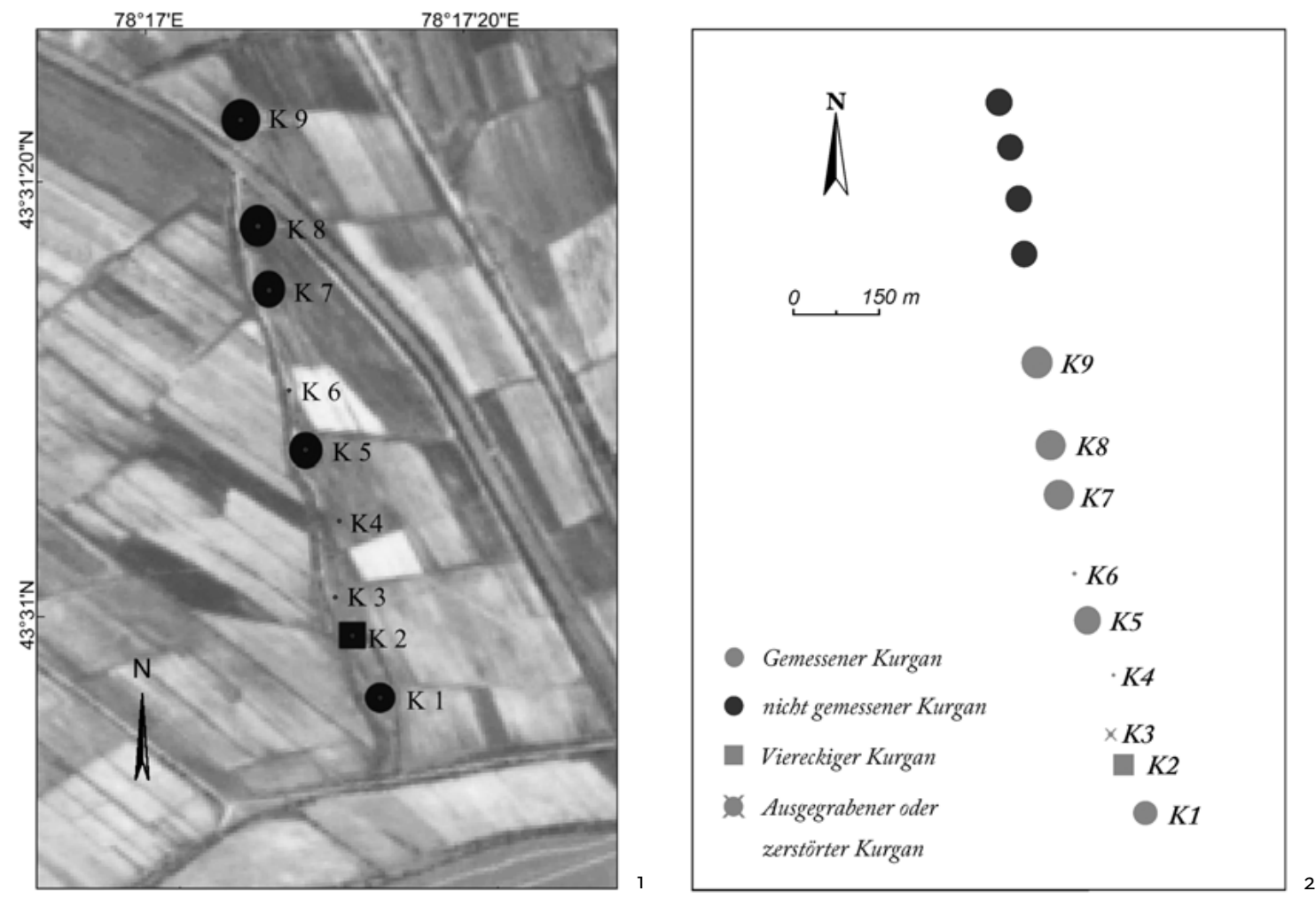

Abb. 161 | Gräberfeld Kyzylšaryk, erste Kurgankette; I. SPOT 2,5 m; 2. Plan

befindet und zum Teil schon in den Dorfgärten und auf privaten Ländereien liegt, so dass nur die südlichsten Kurgane frei zugänglich waren, die ihrerseits auf dem Acker (im Jahre 2008 Maisfelder) standen. Der zweite südlichste Kurgan, dessen Abhänge an den vier Haupthimmelsrichtungen orientiert sind, weist eine viereckige Form auf. Die zweite Kurgankette (Abb. I62-I63) liegt I,6 km südwestlich von der ersten Kette, 2,7 km südlich vom Dorf Kyzylšaryk und 370 m nördlich vom „Großen Almatykanal“ (БАK ${ }^{603}$ ). Sie besteht aus 24 Klein- und Großkurganen, wobei nur die I8 größeren Kurgane gemessen wurden. Außerdem wurden um den südlichsten Kurgan der Kette kleine Konstruktionen aus Steinen, die ohne Ausgrabung unmöglich zu interpretieren sind, festgestellt. Drei davon treten westlich und zwei östlich vom Kurgan auf. Der sechste Kurgan in südlicher Richtung (Nr. I4) weist einen den Kurgan umlaufenden sog. Prozessionsweg auf. Die äußere Markierung dieses „Weges“ wurde durch mittelgroße Steine $(40 \times 30 \times 20 \mathrm{~cm})$ angezeigt. Die Peripherie einiger Kurgane wurde durch moderne Bewässerungskanäle gestört. Die sieben nördlichen Kurgane befinden sich auf dem Ackerland des Dorfes. $3,2 \mathrm{~km}$ südwestlich von der zweiten Kette, 5,5 km südwestlich vom Dorf Kyzylšaryk und Io6 m nördlich vom „Großen Almatykanal“ steht ein alleinstehender Kurgan (Nr. Io), der trotz der Entfernung zur Nekropole gerechnet werden kann (Abb. I64,I). In einem Abstand von II m zum Kurganrand zeigte sich ein den Kurgan umlaufender sog. Prozessionsweg, dessen südlicher Bereich durch eine moderne Asphaltstraße zerstört wurde.

Anhand der Landschaftsplatzierung, der Struktur und äußeren Erscheinungsform können alle großen Kurgane des Gräberfeldes der sakischen Periode der Früheisenzeit zugeordnet werden.

603 Большой Алматинский Канал. 


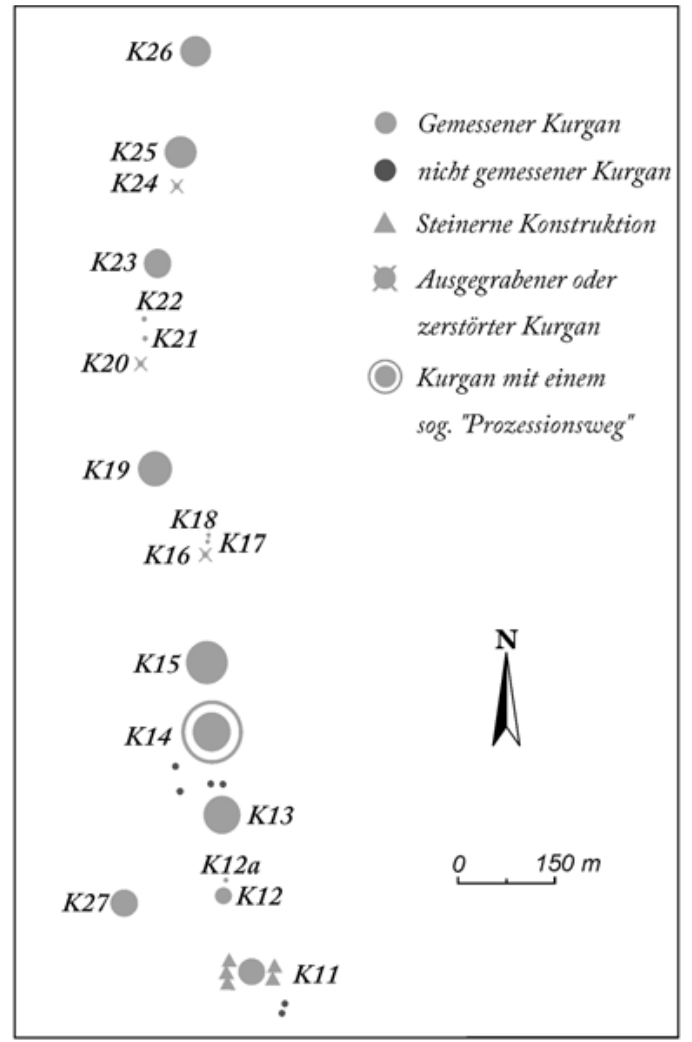

Abb. 162 | Gräberfeld Kyzylšaryk.

Plan der zweiten Kurgankette

Kurgancharakteristik604:

Erste Kurgankette

\section{Kurgan I}

Dm 4I m; H 4,6 m

Lage: N43 30.942 E78 I7.235, auf dem Acker

Form: abgerundet, plattformähnlich mit abgeflachter Kuppe

Abhänge: drei steile, südlicher sanft

Zustand: in der Osthälfte ein Raubtrichter

Sonstiges: im unteren Bereich der Kurganaufschüttung mittelgroße Steine der Kurganabdeckung

\section{Kurgan 2}

L (Seite) $36 \mathrm{~m} ; \mathbf{H ~ 4 , 5 ~ m ~}$

Lage: N43 31.000 E78 I7.204, auf dem Acker

Form: viereckig, pyramidenähnlich mit abgeflachter Kuppe

Abhänge: keine Merkmale

604 Hier wurden nur größere, eingemessene Kurgane charakterisiert, da die restlichen zu klein und dementspre-
Zustand: in der Mitte eine Senke (Raubtrichter?)

Sonstiges: die Abhänge des Kurgan sind an den vier Haupthimmelsrichtungen orientiert; Oberfläche mit einzelnen mittelgroßen Steinen der Kurganabdeckung bedeckt

\section{Kurgan 3}

$\mathrm{Dm}$ ?; $\mathrm{H}$ ?

Lage: N43 31.029 E78 I7.I85

Form: ?

Abhänge: ?

Zustand: Der Kurgan wurde ausgegraben bzw. zerstört. Im mittleren Bereich befinden sich zwei offene Grabgruben; die Grabungsfläche ist weder museifiziert noch rekultiviert. Der Abraum liegt um die Grabgruben herum.

Bemerkung: Im Archiv des Archäologischen Institutes in Almaty gibt es keinen Bericht zu dieser Grabung.

Kurgan 4 (Kleinkurgan)

Dm 24 m; H o,7-0,8 m

Lage: N43 31.088 E78 I7.I86

Form: abgerundete Erhebung

Abhänge: drei steile, südlicher sanft

Zustand: durch den Kurgan verläuft ein Feldweg

Sonstiges: an Oberfläche einzelne mittelgroße Steine

\section{Kurgan 5}

Dm 5I m; H 5 m

Lage: N43 31.I32 E78 I7.I69

Form: durch schlechten Erhaltungszustand keine genaue Feststellung möglich

Abhänge: ?

Zustand: Kurganrand und Kurganperipherie sind überpflügt; im Nordbereich zwei Raubtrichter

Sonstiges: auf der Kurgankuppe quadratische Erhebung $(4 \times 4 \mathrm{~m}$; $\mathrm{H} \circ, 3 \mathrm{~m})$, evtl. modernen Ursprungs

Kurgan 6 (Kleinkurgan)

Dm $25 \mathrm{~m} ; \mathrm{H}$ ?

Lage: N43 3I.I84 E78 I7.I54; auf dem Acker

Form: abgerundete Erhebung

Abhänge: ?

Zustand: die Kurganfläche ist komplett überpflügt

Kurgan 7

Dm 5I m; H 4,5 m

Lage: N43 3I.26I E78 I7.I28

Form: abgerundet, plattformähnlich mit abgeflachter Kuppe

Abhänge: drei steile, südwestlicher sanft

Zustand: im östlichen Bereich ein Raubtrichter; über die Westhälfte verläuft ein Feldweg

Sonstiges: keine Steine an der Oberfläche

chend als nicht $\mathrm{zu}$ den elitären gehörend angesehen werden konnten. 


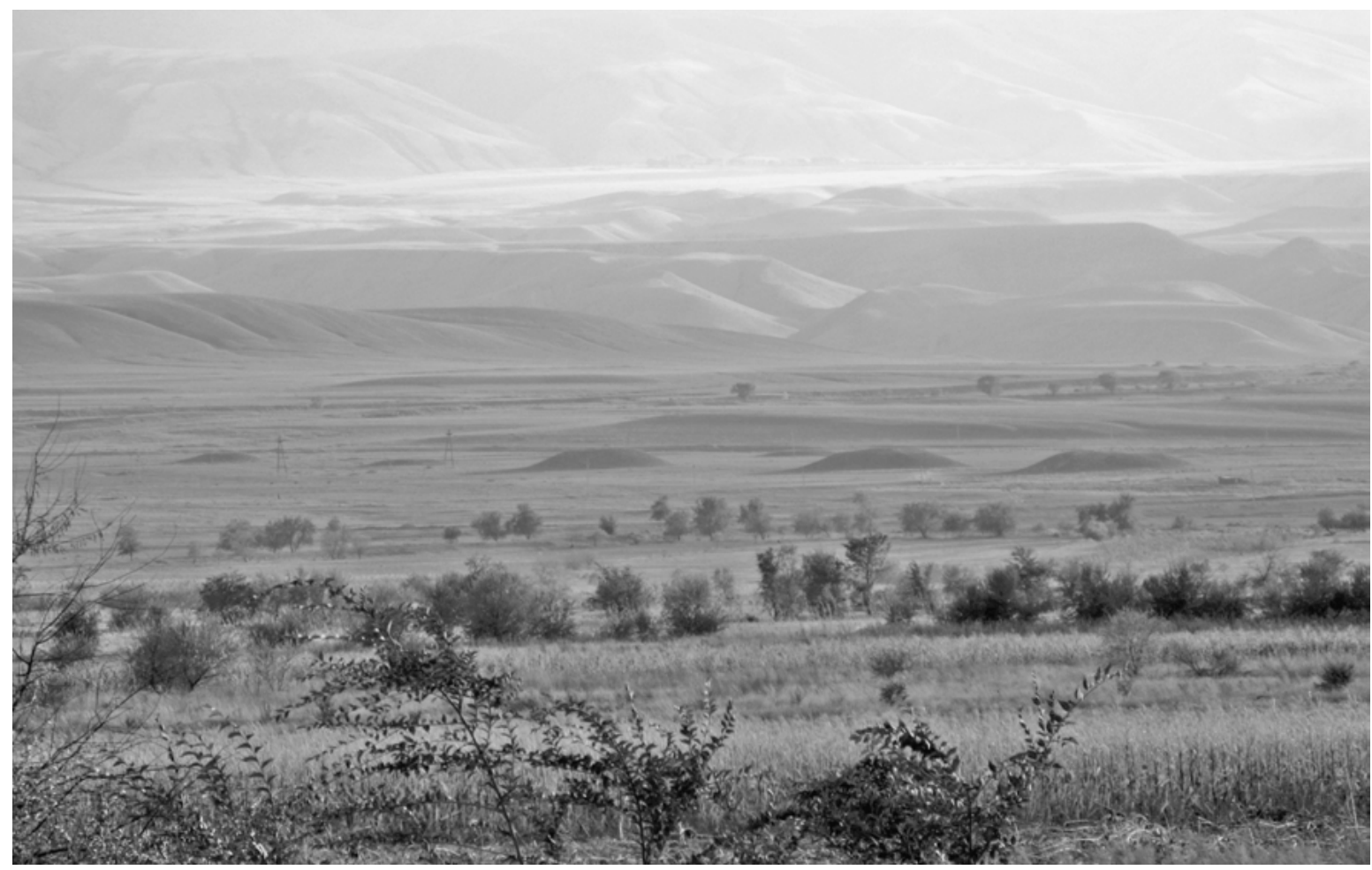

Abb. 163 | Gräberfeld Kyzylšaryk. Zweite Kette. Blick von NO

\section{Kurgan 8}

Dm 58 m; H 5 m

Lage: N43 3I.3I2 E78 I7.I2I

Form: abgerundet, plattformähnlich mit abgeflachter Kuppe

Abhänge: drei steile, südlicher sanft

Zustand: im Ostbereich ein Raubtrichter

Sonstiges: im unteren Bereich der Kurganaufschüttung mittelgroße Steine sichtbar; die Kurgankuppe steinfrei

\section{Kurgan 9}

Dm 57 m; H 5 m

Lage: N43 3I.392 E78 I7.II5

Form: abgerundet, plattformähnlich mit abgeflachter Kuppe

Abhänge: drei steile, südlicher sanft

Zustand: in der Mitte ein Raubtrichter

Sonstiges: im unteren Bereich der Kurganaufschüttung mittelgroße Steine sichtbar; Kurgankuppe steinfrei

Allein stehender Kurgan

Kurgan io (Abb. I64,I-3)

Dm 60 m; Dm mit sog. Prozessionsweg 86 m; H 7 m Lage: N43 29.387 E78 I3.924

Kıo steht allein; $5,3 \mathrm{~km}$ südwestlich von der ersten Kette und 3,2 km südwestlich von der zweiten Kette entfernt.
Form: abgerundet, plattformähnlich mit abgeflachter Kuppe

Abhänge: drei steile, südwestlicher sanft

Weitere Konstruktionen: II m vom Rand des Hügels entfernt befindet sich ein den Kurgan umgebender sog. Prozessionsweg, dessen Breite $2 \mathrm{~m}$ beträgt. Er wird durch große Steine $(\mathrm{ab} 60 \times 40 \times 30 \mathrm{~cm})$ begrenzt.

Zustand: in der Mitte ein Raubtrichter; Der Südbereich der Konstruktion, der Kurganrand und auch der sog. Prozessionsweg sind durch eine moderne Asphaltstraße zerstört; der Nordbereich ist durch einen modernen Baugraben zerstört

Sonstiges: gesamte Oberfläche mit mittelgroßen und großen Steinen $(60 \times 40 \times 30 \mathrm{~cm})$ bedeckt

Zweite Kurgankette

\section{Kurgan II}

Dm 37 m; H 3 m

Lage: N43 30.138 E78 I6.080

Form: abgerundet, plattformähnlich mit abgeflachter Kuppe

Abhänge: drei steile, südlicher sanft

Weitere Konstruktionen: Um den Kurgan herum liegen fünf rechteckige Steinkonstruktionen, davon zwei an der Ostseite und drei an der Westseite; es kann sich hier entweder um Kleinkurgane, Steinkisten oder um etwas anderes handeln. 

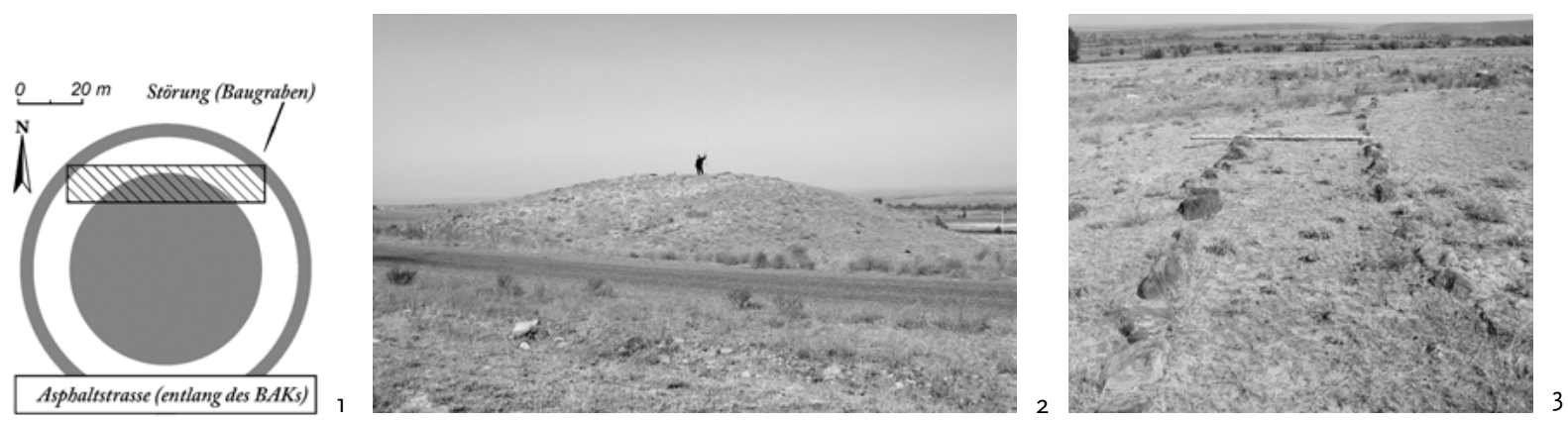

Abb. 164 | Kurgan Io des Gräberfeldes Kyzylšaryk; I. Skizze des allein stehenden Kurgans; 2. Blick von SO; 3. Sog. Prozessionsweg, Westbereich, Blick von NW

Zustand: in der Mitte ein Raubtrichter

Sonstiges: die Oberfläche, ausschließlich der Kurgankuppe, mit mittelgroßen Steinen $(40 \times 30 \times 20 \mathrm{~cm})$ bedeckt

Steinkonstruktionen

Konstruktion I

L 2,9 m; B o,5 m

Lage: N43 30.I40 E78 I6.I04; NO vom Kurgan

Form: Rechteckige Steinkonstruktion, die aus mittelgroßen $(50 \times 30 \times 20 \mathrm{~cm})$ senkrecht aufgestellten Steinen besteht. Der innere Bereich der Konstruktion ist nicht mit Steinen verfüllt.

Ausrichtung: N-S

Sonstiges: klare Deutung der Konstruktion nicht möglich

Konstruktion 2

L 2,9 m; B 2,I m

Lage: N43 30.I33 E78 I6.I03; SO vom Kurgan

Form: Rechteckige Steinkonstruktion, die aus mittelgroßen $(30 \times 20 \times 10 \mathrm{~cm})$ in einer Linie angeordneten Steinen besteht; der innere Bereich der Konstruktion ist nicht mit Steinen verfüllt.

Ausrichtung: W-O

Sonstiges: klare Deutung der Konstruktion nicht möglich

Konstruktion 3

L 2,6 m; B I,5 m

Lage: N43 30.I3I E78 I6.054; SW vom Kurgan

Form: rechteckige Steinkonstruktion, die aus mittelgroßen $(40 \times 30 \times 20 \mathrm{~cm})$ senkrecht aufgestellten Steinen besteht; der innere Bereich der Konstruktion ist nicht mit Steinen verfüllt.

Ausrichtung: N-S

Sonstiges: klare Deutung der Konstruktion nicht möglich Konstruktion 4

L 4,3 m; B I,4 m

Lage: N43 30.136 E78 I6.055; W vom Kurgan

Form: Rechteckige Steinkonstruktion, die aus mittelgroßen $(40 \times 30 \times 20 \mathrm{~cm})$ senkrecht aufgestellten Steinen besteht; der innere Bereich der Konstruktion ist nicht mit Steinen verfüllt.

Ausrichtung: W-O
Sonstiges: klare Deutung der Konstruktion nicht möglich

Konstruktion 5

L 2,8 m; B o,8 m

Lage: N43 30.I45 E78 I6.059; NW vom Kurgan

Form: Rechteckige Steinkonstruktion, die aus mittelgroßen $(40 \times 30 \times 20 \mathrm{~cm})$ senkrecht aufgestellten Steinen besteht; der innere Bereich der Konstruktion ist nicht mit Steinen verfüllt.

Ausrichtung: N-S

Sonstiges: klare Deutung der Konstruktion nicht möglich

Kurgan 12

Dm 20 m; H 2,5 m

Lage: N43 30.190 E78 I6.074

Form: abgerundet, plattformähnlich mit abgeflachter Kuppe

Abhänge: drei steile, südlicher sanft

Zustand: in der Mitte ein Raubtrichter

Sonstiges: die Oberfläche komplett mit mittelgroßen und kleinen Steinen bedeckt

Kurgan I2a (Kleinkurgan)

Dm 6 m; H o,3 m

Lage: N43 30.207 E78 I6.077

Form: abgerundete Erhebung mit einzelnen Steinen an der Oberfläche

Abhänge: keine Merkmale

\section{Kurgan 13}

Dm 55 m; H 6 m

Lage: N43 30.253 E78 I6.083

Form: abgerundet, plattformähnlich mit abgeflachter Kuppe

Abhänge: drei steile, südlicher sanft

Zustand: in der Mitte ein Raubtrichter

Sonstiges: Oberfläche komplett mit mittelgroßen und kleinen Steinen bedeckt 

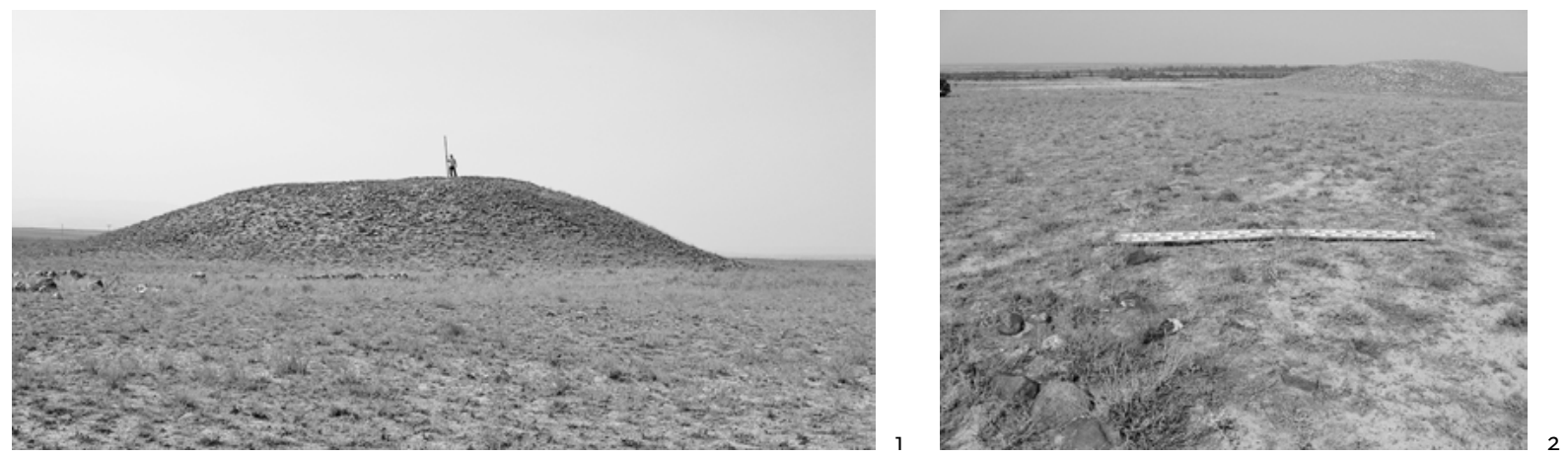

Abb. 165 | Kurgan I4 des Gräberfeldes Kyzylšaryk; I. Blick von O; 2. Sog. Prozessionsweg, Westbereich, Blick von N

Kurgan I4 (Abb. I65)

Dm 56 m; Dm mit dem sog. Prozessionsweg 86 m; H $7 \mathrm{~m}$

Lage: N43 30.319 E78 I6.07I

Form: abgerundet, plattformähnlich mit abgeflachter Kuppe

Abhänge: drei steile, südlicher sanft

Weitere Konstruktionen: $\mathrm{I} 3,5 \mathrm{~m}$ vom Rand des Hügels entfernt liegt ein den Kurgan umlaufender sog. Prozessionsweg, dessen Breite I, $5 \mathrm{~m}$ beträgt. Er wird durch mittelgroße Steine $(\mathrm{ab} 40 \times 30 \times 20 \mathrm{~cm})$ begrenzt. Zwischen dem Kurgan und dem sog. Prozessionsweg befinden sich drei kleine Steinkonstruktionen, die evtl. Kleinkurgane sein könnten.

Zustand: in der Mitte ein Raubtrichter; Der nördliche Randbereich des Kurgans und der Nordteil des sog. Prozessionsweges sind durch zwei Bewässerungskanäle beschädigt; außerdem ist der Ostbereich des sog. Prozessionsweges durch den Pflug zerstört.

Sonstiges: gesamte Oberfläche mit mittelgroßen und kleinen Steinen bedeckt

\section{Kurgan I5}

Dm 6r m; H 7 m

Lage: N43 30.378 E78 I6.070

Form: abgerundet, plattformähnlich mit abgeflachter Kuppe

Abhänge: drei steile, südlicher sanft

Weitere Konstruktionen: An der südlichen und östlichen Peripherie des Kurgans befinden sich acht Kleinkurgane, die sich als kleine runde Erhebungen mit einzelnen Steinen an der Oberfläche darstellen.

Zustand: in der Mitte ein Raubtrichter

Sonstiges: nördliche und westliche Peripherie des Kurgans ist bis zum Kurganrand überpflügt

Kurgan i6 (Kleinkurgan)

Dm 23 m; H o,5 m

Lage: N43 30.466 E78 i6.065

Form: abgerundete Erhebung mit mittelgroßen und kleinen Steinen an der Oberfläche

Abhänge: keine Merkmale
Zustand: in der Mitte ein Raubtrichter

Sonstiges: gesamter Randbereich und die Peripherie des Kurgans überpflügt

Kurgan I7 (Kleinkurgan)

Dm 8 m; H o,4 m

Lage: N43 30.478 E78 I6.065; auf dem Acker

Form: abgerundete Erhebung mit kleinen Steinen an der Oberfläche

Abhänge: keine Merkmale

Zustand: schlecht

Kurgan I8 (Kleinkurgan)

Dm $7 \mathrm{~m} ; \mathrm{H}$ o,2 $\mathrm{m}$

Lage: N43 30.483 E78 I6.066; auf dem Acker

Form: abgerundete Erhebung mit kleinen Steinen an der Oberfläche

Abhänge: keine Merkmale

Zustand: schlecht

\section{Kurgan 19}

Dm 50 m; H 3,5 m

Lage: N43 30.538 E78 I5.997

Form: abgerundet, plattformähnlich mit abgeflachter Kuppe

Abhänge: drei steile, südlicher sanft

Zustand: in der Mitte ein Raubtrichter

Sonstiges: gesamte Oberfläche mit mittelgroßen und kleinen Steinen bedeckt

\section{Kurgan 20 \\ $\mathrm{Dm}$ ?; $\mathrm{H}$ ? \\ Lage: N43 30.6I3 E78 15.990; auf dem Acker \\ Form: ?}

Abhänge: ?

Zustand: Durch den ganzen Kurgan verläuft ein N-S ausgerichteter Grabungsschnitt. Die Grabungsfläche ist weder museifiziert noch rekultiviert; an der Oberfläche sind mittelgroße Steine der Kurganskonstruktion sichtbar.

Bemerkung: Im Archiv des Archäologischen Institutes in Almaty gibt es keinen Bericht zu dieser Grabung. 
Kurgan 2I (Kleinkurgan)

Dm 24 m; H I, 2 m

Lage: N43 30.639 E78 15.995; auf dem Acker

Form: abgerundete Erhebung mit kleinen Steinen an der Oberfläche

Abhänge: keine Merkmale

Zustand: in der Mitte ein Raubtrichter

Kurgan 22 (Kleinkurgan)

Dm I5 m; H o,3 m

Lage: N43 30.655 E78 I5.995; auf dem Acker

Form: abgerundete Erhebung mit kleinen Steinen an der Oberfläche

Abhänge: keine Merkmale

Zustand: keiner Raubtrichter

\section{Kurgan 23}

Dm 40 m; H 2 m

Lage: N43 30.697 E78 i6.oII; auf dem Acker

Form: abgerundet, plattformähnlich mit abgeflachter Kuppe

Abhänge: drei steile, südlicher sanft

Zustand: keiner Raubtrichter

Sonstiges: an der Oberfläche einzelne kleine und große (bis $70 \times 60 \times 40 \mathrm{~cm}$ ) Steine

Kurgan 24 (Kleinkurgan)

Dm IO-I2 $\mathrm{m} ; \mathrm{H}$ ?

Lage: N43 30.758 E78 i6.035; auf dem Acker

Form: ?

Abhänge: ?

Zustand: gesamter Kurgan durch den Pflug beschädigt; an der Oberfläche einzelne kleine und mittelgroße Steine
Kurgan 25

Dm $45 \mathrm{~m} ; \mathrm{H} 2 \mathrm{~m}$

Lage: N43 30.785 E78 I6.04I; auf dem Acker

Form: abgerundet, plattformähnlich mit abgeflachter Kuppe

Abhänge: drei steile, südlicher sanft

Zustand: in der Mitte ein Raubtrichter

Sonstiges: an der Oberfläche einzelne kleine und mittelgroße Steine

Kurgan 26

Dm 45 m; H 2 m

Lage: N43 30.864 E78 r6.06r; auf dem Acker

Form: abgerundet, plattformähnlich mit abgeflachter

Kuppe

Abhänge: drei steile, südlicher sanft

Zustand: keine Raubtrichter

Sonstiges: an der Oberfläche einzelne mittelgroße Steine

\section{Kurgan 27}

Dm 37 m; H 3 m

Lage: N43 30.194 E78 I5.964;

K27 steht westlich, separiert von den übrigen Hügeln der zweiten Kette, in südlichem Bereich der Nekropole Form: abgerundet, plattformähnlich mit abgeflachter Kuppe

Abhänge: drei steile, südlicher sanft

Zustand: keine Raubtrichter

Sonstiges: gesamte Oberfläche mit mittelgroßen und kleinen Steinen bedeckt

Forschungsgeschichte

Im Rahmen der Zusammenstellung der Studie „Denkmäkler der Geschichte und Kultur der Republik Kasachstan“ und der Registrierung der archäologischen Bodendenkmäler im Gebiet Almaty und den Taldy-Kurgan wurde I992 auf der Nekropole ein Survey von V. A. Grošev und A. N. Mar’jašev (Archäologisches Institut, Almaty) durchgeführt. Es wurden einige Kurgane der ersten Kette untersucht (nach unserer Nummerierung: KI, K2, K5, K6, K7), beschrieben und vermessen (Grošev/Mar'jašev I992, I2). Der untersuchte Teil wurde als Gräberfeld Kyzylšaryk 2 (russ. Кызылшарык 2) bezeichnet. Eine Lageskizze oder ein Gräberfeldplan wurden nicht angefertigt.

Lit.: Grošev/Mar'jašev I992, I2, 28. 
Gräberfeld Nordwestlicher Friedhof [FEZ] (Abb. I66; Karte 3 Nr. I): ALT 795 m N43 I7.770 E76 48.9II; Gebiet Almaty (kasach. Алматы облысы), Stadt Almaty (kasach. Алматы); Ausmaß N-S I,6 × O-W $0,5 \mathrm{~km}$.
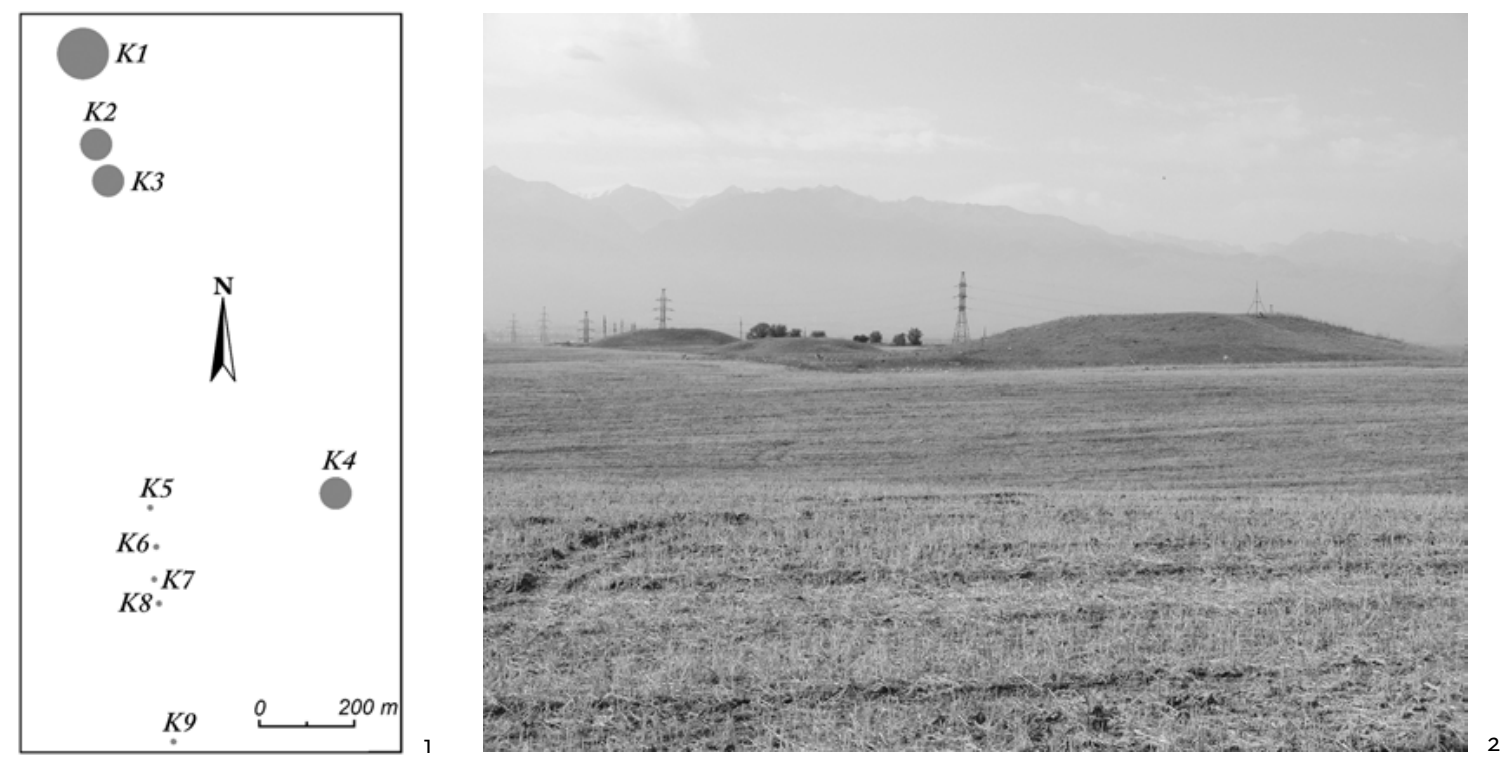

Abb. 166 | Gräberfeld Nordwestlicher Friedhof; I. Plan; 2. Überblick von N

Die Nekropole liegt ca. 6 km nordwestlich der Stadtgrenze von Almaty (kasach. Алматы) und ca. I km östlich vom Heizkraftwerk-2 in Almaty, am linken, westlichen Ufer des Boroldaj (kasach. Боролдай). Sie besteht aus neun Kurganen, wobei die nördlichen vier die größten sind. Der Durchmesser der Hügel misst zwischen $36 \mathrm{~m}$ und IIo m, die Höhe zwischen I,O-I, $5 \mathrm{~m}$ und $9 \mathrm{~m}$. Die Kurgane bilden eine N-S verlaufende Kette und weisen Raubtrichter auf. An der Oberfläche der Kurgane liegen die Steine der Kurganaufschüttung. Die fünf südlichen, kleineren Kurgane sind durch den Pflug stark beschädigt, was die Rekonstruktion des ehemaligen Aussehens nach der Errichtung erschwert. Die Kurgane weisen drei steile und einen, in zwei Fällen südöstlichen, in drei Fällen südwestlichen, in zwei weiteren Fällen exakt östlichen, sanften Abhang auf. Bei den zwei übrigen kann dieses Merkmal wegen des höheren Zerstörungsgrades der Kurgane nicht mehr festgestellt werden. Im Abstand von ca. 33 m zum nördlichsten Kurgan wurde eine ca. Io m breite Steinstreuung um den Kurgan herum festgestellt. Eventuell handelt es sich dort um die Reste entweder eines Steinkreises, oder eines sog. Prozessionsweges, die durch die moderne landwirtschaftliche Nutzung beschädigt wurden. Insgesamt kann festgestellt werden, dass sich das gesamte Gräberfeld auf einem regelmäßig gepflügten Acker befindet und daher die Peripherie aller Kurgane stark beschädigt ist.

Anhand der Struktur und der äußeren Erscheinungsform können alle Kurgane des Gräberfeldes der sakischen Periode der Früheisenzeit zugeordnet werden. 
Kurgancharakteristik:

Kurgan I

Dm IIo m; H 9 m

Lage: N43 I7.933 E76 48.876; nördlichster Kurgan der Nekropole

Form: abgerundet, plattformähnlich mit abgeflachter Kuppe

Abhänge: drei steile, südöstlicher sanft

Zustand: in der Mitte ein Raubtrichter; Peripherie des Kurgans durch den Pflug komplett zerstört

Sonstiges: einzelne kleine und mittelgroße Steine auf der Oberfläche;

Ca. $33 \mathrm{~m}$ um den Kurganrand herum liegt eine ca. Io $\mathrm{m}$ breite Steinstreuung, die aus mittelgroßen und großen Steinen $(\mathrm{ab} 70 \times 50 \times 40 \mathrm{~cm})$ besteht; evtl. handelt es sich hier um die Reste eines Steinkreises bzw. eines sog. Prozessionsweges.

\section{Kurgan 2}

Dm 63 m; $H 5$ m

Lage: N43 I7.829 E76 48.893

Form: abgerundet, plattformähnlich mit abgeflachter Kuppe

Abhänge: drei steile, östlicher sanft

Zustand: in der Mitte ein Raubtrichter; Peripherie des Kurgans durch den Pflug komplett zerstört

Sonstiges: Oberfläche mit einzelnen kleinen Steinen bedeckt

\section{Kurgan 3}

Dm 66 m; H 5 m

Lage: N43 I7.788 E76 48.910

Form: abgerundet, plattformähnlich mit abgeflachter Kuppe

Abhänge: drei steile, östlicher sanft

Zustand: in der Mitte ein Raubtrichter; Peripherie des Kurgans durch den Pflug komplett zerstört

Sonstiges: die Oberfläche steinfrei

\section{Kurgan 4}

Dm 68 m; H 5,5 m

Lage: N43 I7.424 E76 49.256

Form: abgerundet, plattformähnlich mit abgeflachter Kuppe

Abhänge: drei steile, südwestlicher sanft

Zustand: in der Mitte ein Raubtrichter; südlicher Abhang des Kurgans durch eine Baggergrube stark beschädigt; der Nordbereich der Kurganabdeckung durch moderne Eingriffe stark erodiert; im südwestlichen Bereich der Konstruktion befindet sich ein modernes muslimisches Grab; Peripherie des Kurgans durch den Pflug komplett zerstört
Sonstiges: die Oberfläche steinfrei; Ca. 8-Io m vom Kurganrand entfernt liegen um den Kurgan herum einzelne Steine $(\mathrm{ab} 50 \times 30 \times 20 \mathrm{~cm})$, die evtl. zu einer dazugehörigen Konstruktion gehören.

Kurgan 5 (Kleinkurgan)

Dm 38 m; H I,2 m

Lage: N43 I7.4I2 E76 48.965

Form: abgerundet, plattformähnlich mit abgeflachter Kuppe

Abhänge: drei steile, südöstlicher sanft

Zustand: in der Mitte eine minimale Senke (Raubtrichter?); Peripherie des Kurgans überpflügt

Kurgan 6 (Kleinkurgan)

Dm 36 m; H I, O m

Lage: N43 I7.368 E76 48.972

Form: abgerundete Erhebung

Abhänge: ?

Zustand: der Kurgan wurde überpflügt

Sonstiges: an der Oberfläche einzelne große und mittelgroße Steine $(\mathrm{ab} 70 \times 50 \times 30 \mathrm{~cm})$

Kurgan 7 (Kleinkurgan)

Dm 43 m; H I, 5 m

Lage: N43 I7.330 E76 48.968

Form: abgerundet, plattformähnlich mit abgeflachter Kuppe

Abhänge: drei steile, südwestlicher sanft

Zustand: in der Mitte ein Raubtrichter; die Peripherie des Kurgans ist überpflügt

Sonstiges: Oberfläche steinfrei

Kurgan 8 (Kleinkurgan)

Dm 44 m; H I, 5 m

Lage: N43 I7.302 E76 48.974

Form: abgerundete Erhebung

Abhänge: ?

Zustand: der Kurgan wurde überpflügt

Sonstiges: an der Oberfläche liegen einzelne mittelgroße und kleine Steine

Kurgan 9 (Kleinkurgan)

Dm 45 m; H I, 5 m

Lage: N43 I7.I44 E76 48.993

Form: abgerundet, plattformähnlich mit abgeflachter Kuppe

Abhänge: drei steile, südwestlicher sanft

Zustand: in der Mitte ein Raubtrichter; Peripherie des Kurgans überpflügt

Sonstiges: an der Oberfläche liegen mittelgroße und kleine Steine

Lit.: Samašev u.a. 2005a, Ioo. 


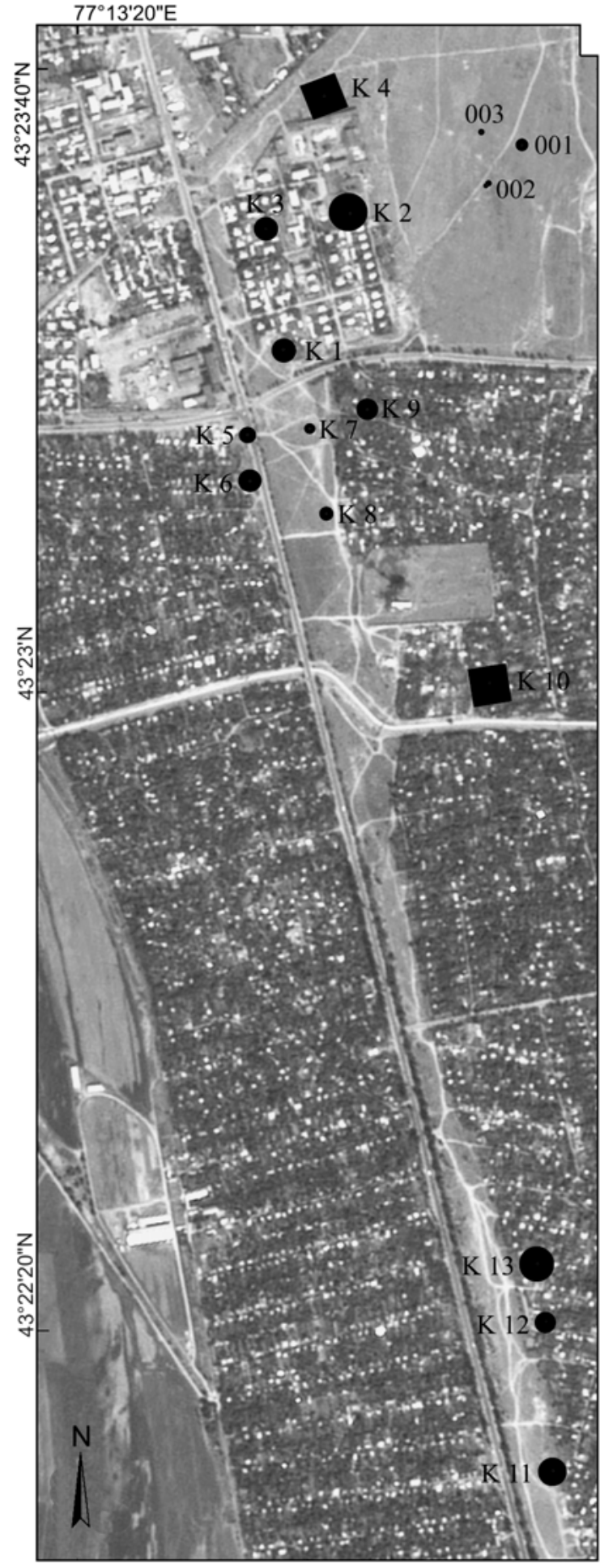

Abb. 167 | Gräberfeld Novoalekseevka (SPOT)
Gräberfeld Novoalekseevka [FEZ] (Abb. I67; Karte 3 Nr. IO): ALT 733 m N43 23.0I8 E77 13.889; Gebiet Almaty (kasach. Алматы облысы), Enbekšikazachskij rajon (kasach. Еңбекшіқазақ ауданы); Ausmaß $\mathrm{N}-2,8 \mathrm{~km} \times$ $\mathrm{O}-\mathrm{W} 0,5 \mathrm{~km}$.

Das Gräberfeld Novoalekseevka befindet sich in der Südhälfte des Dorfes Bajterek (kasach. Байтерек), ehem. Novoalekseevka (russ. Новоалексеевка), Gebiet Almaty und in der Nordhälfte der Talgar-Datschen, an der Kreuzung der Asphaltstraße Bajterek - Talgar und der Begleitstraße des "Großen Almatykanals“ (БAK ${ }^{605}$ ) Issyk - Almaty. Die Tumuli wurden am linken, westlichen Talgar-Ufer (kasach. Талғар) erbaut. Die Nekropole zählt heute I3 große Kurgane, welche eine $\mathrm{N}-\mathrm{S}$ verlaufende Achse bilden und besteht aus zwei Ketten. Im nordöstlichen Bereich befinden sich drei weitere einzelne Kurgane. Da alle Kurgane im modernen Bereich einer Siedlung stehen, sind sie stark beschädigt und überbaut. Zudem zeigen sie alle gewaltige Raubtrichter und werden als Mülldeponien verwendet. Der Durchmesser der Kurgane liegt zwischen $23 \mathrm{~m}$ und 7I $\mathrm{m}$, die Höhe zwischen O,5-I,O $\mathrm{m}$ und Io $\mathrm{m}$. Auf der Oberfläche der Kurgane befinden sich meist mittelgroße Steine $(\mathrm{ab} 30 \times 20 \times 15 \mathrm{~cm})$. Neun Kurgane haben drei steile und einen (immer südwestlichen) sanften Abhang. Zwei Kurgane sind viereckig und bilden ursprünglich eine Plattform mit abgeflachter Kuppe, wobei keine Seite eine besondere Neigung aufweist. Ein niedriger Kleinkurgan zeigt keine besonderen Merkmale bezüglich der Abhänge und in einem Fall konnten diese aufgrund dichter Bebauung nicht bestimmt werden.

Anhand der geographischen Lage, der Struktur und der äußeren Erscheinungsform können alle Kurgane des Gräberfeldes der sakischen Periode der Früheisenzeit zugeordnet werden.

605 Большой Алматинский Канал. 

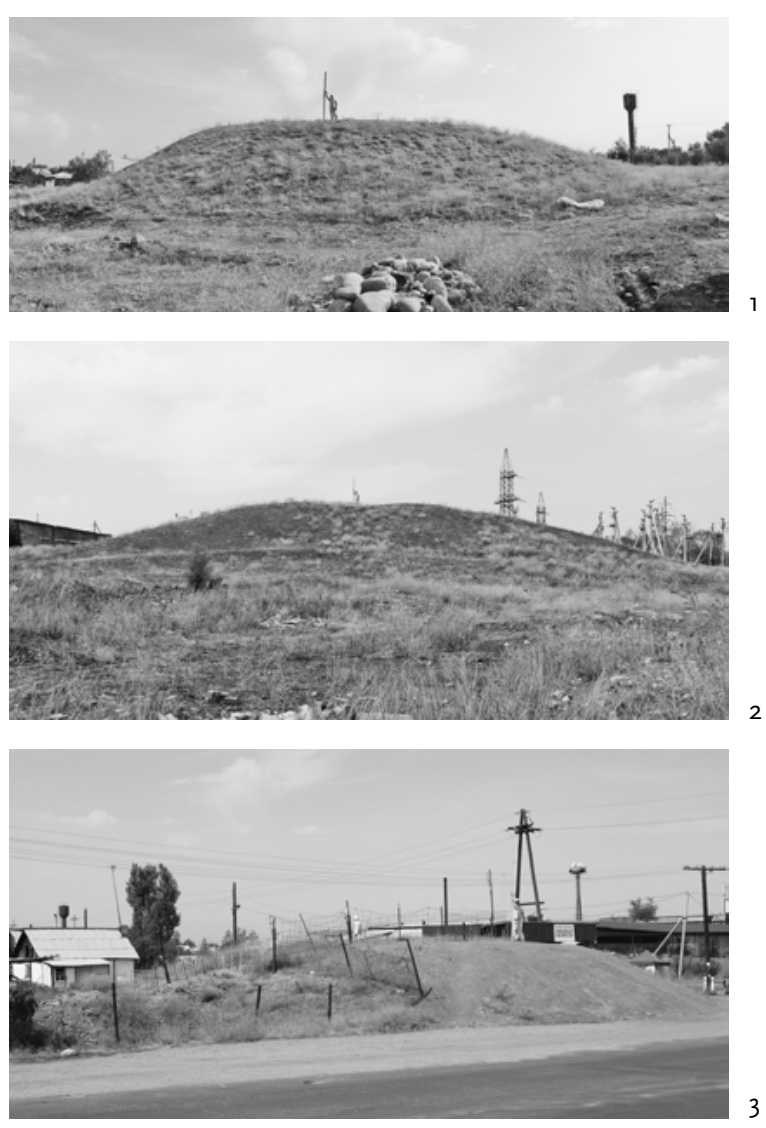

Abb. 168 | Gräberfeld Novoalekseevka; I. Kurgan I, Blick von W; 2. Kurgan 4, Blick von O; 3. Kurgan 5, Blick von SO

Kurgancharakteristik:

Kurgan I (Abb. I68,I)

Dm 45 m; H 7 m

Lage: N43 23.377 E77 I3.608

Form: abgerundet, plattformähnlich mit abgeflachter Kuppe

Abhänge: drei steile, südwestlicher sanft

Zustand: in der Mitte ein Raubtrichter; Peripherie des Kurgans beschädigt

Sonstiges: einzelne kleine und mittelgroße Steine an der Oberfläche

\section{Kurgan 2}

Dm 7I m; H io m

Lage: N43 23.520 E77 I3.702

Form: abgerundet, plattformähnlich mit abgeflachter Kuppe

Abhänge: drei steile, südwestlicher sanft

Zustand: in der Mitte ein Raubtrichter; südlicher und südöstlicher Randbereich des Kurgans durch die Bebauung zerstört

Sonstiges: Oberfläche mit einzelnen kleinen Steinen bedeckt

\section{Kurgan 3}

Dm 45 m; H 5 m

Lage: N43 23.507 E77 I3.580

Form: abgerundet, plattformähnlich mit abgeflachter Kuppe

Abhänge: drei steile, südwestlicher sanft

Zustand: in der Mitte ein Raubtrichter; nördlicher, westlicher und südlicher Randbereich durch moderne Gebäude zerstört; gesamte Peripherie des Kurgans zerstört Sonstiges: Oberfläche mit kleinen und mittelgroßen Steinen bedeckt

Kurgan 4 (Abb. 168,2 )

L (Seitenlänge) $68 \mathrm{~m}$; H $6 \mathrm{~m}$

Lage: N43 23.646 E77 I3.666

Form: viereckig, pyramidenähnlich mit abgeflachter Kuppe

Abhänge: keine Merkmale

Zustand: in der Mitte ein Raubtrichter; Nordseite des Kurganrandes durch einen Feldweg zerstört; Peripherie des Kurgans stark beschädigt

Sonstiges: die Abhänge des Kurgans sind grob an den vier Haupthimmelsrichtungen orientiert; an der Oberfläche einzelne kleine und mittelgroße $(\mathrm{ab} 30 \times 20 \times$ I5 $\mathrm{cm}$ ) Steine

Kurgan 5 (Abb. I68,3)

Dm 35 m; H 3 m

Lage: N43 23.289 E77 I3.545

Form: abgerundet, plattformähnlich mit abgeflachter Kuppe

Abhänge: drei steile, südwestlicher sanft

Zustand: in der Mitte ein Raubtrichter; der nördliche Randbereich durch modernes Gebäude zerstört; Die Westhälfte des Kurgans befindet sich in Privatbesitz, ist daher durch einen Zaun abgesperrt und im Randbereich beschädigt.

Sonstiges: an der Oberfläche einzelne kleine und mittelgroße $(\mathrm{ab} 30 \times 20 \times 15 \mathrm{~cm})$ Steine

\section{Kurgan 6}

Dm 43 m; H 5 m

Lage: N43 23.240 E77 I3.547

Form: abgerundet, plattformähnlich mit abgeflachter Kuppe

Abhänge: drei steile, südwestlicher sanft

Zustand: in der Mitte ein Raubtrichter, der heute als Müllgrube dient; die Südhälfte des Kurgans ist im Randbereich durch ein Gebäude und die dazugehörige Gartenanlage zerstört

Sonstiges: auf der Kurgankuppe einzelne kleine und mittelgroße Steine $(30 \times 20 \times 15 \mathrm{~cm})$

Kurgan 7 (Kleinkurgan)

Dm $23 \mathrm{~m} ; \mathrm{H} 0,5 \mathrm{~m}$

Lage: N43 23.294 E77 I3.636

Form: abgerundete Erhebung

Abhänge: keine Merkmale 
Zustand: in der Mitte ein Raubtrichter; Oberfläche stark beschädigt

Sonstiges: an der Oberfläche mittelgroße und kleine Steine $(30 \times 20 \times 15 \mathrm{~cm})$

Kurgan 8 (Kleinkurgan)

Dm 28 m; H I,O-I,2 m

Lage: N43 23.203 E77 I3.657

Form: abgerundete Erhebung

Abhänge: drei steile, südwestlicher sanft

Zustand: in der Mitte ein Raubtrichter

Sonstiges: an der Oberfläche mittelgroße und kleine Steine $(30 \times 20 \times 15 \mathrm{~cm})$

\section{Kurgan 9}

Dm 49 m; H 7 m

Lage: N43 23.3I5 E77 13.72I; befindet sich in dicht bebautem Gebiet

Form: abgerundet, plattformähnlich mit abgeflachter Kuppe

Abhänge: ?

Zustand: in der Mitte ein Raubtrichter; Der Randbereich und die Peripherie des Kurgans sind dicht bebaut und zerstört.

Sonstiges: an der Oberfläche mittelgroße Steine $(40 \times$ $30 \times 20 \mathrm{~cm})$

\section{Kurgan Io}

L (Seitenlänge) 67 m; H 6 m

Lage: N43 23.0I8 E77 I3.889; befindet sich in dicht bebautem Gebiet

Form: viereckig, pyramidenähnlich mit abgeflachter Kuppe

Abhänge: keine Merkmale

Zustand: in der Mitte ein Raubtrichter; Der Randbereich des Kurgans ist von der westlichen, nördlichen und südlichen Seite durch Bauanlagen und private Gärten komplett zerstört; gesamte Peripherie stark beschädigt

Sonstiges: Die Abhänge des Kurgan sind grob an den vier Haupthimmelsrichtungen orientiert; an der Oberfläche liegen mittelgroße Steine $(45 \times 35 \times 20 \mathrm{~cm})$.

\author{
Kurgan II \\ Dm 54 m; H 4 m \\ Lage: N43 22.I82 E77 I3.948 \\ Form: abgerundet, plattformähnlich mit abgeflachter \\ Kuppe \\ Abhänge: drei steile, südwestlicher sanft \\ Zustand: in der Mitte ein Raubtrichter \\ Sonstiges: an der Oberfläche einzelne mittelgroße \\ Steine $(40 \times 30 \times 20 \mathrm{~cm})$

\section{Kurgan 12} \\ Dm 50 m; H 5 m \\ Lage: N43 22.34I E77 I3.944 \\ Form: abgerundet, plattformähnlich mit abgeflachter \\ Kuppe \\ Abhänge: drei steile, südwestlicher sanft \\ Zustand: in der Mitte ein Raubtrichter; Der Kurgan be- \\ findet sich in dicht bebautem Gebiet, daher sind die \\ südöstliche, südliche und südwestliche Seite des Kur- \\ ganrandes durch einen Feldweg stark beschädigt; die \\ Nordhälfte des Kurgans liegt auf einem privaten \\ Grundstück und ist durch ein Haus im Randbereich \\ komplett zerstört; Peripherie des Kurgans ebenso zer- \\ stört \\ Sonstiges: Oberfläche steinfrei
}

\section{Kurgan 13 \\ Dm 66 m; H 5 m \\ Lage: N43 22.402 E77 I3.934}

Form: abgerundet, plattformähnlich mit abgeflachter Kuppe

Abhänge: drei steile, südwestlicher sanft

Zustand: in der Mitte ein Raubtrichter; Der Kurgan befindet sich in dicht bebautem Gebiet; die Peripherie des Kurgans sowie sein südwestlicher und nördlicher Randbereich sind zerstört.

Sonstiges: an der Oberfläche mittelgroße und kleine Steine $(35 \times 20 \times 15 \mathrm{~cm})$

\section{Forschungsgeschichte}

Im Jahre I955 wurde die Nekropole Novoalekseevka im Rahmen eines archäologischen Grabungspraktikums der Staatlichen Pädagogischen Hochschule „Abaj“ Almaty unter der Leitung von I. I. Kopylov zum Teil untersucht. Nach Angaben von Kopylov bestand das Gräberfeld nicht nur aus Großkurganen, die zwei Nord-Süd verlaufende Ketten bildeten, sondern auch noch aus weiteren vier, westlich gelegenen Kurganketten, die aus Kleinkurganen bestanden. Daher teilte der Ausgräber die Nekropole in seinem Bericht in zwei Teile auf: „Großes Gräberfeld“ und „Kleines Gräberfeld“ (Kopylov I956, 4). Das „Große Gräberfeld“ entspricht der von uns untersuchten Nekropole. Allerdings wurden im Bericht drei große, viereckige Kurgane erwähnt (Kopylov I956, 5). Heute sind dort nur noch zwei davon sichtbar606.

606 Insgesamt konnte vermerkt werden, dass im Jahre I955 das Gräberfeld fast vollständig außerhalb des modernen
Siedlungsgebietes lag und sich dementsprechend in besserem Erhaltungszustand befand. 
Weiterhin wurde der Randbereich der viereckigen Großkurgane während der Untersuchung durch weiße, schwarze und graue Flusskieselsteine markiert, da die Peripherie der Kurgane damals noch ungestört war. Das „Kleine Gräberfeld“ befand sich I,5 km bis 2 km südlich vom Dorf Novoalekseevka (heutiges Bajterek) und westlich der Straße „Novoalekseevka - Talgar“, an der Südgrenze eines Bewässerungskanals, der zwischen der Kolchose „Karl Marx“ und dem Dorf Novoalekseevka angelegt worden war. An der Stelle, an der dieser Kanal nach Nordwesten abbog, befand sich die Nekropole. Das „Kleine Gräberfeld“ bestand aus 35 Kurganen, von denen drei eine viereckige Form aufwiesen. Die restlichen Kurgane hatten eine runde Form. Südlich davon lag einer der viereckigen Kurgane des großen, östlich gelegenen Gräberfeldes. Um diesen viereckigen Kurgan des „Großen Gräberfeldes“ wurden weitere acht Kleinkurgane ${ }^{607}$ festgestellt, die keine systematische Anordnung nachvollziehen ließen. Fast alle Kurgane des „Kleines Gräberfeldes“ waren beraubt.

In unmittelbarer Nähe zur Nekropole Novoalekseevka wurde I883 ein Hort (Abb. I69) entdeckt, welcher aus kupfernen und bronzenen Geräten bestand: dazu zählen ein Sichelmesser (Abb. I69,I), eine einschneidige Schaftlochaxt (Abb. I69,2), ein Tüllenmeißel mit Hohlkehle (Abb. I69,3) und ein Beitel (Abb. 169,4$)^{608}$. Im selben Jahr wurde dort noch ein „kleiner Kessel mit einer Ausgußtülle und einem Griff“ (Kopylov I956, 6) (Abb. I69,5) gefunden. Alle diese Gegenstände wurden gegossen.

I955 wurden auf dem „Kleinen Gräberfeld“ vier Kleinkurgane ausgegraben.

Auflistung der untersuchten Kurgane (Kopylov 1956):

\section{Kurgan № I}

Dm I2 m; H o,4 m

Lage: im Nordbereich der Kleinkurgankette, Io m südlich vom Hauptbewässerungskanal

Form: runde Erhebung

Abhänge: keine Merkmale

Zustand: in der Mitte ein Raubtrichter

Stratigraphie: von oben nach unten

- moderne Humusschicht

- Erdkurganaufschüttung

- gewachsener Boden

Befund: - um Kurganrand liegt ein Steinkreis; Dm io $m$

- rechteckige Grabgrube mit einer Nische entlang der westlichen und nördlichen Wand im Zentrum des Kurgans

- Ausrichtung: W-O

- Maße: unbekannt; Grabtiefe I,45 m, H der Nische $0,55 \mathrm{~m}$

Bestattung: - ein menschliches Skelett, durch die Beraubung zum Teil zerstört; in situ lagen nur Beckenknochen und die Knochen der unteren Extremitäten

- Platzierung: in der Grabnische

- Lage: Rückenstrecker

- Ausrichtung: Kopf nach Westen

- Anthropologische Bestimmung: fehlt

Beigaben (Abb. I7O,I-4) in der Kurganaufschüttung und der Grabverfüllung (gesamte Keramik handgemacht)

- vier Randscherben

- 26 Wandscherben

607 Heute nicht mehr erhalten.
- fünf Wandscherben von dickwandigen Gefäßen

- zwei Schafastragale

- ein Wirbel vom Schaf

Chronologie: Anhand des Fundmaterials ordnet der Ausgräber den Kurgan der Wusun-Periode der jüngeren Eisenzeit, 3. Jh. v. Chr. - 2. Jh. n. Chr., zu (Kopylov I956, II).

\section{Kurgan № 2}

L (Nord- und Südabhänge) I8 m; L (West- und Ostabhänge) I $6 \mathrm{~m}$; $\mathrm{H} \circ, 6 \mathrm{~m}$

Lage: $39 \mathrm{~m}$ S von Kurgan № I

Form: niedrige, viereckige, pyramidenähnliche Form mit abgeflachter Kuppe, die an den vier Haupthimmelsrichtungen orientiert ist

Abhänge: keine Merkmale

Zustand: in der Mitte und im nordöstlichen Bereich des Kurgans jeweils ein Raubtrichter

Stratigraphie: von oben nach unten

- moderne Humusschicht (Mächtigkeit nicht angegeben)

- Löss mit kleinen Kieselsteinen (Mächtigkeit: ca. $0,2 \mathrm{~m}$ )

- Steinschicht aus $20 \times 15 \mathrm{~cm}$ großen Kieselsteinen, die die oberste Schicht der „Pyramide“ bildeten

- „Pyramide“

- gewachsener Boden

- „Pyramide“ (Maße: Seitenlänge unten II,4 m; Seitenlänge oben 8,6 m)

608 Weitere Informationen fehlen. 


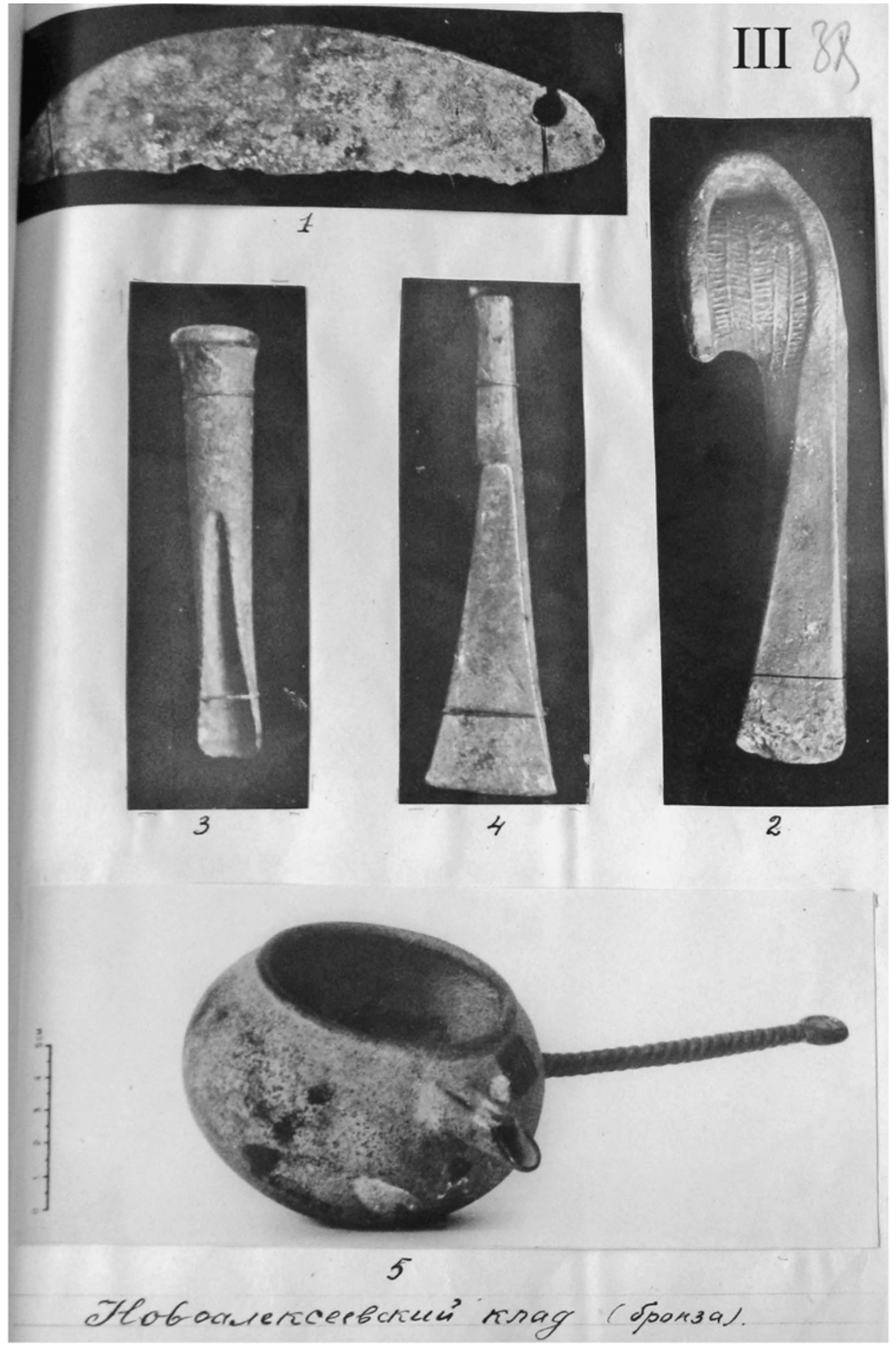

Abb. 169 | Hortfunde (1883) aus der näheren Umgebung des Gräberfeldes Novoalekseevka (Kopylov i956, Taf. III) 

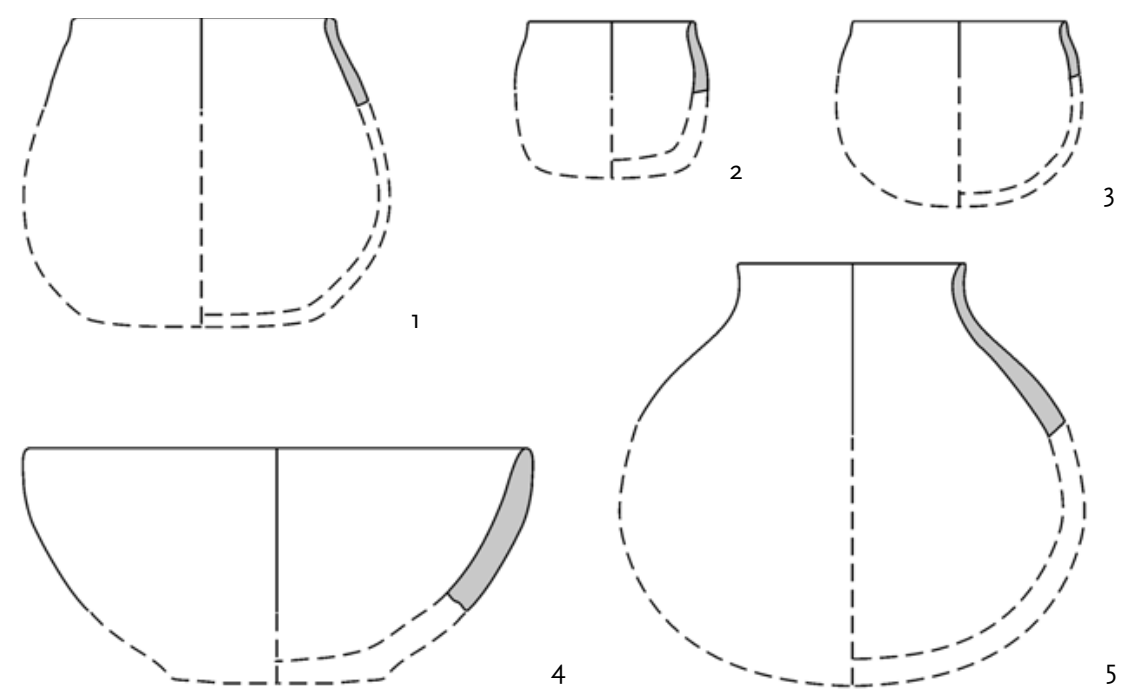

Abb. 170 | Rekonstruktion der Gefäße von Kurganen № I und № 4, ohne Maßstabangaben (I-4 Kurgan I, 5 Kurgan 4; Kopylov 1956, Taf. VI,I-5)

Im Westbereich der „Pyramide“ befanden sich die Überreste einer $0,6 \times 0,7 \mathrm{~m}$ großen, viereckigen Steinkonstruktion.

- Stratigraphie der „Pyramide“ (von oben nach unten)

a. Steinschicht aus eng aneinander liegenden Kieselsteinen (Mächtigkeit - nicht angegeben)

b. Lössschicht mit kleinen Kieselsteinen (Mächtigkeit - nicht angegeben)

c. Steinpackung aus mittelgroßen Kieselsteinen (Mächtigkeit - nicht angegeben)

d. antiker Laufhorizont

e. gewachsener Boden

Befunde: I. - Im nordöstlichen Bereich des Kurgans, ca. $0,3 \mathrm{~m}$ unter der modernen Oberfläche, kam eine Feuerstelle, die aus Holzkohle und Asche bestand, zu Tage.
II. - Unter der „Pyramide“, auf dem antiken Laufhorizont, befanden sich zwei ineinander gebaute, aus Steinen gelegte quatratische Strukturen (Abb. I7I). Beide Quadrate folgten der Orientierung der "Pyramide“ und des Kurgans die Seiten sind an den vier Haupthimmelsrichtungen ausgerichtet worden

- Seitenlänge des äußeren Quadrates IO, $5 \mathrm{~m}$; der Abstand zum „Pyramidenrand" $0,45 \mathrm{~m}$

- Seitenlänge des inneren Quadrates 8,8 m

- Abstand zwischen beiden Quadratumrissen $0,85 \mathrm{~m}$

- die nordöstliche und südöstliche Ecke beider Quadrate wurden durch eine diagonale Linie aus Steinen miteinander verbunden

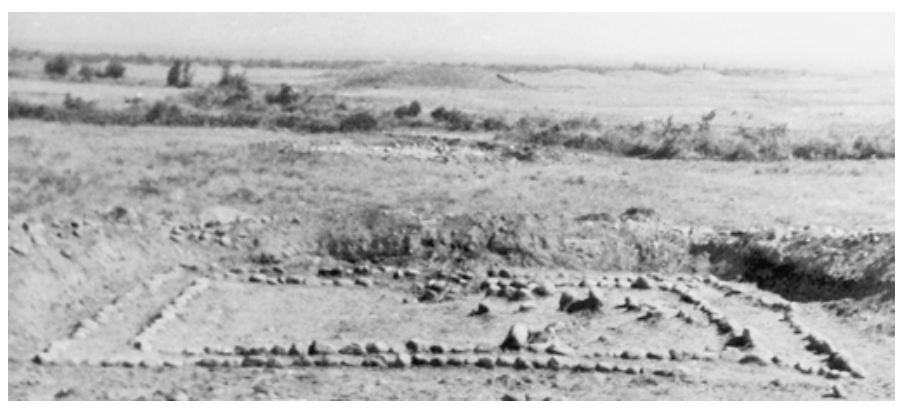

Abb. ודי | „Kleines Gräberfeld“. Kurgan № 2. Konstruktion aus Steinen unter der „Pyramide“(Kopylov I956, Taf. V,7) 
III. - In der Nordostecke der Steinquadrate kam eine Nachbestattung (Nr. I), ohne Grabgrube (in welcher Schicht wurde nicht erwähnt) zum Vorschein.

IV. - Ebenfalls in der Nordostecke des Steinquadrates, allerdings zur Mitte des Kurgans versetzt, befand sich eine weitere grabgrubenlose Nachbestattung (Nr. 2).

V. - rechteckige Grabgrube mit einer Nische entlang der westlichen und nördlichen Wand in der Mitte des Kurgans

- Ausrichtung: W-O

- Maße: unbekannt; die obere Nischengrenze beginnt bei I,52 $\mathrm{m}$ unter der modernen Oberfläche

Bestattungen:

Nachbestattung Nr. I

- Skelett eines Kindes

- Lage: Rückenstrecker

- Ausrichtung: Kopf nach Westen

- Anthropologische Bestimmung: fehlt

- ohne Beigaben

Nachbestattung Nr. 2

- Skelett eines Kindes (durch die Beraubung beschädigt; in situ lagen nur die Knochen des Brustbereiches)

- Lage: Rückenstrecker

- Ausrichtung: Kopf nach Westen

- Anthropologische Bestimmung: fehlt

- ohne Beigaben

* Die mittlere Grabgrube wies gar keine Knochen auf.

Funde: gesamte Keramik handgemacht Kurgan- und „Pyramidenaufschüttung“

- drei Randscherben

- eine Randscherbe, rot verstrichen

- eine Randscherbe mit einer Wulst, außen mit hellgelber Engobe, innen verstrichen

- eine Randscherbe aus gelbem Ton, außen mit brauner Engobe, innen verstrichen

- zwei Wandscherben

- eine Wandscherbe mit äußerer dunkelbrauner Engobe

- eine Bodenscherbe

- Fragment eines Gefäßes, rot verstrichen In der Verfüllung der zentralen Grabgrube

- eine Randscherbe, gelb verstrichen

- eine Wandscherbe

- Fragment eines Gefäßes, rot verstrichen

- Fragment eines dickwandigen Gefäßes mit roter Engobe

- Fragment eines dünnwandigen Gefäßes mit roter Engobe

An der westlichen Nischenwand

- zwei Randscherben; an der Innenseite einer Scherbe Holzkohle und verbrannte Speisereste
- eine Bodenscherbe von demselben Gefäß

* Das Gefäß: rechteckiges Gefäß mit rundem Boden; außen am Boden wurden Fußlöcher eingeprägt, allerdings sind die Gefäßstandfüße nicht erhalten

Chronologie: Anhand des Fundmaterials ordnet der Ausgräber den Kurgan der Wusun-Periode der jüngeren Eisenzeit, 3. Jh. v. Chr. - 2. Jh. n. Chr., zu (Kopylov I956, I9).

\section{Kurgan № 3}

Maße: ?

Lage: in der Nähe von Kurgan № 2

Form: niedrige viereckige, pyramidenähnliche Form mit abgeflachter Kuppe, die an den vier Haupthimmelsrichtungen orientiert ist

Weitere Angaben fehlen; der Kurgan wurde nicht ausgegraben.

\section{Kurgan № 4}

Dm 3 m; H o,I m

Lage: ?

Form: abgerundete steinerne Erhebung

Abhänge: keine Merkmale

Zustand: keine Senke, kein Raubtrichter

Stratigraphie: von oben nach unten

- Steinabdeckung

- gewachsener Boden

Befund: keine $\rightarrow$ Kenotaph

Funde: Es stammen lediglich Keramikscherben (Abb. I70,5); aus der Kurganaufschüttung, drei davon sind Randscherben (gesamte Keramik handgemacht). Chronologie: Wusun-Periode der jüngeren Eisenzeit (Kopylov I956, 7)

\section{Kurgan № 7}

L (Nord- und Südabhänge) I2 m; L (West- und Ostabhänge) $8 \mathrm{~m}$; $\mathrm{H}$ ०,2 $\mathrm{m}$

Lage: $75 \mathrm{~m}$ südwestlich von Kurgan № 2

Form: niedrige, viereckige Erhebung

Abhänge: keine Merkmale

Zustand: kein Raubtrichter

Stratigraphie: von oben nach unten

- moderne Humusschicht (Mächtigkeit $\mathrm{O}, \mathrm{I} \mathrm{m})$

- Löss mit kleinen Kieselsteinen (Mächtigkeit $\mathrm{o}, \mathrm{I} \mathrm{m}$ )

- gewachsener Boden

Baukonstruktionselemente: - zur Westseite des Kurgans ist eine Steinreihe angebaut (Länge und Form sind unbekannt)

- unter der Kurganaufschüttung, auf dem gewachsenen Boden, wurde aus großen Kieselsteinen ein Steinring von $6 \mathrm{~m}$ Dm angelegt

Befund: keine $\rightarrow$ Kenotaph

Funde: keine

Chronologie: ? 
In Vorbereitung auf die Studie „Denkmäler der Geschichte und der Kultur des Gebietes Almaty“ wurde vom Archäologischen Institut „A.Ch. Margulan“, Almaty, im Jahre 2004 in der Umgebung der Nekropole eine Geländeuntersuchung durchgeführt. Die Arbeit verlief unter der Leitung von K. Bajpakov und B. Nurmuchanbetov.

Außer den Kurganen, die auch von uns untersucht wurden, sind im Jahre 2004 noch drei weitere Kurgane, die 260-380 m W-NW vom Gräberfeld (bzw. vom Kurgan 2) entfernt lagen, aufgenommen worden.

Auflistung der aufgenommenen Kurgane (Bajpakov u.a. 2005b):

\section{Kurgan o०I}

Dm 22 m; H 2,6 m

Lage: N43 23.608 E77 I3.97I

Form: abgerundete plattformähnliche Gestalt mit abge-

flachter Kuppe

Abhänge: ?

Zustand: in der Mitte ein Raubtrichter

Sonstiges: an der Oberfläche einzelne mittelgroße

Steine

* Weitere Angaben fehlen

Vorläufige Datierung: 5.-3. Jh. v. Chr.

\section{Kurgan 002}

Dm NO-Hügel II m; Dm SW-Hügel 9,5 m; H o,7 m

Lage: N43 23.538 E77 I3.893

Form: doppelte achtförmige abgerundete Erhebung

Abhänge: keine Merkmale
Zustand: in der Mitte beider Kuppen ein Raubtrichter * Weitere Angaben fehlen

Vorläufige Datierung: 5.-3. Jh. v. Chr.

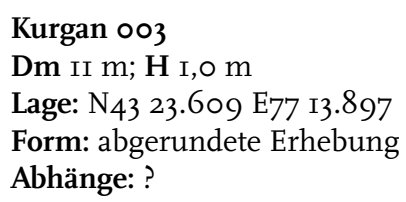

Zustand: in der Mitte und an der Nordseite des Kurganrandes jeweils ein Raubtrichter sowie an der Westseite des Kurganrandes, in einem Abstand von o,5 m einander, noch zwei weitere Raubtrichter

Sonstiges: an der Oberfläche einzelne mittelgroße Steine

* Weitere Angaben fehlen

Vorläufige Datierung: 5.-3. Jh. v. Chr.

Lit.: Ageeva I957, II; Akišev K.A. I974, 6I; Archeologičeskaja karta Kazachstana I960, 308; Bajpakov u.a. 2005b, 5-I9; Kopylov I956, 4-21; Kopylov I958, I58-I77; Ongar 2008, 221, 224; Samašev u.a. 2005a, 38.

Kurgankette Sarytau „A“ [FEZ] (Abb. I72-I73; Karte 3 Nr. 70): ALT I865 m N43 00.852 E79 I7.367; Gebiet Almaty (kasach. Алматы облысы), Rajymbekskij rajon (kasach. Райымбек ауданы); Ausmaß $\mathrm{N}-\mathrm{S} 330 \times \mathrm{O}-\mathrm{W} 480 \mathrm{~m}$.

Die Kette befindet sich am Ostrand des Hochplateaus Kegen (kasach. Кеген), auf einer Flachebene an der Südwestseite der TemirlikBerge (kasach. Темирлик), südlich vom Berg Saryžaz (kasach. Сарыжаз) und westlich der Bergkuppe 2054,8, am rechten, östlichen Ufer des Flusses Kegen (kasach. Кеген). Die Kurgane stehen $195 \mathrm{~km}$ ostsüdöstlich der Stadt Almaty (kasach. Алматы), 4,5 km östlich des Dorfes Kegen (kasach. Кеген) und 3,8 km südöstlich des Dorfes Oktjabr' (russ. Октябрь).

Die von NO nach SW verlaufende Kette be-

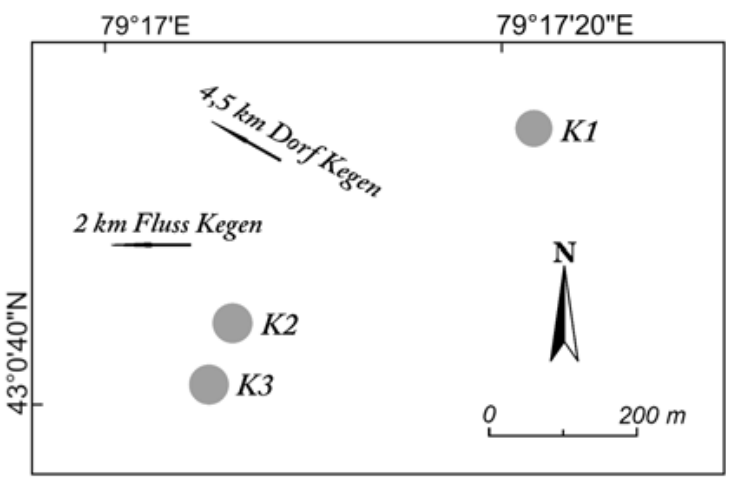

Abb. 172 | Plan der Kurgankette Sarytau „A“ steht aus drei Kurganen, wobei der nördlichste Kurgan abseits von zwei weiteren steht. Alle Kurgane haben drei steile und einen (immer südlichen) sanften Abhang. Der Durchmesser der Kurgane schwankt zwischen $45 \mathrm{~m}$ und $52 \mathrm{~m}$, die Höhe zwischen 3,0 $\mathrm{m}$ und 3,5 m. Nur ein Kurgan weist eine Senke, verursacht von einem Raubtrichter, auf. 
Anhand der Struktur und der äußeren Erscheinungsform können alle Kurgane des Gräberfeldes der sakischen Periode der Früheisenzeit zugeordnet werden.

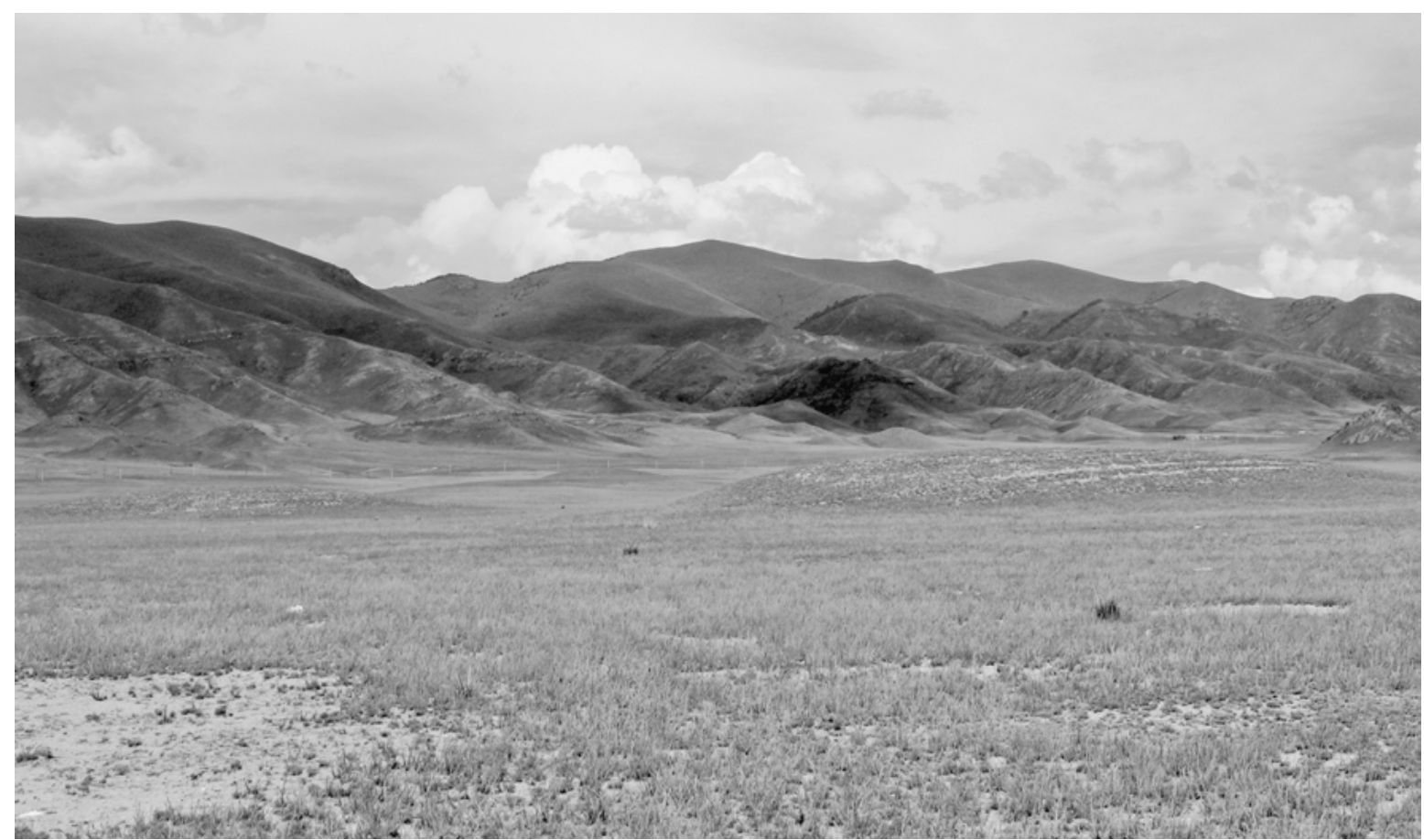

Abb. 173 | Kurgankette Sarytau „A“. Blick von W

Kurgancharakteristik:

\section{Kurgan I}

Dm 45 m; H 3,5 m

Lage: N43 00.852 E79 I7.367; nördlichster Kurgan der Kette

Form: abgerundet, plattformähnlich mit abgeflachter Kuppe

Abhänge: drei steile, südlicher sanft

Zustand: in der Mitte eine Senke

Sonstiges: keine Steine an der Oberfläche; einzelne große Steine (ab $50 \times 30 \times 15 \mathrm{~cm})$ am Kurganrand

\section{Kurgan 2}

Dm 52 m; H 3 m

Lage: N43 00.722 E79 I7.057
Form: abgerundet, plattformähnlich mit abgeflachter Kuppe

Abhänge: drei steile, südlicher sanft

Zustand: keine Senke, kein Raubtrichter

Sonstiges: ganze Oberfläche ist mit mittelgroßen Steinen $(\mathrm{ab} 40 \times 20 \times$ IO $\mathrm{cm})$ bedeckt

\section{Kurgan 3}

Dm 49 m; H 3 m

Lage: N43 00.677 E79 I7.03I

Form: abgerundet, plattformähnlich mit abgeflachter Kuppe

Abhänge: drei steile, südlicher sanft

Zustand: keine Senke, kein Raubtrichter

Sonstiges: gesamte Oberfläche mit mittelgroßen Steinen $(\mathrm{ab} 30 \times \mathrm{IO} \times 5 \mathrm{~cm})$ bedeckt 
Gräberfeld Saty [FEZ] (Abb. I74; Karte 3 Nr. 45): ALT I470 m N43 04.6I8 E78 22.8I9; Gebiet Almaty (kasach. Алматы облысы), Rajymbekskij rajon (kasach. Райымбек ауданы); Ausmaß $\mathrm{N}-\mathrm{S}$ I42 $\times$ O-W I5 $8 \mathrm{~m}$.

Die Nekropole befindet sich im Tal des Flusses Čilik (kasach. Шелек), die zwischen den Bergketten Transili- (kasach. Iле) und Kungej-Alatau (kasach. Күнгей Алатауы) liegt, südlich vom Berg Beskaragaj (kasach. Бесқарағай) am Gebirgsrücken des Akšolak (kasach. Ақшолақ), auf der ersten, linken, nördlichen Uferterrasse des Čilik. Die Kurgane stehen I2I km ostsüdöstlich der Stadt Almaty (kasach.

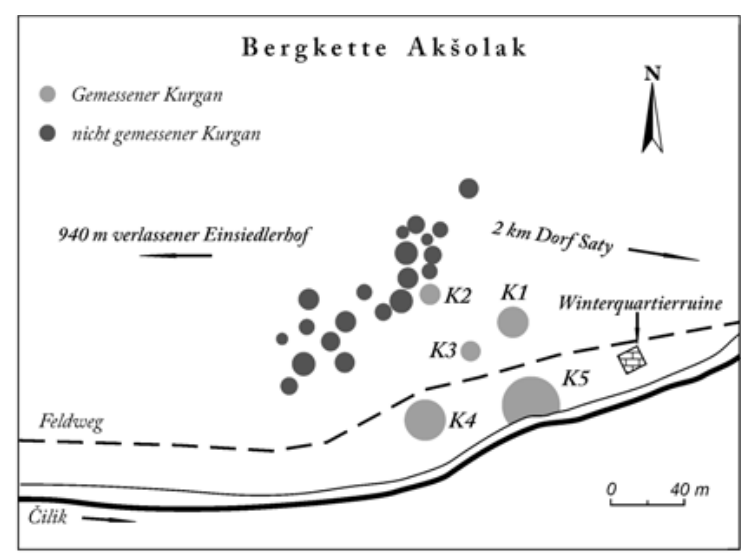

Abb. 174 | Lageskizze des Gräberfeldes Saty Алматы), $2 \mathrm{~km}$ westnordwestlich des Dorfes Saty (kasach. Саты) und $940 \mathrm{~m}$ östlich des verlassenen Einsiedlerhofes entfernt. Flussabwärts, $40 \mathrm{~m}$ nordöstlich vom Kurgan 5 (nach der Arbeitsnummerierung), zeigte sich die Ruine eines Winterquartiers („Zimnik“) aus ethnographischer Zeit.

Die gesamte Nekropole zählt 25 mittelgroße und kleine Kurgane. Die Kurgane bilden mehrere NO-SW verlaufende Ketten. Die fünf größten Kurgane stehen im südöstlichen Bereich der Nekropole und befinden sich dem Fluss am nächesten (Abb. I75). Der Kurgan 5 steht direkt an der Uferkannte, so dass ein Drittel des Kurgans bereits fehlt.

Die restlichen 20 Kurgane sind Kleinkurgane mit einem Durchmesser von 6-8 m und einer Höhe von $0,2-0,5 \mathrm{~m}$. Aufgrund der geringeren Maße wurden diese Kleinkurgane nicht vollständig dokumentiert. Der Durchmesser der größeren Kurgane schwankt zwischen I2 m und 3I m, die Höhe misst von 0,4 m bis zu 3,7 m. Sie alle weisen einen Raubtrichter auf. Die drei größten Kurgane haben drei steile

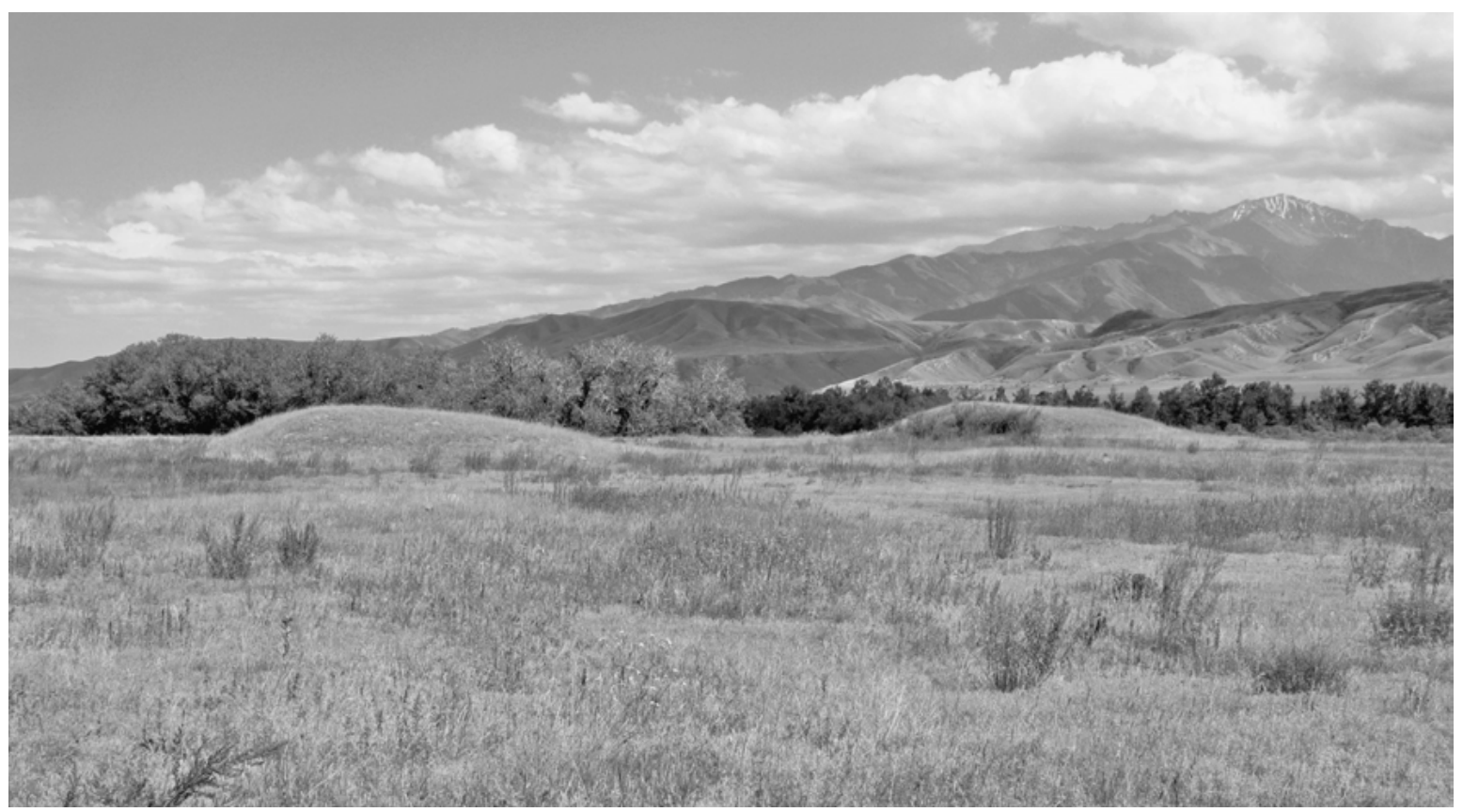

Abb. 175 | Das Gräberfeld Saty. Mittelgroße Kurgane im südöstlichen Bereich. Blick von NW 
und einen (immer südlichen) sanften Abhang. Bei zwei kleineren konnten keine solchen Merkmale festgestellt werden.

Anhand der Landschaftsplatzierung, der Struktur und der äußeren Erscheinungsform können alle Kurgane des Gräberfeldes der sakischen Periode der Früheisenzeit zugeordnet werden.

Kurgancharakteristik:

Kurgan I

Dm I6 m; H 3 m

Lage: N43 04.6I8 E78 22.8I9

Form: abgerundet, plattformähnlich mit abgeflachter

Kuppe

Abhänge: drei steile, südlicher sanft

Zustand: in der Mitte ein Raubtrichter

Sonstiges: einzelne mittelgroße Steine $(\mathrm{ab} 30 \times$ Io $\times$ $5 \mathrm{~cm}$ ) an der Oberfläche

\section{Kurgan 2}

Dm I2 m; H o,4 m

Lage: N43 04.627 E78 22.786

Form: abgerundete, flache Aufschüttung

Abhänge: keine Merkmale

Zustand: in der Mitte eine Senke

Sonstiges: einzelne mittelgroße Steine $(\mathrm{ab} 40 \times 20 \times$ Io $\mathrm{cm}$ ) an der Oberfläche

\section{Kurgan 3}

Dm I2 m; H o,5 m

Lage: N43 04.6ro E78 22.80I

Form: abgerundete, flache Aufschüttung

Abhänge: keine Merkmale
Zustand: in der Mitte ein Raubtrichter

Sonstiges: einzelne mittelgroße Steine $(\mathrm{ab} 30 \times \mathrm{IO} \times$ $5 \mathrm{~cm}$ ) an der Oberfläche

\footnotetext{
Kurgan 4

Dm 2I m; H 2 m

Lage: N43 04.590 E78 22.782

Form: abgerundet, plattformähnlich mit abgeflachter Kuppe

Abhänge: drei steile, südlicher sanft

Zustand: in der Mitte ein Raubtrichter

Sonstiges: gesamte Oberfläche mit Steinen $(\mathrm{ab} 80 \times 40$ $\times 20 \mathrm{~cm}$ bis zum Schotter) bedeckt

Kurgan 5

Dm 3I m; H 3,7 m

Lage: N43 04.593 E78 22.826

Form (rekonstruiert): niedrig, abgerundet, plattformähnlich mit abgeflachter Kuppe

Abhänge: drei steile, südlicher fehlt

Zustand: auf der Kuppe ein Raubtrichter; Südteil bereits in den Fluss abgestürzt

Sonstiges: einzelne mittelgroße Steine $(\mathrm{ab} 40-30 \times$ I5-10 $\times 5 \mathrm{~cm}$ ) an der Oberfläche
}

Gräberfeld Šyrganak-2 [FEZ] (Abb. I76-I77; Karte 3 Nr. 67): ALT I842 m N42 58.515 E79 04.623; Gebiet Almaty (kasach. Алматы облысы), Rajymbekskij rajon (kasach. Райымбек ауданы); Ausmaß N-S $3600 \times \mathrm{O}-\mathrm{W} 330 \mathrm{~m}$.

Die Nekropole befindet sich im Nordwesten des Hochplateaus Kegen (kasach. Кеген), zwischen den Flüssen Žarganak (kasach. Жарганак) und Karkara (kasach. Қарқара). Durch die Asphaltstraße Šyrganak (kasach. Шырғанақ) - Böleksaz (kasach. Бөлексаз)/Kegen (kasach. Кеген) wurde das Gräberfeld fast in der Mitte in eine Nord- und eine Südhälfte geteilt. Das Gräberfeld liegt I78 km ostsüdöstlich der Stadt Almaty (kasach. Алматы), 13,2 km südwestlich des Dorfes Kegen, 2 km nordöstlich des Dorfes Šyrganak und 5,4 km nordwestlich des Dorfes Böleksaz.

Das Gräberfeld besteht aus acht Kurganen, die eine N-S verlaufende Kette bilden. Kurgan 3 (nach der Arbeitsnummerierung) steht leicht nach Westen von der Kette versetzt. Da sich die gesamte Nekropole auf einem Acker befindet, ist die Peripherie der Kurgane zerstört und nur die größeren Kurgane sind erhalten.

Der Durchmesser der Kurgane schwankt zwischen $24 \mathrm{~m}$ und Io4 m, die Höhe zwischen 2,2 $\mathrm{m}$ und II m. Alle Kurgane haben drei steile und einen sanften Abhang. Bei vier Kurganen wurde der sanfte Abhang exakt nach Süden ausgerichtet, bei drei Kurganen - nach Südsüdosten und bei einem Kurgan nach Südosten. Alle Kurgane weisen einen oder mehrere Raubtrichter auf.

Anhand der Struktur und der äußeren Erscheinungsform können die Kurgane der Nekropole der sakischen Periode der Früheisenzeit zugeordnet werden. 


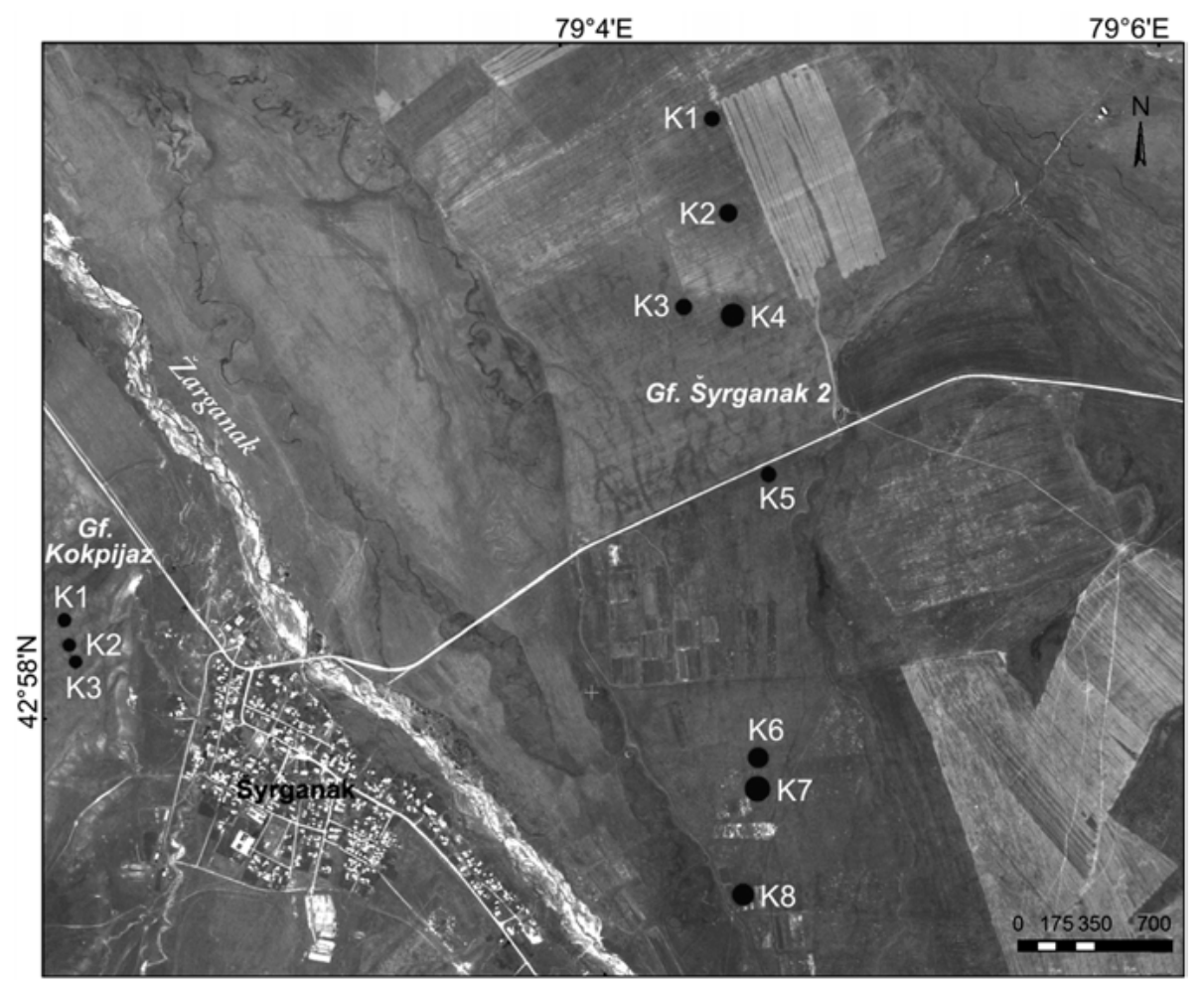

Abb. 176 | Übersicht des Gräberfeldes Šyrganak-2 (SPOT)

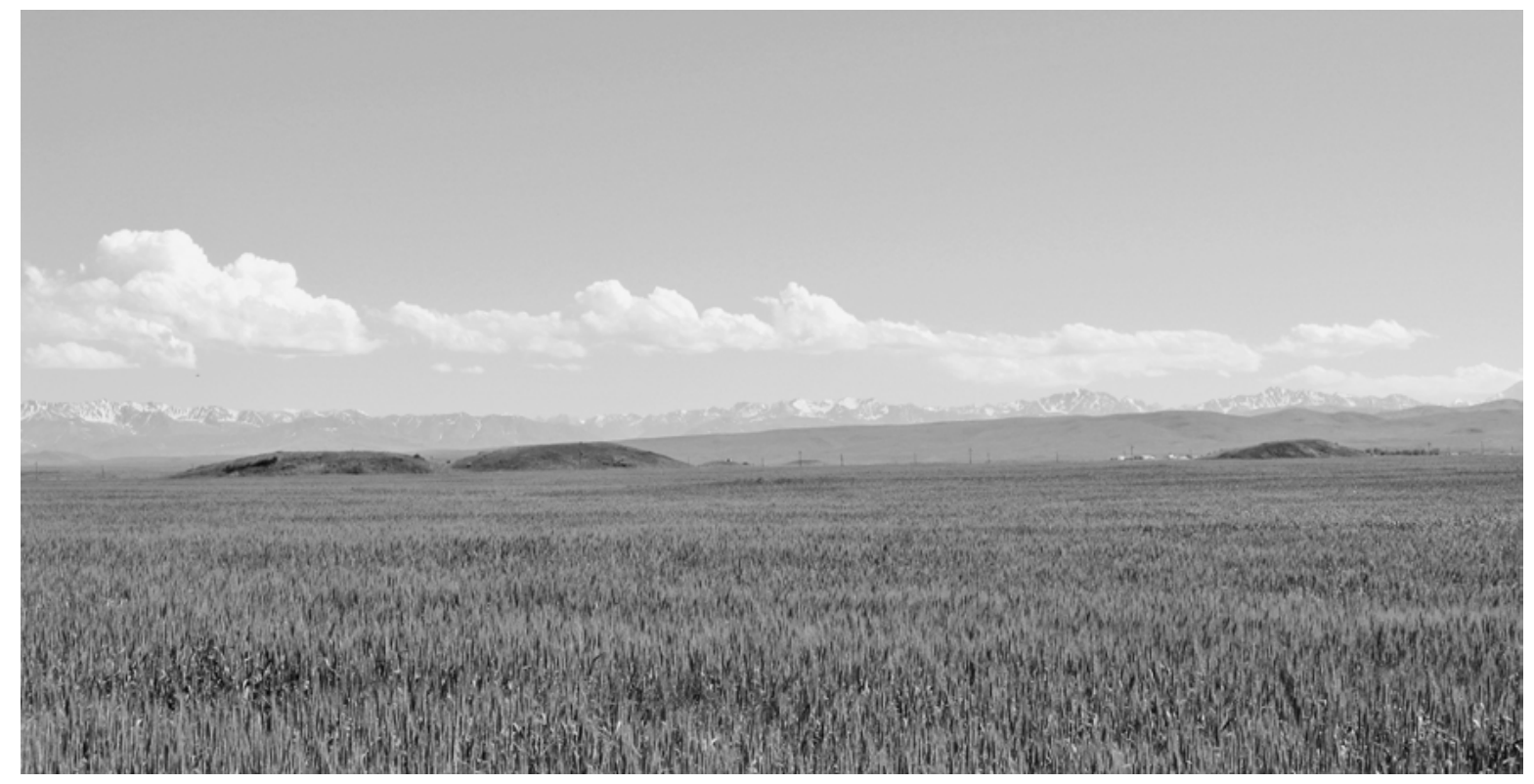

Abb. 177 | Das Gräberfeld Šyrganak-2. Blick von NW 

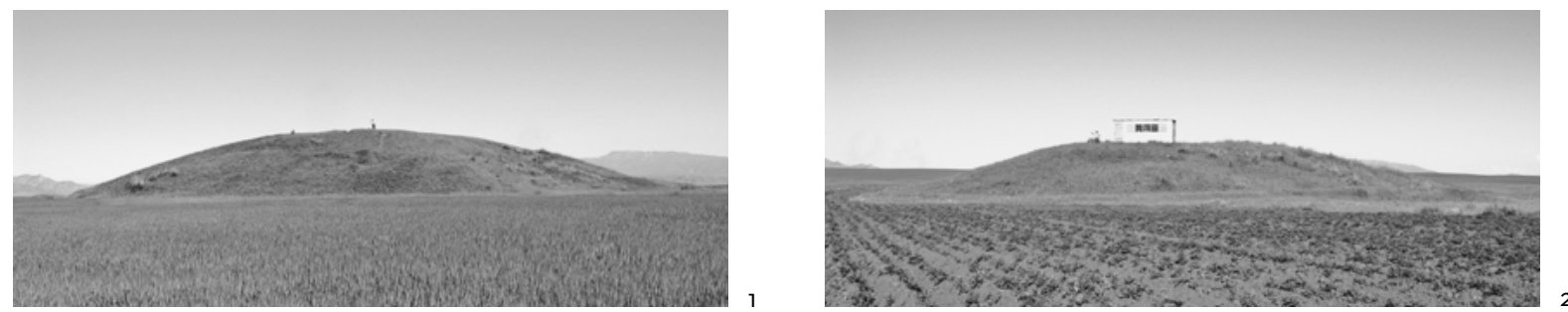

Abb. 178 | Kurgane des Gräberfeldes Šyrganak-2, Blick von W; I. Kurgan 4; 2. Kurgan 7

Kurgancharakteristik:

Kurgan I

Dm 46 m; H 3 m

Lage: N42 59.400 E79 04.485; nördlichster Kurgan der Kette

Form: abgerundet, plattformähnlich mit abgeflachter Kuppe

Abhänge: drei steile, südsüdöstlicher sanft

Zustand: auf der Kuppe mehrere Raubtrichter; Peripherie überpflügt

Sonstiges: keine Steine an der Oberfläche

\section{Kurgan 2}

Dm 54 m; H 6 m

Lage: N42 59.162 E79 04.525

Form: abgerundet, plattformähnlich mit abgeflachter Kuppe

Abhänge: drei steile, südsüdöstlicher sanft

Zustand: in der Mitte ein Raubtrichter; Peripherie überpflügt

Sonstiges: keine Steine an der Oberfläche

\section{Kurgan 3}

Dm 64 m; H 8 m

Lage: N42 58.938 E79 04.356

Form: abgerundet, plattformähnlich mit abgeflachter Kuppe

Abhänge: drei steile, südöstlicher sanft

Zustand: von der Mitte zum Ostrand verläuft ein Raubgraben; Peripherie überpflügt

Sonstiges: einzelne kleine Steine an der Oberfläche

Kurgan 4 (Abb. I78,I)

Dm IO4 m; H iI m

Lage: N42 58.913 E79 04.529

Form: abgerundet, plattformähnlich mit abgeflachter Kuppe

Abhänge: drei steile, südsüdöstlicher sanft

Zustand: in der Mitte ein gewaltiger Raubtrichter; Peripherie überpflügt

Sonstiges: einzelne mittelgroße $(\mathrm{ab} 40 \times \mathrm{I} 5 \times \mathrm{IO} \mathrm{cm})$ und kleine Steine bis zum Schotter an der Oberfläche

\section{Kurgan 5}

Dm 24 m; H 2,2 m

Lage: N42 58.515 E79 04.623

Form: abgerundet, plattformähnlich mit abgeflachter Kuppe

Abhänge: drei steile, südlicher sanft

Zustand: an der Oberfläche vier Raubtrichter

Sonstiges: einzelne kleine Steine $(\mathrm{ab} 20 \times 10 \times 5 \mathrm{~cm})$ an der Oberfläche

\section{Kurgan 6}

Dm 44 m; H 3 m

Lage: N42 57.823 E79 04.54I

Form: abgerundet, plattformähnlich mit abgeflachter Kuppe

Abhänge: drei steile, südlicher sanft

Zustand: auf der Kuppe mehrere Raubtrichter; die Peripherie ist überpflügt

Sonstiges: keine Steine an der Oberfläche

Kurgan 7 (Abb. I78,2)

Dm 72 m; H 7 m

Lage: N42 57.748 E79 04.534

Form: abgerundet, plattformähnlich mit abgeflachter Kuppe

Abhänge: drei steile, südlicher sanft

Zustand: in der Mitte ein gewaltiger Raubtrichter; Peripherie überpflügt; auf der nordwestlichen Hälfte der Kuppe steht eine Bude (!)

Sonstiges: keine Steine an der Oberfläche

\section{Kurgan 8}

Dm 77 m; H 6 m

Lage: N42 57.490 E79 04.460; südlichster Kurgan der Kette

Form: abgerundet, plattformähnlich mit abgeflachter Kuppe

Abhänge: drei steile, südlicher sanft

Zustand: in der Mitte ein gewaltiger Raubtrichter; Peripherie überpflügt

Sonstiges: keine Steine an der Oberfläche 
Forschungsgeschichte und Bemerkungen

Im Jahre 2005 wurden die Kurgane des Gräberfeldes Šyrganak-2 im Laufe einer Revision der archäologischen Bodendenkmäler im Rajymbekskij rajon des Gebietes Almaty vom Turgen-Forschungsteam der Almaty Survey-Expedition (APAЭ) unter der Leitung von A. Gorjačev zum ersten Mal dokumentiert (Bajpakov u.a. 2006, 224-227). Es wurden eine Beschreibung und ein topographischer Plan der Kurgane hergestellt. Jedoch wurden die untersuchten Kurgane zu unterschiedlichen Kurgangruppen, ja sogar Gräberfeldern zugeordnet.

Liste der Fundorte609 (Bajpakov u.a. 2006):

FEZ Gf. Šyrganak-2 (russ. Шырганак-II): Bajpakov u.a. 2006, 224, Abb. 96; ALT 284I m, N42 58'69,3" E79 04'54,I"6ro; *entspricht dem Topoi Survey 2009 - Gf. Šyrganak-2 KI, K2, K3 und K4.

FEZ Ein Kurgan 3,2 km nördlich vom Dorf Šyrganak: Bajpakov u.a. 2006, 226, Abb. 97; ALT I840 m, N42 58'45,3" E79 04'32,o"; *entspricht dem Topoi Survey 2009 - Gf. Šyrganak-2 K5.

FEZ Gf. Kokpijaz-I (russ. Кокпияз-I): Bajpakov u.a. 2006, 227, Abb. 98; ALT I86I m, N42 57'80,6” E79 04'56,8”; *entspricht dem Topoi Survey 2009 - Gf. Šyrganak-2 K6, K7 und K8.

Lit.: Bajpakov u.a. 2006, 224-227.

Gräberfeld Taučilik-6 [FEZ und frühtürkische Periode] (Abb. I79-I80; Karte 3 Nr. 42): ALT I607 m N43 02.797 E78 г5.93і; Gebiet Almaty (kasach. Алматы облысы), Rajymbekskij rajon (kasach. Райымбек ауданы); Ausmaß N-S $500 \times$ O-W $800 \mathrm{~m}$.

Die Nekropole befindet sich im Tal des Flusses Čilik (kasach. Шелек), die zwischen den Bergketten Transili- (kasach. Іле) und Kungej-Alatau (kasach. Күнгей Алатауы) liegt. Die Tumuli stehen südlich vom Gebirgsrücken Akšolak (kasach. Ақшолақ), auf der dritten, linken, nördlichen Uferterrasse des Čilik. Die Kurgane finden sich iı2 km ostsüdöstlich der Stadt Almaty (kasach. Алматы), І2,4 km westsüdwestlich des Dorfes Saty (kasach. Саты), zwischen zwei verlassenen Einsiedlerhöfen.

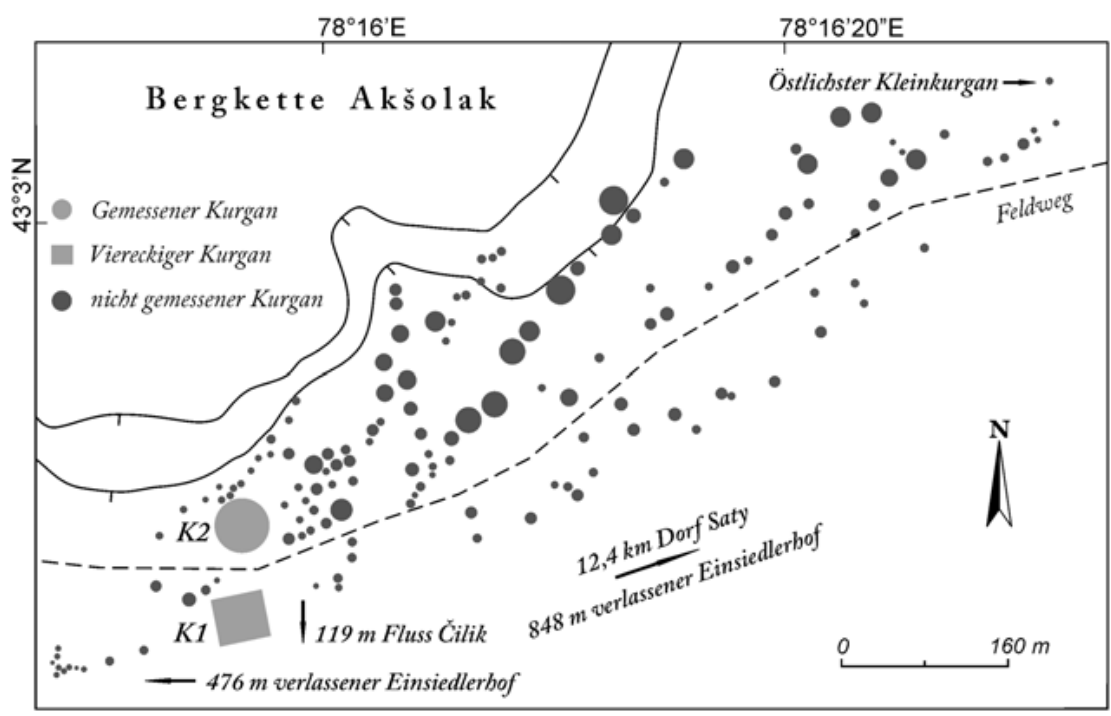

Abb. 179 | Plan des Gräberfeldes Taučilik-6 (z.T. nach Bajpakov u.a. 2006, I53)

609 Am Sommer 2009 führte an dem Ort auch Topoi (A. Gass) in Zusammenarbeit mit dem Archäologischen Institut „A. Ch. Margulan“, Almaty (B. Nurmuchanbe- tov, Z. Samašev) ein Survey durch, der hier als „Topoi Survey 2009" bezeichnet wird. 6ro Grad, Minuten, Sekunden - System. 
Die gesamte Nekropole zählt zwei große und I44 kleine Kurgane. Die Kleinkurgane bilden zehn NO-SW verlaufende Ketten. Ihr Durchmesser schwankt zwischen 4 und $30 \mathrm{~m}$ und die Höhe misst 0,2-2,० m. Fast alle Kleinkurgane weisen einen Raubtrichter auf. Die östlichsten Kurgane des Gräberfeldes, die den Verlauf der Ketten erweiterten, stellen statt abgerundeten Erhebungen, wie die westlich gelegenen Kleinkurgane, flache quadratische Umfriedungen dar. Daher konnte angenommen werden, dass die östlich gelegenen Kurgane in der späteren, frühtürkischen Periode gebaut worden sind. Aufgrund der geringen Größe wurden die Kleinkurgane nicht komplett dokumentiert. Die zwei größten Kurgane liegen im südwestlichen Bereich der Nekropole. Der Kurgan I (nach der Arbeitsnummerierung) weist eine viereckige Form mit abgeflachter Kuppe auf. Die Seiten des Kurgans sind grob an den vier Haupthimmelsrichtungen orientiert. Die Seitenlänge bzw. der Durchmesser der größeren Kurgane misst $43 \mathrm{~m}$ und $52 \mathrm{~m}$, die Höhe $4 \mathrm{~m}$ und $5 \mathrm{~m}$. Beide Kurgane weisen mindestens einen Raubtrichter auf und haben drei steile und einen (immer südlichen) sanften Abhang.

Anhand der Struktur und der äußeren Erscheinungsform können die Kurgane der Nekropole der sakischen Periode der Früheisenzeit und zur frühtürkischen Periode des frühen Mittelalters zugeordnet werden.

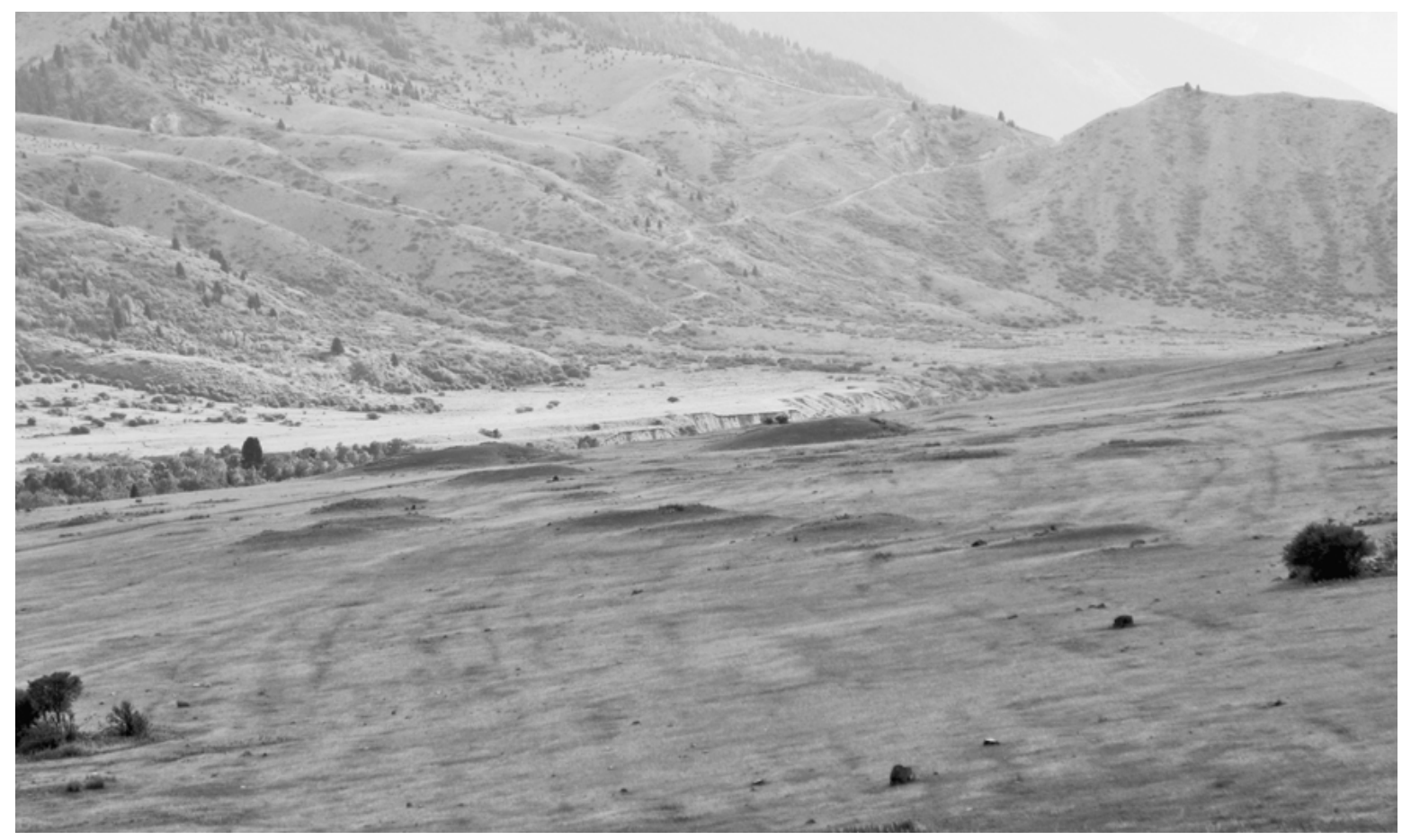

Abb. 180 | Das Gräberfeld Taučilik-6. Blick von NO

Kurgancharakteristik:

\section{Kurgan I}

Seitenlänge $43 \mathrm{~m} ; \mathrm{H} 4 \mathrm{~m}$

Lage: N43 02.797 E78 I5.93I

Form: viereckig, pyramidenähnlich mit abgeflachter Kuppe

Abhänge: drei steile, südlicher sanft

Zustand: in der Mitte und in der Südostecke jeweils ein Raubtrichter
Sonstiges: die Abhänge des Kurgans sind grob an den vier Haupthimmelsrichtungen orientiert; Oberfläche mit mittelgroßen und kleinen (bis zu Schottergröße) Steinen bedeckt; An beiden nördlichen Seitenkanten der pyramidenförmigen Kurganaufschüttung sind die Steine von der Kurgankrepis sichtbar. 


\section{Kurgan 2}

Dm 52 m; H 5 m

Lage: N43 02.842 E78 I5.939

Form: abgerundet, plattformähnlich mit abgeflachter Kuppe

Lit.: Bajpakov u.a. 2006, I53.

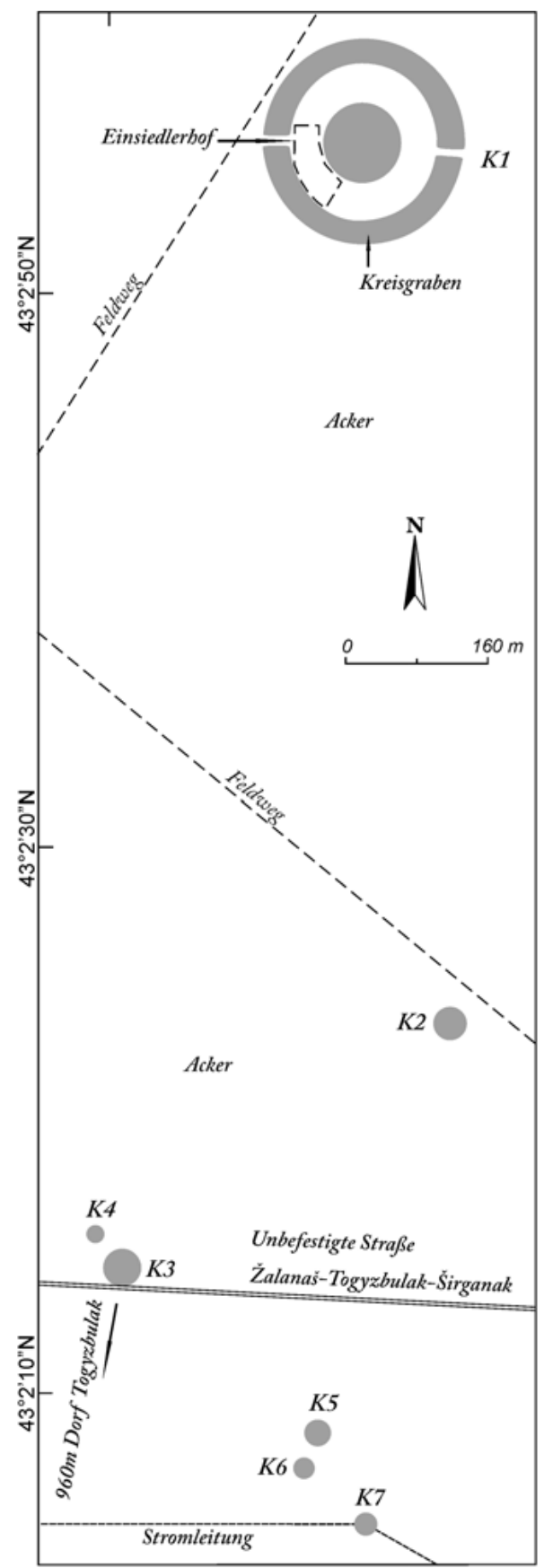

Abb. 181 | Plan des Gräberfeldes Togyzbulak
Abhänge: drei steile, südlicher sanft

Zustand: in der Mitte ein Raubtrichter

Sonstiges: die Oberfläche ist mit mittelgroßen (ab $50 \times$ $30 \times 15 \mathrm{~cm}$ ) Steinen bedeckt

Gräberfeld Togyzbulak [FEZ] (Abb. I8I-I82; Karte 3 Nr. 46): ALT I840 m N43 02.9I4 E78 43.503; Gebiet Almaty (kasach. Алматы облысы), Rajymbekskij rajon (kasach. Райымбек ауданы); Ausmaß N-S I700 × O-W $400 \mathrm{~m}$.

Die Nekropole befindet sich im Südwesten des Talkessels Žalanaš (kasach. Жалаңаш), an der Nordseite der Bergkette Kungej-Alatau (kasach. Күнгей Алатауы), westlich des Čaryn Canyon (kasach. Шарын), auf dem linken, westlichen Ufer des Šet-Merke (kasach. Шет Меркі). Durch den Bau der unbefestigten Straße Žalanaš (kasach. Жалаңаш) - Togyzbulak (kasach. Тоғызбұлақ) - Šyrganak (kasach. Шырғанақ) wurde das Gräberfeld in der Südhälfte quer geteilt. Die Nekropole liegt $149 \mathrm{~km}$ ostsüdöstlich von der Stadt Almaty (kasach. Алматы) entfernt. Der nördlichste Kurgan befindet sich 2,5 km nördlich des Dorfes Togyzbulak, die drei südlichsten Kurgane liegen an dessen Nordgrenze. Das Gräberfeld besteht aus sieben Kurganen, die eine N-S verlaufende Kette bilden. Die Kurgane 3 und 4 (nach der Arbeitsnummerierung) stehen leicht nach Westen versetzt. Da sich die Nordhälfte der Nekropole auf

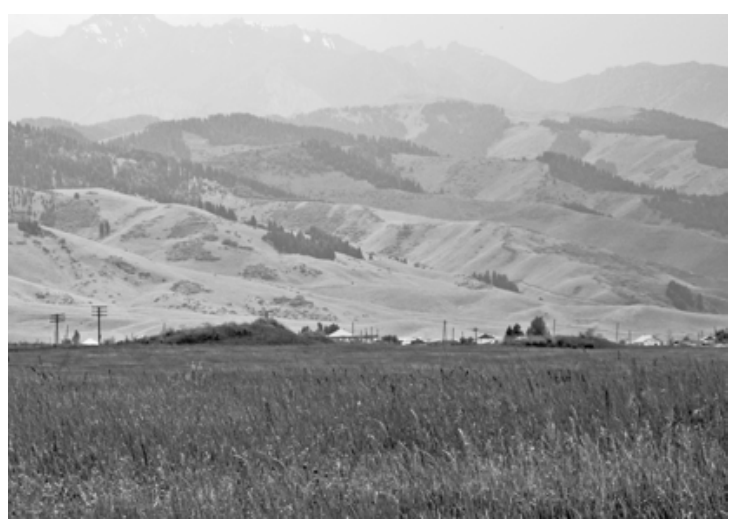

Abb. 182 | Das Gräberfeld Togyzbulak. Blick von NO 
einem Acker befindet, ist die Peripherie der Kurgane zerstört. Die Kette weist keine architektonischen Merkmale, mit Ausnahme des nördlichsten Kurgans (KI) auf. Er ist auch gleichzeitig der größte Kurgan des Gräberfeldes. Um den Kurgan herum wurde ein Kreisgraben angelegt. An der westlichen und östlichen Seite bricht der Graben ab. Diese Bereiche kann man als zwei Eingänge interpretieren. Der Durchmesser der Kurgane schwankt zwischen I9 $\mathrm{m}$ und 89 m (223 m mit dazugehörenden Anlagen), die Höhen zwischen I $m$ und Io m. Alle Kurgane haben drei steile und einen (immer südlichen) sanften Abhang und weisen einen Raubtrichter auf.

Anhand der Struktur und äußeren Erscheinungsform können die Kurgane der Nekropole der sakischen Periode der Früheisenzeit zugeordnet werden.

Kurgancharakteristik:

Kurgan I (Abb. I83,I)

Dm 89 m; Dm Kreisgraben 223 m; H io m

Lage: N43 02.9I4 E78 43.503; nördlichster Kurgan der Kette

Form: abgerundet, plattformähnlich mit abgeflachter Kuppe

Abhänge: drei steile, südlicher sanft

Weitere Konstruktionen: In einem Abstand von $44 \mathrm{~m}$ um den Kurgan herum wurde ein Kreisgraben von bis $\mathrm{zu} 24 \mathrm{~m}$ Breite und 2,0-2,5 m Tiefe angelegt (Abb. I83,2). An der westlichen Seite (heute beschädigt, dient als eine Einfahrt zum Einsiedlerhof) und der östlichen (leicht nach Süden versetzt) bricht der Graben ab; diese Bereiche kann man als zwei Eingänge von I3 $\mathrm{m}$ (?) und $9 \mathrm{~m}$ Breite interpretieren.

Zustand: in der Mitte ein gewaltiger Raubtrichter; Der Aushub des Raubtrichters überdeckt den nordöstlichen Abhang der Kurganaufschüttung. Im südwestlichen Bereich der Konstruktion, zwischen dem Kurganrand und dem Graben, befindet sich ein Einsiedlerhof (ehem. hydromelioratorische Station). Peripherie überpflügt

Sonstiges: Oberfläche mit kleinen (bis zu Schottergröße) Steinen bedeckt

\section{Kurgan 2}

$\mathrm{Dm}_{3} 6 \mathrm{~m} ; \mathrm{H} 2 \mathrm{~m}$

Lage: N43 02.38I E78 43.566

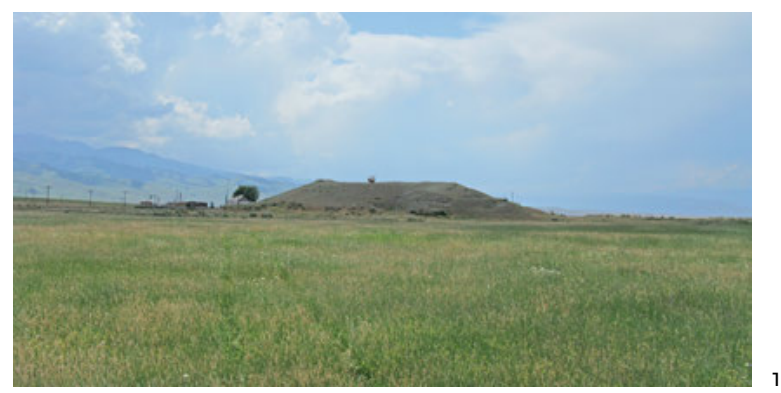

Form: abgerundet, plattformähnlich mit abgeflachter Kuppe

Abhänge: drei steile, südlicher sanft

Zustand: in der Mitte ein Raubtrichter; Peripherie überpflügt

Sonstiges: keine Steine an der Oberfläche

\section{Kurgan 3}

Dm $42 \mathrm{~m} ; \mathrm{H} 3,5 \mathrm{~m}$

Lage: N43 02.23I E78 43.274

Form: abgerundet, plattformähnlich mit abgeflachter Kuppe

Abhänge: drei steile, vierter fehlt

Zustand: in der Mitte ein Raubtrichter; Südabhang des Kurgans durch unbefestigte Straße zerstört

Sonstiges: keine Steine an der Oberfläche

Kurgan 4 (Kleinkurgan)

Dm i9 m; H i $\mathrm{m}$

Lage: N43 02.252 E78 43.258

Form: abgerundet, plattformähnlich mit abgeflachter Kuppe

Abhänge: drei steile, südlicher sanft

Zustand: in der Mitte ein Raubtrichter; die Peripherie ist überpflügt

Sonstiges: keine Steine an der Oberfläche

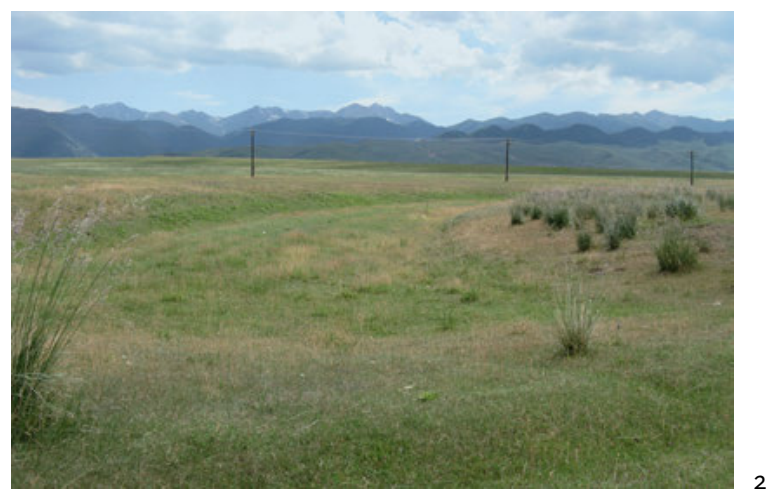

Abb. 183 | Kurgan I des Gräberfeldes Togyzbulak; I. Blick von O; 2. Kreisgraben um Kurgan, OSO Bereich. Blick von N 
Kurgan 5

Dm 29 m; H 3 m

Lage: N43 02.I26 E78 43.435

Form: abgerundet, plattformähnlich mit abgeflachter Kuppe

Abhänge: drei steile, südlicher sanft

Zustand: in der Mitte ein Raubtrichter

Sonstiges: keine Steine an der Oberfläche; Nördlich vom Kurgan befindet sich eine Senke, die evtl. durch den Aushub des Bodens für das Errichten der Kurganaufschüttung entstand.

\section{Kurgan 6}

Dm 22 m; H 2 m

Lage: N43 02.I06 E78 43.424

Form: abgerundet, plattformähnlich mit abgeflachter Kuppe
Abhänge: drei steile, südlicher sanft

Zustand: in der Mitte eine Senke

Sonstiges: einzelne mittelgroße Steine $(\mathrm{ab} 40 \times 20 \times$ Io $\mathrm{cm}$ ) an der Oberfläche

\section{Kurgan 7}

Dm 24 m; H 2 m

Lage: N43 02.069 E78 43.472; der südlichste Kurgan der Kette

Form: abgerundet, plattformähnlich mit abgeflachter Kuppe

Abhänge: drei steile, südlicher sanft

Zustand: auf dem Kurgan steht ein Strommast

Sonstiges: einzelne mittelgroße Steine $(\mathrm{ab} 40 \times 20 \times$ Io $\mathrm{cm}$ ) an der Oberfläche

Gräberfeld Turgen [FEZ] (Abb. I84-I85; Karte 3 Nr. I9): ALT 826 m N43 27.092 E77 35.708; Gebiet Almaty (kasach. Алматы облысы), Enbekšikazachskij rajon (kasach. Еңбекшіқазақ ауданы); Ausmaß N-S 6,7 × O-W 4,I km.

Der Fundort Turgen befindet sich $57 \mathrm{~km}$ nordöstlich von der Stadt Almaty (kasach. Алматы), an beiden Ufern des Flusses Turgen (kasach. Турген), dort wo der Fluss aus der Turgen-Schlucht austritt. Der westliche Teil der Nekropole (linkes Ufer des Turgen) liegt ca. I, $5 \mathrm{~km}$ nördlich vom Dorf Turgen (kasach. Турген) entfernt, auf 826 m Höhe. Der östliche Teil des Gräberfeldes liegt im Dorf Karakemer (kasach. Қарақемер) und nördlich einer Weinplantage auf 9I6 m Höhe. Die gesamte Nekropole zählt über 30 große und mittelgroße Kurgane. Davon wurden 23 vergemessen und untersucht. Noch ca. zehn Kurgane befinden sich auf gesperrtem Gebiet im Dorf Karakemer. Von den 23 untersuchten Kurganen liegen 20 am linken, westlichen Ufer des Turgen. Sie bilden zwei Kurganketten. Die dritte Kurgankette liegt am rechten, östlichen Ufer und besteht aus 13-I5 Kurganen6r. Die Richtung des Verlaufs der Kurganketten entspricht dem Lauf des Flusses Turgen, nämlich von Süd nach Nord. Der Durchmesser der Kurgane schwankt zwischen I2 $\mathrm{m}$ und I2I $\mathrm{m}$ (200 m mit dazugehörigen Steinkonstruktionen), die Höhe misst zwischen 0,2 m und bis zu Io m. Alle Kurgane des Gräberfeldes weisen einen oder mehrere Raubtrichter auf. Die Kurgane haben drei steile und einen sanften Abhang. Bei I5 Kurganen liegt der sanfte Abhang im Süden, bei drei Kurganen im Südosten und bei einem Kurgan im Südwesten. Zwei Kurgane haben aufgrund ihrer geringen Größe gar keine besonderen Merkmale bezüglich der Abhänge und in drei Fällen konnten sie wegen des hohen Zerstörungsgrades des Kurgans nicht bestimmt werden.

Der sechste Kurgan im Norden der mittleren Kette hat eine viereckige Form und besaß ursprünglich eine Plattform. Kurgan $3^{\text {Gr2 }}$ derselben Kette ist mit einem sog. Prozessionsweg umgeben. Die äußere Markierung dieses Weges wurde durch rote Steine angezeigt. Zwischen dem Kurganrand und dem sog. Prozessionsweg wurden 4I Steinanhäufungen (Kleinkurgane?), die Durchmesser zwischen I,5 m 6,3 $\mathrm{m}$ aufweisen, gezählt. Im Abstand von weiteren $26 \mathrm{~m}$ vom sog. Prozessionsweg und etwa 6I $\mathrm{m}$ vom Kurganrand entfernt befindet sich ein umlaufender Steinkreis, der aus hellgrauen Steinen besteht.

Kurgan 4 dieser Kette hat im Abstand von I6 m einen umlaufenden Doppelkreis bzw. einen sog. Prozessionsweg aus Steinen, dessen Breite bis zu $2 \mathrm{~m}$ reicht und der aus weißen und roten Steinen be-

6II Wegen der dichten modernen Bebauung und der Lage einiger der Hügel auf Sperrgebiet konnte die genaue Zahl der Kurgane nicht bestimmt werden.
6I2 Nach der Arbeitsnummerierung. 


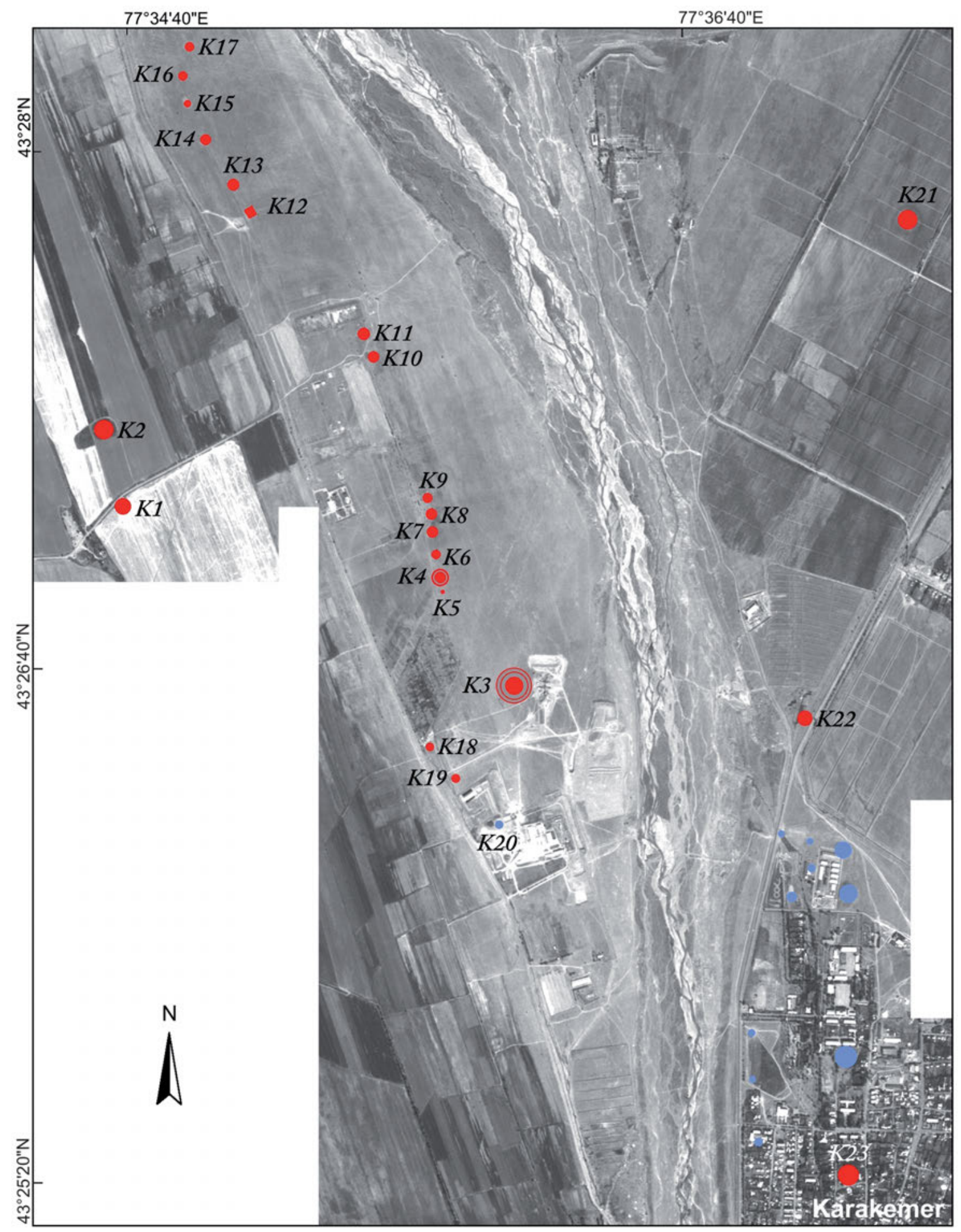

Abb. 184 | Gräberfeldplan Turgen (SPOT) 


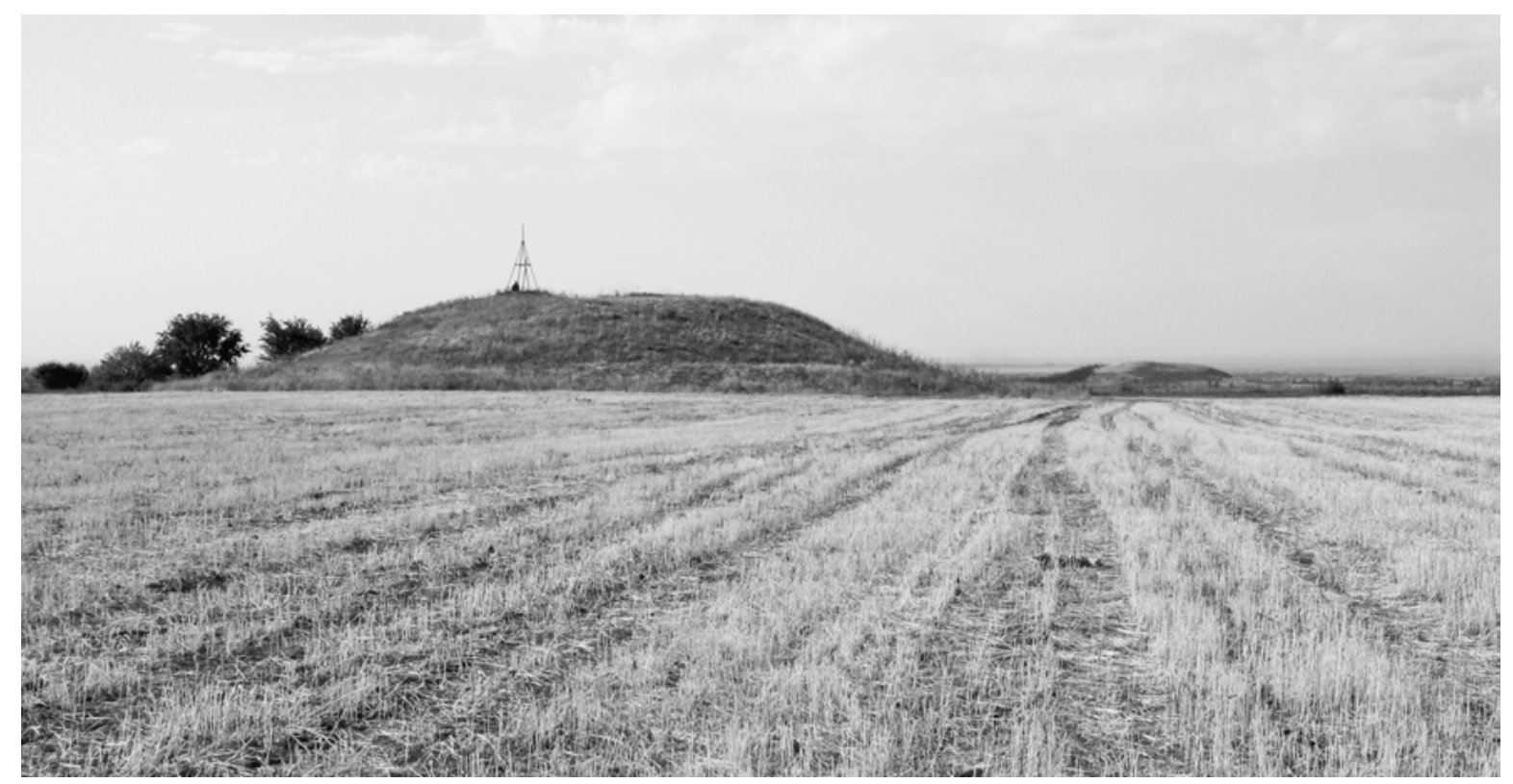

Abb. 185 | Gräberfeld Turgen. Blick von S

steht. Im nordöstlichen Bereich des Kurgans, zwischen dem Steinkreis/sog. Prozessionsweg und dem Kurganrand, wurde eine niedrige runde Steinanhäufung (Kleinkurgan) festgestellt. Alle anderen Kurgane weisen keine besonderen architektonischen Merkmale auf.

Anhand der Landschaftsplatzierung, der Struktur und der äußeren Erscheinungsform können alle Kurgane des Gräberfeldes der sakischen Periode der Früheisenzeit zugeordnet werden.

Kurgancharakteristik:

Westkette (westliches Ufer des Flusses Turgen)

\section{Kurgan I}

Dm 87 m; H 8 m

Lage: N43 27.138 E77 34.604; südlichster Kurgan der Kette

Form: abgerundet, plattformähnlich mit abgeflachter Kuppe

Abhänge: drei steile, südlicher sanft

Zustand: in der Mitte keine Senke, ein trigonometrischer Mast auf der Kurganspitze; Peripherie komplett überpflügt

Sonstiges: an der Oberfläche fast keine Steine

\section{Kurgan 2}

Dm 87 m; H 8 m

Lage: N43 27.337 E77 34.537; nördlichster Kurgan der Kette

Form: abgerundet, plattformähnlich mit abgeflachter Kuppe

Abhänge: drei steile, südlicher sanft

Zustand: in der Mitte ein Raubtrichter; Peripherie komplett überpflügt
Sonstiges: an der Oberfläche einzelne mittelgroße Steine $(\mathrm{ab} 35 \times 20 \times 15 \mathrm{~cm})$

Funde: Lesefunde

- Zwei Wandscherben rot bis orange; mittelbis fein gemagert, etwas porös; scheibengedreht; außen geglättet; Maße: I $-45 \times 30 \times$ Io $\mathrm{mm} ; 2-48 \times 29 \times 9 \mathrm{~mm}$

Chronologie: FEZ, sakische bis Wusun-Periode

Mittlere Kette (westliches Ufer des Flusses Turgen)

Kurgan 3 (Abb. I86)

Dm 70 m; Dm mit sog. Prozessionsweg 139 m; Dm mit Steinkreis $200 \mathrm{~m} ; \mathbf{H} 7 \mathrm{~m}$

Lage: N43 26.63I E77 35.997

Form: abgerundet, plattformähnlich mit abgeflachter Kuppe

Abhänge: drei steile, südlicher sanft

Weitere Konstruktionen: Um den Kurganrand verläuft ein $3 \mathrm{~m}$ breiter Streifen, der aus roten, großen und mittelgroßen Steinen $(60 \times 40 \times 30 \mathrm{~cm})$ besteht; evtl. handelt es sich hier um eine Art von Kurgankrepis (?). In der Peripherie des Kurgans befinden sich 4I kleine, 

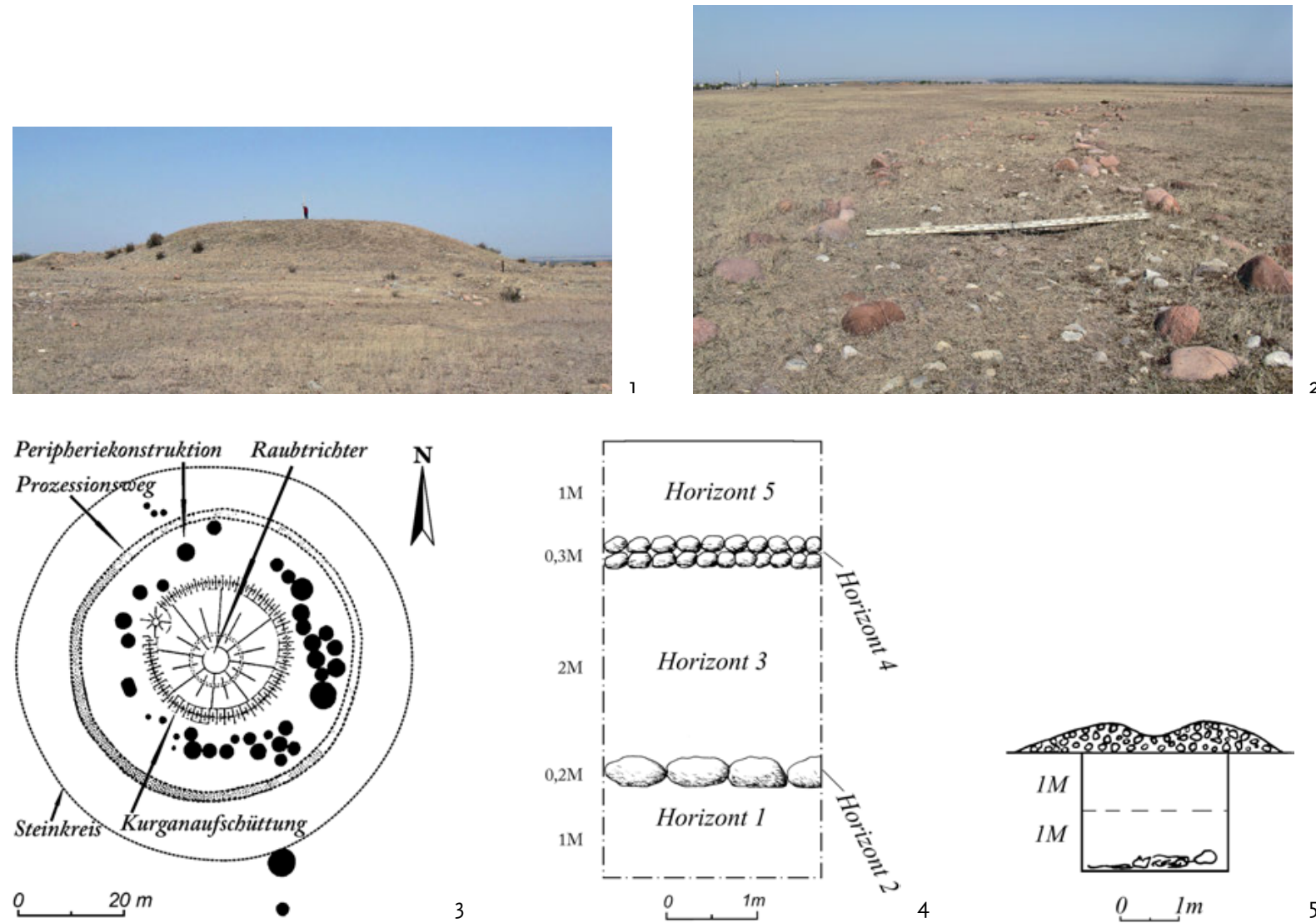

Abb. 186 | Kurgan 3 des Gräberfeldes Turgen; I. Blick von OSO; 2. Sog. Prozessionsweg, Westbereich, Blick von S;

3. Plan (Nurmuchanbetov I998, 50, Abb. 7); 4-5 nach Dublickij I946a „Kurgan auf der Höhe 379“ (graphische Nachbearbeitung von M.-R. Boroffka), 4. Suchschnitt Nr. 2, SO-SW (Zeichenblatt 4); 5. Schnitt der Nachbestattungen. Gräber 2 und 5 (Zeichenblatt 2 )

flache, runde bzw. ovale Steinanhäufungen (Kleinkurgane?), deren Dm I, $5 \mathrm{~m}-6,3 \mathrm{~m}$ misst. $30 \mathrm{~m}$ vom Rand des Kurgans entfernt verläuft ein umlaufender sog. Prozessionsweg, dessen Breite $3 \mathrm{~m}$ beträgt (Abb. I86,2). Dieser wird durch große, rote Steine $(a b$ $60 \times 40 \times 30 \mathrm{~cm}$ ) begrenzt, während das Innere mit weißgrauen Flusskieselsteinen gepflastert ist. $26 \mathrm{~m}$ von der äußeren Grenze des sog. Prozessionsweges und 6I $\mathrm{m}$ vom Kurganrand entfernt befindet sich ein umlaufender Steinkreis, der aus grauen großen und mittelgroßen Steinen $(\mathrm{ab} 50 \times 30 \times 20 \mathrm{~cm})$ gebaut wurde

Zustand: in der Mitte ein Raubtrichter, dessen Aushub im nordwestlichen Bereich des Kurganrandes liegt

Sonstiges: gesamte Oberfläche mit mittelgroßen Steinen $(\mathrm{ab} 50 \times 30 \times 20 \mathrm{~cm})$ bedeckt; größter Komplex der Nekropole

Bemerkungen: I939 wurde der Kurgan von B. N. Dublickij, einem Mitarbeiter des Institutes der Nationalkultur (Almaty), zum Teil untersucht. Der Kurgan wurde als „Kurgan auf der Höhe 379“ bezeichnet (Dublickij I939a, 5-8).
Zustand (1939): in der Mitte ein Raubtrichter

- Dublickij hatte zwei Suchschnitte angelegt. Suchschnitt Nr. r: in der Südhälfte des Kurgans zwischen Raubtrichter und Kurganrand

- Maße: $9 \times 3,5 \times 4,75 \mathrm{~m}$

- Der Suchschnitt Nr. I wurde nicht bis zum gewachsenen Boden gegraben.

Suchschnitt Nr. 2: im südöstlichen Bereich des Raubtrichters

- Maße: $6 \times 2,25 \times 4,5 \mathrm{~m}$

- Der Suchschnitt Nr. 2 wurde bis zum gewachsenen Boden gegraben.

- Stratigraphie des Kurgans nach dem Suchschnitt Nr. 2 (von unten nach oben; Abb. I86,4):

Horizont 1 - gewachsener Boden

Horizont 2 - Steinpflaster aus mittelgroßen und großen $(\mathrm{ab} 40 \times 50 \mathrm{~cm})$ Flusskieselsteinen; es wurde als „Fundament" bezeichnet; Mächtigkeit $0,2 \mathrm{~m}$ Horizont 3-2 m dicker Löss- mit Schotterschicht Horizont 4- doppelte Steinreihe, die miteinander durch einen Lehmmörtel verbunden wurde; Mächtigkeit o,3 m 
Horizont 5 - Humus mit kleinen und mittelgroßen Steinen vermischt (letzter Schicht); Mächtigkeit I,o m Weitere Konstruktionen des Kurgans: In der Peripherie des Kurgans und am Kurganrand wurden I5 Steinanhäufungen (Kleinkurgane) festgestellt; zwei davon (Gräber 2 und 5) wurden ausgegraben. Beide Gräber wurden von Dublickij als Nachbestattungen interpretiert.

Grab 2 (Abb. I86,5): Westbereich des Kurganrandes

- durch eine ovale Erhebung aus Steinen markiert

- Maße: $\mathrm{I} \times 0,75 \times 2 \mathrm{~m}$

- Ausrichtung: N-S

- Form: nicht erwähnt

- Auf dem Grabboden lag ein Skelett; das mit Erde, die mit Steinen vermischt worden war, zugeschüttet worden war (Mächtigkeit der Schicht I,O m). Es folgte eine I,O m dicke Schicht, die nur aus Erde bestand und bis zum antiken Laufhorizont reichte; an der Oberfläche wurde eine Steinanhäufung gebaut.

* Die Stratigraphie der Grabverfüllung gilt für beide Gräber, allerdings wurde die Mächtigkeit der Schicht für das Grab 5 dabei nicht angegeben.

Bestattung - Lage: Rückenstrecker

- Ausrichtung: mit dem Kopf nach Norden

- Anthropologische Bestimmung: fehlt

Funde: keine

Grab 5: Nordwestbereich des Kurganrandes

- Maße: $3 \times 2,5 \times 3 \mathrm{~m}$

- Ausrichtung: NW-SE

- Form: nicht erwähnt

- Auf dem Grabboden lag ein Skelett

- Bestattung - Lage: Rückenstrecker

- Ausrichtung: mit dem Kopf nach Westen

Funde: keine

- Anthropologische Bestimmung: fehlt

nach Dublickij (I939): Andronovo-Zeit

\section{Kurgan 4}

Dm 5 I m; Dm doppelter Steinkreis/sog. Prozessionsweg $84 \mathrm{~m} ; \mathbf{H ~ 6 , 5 ~ m ~}$

Lage: N43 26.923 E77 35.733

Form: abgerundet, plattformähnlich mit abgeflachter Kuppe

Abhänge: drei steile, südlicher sanft

Weitere Konstruktionen: 30 m vom Rand des Kurgans entfernt verläuft ein umlaufender, doppelter Steinkreis / sog. Prozessionsweg, dessen Breite bis zu $2 \mathrm{~m}$ beträgt. Er wird durch große rote und weiße Steine $(\mathrm{ab} 50 \times 40$ $\times 30 \mathrm{~cm})$ markiert. Da diese Konstruktion in einem schlechten Erhaltungszustand ist, ist schwer feststellbar, ob es sich um einen einfachen Steinkreis, einen doppelten Steinkreis bzw. einen sog. Prozessionsweg handelt; zwischen dem Kurganrand und dem doppelten Steinkreis/sog. Prozessionsweg, nordöstlich vom Kurgan befindet sich ein Kleinkurgan (4).
Zustand: Durch die gesamte Kuppe des Kurgans verläuft von Norden nach Süden ein Graben von 6,5 m Breite, der von Raubgräbern angelegt wurde; in der Osthälfte des Kurgans ein weiterer Raubtrichter

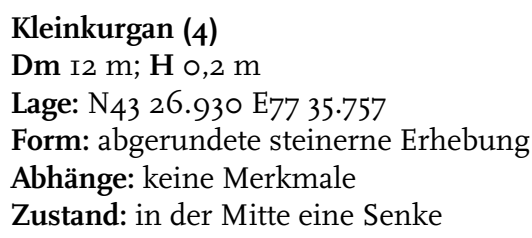

Kurgan 5 (Kleinkurgan)

Dm 28 m; H o, 5 m

Lage: N43 26.885 E77 35.737

Form: abgerundete Erhebung

Abhänge: keine Merkmale

Zustand: in der Mitte eine Senke

Sonstiges: Der Kurgan besteht aus mittelgroßen und kleinen Steine (ab $40 \times 20 \times 10 \mathrm{~cm}$ ) und aus Erde.

\section{Kurgan 6}

Dm 44 m; H 3 m

Lage: N43 26.985 E77 35.72I

Form: abgerundet, plattformähnlich mit abgeflachter Kuppe

Abhänge: drei steile, südlicher sanft

Zustand: Durch den mittleren Bereich des Kurgans verläuft von Norden nach Süden ein Raubgraben, der in seiner Mitte ein Raubtrichter aufweist.

Sonstiges: an der Oberfläche liegen einzelne Steine

Kurgan 7 (Abb. I87,I)

Dm 54 m; H 5 m

Lage: N43 27.043 E77 35.706

Form: abgerundet, plattformähnlich mit abgeflachter Kuppe

Abhänge: drei steile, südlicher sanft

Zustand: In der Mitte gab es ursprünglich einen Raubtrichter65; da der Kurgan I997 im Laufe einer Grabung von B. Nurmuchanbetov und G. Legoboi zum Teil ausgegraben worden ist, ist nur der Westrand und das nordöstliche Viertel des Kurgan erhalten geblieben.

Stratigraphie der Kurganaufschüttung: keine Steine an der Oberfläche; Die Überreste vom Ostprofil des Westrandes und vom West- und Südprofil des nordöstlichen Viertels zeigen, dass die Kurganaufschüttung aus lehmigem, beigefarbenen Sand mit kleinen Kieselsteinen (siehe Skizze des Ostprofils des Westrandes: Nr. I-4) und Steinpackungen, die nacheinander folgten, bestand. Bei den Schichten I-4 ist es unklar, ob sie aufgeschüttet bzw. aus Rasensoden aufgebaut worden waren (Abb. I87,2).

Bemerkungen: zu der Grabung von I997 gibt es einen Bericht im Archiv des Archäologischen Institutes, Almaty: Bajpakov/Mar'jašev I998, 27-50, Abb. I-7

6I3 Nach Aussage von B. Nurmuchanbetov. 

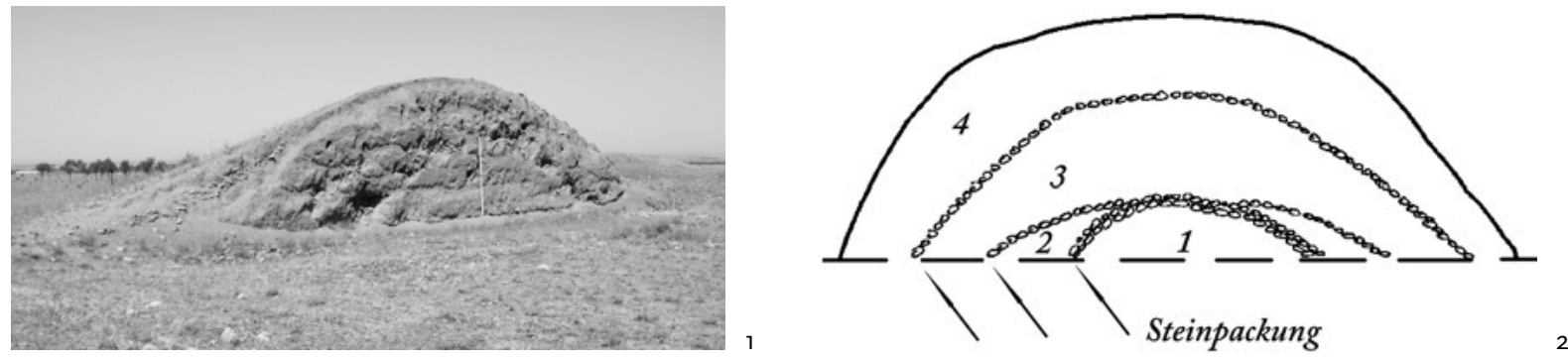

Abb. 187 | Kurgan 7 des Gräberfeldes Turgen; I. Westrand, Blick von SO; 2. Skizze des Ostprofils des Westrandes vom Kurgan

Nurmuchanbetov I998, 27-50

- Dm $47 \mathrm{~m} ; \mathrm{H} 4,7 \mathrm{~m}$

- Zustand: in der Mitte ein Raubtrichter

- weitere Konstruktionen: IO-I5 m vom Kurganrand entfernt befand sich ein $3 \mathrm{~m}$ breiter und ca. o, I $\mathrm{m}$ hoher Wall, der aus Erde und Steinen bestand.

- Durch den mittleren Bereich des Kurgans wurde mit einem Bulldozer ein N-S verlaufender und $15 \mathrm{~m}$ breiter Schnitt angelegt. Da durch den südöstlichen Bereich der Kurganaufschüttung ein Raubgang verlief, wurde das südöstliche Viertel später abgebaut.

Befund - rechteckige Grabgrube in der Mitte des Kurgans

- Maße: L 3,2 m; B 2 m; T ${ }^{614}$ I,7 m

- Ausrichtung: W-E

- weitere Bauelemente: die Wände der Grabgrube wurden zusätzlich durch das Mauerwerk verstärkt. In der Mitte der Grabgrube wurde ein Holzrahmen, der durch den Raubgang zum Teil zerstört worden war, angebaut.

- Zustand der Grabgrube: die südöstliche Ecke durch den Raubgang zerstört

Funde - auf dem Grabboden lagen die Überreste einer Filzdecke (?)

- an der Westwand des Holzrahmens stand ein Krug

- In der Nähe vom Krug lagen einzelne stark korrodierte Eisenfragmente.

- An der Nordwand des Holzrahmens, nahe seiner Westecke, befanden sich eine Haarnadel aus Bronze und zwei rechteckige verzierte Plättchen aus Gold.

Bestattung - jegliche Knochen fehlten

Chronologische Einordnung - 5.-4. Jh. v. Chr.

6I4 Von wo aus die Tiefe gemessen worden ist, wurde nicht erwähnt.

\section{Kurgan 8}

Dm 5 I m; H 4 m

Lage: N43 27.092 E77 35.708

Form: abgerundet, plattformähnlich mit abgeflachter

Kuppe

Abhänge: drei steile, südlicher sanft

Zustand: in der Mitte ein Raubtrichter

Sonstiges: fast keine Steine an der Oberfläche

\section{Kurgan 9}

Dm 43 m; H 3 m

Lage: N43 27.I33 E77 35.694

Form: abgerundet, plattformähnlich mit abgeflachter Kuppe

Abhänge: drei steile, südlicher sanft

Zustand: in der Mitte zwei Raubtrichter

Sonstiges: Die Kurgankuppe ist kahl; der Randbereich des Kurgans ist mit mittelgroßen Steinen $(\mathrm{ab} 35 \times 20 \times$ Io $\mathrm{cm}$ ) gepflastert.

\section{Kurgan Io}

Dm 52 m; H 4 m

Lage: N43 27.510 E77 35.513

Form: abgerundet, plattformähnlich mit abgeflachter Kuppe

Abhänge: drei steile, südöstlicher sanft

Zustand: in der Mitte ein W-O ausgerichteter Raubgraben

Sonstiges: Oberfläche ist mit mittelgroßen und kleinen Steinen $(\mathrm{ab} 30 \times 20 \times 10 \mathrm{~cm}$ ) bedeckt

\section{Kurgan II}

Dm 58 m; H 5 m

Lage: N43 27.572 E77 35.487

Form: abgerundet, plattformähnlich mit abgeflachter Kuppe

Abhänge: drei steile, südlicher sanft

Zustand: in der Mitte ein T-förmiger Raubgraben Sonstiges: Oberfläche ist mit mittelgroßen und kleinen Steinen $(\mathrm{ab} 30 \times 20 \times 10 \mathrm{~cm})$ bedeckt 


\section{Kurgan I2}

Seitenlänge $42 \mathrm{~m} ; \mathrm{H} 3,5 \mathrm{~m}$

Lage: N43 27.902 E77 35.090

Form: viereckig, pyramidenähnlich mit abgeflachter

Kuppe

Abhänge: drei steile, südlicher sanft

Zustand: in der Mitte ein Raubtrichter

Sonstiges: Die Abhänge des Kurgans sind grob an den vier Haupthimmelsrichtungen orientiert; die Oberfläche ist mit einzelnen mittelgroßen und kleinen Steinen bedeckt.

Kı2 ist der einzige viereckige Kurgan der Nekropole.

\section{Kurgan I3}

Dm 54 m; H 4 m

Lage: N43 27.975 E77 35.032

Form: abgerundet, plattformähnlich mit abgeflachter Kuppe

Abhänge: drei steile, südöstlicher sanft

Zustand: in der Mitte ein Raubtrichter

Sonstiges: einzelne Steine an der Oberfläche

\section{Kurgan I4}

Dm 46 m; H 4,5 m

Lage: N43 28.094 E77 34.933

Form: abgerundet, plattformähnlich mit abgeflachter Kuppe

Abhänge: drei steile, südöstlicher sanft

Zustand: in der Mitte ein Raubtrichter

Sonstiges: einzelne Steine an der Oberfläche

\section{Kurgan I5}

(Dm und H nach Nurmuchanbetov u.a. I992, 30)

Dm 25 m; H evtl. 2,5 m

Lage: N43 28.196 E77 34.877

Form: ?

Abhänge: ?

Zustand: der Kurgan wurde I992 im Zuge von Rettungsgrabungen im Gebiet Almaty von B. Nurmuchanbetov unter Verwendung eines Bulldozers ausgegraben. Heute sieht man einen $\mathrm{N}-\mathrm{S}$ verlaufenden Grabungsschnitt mit einer zum Teil erodierten Grabgrube.

Bemerkungen: Die Grabung von 1992 wurde in zwei Berichten im Archiv des Archäologischen Institutes, Almaty erwähnt: Bajpakov I992 und Nurmuchanbetov u.a. 1992

Nurmuchanbetov u.a. 1992, 30:

- Bereits beim Eintreffen der Rettungsgrabungsmannschaft fehlte die Kurgankuppe fast komplett; die Kurganaufschüttung wurde für die Errichtung der Nutzungsasphaltstraße des „Großen Almatykamals“ verwendet.

- Nur der Randbereich des Kurgans, der vier bis fünf intakt gebliebene stratigraphische Schichten beinhaltete, ist erhalten geblieben.
- Die Grabgrube wurde durch das Abtragen/ die Zerstörung der Kurganaufschüttung nicht beschädigt.

Weitere Information fehlt

\section{Kurgan 16}

(Dm und H nach Nurmuchanbetov u.a. I992, 30)

Dm 30 m; H evtl. 3 m

Lage: N43 28.263 E77 34.867

Form: ?

Abhänge: ?

Zustand: Der Kurgan wurde I992 im Zuge von Rettungsgrabungen in Gebiet Almaty von B. Nurmuchanbetov unter Verwendung eines Bulldozers ausgegraben; heute sieht man ein N-S verlaufenden Grabungsschnitt mit einer zum Teil erodierten Grabgrube.

Sonstiges: wie beim Kurgan I5

\section{Kurgan 17}

Dm 45 m; H 2 m

Lage: N43 28.342 E77 34.893; nördlichster Kurgan der mittleren Kette

Form: niedrig, abgerundet, plattformähnlich mit abgeflachter Kuppe

Abhänge: drei steile, südlicher sanft

Zustand: in der Mitte ein Raubtrichter

Sonstiges: Oberfläche mit mittelgroßen und kleinen Steinen $(\mathrm{ab} 25 \times 20 \times$ IO $\mathrm{cm}$ ) bedeckt

\section{Kurgan 18}

Dm $30 \mathrm{~m} ; \mathrm{H} 3 \mathrm{~m}$

Lage: N43 26.477 E77 35.673

Form: abgerundet, plattformähnlich mit abgeflachter Kuppe

Abhänge: drei steile, südlicher sanft

Zustand: in der Mitte ein Raubtrichter

Sonstiges: Oberfläche mit mittelgroßen und kleinen Steinen $(\mathrm{ab} 30 \times 20 \times 10 \mathrm{~cm})$ bedeckt

\section{Kurgan I9}

Dm 32 m; H 2,4 m

Lage: N43 26.392 E77 35.765

Form: abgerundet, plattformähnlich mit abgeflachter Kuppe

Abhänge: drei steile, südsüdöstlicher sanft

Zustand: in der Mitte und im nördlichen Bereich jeweils ein Raubtrichter

Sonstiges: fast keine Steine an der Oberfläche

\section{Kurgan 20}

Dm 46 m; H ? m

Lage: GPS-Koordinaten - nicht gemessen; der südlichste Kurgan der mittleren Kurgankette; laut Google Earth [2010] - N43 26.267 E77 35.930

Form: abgerundet, plattformähnlich mit abgeflachter Kuppe

Abhänge: drei steile, südlicher sanft

Zustand: ? 


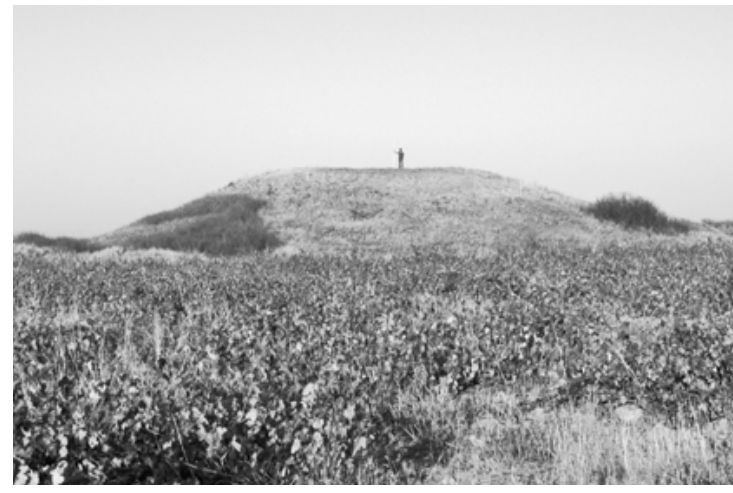

Abb. 188 | Kurgan 2I. Blick von W

Sonstiges: Der Zugang zum Kurgan wurde nicht genehmigt, da sich K2O auf dem Gelände eines Unternehmens befindet; damit konnte das Objekt nicht vollständig untersucht werden.

Ostkette (östliches Ufer des Turgen)

Kurgan 2I (Abb. I88)

Dm 88 m; H 8 m

Lage: N43 27.826 E77 37.468; nördlichster Kurgan der Ostkette

Form: abgerundet, plattformähnlich mit abgeflachter Kuppe

Abhänge: drei steile, südwestlicher sanft

Zustand: in der Mitte ein Raubtrichter; Da sich der Kurgan in einer Weinplantage befindet, ist seine Peripherie komplett zerstört.

Sonstiges: fast keine Steine an der Oberfläche
Kurgan 22

Dm 69 m; H 7 m

Lage: N43 26.522 E77 37.035

Form: abgerundet, plattformähnlich mit abgeflachter Kuppe

Abhänge: drei steile, südlicher sanft

Zustand: in der Mitte und im ostnordöstlichen Bereich des Kurgans jeweils ein Raubtrichter; Peripherie durch den Pflug zerstört

Sonstiges: fast keine Steine an der Oberfläche

\section{Kurgan 23}

Dm I2I m; H IO $\mathrm{m}$

Lage: N43 25.324 E77 37.I35; südlichster Kurgan der Ostkette; befindet sich direkt im Dorf Karakemer

Form: ursprüngliche Form ist unbekannt

Abhänge: ?

Zustand: zum Teil deformiert und stark beschädigt; Die Ost- und Nordseite sind dicht bebaut, so dass die Grundstückszäune unmittelbar am Kurgan stehen; der südliche Randbereich ist durch eine Asphaltstraße zerstört; die Südseite ist durch einen Asphaltparkplatz und einen Asphaltweg, die direkt auf den Kurgan gebaut worden sind, stark beschädigt; die Kurgankuppe ist planiert und zum Teil auch asphaltiert.

Sonstiges: Nach Aussage von B. Nurmuchanbetov baute man in den 8oer Jahren des 20. Jh. auf dem K23 ein Kino mit dazugehörigem Parkplatz, vor Kurzem stürzte das Kino ein.

\section{Forschungsgeschichte}

F. W. Radloff untersuchte im Jahre 1869 das linke, westliche Ufer des Turgen beim Dorf Michajlovskoeбis (russ. Михайловское) und stellte dort zehn Kurgane, deren Aufschüttung aus Stein und Erde bestand, fest. Im gleichen Jahr wurden von ihm einige Kurgane ausgegraben. Man fand eine Brandbestattung in einer Grabgrube. Als Funde wurden Scherben von mehreren Gefäßen und stark korrodierte Fragmente eines Eisenschwertes erwähnt (Archeologičeskaja karta Kazachstana I960, 307-308).

Im Jahre I934 führte der Mitarbeiter des Institutes für nationale Kultur (Alma-Ata), Riza Sulejmanov, eine Erkundung um die Dörfer Turgen und Karakemer durch. In der Nähe des Dorfes Karakemer stellte er 26 Kurgane ${ }^{616}$ fest und bezeichnete sie als „Karakemer Kurgane“ (Bernštam/Dublickij I936, 4-5). Zwei davon wurden von ihm im gleichen Jahr ausgegraben.

Auflistung der beiden untersuchten Kurgane (Bernštam/Dublickij I936, 5-6):

„Karakemerskij Kurgan“

Dm I48 m; H 7,5 m

Lage: in der Nähe vom Dorf Karakemer

Form: ?

6I5 Michajlovskoe ist die ehemalige Bezeichnung des Dorfes Turgen (Proskurin 2003).
Zustand: in der Mitte ein Raubtrichter

Bemerkung: da der Kurgan zu groß war, wurde dort nur ein schachtartiger Suchschnitt im Raubtrichter angelegt; die Grabgrube wurde nicht gefunden.

6I6 Evtl. sind das die Kurgane, die am östlichen Ufer des Turgen liegen. 
Stratigraphie des Kurgans: ?

Weitere Konstruktionen: um den Kurgan herum drei

Steinkreise ${ }^{617}$

Chronologie: ?

„Kurgan am Steilhang des Turgen-Ufers“

Dm 60 m; H 2,8 m

Lage: am Ufer des Turgen

Form: ?

Zustand: ?

Befunde: - Grabkammer (Platzierung - nicht angegeben; Form - nicht angegeben; Ausrichtung - nicht angegeben; Maße - fehlt)

- Nachbestattung in einer Grabgrube mit Absätzen (Platzierung - nicht angegeben; Form - nicht angegeben; Ausrichtung nicht angegeben; Maße - fehlt)

- Die Grabkammer bestand aus in drei Reihen aufeinandergelegten, weißgefärbten Flusskieselsteinen; der Grabboden wurde mit dünnen Brettern bedeckt; in der Nordostecke der Kammer standen zwei Holzpfosten.
Bestattung: - auf den Bodenbrettern ein Skelett (Platzierung - nicht angegeben; Lage - nicht angegeben; Ausrichtung - nicht angegeben; anthropologische Bestimmung - fehlt)

Beigaben: - in der Nähe vom Skelett eine Perle (Material - nicht angegeben; Maß - fehlt)

Bemerkung: I926 wurden in der Kurganaufschüttung von Dorfbewohnern ca. 50 ähnliche, dreieckige Plättchen aus Kupfer (?) gefunden; jedes Plättchen war verziert und beinhaltete eine kurze Inschrift; seit I936 gelten diese Plättchen als verschollen.

- Nachbestattung: Grabgrube mit Absätzen, die die Auflagefläche für quer verlegte Halbbohlen waren; über den Halbbohlen lag Reisig

Bestattung: - ein Skelett

- Platzierung: nicht angegeben

- Lage: nicht angegeben

- Ausrichtung: Kopf nach Westen

- Anthropologische Bestimmung: fehlt

Beigaben: - keine Chronologie: ?

Im Auftrag des Institutes der Nationalkultur unternahm der Mitarbeiter der Staatlichen Eremitage A. N. Bernštam im Jahre I936 eine Besichtigung der Nekropole (Bernštam I94Ib, 6). Er vermerkte, dass der Zustand der Kurgane sehr schlecht sei und dass mehrere Kurgane beraubt waren. Im Jahre I939 untersuchten die Mitarbeiter der Archäologische Siebenstromland-Expedition (CAЭ) unter Bernštams Leitung erneut die Kurgane am Rande der Dörfer Turgen und Karakemer. Im Auftrag von Bernštam führte B. N. Dublickij die Vermessung und die Anfertigung eines Gesamtplanes des Gräberfeldes durch. An beiden Ufern des Flusses Turgen stellte Dublickij insgesamt 28 Großkurgane fest. Die Kurgane bildeten mehrere Ketten, die Nord-Süd ausgerichtet worden waren. Der Forscher dokumetierte fünf Kurganketten.

Auflistung der Ketten (Dublickij I939a, I-3):

Rechtes, östliches Ufer des Turgen

Kette Nr. I: fünf Kurgane, N-S Ausrichtung; befand sich auf dem Gelände der Kara-Kemer Arbeiterfakultät des Kasachischen Mirzojans Landwirtschaftsinstitutes; Die Kurgane der Kette wiesen mindestens einen Raubtrichter auf und hatten eine abgerundete, plattformähnliche Form mit abgeflachter Kuppe; weitere architektonische Merkmale fehlten.

Kette Nr. 2: fünf Kurgane, N-S Ausrichtung, o,5 km nordwestlich von Kette Nr. I.

Linkes, westliches Turgen-Ufer

Kette Nr. 3: fünf Kurgane, NW-SO Ausrichtung; Die beiden südöstlichsten Kurgane wurden als die größten Kurgane des gesamten linken Ufers angegeben. Der südöstlichste war der Größte (Dublickij I939a, 5 - „Kurgan auf der Höhe 379) ${ }^{\text {6r8; }}$ er wurde zum Teil von B. N. Dublickij untersucht (Abb. I89), bzw. ausgegraben.

6I7 Es wurde nicht erwähnt, ob es sich hier um drei Steinkreise bzw. um einen sog. Prozessionsweg und einen Steinkreis handelte.
6I8 Nach unserer Arbeitsnummerierung (2008) entspricht dieses Objekt dem Kurgan 3. 
Kette Nr. 4 befand sich 0,5 km nordnordöstlich von Kette Nr. 3; Ausrichtung und Anzahl der Kurgane wurden nicht angegeben.

Kette Nr. 5: fünf Kurgane, NNW-SSO Ausrichtung, westlich von Kette Nr. 4; bestand nur aus Kleinkurganen.

I94I datierte A. N. Bernštam die Nekropole in das 3. Jh. v. Chr. bis I.-2. Jh. n. Chr. (Bernštam I94Ib, 6) und interpretierte die Kurgane des Gräberfeldes Turgen als die Kurgane vom „sarmatischen Typ“ (Bernštam i94Ib, 27).

Die gleiche Datierung schlug E. I. Ageeva vor, als unter ihrer Leitung die Archäologische Siebenstromland-Expedition (CAЭ) den Fundort im Jahre 1956 wiederholt untersuchte (Archeologičeskaja karta Kazachstana i960, 308).

Im Rahmen von Rettungsgrabungen im Gebiet Almaty wurden im Jahre I992 zwei Kurgane ausgegraben, die durch den Bau des „Großen Almaty-Kanals“ beschädigt worden waren (БАК ${ }^{6 r 9)}$ (Bajpakov I992, 56). Die Rettungsgrabung wurde durch das Kleinstunternehmen „Atalyk“ unter der Leitung von B. Nurmuchanbetov durchgeführt (Nurmuchanbetov u.a. I992, 30, 36, Abb. 5). Die von Nurmuchanbetov untersuchten Kurgane wurden während unseres Surveys (2008) als Kurgane I5 und I6 aufgenommen ${ }^{620}$.
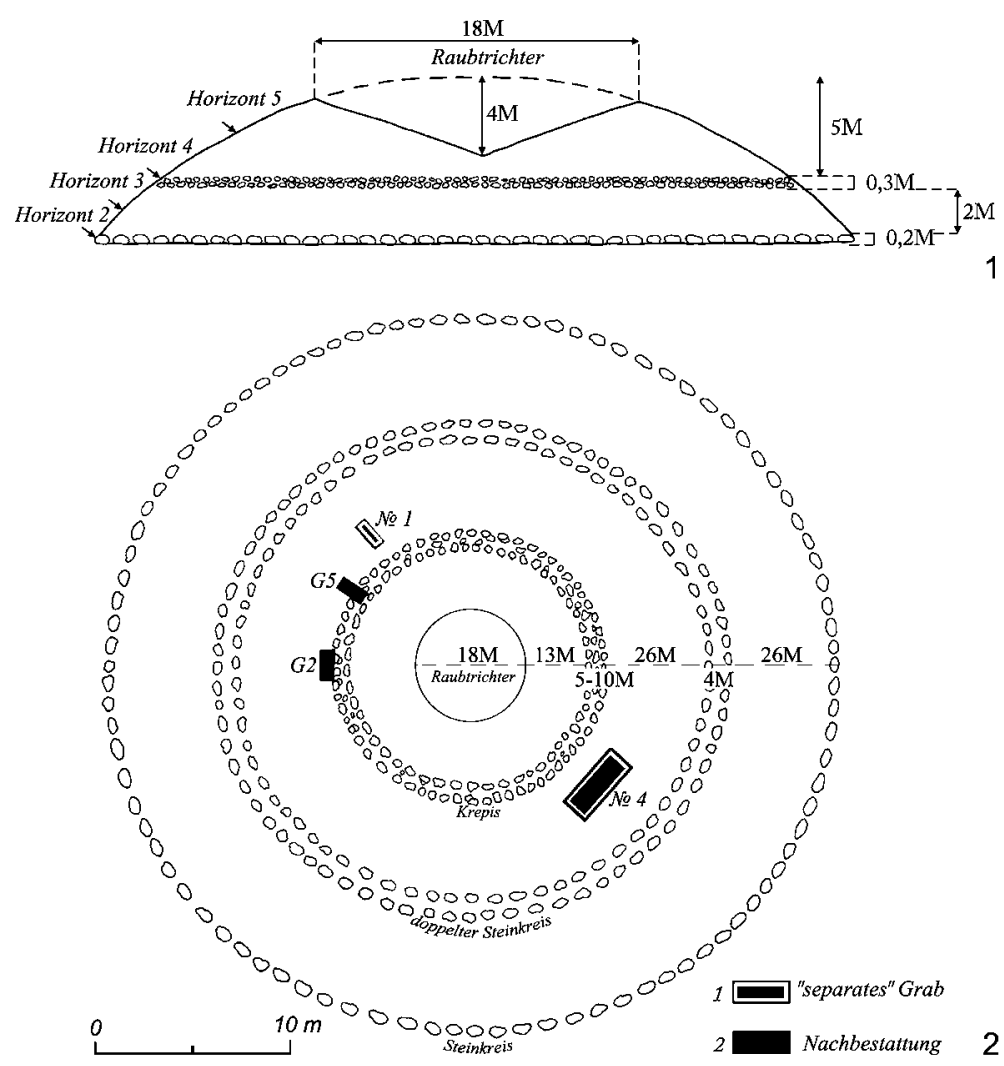

Abb. 189 | „Kurgan auf der Höhe 379“. Plan und Schnitt (Dublickij I946a,

Zeichenblätter 2 und 5; graphische Nachbearbeitung von M.-R. Boroffka)

6г9 Большой Алматинский Канал.

620 Siehe Kurgancharakteristik. 
I997 untersuchte das Kasachisch-Italienische Forschungsteam der Südkasachischen Archäologischen Expedition (ЮKКАЭ) unter der Leitung von B. Nurmuchanbetov und G. Legoboi einen mittelgroßen Kurgan auf dem Gräberfeld (Nurmuchanbetov I998, 27-50). Der vom Forschungsteam untersuchte Grabhügel wurde während des Surveys 2008 als Kurgan 7 aufgenommen ${ }^{62 r}$. Ferner wurde Kurgan $3^{622}$ vermessen und skizziert. Das Objekt wurde als „rituelle Konstruktion Nr. 2“ bzw. als „Kurgan-Tempel“ bezeichnet (Nurmuchanbetov I998, 35).

Im Auftrag des Archäologischen Institutes „A. Ch. Margulan“ (Almaty) arbeitete im Sommer $2008^{623}$ das Turgen-Forschungsteam der Archäologischen Expedition unter der Leitung von A. Gorjačev an dem Projekt „Kulturerbe“ und untersuchte archäologische Bodendenkmäler der Turgen-Schlucht. An dem Gräberfeld Turgen führte A. Gorjačev einen Survey durch und gliederte mehrere Fundorte daraus.

Liste der Fundorte (Mar'jašev/Gorjačev 2009a):

FEZ Gf. Karakemer-I (russ. Каракемер-I): Mar'jašev/Gorjačev 2009a, 9-Io; ALT 9Io m, N43 25'56,I" E77 36'82,9"624; *entspricht dem Topoi Survey 2008 - K22, K23 und den nicht gemessenen Kurganen, die sich im gesperrten Militärgebiet befinden; insgesamt 22 Kurgane; Dm der Kurgane I2-I50 m; H I-IO m; Abstand zwischen den Kurganen 30-400 m; um einige Kurgane wurden Steinringe festgestellt.

FEZ Gf. Turgen' (russ. Тургень), Gruppe I: Mar’jašev/Gorjačev 2009a, I5-I6; ALT 851 m, N43 26'42,3" E77 35'79,I"; *entspricht dem Topoi Survey 2008 - KI8, KI9 und K20; insgesamt drei Kurgane.

FEZ Gf. Turgen', Gruppe II: Mar'jašev/Gorjačev 2009a, I7-20; ALT 864 m, N43 26'65,4" E77 35'82,3"; *entspricht dem Topoi Survey 2008 - K3; ein Kurgan.

FEZ Gf. Turgen', Gruppe III: Mar'jašev/Gorjačev 2009a, 2I-22; ALT 848 m, N43 26'92,5" E77 35'73,6"; *entspricht dem Topoi Survey 2008 - K4, K5, K6, K7, K8 und K9; insgesamt sechs Kurgane.

FEZ Gf. Turgen', Gruppe IV: Mar'jašev/Gorjačev 2009a, 23-24; ALT 8I4 m, N43 27'52,I" E77 35'54,5"; *entspricht dem Topoi Survey 2008 - Kio und KII; insgesamt zwei Kurgane.

FEZ Gf. Turgen', Gruppe VIII: Mar'jašev/Gorjačev 2009a, 29-30; ALT 76I m, N43 28'34,5” E77 34'89,I"; *entspricht dem Topoi Survey 2008 - Kı2, Ki3, Ki4, KI5, Ki6 und Ki7; insgesamt sechs Kurgane; A. Gorjačev zählte dort 8 Kurgane, da die zwei südlichsten Kleinkurgane sind, wurden sie von uns nicht vermessen.

Zwei FEZ Kurgane: Mar'jašev/Gorjačev 2009a, 3I-32; ALT 824 m, N43 27'I4,I” E77 34'60,8"; *entspricht dem Topoi Survey 2008 - KI und K2.

Lit.: Akišev K.A. 1974, 61; Archeologičeskaja karta Kazachstana 1960, 308; Bajpakov 1992, 56; Bernštam I938, I9; Bernštam I94Ib, 6; Bernštam I948a, 8I; Bernštam/Dublickij I936, 5-6; Dublickij I939a, I-8, I/93/8I; Dublickij I946a, I-I6; Gass 20IIa, 6I-65, Fig. 3, 8-I3; Mar'jašev/Gorjačev 2009a, 9-10, I5-24, 29-32; Mar'jašev/Gorjačev 2009b, 7-8, Foto I3-I4; Nurmuchanbetov I998, 27-50; Nurmuchanbetov u.a. 1992, 30, 36; Ongar 2008, 221; Parzinger 2004,56 .

62I Siehe Kurgancharakteristik.

622 Nach unserer Nummerierung.

623 Im Herbst 2008 führte hier auch Topoi (A. Gass, M. Blättermann) in Zusammenarbeit mit dem Archäologischen Institut „A. Ch. Margulan“, Almaty (B. Nurmu- chanbetov, Z. Samašev) einen Survey durch. Um beide Surveys zu unterscheiden, wird die Surveyarbeit von Topoi als „Topoi Survey 2008 “ bezeichnet.

624 Grad, Minuten, Sekunden - System. 


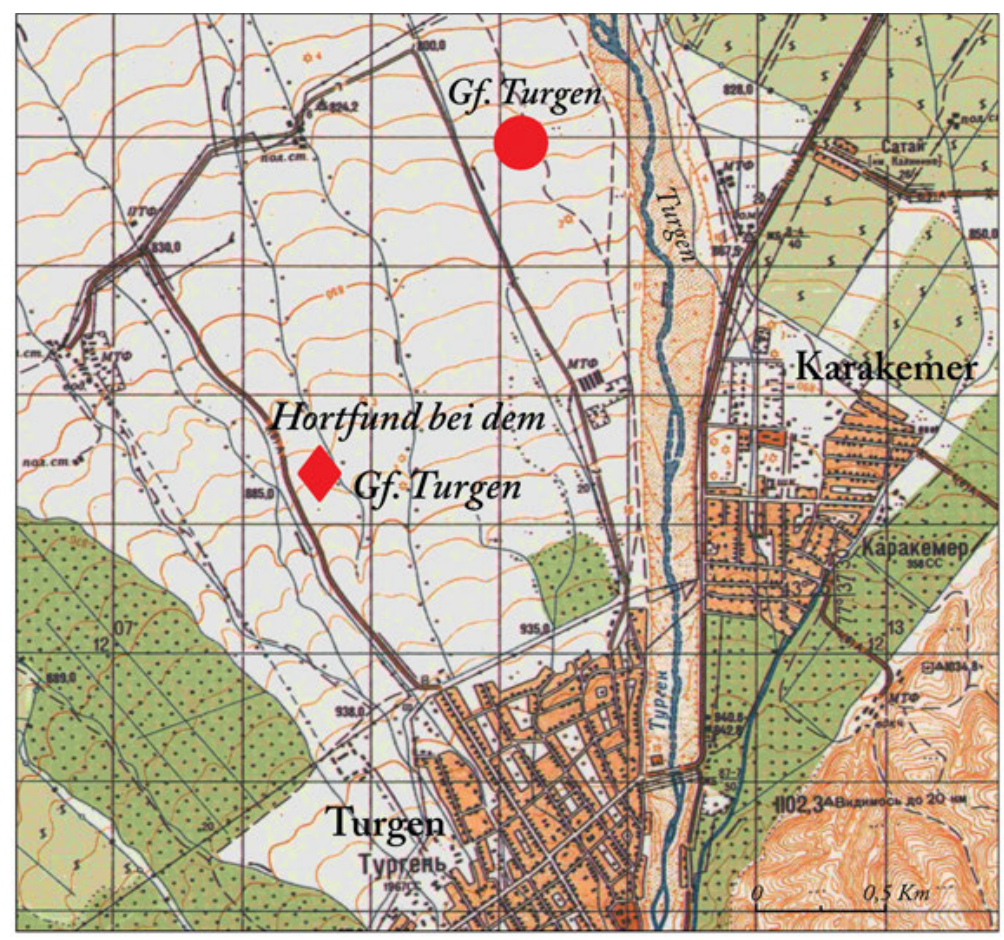

Abb. 190 | Die Lage des Hortfundes beim Gräberfeld

\section{Ergänzung}

Im Spätfrühling 2008 wurde auf dem Acker (Abb. I90), 2,8 km nordnordwestlich des Dorfes Turgen und 3,3 km südwestlich des Gräberfeldes Turgen (ALT 9II m, N43 25.I37 E77 34.6I3), während des Maisanbaus ein Opfertisch ${ }^{625}$ gefunden (Abb. I9I,4), der sich $0,2-0,5 \mathrm{~m}$ unter der modernen Oberfläche befand. Der Opfertisch aus Bronze war $95 \times 9 \mathrm{I} \times \mathrm{I} 5 \mathrm{~cm}$ groß und bestand aus einer Platte, deren Kanten nach oben und noch zusätzlich nach außen gebogen worden waren und ursprünglich vier Tischbeine hatte. Drei davon sind erhalten geblieben, wobei eines davon abgebrochen war. In der Mitte aller vier Seiten wurden im unteren Bereich der Platte vier Haltegriffe angebracht. Gleich nach der Entdeckung des Opfertisches gelangte dieses Objekt ins Restauratorenlabor „Ostrov Krym“ (Almaty). Da die Oberseite der Tischplatte mehrere dunkle rußhaltige Verfärbungen aufwies, wurde beschlossen, diese zu dokumentieren und aufzunehmen (Abb. I9I,5). Nach der Restaurierung wurde der Opfertisch an das Zentrale Staatliche Museum der Republik Kasachstan (Almaty) übergeben $^{626}$.

Im September 2008 wurde die Fundstelle von uns besichtigt. Es wurden GPS-Koordinaten aufgenommen und aufgelesene Gefäßfragmente vom nahen Acker dokumentiert (Abb. I9I,I-3) Sie könnten in direktem Zusammenhang mit der Niederlegung des Opfertisches stehen.

Auflistung der Lesefunde vom Fundort „Hortfund bei dem Gräberfeld Turgen“:

625 Erste Veröffentlichung Tulegenov/Ivanov 2012.
626 Für die Information bezüglich des Opfertisches möchte ich mich herzlich bei B. Nurmuchanbetov, G. Bazarbaeva, G. Džumabekova und K. Altynbekov bedanken. 

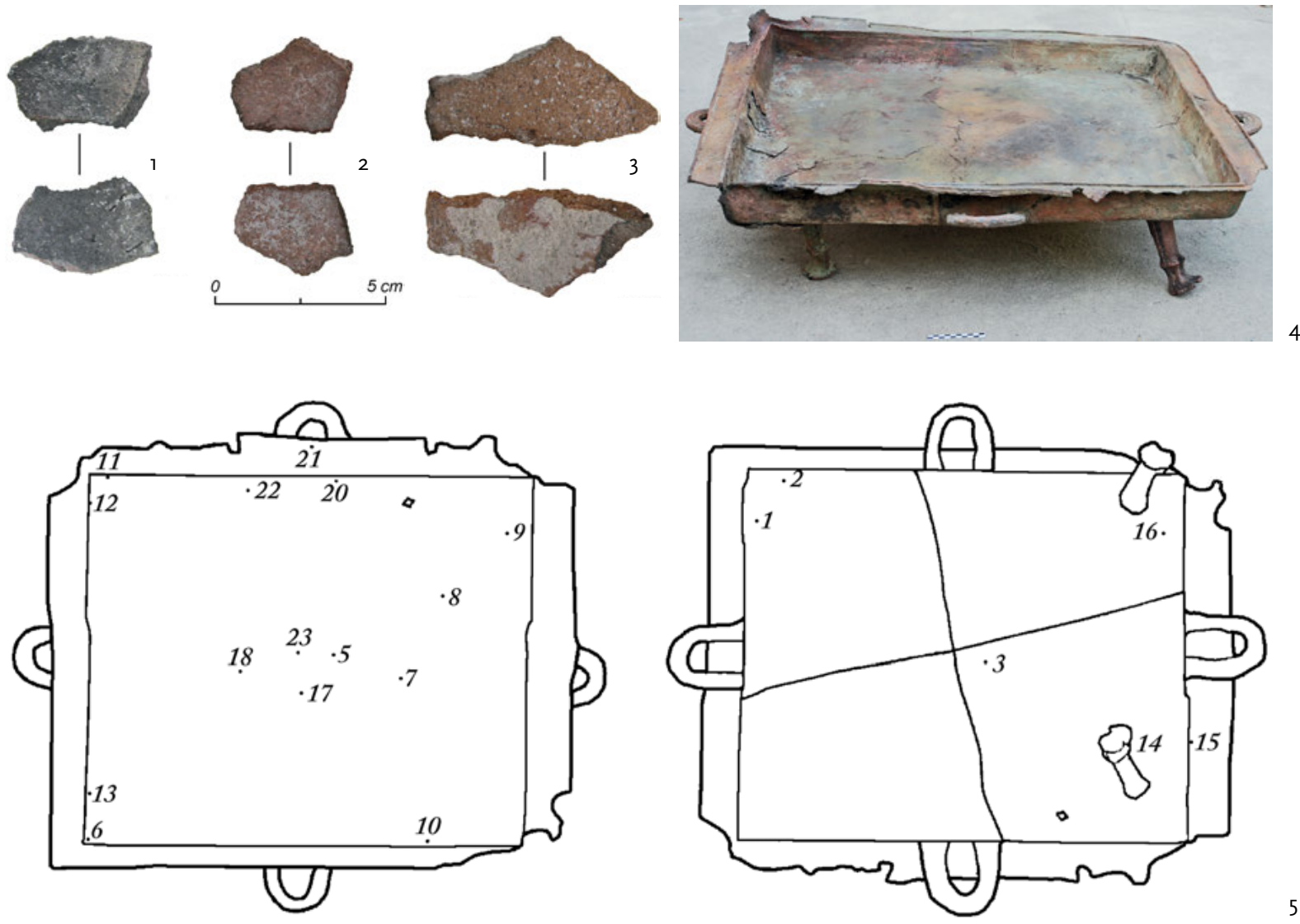

Abb. 19 | Hortfund beim Gräberfeld Turgen; I-3. Lesefunde vom Acker aus der Nähe des Hortfundes; 4. Opfertisch (Foto K. Altynbekov); 5. Schema der Probenentnahme (Skizze K. Altynbekov)

I. Wandscherbe $42 \times 23 \times 8 \mathrm{~mm}$; dunkelgrau bis braun; mittelstark gemagert mit groben Sandpartikeln; eher scheibengedreht; Früheisenzeit, sakische Periode.

2. Wandscherbe $35 \times 29 \times 5 \mathrm{~mm}$; rot; mittelfein gemagert mit leichter weißer Patina an der Außenseite; scheibengedreht (?); Früheisenzeit, sakische Periode.

3. Wandscherbe $68 \times 32 \times 9 \mathrm{~mm}$; rot; grob gemagert mit Sandpartikeln; scheibengedreht (?); Früheisenzeit, sakische Periode.

Im April 2009 wurden die Rußpartikeln aus Brandrückständen der Proben Nr. 5 und Nr. 23 von der Oberseite des Opfertisches ${ }^{627}$ vom Autor zur AMS-14C-Datierung ins Leibniz-Labor für Altersbestimmung und Isotopenforschung der Christian-Albrecht-Universität in Kiel übermittelt. Das Ergebnis zeigte, dass der Opfertisch am Ende des 4. - Anfang des 3. Jh. v. Chr. genutzt wurde.

627 Mein Dank gilt K. Altynbekov, G. Bazarbaeva und G. Džumabekova für das zur Verfügung gestellte Fundmaterial. 
KIA428I5 Probe 5; Restaurierungslabor „Ostrov Krym“

Ruß, an der Oberfläche eines bronzenen Opfertisches, Hortfund bei dem Gräberfeld Turgen, Kasachstan, Gebiet Almaty, Siebenstromland, Entnahmetiefe: $0,2-0,5 \mathrm{~m}$

\begin{tabular}{|c|c|c|c|}
\hline Fraktion & PMC (korrigiert) $\dagger$ & Radiokarbonalter & $d^{13} \mathrm{C}(\%) \neq$ \\
\hline Ruß, Huminsäure, 4,9 mg C & $75,73 \pm 0,18$ & $2235 \pm 20 \mathrm{BP}$ & $-22,55 \pm 0, \mathrm{II}$ \\
\hline Radiocarbon Age: & $\mathrm{BP}$ & \multicolumn{2}{|l|}{$2234 \pm 20$} \\
\hline One Sigma Range: & $\mathrm{cal} \mathrm{BC}$ & \\
\hline (Probability 68,3\%) & & & 29I-23I (Probability 5I,9\%) \\
\hline & & \multicolumn{2}{|c|}{ 2I7-2I5 (Probability o,7\%) } \\
\hline $\begin{array}{l}\text { Two Sigma Range: } \\
\text { (Probability } 05.4 \% \text { ) }\end{array}$ & cal BC & \multicolumn{2}{|c|}{$\begin{array}{l}384-348 \text { (Probability 22,9\%) } \\
316-208 \text { (Probability 72,5\%) }\end{array}$} \\
\hline
\end{tabular}

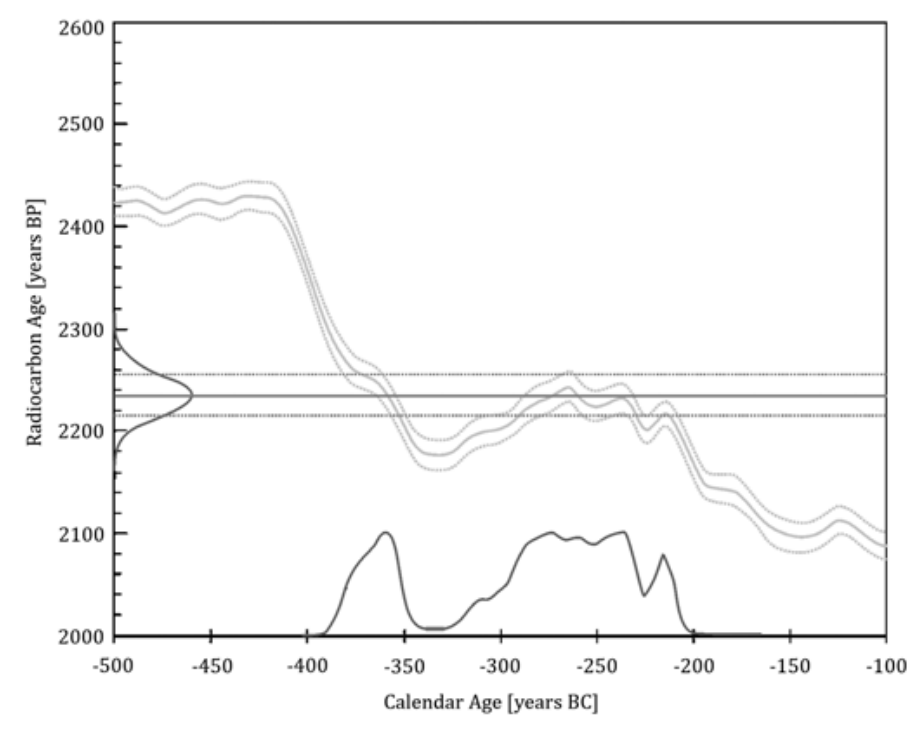

Abb. 192 | Diagramm des Datierungsergebnises der Probe KIA428I5

KIA428I6 Probe 23; Restaurierungslabor „Ostrov Krym“

Ruß, an der Oberfläche eines bronzenen Opfertisches, Hortfund bei dem Gräberfeld Turgen, Kasachstan, GebietAlmaty, Siebenstromland, Entnahmetiefe: $0,2-0,5 \mathrm{~m}$

\begin{tabular}{|c|c|c|c|}
\hline Fraktion & PMC (korrigiert)† & Radiokarbonalter & $d^{13} C(\%) \div$ \\
\hline Ruß, Huminsäure, 4,3 mg C & $76,10 \pm 0,19$ & $2195 \pm 20 \mathrm{BP}$ & $-23,7 \mathrm{I} \pm 0, \mathrm{IO}$ \\
\hline Radiocarbon Age: & $\mathrm{BP}$ & \multicolumn{2}{|l|}{$2194 \pm 20$} \\
\hline One Sigma Range: & cal BC & \multicolumn{2}{|c|}{ 354-292 (Probability 49,2\%) } \\
\hline (Probability 68,3\%) & & \multicolumn{2}{|c|}{ 230-2I7 (Probability IO,2 \%) } \\
\hline & & \multicolumn{2}{|c|}{ 2I5-203 (Probability 8,9\%) } \\
\hline $\begin{array}{l}\text { Two Sigma Range: } \\
\text { (Probability 95,4\%) }\end{array}$ & cal BC & \multicolumn{2}{|c|}{$\begin{array}{l}36 \text { I-27I (Probability 59,I\%) } \\
\text { 264-196 (Probability 36,3\%) }\end{array}$} \\
\hline
\end{tabular}




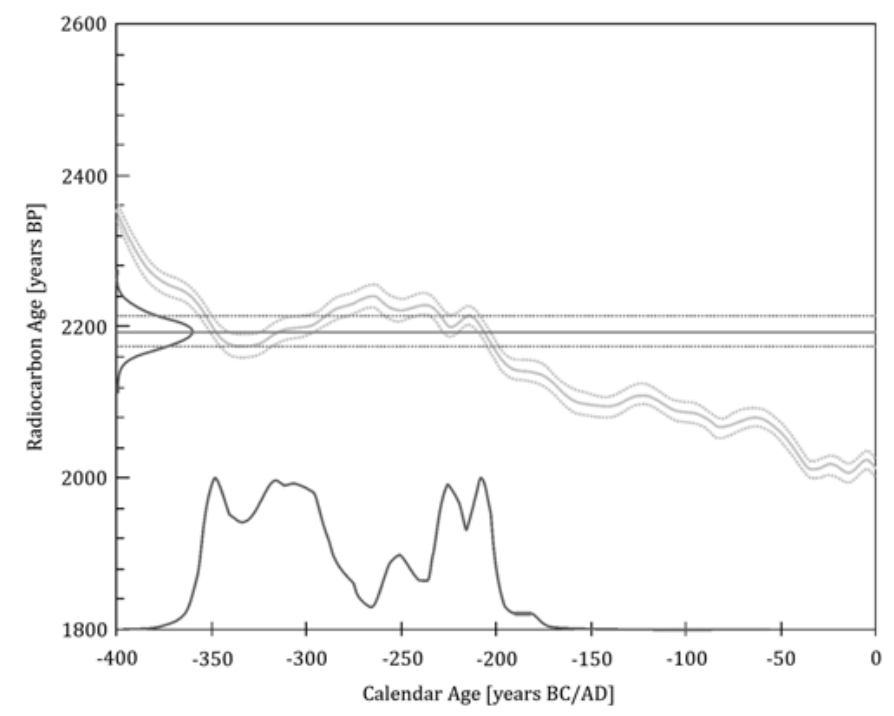

Abb. 193 | Diagramm des Datierungsergebnises der Probe KIA428ı6

Gräberfeld Ulžan [FEZ] (Abb. I94; Karte 3 Nr. 3): ALT 730 m N43 I7.884 E76 52.IO2; Gebiet Almaty (kasach. Алматы облысы); Stadt Almaty (kasach. Алматы); Ausmaß N-S 640 m × O-W $80 \mathrm{~m}$.

Das Gräberfeld Ulžan liegt im nordwestlichen Teil der Stadt Almaty (kasach. Алматы), im Kleinsiedlungsgebiet Ulžan (kasach. Улжан) am rechten, östlichen Ufer des Flusses Bol'šaja Almatinka (kasach. Үлкен Алматы). Die Nekropole zählt fünf Großkurgane, die eine $\mathrm{N}-\mathrm{S}$ verlaufende Kette bilden.

Da das Gräberfeld sich in einem dicht bebauten Gebiet befindet, sind alle Kurgane stark beschädigt und zum Teil zerstört. Im Rahmen von Rettungsgrabungen wurden alle Kurgane im Jahre 2007 komplett oder zum Teil durch das Archäologische Institut „A. Ch. Margulan“ (Almaty) untersucht. Zum Zeitpunkt unserer Untersuchungen im Jahre 2008 blieb nur Kurgan I zum Teil erhalten. Alle weiteren Bauten wurden komplett ausgegraben, so dass teils zerstörte Profilstege und unter Wasser stehende Grabgruben zurückblieben. Der zweite nördlichste Kurgan (nach der Arbeitsnummerierung K4) wurde komplett vom Besitzer des Grundstückes abge-

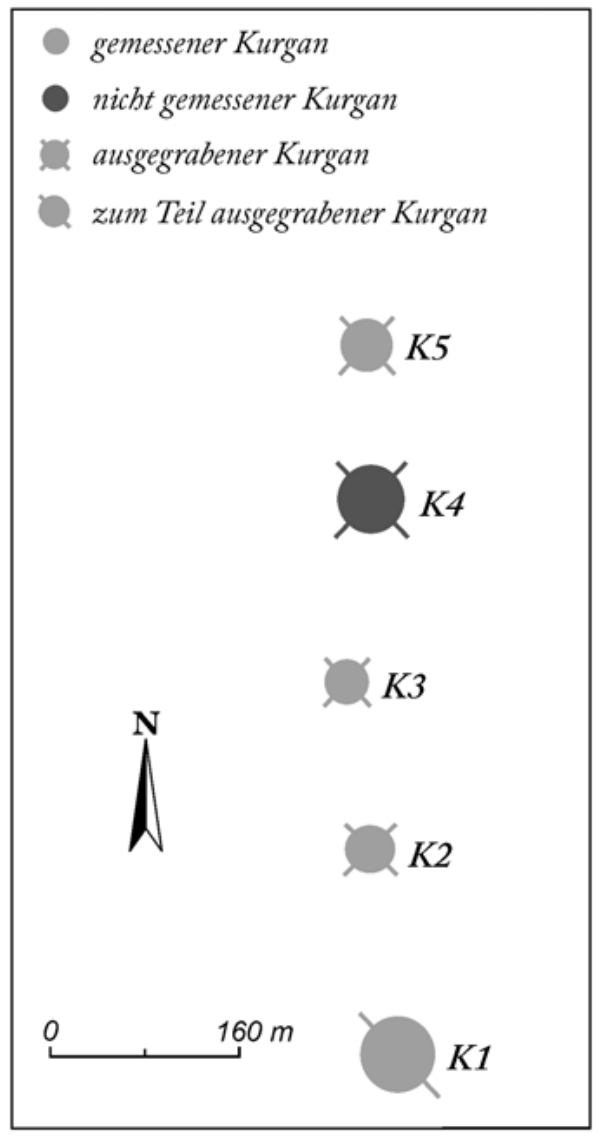

Abb. 194 | Gräberfeldplan Ulžan 
tragen. Am Rande des mittleren Kurgans wurde ein Wall festgestellt. Weitere architektonische Merkmale waren an der Oberfläche nicht sichtbar. Der Durchmesser der Kurgane schwankt zwischen $36 \mathrm{~m}$ und $59 \mathrm{~m}$, die Höhe misst von 3,2 m bis zu $8 \mathrm{~m}$. Bezüglich des Zustandes sowohl der Aufschüttung als auch der Abhänge der Kurgane konnten keine Aussagen gemacht werden, mit Ausnahme von Kurgan 2. Da die Grabungsergebnisse publiziert sind (Nurpeisov u. a 2008, 225-240), kann festgehalten werden, dass der Kurgan beraubt worden war. Zumindest auf den zwei südlichsten Kurganen befanden sich im Mittelalter Halbgrubenhäuser (russ. poluzemljanki).

Aufgrund der Landschaftsplatzierung, inneren Struktur und den aktuellen Grabungsergebnissen ${ }^{628}$ können alle Kurgane des Gräberfeldes der sakischen Periode der Früheisenzeit zugeordnet werden.

Kurgancharakteristik:

Kurgan I

Dm 59 m; H 8 m

Lage: N43 I7.884 E76 52.IO2

Form: abgerundet plattformähnlich

Abhänge: ?

Weitere Konstruktionen: Im mittleren Bereich der Kurgankuppe, leicht nach Süden versetzt, befinden sich die Überreste eines Halbgrubenhaus, das im Mittelalter erbaut worden ist.

Zustand: gesamter Fußbereich des Hügels bebaut und durch moderne Wege und Straßen zerstört; durch die Mitte verläuft ein $\mathrm{O}-\mathrm{W}$ ausgerichteter, $3 \mathrm{~m}$ breiter und $2 \mathrm{~m}$ tiefer Suchschnitt

Bemerkungen: In 2007 wurde der Kurgan durch die Rettungsgrabung des Archäologischen Institutes „A. Ch. Margulan“ unter der Leitung von Z. Samašev und M. Nurpeisov zum Teil untersucht; durch den Kurgan wurde ein O-W ausgerichteter Suchschnitt gelegt. Allerdings wurde nach Io Tagen Arbeit ${ }^{629}$ die Ausgrabung unterbrochen.

Kurgan 2 (Abb. I95)

Dm 48 m; H 3,2 m

Lage: N43 I7.978 E76 52.086

Form: pyramidenähnlich mit abgeflachter Kuppe

Abhänge:?

Zustand: zwei Drittel der Kurganaufschüttung bereits abgetragen; erhalten sind Teile eines mittleren NW-SO verlaufenden Profilsteges von I,5 m Breite, ein nordöstliches Segment und die Grabgrube in der Mitte des Kurgans

Bemerkungen: 2007 wurde der Kurgan durch die Rettungsgrabung des Archäologischen Institutes „A. Ch. Margulan“ unter der Leitung von M. Nurpeisov ausgegraben (Nurpeisov u.a. 2008, 225-240).

Nach Nurpeisov u.a. 2008:

Zustand (2007): in der Mitte ein Raubtrichter; südlich vom Raubtrichter eine 8-förmige Senke (wie die Untersuchung zeigte, handelte es sich hier um die Überreste eines mittelalterlichen Halbgrubenhauses (russ. polu-

628 An dieser Stelle möchte ich mich für die Information bezüglich der Rettungsgrabungen bei Z. Samašev, M. Nurpeisov, G. Džumabekova und G. Bazarbaeva herzlich bedanken. zemljanka); hier kamen ein fragmentarisch erhaltenes Tandur und Keramik mit Aufgussglasur zum Vorschein); südlicher und östlicher Kurganrandbereich durch Wege zerstört; im nördlichen Bereich des Kurganrandes stand ein Haus; im nordöstlichen Bereich ein Zaun

Kurganaufbau (Abb. I95,4):

- mit Holzbohlen abgedeckte Grabgrube;

- Holzbohlen von Süd- und Nordseiten mit mittelgroßen Steinen $(\mathrm{ab} 35 \times 25 \mathrm{~cm})$ abgedeckt;

- Steinabdeckung und Holzbohlen mit gelbem Lehm überdeckt (Mächtigkeit o,6 m), so dass eine länglichovale Erhebung entstand;

- darüber o,6 m dicke Schicht hellgrauen Lehms;

- darüber O,I-0,2 m mächtige Schicht graubrauen sandigen Lehms;

- Konstruktion letzendlich mit Steinschicht bedeckt;

Die errichtete Halbkugel über der Grabgrube maß I,5-I,6 $\mathrm{m}$ Höhe und $\mathrm{I} 2 \mathrm{~m}$ im Durchmesser (Abb. I95,2-4)

- die Konstruktion ist von einem gestampften Lehmboden umgeben (Mächtigkeit $0,4 \mathrm{~m})$;

- auf der Konstruktion gestampften Lehmziegel $(20 \times 40 \mathrm{~cm})$ mit Lehm-Mörtel (Mächtigkeit $\mathrm{I}, \mathrm{O} \mathrm{m}$ ) verbunden, die eine Plattform bilden;

- Plattform mit einer Schicht sandigen Lehm überzogen (Mächtigkeit ca. $2 \mathrm{~m}$ );

- darüber eine 0,05-0,I5 $\mathrm{m}$ dicke Lehmmörtelschicht;

- darüber weitere Schicht aus sandigem Lehm (Mächtigkeit ca. I m);

- zuletzt eine Steinschicht aus mittelgroßen Steinen $(\mathrm{ab} 30 \times 20 \mathrm{~cm})$, die gesamten Kurgan abdeckt;

629 Nach Aussage von M. Nurpeisov. 

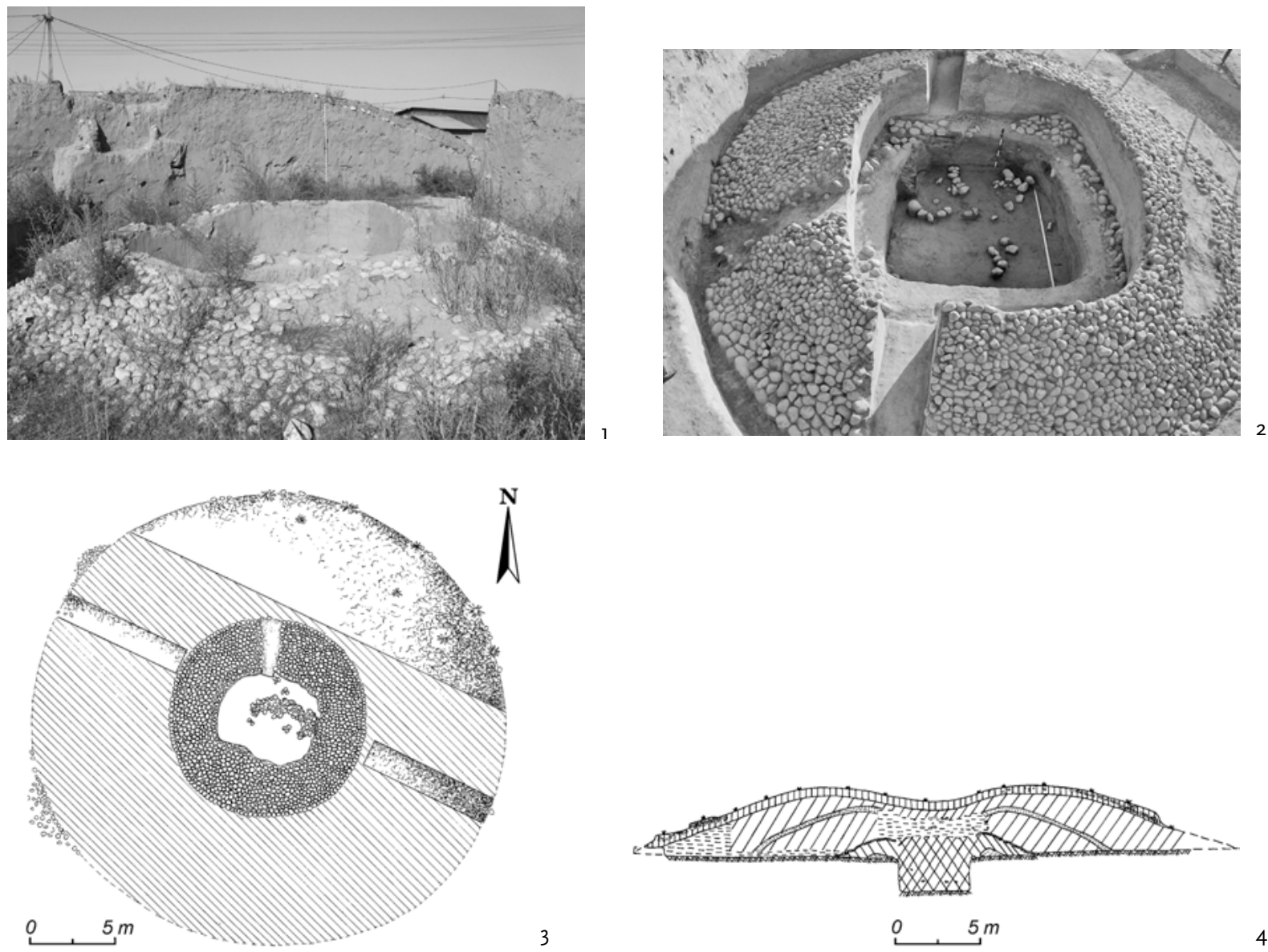

Abb. 195 | Kurgan 2 des Gräberfeldplanes Ulžan; I. Mittlerer Bereich, im Vordergrund die Grabgrube, Blick von S; 2. Grabgrube, Blick von W; 3. Plan; 4. Profil I; 2.-4. nach Nurpeisov u.a. 2008, 235, 239, Abb. I-2.8)

Befund - rechteckige Grabgrube mit abgerundeten Ecken in der Mitte des Kurgans

- Maße: 4,5 ×3,0 × 2,I m

- Ausrichtung: NW-SO

- Weitere Bauelemente: Grabgrube mit Holzbohlen (L 5 m; B o,2 $\mathrm{m}$ ) abgedeckt

- Zustand der Grabgrube: durch mehrfache Beraubung stark zerstört

Bestattung - einzelne zerstreute menschliche Knochen Funde - an der Westwand der Grabgrube ein zerscherbter Krug

Datierung ${ }^{630}$

- Tierknochen von Pferd und Rind

- Tierknochen aus der Kurganaufschüttung Poz-37295: cal AD 545-645

Holzbohle aus der Grabgrube - Poz-37296: cal BC 365-III

630 Nachweise zu den Proben im Einzelnen finden sich im Appendix I Nr. I9 und 20.

\section{Kurgan 3}

Dm $_{3} 6 \mathrm{~m} ; \mathrm{H}_{4} \mathrm{~m}$

Lage: N43 I8.053 E76 52.082

Form: ?

Abhänge:?

Weitere Konstruktionen: Um den Kurganrand herum verläuft ein 2,3 $\mathrm{m}$ hoher und 4,2 $\mathrm{m}$ breiter Wall, dessen inneres Ende sich oberhalb der Steinpackung des Kurgans befindet.

Zustand: zwei Drittel der Kurganaufschüttung bereits abgetragen; beide Enden eines mittleren $\mathrm{W}-\mathrm{O}$ verlaufenden Profilsteges von I,5 $\mathrm{m}$ Breite noch sichtbar sowie ein nördliches und ein südliches Segment

Sonstiges: keine Steine an der Oberfläche der Kurganabdeckung; Die offengelassenen Profile zeigen, dass der Kurgan aus gestampftem Lehm gebaut worden war, dessen Oberfläche noch mit mittelgroßen Steinen (ab $30 \times 20 \mathrm{~cm}$ ) verstärkt wurde; eine innere Abdeckung aus Steinen wurde nicht festgestellt. 
Bemerkungen: 2007 wurde der Kurgan durch die Rettungsgrabung des Archäologischen Institutes „A. Ch. Margulan“ausgegraben;

Die Ergebnisse der Grabung sind noch nicht publiziert, im Archiv des Archäologischen Institutes (Almaty) wurden keine Grabungsberichte gefunden.

Nach Nurpeisov u.a. 2008, 232

- Grabgrube (Form ?, Maße ?, Ausrichtung ?, Bestattung ?, Funde ?) in der Mitte des Kurgans Grabgrube mit Halbbohlen oder Bretter bedeckt

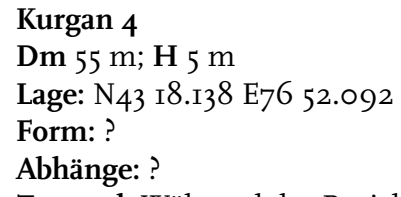
Herbst 2008 wurde der Kurgan vom Grundstücksbesitzer komplett abgetragen und planiert.

Bemerkungen: 2007 wurde der Kurgan durch die Rettungsgrabung des Archäologischen Institutes „A. Ch. Margulan"untersucht;

Die Ergebnisse der Grabung sind noch nicht publiziert, im Archiv des Archäologischen Institutes (Almaty) wurden keine Grabungsberichte gefunden.

Nach Nurpeisov u.a. 2008, 232-233

- Grabgrube in der Mitte des Kurgans

- Form - nicht angegeben

- Maße $3 \times 3,5 \times 2,8 \mathrm{~m}$
- Ausrichtung W-E

- Bestattung - nicht angegeben

Der Kurgan wies eine Steinabdeckung auf.
Kurgan 5
Dm 4I m; H 3,3 m
Lage: N43 I8.207 E76 52.09I
Form: ?
Abhänge:?
Zustand: Kurgan komplett abgetragen; beide Enden eines mittleren $\mathrm{W}-\mathrm{O}$ verlaufenden Profilsteges von I,5 $\mathrm{m}$ Breite noch sichtbar
Sonstiges: an der Oberfläche keine Steine der Kurgan- abdeckung; Die offengelassenen Profile zeigen, dass der Kurgan aus gestampftem Lehm erbaut wurde, des- sen Oberfläche noch mit mittelgroßen Steinen $(\mathrm{ab} 30 \times$ $20 \mathrm{~cm}$ ) verstärkt wurde.
Von der Nordseite des Kurganrandes zur zentral ange- legten Grabgrube führte ein Dromos oder ein Raubgang. Bemerkungen: 2007 wurde der Kurgan durch die Ret- tungsgrabung des Archäologischen Institutes „A. Ch. Margulan“ erforscht. Die Ergebnisse der Grabung sind noch nicht publiziert, im Archiv des Archäologischen Institutes (Almaty) wurden keine Grabungsberichte ge- funden.
Nach Nurpeisov u.a. 2008, 232:
- Grabgrube in der Mitte des Kurgans (Maße ?, Ausrichtung ?, Bestattung ?, Funde ?)
Grabgrube mit Halbbohlen oder mit Brettern bedeckt

Lit.: Nurpeisov u.a. 2008, 225-240; Samašev u.a. 2005a, IoI.

Gräberfeld Žalauly-2 [FEZ] (Abb. I96-I98; Karte 3 Nr. 62): ALT ı820 m N43 03.663 E79 04.653; Gebiet Almaty (kasach. Алматы облысы), Rajymbekskij rajon (kasach. Райымбек ауданы); Ausmaß N-S I $900 \times \mathrm{O}-\mathrm{W} 700 \mathrm{~m}$.

Im Nordwesten des Hochplateaus Kegen (kasach. Кеген), an der Südseite des Bergrückens Kuluktau (kasach. Қулықтау), auf zwei Riedelkanten, die sich auf dem rechten, nördlichen Ufer des Flusses Kegen (kasach. Кеген) befinden sowie südöstlich davon, liegt die Nekropole Žalauly-2. Das Gräberfeld befindet sich $177 \mathrm{~km}$ ostsüdöstlich der Stadt Almaty (kasach. Алматы), І2 km nordwestlich des Dorfes Kegen und 3,2 km westsüdwestlich des Dorfes Žalauly (kasach. Жалаулы). Die Ostkette grenzt im Osten an einen modernen muslimischen Friedhof und befindet sich $200 \mathrm{~m}$ südlich eines Schäfereihofes. Insgesamt wurden auf der Nekropole 68 Kurgane von unterschiedlicher Größe und drei flache, rechteckige Umfriedungen ${ }^{63}$, die sich am Rand des Kurgans 6I (nach der Arbeitsnummerierung) zeigten, festgestellt.

Die Kurgane bilden fünf N-S verlaufende Ketten ${ }^{632}$, wobei die zwei westlichen und die mittlere Kette, die sich auf den Riedelkanten befinden, deren Verlauf wiederholen und eine gewisse Abweichung vom erwähnten Verlauf aufweisen.

63I Chronologische Zuordnung ist ohne Ausgrabung unmöglich.

632 Die erste westliche Kette (K39-K45 und K49-K6o) bestand aus ig kleinen- und mittelgroßen Kurganen; die zweite Westkette $\left(\mathrm{K}_{4} 6-\mathrm{K}_{4} 8\right)$ aus drei Kleinkurganen; die mittlere Kette (KI-K3 8 ) aus 38 Klein-, Mittelgroßund Großkurganen; die zweite Ostkette (K67-K68) aus zwei mittelgroßen Kurganen und die östlichste Kette (K6I-K66) aus sechs mittelgroßen Kurganen sowie aus drei flachen, rechteckigen Umfriedungen. 


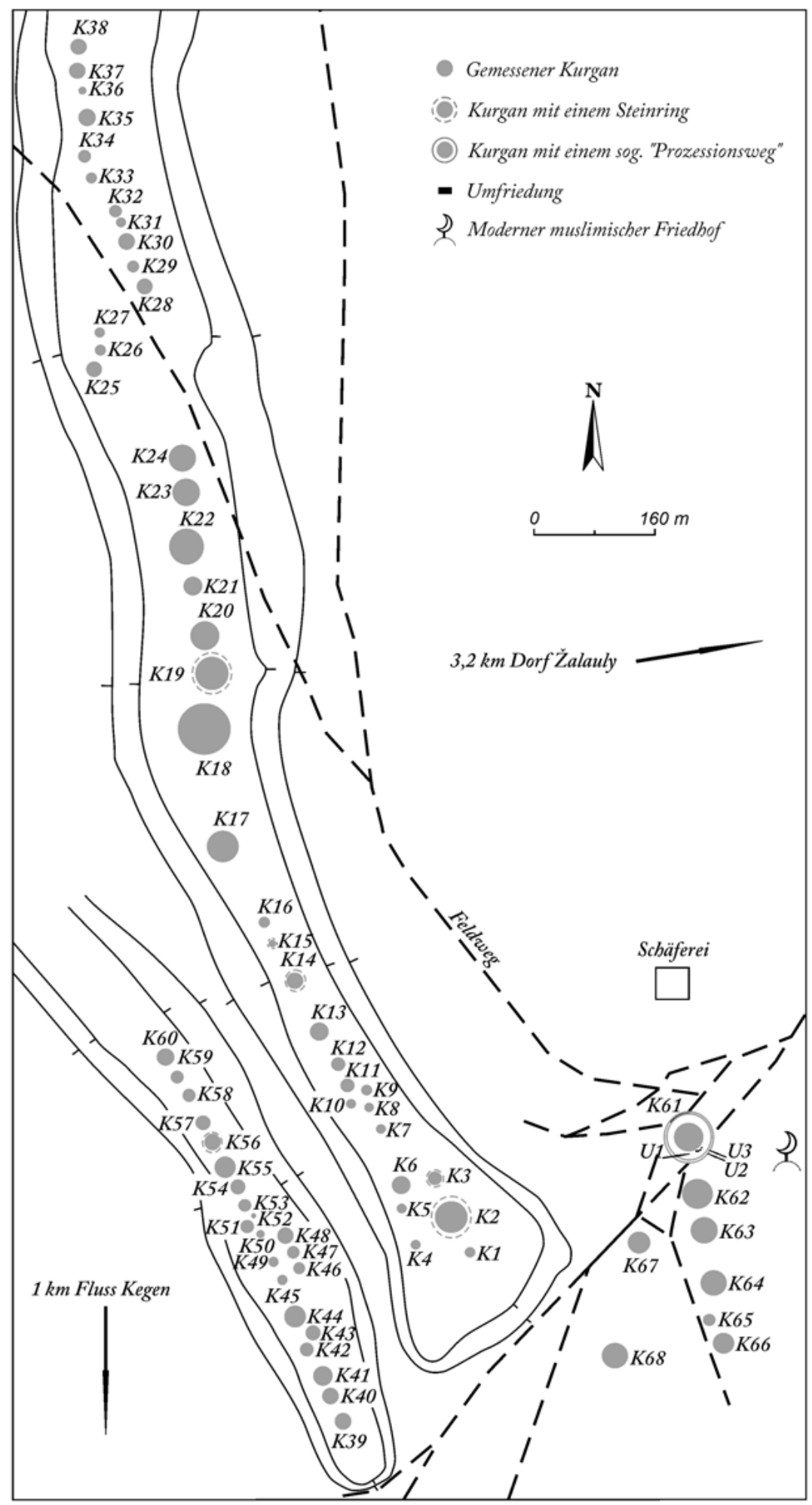

Abb. 196 | Plan des Gräberfeldes Žalauly-2 


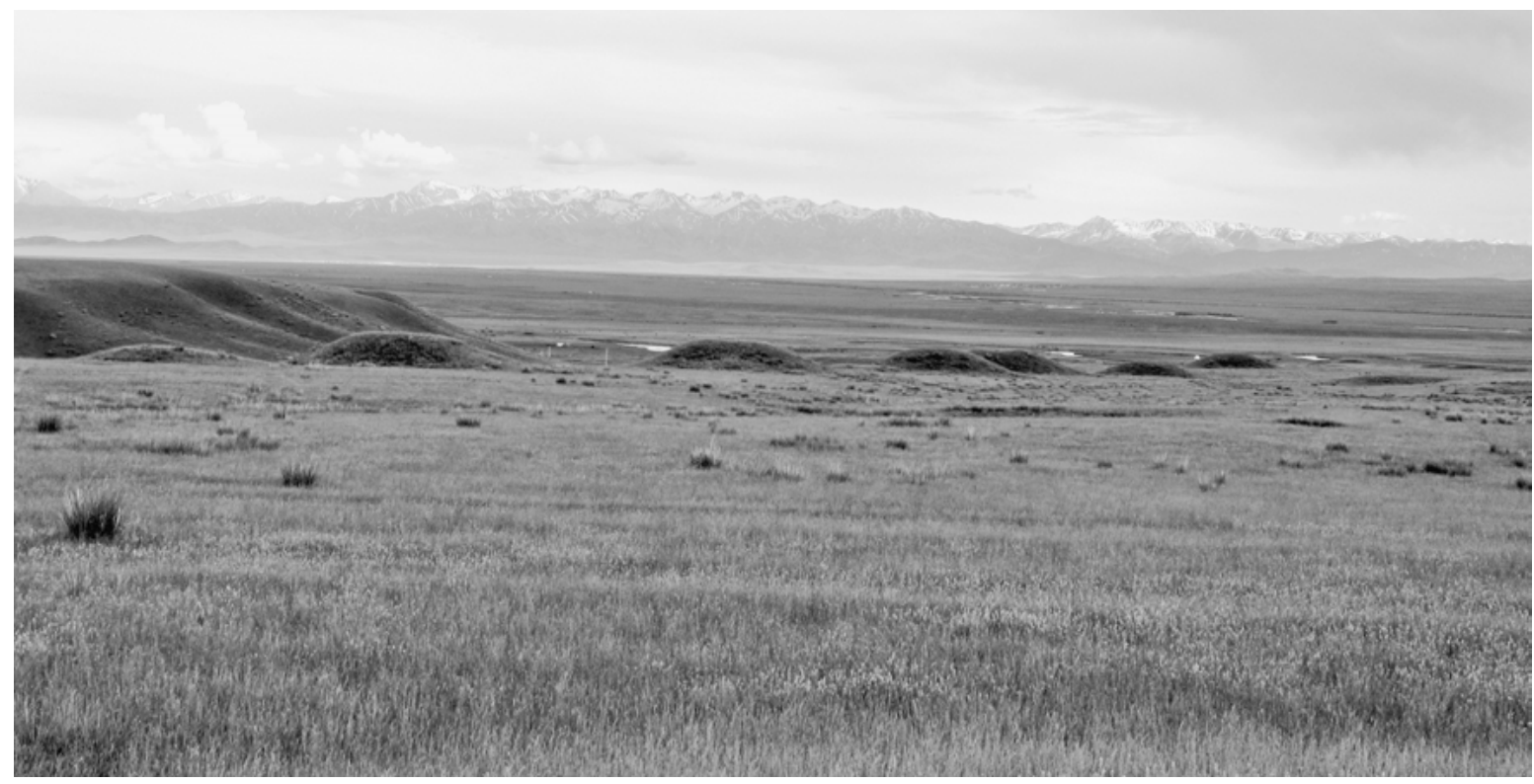

Abb. 197 | Gräberfeld Žalauly-2. Nordhälfte. Blick von NNW

Die Grabanlagen messen zwischen $6 \mathrm{~m}$ und $69 \mathrm{~m}$ im Durchmesser und erreichen Höhen zwischen o,2 $\mathrm{m}$ und $6 \mathrm{~m}$. Jeder dritte Kleinkurgan, jedoch nur ein Großkurgan (K44), weisen keine Senke bzw. keinen Raubtrichter auf. Die restlichen Kurgane weisen ein bis vier Raubtrichter auf. Fast alle Kurgane (6o Objekte) haben drei steile und einen sanften Abhang. Bei 58 Kurganen liegt der sanfte Abhang exakt im Süden, bei zwei weiteren im Südosten. Die übrigen acht Kurgane zeigen aufgrund ihrer geringen Größe keine Merkmale der Aufschüttung. Einen Kurgan der westlichen und fünf Kurgane der mittleren Ketten sind jeweils von einem Steinkreis umgeben. Um den größten Kurgan (K6I) der östlichsten Kette verläuft ein umlaufender sog. Prozessionsweg (? $\left.{ }^{633}\right)$. Die äußere Markierung dieses Weges wurde durch große Steine angezeigt. Die übrigen Kurgane weisen keine architektonischen Merkmale auf.

Anhand der Landschaftsplatzierung, der Struktur und äußeren Erscheinungsform können alle Kurgane des Gräberfeldes der sakischen Periode der Früheisenzeit zugeordnet werden.

Kurgancharakteristik:

Mittlere Kette

Kurgan I (Kleinkurgan)

Dm I2 m; H o,4 m

Lage: N43 03.266 E79 04.888; südlichster Kurgan der Kette

Form: abgerundete Erhebung

Abhänge: keine Merkmale

Zustand: in der Mitte ein Raubtrichter

Sonstiges: Oberfläche mit mittelgroßen Steinen (ab 60 $\times 40 \times 20 \mathrm{~cm}$ ) bedeckt

633 Da durch die Peripherie des Kurgans mindestens vier Feldwege verlaufen, ist der Erhaltungszustand des sog. „Prozessionsweges“ sehr schlecht.

\section{Kurgan 2}

Dm 36 m; Dm Steinkreis 57 m; H 3,5 m

Lage: N43 03.29I E79 04.872

Form: abgerundet, plattformähnlich mit abgeflachter Kuppe

Abhänge: drei steile, südlicher sanft

Weitere Konstruktionen: Um den Kurgan herum verläuft in einem Abstand von I0,5 $\mathrm{m}$ ein Steinkreis, der aus mittelgroßen Steinen $(\mathrm{ab} 60 \times 40 \times 30 \mathrm{~cm})$ gebaut wurde; der Steinkreis ist nur zum Teil erhalten.

Zustand: in der Mitte ein Raubtrichter Sonstiges: keine Steine an der Oberfläche 


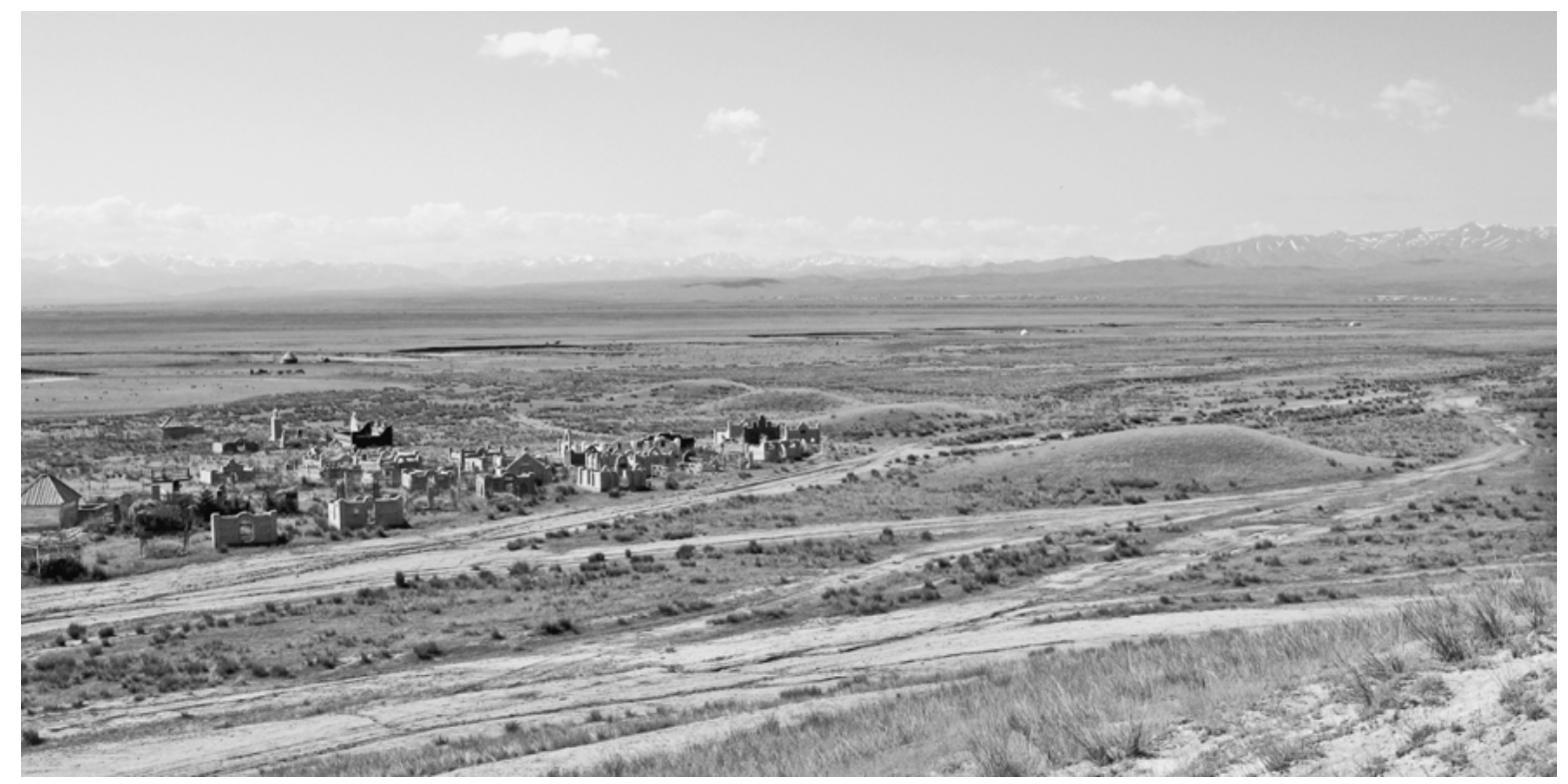

Abb. 198 | Gräberfeld Žalauly-2. Nordhälfte. Blick von NO

Kurgan 3 (Kleinkurgan)

Dm I5 m; Dm Steinkreis 25 m; H 0,5 m

Lage: N43 03.320 E79 04.857

Form: niedrig, abgerundet, mit abgeflachter Kuppe

Abhänge: drei steile, südlicher sanft

Weitere Konstruktionen: Um den Kurgan herum verläuft im Abstand von $5 \mathrm{~m}$ ein Steinkreis, der aus mittelgroßen Steinen $(\mathrm{ab} 30 \times 10 \times 5 \mathrm{~cm})$ gebaut wurde; der Steinkreis ist nur zum Teil erhalten.

Zustand: in der Mitte ein Raubtrichter

Sonstiges: keine Steine an der Oberfläche

Kurgan 4 (Kleinkurgan)

Dm I2 m; H o, 5 m

Lage: N43 03.273 E79 04.835

Form: niedrig, abgerundet, mit abgeflachter Kuppe

Abhänge: drei steile, südlicher sanft

Zustand: in der Mitte ein Raubtrichter

Sonstiges: Oberfläche mit kleinen Steinen $(\mathrm{ab}$ I $5 \times 5 \times$ $2 \mathrm{~cm}$ ) bedeckt

Kurgan 5 (Kleinkurgan)

Dm I2 m; H o, 4 m

Lage: N43 03.300 E79 04.823

Form: niedrig, abgerundet, mit abgeflachter Kuppe

Abhänge: drei steile, südlicher sanft

Zustand: in der Mitte ein Raubtrichter

Sonstiges: Oberfläche mit kleinen Steinen $(\mathrm{ab}$ I $5 \times 5 \times$ $2 \mathrm{~cm}$ ) bedeckt

Kurgan 6 (Kleinkurgan)

Dm 23 m; H o, 5 m

Lage: N43 03.3I7 E79 04.823
Form: niedrig, abgerundet, mit abgeflachter Kuppe

Abhänge: drei steile, südlicher sanft

Zustand: keine Senke, kein Raubtrichter

Sonstiges: an der Oberfläche einzelne mittelgroße Steine $(25 \times 5 \mathrm{~cm})$

Kurgan 7 (Kleinkurgan)

Dm I2 $\mathrm{m} ; \mathrm{H} \circ, 5 \mathrm{~m}$

Lage: N43 03.357 E79 04.806

Form: niedrig, abgerundet, mit abgeflachter Kuppe

Abhänge: drei steile, südlicher sanft

Zustand: keine Senke, kein Raubtrichter

Sonstiges: Oberfläche mit kleinen Steinen $(\mathrm{ab} 20 \times$ IO $\times$ $5 \mathrm{~cm}$ ) bedeckt

Kurgan 8 (Kleinkurgan)

Dm I2 m; H o, 5 m

Lage: N43 03.373 E79 04.796

Form: niedrig, abgerundet, mit abgeflachter Kuppe

Abhänge: drei steile, südlicher sanft

Zustand: keine Senke, kein Raubtrichter

Sonstiges: an der Oberfläche einzelne mittelgroße Steine $(25 \times 5 \mathrm{~cm})$

Kurgan 9 (Kleinkurgan)

Dm I4 m; H I m

Lage: N43 03.386 E79 04.795

Form: niedrig, abgerundet, mit abgeflachter Kuppe

Abhänge: drei steile, südlicher sanft

Zustand: keine Senke, kein Raubtrichter

Sonstiges: an der Oberfläche einzelne mittelgroße Steine $(25 \times 5 \mathrm{~cm})$ 

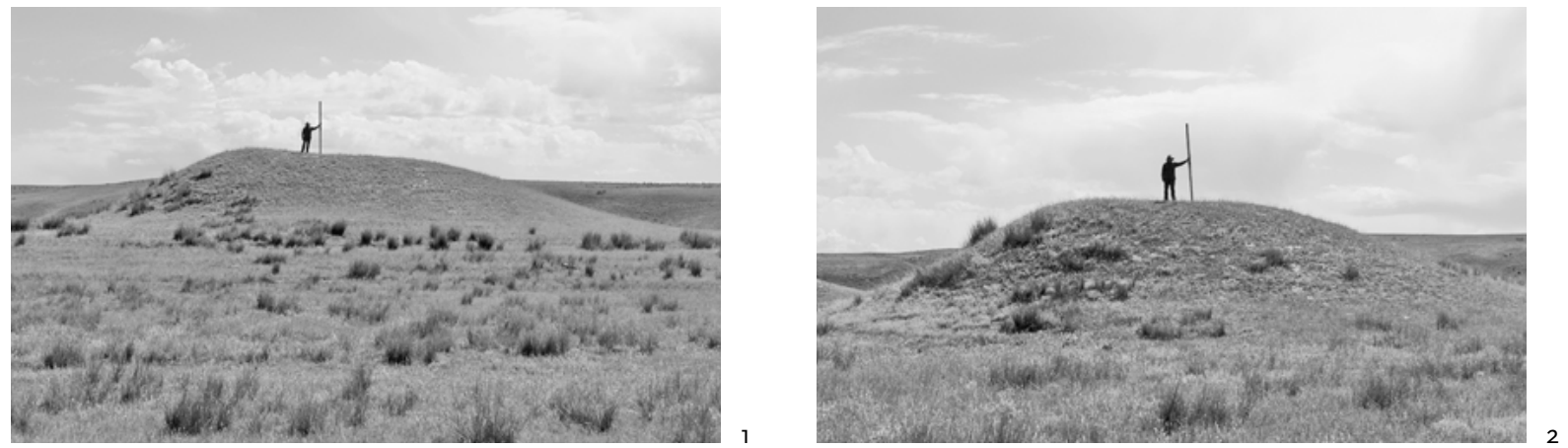

Abb. 199 | Kurgane des Gräberfeldes Žalauly-2, Blick von W; I. Kurgan I7; 2. Kurgan 20

Kurgan ıо (Kleinkurgan)

Dm I2 m; H o,5 m

Lage: N43 03.377 E79 04.778

Form: niedrig, abgerundet, mit abgeflachter Kuppe

Abhänge: drei steile, südlicher sanft

Zustand: keine Senke, kein Raubtrichter

Sonstiges: keine Steine an der Oberfläche

Kurgan II (Kleinkurgan)

Dm I7 m; H I $\mathrm{m}$

Lage: N43 03.393 E79 04.776

Form: niedrig, abgerundet, mit abgeflachter Kuppe

Abhänge: drei steile, südlicher sanft

Zustand: keine Senke, kein Raubtrichter

Sonstiges: an der Oberfläche einzelne mittelgroße Steine $(25 \times 5 \mathrm{~cm})$

Kurgan I2 (Kleinkurgan)

Dm I8 m; H I m

Lage: N43 03.406 E79 04.767

Form: niedrig, abgerundet, mit abgeflachter Kuppe

Abhänge: drei steile, südlicher sanft

Zustand: in der Mitte ein Raubtrichter

Sonstiges: keine Steine an der Oberfläche

Kurgan I3 (Kleinkurgan)

Dm 24 m; H I m

Lage: N43 03.428 E79 04.749

Form: niedrig, abgerundet, mit abgeflachter Kuppe

Abhänge: drei steile, südlicher sanft

Zustand: keine Senke, kein Raubtrichter

Sonstiges: an der Oberfläche einzelne mittelgroße

Steine $(\mathrm{ab} 40 \times 10 \times 5 \mathrm{~cm})$

Kurgan I4 (Kleinkurgan)

Dm 20 m; Dm Steinkreis 23 m; H I m

Lage: N43 03.464 E79 04.729

Form: niedrig, abgerundet, plattformähnlich mit abgeflachter Kuppe

Abhänge: drei steile, südlicher sanft

Weitere Konstruktionen: Um den Kurgan herum verläuft im Abstand von I,5 m ein Steinkreis, der aus mit- telgroßen Steinen $(\mathrm{ab} 30 \times 20 \mathrm{~cm})$ gebaut wurde; der Steinkreis ist nur zum Teil erhalten.

Zustand: in der Mitte ein Raubtrichter

Sonstiges: an der Oberfläche einzelne kleine Steine $(\mathrm{I} 5 \times 5 \mathrm{~cm})$

Kurgan I5 (Kleinkurgan)

Dm 9 m; Dm Steinkreis I5 m; H o,7 m

Lage: N43 03.495 E79 04.709

Form: niedrig, abgerundet, mit abgeflachter Kuppe

Abhänge: drei steile, südlicher sanft

Weitere Konstruktionen: Um den Kurgan herum verläuft im Abstand von $3 \mathrm{~m}$ ein Steinkreis, der aus mittelgroßen Steinen (ab $30 \times$ I $5 \mathrm{~cm}$ ) gebaut wurde; der Steinkreis ist nur zum Teil erhalten.

Zustand: drei Raubtrichter

Sonstiges: die Oberfläche ist mit mittelgroßen (bis zum Schotter) Steinen bedeckt

Kurgan I6 (Kleinkurgan)

Dm I4 m; H o,7 m

Lage: N43 03.5II E79 04.70I

Form: niedrig, abgerundet, mit abgeflachter Kuppe

Abhänge: drei steile, südlicher sanft

Zustand: in der Mitte ein Raubtrichter

Sonstiges: an der Oberfläche einzelne kleine Steine $(\mathrm{I} 5 \times 5 \mathrm{~cm})$

Kurgan I7 (Abb. I99,I)

Dm 42 m; H 5 m

Lage: N43 03.57I E79 04.666

Form: abgerundet, plattformähnlich mit abgeflachter Kuppe

Abhänge: drei steile, südlicher sanft

Zustand: in der Mitte ein Raubtrichter

Sonstiges: an der Oberfläche einzelne mittelgroße Steine $(\mathrm{ab} 30 \times 20 \times 10 \mathrm{~cm})$

\section{Kurgan 18}

Dm 69 m; H 3,5 m

Lage: N43 03.663 E79 04.653

Form: abgerundet, plattformähnlich mit abgeflachter Kuppe 
Abhänge: drei steile, südlicher sanft

Zustand: in der Mitte ein Raubtrichter

Sonstiges: keine Steine an der Oberfläche

\section{Kurgan 19}

Dm 43 m; Dm Steinkreis 57 m; H 6 m

Lage: N43 03.695 E79 04.664

Form: abgerundet, plattformähnlich mit abgeflachter Kuppe

Abhänge: drei steile, südlicher sanft

Weitere Konstruktionen: Um den Kurgan herum verläuft im Abstand von $7 \mathrm{~m}$ ein Steinkreis, der aus mittelgroßen Steinen (ab $35 \times$ I $5 \mathrm{~cm}$ ) gebaut wurde; der Steinkreis ist nur zum Teil erhalten.

Zustand: in der Mitte ein Raubtrichter

Sonstiges: keine Steine an der Oberfläche

Kurgan 20 (Abb. I99,2)

Dm 36 m; H 4,5 m

Lage: N43 03.723 E79 04.66I

Form: abgerundet, plattformähnlich mit abgeflachter Kuppe

Abhänge: drei steile, südlicher sanft

Zustand: in der Mitte ein Raubtrichter

Sonstiges: an der Oberfläche einzelne mittelgroße

Steine $(\mathrm{ab} 25 \times \mathrm{I} 5 \times \mathrm{IO} \mathrm{cm})$

Kurgan 2I (Kleinkurgan)

Dm 20 m; H I, 5 m

Lage: N43 03.757 E79 04.650

Form: abgerundet, plattformähnlich mit abgeflachter Kuppe

Abhänge: drei steile, südlicher sanft

Zustand: in der Mitte ein Raubtrichter

Sonstiges: an der Oberfläche einzelne mittelgroße

Steine $(\mathrm{ab} 25 \times \mathrm{I} 5 \times$ IO $\mathrm{cm})$

\section{Kurgan 22}

Dm 44 m; H 3,5 m

Lage: N43 03.779 E79 04.645

Form: abgerundet, plattformähnlich mit abgeflachter Kuppe

Abhänge: drei steile, südlicher sanft

Zustand: in der Mitte ein Raubtrichter

Sonstiges: keine Steine an der Oberfläche

\section{Kurgan 23}

Dm 34 m; H 3 m

Lage: N43 03.826 E79 04.649

Form: abgerundet, plattformähnlich mit abgeflachter Kuppe

Abhänge: drei steile, südlicher sanft

Zustand: in der Mitte ein Raubtrichter

Sonstiges: keine Steine an der Oberfläche

Kurgan 24 (Kleinkurgan)

Dm 36 m; H I, 6 m

Lage: N43 03.849 E79 04.644
Form: abgerundet, plattformähnlich mit abgeflachter Kuppe

Abhänge: drei steile, südlicher sanft

Zustand: keine Senke, kein Trichter

Sonstiges: keine Steine an der Oberfläche

Kurgan 25 (Kleinkurgan)

Dm i9 m; H I,2 m

Lage: N43 03.915 E79 04.565

Form: abgerundet, plattformähnlich mit abgeflachter

Kuppe

Abhänge: drei steile, südlicher sanft

Zustand: in der Mitte ein Raubtrichter

Sonstiges: keine Steine an der Oberfläche

Kurgan 26 (Kleinkurgan)

Dm I4 m; H o,3 m

Lage: N43 03.929 E79 04.568

Form: flache abgerundete Erhebung

Abhänge: keine Merkmale

Zustand: keine Senke, kein Raubtrichter

Sonstiges: keine Steine an der Oberfläche

Kurgan 27 (Kleinkurgan)

Dm I2 m; H o,2 m

Lage: N43 03.942 E79 04.568

Form: flache abgerundete Erhebung

Abhänge: drei steile, südlicher sanft

Zustand: keine Senke, kein Raubtrichter

Sonstiges: keine Steine an der Oberfläche

Kurgan 28 (Kleinkurgan)

Dm 20 m; H I m

Lage: N43 03.973 E79 04.6I5

Form: flache abgerundete Erhebung

Abhänge: keine Merkmale

Zustand: keine Senke, kein Raubtrichter

Sonstiges: an der Oberfläche einzelne mittelgroße Steine $(\mathrm{ab} 25 \times 10 \times 5 \mathrm{~cm})$

Kurgan 29 (Kleinkurgan)

Dm I4 m; H o, 5 m

Lage: N43 03.989 E79 04.604

Form: flache abgerundete Erhebung

Abhänge: drei steile, südlicher sanft

Zustand: keine Senke, kein Raubtrichter

Sonstiges: keine Steine an der Oberfläche

Kurgan 30 (Kleinkurgan)

Dm 2I m; H I m

Lage: N43 04.007 E79 04.599

Form: flache abgerundete Erhebung

Abhänge: keine Merkmale

Zustand: in der Mitte ein Raubtrichter

Sonstiges: Oberfläche mit mittelgroßen Steinen (bis zu Schottergröße) bedeckt 
Kurgan 3I (Kleinkurgan)

Dm I2 m; H o,2 m

Lage: N43 04.02I E79 04.595

Form: flache abgerundete Erhebung

Abhänge: keine Merkmale

Zustand: keine Senke, kein Raubtrichter

Sonstiges: keine Steine an der Oberfläche

Kurgan 32 (Kleinkurgan)

Dm I6 m; H o,5 m

Lage: N43 04.029 E79 04.589

Form: flache abgerundete Erhebung

Abhänge: drei steile, südlicher sanft

Zustand: in der Mitte ein Raubtrichter

Sonstiges: an der Oberfläche einzelne mittelgroße Steine $(\mathrm{ab} 20 \times 10 \times 5 \mathrm{~cm})$

Kurgan 33 (Kleinkurgan)

Dm I4 m; H o,2 m

Lage: N43 04.053 E79 04.567

Form: flache abgerundete Erhebung

Abhänge: keine Merkmale

Zustand: in der Mitte ein Raubtrichter

Sonstiges: an der Oberfläche einzelne mittelgroße

Steine $(\mathrm{ab} 20 \times 10 \times 5 \mathrm{~cm})$

Kurgan 34 (Kleinkurgan)

Dm I6 m; H O, 5 m

Lage: N43 04.070 E79 04.56I

Form: flache abgerundete Erhebung

Abhänge: drei steile, südlicher sanft

Zustand: in der Mitte ein Raubtrichter

Sonstiges: an der Oberfläche einzelne mittelgroße

Steine $(\mathrm{ab} 20 \times 10 \times 5 \mathrm{~cm})$

Kurgan 35 (Kleinkurgan)

Dm 2I m; H I m

Lage: N43 04.099 E79 04.567

Form: abgerundet, plattformähnlich mit abgeflachter Kuppe

Abhänge: drei steile, südlicher sanft

Zustand: in der Mitte ein Raubtrichter

Sonstiges: an der Oberfläche einzelne mittelgroße

Steine $(\mathrm{ab} 40 \times 20 \times 10 \mathrm{~cm})$

Kurgan 36 (Kleinkurgan)

Dm Io m; H o,3 m

Lage: N43 04.II7 E79 04.563

Form: flache abgerundete Erhebung

Abhänge: keine Merkmale

Zustand: in der Mitte ein Raubtrichter

Sonstiges: Oberfläche mit mittelgroßen (bis zu Schottergröße) Steinen bedeckt
Kurgan 37 (Kleinkurgan)

Dm 20 m; H I m

Lage: N43 04.I3I E79 04.559

Form: abgerundet, plattformähnlich mit abgeflachter Kuppe

Abhänge: drei steile, südlicher sanft

Zustand: in der Mitte ein Raubtrichter

Sonstiges: an der Oberfläche einzelne mittelgroße

Steine $(\mathrm{ab} 35 \times 20 \times 5 \mathrm{~cm})$

Kurgan 38 (Kleinkurgan)

Dm 20 m; H I, 5 m

Lage: N43 04.I49 E79 04.56I; nördlichster Kurgan der Kette

Form: abgerundet, plattformähnlich mit abgeflachter Kuppe

Abhänge: drei steile, südlicher sanft

Zustand: in der Mitte ein Raubtrichter

Sonstiges: an der Oberfläche einzelne mittelgroße

Steine $(\mathrm{ab} 35 \times 20 \times 5 \mathrm{~cm})$

Westlichste Kurgankette

Kurgan 39 (Kleinkurgan)

Dm 2I m; H I m

Lage: N43 03.I5I E79 04.756; südlichster Kurgan der Kette

Form: niedrig, abgerundet, plattformähnlich mit abge-

flachter Kuppe

Abhänge: drei steile, südlicher sanft

Zustand: in der Mitte ein Raubtrichter

Sonstiges: keine Steine an der Oberfläche

Kurgan 40 (Kleinkurgan)

Dm 2I m; H o,7 m

Lage: N43 03.I69 E79 04.743

Form: abgerundet, mit abgeflachter Kuppe

Abhänge: drei steile, südlicher sanft

Zustand: keine Senke, kein Raubtrichter

Sonstiges: keine Steine an der Oberfläche

Kurgan 4I (Kleinkurgan)

Dm 25 m; H I m

Lage: N43 03.I86 E79 04.738

Form: abgerundet, plattformähnlich mit abgeflachter Kuppe

Abhänge: drei steile, südlicher sanft

Zustand: keine Senke, kein Raubtrichter

Sonstiges: keine Steine an der Oberfläche

Kurgan 42 (Kleinkurgan)

Dm I7 m; H I m

Lage: N43 03.202 E79 04.723

Form: abgerundet, plattformähnlich mit abgeflachter Kuppe

Abhänge: drei steile, südlicher sanft

Zustand: keine Senke, kein Raubtrichter

Sonstiges: keine Steine an der Oberfläche 
Kurgan 43 (Kleinkurgan)

Dm I9 m; H I, 5 m

Lage: N43 03.2I5 E79 04.732

Form: abgerundet, plattformähnlich mit abgeflachter Kuppe

Abhänge: drei steile, südlicher sanft

Zustand: keine Senke, kein Raubtrichter

Sonstiges: an der Oberfläche einzelne mittelgroße

Steine $(\mathrm{ab} 25 \times 15 \times 5 \mathrm{~cm})$

\section{Kurgan 44}

Dm 27 m; H 3 m

Lage: N43 03.225 E79 04.7I4

Form: abgerundet, plattformähnlich mit abgeflachter Kuppe

Abhänge: drei steile, südlicher sanft

Zustand: keine Senke, kein Raubtrichter

Sonstiges: an der Oberfläche einzelne mittelgroße

Steine $(\mathrm{ab} 30 \times \mathrm{I} 5 \times 5 \mathrm{~cm})$

Kurgan 45 (Kleinkurgan)

Dm I2 m; H o, 3 m

Lage: N43 03.252 E79 04.702

Form: flache abgerundete Erhebung

Abhänge: drei steile, südlicher sanft

Zustand: in der Mitte ein Raubtrichter

Sonstiges: an der Oberfläche einzelne mittelgroße

Steine $(\mathrm{ab} 30 \times \mathrm{I} 5 \times 5 \mathrm{~cm})$

Kurgan 49 (Kleinkurgan)

Dm I2 m; H o, 5 m

Lage: N43 03.265 E79 04.694

Form: abgerundete Erhebung mit abgeflachter Kuppe

Abhänge: drei steile, südlicher sanft

Zustand: keine Senke, kein Raubtrichter

Sonstiges: an der Oberfläche einzelne mittelgroße

Steine $(\mathrm{ab} 30 \times 15 \times 5 \mathrm{~cm})$

Kurgan 50 (Kleinkurgan)

Dm Io m; H o,5 m

Lage: N43 03.286 E79 04.683

Form: abgerundete Erhebung mit abgeflachter Kuppe

Abhänge: drei steile, südlicher sanft

Zustand: keine Senke, kein Raubtrichter

Sonstiges: keine Steine an der Oberfläche

Kurgan 5I (Kleinkurgan)

Dm I 5 m; H I m

Lage: N43 03.293 E79 04.672

Form: abgerundete Erhebung mit abgeflachter Kuppe

Abhänge: drei steile, südlicher sanft

Zustand: in der Mitte ein Raubtrichter

Sonstiges: keine Steine an der Oberfläche

Kurgan $5 \mathbf{2}$ (Kleinkurgan)

Dm 6 m; H o,2 m

Lage: N43 03.30I E79 04.678

Form: abgerundete Erhebung
Abhänge: keine Merkmale

Zustand: in der Mitte ein Raubtrichter

Sonstiges: keine Steine an der Oberfläche

Kurgan 53 (Kleinkurgan)

Dm I5 m; H I,3 m

Lage: N43 03.307 E79 04.669

Form: abgerundet, plattformähnlich mit abgeflachter

Kuppe

Abhänge: drei steile, südlicher sanft

Zustand: in der Mitte ein Raubtrichter

Sonstiges: keine Steine an der Oberfläche

Kurgan 54

Dm 20 m; H 2 m

Lage: $\mathrm{N}_{43} 03.322 \mathrm{E} 7904.664$

Form: abgerundet, plattformähnlich mit abgeflachter

Kuppe

Abhänge: drei steile, südlicher sanft

Zustand: in der Mitte ein Raubtrichter

Sonstiges: an der Oberfläche einzelne mittelgroße

Steine $(\mathrm{ab} 25 \times \mathrm{I} 5 \times 5 \mathrm{~cm})$

Kurgan 55

Dm 27 m; H 3 m

Lage: N43 03.337 E79 04.65I

Form: abgerundet, plattformähnlich mit abgeflachter Kuppe

Abhänge: drei steile, südlicher sanft

Zustand: in der Mitte ein Raubtrichter

Sonstiges: keine Steine an der Oberfläche

Kurgan 56 (Kleinkurgan)

Dm I9 m; Dm Steinkreis 24 m; H I,3 m

Lage: N43 03.355 E79 04.64I

Form: niedrig, abgerundet, mit abgeflachter Kuppe

Abhänge: drei steile, südlicher sanft

Weitere Konstruktionen: Um den Kurgan herum verläuft im Abstand von 2,5 $\mathrm{m}$ ein Steinkreis, der aus mittelgroßen Steinen (ab $20 \times 10 \times 5 \mathrm{~cm}$ ) gebaut wurde; der Steinkreis ist nur zum Teil erhalten.

Zustand: in der Mitte ein Raubtrichter

Sonstiges: an der Oberfläche einzelne mittelgroße Steine $(\mathrm{ab} 35 \times 20 \times 5 \mathrm{~cm})$

Kurgan 57 (Kleinkurgan)

Dm I8 m; H I, 5 m

Lage: N43 03.368 E79 04.633

Form: abgerundet, plattformähnlich mit abgeflachter Kuppe

Abhänge: drei steile, südlicher sanft

Zustand: in der Mitte ein Raubtrichter

Sonstiges: Oberfläche mit kleinen Steinen $(\mathrm{ab} 20 \times 5 \mathrm{~cm}$ bis zum Schotter) bedeckt

Kurgan 58 (Kleinkurgan)

Dm I6 m; H I $m$

Lage: N43 03.388 E79 04.620 
Form: niedrig, abgerundet, plattformähnlich mit abgeflachter Kuppe

Abhänge: drei steile, südlicher sanft

Zustand: in der Mitte ein Raubtrichter

Sonstiges: an der Oberfläche einzelne kleine Steine (ab $20 \times 10 \times 5 \mathrm{~cm})$

Kurgan 59 (Kleinkurgan)

Dm I6 m; H I m

Lage: N43 03.402 E79 04.609

Form: niedrig, abgerundet, plattformähnlich mit abgeflachter Kuppe

Abhänge: drei steile, südlicher sanft

Zustand: in der Mitte ein Raubtrichter

Sonstiges: an der Oberfläche einzelne kleine Steine (ab $20 \times 10 \times 5 \mathrm{~cm})$

\section{Kurgan 60}

Dm 22 m; H 2 m

Lage: N43 03.420 E79 04.597; nördlichster Kurgan der Kette

Form: abgerundet, plattformähnlich mit abgeflachter Kuppe

Abhänge: drei steile, südlicher sanft

Zustand: in der Mitte ein Raubtrichter

Sonstiges: an der Oberfläche einzelne mittelgroße (ab $50 \times 30 \times 10 \mathrm{~cm})$ und kleine Steine $(\mathrm{ab} 20 \times 10 \times 5 \mathrm{~cm})$

Zweitwestlichste Kurgankette

Kurgan 46 (Kleinkurgan)

Dm I4 m; H I m

Lage: N43 03.260 E79 04.72I; südlichster Kurgan der Kette

Form: abgerundete Erhebung mit abgeflachter Kuppe Abhänge: drei steile, südlicher sanft

Zustand: keine Senke, kein Raubtrichter

Sonstiges: keine Steine an der Oberfläche

Kurgan 47 (Kleinkurgan)

Dm I4 m; H o, 5 m

Lage: N43 03.274 E79 04.7I7

Form: niedrige, abgerundete Erhebung mit abgeflachter Kuppe

Abhänge: drei steile, südlicher sanft

Zustand: keine Senke, kein Raubtrichter

Sonstiges: keine Steine an der Oberfläche

Kurgan 48 (Kleinkurgan)

Dm 2I m; H o,5 m

Lage: N43 03.286 E79 04.709; nördlichster Kurgan der Kette

Form: niedrige, abgerundete Erhebung mit abgeflachter Kuppe

Abhänge: drei steile, südlicher sanft

Zustand: keine Senke, kein Raubtrichter

Sonstiges: keine Steine an der Oberfläche
Östlichste Kurgankette

Kurgan 6i

Dm 37 m; Dm sog. Prozessionsweg (rekonstruiert) $62 \mathrm{~m} ; \mathrm{H} 4 \mathrm{~m}$

Lage: N43 03.343 E79 05.I07; nördlichster Kurgan der Kette

Form: abgerundet, plattformähnlich mit abgeflachter Kuppe

Abhänge: drei steile, südlicher sanft

Weitere Konstruktionen: II m vom Rand des Hügels entfernt liegt ein nur in der Nordhälfte erhaltener umlaufender sog. Prozessionsweg von I,5 m Breite, der durch große Steine $(\mathrm{ab} 50 \times 20 \times 10 \mathrm{~cm})$ begrenzt wird. Im südöstlichen Bereich zwischen dem Kurganrand und dem sog. Prozessionsweg befinden sich drei flache, rechteckige Umfriedungen.

Zustand: in der Mitte ein Raubtrichter; gesamte Peripherie des Kurgans durch mehrere Feldwege stark beschädigt; südsüdöstlicher Peripheriebereich durch modernen muslimischen Friedhof zerstört

Sonstiges: einzelne mittelgroße und kleine (bis zu Schottergröße) Steine an der Oberfläche

Steinonstruktionen

Umfriedung I

L 4,5 m; B I,O m

Lage: N43 03.328 E79 05.I07; östlich gelegene Konstruktion

Form: rechteckige Steinkonstruktion aus mittelgroßen $(\mathrm{ab} 50 \times 30 \times 20 \mathrm{~cm})$ in Reihen angeordneten Steinen; innerer Bereich der Konstruktion steinfrei

Ausrichtung: W-O

Sonstiges: klare Deutung der Konstruktion nicht möglich

Umfriedung 2

L 3,O m; B ०,6 m

Lage: N43 03.33I E79 05.I2I; zentral gelegene Konstruktion

Form: rechteckige Steinkonstruktion aus mittelgroßen $(\mathrm{ab} 50 \times 30 \times 20 \mathrm{~cm})$ in Reihen angeordneten Steinen; innerer Bereich der Konstruktion steinfrei

Ausrichtung: W-O

Sonstiges: klare Deutung der Konstruktion nicht möglich

Umfriedung 3

L 2,2 m; B ०,9 m

Lage: N43 03.339 E79 05.I24; westlich gelegene Konstruktion

Form: rechteckige Steinkonstruktion aus mittelgroßen $($ ab $50 \times 30 \times 20 \mathrm{~cm})$ in Reihen angeordneten Steinen; innerer Bereich der Konstruktion steinfrei

Ausrichtung: W-O

Sonstiges: klare Deutung der Konstruktion nicht möglich 


\section{Kurgan 62}

Dm $40 \mathrm{~m} ; \mathrm{H}_{3} \mathrm{~m}$

Lage: N43 03.30I E79 05.IIO

Form: abgerundet, plattformähnlich mit abgeflachter Kuppe

Abhänge: drei steile, südlicher sanft

Zustand: in der Mitte ein Raubtrichter

Sonstiges: an der Oberfläche einzelne mittelgroße

Steine $(\mathrm{ab} 30 \times 20 \times 10 \mathrm{~cm})$

\section{Kurgan 63}

Dm 34 m; H 3,5 m

Lage: N43 03.275 E79 05.II4

Form: abgerundet, plattformähnlich mit abgeflachter Kuppe

Abhänge: drei steile, südlicher sanft

Zustand: in der Mitte ein Raubtrichter

Sonstiges: keine Steine an der Oberfläche

\section{Kurgan 64}

Dm 34 m; H 3 m

Lage: N43 03.237 E79 05.II8

Form: abgerundet, plattformähnlich mit abgeflachter Kuppe

Abhänge: drei steile, südlicher sanft

Zustand: auf der Kuppe zwei Raubtrichter

Sonstiges: keine Steine an der Oberfläche

Kurgan 65 (Kleinkurgan)

Dm I6 m; H o,7 m

Lage: N43 03.209 E79 05.I20

Form: abgerundete Erhebung mit abgeflachter Kuppe

Abhänge: drei steile, südlicher sanft

Zustand: keine Senke, kein Raubtrichter

Sonstiges: an der Oberfläche einzelne kleine Steine (ab

$20 \times 10 \times 5 \mathrm{~cm})$

Forschungsgeschichte und Bemerkungen

Im Jahre 2006 wurden die Kurgane des Gräberfeldes Žalauly-2 im Zuge einer Revision der archäologischen Bodendenkmäler im Rajymbekskij rajon des Gebietes Almaty vom Turgen-Forschungsteam der Almaty Survey-Expedition (APAЭ) unter der Leitung von A. Gorjačev zum ersten Mal dokumentiert (Bajpakov/Gorjačev 2007, 92, 96-98). Es wurden eine Beschreibung und ein topographischer Plan der Kurgane hergestellt. Jedoch wurden nicht alle Kurgane aufgenommen und die dokumentierten wurden unterschiedlichen Gräberfeldern zugeordnet.

Liste der Fundorte ${ }_{34}$ (Bajpakov/Gorjačev 2007):

FEZ Gf. Žalauly-IV (russ. Жалаулы-IV): Bajpakov/Gorjačev 2007, 97, Abb. 75; ALT ı821 m, N43 03'28,9" E79 04'86,4"635; *entspricht dem Topoi Survey 2009 - Gf. Žalauly-2 K2-Ki6 (Kurgane I und I5 - laut Arbeitsnummerierung - wurden damals nicht aufgenommen).

634 Im Sommer 2009 führte auch Topoi (A. Gass) in $\mathrm{Zu}-$ sammenarbeit mit dem Archäologischen Institut „A Ch. Margulan“, Almaty (B. Nurmuchanbetov, Z. Sama-
Kurgan 66

$29 \mathrm{~m} ; \mathrm{H} \mathrm{2,5} \mathrm{m}$

Kette

Form: abgerundet, plattformähnlich mit abgeflachter Kuppe

Abhänge: drei steile, südlicher sanft

Zustand: auf der Kuppe drei Raubtrichter

Sonstiges: an der Oberfläche liegen einzelne kleine

Zweitöstlichste Kurgankette

\section{Kurgan 67}

Dm 28 m; H 2,3 m

Lage: N43 03.268 E79 05.050; nördlichster Kurgan der Kette

Kuppe

Abhänge: drei steile, südöstlicher sanft

Zustand: in der Westhälfte ein Raubtrichter

Sonstiges: an der Oberfläche kleine Steine, bis zu Schottergröße

\section{Kurgan 68}

Dm 33 m; H I,6 m

Lage: N43 03.I87 E79 05.018; südlichster Kurgan der Kette

Form: abgerundet, plattformähnlich mit abgeflachter Kuppe

Abhänge: drei steile, südöstlicher sanft

Zustand: vier Raubtrichter

Sonstiges: an der Oberfläche einzelne mittelgroße (ab $35 \times 20 \times 5 \mathrm{~cm}$ ) Steine und Schotter Steine $(\mathrm{ab} 20 \times 10 \times 5 \mathrm{~cm})$ 
FEZ Gf. Žalauly-II (russ. Жалаулы-II): Bajpakov/Gorjačev 2007, 98, Abb. 76; ALT I839 m, N43 03'56,6" E79 04'66,6"; *'entspricht dem Topoi Survey 2009 - Gf. Žalauly-2 Ki7-K33 (Kurgane 26 und 34-38 - laut Arbeitsnummerierung - wurden damals nicht aufgenommen).

FEZ Gf. Žalauly-V (russ. Жалаулы-V): Bajpakov/Gorjačev 2007, 92, Abb. 7I; ALT ı835 m, N43 03'4I,8" E79 04'60,0"; *entspricht dem Topoi Survey 2009-Gf. Žalauly-2 K39-K60 (Kurgan 47 - laut Arbeitsnummerierung - wurde damals nicht aufgenommen).

FEZ Gf. Žalauly-III (russ. Жалаулы-III): Bajpakov/Gorjačev 2007, 96, Abb. 74; ALT ı8०8 m, N43 03'34,2" E79 05'I0,7"; *entspricht dem Topoi Survey 2009 - Gf. Žalauly-2 K6I-K68.

Lit.: Bajpakov/Gorjačev 2007, 92, 96-98, Abb. 7I, 74-76.

Gräberfeld Žalauly-8 [FEZ] (Abb. 200-20I; Karte 3 Nr. 60): ALT I8I2 m N43 or.95I E79 03.138; Gebiet Almaty (kasach. Алматы облысы), Rajymbekskij rajon (kasach. Райымбек ауданы); Ausmaß N-S $470 \times$ O-W 330 m.

Die Nekropole liegt im Nordwesten des Hochplateaus Kegen (kasach. Кеген), an der Südseite des Bergrückens Kuluktau (kasach. Қулықтау), auf einer Riedelkante, die sich auf dem rechten, nördlichen Ufer des Flusses Kegen (kasach. Кеген) befindet. Das Gräberfeld ist I75 km ostsüdöstlich von der Stadt Almaty (kasach. Алматы), I4 km westlich vom Dorf Kegen und $7,3 \mathrm{~km}$ südwestlich vom Dorf Žalauly (kasach. Жалаулы) entfernt. In der Südhälfte der

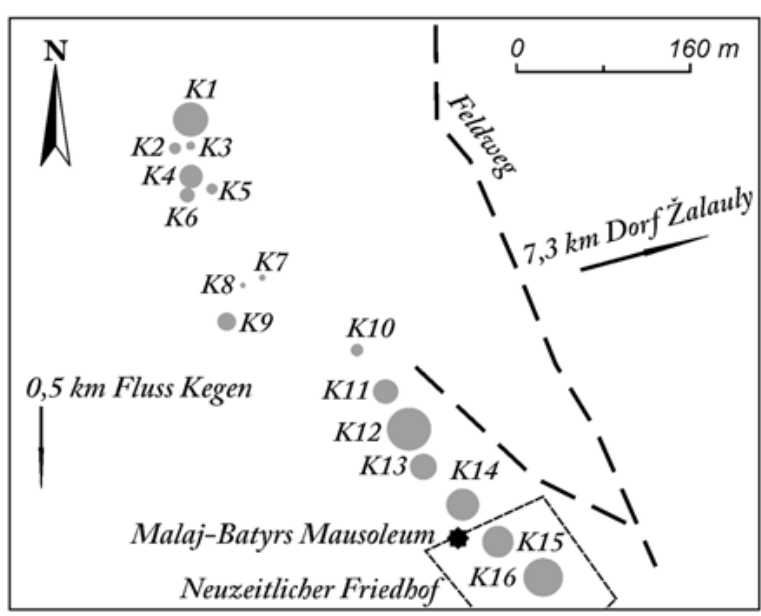

Abb. 200 | Plan des Gräberfeldes Žalauly-8 Nekropole befindet sich ein kasachischer Friedhof aus ethnographischer Zeit, dessen Zentrum ein „Malaj-Batyrs-Mausoleum“ (kasach. Малай батыр) bildet.

Insgesamt wurden hier I6 Kurgane festgestellt. Die Kurgane stehen in einer NW-SO ausgerichteten Kette, die den Verlauf der Riedelkante verfolgte. Die Grabanlagen messen zwischen $5 \mathrm{~m}$ und $38 \mathrm{~m}$ im Durchmesser und erreichen Höhen zwischen 0,3 $\mathrm{m}$ und $4 \mathrm{~m}$. Bei zehn Kurganen ist ein Raubtrichter, der sich jeweils mittig befindet, festgestellt. Bei sechs weiteren Kurganen ${ }^{636}$ wurde keine Senke bzw. kein Raubtrichter beobachtet. Zehn größere Kurgane haben drei steile und einen (immer südlichen) sanften Abhang. Die übrigen sechs Kurgane zeigen aufgrund ihrer geringen Größe keine Merkmale der Aufschüttung. Um alle Kleinkurgane auf der Nordhälfte der Nekropole befinden sich direkt um den Kurganrand Kreisgräben. Der zentral angelegte Kurgan 8 (nach der Arbeitsnummerierung) ist flach und durch einen doppelten Steinkreis gekennzeichnet. Die übrigen Kurgane weisen keine besonderen architektonischen Merkmale auf.

Anhand der Landschaftsplatzierung, inneren Struktur und äußeren Erscheinungsform können die Kurgane des Gräberfeldes der sakischen Periode der Früheisenzeit zugeordnet werden.

636 Hier handelte es sich ausschließlich nur um Kleinkurgane. 


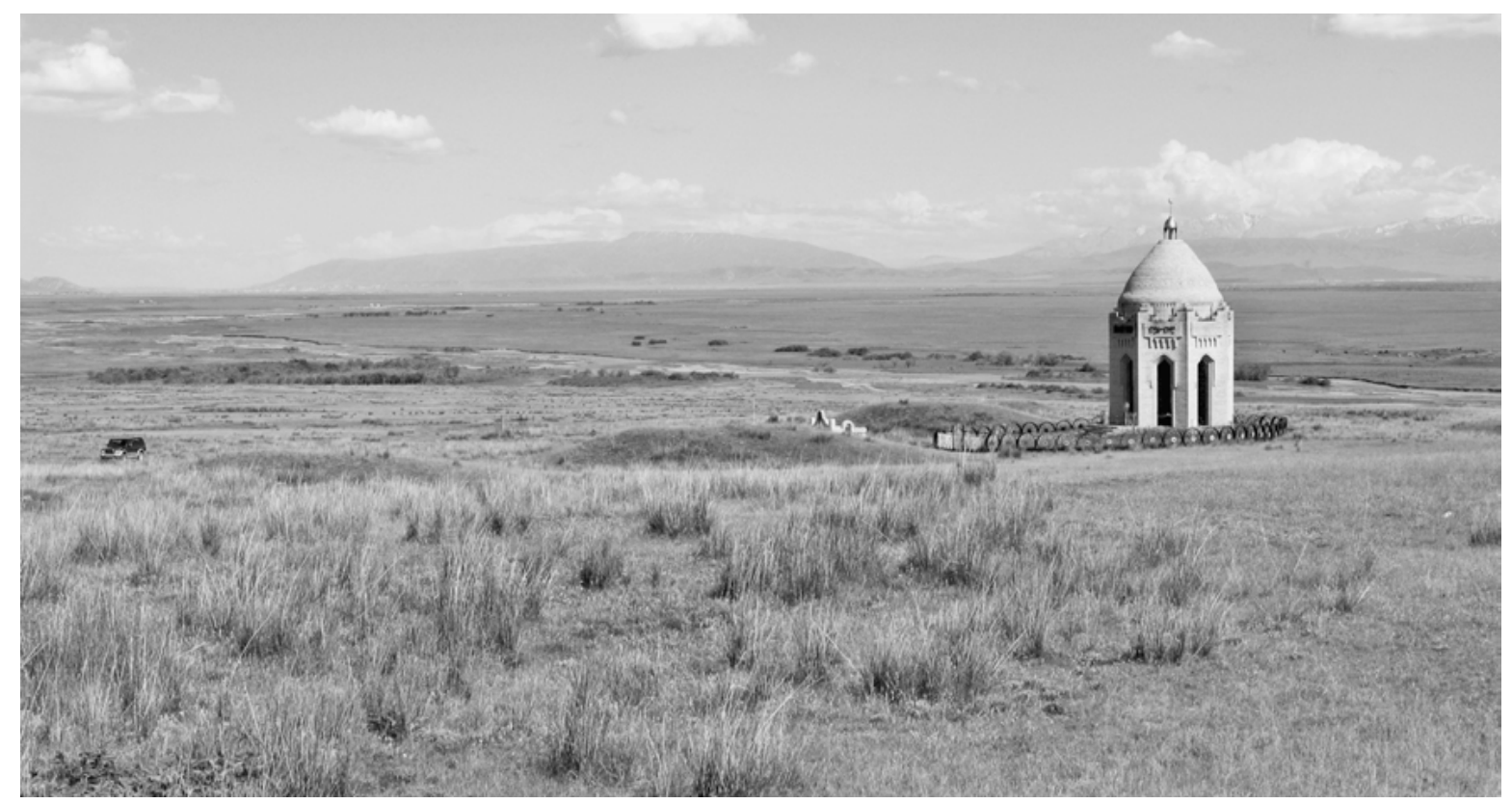

Abb. 201 | Gräberfeld Žalauly-8. Blick von NW

Kurgancharakteristik:

Kurgan I

Dm 3I m; H 3 m

Lage: N43 02.II4 E79 03.005; nördlichster Kurgan der Kette

Form: abgerundet, plattformähnlich mit abgeflachter Kuppe

Abhänge: drei steile, südlicher sanft

Zustand: in der Mitte ein Raubtrichter

Sonstiges: keine Steine an der Oberfläche

Kurgan 2 (Kleinkurgan)

Dm Io m; Dm Kreisgraben I4 m; H o,5 m

Lage: N43 02.096 E79 02.990

Form: abgerundete flache Erhebung

Abhänge: keine Merkmale

Weitere Konstruktionen: direkt am Kurganrand ein umlaufender Kreisgraben von bis $\mathrm{zu} 2 \mathrm{~m}$ Breite und o,5 $\mathrm{m}$ Tiefe

Zustand: keine Senke, kein Raubtrichter

Sonstiges: keine Steine an der Oberfläche

Kurgan 3 (Kleinkurgan)

Dm 7 m; Dm Kreisgraben II m; H o,5 m

Lage: N43 02.097 E79 03.00I

Form: abgerundete flache Erhebung

Abhänge: keine Merkmale

Weitere Konstruktionen: direkt am Kurganrand umlaufender Kreisgraben von bis $\mathrm{zu} 2 \mathrm{~m}$ Breite und $0,5 \mathrm{~m}$ Tiefe

Zustand: keine Senke, kein Raubtrichter

Sonstiges: keine Steine an der Oberfläche
Kurgan 4 (Kleinkurgan)

Dm 20 m; H I,7 m

Lage: $\mathrm{N}_{43} 02.083$ E79 03.002

Form: abgerundet, plattformähnlich mit abgeflachter Kuppe

Abhänge: drei steile, südlicher sanft

Zustand: in der Mitte ein Raubtrichter

Sonstiges: Oberfläche zum Teil mit Schotter bedeckt

Kurgan 5 (Kleinkurgan)

Dm Io m; Dm Kreisgraben i4 m; H o, 5 m

Lage: N43 02.075 E79 03.014

Form: abgerundete flache Erhebung

Abhänge: keine Merkmale

Weitere Konstruktionen: direkt am Kurganrand umlaufender Kreisgraben von bis $\mathrm{zu} 2 \mathrm{~m}$ Breite und $0,5 \mathrm{~m}$ Tiefe

Zustand: keine Senke, kein Raubtrichter Sonstiges: keine Steine an der Oberfläche

Kurgan 6 (Kleinkurgan)

Dm I4 m; Dm Kreisgraben I8 m; H I,5 m

Lage: N43 02.073 E79 02.997

Form: niedrig, abgerundet, mit abgeflachter Kuppe

Abhänge: keine Merkmale

Weitere Konstruktionen: direkt am Kurganrand umlaufender Kreisgraben von bis $\mathrm{zu} 2 \mathrm{~m}$ Breite und $0,5 \mathrm{~m}$ Tiefe

Zustand: keine Senke, kein Raubtrichter Sonstiges: keine Steine an der Oberfläche 
Kurgan 7 (Kleinkurgan)

Dm 6 m; Dm Kreisgraben Io m; H o,3 m

Lage: N43 02.029 E79 03.046

Form: abgerundete flache Erhebung

Abhänge: keine Merkmale

Weitere Konstruktionen: direkt am Kurganrand umlau-

fender Kreisgraben von bis $\mathrm{zu} 2 \mathrm{~m}$ Breite und o,2 $\mathrm{m}$

Tiefe

Zustand: keine Senke, kein Raubtrichter

Sonstiges: keine Steine an der Oberfläche

Konstruktion 8 (Flachkurgan)

Dm 5 m; H Flachkurgan (gar keine Erhebung)

Lage: N43 02.026 E79 03.032

Form: doppelter Steinkreis

Zustand: keine Senke, kein Raubtrichter

Sonstiges: I m Abstand zwischen den Steinkreisen, Dm des inneren Kreises $3 \mathrm{~m}$, beide Kreise aus großen (ab $60 \times 30 \times 20 \mathrm{~cm}$ ) Steinen

Kurgan 9 (Kleinkurgan)

Dm I6 m; Dm Kreisgraben 22 m; H I,5 m

Lage: N43 02.008 E79 03.020

Form: abgerundet, plattformähnlich mit abgeflachter Kuppe

Abhänge: drei steile, südlicher sanft

Weitere Konstruktionen: direkt am Kurganrand umlaufender Kreisgraben von bis $\mathrm{zu} 3 \mathrm{~m}$ Breite und $0,5 \mathrm{~m}$ Tiefe

Zustand: in der Mitte ein Raubtrichter

Sonstiges: keine Steine an der Oberfläche

Kurgan ıо (Kleinkurgan)

Dm I2 m; H I m

Lage: N43 01.990 E79 03.108

Form: niedrig, abgerundet, mit abgeflachter Kuppe

Abhänge: drei steile, südlicher sanft

Zustand: in der Mitte ein Raubtrichter

Sonstiges: Oberfläche mit kleinen $(\mathrm{ab} 20 \times 10 \times 5 \mathrm{~cm}$, bis zum Schotter) Steinen bedeckt

Kurgan II (Kleinkurgan)

Dm 2I m; H I,5 m

Lage: N43 OI.97I E79 03.I24

Form: abgerundet, plattformähnlich mit abgeflachter Kuppe

Abhänge: drei steile, südlicher sanft

Zustand: in der Mitte ein Raubtrichter
Sonstiges: an der Oberfläche einzelne mittelgroße Steine $(35 \times 5 \mathrm{~cm})$

Kurgan 12

Dm 38 m; H 4 m

Lage: N43 OI.95I E79 03.138

Form: abgerundet, plattformähnlich mit abgeflachter Kuppe

Abhänge: drei steile, südlicher sanft

Zustand: in der Mitte ein Raubtrichter

Sonstiges: Oberfläche mit Schotter bedeckt

Kurgan I3 (Kleinkurgan)

Dm 22 m; H I, 5 m

Lage: N43 OI.93I E79 03.I47

Form: abgerundet, plattformähnlich mit abgeflachter Kuppe

Abhänge: drei steile, südlicher sanft

Zustand: in der Mitte ein Raubtrichter

Sonstiges: an der Oberfläche einzelne mittelgroße Steine $(35 \times 5 \mathrm{~cm})$

\section{Kurgan 14}

Dm 28 m; H 2 m

Lage: N43 OI.913 E79 03.I70

Form: abgerundet, plattformähnlich mit abgeflachter Kuppe

Abhänge: drei steile, südlicher sanft

Zustand: in der Mitte ein Raubtrichter

Sonstiges: keine Steine an der Oberfläche

\section{Kurgan I5}

Dm 28 m; $\mathrm{H}_{3} \mathrm{~m}$

Lage: N43 or.892 E79 03.I94

Form: abgerundet, plattformähnlich mit abgeflachter Kuppe

Abhänge: drei steile, südlicher sanft

Zustand: in der Mitte ein Raubtrichter

Sonstiges: keine Steine an der Oberfläche

\section{Kurgan 16}

Dm 34 m; H 2,2 m

Lage: N43 OI.872 E79 03.225

Form: abgerundet, plattformähnlich mit abgeflachter Kuppe

Abhänge: drei steile, südlicher sanft

Zustand: in der Mitte ein Raubtrichter

Sonstiges: keine Steine an der Oberfläche

\section{Forschungsgeschichte und Bemerkungen}

Das Gräberfeld Žalauly-8 wurde erstmalig 2003 im Bericht der Südkasachischen komplex-archäologischen Expedition als Nekropole „Žalauly-5“ (Bajpakov 2003, IIo) erwähnt. Hier wurden sieben mittelgroße Kurgane festgestellt und beschrieben sowie ein Übersichtsfoto angefertigt.

Im Jahre 2006 wurden die Kurgane des Gräberfeldes im Laufe einer Revision der archäologischen Bodendenkmäler im Rajymbekskij rajon des Gebietes Almaty vom Turgen-Forschungsteam der Almaty Survey-Expedition (APAЭ) unter der Leitung von A. Gorjačev erneut dokumentiert (Bajpakov/Gorjačev 
2007, 8I-82). Es wurden eine Beschreibung und ein topographischer Plan der Kurgane hergestellt. Jedoch wurden nicht alle Kurgane aufgenommen und die dokumentierten Kurgane einer Kette als zwei unterschiedliche Gräberfelder angesprochen.

Liste der Fundorte637 (Bajpakov/Gorjačev 2007):

FEZ Gf. Žalauly-VII (russ. Жалаулы-VII): Bajpakov/Gorjačev 2007, 82, Abb. 63; ALT ı829 m, N43 02'03,3”' E79 03'००,3”'638; *entspricht dem Topoi Survey 2009 - Gf. Žalauly-8 KI-K9 (Kurgane 2, 5 und 8 - nach der Arbeitsnummerierung - wurden damals nicht aufgenommen).

FEZ Gf. Žalauly-VIII (russ. Жалаулы-VIII): Bajpakov/Gorjačev 2007, 8I, Abb. 62; ALT ı804 m, N43 OI'87,4" E79 03'22,4"; *entspricht dem Topoi Survey 2009 - Gf. Žalauly-2 Kio-Ki6.

Lit.: Bajpakov 2003, IIo, Abb. I; Bajpakov/Gorjačev 2007, 8I-82, Abb. 62-63.

Gräberfeld Žoan Tobe ${ }^{639}$ [FEZ] (Abb. 202; Karte 3 Nr. 27): ALT 598 m N43 38.903 E78 23.307; Gebiet Almaty (kasach. Алматы облысы), Enbekšikazachskij rajon (kasach. Еңбекшіқазақ ауданы); Aus$\mathrm{maßN}$ N-S $660 \times \mathrm{O}-\mathrm{W} 860 \mathrm{~m}$.

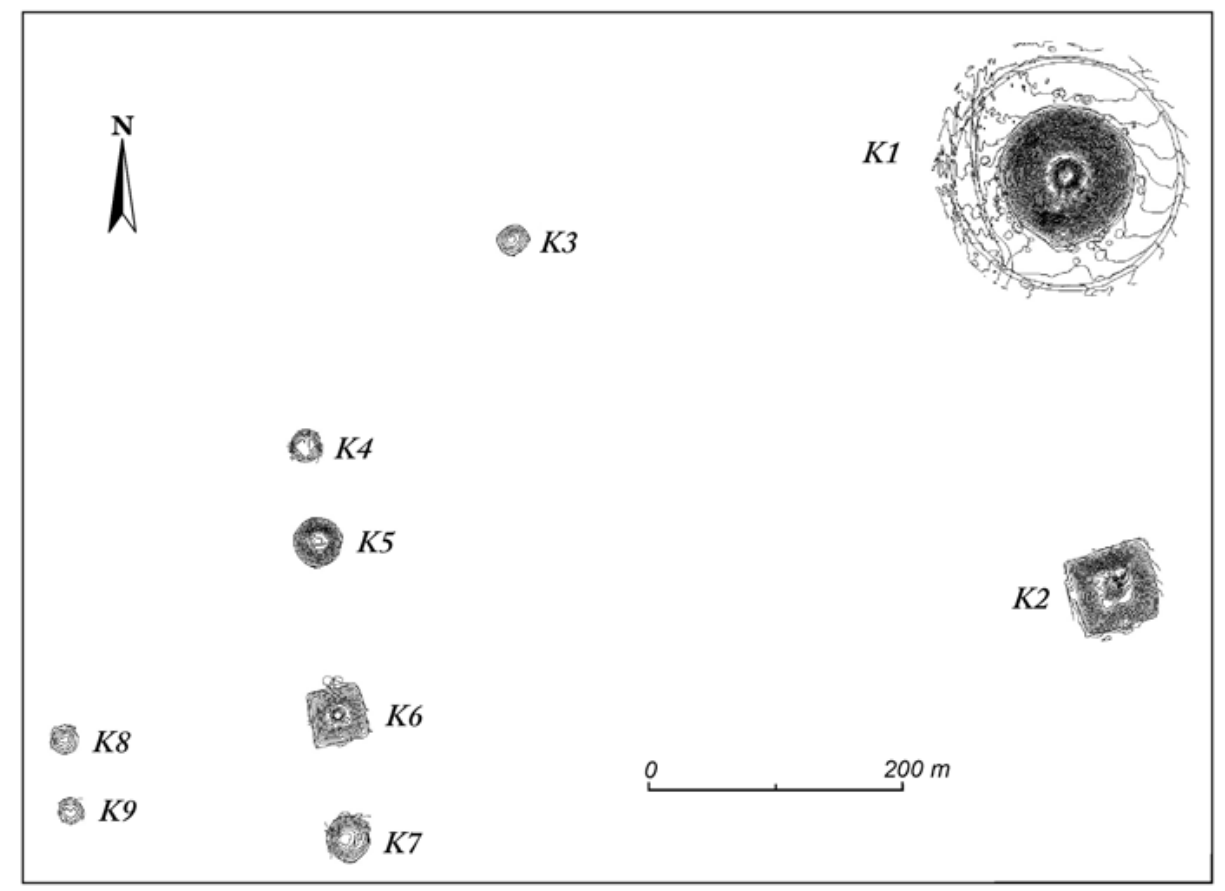

Abb. 202 | Gräberfeldplan Žoan Tobe (J. Voigtländer640)

637 Im Sommer 2009 führte auch Excellence Cluster Topoi (A. Gass) in Zusammenarbeit mit dem Archäologischen Institut „A. Ch. Margulans“, Almaty (B. Nurmuchanbetov, Z. Samašev) vor Ort einen Survey durch, der hier als „Topoi Survey 2009" bezeichnet wird.

638 Grad, Minuten, Sekunden - System.

639 Das Gräberfeld wurde in der Literatur und den Primär- quellen auch als Zhuan-Tobe (Gass, im Druck, Abb. 8), Žuan Tobe (Maksimova I956a, 3-8), Džuan-Tobe (Čarikov I956a, 29-36; Čarikov I956b, 27-55), Džuvan-Tobe (Pacevič I956, 32-38) oder Džuvantobe (Maksimova I96oa; Zadneprovskij I992, 76) bezeichnet.

640 Beuth-Hochschule für Technik, Berlin. 
Die Nekropole Žoan Tobe befindet sich 125 km nordöstlich der Stadt Almaty (kasach. Алматы), II,3 km ostnordöstlich des Dorfes Čilik (kasach. Шелек) und 7,4 km ostnordöstlich des Dorfes Masak (kasach. Масақ) am rechten, östlichen Ufer des Flusses Kuršilik (kasach. Куршелек). Die Nekropole besteht aus neun großen und mittelgroßen Kurganen. Die Kurgane bilden drei N-S verlaufende Ketten.

Die Ostkette besteht nur aus zwei Kurganen (KI und K2 nach der Arbeitsnummerierung), wobei Kurgan I der größte ist und im nordöstlichen Bereich des Gräberfeldes steht. Im Abstand von $33 \mathrm{~m}$ vom Rand ist der Kurgan mit einem gepflasterten, Weg umgeben. Zwischen dem Kurganrand und dem Weg zeigen sich 28 Steinkonstruktionen (Kleinkurgane mit Einzelbestattungen). Kurgan 2 ist der zweitgrößte Kurgan der Nekropole und weist eine viereckige Form auf. Die zweite, mittlere Kette besteht aus fünf mittelgroßen Kurganen. Kurgan 3 befindet sich abseits, weiter nordöstlich von den übrigen Kurganen der Kette. Der zweite, südlichste Kurgan weist eine viereckige Form auf. Die westliche, dritte Kette bestand aus den zwei kleinsten Kurganen der gesamten Nekropole. Der Durchmesser der Kurgane schwankt zwischen I9 $\mathrm{m}$ und II3 $\mathrm{m}$ ( $185 \mathrm{~m}$ mit dazugehörenden Steinkonstruktionen), die Höhe misst von I $\mathrm{m}$ bis zu II m. Alle Kurgane des Gräberfeldes weisen einen oder mehrere Raubtrichter auf. Acht Kurgane haben drei steile und einen (immer südlichen) sanften Abhang. Bei dem letzten, südöstlichsten Kurgan 9 konnte diese Neigung aufgrund des mehrmaligen Überpflügens nicht bestimmt werden.

Anhand der Landschaftsplatzierung, der Struktur und der äußeren Erscheinungsform können alle Kurgane der Nekropole der sakischen Periode der Früheisenzeit zugeordnet werden.

Kurgancharakteristik:

Kurgan I (Abb. 203,I-2)

Dm II3 m; Dm mit dem sog. Prozessionsweg I85 m; $\mathrm{H}$ II $\mathrm{m}$

Lage: N43 38.903 E78 23.307

Form: abgerundet, plattformähnlich mit abgeflachter Kuppe

Abhänge: drei steile, südlicher sanft

Weitere Konstruktionen: 33 m vom Rand des Kurgans entfernt liegt ein umlaufender sog. Prozessionsweg von 3,0-3,5 m Breite; dieser wird durch mittelgroße Flusskieselsteine $(\mathrm{ab} 40 \times 30 \times 15 \mathrm{~cm})$ begrenzt (Abb. 203,3-6). Im Inneren befindet sich eine Schicht aus gestampftem Lehm vermischt mit Steinen. Stratigraphie des sog. Prozessionsweges: I. anstehender Boden; 2. Fundament aus mittelgroßen Flusskieselsteinen; 3. große längliche Steine, die ein „Wegebett“ bilden und als äußere Markierungsgrenze dienen; 4. lehmige Schicht mit Steinschutt als eine Art Verfüllung des Wegebettes; zwischen dem Kurganrand und dem sog. Prozessionsweg 28 Kleinkurgane mit Einzelbestattungen mit einem Durchmesser von 3,6 m $8,5 \mathrm{~m}$

Zustand: in der Mitte ein gewaltiger Raubtrichter Sonstiges: gesamte Oberfläche mit mittelgroßen (ab $40 \times 30 \times 20 \mathrm{~cm})$ und kleinen Steinen bedeckt; größter Kurgan der Nekropole

64I Für die Information bezüglich der Ausgrabung der Kasachisch-Deutschen Archäologischen Expedition im Sommer 2008 auf dem Gräberfeld Žoan Tobe möchte
Bemerkungen: Im Sommer 2008 wurde der Kurgan von der Kasachisch-Deutschen Archäologischen Expedition untersucht ${ }^{64}$;

Im nördlichen und östlichen Kurganrandbereich wurden zwei Flächen freigelegt (nördliche Fläche: Objekte 1 und 2; östliche Fläche: Objekte 7 und $8^{642}$ );

Der sog. Prozessionsweg wurde an zwei Stellen geschnitten (im Nordbereich: Objekt 31-Nord; im Südostbereich: Objekt 31-Ost);

In der Peripherie des Kurgans, im Nordbereich, wurden noch zusätzlich zwei Sondagen angelegt, die jedoch keine Befund- und Fundsituation aufwiesen;

Objekt I (Abb. 57, 59-62): ovale Steinkonstruktion $\overline{(4,2 \times 3,6} \mathrm{m} ; \mathrm{H}$ o,I2 m), äußere Grenze durch größere Steine $(\mathrm{ab} 50 \times 40 \times 25 \mathrm{~cm})$ markiert;

- In der Mitte eine langovale Grabgrube, die NNW-SSO ausgerichtet worden war

- Maße: 2,2 × I,2 ×0,6 m

- Auf dem Boden ein Skelett in Rückenstrecker-Position mit dem Kopf nach NNW

- Beigaben: fehlen

Objekt 2 (Abb. 58-59, 63-64): eiförmige Steinkonstruktion $(4,6 \times 4,4 \mathrm{~m}$; H O,I5 m) deren äußere Grenze durch größere Steine $(\mathrm{ab} 50 \times 40 \times 25 \mathrm{~cm})$ markiert war;

ich mich bei H. Parzinger, Z. Samašev, A. Nagler, M. Nawroth und M.-R. Boroffka herzlich bedanken. 642 Objekt 8 wurde nicht ausgegraben. 

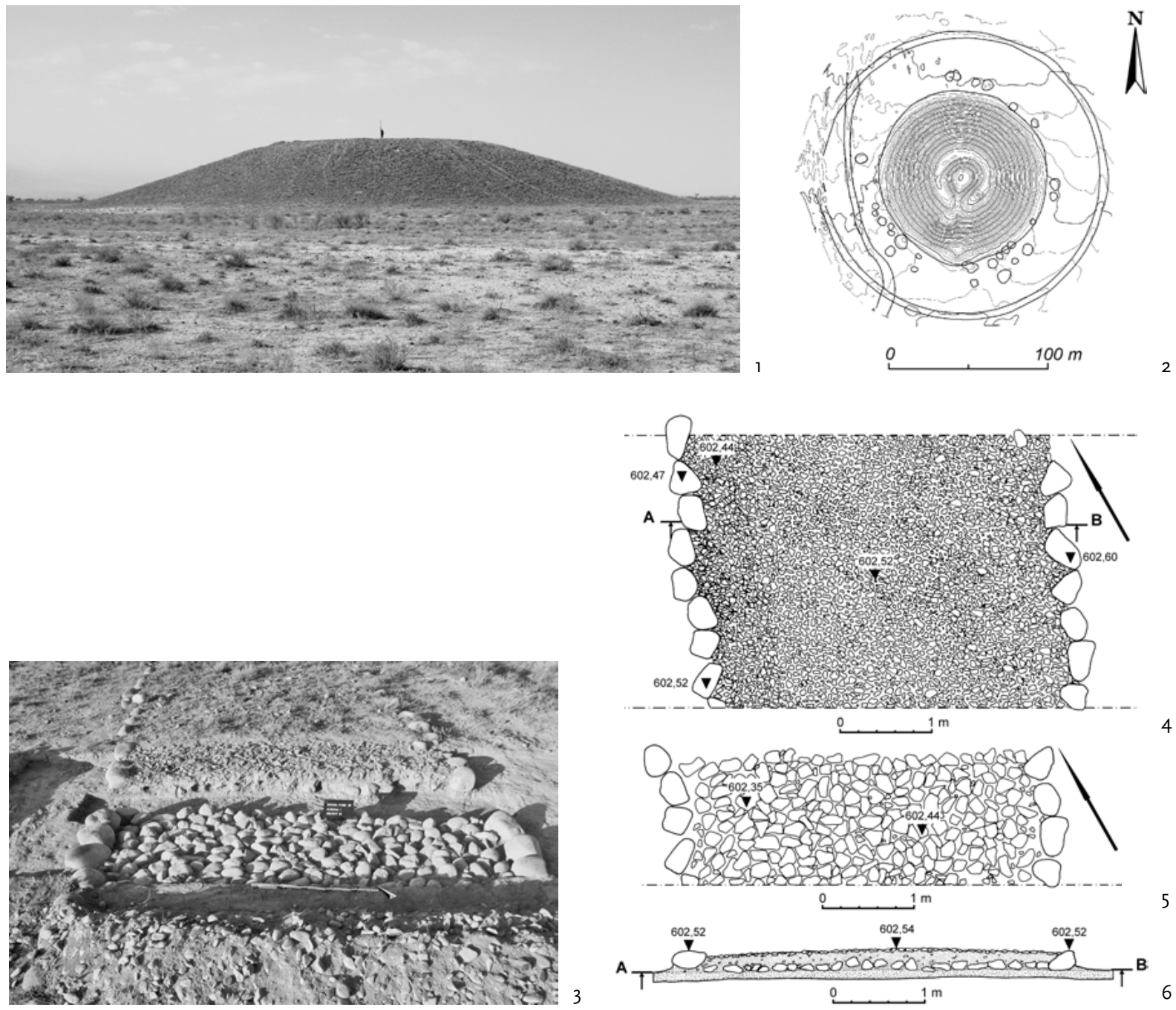

Abb. 203 | Kurgan I des Gräberfeldes Žoan Tobe; I. Blick von O; 2. I. Plan (J. Voigtländer); 3-6. Sog. Prozessionsweg, Objekt 3I-Ost (Foto: M. Nawroth, Zeichnung: M.-R. Boroffka)

- In der Mitte eine rechteckige Grabgrube mit abgerundeten Ecken, NW-SO ausgerichtet

- Maße: $2,3 \times \mathrm{I}, \mathrm{I} 5 \times 0,6 \mathrm{~m}$

- Auf dem Boden ein Skelett in Rückenstrecker-Position mit dem Kopf nach NW

- Beigaben: fehlen

Datierung - Hd-28I76: cal AD 983-IO28643

Objekt 7 (Abb. 65-69): unregelmäßige, eher abgerundete Steinkonstruktion $(7, \mathrm{I} \times 7,0 \mathrm{~m}$; $\mathrm{H} \circ, 2 \mathrm{~m})$, äußere Grenze durch größere Steine $(\mathrm{ab} 45 \times 30 \times 20 \mathrm{~cm})$ markiert;

643 Nachweise zur Probe befinden sich im Appendix I Nr. I4.

644 Archäozoologische Bestimmung von Prof. Dr. rer. nat. Norbert Benecke, Deutsches Archäologisches Institut,
- Im inneren Bereich der Steinkonstruktion ein zweites Steinkranz von ovaler Form $(5,3 \times 4,5 \mathrm{~m})$;

- In der Mitte eine langovale Grabgrube, die mit leichter östlicher Abweichung N-S ausgerichtet worden war; in der Verfüllung der Grabgrube befand sich ein Stück eines linken Schulterblattes vom Pferd ${ }^{644}$.

- Maß: $2,0 \times 0,55 \times 0,4 \mathrm{~m}$

- Auf dem Grabboden untere Extremitäten eines Skelettes in situ; Rückenstrecker-Position mit dem Kopf nach $\mathrm{N}$

Beigaben: fehlen

Naturwissenschaftliches Referat an der Zentrale, Archäozoologie. 


\section{Kurgan 2}

Seitenlänge $60 \mathrm{~m} ; \mathrm{H} 5,7 \mathrm{~m}$

Lage: N43 38.722 E78 23.352

Form: viereckig, pyramidenähnlich mit abgeflachter Kuppe

Abhänge: drei steile, südlicher sanft

Zustand: in der Mitte ein Raubtrichter; im Ostbereich des Raubtrichters eine durch einen Bagger ausgehobene Grube (Tiefe I,5-2,o m); Peripherie überpflügt

Sonstiges: Die Abhänge des Kurgans sind grob an den vier Haupthimmelsrichtungen orientiert; die Oberfläche ist mit mittelgroßen und kleinen (bis zum Schotter) Steinen bedeckt.

\section{Kurgan 3}

Dm 25 m; H 2 m

Lage: N43 38.862 E78 22.989

Form: abgerundet, plattformähnlich mit abgeflachter Kuppe

Abhänge: drei steile, südlicher sanft

Zustand: in der Mitte eine Senke; die Peripherie ist überpflügt

Sonstiges: die Oberfläche ist mit mittelgroßen und kleinen (bis zum Schotter) Steinen bedeckt

Kurgan 4 (Kleinkurgan)

Dm 25 m; H I,6 m

Lage: N43 38.77I E78 22.875

Form: niedrig, abgerundet, plattformähnlich mit abgeflachter Kuppe

Abhänge: drei steile, südlicher sanft

Zustand: in der Mitte ein Raubtrichter; Peripherie überpflügt

Sonstiges: Oberfläche mit kleinen Kieselsteinen bedeckt

\section{Kurgan 5}

Dm $40 \mathrm{~m} ; \mathrm{H}_{4} \mathrm{~m}$

Lage: N43 38.727 E78 22.880

Form: abgerundet, plattformähnlich mit abgeflachter Kuppe

Abhänge: drei steile, südlicher sanft

Zustand: in der Mitte ein Raubtrichter; Peripherie überpflügt

Sonstiges: unterer Bereich der Kurganaufschüttung mit mittelgroßen Steinen bedeckt; oberer Bereich der Kurganaufschüttung mit kleinen Kieselsteinen und mit Schotter bedeckt

\section{Kurgan 6}

Seitenlänge $52 \mathrm{~m} ; \mathrm{H} 3,7 \mathrm{~m}$

Lage: N43 38.652 E78 22.895

Form: viereckig, pyramidenähnlich mit abgeflachter Kuppe

Abhänge: drei steile, südlicher sanft

Weitere Konstruktionen: in der nordwestlichen Ecke der Kurganaufschüttung ist die Krepis sichtbar

Zustand: in der Mitte ein Raubtrichter; Peripherie überpflügt
Sonstiges: Die Abhänge des Kurgan sind grob an den vier Haupthimmelsrichtungen orientiert. Oberfläche mit mittelgroßen und kleinen (bis zum Schotter) Steinen bedeckt

\section{Kurgan 7}

Dm 4I m; H 3,8 m

Lage: N43 38.600 E78 22.904

Form: ursprüngliche Form ist unklar

Abhänge: drei steile, südlicher sanft

Zustand: in der Osthälfte ein Raubtrichter; Kurgankuppe planiert, in der Mitte steht ein trigonometrischer Pfostenpunkt

Sonstiges: Oberfläche mit kleinen Kieselsteinen bedeckt

Kurgan 8 (Kleinkurgan) (Abb. 204,I)

Dm 2I m; H I,2 m

Lage: N43 38.640 E78 22.733

Form: niedrig, durch den Pflug zerstört

Abhänge: drei steile, südlicher sanft

Zustand: in der Mitte und in der Südhälfte jeweils ein Raubtrichter

Sonstiges: Oberfläche mit mittelgroßen Steinen und Kieselsteinen bedeckt; Abhänge des Kurgans grob an den vier Haupthimmelsrichtungen orientiert

Bemerkungen: Im Sommer 2008 wurde der Kurgan von der Kasachisch-Deutschen Archäologischen Expedition ausgegraben.

Kurganaufbau:

- Nach dem Ausheben der Grabgrube wurde der Aushub hauptsächlich südlich und nördlich der Grabgrube gelagert.

- Die Grabgrube wurde mit sandigem Lehm, Schotter und kleinen Kieselsteinen zugeschüttet.

- Über die Grabgrube baute man aus sandigem feinem Lehm eine Halbkugel (Dm II,7 $\mathrm{m} \mathrm{H} \mathrm{I,7} \mathrm{m),} \mathrm{die} \mathrm{sich} \mathrm{in} \mathrm{der} \mathrm{Mitte} \mathrm{des}$ Kurgans befand.

- Die Halbkugel wurde mit feinem dünnflüssigem Lehm versiegelt (Mächtigkeit der Schicht bis o,or m).

- Auf den dünnflüssigen Lehm wurde eine Schicht mittelgroßer (ab $20 \times$ Io cm) Steine aufgelegt.

- Darüber folgte eine viereckige pyramidenförmige Konstruktion mit abgeflachter Kuppe aus hartem, zum Teil gestampftem Lehm mit Sand- und Kiesanteilen, die an den Seiten verstärkt wurde. Die Konstruktion wies drei steile und einen sanften (der südliche) Abhang auf.

- Die äußere Grenze des Kurgans in dieser Bauphase wurde durch auf dem gewachsenem Boden gelegten Steinreihen markiert, die ein Viereck bildeten. Die Seiten waren grob an den vier Haupthimmelsrichtungen orientiert (eine Art der Umfriedung). 

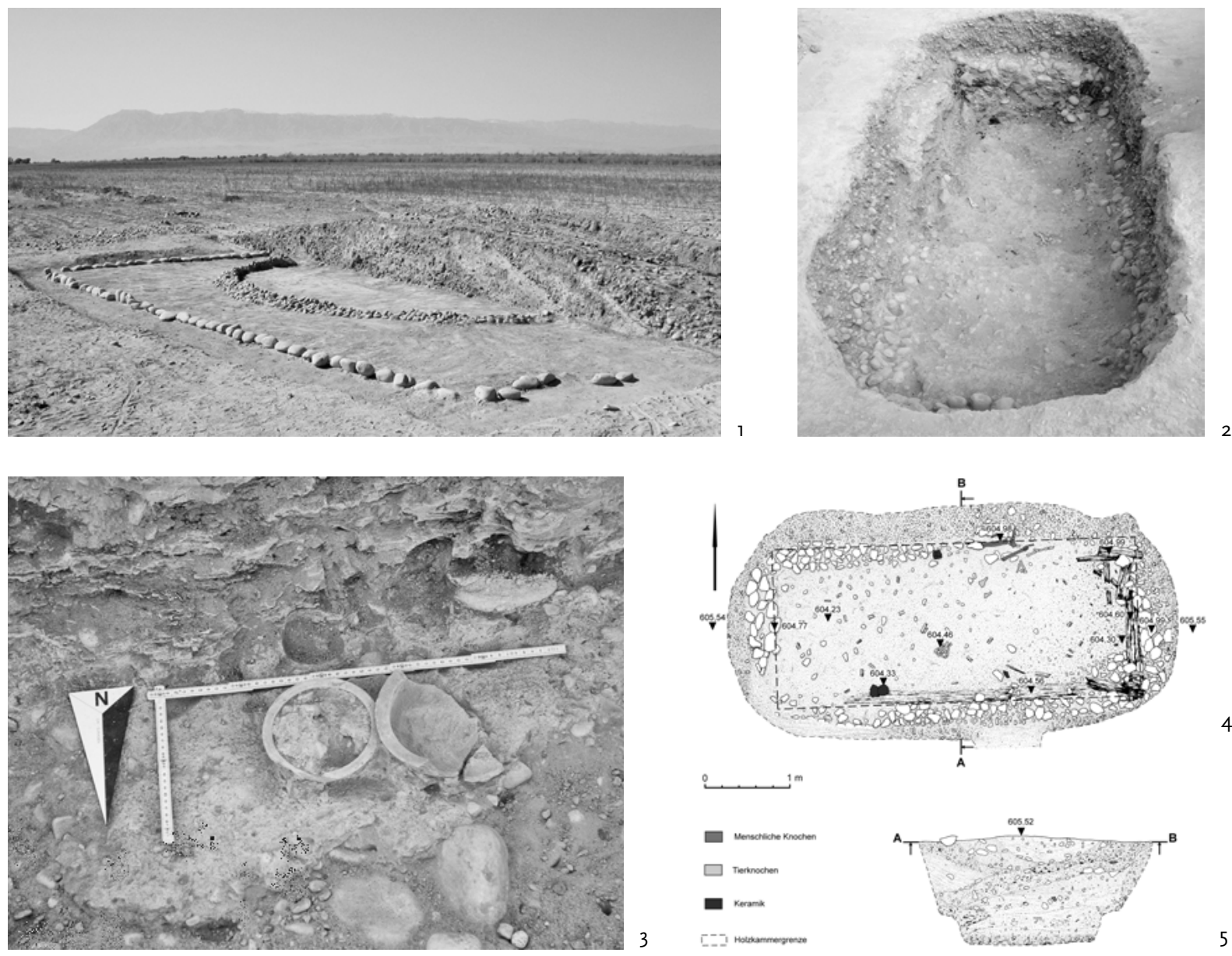

Abb. 204 | Kurgan 8 (Foto: M. Nawroth, Zeichnung: M.-R. Boroffka); r. Osthälfte, Blick von NO; 2. Grab, Blick von W; 3. Fundsituation in der Grabgrube; 4-5. Grabgrube, Planum und Profil

- Die Seiten der Konstruktion wurden mit feinem dünnflüssigem Lehm versiegelt (Mächtigkeit der Schicht bis ०,oI8 m).

- Darauf folgte eine weitere Steinschicht, die wiederum mit einer Aufschüttung aus mittelgroßen Steinen, Kieselsteinen und lehmigem Sand bedeckt worden ist.

- Dies war die letzte Schicht, so dass der Kurgan seine endgültige Form als viereckige Pyramide mit abgeflachter Kuppe bekommen hat.

Befund - rechteckige Grabgrube mit Absätzen und abgerundeten Ecken in der Mitte des Kurgans; die Wände der Grabgrube laufen schräg nach unten (Abb. 204,2.4-5)

- Maße: 5,3 × 2,7 × I,3 m

- Ausrichtung: W-O

- Weitere Bauelemente: Auf dem Grabboden lag ein Holzrahmen (rekonstruierte Größe 4,3 × I,9 m), dessen NO-Hälfte noch intakt war. Der Raum zwischen den Grabwänden und dem Holzrahmen war mit mittelgroßen und kleinen Steinen verfüllt

- Zustand der Grabgrube: durch die Beraubung stark zerstört und mit verschiedenen Mischschichten verfüllt

Bestattung - an der Nordwand, mittig, lagen einzelne menschliche Langknochen ${ }^{6} 45$

Funde - In der Mitte der Kurganaufschüttung, in einer der oberen Schichten befand sich ein neuzeitliches, fragmentiertes Gefäß: beige, scheibengedreht, feingemagert; $\mathrm{H}$ 22,8 cm; BDm Io,8 cm; Dm Schulter I9, $6 \mathrm{~cm}$; Wanddicke 2,0 cm (Abb. 206,9).

- Unter der Kurganaufschüttung, auf dem gewachsenen Boden, im nordöstlichen Teil der Umfriedung lag eine Hülse aus

645 Dazu siehe den Beitrag von Dr. Julia Gresky, Paläopathologische und anthropologische Untersuchungen an den menschlichen Skeletten aus Žoan Tobe, Kasachstan. 

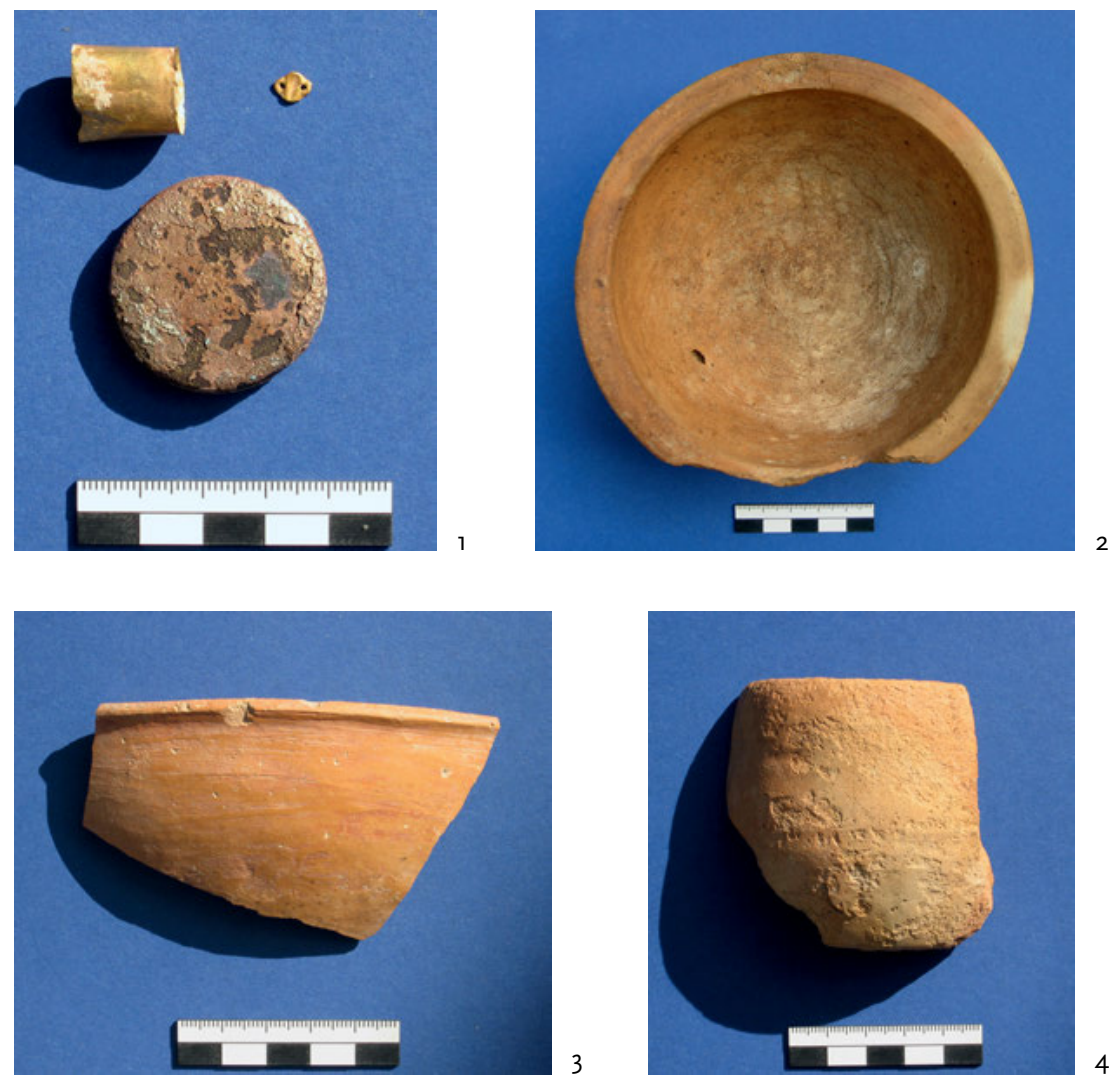

Abb. 205 | Kurgan 8, Funde; Ia Gold, Ib gelbes Metall (evtl. Gold), Ic Bronze, 2-4 Ton

(Foto: M.-R. Boroffka)

Gold mit ovalem Querschnitt, die zur Verzierung einer Reitpeitsche dienen könnte; L I, $6 \mathrm{~cm}$; B max. I, $6 \mathrm{~cm}$; B. min. I,O cm (Abb. 205,Ia; 206,2).

- Unter der Kurganaufschüttung, auf dem gewachsenen Boden, außerhalb aber dicht an der nördlichen Seite der Umfriedung kam ein runder Gegenstand aus Bronze mit einer rechteckigen Öse an der Innenseite (Riemenzier?) zum Vorschein: Dm 3,5 cm (Abb. 205,IC; 206,3).

- In der Grabgrube neben den menschlichen Knochen fand sich ein rautenförmiges Plättchen aus gelben Metall (evtl. Gold) mit zwei Löchern (vermutlich Gewandverzierung): $8 \mathrm{~mm} \times 6 \mathrm{~mm}$; Dm Bohrungen $0,5 \mathrm{~mm}$ (Abb. 205,Ib; 206,I).

- An unterschiedlichen Stellen der Grabgrube, nah zum Holzrahmen befanden sich drei fragmentarisch erhaltene Schalen /orange bis rotorange, scheibengedreht, fein gemagert (Abb. 204,3); I. Eine flach-

646 Archäozoologische Bestimmung von Prof. Dr. rer. nat. Norbert Benecke, Deutsches Archäologisches Institut, bödige Schale mit Kanneluren in ihrer oberen Hälfte; RDm 20,6 cm; BDm 9,5 cm; $\mathrm{H}$ 7,I cm; Wanddicke $0,6 \mathrm{~cm}$ (Abb. 206,7); 2. Eine ähnliche Schale; RDm $\mathrm{I} 6,5 \mathrm{~cm}$; BDm 7,7 cm; H 5,2 cm; Wanddicke $0,6 \mathrm{~cm}$ (Abb. 205,2; 206,4); 3. Eine fragmentarisch erhaltene Schale, bzw. Randscherben einer Schale; RDm (rekonstruiert) ca. I9,7 cm; Wanddicke 0,6 cm (Abb. 205,3; 206,5) und 4. ein flachbödiger Napf ohne Verzierung ebenso orange bis rotorange, scheibengedreht, jedoch mittelfein gemagert; RDm 8,3 cm; Dm Schulter 8,9 cm; BDm $5,2 \mathrm{~cm} ; \mathrm{H} 6,5 \mathrm{~cm}$; Wanddicke $0,3 \mathrm{~cm}$ (Abb. 205,4; 206,6) sowie eine Randscherbe (Abb. 206,8).

- In der Mitte des Grabbodens und neben den menschlichen Knochen lagen einzelne Tierknochen von zwei Schafsskeletten, je ein männliches und ein weibliches Tier im Alter von ca. 6 Monaten, sowie zwei Schwanzwirbel vom Pferd ${ }^{6} 6$.

Naturwissenschaftliches Referat an der Zentrale, Archäozoologie. 

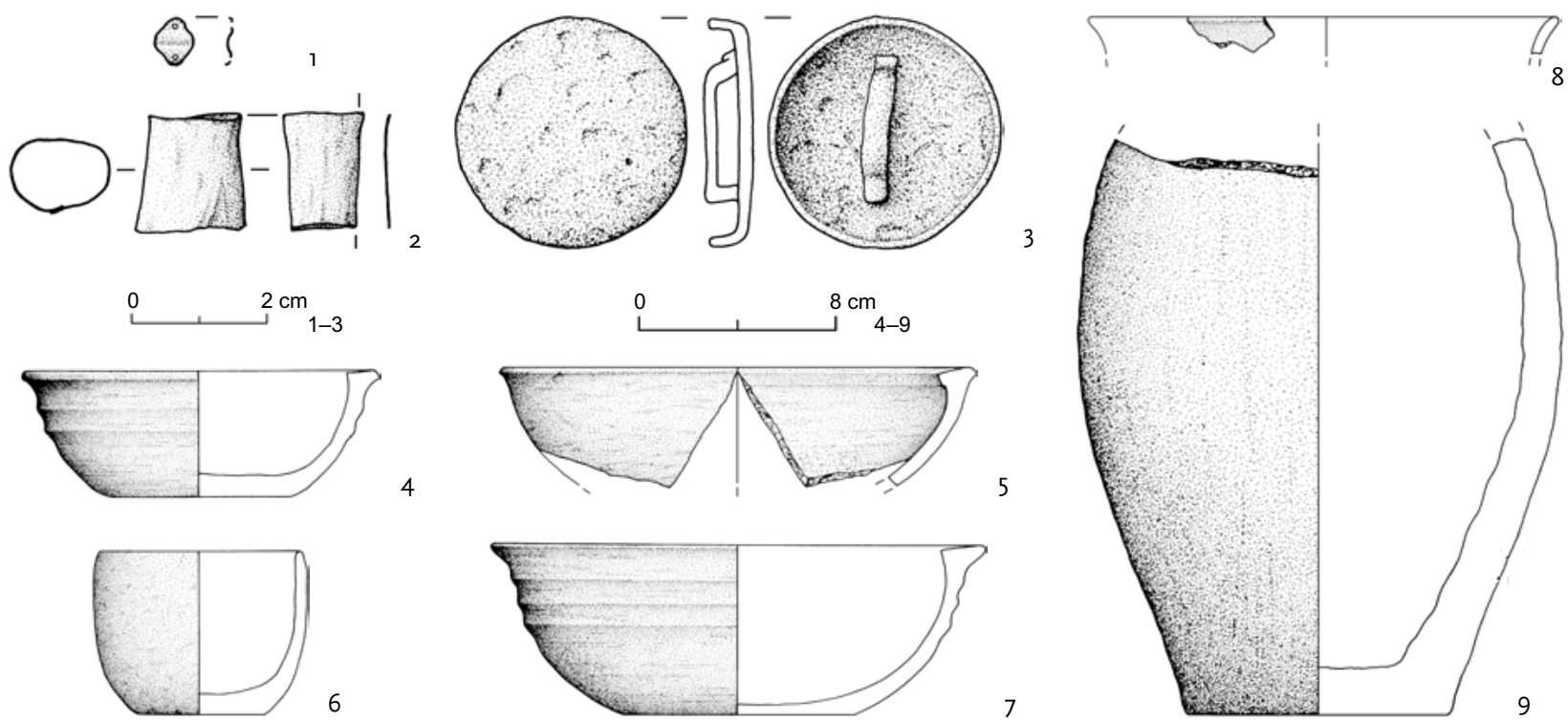

3

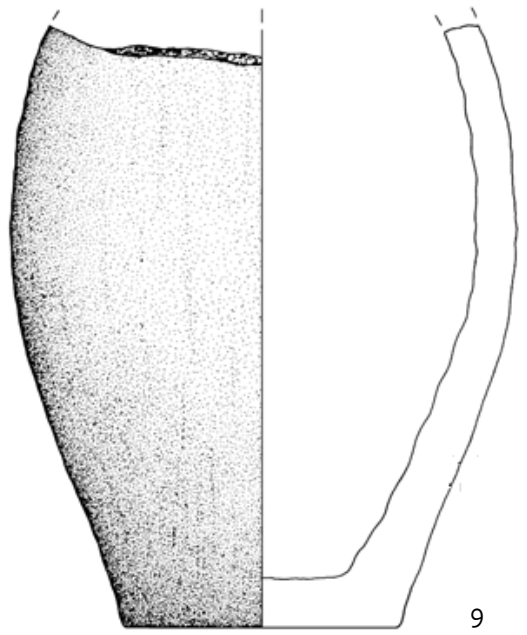

Abb. 206 | Gräberfeld Žoan Tobe. Kurgan 8. Funde (I gelbes Metall (evtl. Gold); 2 Gold; 3 Bronze; 4-9 Keramik; 2-3 Kurgan; I.4-8 Grabgrube; 9 Raubschacht) Zeichnung: M.-R. Boroffka

Datierung - Hd-28054: cal BC 358-48647.

Metallanalyse ${ }^{6} 48$ - I. Materialien und Methoden:

I.I. Atomabsorptionsspektrometrie (AAS):

Gemessen wird mit einem Flammen-AAS-

Gerät der Firma Philips mit der Bezeichnung PU 9100 in einer Luft/AcethylenFlamme mit kontinuierlichem Betrieb. Es besitzt eine Untergrundkompensation (Deuterium-Lampe) und die Empfindlichkeit bzw. Nachweisgrenze des jeweiligen Elements richtet sich nach der gewählten Wellenlänge und nach der Einwaage. $20 \mathrm{mg}$ Bohrspäne werden in Salpetersäure und Salzsäure aufgelöst und in einem Messkolben mit destilliertem Wasser auf $20 \mathrm{ml}$ aufgefüllt. Aus dieser Lösung werden I2 Elemente gemessen, wobei das Hauptelement Kupfer als Differenz zu ı००\% angegeben wird.

I.2. Mikro-Röntgenfluoreszenzanalyse ( $\mu$-XRF): Die Röntgenfluoreszenzanalyse ergibt eine semi-quantitative Übersicht über den Gehalt der Elemente einer Probe. Die Untersuchung wird mit Hilfe des transportablen ArtTAX Pro (ehemals Fa. Röntec $\mathrm{GmbH}$, jetzt Bruker) durchgeführt.

Messbedingungen: $45 \mathrm{kV}$, го $\mu \mathrm{A}$, Io० s LifeTime, $50 \mathrm{keV}$, Spektrenentfaltung unter

647 Nachweise zur Probe befinden sich im Appendix I Nr. I5.

648 Die Metallanalyse führte das Rathgen-Labor der SMBPK durch. Für die Mitteilung der Ergebnisse möchte ich
60 cycl. Das Gerät ist ein energiedispersives Mikro-Röntgenfluoreszenz-Analysegerät mit Molybdän-Röhre (3०W), stickstofffreiem SDD-Detektor und Polykapillarlinse (80-Iooum Spot).

II. Ergebnisse: Die Bronzeprobe der Riemenzier(?) (Abb. 205,Ic; 206,3) wurde mit Hilfe der oben beschriebenen Atomabsorptionsspektrometrie analysiert. Die Legierung hat die folgende Zusammensetzung (in \%, Tabelle 3I). Auffallend sind die niedrigen Spurenelementkonzentrationen der zinnarmen Zinnbronze, mit der Ausnahme von Antimon.

Das Goldblech der Hülse (Abb. 205,ra; 206,2 ) evtl. von einer Reitpeitsche wurde mit Hilfe der $\mu$-XRF analysiert und hat folgende Zusammensetzung: Tabelle 32. Das relative Goldgehalt von $77 \%$ wäre noch mit natürlichem Elektron oder Elektrum (von griech. $\varepsilon \grave{\lambda} \varepsilon x \tau \varrho o v$ (elektron) vereinbar.

Kurgan 9 (Kleinkurgan)

Dm ig m; H I,2 $\mathrm{m}$

Lage: N43 38.6I3 E78 22.738

Form: rundliche, stark abgeflachte Erhebung

Abhänge: ?

mich beim Direktor des Rathgen-Labors der SMB-PK Prof. Dr. S. Simon, sowie bei Prof. Dr. H. Parzinger, Dr. M. Nawroth und M.-R. Boroffka bedanken. 
Tabelle 31 | Legierungszusammensetzung der bronzenen Riemenzier

\begin{tabular}{|l|l|l|l|l|l|l|l|l|l|l|l|l|l|}
\hline Probename & $\mathbf{C u}$ & $\mathbf{S n}$ & $\mathbf{P b}$ & $\mathbf{Z n}$ & $\mathbf{F e}$ & $\mathbf{N i}$ & $\mathbf{A g}$ & $\mathbf{S b}$ & As & $\mathbf{B i}$ & $\mathbf{C o}$ & $\mathrm{Au}$ & $\mathbf{C d}$ \\
\hline $\begin{array}{l}\text { Bronze } \\
\text { Riemenzier(?) }\end{array}$ & 96,08 & 3,70 & $0, \mathrm{II} 0$ & $0,02 \mathrm{I}$ & 0,024 & $<0,0 \mathrm{I}$ & 0,007 & 0,057 & $<0, \mathrm{IO}$ & $<0,025$ & $<0,0 \mathrm{I}$ & $<0,02$ & $<0,002$ \\
\hline
\end{tabular}

Tabelle 32 | Quantitative Zusammensetzung des Goldblechs

\begin{tabular}{|l|l|l|l|}
\hline & $\% \mathbf{C u}$ & $\% \mathbf{A g}$ & $\% \mathbf{A u}$ \\
\hline Goldblech & 3,45 & $2 \mathrm{I}, \mathrm{OI}$ & 76,95 \\
\hline
\end{tabular}

Zustand: in der Mitte ein Raubtrichter, Kurgan überpflügt

Sonstiges: Oberfläche mit mittelgroßen Steinen und Kieselsteinen bedeckt;

kleinster Kurgan der Nekropole

Bemerkungen: Im Sommer 2008 wurde der Kurgan von der Kasachisch-Deutschen Archäologischen Expedition ausgegraben.

Kurganaufbau:

- Aushub südlich und nördlich der Grabgrube;

- Grabgrube mit Schotter und kleinen Kieselsteinen verfüllt;

- Über die Grabgrube wurde eine Halbkugel aus sandigem, feinem Lehm gebaut (Dm Io,6 m H $\mathrm{I}, 2 \mathrm{~m})$.

- Die Halbkugel wurde mit feinem dünnflüssigem Lehm versiegelt (Mächtigkeit der Schicht bis o,or $\mathrm{m}$ ).

- Auf den dünnflüssigen Lehm wurde eine Schicht aus mittelgroßen (ab $20 \times 10 \mathrm{~cm}$ ) Steinen aufgelegt.

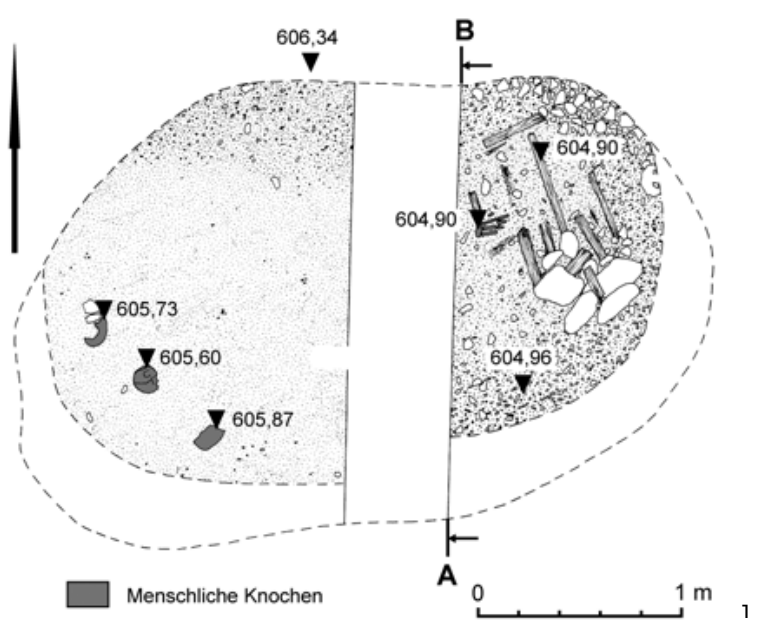

- Darüber folgte eine weitere Halbkugel aus hartem, zum Teil gestampftem Lehm mit Sand- und Kiesanteilen; die Seiten sind besonders verstärkt.

- Die Seiten der Konstruktion wurden mit feinem dünnflüssigem Lehm versiegelt (Mächtigkeit der Schicht bis zu 0,02 m).

- Darauf folgte eine weitere Steinschicht, die letztendlich mit einer Aufschüttung aus mittelgroßen Steinen, Kieselsteinen und lehmigem Sand bedeckt worden war.

- Dies war die letzte Schicht, so dass der Kurgan seine endgültige Form angenommen hat.

Befund - längliche Grabgrube mit stark abgerundeten Ecken in der Mitte des Kurgans; die Wände der Grabgrube laufen leicht schräg nach unten (Abb. 207)

- Maße: $3,5 \times 2,2 \times 1,5 \mathrm{~m}$

- Ausrichtung: W-O

- Weitere Bauelemente: auf dem Boden der Osthälfte lagen Holzfragmente; eines davon stand senkrecht im mittleren Bereich der Nordwand.

- Zustand der Grabgrube: durch die Beraubung stark zerstört und mit mehreren inhomogenen Schichten verfüllt

Bestattung - vereinzelt Menschenknochen (Schädelfragmente und Fußknochen) in der Westhälfte der Grabgrube ${ }^{6} 49$

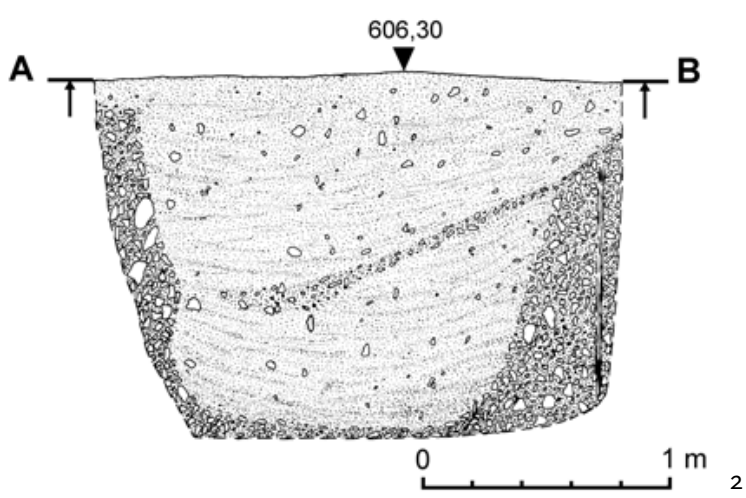

Abb. 207 | Kurgan 9. Grab. Planum und Profil (Zeichnung: M.-R. Boroffka)

649 Dazu siehe den Beitrag von Dr. Julia Gresky, Paläopathologische und anthropologische Untersuchungen an den menschlichen Skeletten aus Žoan Tobe, Kasachstan. 
Funde - im nordöstlichen Bereich der Kurganaufschüttung ein Eisenmesser, das eine leicht krumme Klinge mit nah zum Griff abgeschliffener Schneideseite und einen rechteckigen Querschnitt des Griffes hat; Gesamtlänge $10,5 \mathrm{~cm}$; L Griff $4,3 \mathrm{~cm}$; L Klinge 6,2 cm; B I,6 cm (Abb. 208,I,3)

Bolzen (?) aus Eisen in der Kurganaufschüttung; L 2,9 cm; Dm 0,5 cm (Abb. 208,2.4)

- In der Südhälfte der Kurganaufschüttung, vom Lehm-Sandgemisch überlagert, zwischen dem ersten und zweiten Steinschichten, befand sich eine Sammlung verkohlter Körner und Samen, die archäobotanisch untersucht650 und für ${ }_{14} \mathrm{C}$-Datierung verwendet worden sind

Datierung - Hd-280I9: cal BC I69-cal AD 4865
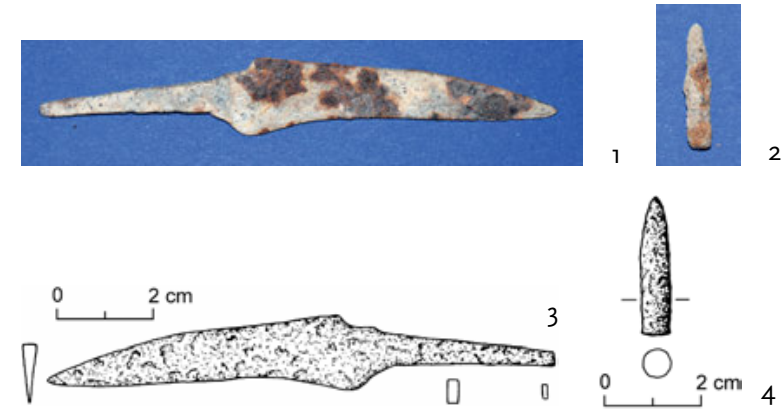

Abb. 208 | Kurgan 9. Funde (Eisen); I. 3. Messer;

2. 4. Bolzen (?); Foto und Zeichnung: M.-R. Boroffka

Forschungsgeschichte

Drei bis fünf Kilometer nordöstlich, nördlich und nordwestlich von der Nekropole befindet sich eine hohe Konzentration an Kleinkurganen, die ebenso N-S verlaufende Ketten bilden. Anhand der Feldtagebücher und der Grabungsberichte, die im Archiv des Archäologischen Institutes „A. Ch. Margulan“ (Almaty) aufbewahrt wurden, konnte rekonstruiert werden, dass diese Kurgankonzentrationen zur Nekropole „Džuvantobe“ gehörte, die ${ }_{195} 6$ durch die archäologische Siebenstromland-Expedition unter der Leitung von E. I. Ageeva untersucht worden ist.

Es wurden insgesamt I9 Kleinkurgane ausgegraben (Čarikov I956a, 29-36; Čarikov I956b, 27-55; Maksimova I956a, 3-8; Maksimova I960a, 62; Pacevič 1956, 32-38). Der Durchmesser der untersuchten Kurgane schwankte zwischen vier und zwölf Metern, die Höhe zwischen o,I $\mathrm{m}$ und $0,5 \mathrm{~m}$. Alle Kleinkurgane waren rund. In überwiegender Zahl enthielten sie rechteckige Grabgruben mit abgerundeten Ecken im Zentrum des Kurgans. Einige Grabgruben waren rechteckig oder langoval. Die meisten Gruben dieser Form befanden sich im Zentrum der Kurgane, einige auch in der Ost-, Nord- oder Südhälfte. Ein Drittel aller Gräber wurde mit Holz abgedeckt. Mit einer Ausnahme waren alle Gräber W-O ausgerichtet. In einem Fall verlief die Ausrichtung in einer NW-SO Achse. Die Grabgruben waren I,6 m bis 3,O $\mathrm{m}$ lang, $0,5 \mathrm{~m}$ bis I,2 $\mathrm{m}$ breit und $0,4 \mathrm{~m}$ bis I,I $\mathrm{m}$ tief. In überwiegender Zahl handelte es sich hier um Einzelbestattungen erwachsener Personen. Man fand auch eine Doppelbestattung (eine erwachsene

$6_{50}$ Die archäobotanische Bestimmung erfolgte durch Drs. Reinder Neef vom Deutschen Archäologischen Institut, Naturwissenschaftliches Referat an der Zentrale, Archäobotanik. Es handelte sich um mehrere Schlämmproben, von denen zwei pflanzliche Reste enthielten. Neef schreibt dazu: „Probe 9: Erdprobe von ca. 3 Litern aus dem Südteil des Abschnittes zwischen Profil 2 und 3. In dieser Probe war kaum Holzkohle vorhanden, dafür aber viele Getreidekörner: ca. 275 Körner von einer kompakten Form eines Nacktweizens (Triticum aestivum ssp. sphaerococcum ) und zwei von Gerste (Hordeum vulgare). Sonst gab es I27 Ährenspindelglieder vom T. aestivumTyp, 5 Ährchenbasen von Einkorn/Emmerweizen (T. mono-/dicoccum) und viele Strohhalmreste. Zwergweizen unterscheidet sich von Saatweizen durch seine dichtblütigen Ähren und seine kompakten, fast rundlichen Körner. Es ist ein hochwertiger Weizen zum Brotbacken, jedoch braucht er relativ fruchtbare Böden. - Probe i7: Erdprobe von insgesamt ca. 3 Litern aus dem Südteil des
Streifens zwischen Profil 4 und 5. Die Probe enthielt ca. I25 Körner von mehreren Hirsearten: Rispenhirse (Panicum miliaceum), Kolbenhirse (Setaria italica) und einer wilden Hirse-Art, am ehesten wohl Grüner Borstenhirse (Setaria cf. viridis). Grüne Borstenhirse gilt als Stammform des Sommergetreides Kolbenhirse. Die frühesten Funde von Kolbenhirse sind aus dem 6. Jt. v. Chr. aus Nordchina. Grüne Borstenhirse gilt als eine Kulturform der Borstenhirse, die nur selten vorkam. Generell können Hirsearten zu Bier, Brei oder Fladenbrot oder auch als Grünfutter für das Vieh verarbeitet worden sein. In dieser Probe war sehr viel Holzkohle vorhanden. Es waren Ästchen und Zweige von einem Zwergstrauch aus der Gänsefussfamilie (Chenopodiaceae). Diese sind typisch für trockene Steppen und kommen auch auf stark versalzten Böden vor“ (R. Neef, Vorläufiger unpublizierter Bericht zu den botanischen Proben aus dem Kurgan 9 des Gräberfeldes Žoan Tobe (Kasachstan), 2008).

65I Nachweise zur Probe finden sich im Appendix I Nr. I6. 

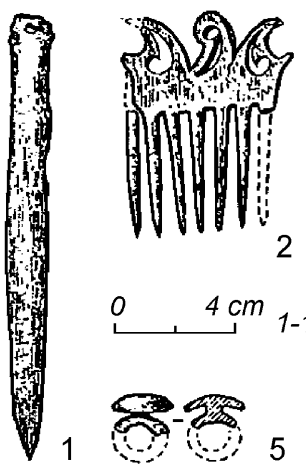

$\underset{+}{0 \quad 4 \mathrm{~cm}} 1-10$
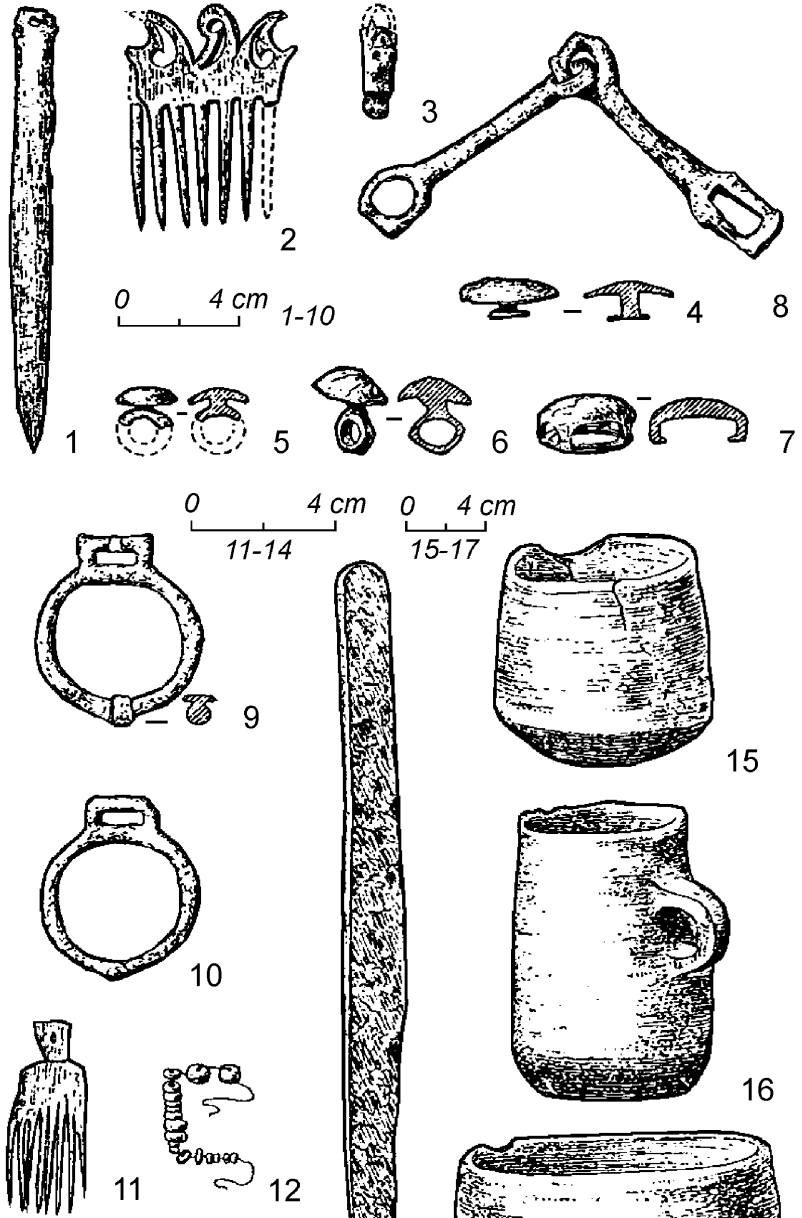

$$
00000008
$$
13

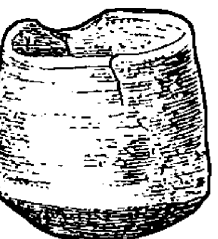

15

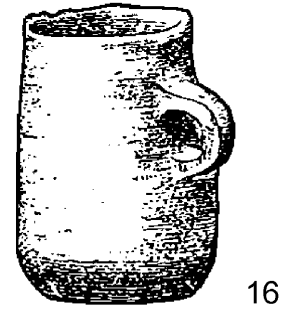

16

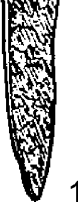

14

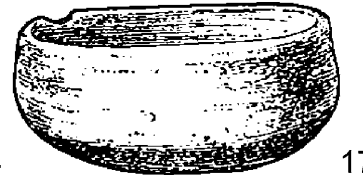

Abb. 209 | Fundrepertoire des Gräberfeldes Džuvantobe. I-IO Kurgan I2; II, I3-I4 Kurgan 48; I2 Kurgan IO; I5 Kurgan 44; I6 Kurgan 70; I7 Kurgan 49 (Maksimova I96oa, I-Io Abb. II,5-I4; II-I7 Abb. I2,I-8)
Person und ein Kind) und eine separate Pferdebestattung. In zwei Gräbern waren Kinder beerdigt. Fast alle Bestatteten lagen in einer Rückenstreckerposition. Nur ein Skelett war ein Rückenhocker. Alle Skelette lagen mit dem Kopf nach Westen. Zum Beigabenrepertoire gehörten Messer (Abb. 209,I und 209,I4), Trensen mit Steigbügelenden (Abb. 209,8), Riemenverteiler (Abb. 209,7), Besatzstücke (Abb. 209,4-6), Schnallen (Abb. 209,9-Io), Pfrieme und Ohrringe aus Bronze, ein Kamm (Abb. 209,2) und ein Fragment einer Statuette (Pferdekopf?) aus Knochen (Abb. 209,3), ein Holzkamm (Abb. 209,II), ein Spinnwirtel aus Kalkstein, Perlen aus Glaspaste, Aragonit bzw. Pyrit (Abb. 209,I2-I3), Krüge (Abb. 209,I6), eine Schale (Abb. 209,I7), ein Topf (Abb. 209,I5), Tierknochen (KWK) und Holzreste.

Im Sommer 2008 untersuchte die Kasachisch-Deutsche Archäologische Expedition die Peripherie des Kurgans I und grub die Kurgane 8 und 9 aus. ${ }^{652}$

Lit.: Ageeva 1957, 52/6r; Akišev K.A. 1967, 67; Artamonov 1973, 36; Črikov 1956a, 29-36; Črikov I956b, 27-55; Gass 20I1a, 67-68, Fig. 3, 23; Gass 20IIb, 2I3, Abb. 9; Gass (im Druck); Maksimova I956a, 3-8; Maksimova I956b, 33-42; Maksimova I960a, 6o-64; Nagler 2009, 406-408, Abb. 72-75; Nagler u.a. 2010, 49-54; Opis' predmetov I956, 8 , I3-I4, I8-23, 25-26; Pacevič I956, 32-38; Samašev u.a. 2009, 350-352; Semirečenskaja archeologičeskaja ekspedicija I956, I-I3; Zadneprovskij I992, 76.

Gräberfeld Žylysaj-I [FEZ und frühtürkische Periode] (Abb. 2IO-2II; Karte 3 Nr. 50): ALT I456 m N43 09.427 E78 57.829; Gebiet Almaty (kasach. Алматы облысы), Rajymbekskij rajon (kasach. Райымбек ауданы); Ausmaß N-S $752 \times$ O-W Ioo m.

Das Gräberfeld Žylysaj-I liegt auf der Ebene zwischen dem Čaryn Canyon (kasach. Шарын) und dem Bergrücken Kuluktau (kasach. Қулықтау), und zwar an dessen nördlichen Fuß, zwischen zwei ausgetrockneten Bachbetten. Die Nekropole befindet sich ${ }^{6} 67 \mathrm{~km}$ östlich der Stadt Almaty (kasach. Алматы), $4 \mathrm{~km}$ westlich des Dorfes Uzynbulak (kasach. Ұзынбұлақ) sowie $3 \mathrm{~km}$ südsüdöstlich des Dorfes Žylysaj (kasach. Жылысай). Die gesamte Nekropole zählt I8 mittelgroße und kleine Kurgane.

$652 \mathrm{Zu}$ den Ausgrabungen der Kasachisch-Deutschen Archäologischen Expedition im Sommer 2008 siehe die Kurgancharakteristik. 
Die Kurgane bilden drei N-S verlaufende Ketten, wobei nur in der mittleren Kette große Kurgane vorkommen. Die östliche und westliche Kette bestehen aus Kleinkurganen.

Die mittlere Kette weist I3 Kurgane auf. In der Peripherie von acht dieser Kurgane wurden weitere Steinkonstruktionen errichtet. Es handelt sich um sog. Prozessionswege (bei sieben Kurganen), um Steinkreise (bei einem Kurgan) und um kleinere Steinanhäufungen (bei drei Kurganen), die als Kleinkurgane angesprochen werden können. Ferner weist einer der Kurgane (K6 nach der Arbeitsnummerierung) eine viereckige Form der Aufschüttung auf. Dementsprechend verläuft der sog. Prozessionsweg um diesen Kurgan. Die äußere Markierung dieser Wege wurde durch große, senkrecht angebaute Steine angezeigt.

In drei Fällen wurden zwischen dem Kurganrand und dem sog. Prozessionsweg jeweils in der Nordhälfte flache, quadratische Umfriedungen (zwei bei K6, zwei bei K7 und eine bei K9), die sicher der frühtürkischen Periode zugeordnet werden können, gebaut. Um Kurgan 8, der sich relativ zentral innerhalb der Kette steht, wurde im Abstand von 7 m vom Kurganrand eine sehr schlecht erhaltene, umlaufende Steinkonstruktion festgestellt. Es kann sich hier sowohl um einen Steinkreis als auch um einen sog. Prozessionsweg handeln.

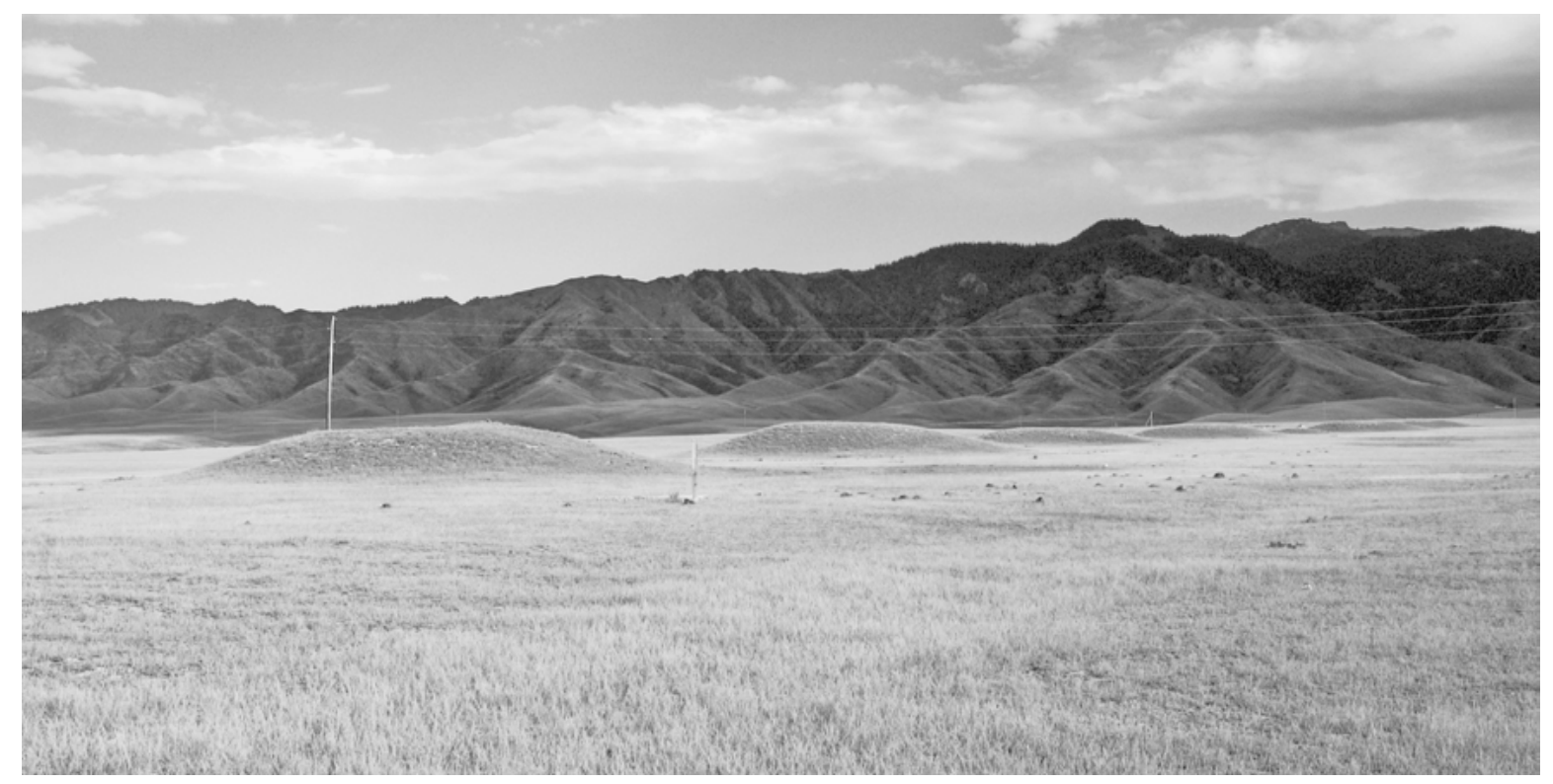

Abb. 211 | Gräberfeld Žylysaj-I. Blick von NW

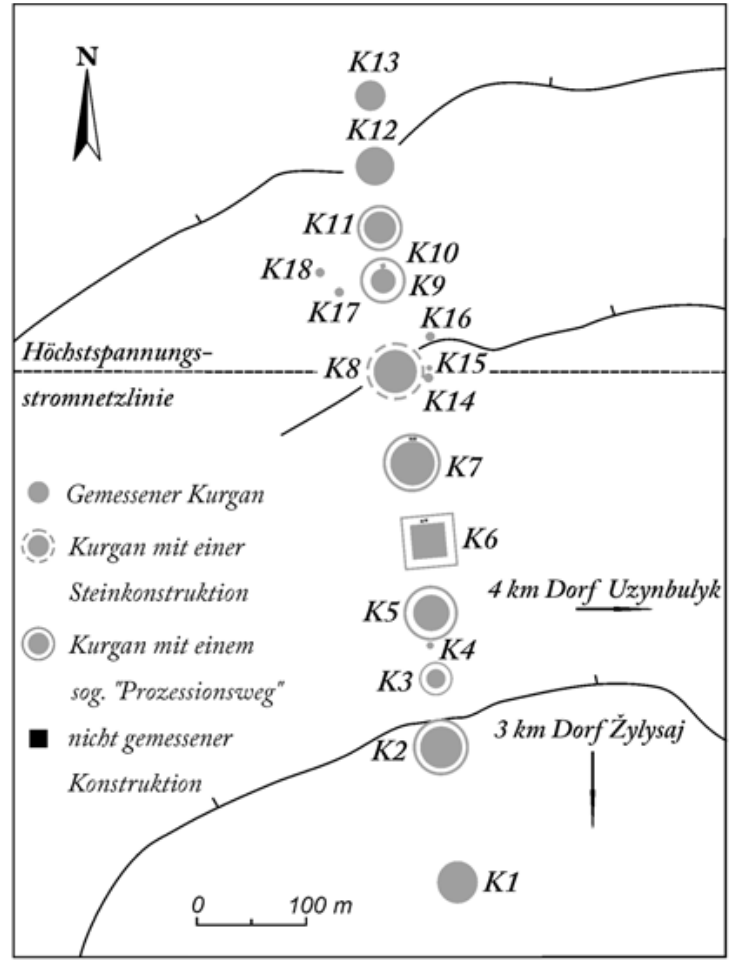

Abb. 210| Plan des Gräberfeldes Žylysaj-I 
Weitere architektonische Merkmale wurden auf der Nekropole nicht festgestellt.

Der Durchmesser der Kurgane schwankt zwischen 5 m und 39 m (5I m mit dazugehörigen Steinkonstruktionen), die Höhe misst zwischen o,I5 m bis zu $4 \mathrm{~m}$. Alle Kurgane des Gräberfeldes weisen eine Senke bzw. einen Raubtrichter auf. Elf größere Kurgane haben drei steile und einen (immer südlichen) sanften Abhang. Aufgrund der geringen Größe konnten bei den restlichen sieben Kurganen keine besonderen Merkmale der Abhänge bestimmt werden.

Anhand der Struktur und der äußeren Erscheinungsform können die Kurgane der Nekropole der sakischen Periode der Früheisenzeit und zur frühtürkischen Periode des frühen Mittelalters zugeordnet werden.
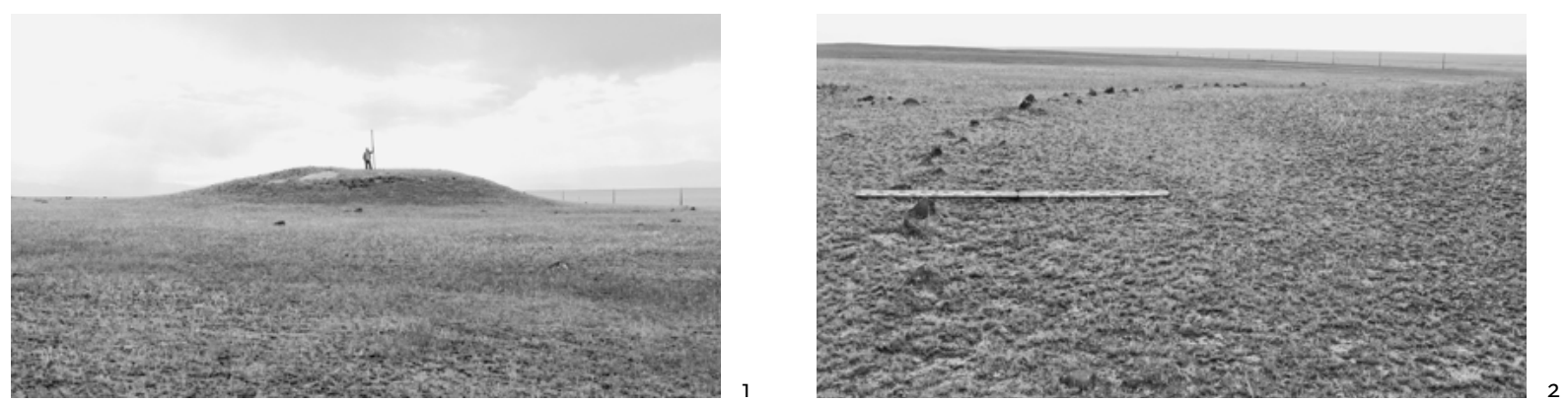

Abb. 212 | Kurgan 5 des Gräberfeldes Žylysaj-I; I. Blick von O; 2. Sog. Prozessionsweg, Nordbereich, Blick von O

Kurgancharakteristik:

Mittlere Kurgankette

\section{Kurgan I}

Dm 35 m; H 3 m

Lage: N43 09.258 E78 57.838; südlichster Kurgan der Kette

Form: abgerundet, plattformähnlich mit abgeflachter Kuppe

Abhänge: drei steile, südlicher sanft

Zustand: in der Mitte ein Raubtrichter

Sonstiges: an der Oberfläche mittelgroße $(\mathrm{ab} 40 \times 25 \times$ I5 $\mathrm{cm}$ ) Steine

\section{Kurgan 2}

Dm 37 m; Dm sog. Prozessionsweg 50 m; H 4 m

Lage: N43 09.325 E78 57.832

Form: abgerundet, plattformähnlich mit abgeflachter Kuppe

Abhänge: drei steile, südlicher sanft

Weitere Konstruktionen: $6 \mathrm{~m}$ vom Rand des Kurgans entfernt umlaufender sog. Prozessionsweg von I $\mathrm{m}$ Breite; dieser durch große, senkrecht angebaute Steine begrenzt

Zustand: in der Mitte ein Raubtrichter

Sonstiges: an der Oberfläche mittelgroße $(\mathrm{ab} 40 \times 25 \times$ I5 cm) und kleine (bis zu Schottergröße) Steine
Kurgan 3 (Kleinkurgan)

Dm I7 m; Dm sog. Prozessionsweg 28 m; H I, 5 m

Lage: N43 09.359 E78 57.830

Form: abgerundet, plattformähnlich mit abgeflachter Kuppe

Abhänge: drei steile, südlicher sanft

Weitere Konstruktionen: $5 \mathrm{~m}$ vom Rand des Kurgans entfernt umlaufender sog. Prozessionsweg von I m Breite, der durch große, senkrecht angebaute Steine begrenzt wird

Zustand: in der Mitte eine Senke

Sonstiges: an der Oberfläche mittelgroße $(\mathrm{ab} 40 \times 25 \times$ I5 $\mathrm{cm}$ ) und kleine (bis zu Schottergröße) Steine

Kurgan 4 (Kleinkurgan)

Dm 6,5 m; H o,I 5 m

Lage: N43 09.375 E78 57.828

Form: flache, abgerundete Steinanhäufung

Abhänge: keine

Zustand: in der Mitte eine Senke

Sonstiges: der Kurgan wurde aus mittelgroßen und kleinen Steinen gebaut

Kurgan 5 (Abb. 2I2,I)

Dm 3I m; Dm sog. Prozessionsweg 49 m; H 3,5 m

Lage: N43 09.392 E78 57.829

Form: abgerundet, plattformähnlich mit abgeflachter Kuppe

Abhänge: drei steile, südlicher sanft 
Weitere Konstruktionen: 7-8 m vom Rand des Kurgans entfernt umlaufender sog. Prozessionsweg von I m Breite, der durch große, senkrecht angebaute Steine begrenzt wird (Abb. 2I2,2)

Zustand: in der Mitte ein Raubtrichter

Sonstiges: an der Oberfläche große (ab $70 \times 30 \times 10 \mathrm{~cm})$, mittelgroße $(\mathrm{ab} 40 \times 20 \times 15 \mathrm{~cm})$ und kleine (bis $\mathrm{zu}$ Schottergröße) Steine

\section{Kurgan 6}

L (Seite) $28 \mathrm{~m}$; L (Seite des sog. Prozessionsweges) $45 \mathrm{~m} ; \mathrm{H} 3 \mathrm{~m}$

Lage: N43 09.427 E78 57.829

Form: viereckig, pyramidenähnlich mit abgeflachter Kuppe

Abhänge: drei steile, südlicher sanft

Weitere Konstruktionen: in einem Abstand von $8 \mathrm{~m}$ zum Kurgan umlaufender sog. Prozessionsweg von i m Breite, der die viereckige Kurganform nachvollzieht; zwischen Kurgan und sog. Prozessionsweg, in der Nordhälfte dieses Raumes, zwei flache quadratische Umfriedungen, die $2 \times 2 \mathrm{~m}$ groß sind und mit den Seiten an den vier Haupthimmelsrichtungen ausgerichtet waren

Zustand: in der Mitte ein Raubtrichter

Sonstiges: Die Seiten des Kurgans und des sog. Prozessionsweges sind grob an den vier Haupthimmelsrichtungen orientiert. An den westlichen Seitenkanten der pyramidenförmigen Kurganaufschüttung sind die Steine der Kurgankrepis sichtbar. Gesamte Oberfläche mit mittelgroßen $(\mathrm{ab} 40 \times 25 \times \mathrm{I} 5 \mathrm{~cm})$, kleinen und schottergroßen Steinen bedeckt

Bemerkung: beide flache, quadratische Umfriedungen am Kurganrand können anhand ihrer Erscheinungsform der frühtürkischen Periode des frühen Mittelalters zugeordnet werden

\section{Kurgan 7}

Dm 39 m; Dm sog. Prozessionsweg 5I m; H 3 m

Lage: N43 09.466 E78 57.825

Form: abgerundet, plattformähnlich mit abgeflachter Kuppe

Abhänge: drei steile, südlicher sanft

Weitere Konstruktionen: $5 \mathrm{~m}$ vom Rand des Kurgans entfernt umlaufender sog. Prozessionsweg von I $\mathrm{m}$ Breite, der durch große, senkrecht angebaute Steine begrenzt wird;

Zwischen dem Kurgan und dem sog. Prozessionsweg in der Nordhälfte befinden sich zwei flache, quadratische Umfriedungen, die $2 \times 2 \mathrm{~m}$ groß sind; die Seiten waren an den vier Haupthimmelsrichtungen ausgerichtet.

Zustand: in der Mitte ein Raubtrichter

Sonstiges: an der Oberfläche einzelne mittelgroße (ab $40 \times 20 \times 15 \mathrm{~cm}$ ) und kleine (bis zu Schottergröße) Steine

Bemerkung: beide flachen, quadratischen Umfriedungen am Kurganrand können anhand ihrer Erschei- nungsform der frühtürkischen Periode des frühen Mittelalters zugeordnet werden

\section{Kurgan 8}

Dm 37 m; Dm Steinkonstruktion 5I m; H 3 m

Lage: N43 09.5II E78 57.8I3

Form: abgerundet, plattformähnlich mit abgeflachter Kuppe

Abhänge: drei steile, südlicher sanft

Weitere Konstruktionen: in einem Abstand von $7 \mathrm{~m}$ vom Rand des Kurgans umlaufende Steinkonstruktion in schlechtem Erhaltungszustand, die aus senkrechten Steinen gebaut wurde

Zustand: in der Mitte ein Raubtrichter; im östlichen Randbereich Strommast

Sonstiges: an der Oberfläche einzelne mittelgroße (ab $40 \times 20 \times 15 \mathrm{~cm})$, kleine und schottergroße Steine

Bemerkung: Da die Steinkonstruktion um den Kurgan herum nur zum Teil erhalten war, kann nicht festgestellt werden, ob es sich hier ursprünglich um einen Steinkreis oder einen sog. Prozessionsweg gehandelt hat.

\section{Kurgan 9}

Dm 2I m; Dm sog. Prozessionsweg 42 m; H 2 m

Lage: N43 09.556 E78 57.807

Form: abgerundet, plattformähnlich mit abgeflachter Kuppe

Abhänge: drei steile, südlicher sanft

Weitere Konstruktionen: 8-9 m vom Rand des Kurgans entfernt umlaufender sog. Prozessionsweg von I m Breite, der durch große, senkrecht angebaute Steine begrenzt wird;

zwischen dem Kurgan und dem sog. Prozessionsweg, in der Nordhälfte flache quadratische Umfriedung (Kleinkurgan Io)

Zustand: in der Mitte ein Raubtrichter; vom sog. Prozessionsweg nur südöstliche Bereich erhalten

Sonstiges: an der Oberfläche einzelne mittelgroße (ab $40 \times 20 \times 15 \mathrm{~cm}$ ) und kleine (bis zu Schottergröße) Steine

Kurgan ro (Kleinkurgan)

Maß $5 \times 5 \mathrm{~m} ; \mathbf{H} \circ, 2 \mathrm{~m}$

Lage: N43 09.562 E78 57.807

Form: quadratische Umfriedung

Zustand: in der Mitte ein Raubtrichter

Sonstiges: Seiten der Umfriedung an den vier Haupthimmelsrichtungen orientiert

Bemerkung: frühtürkische Periode

Kurgan II

Dm 27 m; Dm sog. Prozessionsweg 4I m; H 3 m

Lage: N43 09.582 E78 57.806

Form: abgerundet, plattformähnlich mit abgeflachter Kuppe

Abhänge: drei steile, südlicher sanft

Weitere Konstruktionen: $6 \mathrm{~m}$ vom Rand des Kurgans entfernt umlaufender sog. Prozessionsweg von I $\mathrm{m}$ 
Breite, der durch große, senkrecht angebaute Steine begrenzt wird

Zustand: in der Mitte ein Raubtrichter

Sonstiges: die Oberfläche ist mit mittelgroßen $(\mathrm{ab} 70 \times$ $20 \times 25 \mathrm{~cm}$ ) und kleinen (bis zu Schottergröße) Steinen bedeckt

\section{Kurgan I2}

Dm 34 m; H 3 m

Lage: N43 09.6I5 E78 57.806

Form: abgerundet, plattformähnlich mit abgeflachter Kuppe

Abhänge: drei steile, südlicher sanft

Zustand: in der Mitte ein Raubtrichter

Sonstiges: gesamte Oberfläche mit mittelgroßen Steinen $(\mathrm{ab} 40 \times 20 \times 10 \mathrm{~cm})$ bedeckt

Kurgan I3 (Kleinkurgan)

Dm 27 m; H I, 5 m

Lage: N43 09.647 E78 57.805; nördlichster Kurgan der Kette

Form: abgerundet, plattformähnlich mit abgeflachter Kuppe

Abhänge: drei steile, südlicher sanft

Zustand: in der Mitte ein Raubtrichter

Sonstiges: gesamte Oberfläche mit mittelgroßen Steinen ( $\mathrm{ab} 40 \times 20 \times$ IO cm, bis zum Schotter) bedeckt

Ostkette

Kurgan I4 (Kleinkurgan)

Dm 7 m; H o,3 $\mathrm{m}$

Lage: N43 09.507 E78 57.835; südlichster Kurgan der Kette

Form: flache, abgerundete Steinanhäufung

Abhänge: keine

Zustand: in der Mitte ein Raubtrichter

Sonstiges: Kurgan aus mittelgroßen $(\mathrm{ab} 60 \times 20 \mathrm{~cm})$ und kleinen Steinen erbaut

Lit.: Bajpakov u.a. 2006, 349, 353.

\author{
Kurgan 55 (Kleinkurgan) \\ Dm $5 \mathrm{~m} ; \mathrm{H} \mathrm{O,2} \mathrm{m}$ \\ Lage: N43 09.512 E78 57.836 \\ Form: flache, abgerundete Steinanhäufung \\ Abhänge: keine \\ Zustand: in der Mitte ein Raubtrichter \\ Sonstiges: Kurgan aus mittelgroßen $(\mathrm{ab} 70 \times 40 \times$ \\ I5 $\mathrm{cm}$ ) und kleinen Steinen erbaut
}

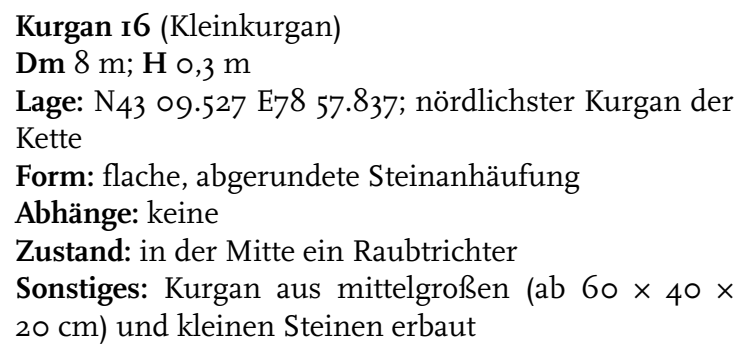

Westkette

Kurgan I7 (Kleinkurgan)

Dm 8 m; H o,4 m

Lage: N43 09.55I E78 57.777; südlichster Kurgan der Kette

Form: flache, abgerundete Steinanhäufung

Abhänge: keine

Zustand: in der Mitte ein Raubtrichter

Sonstiges: aus mittelgroßen $(\mathrm{ab} 50 \times \mathrm{I} 5 \mathrm{~cm})$ und kleinen Steinen erbaut

\author{
Kurgan I8 (Kleinkurgan) \\ Dm 7 m; H o,3 m \\ Lage: N43 09.562 E78 57.765; nördlichster Kurgan der \\ Kette \\ Form: flache, abgerundete Steinanhäufung \\ Abhänge: keine \\ Zustand: in der Mitte ein Raubtrichter \\ Sonstiges: aus mittelgroßen $\left(\mathrm{ab} 50 \times \mathrm{I}_{5} \mathrm{~cm}\right)$ und klei- \\ nen Steinen erbaut
}

Komplex Aščybulak [FEZ - frühtürkische Periode(?)] (Abb. 213-2I4; Karte 3 Nr. 23): ALT 775 m N43 28.355 E77 47.I48; Gebiet Almaty (kasach. Алматы облысы), Enbekšikazachskij rajon (kasach. Еңбекшіқазақ ауданы); Ausmaß N-S $56 \times$ O-W 42 m.

Der archäologische Komplex Aščybulak befindet sich an der Nordseite der Bergkette Transili-Alatau (kasach. Іле Алатауы), im Lösshügelland, nördlich des Berges Burgansu (kasach. Бұрғансу), am linken, westlichen Ufer des Flusses Kury-Aščybulak (kasach. Құры-Ащыбұлақ), kurz vor der Mündung des Flusses im nördlich von Transili-Alatau gelegenen Flachland. Westlich vom Komplex verläuft ein Bewässerungsgraben. Der Fundort liegt 74,5 km nordöstlich von der Stadt Almaty (kasach. Алматы) und I,7 km südlich des Dorfes Aščbulak (kasach. Ащыбұлақ) entfernt. Der Komplex besteht aus einem Turtkul und einer nicht klar definierbaren Konstruktion, die sich $32 \mathrm{~m}$ nordwestlich vom Turtkul befindet. Der gesamte Komplex verläuft von SO nach NW entlang des Flussbettes. 


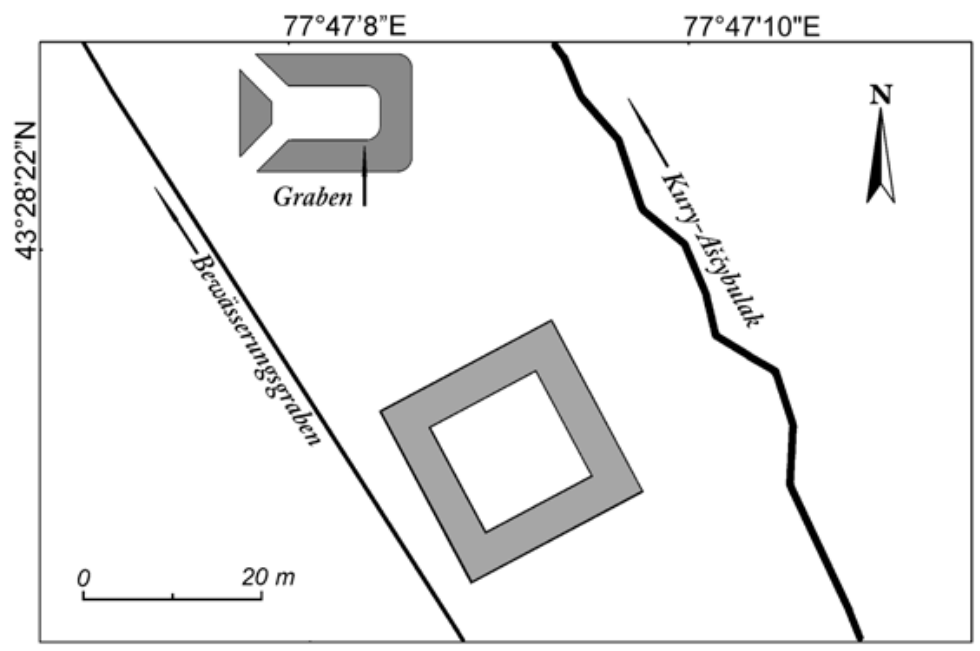

Abb. 213 | Skizze des Komplexes Aščybulak

Turtkul: Den Mittelpunkt des Komplexes bildet eine Befestigung/ Turtkul mit einem Ausmaß von $23 \times$ $23 \mathrm{~m}$, deren Ecken an den vier Haupthimmelsrichtungen orientiert sind. Das Turtkul zeigt sich als eine quadratische Konstruktion, die von einem Wall begrenzt wurde. Die Breite des Walls beträgt im oberen Bereich ca. $2 \mathrm{~m}$ und im unteren Bereich 4-6 m. Die äußere Grenze des Schutzwalls an der nordöstlichen und der südöstlichen Seite ist schwer zu erkennen, da sie mit den natürlichen Hängen des Lösshügels nahezu eine Einheit bildet. Die Höhe des Walls misst im inneren Bereich I $m$ und im äußeren I,5-2 m. An den östlichen und nördlichen Seiten des Walls wurden einige Steinsetzungen festgestellt, die aus großen $(\mathrm{ab} 70 \times 50 \mathrm{~cm})$ Steinen bestanden.
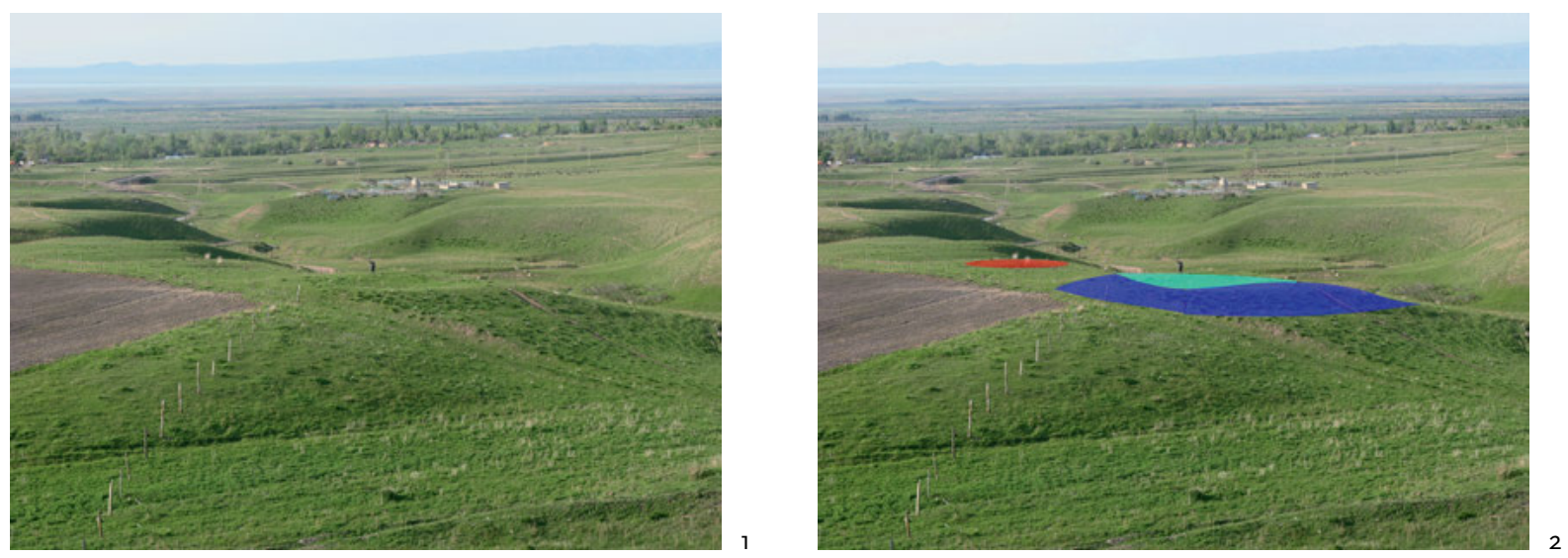

Abb. 214 | Komplex Aščybulak. Blick von SW

Der innere Bereich des Turtkuls stellt eine planierte, quadratische Fläche dar, die keine weiteren Merkmale aufweist. Hier kamen an der Oberfläche zwei rötliche Wandscherben (Abb. 2I5) zum Vorschein. 

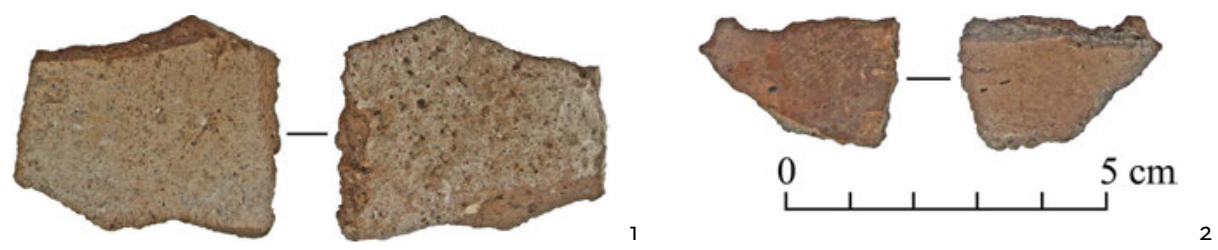

Abb. 215 | Komplex Aščybulak. Turtkul. Lesefunde

\section{Charakteristik der Lesefunde}

I. Wandscherbe 4,2 ×3,0 $\times 0,6 \mathrm{~cm}$; orange-beige; mittelfein gemagert; ältere Eisenzeit bis frühes Mittelalter.

2. Wandscherbe $2,9 \times 2,0 \times 0,8 \mathrm{~cm}$; rotorange; fein gemagert; scheibengedreht; ältere Eisenzeit bis frühes Mittelalter.

Nordwestlich gelegene Konstruktion (Abb. 216): 32 m nordwestlich vom Turtkul zeigt sich eine rechteckige, 9,5 $\times$ 15,5 $\mathrm{m}$ große Konstruktion mit abgerundeten Ecken. Sie stellt eine O-W ausgerichtete Erderhebung von I m Höhes5s dar, die 6 × I2 m maß. In der Südhälfte dieser Konstruktion wurden einzelne mittelgroße Steine $(\mathrm{ab} 40 \times 20 \mathrm{~cm}$ ) festgestellt. Diese Erhebung ist von einem 3,5 m breiten und o,6 $\mathrm{m}$ tiefen Graben umgeben, der an der südwestlichen und nordwestlichen Ecke unterbrochen ist. Es kann hier um sog. Eingangsbereiche handeln. Eine genaue Ansprache der Konstruktion ist ohne Ausgrabung nicht möglich.

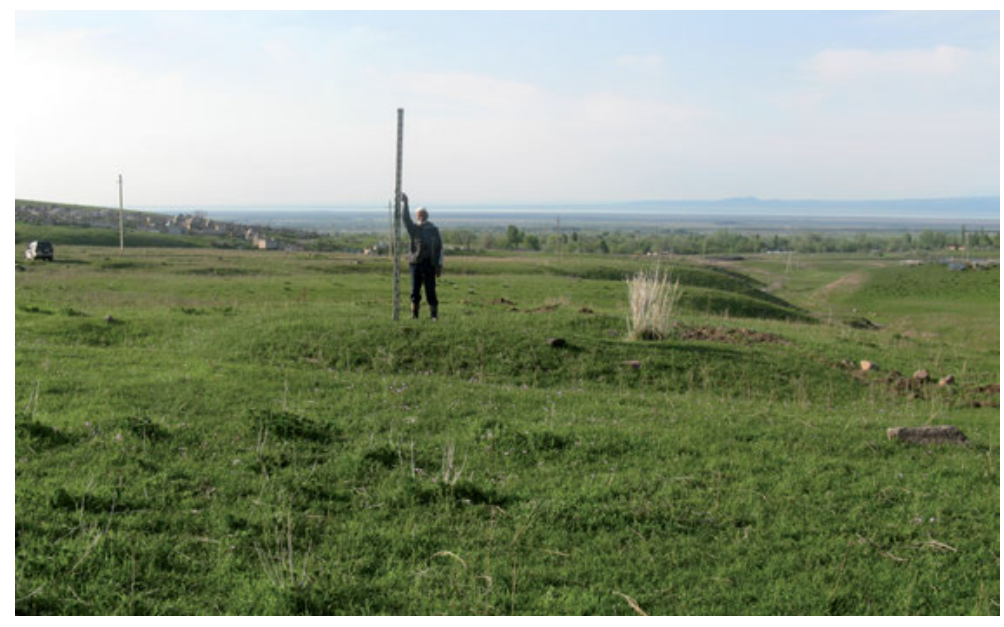

Abb. 216 | Komplex Aščybulak. Nordwestlich gelegene Konstruktion. Blick von S

Anhand der inneren Struktur und der äußeren Erscheinungsform der einzelnen Teile des Komplexes sowie der Lesefunde kann der Komplex Aščybulak der sakischen Periode der Früheisenzeit bis zur frühtürkischen Periode des frühen Mittelalters datiert werden.

Die äußere Erscheinungsform von der Befestigung ist für das Mittelalter Kasachstans bekannt und stellt evtl. die letzte Nutzungsphase des Komplexes dar. Durch die geographische Lage und die chrono-

653 Vom Boden des Grabens gemessen. 
logische Tiefe der Fundstelle, die die Lesefunde aufzeigen, kann von einer wiederholten Nutzung des Siedlungsplatzes in unterschiedlichen Zeitperioden (von der älteren Eisenzeit bis zum Mittelalter) ausgegangen werden.

\section{Komplex Kiikpaj [FEZ - frühtürkische Periode]} (Abb. 2I7; Karte 3 Nr. 24): ALT $844 \mathrm{~m} \mathrm{~N} 43$ 28.286 E77 48.988; Gebiet Almaty (kasach. Алматы облысы), Enbekšikazachskij rajon (kasach. Еңбекшіқазақ ауданы); Ausmaß N-S $587 \times$ O-W I76 m.

Der archäologische Komplex Kiikpaj befindet sich an der Nordseite der Bergkette TransiliAlatau (kasach. Іле Алатауы), an den nördlichen Ausläufern des Lösshügellandes, am linken, westlichen Ufer des Flusses Kiikbaj (kasach. Киікбай), und zwar an der Stelle, wo der Fluss aus dem Uročišče Kiikpaj (kasach. Киікпай) ausströmt (Abb. 2I8). Der Fundort liegt $74 \mathrm{~km}$ nordöstlich von der Stadt Almaty (kasach. Алматы), $9 \mathrm{~km}$ südwestlich vom Dorf

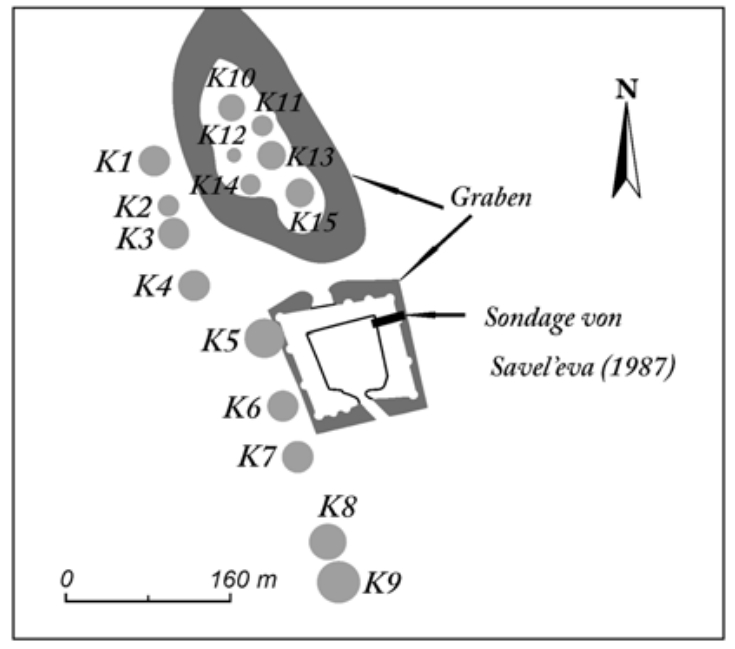

Abb. 217 | Plan des Komplexes Kiikpaj Teskensu (kasach. Тескенсу) und $3 \mathrm{~km}$ südlich vom Dorf Aščybulak (kasach. Ащыбұлақ) entfernt.

Der Komplex besteht aus einer befestigten Anlage, sog. Turtkul - im südlichen Bereich des Komplexes, einer Kurganenkette - westlich davon und einen künstlich errichteten „Plateau“ auf dessen Oberfläche sechs weitere Kurgane stehen - nördlich vom Turtkul. Nördlich und nordwestlich vom Komplex liegt ein kasachischer Friedhof aus ethnographischer Zeit, auf dem jedoch auch einige moderne Gräber angelegt wurden. Der archäologische Komplex dehnt sich von Süden nach Norden aus.

Turtkul (Abb. 219) N43 28.286 E77 48.988: Das Turtkul, dass mit den Seiten an den vier Haupthimmelsrichtungen - mit leichter Abweichung nach Westen - ausgerichtet wurde, bildet den Mittel-

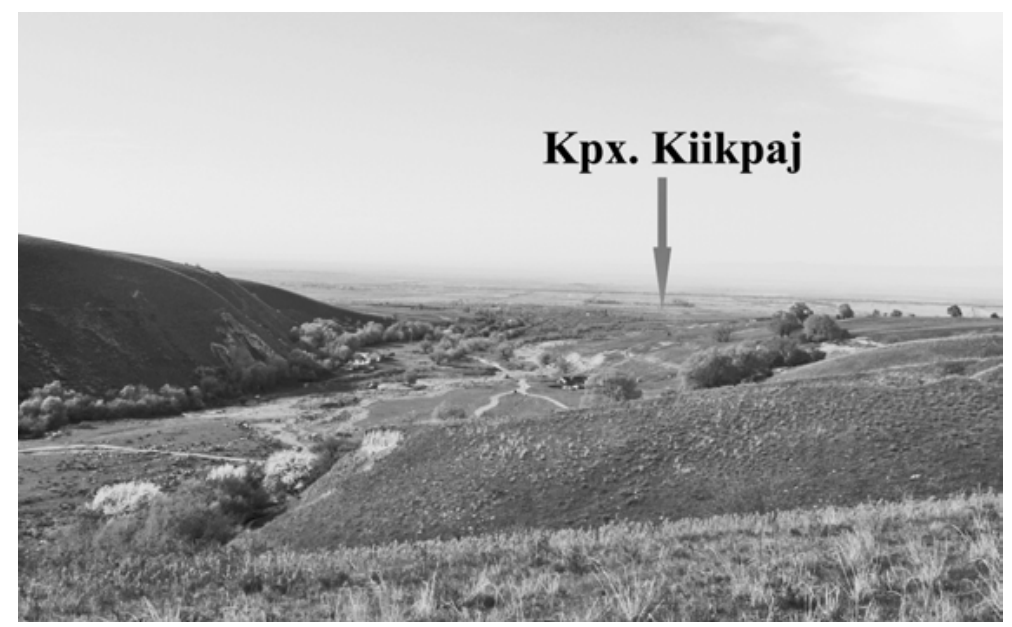

Abb. 218 | Komplex Kiikpaj. Landschaftslage. Blick von S 


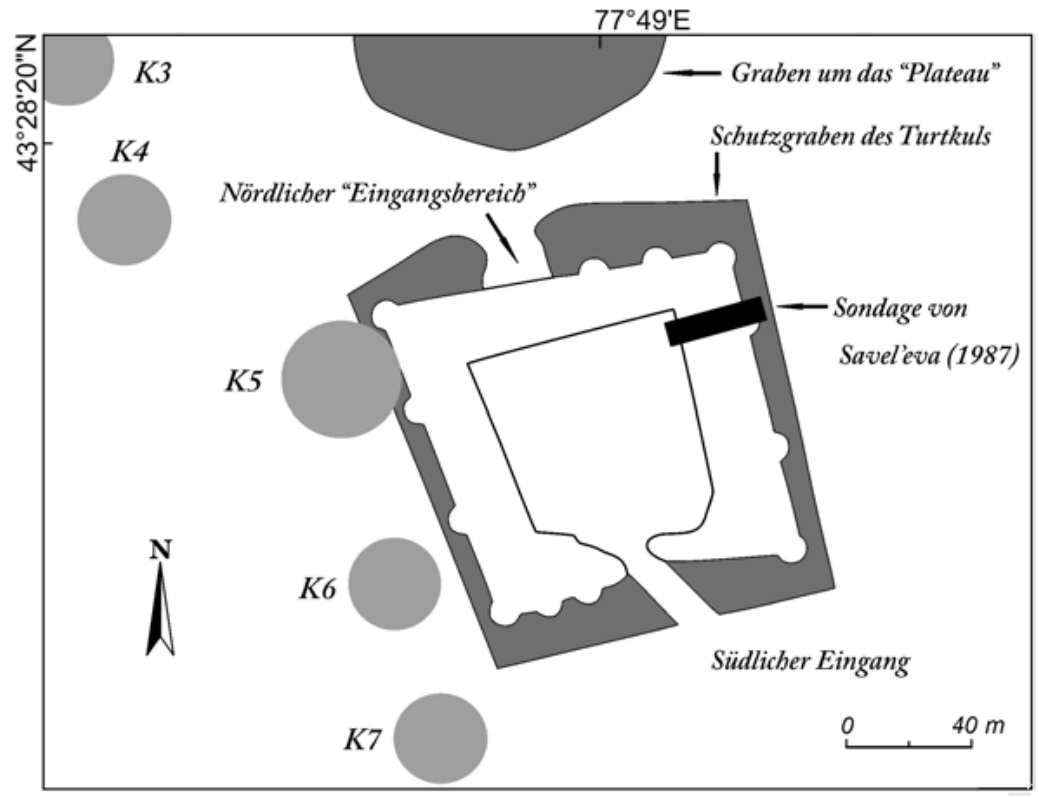

Abb. 219 | Komplex Kiikpaj. Skizze des Turtkuls

punkt des Komplexes. Das Ausmaß der Konstruktion beträgt $87 \mathrm{~m}(\mathrm{~W}-\mathrm{O}) \times 92 \mathrm{~m}(\mathrm{~N}-\mathrm{S})^{654}$. Das Turtkul ist eine viereckige Anlage, die von einem Wall begrenzt wurde. Die Breite des Schutzwalls beträgt im oberen Bereich 4-6 m und im unteren Bereich 20 m. Die Höhe des Walls misst auf der Spitze 2 m. Um den Turtkul herum verläuft ein 3-5 m breiter Graben, so dass die Gesamtgröße der Konstruktion I2 I m $(\mathrm{W}-\mathrm{O}) \times$ I29 $\mathrm{m}(\mathrm{N}-\mathrm{S})$ erreicht. Durch den im Durchschnitt 2-2,5 $\mathrm{m}$ tiefen Schutzgraben und den etwa $2 \mathrm{~m}$ hohen Wall mussten mindestens 4 Höhenmeter überwunden werden, um in die Befestigung eindringen zu können. Die abgerundeten Erhebungen an den Ecken des Turtkuls sind als Überreste von Wachtürmen zu deuten. Zusätzlich befinden sich je zwei solcher Türme an den Längsseiten der Verteidigungsmauer. Die nördliche und die südliche Seite weisen je einen Eingangsbereich auf, wobei an der Südseite sowohl der Schutzgraben als auch der Wall unterbrochen sind, an der Nordseite dagegen lediglich der Graben. Die Grabenunterbrechung an der Nordseite ist Nord-Süd ausgerichtet. An der Südseite verläuft sie schräg von Nordosten nach Südwesten im inneren Bereich des Turtkuls.

Der Graben in der Nordhälfte der Westseite wurde von einem früheisenzeitlichen Kurgan überbaut. Die Ostseite des Schutzwalls weist heute eine Unterbrechung auf. Sie kennzeichnet die Grabungssondage von T. Savel'eva aus dem Jahre i986, die nicht rekultiviert wurde.

Der Innenraum des Turtkuls stellt eine planierte, fast quadratische Fläche dar, die einige rechteckig bis ovalen Gruben und einige Steinkonzentrationen (mittelgroße Steine, ab $30 \times 2010 \mathrm{~cm}$ ) aufweist. Sowohl der innere Bereich des Turtkuls als auch die östlich und südlich angrenzenden Flächen sind überpflügt worden und werden immer noch sehr aktiv ackerbaulich genutzt. Östlich der Ostseite des Schutzgrabens wurden an der Oberfläche drei Wandscherben (Abb. 220) aufgelesen.

Charakteristik der Lesefunde

I. Wandscherbe 4 , I $\times 3,8 \times 0,8 \mathrm{~cm}$; außen beige, innen rotorange; sehr fein gemagert; scheibengedreht; Zeitstellung: Mittelalter bis Neuzeit.

2. Wandscherbe $2,2 \times 2,2 \times 0,5 \mathrm{~cm}$; rotrosa; grob gemagert; handgemacht; Zeitstellung: ältere Eisenzeit bis frühes Mittelalter.

654 Von den mittleren Punkten des Schutzwalls gemessen. 

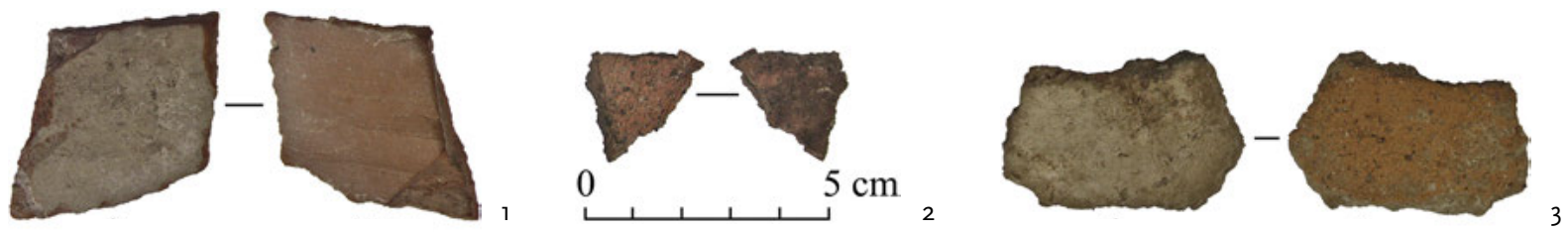

Abb. 220 | Komplex Kiikpaj. Östlich vom Turtkul. Lesefunde

3. Wandscherbe 4,6 × 3,0 × 0,6 cm; außen beige, innen rotorange; grob gemagert; handgemacht; Zeitstellung: ältere Eisenzeit bis frühes Mittelalter.

Das keramische Fundmaterial weist auf eine chronologische Tiefe von der Früheisenzeit über die sakische Periode bis zum Mittelalter hin.

Kurgankette (Abb. 22I): Westlich vom Turtkul liegt eine NNW-SSO ausgerichtete Kette, die aus neun mittelgroßen Kurganen besteht. Die Kurgane weisen keine architektonischen Merkmale auf. Kurgan 5 (nach der Arbeitsnummerierung) überdeckt den nordwestlichen Bereich des Grabens vom Turtkul.

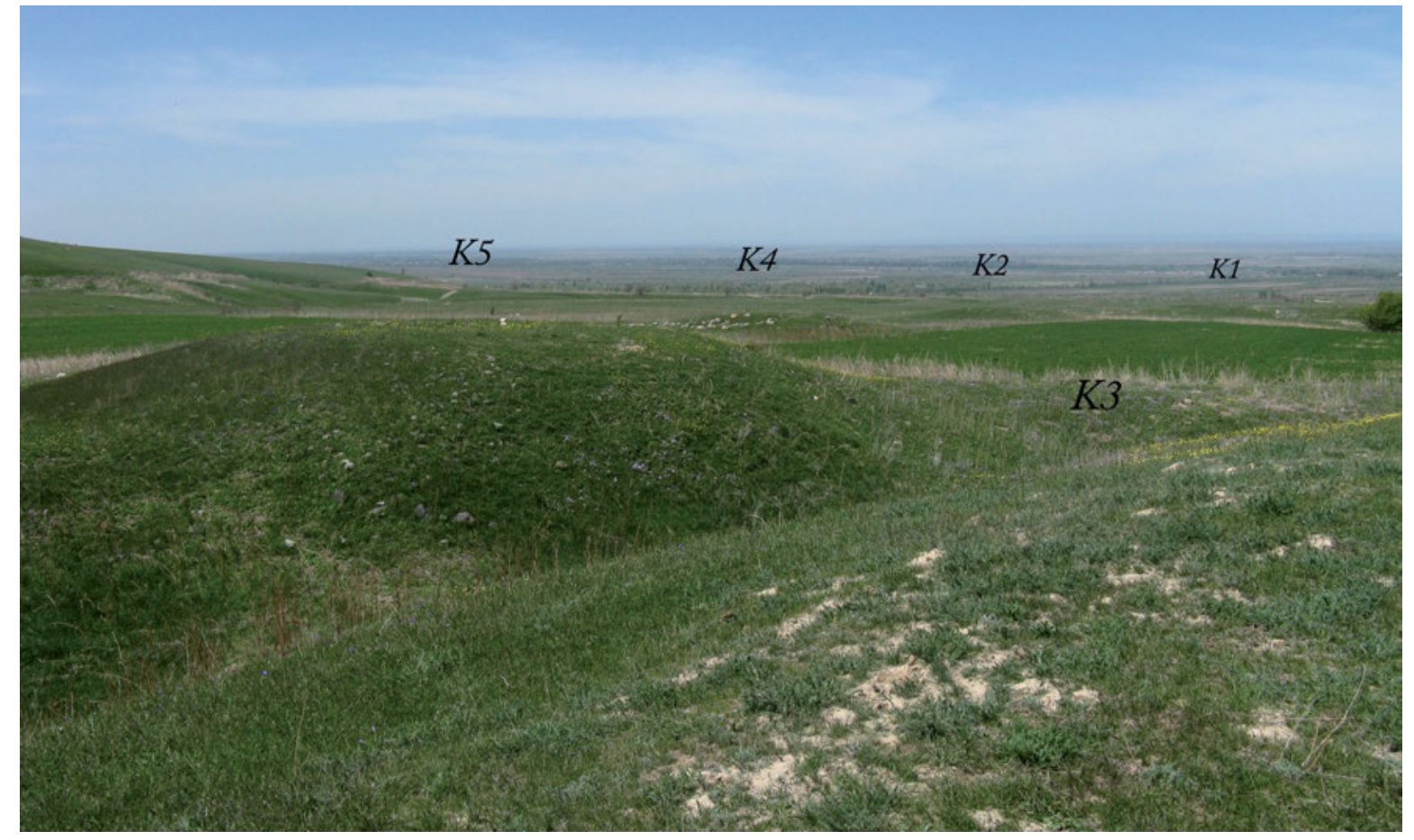

Abb. 221 | Komplex Kiikpaj. Nordhälfte der Kette. Blick von SO

Der Durchmesser der Kurgane schwankt zwischen $20 \mathrm{~m}$ und $40 \mathrm{~m}$, die Höhe zwischen $0,5 \mathrm{~m}$ und 3,5 m. Alle Kurgane haben drei steile und einen (immer südlichen) sanften Abhang. Bei allen Kurganen wurde ein Raubtrichter in der Mitte des Kurgans festgestellt.

Anhand der Struktur und der äußeren Erscheinungsform können die Kurgane der Nekropole der sakischen Periode der Früheisenzeit zugeordnet werden. 
Kurgancharakteristik:

Kurgan I

Dm 30 m; H I, 5 m

Lage: N43 28.388 E77 48.854; nördlichster Kurgan der Kette

Form: niedrig, abgerundet, plattformähnlich mit abgeflachter Kuppe

Abhänge: drei steile, südlicher sanft

Zustand: in der Mitte ein Raubtrichter

Sonstiges: Oberfläche mit mittelgroßen Steinen (ab 35 $\times 20 \times 15 \mathrm{~cm}$ ) bedeckt

Kurgan 2 (Kleinkurgan)

Dm $20 \mathrm{~m} ; \mathrm{H} \circ, 5 \mathrm{~m}$

Lage: N43 28.363 E77 $48.86_{3}$

Form: niedrig, abgerundet, plattformähnlich mit abgeflachter Kuppe

Abhänge: drei steile, südlicher sanft

Zustand: in der Mitte ein Raubtrichter

Sonstiges: Oberfläche mit mittelgroßen Steinen (ab 25 $\times 20 \times 15 \mathrm{~cm}$ ) bedeckt

\section{Kurgan 3}

Dm 30 m; H I m

Lage: N43 28.350 E77 48.866

Form: niedrig, abgerundet, plattformähnlich mit abgeflachter Kuppe

Abhänge: drei steile, südlicher sanft

Zustand: in der Mitte ein Raubtrichter

Sonstiges: Oberfläche mit mittelgroßen Steinen (ab 35 $\times 20 \times 15 \mathrm{~cm}$ ) bedeckt

\section{Kurgan 4}

Dm $30 \mathrm{~m} ; \mathrm{H}$ I, $5 \mathrm{~m}$

Lage: N43 28.322 E77 48.879

Form: abgerundet, plattformähnlich mit abgeflachter Kuppe

Abhänge: drei steile, südlicher sanft

Zustand: in der Mitte ein Raubtrichter

Sonstiges: Oberfläche mit mittelgroßen Steinen (ab 35

$\times 20 \times \mathrm{I} 5 \mathrm{~cm}$ ) bedeckt

\section{Kurgan 5}

Dm 37 m; H 3,5 m

Lage: N43 28.29I E77 48.932

Form: abgerundet, plattformähnlich mit abgeflachter Kuppe

Abhänge: drei steile, südlicher sanft
Zustand: in der Mitte ein Raubtrichter

Sonstiges: Oberfläche mit mittelgroßen Steinen (ab 40 $\times 20 \times$ I $5 \mathrm{~cm}$ ) bedeckt; die Osthälfte des Kurgans überdeckt den nordwestlichen Bereich des Grabens vom Turtkul

\section{Kurgan 6}

Dm $30 \mathrm{~m} ; \mathrm{H} \circ, 8 \mathrm{~m}$

Lage: N43 28.256 E77 48.940

Form: niedrig, abgerundet, plattformähnlich mit abgeflachter Kuppe

Abhänge: drei steile, südlicher sanft

Zustand: in der Mitte ein Raubtrichter

Sonstiges: Oberfläche mit mittelgroßen Steinen (ab 35 $\times 20 \times 15 \mathrm{~cm}$ ) bedeckt

\section{Kurgan 7}

Dm 30 m; H 2 m

Lage: N43 28.229 E77 48.950

Form: abgerundet, plattformähnlich mit abgeflachter Kuppe

Abhänge: drei steile, südlicher sanft

Zustand: in der Mitte ein Raubtrichter

Sonstiges: Oberfläche mit mittelgroßen Steinen (ab 40 $\times 20 \times 15 \mathrm{~cm}$ ) bedeckt

\author{
Kurgan 8 \\ Dm 35 m; H I,2 m \\ Lage: N43 28.185 E77 48.969 \\ Form: niedrig, abgerundet, plattformähnlich mit abge- \\ flachter Kuppe \\ Abhänge: drei steile, südlicher sanft \\ Zustand: in der Mitte ein Raubtrichter \\ Sonstiges: Oberfläche mit mittelgroßen Steinen (ab 25 \\ $\times$ I5 $\times$ IO $\mathrm{cm}$ ) bedeckt
}

\section{Kurgan 9}

Dm 40 m; H 3 m

Lage: N43 28.I63 E77 48.976; südlichster Kurgan der Kette

Form: abgerundet, plattformähnlich mit abgeflachter Kuppe

Abhänge: drei steile, südlicher sanft

Zustand: in der Mitte ein Raubtrichter

Sonstiges: Oberfläche mit mittelgroßen Steinen (ab 40 $\times 20 \times 15 \mathrm{~cm}$ ) bedeckt

„Plateau“ (Abb. 222) N43 28.388 E77 48.938: Nördlich vom Turtkul befindet sich ein ovales, N-S ausgerichtetes Plateau, das von einem 6-7 $\mathrm{m}$ tiefen und $9 \mathrm{~m}$ (im unteren Bereich) bis $30 \mathrm{~m}$ (im oberen Bereich) breiten Graben umgeben war. Der Graben ist im Nordosten unterbrochen. Das „Plateau“ und der Graben haben eine Gesamtgröße von $216 \times 130 \mathrm{~m}$. Auf dem „Plateau“ befinden sich sechs Kleinkurgane, die zwei NNW-SSO verlaufende Ketten bilden und in der älteren Eisenzeit datiert werden können. Der Durchmesser der Kurgane schwankt zwischen I4 m und 27 m, die Höhe zwischen $0,3 \mathrm{~m}$ und I,5 m. Nur ein Kurgan hat drei steile und einen südlichen, sanften Abhang. Alle weiteren 


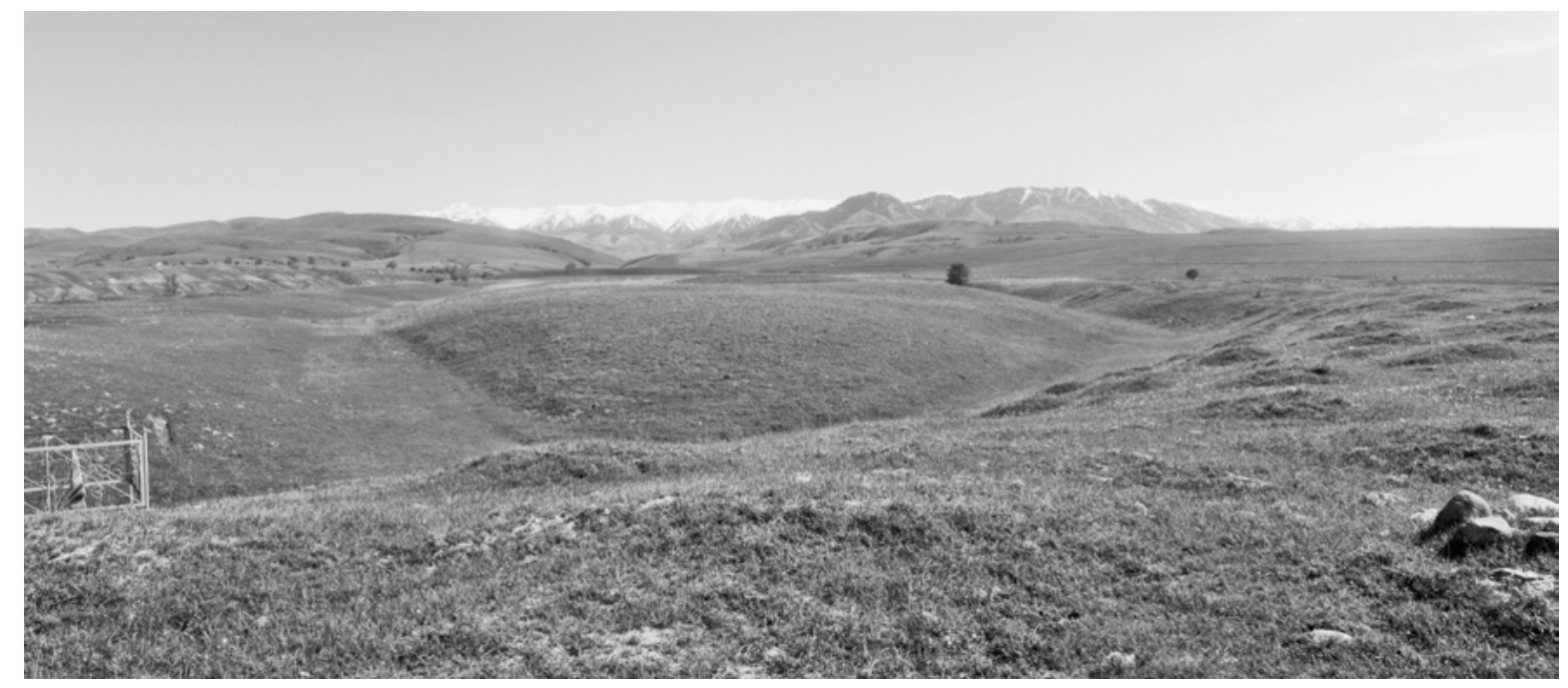

Abb. 222 | Komplex Kiikpaj. „Plateau“. Blick von N

Kleinkurgane sind als abgerundete Erhebungen ohne bemerkenswerte Merkmale der Abhänge sichtbar. Bei allen Kurganen auf dem „Plateau“ wurde in der Mitte eine Senke bzw. ein Raubtrichter festgestellt.

Eine genaue Deutung des „Plateaus“ und des Grabens ist bis jetzt unklar.

Charakteristik der Kleinkurgane auf dem „Plateau“:

Kurgan Io (Kleinkurgan)

Dm 25 m; H I, 5 m

Lage: N43 28.4I4 E77 48.9I0; nördlichster Kurgan auf dem „Plateau“

Form: abgerundete Erhebung

Abhänge: drei steile, südlicher sanft

Zustand: in der Mitte ein Raubtrichter

Sonstiges: Oberfläche mit mittelgroßen Steinen (ab 25 $\times$ I5 $\times$ IO $\mathrm{cm}$ ) bedeckt

\section{Kurgan II (Kleinkurgan)}

Dm 20 m; H o,7 m

Lage: N43 28.404 E77 48.932

Form: abgerundete Erhebung

Abhänge: keine Merkmale

Zustand: in der Mitte ein Raubtrichter

Sonstiges: Oberfläche mit mittelgroßen Steinen $(\mathrm{ab} 20$ $\times$ I5 $\times$ IO $\mathrm{cm}$ ) bedeckt

Kurgan I2 (Kleinkurgan)

Dm I4 m; H o,3 m

Lage: N43 28.389 E77 48.9II

Form: abgerundete Erhebung

Abhänge: keine Merkmale

Zustand: in der Mitte ein Raubtrichter

Sonstiges: Oberfläche mit mittelgroßen Steinen $(\mathrm{ab} 20$ $\times$ I 5 × $10 \mathrm{~cm}$ ) bedeckt
Kurgan I3 (Kleinkurgan)

Dm 27 m; H o,5 m

Lage: N43 28.388 E77 48.938

Form: abgerundete Erhebung

Abhänge: keine Merkmale

Zustand: in der Mitte ein Raubtrichter

Sonstiges: Oberfläche mit einzelnen mittelgroßen Steinen $(\mathrm{ab} 20 \times 15 \times 10 \mathrm{~cm})$ bedeckt

Kurgan I4 (Kleinkurgan)

Dm $20 \mathrm{~m} ; \mathrm{H} \circ, 3 \mathrm{~m}$

Lage: N43 28.373 E77 48.923

Form: abgerundete Erhebung

Abhänge: keine Merkmale

Zustand: in der Mitte ein Raubtrichter

Sonstiges: keine Steine an der Oberfläche

Kurgan 5 (Kleinkurgan)

Dm 27 m; H o, 5 m

Lage: N43 28.368 E77 48.958; südlichster Kurgan auf dem "Plateau“

Form: abgerundete Erhebung

Abhänge: keine Merkmale

Zustand: in der Mitte ein Raubtrichter

Sonstiges: Oberfläche mit mittelgroßen Steinen (ab 25

$\times 20 \times 15 \mathrm{~cm}$ ) bedeckt 
Analogien zur äußeren Form des Turtkul sind für das Mittelalter Kasachstans bekannt. Eine letzte Nutzungsphase könnte in dieser Zeit stattgefunden haben. Aufgrund der geographische Lage und der chronolgischen Tiefe, die die Lesefunde aufzeigen, kann von einer wiederholten Nutzung des Siedlungsplatzes in unterschiedlichen Zeitperioden (Früheisenzeit bis Mittelalter) ausgegangen werden.

Anhand der Struktur und der äußeren Erscheinungsform einzelner Bereiche des Komplexes sowie der Lesefunde kann vermutet werden, dass Gräberfeld und Siedlung der Fundstelle Kiikpaj von der sakischen Periode der Früheisenzeit über die frühtürkische Periode des frühen Mittelalters bis zur Neuzeit genutzt wurden.

Forschungsgeschichte

Im Auftrag des Institutes „Kazproektrestavracija“655 und des Kulturministeriums der Kasachischen SSR führte I985 die Archäologische Expedition der Kasachischen Pädagogischen Hochschule „Abaj“ unter der Leitung von A. N. Mar’jašev im Rahmen der Bestandsaufnahme und Registrierung der archäologischen Bodendenkmäler im Gebiet Almaty einen Survey auf dem Fundstellenkomplex Kiikpaj durch (Mar'jašev u.a. I986, 29-30). Es wurden nur das Turtkul und der Kurgan 5 beschrieben. Der Siedlungsplatz wurde als ein mittelalterlicher Burgwall interpretiert. Westlich und nordwestlich vom Turtkul wurden Spuren künstlicher Bewässerung festgestellt. Eine Lageskizze oder ein Gräberfeldplan wurden nicht angefertigt.

Im Rahmen einer Bestandsaufnahme der archäologischen Bodendenkmäler im Gebiet Almaty untersuchte 1987 die archäologische Almaty-Expedition unter der Leitung von T. V. Savel'eva die Fundstelle erneut. Das Interesse der Forscher konzentrierte sich nur auf die befestigte Siedlung (Nurmuchanbetov/Savel'eva I988, I0-II; Savel'eva I994, 49-50; Bajpakov u.a. 2002, 30). Quer durch die Nordhälfte des Ost-

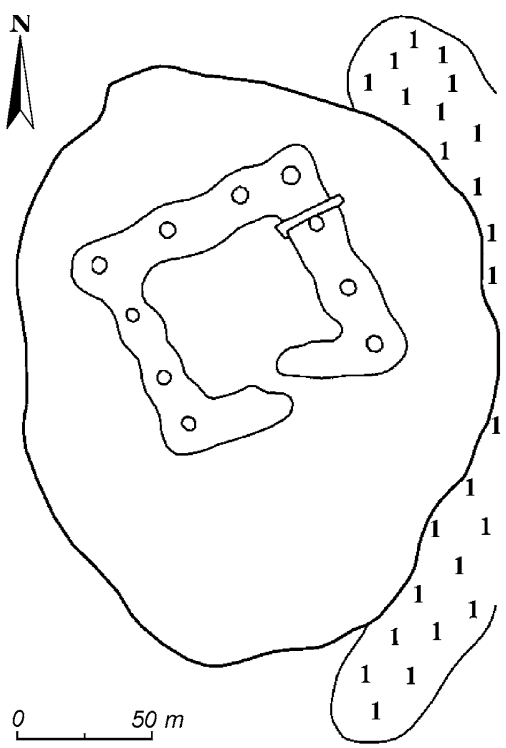

Abb. 223 | Burgwall Kiikpaj. Plan (Savel'eva I994, Abb. I5) walls wurde eine $32 \times 8 \mathrm{~m}$ breite Sondage gelegt (Abb. 223). Zudem wurde im inneren Bereich des Turtkuls eine $2 \times 2 \mathrm{~m}$ große Fläche bis zu o,3 $\mathrm{m}$ tief ausgegraben (Savel'eva I994, 49-50). Die quadratische Fläche wies keine Spuren von Architektur auf. Bei der Untersuchung wurden einige Scherben von scheibengedrehten Gefäßen, ein Fragment eines Keramikrohres, eine Karneolperle und ein tropfenförmiger Schleifstein, der an einer Seite durchbohrt worden war, gefunden. Die quer des Walls angelegte Sondage zeigte, dass die Siedlungsfläche von einer Verteidigungsmauer umschlossen wurde. Die Mauer maß an der Basis I5,5 $\mathrm{m}$ und war 3,5 $\mathrm{m}$ hoch. Diese Mauer wurde in einer Lehmstampfbautechnik errichtet. Im mittleren Bereich des Turtkuls wurden einige Scherben aufgelesen. Die Ausgräberin datierte die Konstruktion in das Io.-I2. Jh. n. Chr.

Lit.: Bajpakov u.a. 2002, 30, Abb. II-I2; Gass 20IIb, 220, Abb. 28-29; Gass (im Druck); Mar’jašev u.a. I986, 29-30; Nurmuchanbetov/Savel'eva I988, I0-II; Savel'eva I994, 49-50, Abb. I5.

655 Projektentwicklungsinstitut für Konservierung und Restaurierung der Kulturdenkmäler „Kazproektrestavracija“. 
Komplex Sarytau [FEZ und frühtürkische Periode(?)] (Abb. 224; Karte 3 Nr. 72): ALT I9I2 m N42 59.89 I E79 20.050; Gebiet Almaty (kasach. Алматы облысы), Rajymbekskij rajon (kasach. Райымбек ауданы); Ausmaß N-S $546 \times$ O-W 544 m.

Der archäologische Komplex Sarytau befindet sich am Ostrand des Hochplateaus Kegen (kasach. Кеген), an einer Schnittstelle zwischen einer Schlucht und einem kleinen Längstal an der Südwestseite der Temirlik-Berge (kasach. Темирлик). Die Fundstelle liegt südlich vom Berg Sarytau (kasach. Caрытау), am rechten, östlichen Ufer des Flusses Kegen (kasach. Кеген), I99 km ostsüdöstlich der Stadt Almaty (kasach. Алматы), 9,3 km südöstlich des Dorfes Kegen (kasach. Кеген) und 5,7 km westsüdwestlich des Dorfes Aktasty (kasach. Ақтасты). Der Komplex setzt sich aus einer mit Petroglyphen bemalten Felswand, einer Siedlungsfläche und einem Gräberfeld, welches zehn Kurganketten bildet, zusammen.

Petroglyphenfundstelle (Abb. 225,I, ALT i960 m N43 00.024 E79 20.042): Im nordwestlichen Bereich des Komplexes, an einem rötlich glänzenden Felsen eines namenlosen Berges, der sich in der nördlich der Siedlung gelegenen Schlucht befindet, wurden mehrere Petroglyphen festgestellt. Es

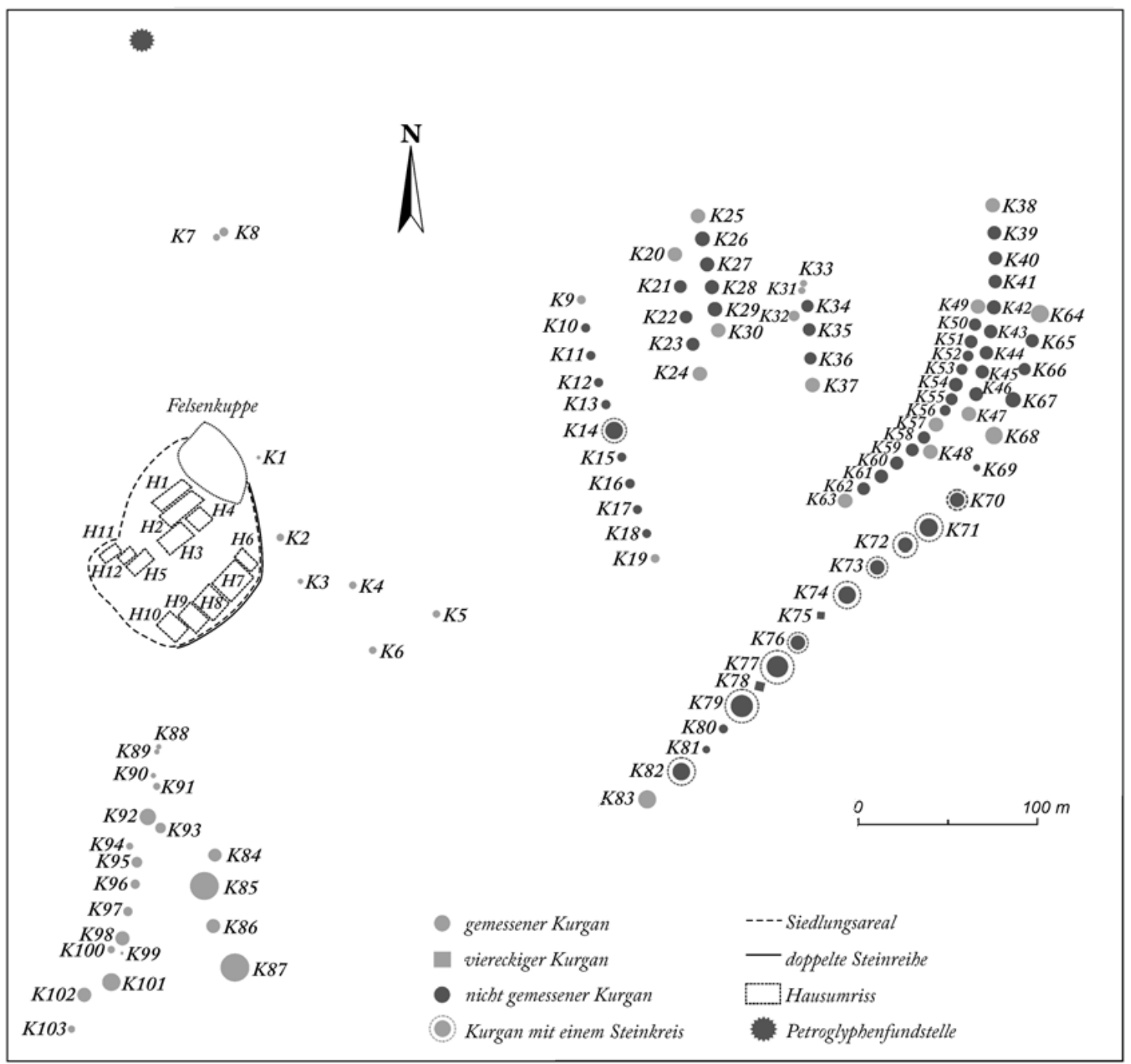

Abb. 224 | Skizze des Komplexes Sarytau 

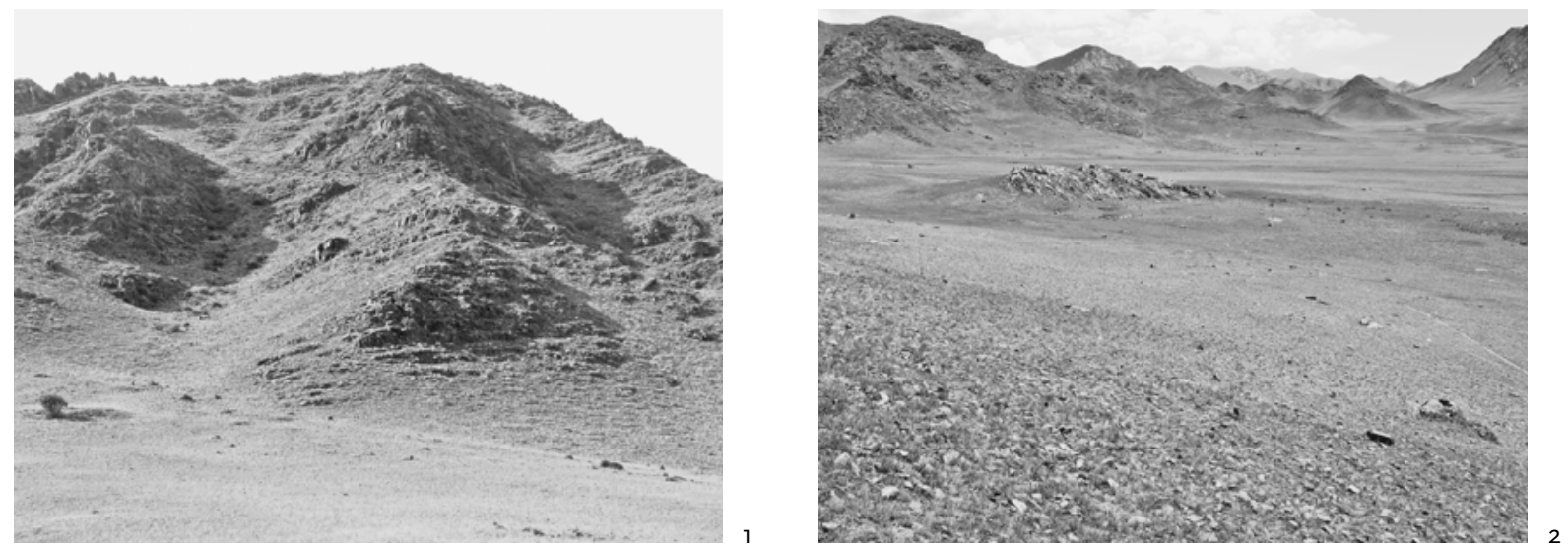

Abb. 225 | Komplex Sarytau; I. Petroglyphenfundstelle, Blick von S; 2. Siedlungsfläche. Blick von W

handelte sich dabei um anthropomorphe und zoomorphe Darstellungen sowie um einige SanskritInschriften ${ }^{65}$.

Siedlungsfläche (Abb. 225,2): Südlich der Petroglyphenfundstelle, im westlichen Bereich des Gesamtkomplexes, befindet sich eine Siedlung. Sie liegt am Fuß des Berghanges, südlich einer Felsenkuppe, an der Stelle, wo die Schlucht in das längs verlaufende Tal übergeht. Der nordwestliche Siedlungsbereich befindet sich so im Schutze des Berges, der südöstliche Bereich öffnet sich hingegen zur offenen Landschaft

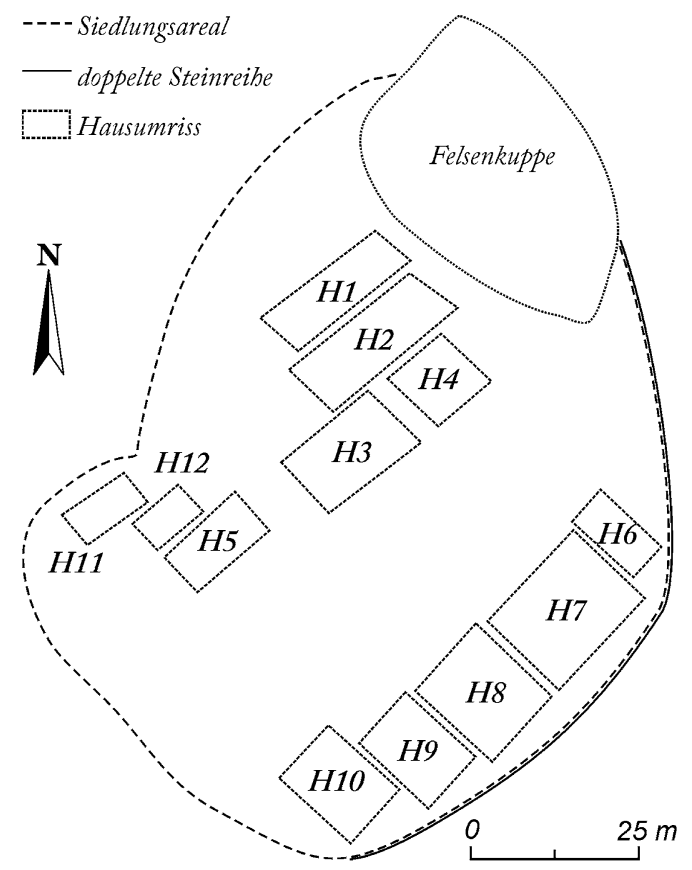

Abb. 226 | Komplex Sarytau. Siedlung. Plan

656 Laut der Aussage von Z. Samašev können die unterschiedlichen Darstellungen der Bronzezeit, der früheren Eisenzeit und der Neuzeit zugeordnet werden. hin. Die Grenze dieses Siedlungsareals wurde durch eine doppelte, I $m$ breite Steinreihe markiert, die evtl. als Fundament der äußeren „Umfriedung“ gedient haben könnte. Die Siedlungsstelle hat in der Aufsicht eher eine ovale Form, die in der N-S Ausdehnung eine Größe von iıo $\times 90,5 \mathrm{~m}$ aufweist (Abb. 226). Im inneren Siedlungsbereich wurden 4-I2 Überreste von Häusern festgestellt. Im Befund zeichnen sich diese Häuser in der Nordhälfte als rechteckige Gruben $\mathrm{ab}$, die von großen Steinen umgeben waren und evtl. als Fundamentreste interpretiert werden können. Es kann sich hier um Halbgrubenhäuser (sog. Poluzemljanki) handeln. In der Südhälfte wurden $\mathrm{zu}$ einem Rechteck formierte Steinreihen dokumentiert, die evtl. als Subkonstruktion eines rechteckigen Hauses interpretiert werden können. Die Wohnbauten sind in etwa drei Hausreihen angeordnet. Ihre genaue Zahl kann nur durch die Ausgrabung der Siedlungsfläche festgestellt werden. Die Befundkonzentration in der nordwestlichen Hälfte besteht aus zwei Reihen und ist nach einer NW-SO Achse ausgerichtet. Die dritte Reihe, die sich in der südöstlichen Hälfte befindet, ist NO-SW orientiert. 

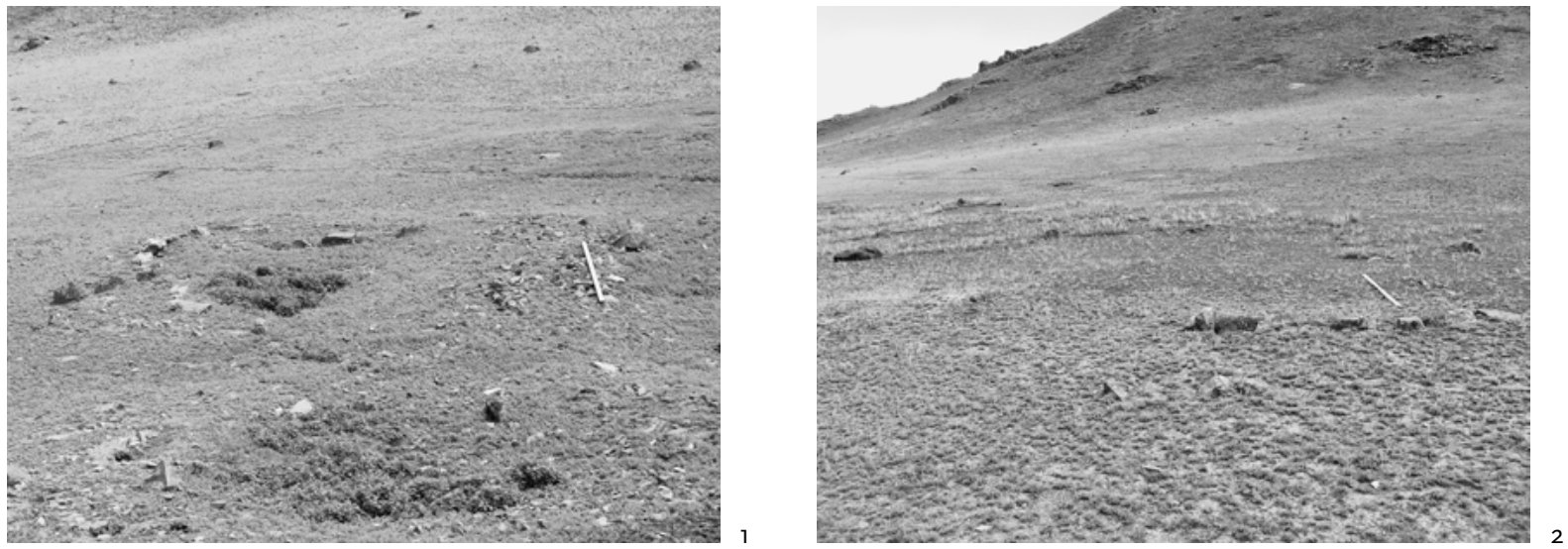

Abb. 227 | Siedlungsbereich des Komplexes Sarytau; I. Haus 3, Blick von NO; 2. Konstruktion 8, Blick von SO

\section{Charakteristik der Häuser:}

Erste, nördliche Hausreihe

\section{Haus I}

Lage: N42 59.89I E79 20.050; nördlichstes Haus der Reihe

Maße: $20,5 \times 6,4 \mathrm{~m}$

Form: rechteckige, ca. $0,5 \mathrm{~m}$ tiefe Grube

Ausrichtung: NO-SW

Deutung: Halbgrubenhaus (russ. Poluzemljanka)

\section{Haus 2}

Lage: N42 59.880 E79 20.039; unmittelbar SO des Hauses I

Maße: $24,0 \times 9,2 \mathrm{~m}$

Form: rechteckige, ca. $0,5 \mathrm{~m}$ tiefe Grube

Ausrichtung: NO-SW

Sonstiges: Hausgrube von einzelnen, mittelgroßen Steinen des Hausfundamentes (?) umrandet

Deutung: Halbgrubenhaus (russ. Poluzemljanka)

Haus 3 (Abb. 227,I)

Lage: N42 59.880 E79 20.047; unmittelbar S des Hauses 2

Maße: $16,9 \times 10,6 \mathrm{~m}$

Form: rechteckige, ca. $0,7 \mathrm{~m}$ tiefe Grube

Ausrichtung: NO-SW

Sonstiges: Hausgrube von großen Steinen des Hausfundamentes (?) umrandet

Deutung: Halbgrubenhaus (russ. Poluzemljanka)

Haus 4

Lage: N42 59.879 E79 20.052; unmittelbar SO des Hauses 2 und NO des Hauses 3

Maße: Io, 6 × 10,6 m

Form: quadratische, ca. $0,4 \mathrm{~m}$ tiefe Grube

Ausrichtung: Hausecken an den vier Haupthimmelsrichtungen orientiert
Sonstiges: kleinste sichtbare Konstruktion dieser Hausreihe; Hausgrube von großen Steinen des Hausfundamentes (?) umrandet

Deutung: Halbgrubenhaus (russ. Poluzemljanka)

Zweite, südöstliche „Hausreihe“

Konstruktion 6 ( $\mathrm{H} 6)$

Lage: N42 59.866 E79 20.066; äußerste N gelegene Konstruktion

Maße: $\mathrm{i} 2,7 \times 7 \mathrm{~m}$

Form: ein Rechteck bildende Steinreihe

Ausrichtung: NW-SO

Sonstiges: Steineihe aus mittelgroßen Steinen des Hausfundamentes (?)

Deutung: Subkonstruktion eines rechteckigen Hauses (?)

Konstruktion 7 ( $\mathrm{H} 7)$

Lage: N42 59.857 E79 20.064; unmittelbar SW der Konstruktion 6

Maße: $19,9 \times 15,4 \mathrm{~m}$

Form: ein Rechteck bildende Steinreihe

Ausrichtung: NO-SW

Sonstiges: Reihe aus mittelgroßen Steine des Hausfundamentes (?)

Deutung: Subkonstruktion eines rechteckigen Hauses (?)

Konstruktion 8 (H 8; Abb. 227,2)

Lage: N42 59.864 E79 20.067; unmittelbar SW der Konstruktion 7

Maße: I6,2 × 14,3 m

Form: ein Rechteck bildende Steinreihe

Ausrichtung: NW-SO

Sonstiges: Reihe bestehend aus mittelgroßen Steinen des Hausfundamentes (?) 
Deutung: Subkonstruktion eines rechteckigen Hauses (?)

Konstruktion 9 ( $\mathrm{H}$ 9)

Lage: N42 59.864 E79 20.069; unmittelbar SW der Konstruktion 8

Maße: I4,8 × II,o m

Form: ein Rechteck bildende Steinreihen

Ausrichtung: NW-SO

Sonstiges: Reihe bestehend aus mittelgroßen Steinen des Hausfundamentes (?)

Deutung: Subkonstruktion eines rechteckigen Hauses (?)

Konstruktion Io (H IO)

Lage: N42 59.855 E79 20.068; unmittelbar W der Konstruktion 9; äußerste $\mathrm{S}$ gelegene Konstruktion

Maße: I4,8 × II,O m

Form: ein Rechteck bildende, angelegte Steinreihe

Ausrichtung: NW-SO

Sonstiges: Reihe bestehens aus mittelgroßen Steinen des Hausfundamentes (?)

Deutung: Subkonstruktion eines rechteckigen Hauses (?)

Dritte, südwestliche „Hausreihe“

Konstruktion 5 ( $\mathrm{H}_{5}$ )

Lage: N42 59.874 E79 20.042; äußerste östlich gelegene Konstruktion
Maße: I4,I $\times 7,8 \mathrm{~m}$

Form: rechteckige, ca. 0,3 $\mathrm{m}$ tiefe Grube

Ausrichtung: NO-SW

Sonstiges: Hausgrube von mittelgroßen Steinen des Hausfundamentes (?) umrandet

Deutung: Halbgrubenhaus (russ. Poluzemljanka)

Konstruktion II (H II)

Lage: N42 59.874 E79 20.022; äußerste, W gelegene Konstruktion

Maße: II,3 × 6,4 m

Form: zu einem Rechteck formierte Steinreihe

Ausrichtung: NO-SW

Sonstiges: Reihen bestehen aus mittelgroßen Steine des Hausfundamentes (?)

Deutung: Subkonstruktion eines Rechteckhauses (?)

Konstruktion 12 (H I2)

Lage: N42 59.872 E79 20.025; dicht zwischen den Konstruktionen 5 und II

Maße: $9,2 \times 5,6 \mathrm{~m}$

Form: zu einem Rechteck formierte Steinreihe

Ausrichtung: NO-SW

Sonstiges: Reihen bestehen aus mittelgroßen Steinen des Hausfundamentes (?)

Deutung: Subkonstruktion eines Rechteckhauses (?)

Es könnte jedoch auch sein, dass die Hausgruben sowie die rechteckigen Steinreihen jeder „Hausreihe“ zu einer übergeordneten Konstruktion gehören, so dass es sich ebenso um einen komplexeren Bautyp handeln könnte. Das kann jedoch erst nach der Ausgrabung festgestellt werden.

Im Bereich der Häuser der ersten Reihe wurden an der Oberfläche einige Lesefunde - Keramikfragmente (Abb. 228,I-8) und ein Angelhaken aus Eisen (Abb. 228,9) - aufgehoben. Das Fundmaterial deutet auf eine eher früheisenzeitliche Datierung der Siedlungsfläche hin. Es kann auch nicht ausgeschlossen werden, dass einige Funde auch der frühtürkischen Periode des frühen Mittelalters zuzuordnen sind.

Charakteristik der Lesefunde

I. Randscherbe (aus zwei Fragmenten bestehend) $6,8 \times 3,5 \times 0,7 \mathrm{~cm} ; \varnothing$ ca. $26 \mathrm{~cm}$; außen dunkelgrau, innen rotbeige; fein gemagert mit kleinen Sandpartickeln und etwas Organik; innen und außen grob verstrichen; eher scheibengedreht; Zeitstellung: ältere Eisenzeit bis frühes Mittelalter.

2. Randscherbe 4,I $\times 2,4 \times 0,8 \mathrm{~cm} ; \varnothing$ ca. I2 cm; hellrotbeige; sehr fein gemagert; hart gebrannt; scheibengedreht, mit Druckspuren; Zeitstellung: ältere Eisenzeit.

3. Wandscherbe 9,4 ×6,I $\times$ I, $\mathrm{cm}$; außen rot, innen braungrau mit schwarzen Flecken; sehr grob gemagert mit Sand und Kies; handgemacht; Zeitstellung: eher frühes Mittelalter.

4. Wandscherbe 2,5 $\times$ I, $9 \times 0,6 \mathrm{~cm}$; rotorange; fein gemagert; hart gebrannt; scheibengedreht; Zeitstellung: älere Eisenzeit.

5. Wandscherbe 4,7 × 4,2 $\times 0,7 \mathrm{~cm}$; rot; mittelfein gemagert mit Sand; innen und außen verstrichen; handgemacht; Zeitstellung: ältere Eisenzeit bis frühes Mittelalter.

6. Wandscherbe 5,3 ×3,8 $\times$ I, $3 \mathrm{~cm}$; außen beige, innen rot; sehr fein gemagert mit feinem Sand; innen und außen verstrichen; handgemacht; Zeitstellung: ältere Eisenzeit bis frühes Mittelalter. 

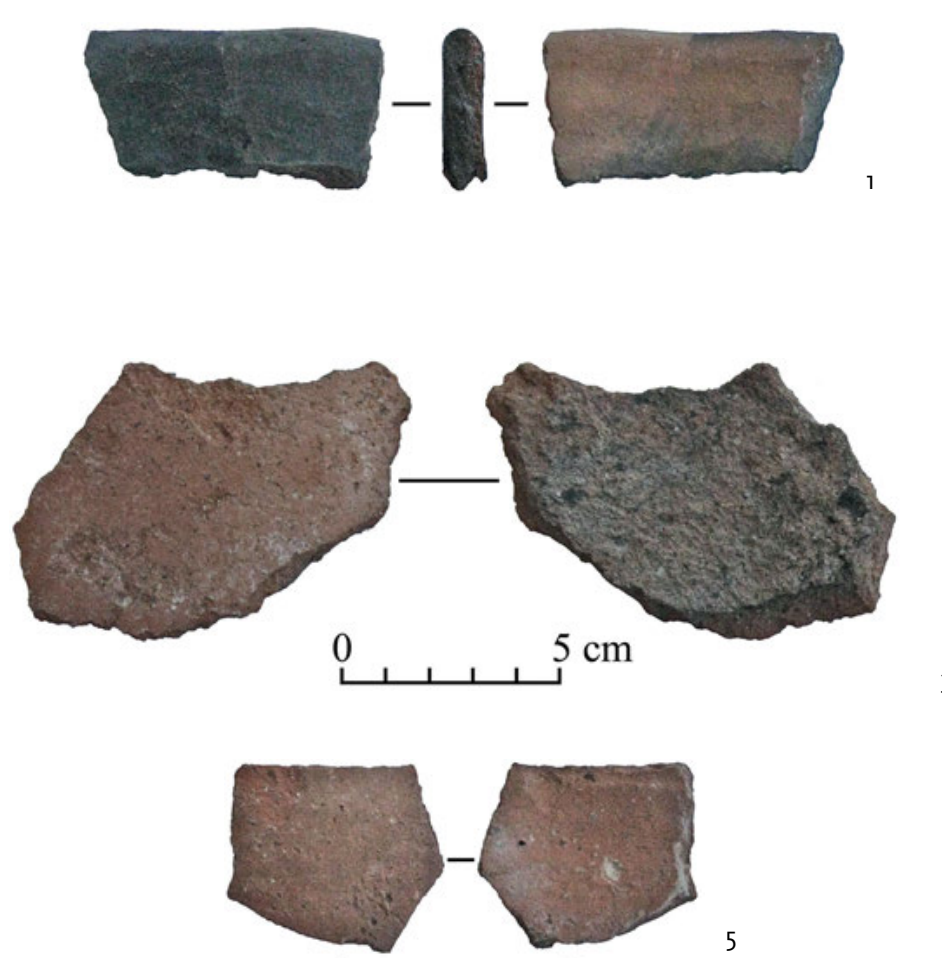

5

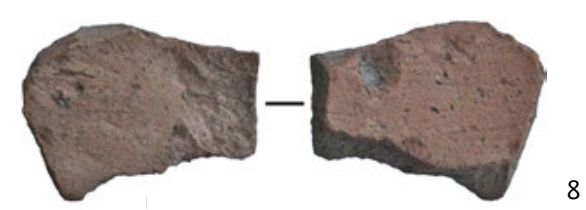

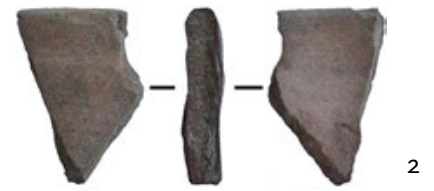

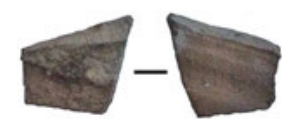

4
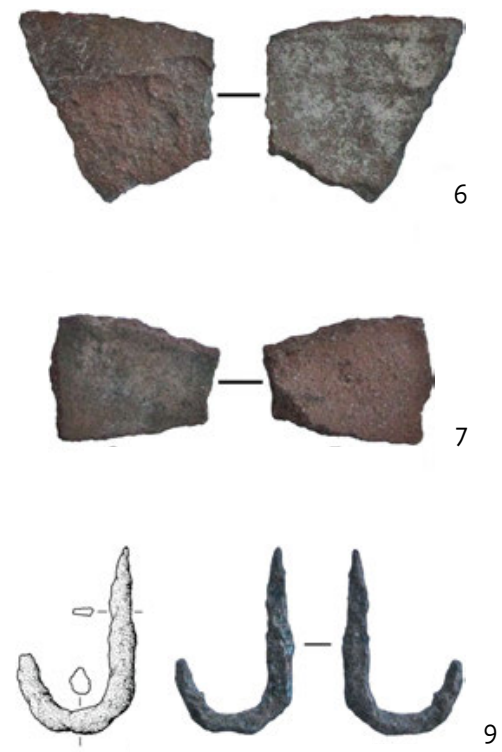

Abb. 228 | Komplex Sarytau. Siedlungsbereich. Lesefunde (I-2 Randscherben, 3-8 Wandscherben, 9 eiserner Angelhaken; Zeichnung M.-R. Boroffka)

7. Wandscherbe 4,6 ×4,I ×0,6 cm; rotbraun; fein gemagert; von außen verstrichen; handgemacht; Zeitstellung: ältere Eisenzeit.

8. Wandscherbe $3,5 \times 2,8 \times 0,8 \mathrm{~cm}$; außen beige, innen rot; mittelfein gemagert mit Sand; hart gebrannt; außen verstrichen; handgemacht; Zeitstellung: eher ältere Eisenzeit.

9. Angelhaken aus Eisen 4,5 × 2,7 cm, D o,3-0,4 cm; stark korrodiert; im Querschnitt unregelmäßig; Zeitstellung: unklar.

Nekropole (Abb. 229): Das Gräberfeld besteht aus I03 Kleinkurganen ${ }^{657}$, die zehn Ketten ${ }^{68} 8$ bilden und liegt östlich und südlich der Siedlungsfläche. Der Verlauf der Ketten ist unterschiedlich, was durch unterschiedliche Platzierungen innerhalb der Schlucht oder des Längstals zu erklären ist.

657 Aufgrund der geringen Maße wurden die Kleinkurgane der östlichen Hälfte der Nekropole nicht komplett dokumentiert. Es wurden lediglich der erste und der letzter Kurgan der Kette gemessen sowie ein Kurgan an der Knickstelle, falls die Kette nicht gerade verlief.
658 Erste Kette: KI-K8; zweite Kette: K9-Kı9; dritte Kette: $\mathrm{K}_{2} \mathrm{O}-\mathrm{K}_{24}$; vierte Kette: $\mathrm{K}_{25}-\mathrm{K}_{3} \mathrm{O}$; fünfte Kette: $\mathrm{K}_{3} \mathrm{I}-\mathrm{K}_{37}$; sechste Kette: $\mathrm{K}_{3} 8-\mathrm{K}_{4} 8$; siebte Kette: $\mathrm{K}_{49}-\mathrm{K}_{3}$; achte Kette: K64-K83; neunte Kette: K84-K87; zehnte Kette: K88-Kio3 (nach der Arbeitsnummerierung). 


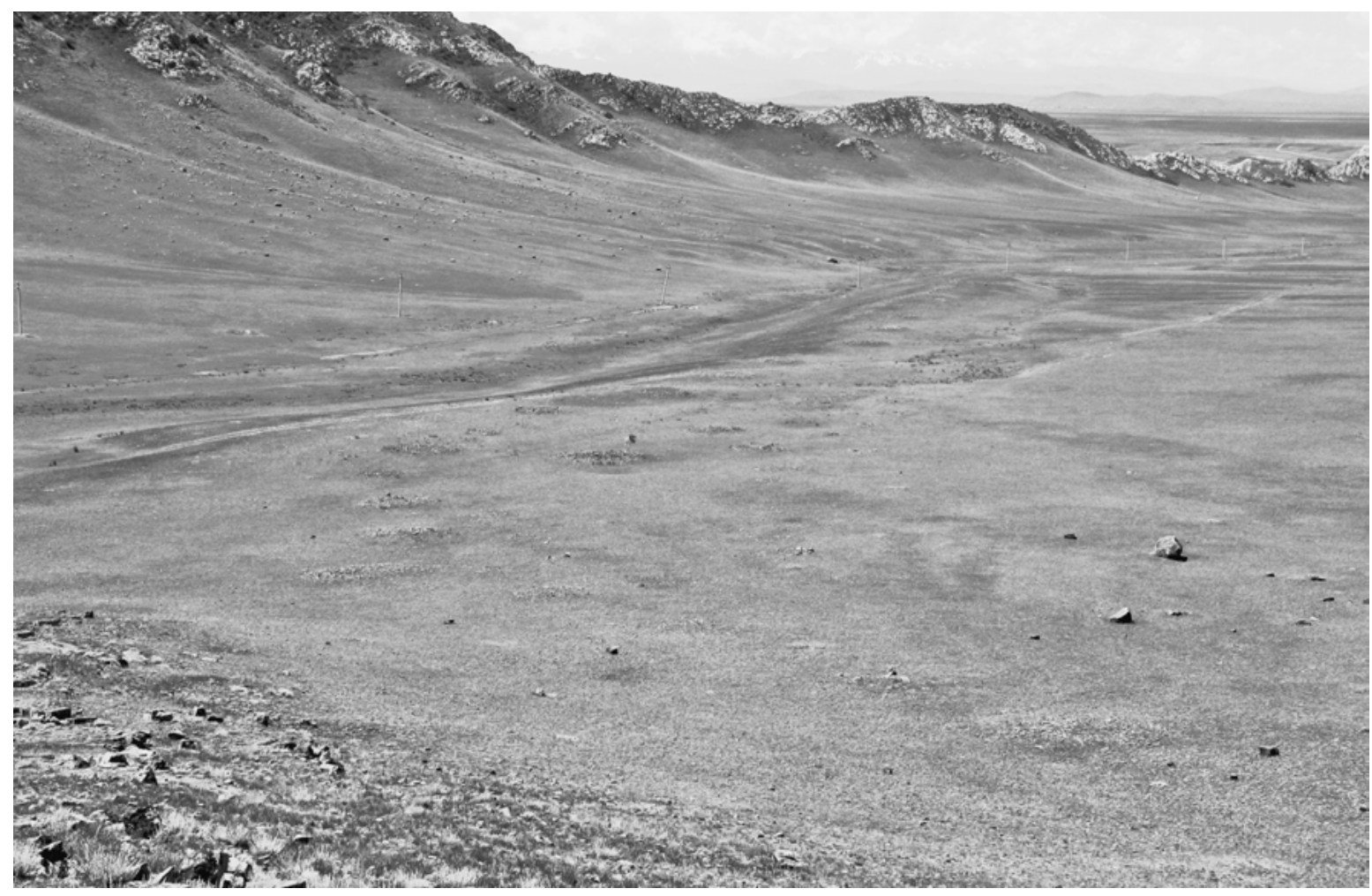

Abb. 229 | Komplex Sarytau. Nekropole. Blick von N

Die erste Kette (KI-K8) besteht aus acht Kleinkurganen und ist NW-SO ausgerichtet. Sie ist eher zentral gelegen und befindet sich am nächsten zur Siedlung. Die Kette beginnt in der Schlucht im Nordwesten und läuft in das Längstal aus.

Die Osthälfte des Komplexes ist von der zweiten bis achten Kette gebildet. Die zweite Kette (K9-Kig) besteht aus elf Kurganen und ist NNW-SSO ausgerichtet. Sie beginnt im Norden an einem Bergfuß und verläuft abwärts gen Tal. Der mittlere Kurgan der Kette (KI4) ist der größte und weist im Abstand von $4 \mathrm{~m}$ vom Kurganrand einen umlaufenden Steinkreis auf.

Die Kurgane $20-37$ bilden drei weitere Ketten, die eine N-S Ausrichtung haben. Diese drei Kurganketten beginnen im Norden an einem Bergfuß und verlaufen ebenso abwärts gen Tal. Die Kurgane aller drei Ketten weisen keine architektonischen Merkmale auf. Die Kurgane $38-49$ bilden zwei leicht gekrümmt verlaufende Ketten, die im Norden an einem Bergfuß beginnen und Richtung W-SW dem Verlauf dem Grat einer Bergkuppe folgen. Die achte Kette $\left(\mathrm{K}_{4}-\mathrm{K} 83\right)$ besteht aus 20 Kurganen und ist NO-SW ausgerichtet. Sie zeigt sich am östlichsten Punkt des Gesamtkomplexes. Die Kette beginnt im Nordosten an einem Bergfuß und verläuft abwärts gen Tal. In der Südhälfte der Kette befinden sich größere Kurgane. Um die neun größten Kurgane der Kette wurde im Abstand von 3-4 m vom Kurganrand je ein umlaufender Steinkreis errichtet. Zwei Kurgane dieser Kette (K 75 und K78), die sich ebenso in der Südhälfte der Kette befinden, weisen eine viereckige Form auf. Die Seiten beider Kurgane sind grob an den vier Haupthimmelsrichtungen orientiert. Die neunte und zehnte Kette liegen im südwestlichen Bereich des Komplexes. Beide Ketten nehmen ihren Anfang im Norden, am Bergfuß und verlaufen nach Süden abwärts gen Tal. Kurgan 99 der zehnten Kette stellt sich als eine frühtürkische quadratische Umfriedung heraus, deren Seiten an den vier Haupthimmelsrichtungen orientiert sind. 
Der Durchmesser der Kurgane schwankt zwischen $2 \mathrm{~m}$ und $16 \mathrm{~m}$ (20 m zusammen mit den Steinkonstruktionen), die Höhe zwischen o,I $\mathrm{m}$ und o,6 m. Da alle Kurgane des Gräberfeldes flach sind und als abgerundete Steinanhäufungen erscheinen, wurde bei ihnen keine Senke bzw. kein Raubtrichter festgestellt659.

Anhand der Struktur und der äußeren Erscheinungsform können die Kurgane der Nekropole der sakischen Periode der Früheisenzeit und der frühtürkischen Periode des frühen Mittelalters zugeordnet werden.

Kurgancharakteristik:

Erste Kurgankette

Kurgan I (Kleinkurgan)

Dm 2 m; $\mathrm{H} \circ, 2 \mathrm{~m}$

Lage: N42 59.898 E79 20.080

Form: abgerundete Steinanhäufung

Abhänge: keine

Zustand: kein Trichter, keine Senke

Kurgan 2 (Kleinkurgan)

Dm 4 m; H o,2 m

Lage: N42 59.874 E79 20.088

Form: abgerundete Steinanhäufung

Abhänge: keine

Zustand: kein Trichter, keine Senke

Kurgan 3 (Kleinkurgan)

Dm 3 m; H o, I m

Lage: N42 59.86I E79 20.095

Form: abgerundete mit Steinen vermischte Erhebung

Abhänge: keine

Zustand: kein Trichter, keine Senke

Kurgan 4 (Kleinkurgan)

Dm $4 \mathrm{~m} ; \mathrm{H} \circ, 3 \mathrm{~m}$

Lage: N42 59.859 E79 20.II6

Form: abgerundete Steinanhäufung

Abhänge: keine

Zustand: kein Trichter, keine Senke

Kurgan 5 (Kleinkurgan)

Dm 4 m; H o,2 m

Lage: N42 59.849 E79 20.I49

Form: abgerundete Steinanhäufung

Abhänge: keine

Zustand: kein Trichter, keine Senke

Kurgan 6 (Kleinkurgan)

Dm 4 m; H o,I m

Lage: N42 59.839 E79 20.123; südlichster Kurgan der Kette

Form: abgerundete Steinanhäufung
Abhänge: keine

Zustand: kein Trichter, keine Senke

Kurgan 7 (Kleinkurgan)

Dm $4 \mathrm{~m} ; \mathrm{H}$ o, I m

Lage: N42 59.964 E79 20.068

Form: abgerundete Steinanhäufung

Abhänge: keine

Zustand: kein Trichter, keine Senke

Kurgan 8 (Kleinkurgan)

Dm $4 \mathrm{~m} ; \mathrm{H}$ o, I m

Lage: N42 59.966 E79 20.072; nördlichster Kurgan der Kette

Form: abgerundete Steinanhäufung

Abhänge: keine

Zustand: kein Trichter, keine Senke

Zweite Kurgankette

Kurgane 9-I9 (Kleinkurgane)

Dm 4-6 m; H o,I-O,4 m

Dm (KI4) Io m; Dm (KI4) Steinkreis I8 m; H (KI4) o,3 m

Lage: K9 N42 59.940 E79 20.2I4

Ki9 N42 59.862 E79 20.236

Form: abgerundete Steinanhäufungen

Abhänge: keine

Weitere Konstruktionen (KI4): um den Kurgan herum verläuft, in einem Abstand von $4 \mathrm{~m}$ vom Rand, ein Steinkreis aus mittelgroßen Steinen

Zustand: kein Trichter, keine Senke

Sonstiges: KI4 ist der größte Kurgan der Kette

Dritte Kurgankette

Kurgane 20-24 (Kleinkurgane)

Dm 4-6 m; H O,I-O,4 m

Lage: $\mathrm{K}_{2} \mathrm{O} \mathrm{N}_{42} 59.952$ E79 20.253

K24 N42 59.9I6 E79 20.260

Form: abgerundete Steinanhäufungen

Abhänge: keine

Zustand: kein Trichter, keine Senke

659 Was jedoch nicht bedeuten soll, dass sie unberaubt waren. 
Vierte Kurgankette

Kurgane 25-30 (Kleinkurgane)

Dm 4-6 m; H o,I-O,4 m

Lage: $\mathrm{K}_{25} \mathrm{~N}_{42} 59.96_{3} \mathrm{E}_{79} 20.26_{3}$ K30 N42 59.929 E79 20.269

Form: abgerundete Steinanhäufungen Abhänge: keine

Zustand: kein Trichter, keine Senke

Fünfte Kurgankette

Kurgane 3I-37 (Kleinkurgane)

Dm 4-6 m; H o,I-O,4 m

Lage: K3I N42 59.940 E79 20.304 $\mathrm{K}_{32} \mathrm{~N}_{42} 59.932$ E79 20.300 K33 N42 59.94I E79 20.305 K37 N42 59.912 E79 20.306

Form: abgerundete Steinanhäufungen Abhänge: keine

Zustand: kein Trichter, keine Senke

Sechste Kurgankette

Kurgane 38-48 (Kleinkurgane)

Dm 4-6 m; H o,I-O,4 m

Lage: $\mathrm{K}_{3} 8 \mathrm{~N}_{42} 59.9 \mathrm{G}_{2} \mathrm{E}_{79} 20.383$ K47 N42 59.90I E79 20.369 $\mathrm{K}_{4} 8 \mathrm{~N}_{42} 59.890$ E79 20.352

Form: abgerundete Steinanhäufungen Abhänge: keine

Zustand: kein Trichter, keine Senke

Siebte Kurgankette

Kurgane 49-63 (Kleinkurgane)

Dm 4-6 m; H o,I-O,4 m

Lage: K49 N42 59.932 E79 20.375

$\mathrm{K}_{57} \mathrm{~N}_{42} 59.897$ E79 20.355

K63 N42 59.876 E79 20.3I7

Form: abgerundete Steinanhäufungen

Abhänge: keine

Zustand: kein Trichter, keine Senke

Achte Kurgankette

Kurgane 64-83 (Kleinkurgane)

Dm 4-I2 m; Dm Steinkreis bis zu 20 m; H O,I-O,5 m

Lage: K64 N42 59.929 E79 20.399

K68 N42 59.893 E79 20.378
K83 N42 59.79I E79 20.230

Form: abgerundete Steinanhäufungen; $\mathrm{K}_{75}$ und $\mathrm{K}_{7} 8$ viereckige Umfriedungen

Weitere Konstruktionen: um die $\mathrm{K}_{70}-\mathrm{K}_{74}, \mathrm{~K}_{76} \mathrm{~K}_{77}$, $\mathrm{K} 79$ und K82 verläuft, in einem Abstand von 3-4 m vom Rand, je ein Steinkreis aus mittelgroßen Steinen Zustand: kein Trichter, keine Senke

Sonstiges: Die Seiten von $\mathrm{K}_{75}$ und $\mathrm{K}_{7} 8$ sind an den vier Haupthimmelsrichtungen orientiert

Bemerkung: K75 und K78 - frühtürkische Periode

Neunte Kurgankette

Kurgane 84-87 (Kleinkurgane)

Dm 7-I6 m; H 0,2-0,6 m

Lage: K84 N42 59.78I E79 20.055

K85 N42 59.772 E79 20.050

K86 N42 59.760 E79 20.052

K87 N42 59.747 E79 20.06I

Form: abgerundete Steinanhäufungen

Abhänge: keine

Zustand: kein Trichter, keine Senke

Zehnte Kurgankette

Kurgane 88-I03 (Kleinkurgane)

Dm 3-IO m; H O,I-O,5 m

Lage: K88 N42 59.8I4 E79 20.034

K89 N42 59.8I3 E79 20.033

K9o N42 59.806 E79 20.03I

K9I N42 59.803 E79 20.033

K92 N42 59.793 E79 20.028

K93 N42 59.790 E79 20.034

$\mathrm{K}_{94} \mathrm{~N}_{42} 59.785$ E79 20.02I

K95 N42 59.780 E79 20.023

K96 N42 59.773 E79 20.022

K97 N42 59.766 E79 20.018

K98 N42 59.758 E79 20.015

K99 N42 59.753 E79 20.016

KIOO N42 59.754 E79 20.0II

Kior N42 59.745 E79 20.010

KIO2 N42 59.74I E79 I9.999

KIO3 N42 59.732 E79 I9.993

Form: abgerundete Steinanhäufungen; K99 quadratische Umfriedung

Zustand: kein Trichter, keine Senke

Sonstiges: Die Seiten der Umfriedung des K99 sind an den vier Haupthimmelsrichtungen orientiert

Bemerkung: K99 - frühtürkische Periode 
Siedlung Aktasty [FEZ, frühtürkische Periode, Neuzeit (?)] (Abb. 230; Karte 3 Nr. 73): ALT I956 m N43 00.340 E79 23.00I; Gebiet Almaty (kasach. Алматы облысы), Rajymbekskij rajon (kasach. Райымбек ауданы); Ausmaß N-S II5 $\times \mathrm{O}-\mathrm{W} 76 \mathrm{~m}$.

Die Siedlung Aktasty befindet sich am Ostrand des Hochplateaus Kegen (kasach. Keген), an der Südseite der Temirlik-Berge (kasach. Темирлик), am südlichsten Ausläufer des Berges Sarytau (kasach. Сарытау), am Fuß der westsüdwestlich gelegenen Bergkuppe 2106,2, am rechten, östlichen Ufer des Flusses Kegen (kasach. Кеген). Der Siedlungsplatz liegt 202 km ostsüdöstlich der Stadt Almaty (kasach. Алматы), I3 km östlich vom Dorf Kegen (kasach. Кеген) und I,6 km östlich vom Dorf Aktasty (kasach. Aқтасты).

Durch die Lage am Fuße der Bergkuppe ist die Siedlung von der nördlichen, südlichen und östlichen Seite durch die Bergformationen geschützt. Ein Zugang zur flachen Ebene befindet sich nur im Süden. Durch die Anpassung an das Gelände hat die Siedlungsstelle in der Aufsicht eher eine rechteckige Form (Abb. 23I,I), welche eine größere N-S Ausdehnung aufweist. Im inneren Siedlungsbereich wurden acht Überreste von unterschiedlichen Bauten festgestellt (Abb. 23I,2). Es handelt sich um rechteckig angeordnete Doppelsteinreihen, die evtl. zu den Fundamentresten der Doppelwandhäuser gehören könnten. Die Bauelemente könnten fünf Hausüberresten entsprechen. Sie fanden sich im nördlichen und östlichen Bereich der Siedlung. Der Abstand zwischen den Steinreihen einer Wand beträgt im Durchschnitt ca. I m. Die Häuser der Westhälfte wurden durch rechteckige Gruben und vereinzelte Steine, die die Gruben umgeben und evtl. zu den Fundamentresten gehörten, markiert. Es könnte sich hier um Halbgrubenhäuser (russ. Poluzemljanki) handeln. In der Nordhälfte kam noch eine runde Grube zum Vorschein (Abfallgrube?). Die Wohnbauten werden von drei Hausgruppen repräsentiert. Mit Ausnahme der Konstruktionen $\mathrm{H}_{3}, \mathrm{H} 7$ und $\mathrm{H} 8$ (nach der Arbeitsnummerierung) wurden die „Häuser“ N-S ausgerichtet. Das „Haus 3“ wurde in einer W-O Achse gebaut. Die nördlichste Konstruktion (H7) war NO-SW orientiert. Und der Bau H8 wies eine rundliche Form auf.

Drei Konstruktionen $\mathrm{H}_{1}, \mathrm{H}_{2}$ und $\mathrm{H}_{7}$ wurden in der Mitte quer durch eine weitere Steinreihe getrennt, so dass die Häuser zweigeteilt sind. Bei Konstruktion 4 wurden zwei solche quer gebauten Reihen festgestellt, so dass es sich hier um ein dreigeteiltes Haus handeln könnte.

Charakteristik der Häuser:

Östliche Gruppe

Haus I

Lage: N43 00.344 E79 23.0I5; östlichstes Haus der Siedlung

Maße: $2 \mathrm{I}, 3 \times 9,2 \mathrm{~m}$

Form: Rechteck bildende Doppelsteinreihen; in der Mitte quer durch eine weitere Steinreihe gegliedert Ausrichtung: N-S
Deutung: zweigeteiltes Doppelwandhaus

Haus 2 (Abb. 232)

Lage: N43 00.340 E79 23.00I; 4,5 m W des Hauses I Maße: $20,6 \times 16,4 \mathrm{~m}$

Form: Rechteck bildende Doppelsteinreihen; in der Mitte quer durch eine weitere Steinreihe gegliedert Ausrichtung: N-S Deutung: zweigeteiltes Doppelwandhaus 

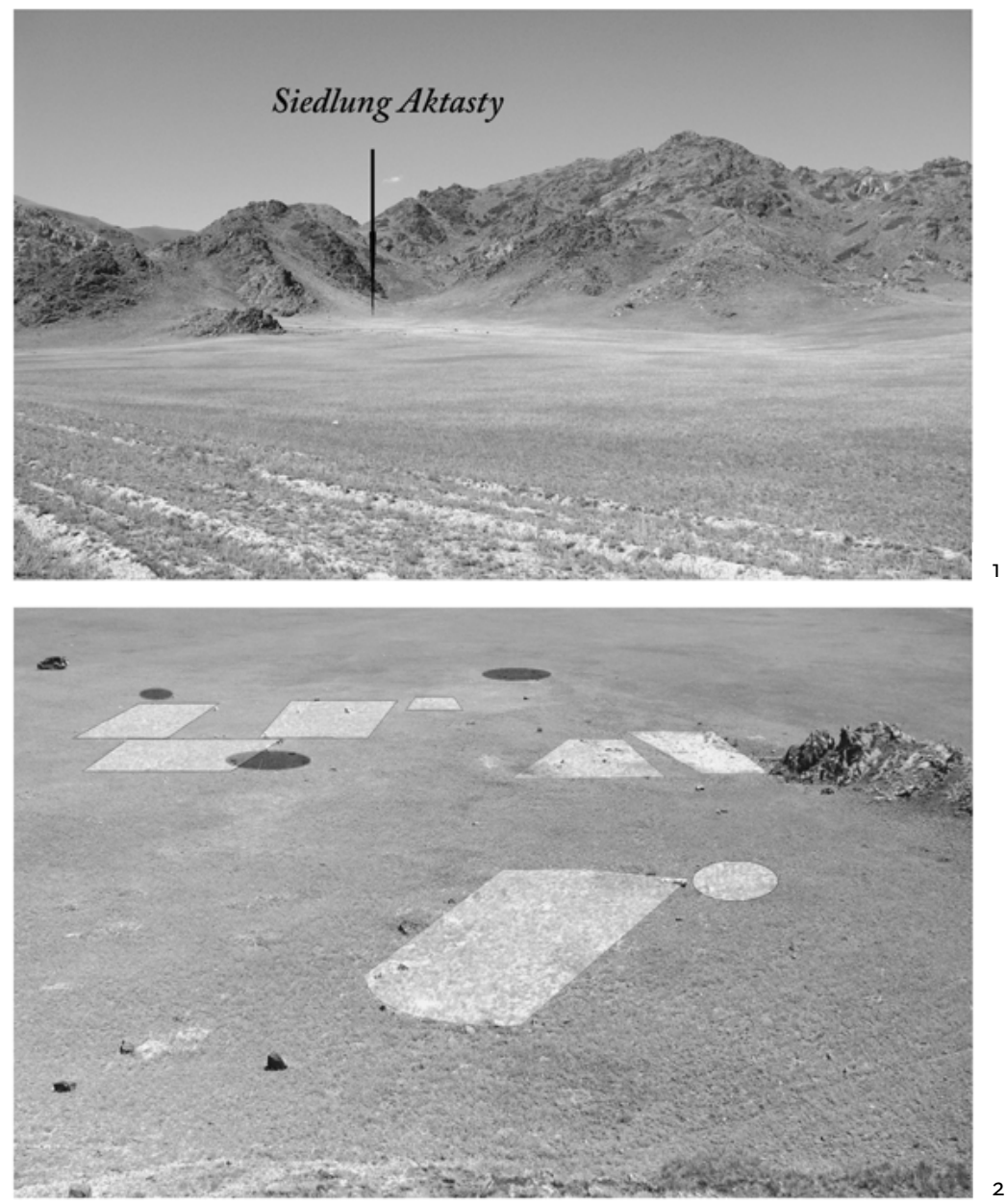

Abb. 231 | Siedlung Aktasty; I. Siedlungsfläche, Blick von S; 2. Übersicht, Blick von N

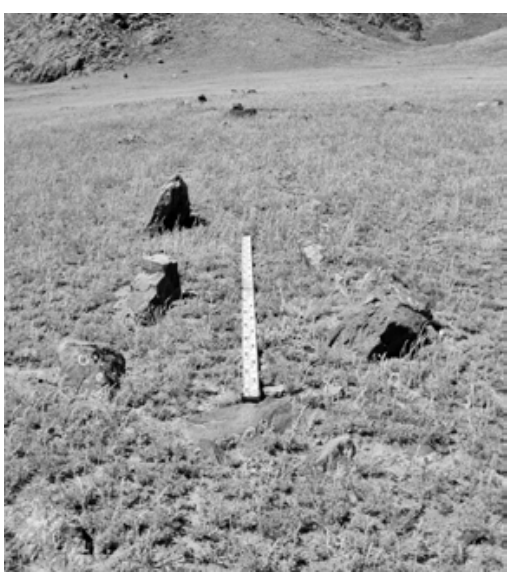

Abb. 232 | Östliche Doppelwand von Haus 2. Blick von $\mathrm{S}$
Haus 3

Lage: N43 00.333 E79 22.989; W vom Haus 2, in unmittelbarer Nähe

Maße: $10,7 \times 7,8 \mathrm{~m}$

Form: Rechteck bildende Steinreihen

Ausrichtung: W-O

Sonstiges: an die südliche Steinreihe wurde ein senkrecht stehender Steinquader $(40 \times 36 \times 105 \mathrm{~cm}) \mathrm{mit}$ einer Bohrung (Dm $27 \mathrm{~cm}$; Tiefe $35 \mathrm{~cm}$ ) angebaut

Deutung: Doppelwandhaus

\section{Haus 4}

Lage: N43 00.349 E79 23.004; im Zwischenraum N und nahe der Häuser I und 2

Maße: I9,9 × I2,8 m

Form: Rechteck bildende Doppelsteinreihen; in der Mitte quer durch zwei weitere Steinreihen getrennt Ausrichtung: N-S 
Sonstiges: Die Nordhälfte der Doppelsteinreihe der westlichen Wand ist durch die Aufschüttung eines frühtürkischen Kurgans überlagert.

Deutung: dreigeteiltes Doppelwandhaus

Westliche Gruppe

Haus 5

Lage: N43 00.346 E79 22.983; östlich gelegene Konstruktion

Maße: 14,2 × 6,4 m

Form: rechteckige, ca. $\circ, 5 \mathrm{~m}$ tiefe Grube

Ausrichtung: N-S

Sonstiges: Hausgrube ist von einzelnen mittelgroßen Steinen des Hausfundamentes (?) umrandet

Deutung: Halbgrubenhaus (russ. Poluzemljanka)

Haus 6

Lage: N43 00.348 E79 22.977; W gelegene Konstruktion Maße: $15,6 \times 7,8 \mathrm{~m}$

Form: rechteckige, ca. $\circ, 4 \mathrm{~m}$ tiefe Grube

Ausrichtung: N-S

Sonstiges: die Hausgrube ist von einzelnen großen

Steinen des Hausfundamentes (?) umrandet

Deutung: Halbgrubenhaus (russ. Poluzemljanka)

Bemerkungen: An der Oberfläche im Zentrum des

Hauses, nahe der Ostwand, kam eine Bronzemünze zum Vorschein (Dm 25 mm; Dicke I mm; in der Mitte eine quadratische $6 \times 6$ mm Öffnung; Abb. 233,II). Die Prägung des Avers zeigt die vier chinesische Hieroglyphen („Bao“, „Zhe“, „Qianlong“ und ein nicht mehr erkennbares Zeichen) sowie zwei weitere an dem Revers. Nach Jen 2000, I89-I90: eine chinesische Bao Zhe Münze bzw. Käsch-Münze, die unter der Regierung des Kaisers Qianlong zwischen 1756 und 1796 extra für die Xinjang-Provinz geprägt wurde.

Nördliche Gruppe

Haus 7

Lage: N43 00.368 E79 22.98I

Maße: $17, \mathrm{I} \times 8,5 \mathrm{~m}$

Form: Rechteck bildende Doppelsteinreihen; in der Mitte quer durch eine weitere Steinreihe gegliedert Ausrichtung: NO-SW

Deutung: zweigeteiltes Doppelwandhaus

Konstruktion 8 ( $\mathrm{H} 8)$

Lage: N43 00.367 E79 22.975

Maße: Dm 3,6 m

Form: abgerundete $0,3 \mathrm{~m}$ tiefe Grube

Ausrichtung: keine

Deutung: Abfallgrube (?)

Es könnte jedoch auch sein, dass die Gruben der Häuser und die rechteckigen Steinkonstruktionen zu einer größeren Konstruktion gehören, so dass es sich hier um einen komplexeren Bautyp handeln würde. Dies kann erst nach der Ausgrabung festgestellt werden.

Außer den bereits erwähnten Lesefunden wurden auf der Siedlungsfläche noch weitere Funde Keramikfragmente (Abb. 233,I-9) und ein fragmentarisch erhaltener Mühlstein (Abb. 233,IO) - entdeckt. Das Fundmaterial deutet auf eine chronologische Streuung von der sakischen Periode der Früheisenzeit bis zur Neuzeit.

Charakteristik der Lesefunde

I. Randscherbe mit nach außen verdicktem Rand 2,7 × 2,8 $\times 0,7 \mathrm{~cm}$; braunbeige; fein gemagert mit kleinen Sandpartikeln; außen verstrichen; handgemacht; Zeitstellung: ältere Eisenzeit bis frühes Mittelalter.

2. Randscherbe mit nach außen verdicktem Rand 2,4 $\times 2,3 \times 0,3 \mathrm{~cm} ; \mathrm{RDm} 5 \mathrm{~cm}$; beigeorange; fein gemagert mit kleinen Sandpartikeln; außen grob geglättet; innen verstrichen; Zeitstellung: eher Mittelalter.

3. Wandscherbe 3,6 × 2,9 $\times 0,9 \mathrm{~cm}$; beigeorange; mittelgrob mit Sand gemagert; außen und innen geglättet; scheibengedreht; Zeitstellung: eher ältere Eisenzeit.

4. Wandscherbe 3,9 × 2,7 ×0,9 cm; beigegelb; mittelgrob mit Sand gemagert; außen und innen geglättet; scheibengedreht; Zeitstellung: ältere Eisenzeit.

5. Wandscherbe 3,5 × I, $8 \times 0,6 \mathrm{~cm}$; außen rotorange, innen braungrau; mittelgrob mit Sand gemagert; außen geglättet; Zeitstellung: ältere Eisenzeit bis frühes Mittelalter.

6. Wandscherbe 3,3 $\times 2,5 \times 0,7 \mathrm{~cm}$; braun; fein gemagert mit einzelnen Sandpartikeln; innen und außen geglättet; scheibengedreht; Zeitstellung: Früheisenzeit, sakische Periode (?).

7. Wandscherbe 3,2 $\times 2,8 \times 0,5 \mathrm{~cm}$; außen beigegrau, innen beige; mittelgrob mit Sand gemagert; außen geglättet; handgemacht; Zeitstellung: jüngere Eisenzeit. 

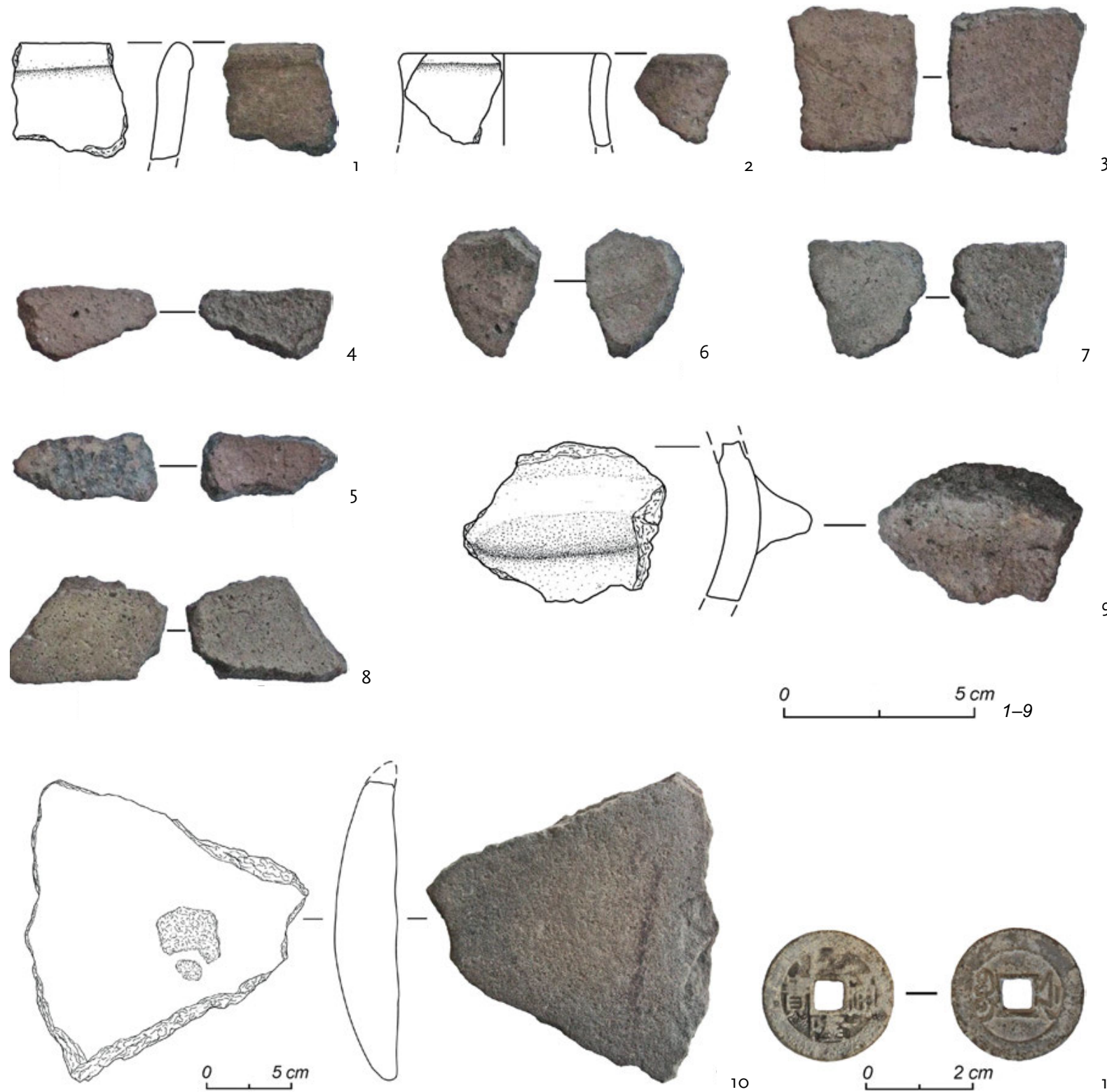

Abb. 233 | Siedlung Aktasty. Lesefunde (I-2 Randscherben, 3-8 Wandscherben, 9 Wandscherbe mit Griff; ıo Mühlstein, Fragment; II chinesische Bao Zhe Münze, Bronze; Zeichnung M.-R. Boroffka)

8. Wandscherbe 3,8 × I,6 × 0,5 cm; innen rot, äußere Tonschicht fehlt; mittelfein mit Sand gemagert; handgemacht; Zeitstellung: ältere Eisenzeit.

9. Wandscherbe mit Griff (vom Tonkessel?) 5,I × 3,8 $\times 2,2 \mathrm{~cm}$; beigerot; grob gemagert mit Steinund Sandpartikeln; innen grob verstrichen; handgemacht; Zeitstellung: ältere Eisenzeit bis frühes Mittelalter.

Iо. Mühlstein (fragmentarisch erhalten) $16,9(5, \mathrm{I}) \times \mathrm{I} 6, \mathrm{I} \mathrm{cm}, \mathrm{D} 3,7 \mathrm{~cm}$; feiner, dichter, dunkelgraubrauner Sandstein; auf beiden Seiten gut geschliffen, schmale Seite weist Spuren einer Bohrung auf; Zeitstellung: ethnographische Zeit. 
Im Siedlungsbereich kamen noch drei Kleinkurgane zum Vorschein. Die Kurgane sind als ziemlich flache, abgerundete Steinkonstruktion sichtbar, deren Ränder durch große Steine markiert worden waren. Im inneren Bereich ist eine Schotterpflasterung erhalten. Aufgrund dieser Informationen ist davon auszugehen, dass diese Kurgane der frühtürkischen Periode des früheren Mittelalters angehören. Der Kurgan I (nach der Arbeitsnummerierung) überlagert zum Teil die westliche Doppelwand des Hauses 4. Anhand der Vertikalstratigraphie kann man davon ausgehen, dass die Hauskonstruktion früher als der Kurgan errichtet worden war.

470 m südsüdwestlich der Siedlung liegt eine N-S ausgerichtete Kette, die über zehn Kleinkurgane der sakischen Periode der Früheisenzeit aufweist.

Siedlung Bachtijar [FEZ - frühtürkische Periode] (Abb. 234; Karte 3 Nr. 21): ALT 889 m N43 26.695 E77 42.516; Gebiet Almaty (kasach. Алматы облысы), Enbekšikazachskij rajon (kasach. Еңбекшіқазақ ауданы); Ausmaß N-S $92 \times \mathrm{O}-\mathrm{W} 78 \mathrm{~m}$.

Die Siedlung Bachtijar befindet sich an der Nordseite der Bergkette Transili-Alatau (kasach. Іле Алатауы), auf den nördlichen Ausläufern des Lösshügellandes vom Berg Taldybulak (kasach. Талдыбұлақ), am rechten, östlichen Ufer des Flusses Bachtijar (kasach. Бахтияр), an der Stelle, wo der Fluss aus den Bergen ins Flachland strömt. Der Siedlungsplatz liegt $68 \mathrm{~km}$ ostnordöstlich der Stadt Almaty (kasach. Алматы), 3,5 km östlich des Dorfes Taldybulak (kasach. Талдыбұлақ) und 7,4 km südwestlich des Dorfes Aščbulak (kasach. Ащыбұлақ).

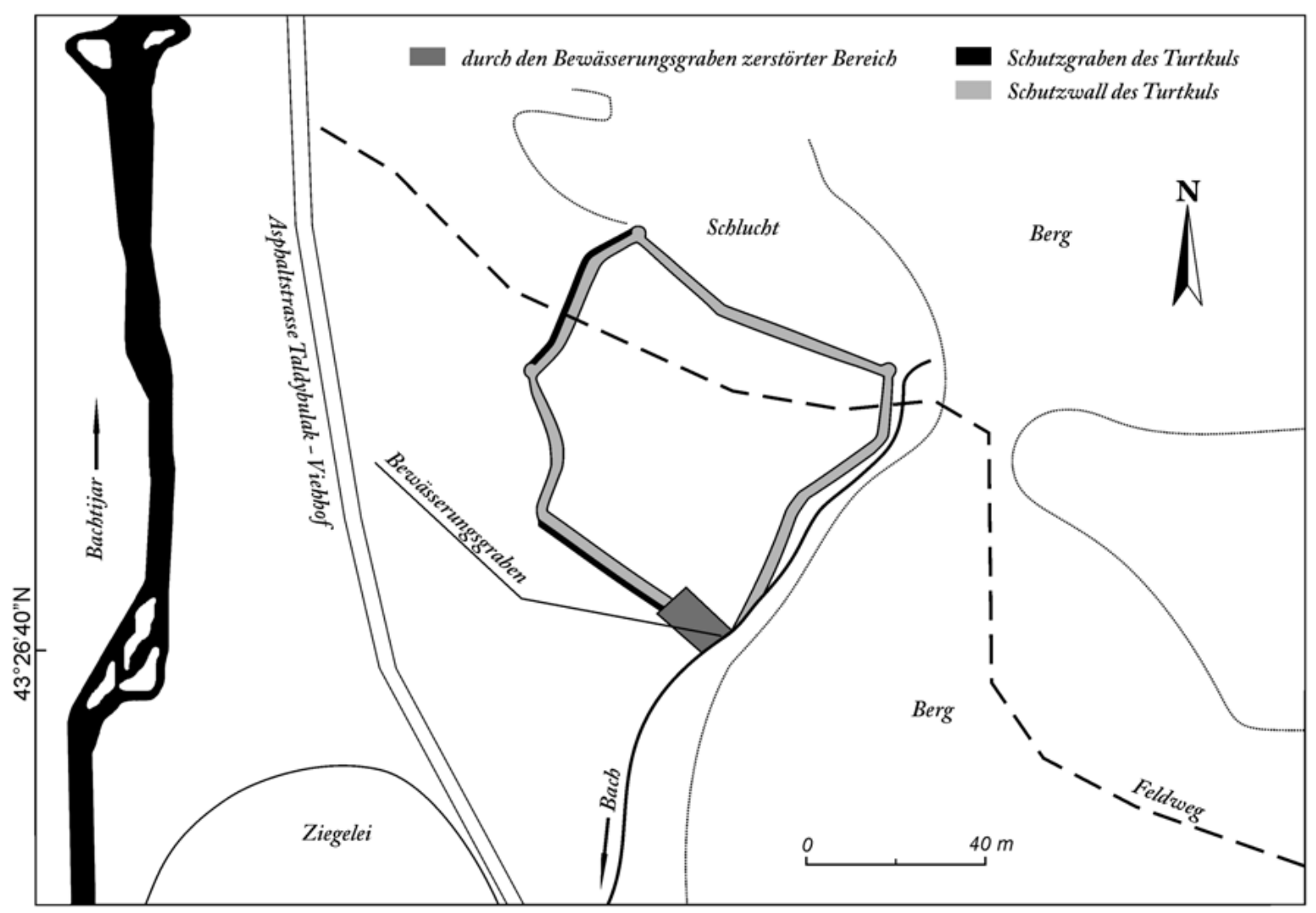

Abb. 234 | Lageskizze der Siedlung Bachtijar 
Die im Planum nahezu rechteckige (die Westecke ist „abgeschnitten“) Siedlung ist durch das WallGraben-System an der Oberfläche sichtbar. An der Südwestseite gewährt der Fluss einen natürlichen Schutz, an der Ost- und Südseite der Berg sowie an der Nordostseite die Schlucht. Lediglich die Nordwestseite bleibt zur Ebene hin offen. Die Ecken der Befestigungsanlage sind nach den vier Haupthimmelsrichtungen ausgerichtet. Eine Ausnahme bildet die Westecke, da dort reliefbedingt eine fünfte Ecke hinzugefügt werden musste. Die Siedlungsfläche ist von einem Wall umgeben. Die Breite des Schutzwalls beträgt 5-7 m. Die Höhe des Walls misst im Innenraum 0,5 m, jedoch außen I,O-I,5 m. Um die westlich gelegenen Seiten der Befestigung, die die keinen natürlichen Schutz aufweisen, wurde ein Schutzgraben gebaut, der O,5-I,O $\mathrm{m}$ tief und I,5-2,0 $\mathrm{m}$ breit ist. Weiterhin weisen die westlich gelegenen Seiten des Schutzwalls noch Steinsetzungen an der Oberfläche auf, die als Fundamentsreste der Verteidigungsmauer (?) interpretiert werden konnten. An den nordwestlichen, nördlichen und östlichen Ecken des Walls sind abgerundete Erhebungen sichtbar, die als Überreste von Wachtürmen gedeuten werden können. Die Südecke der Konstruktion ist durch einen modernen Bewässerungsgraben völlig zerstört. Bemerkenswerterweise konnte kein Eingangsbereich durch das Schutzsystem festgestellt werden. Im inneren Siedlungsraum wurden keine Befunde festgestellt. Direkt durch Siedlungsfläche verläuft ein moderner Feldweg. Hier wurden einige Lesefunde (Abb. 235) gemacht. Das keramische Fundmaterial weist eine chronologische Streuung von der sakischen Periode der Früheisenzeit bis zum Mittelalter auf.

Charakteristik der Lesefunde

I. Wandscherbe (von einem Hum?) 8,7 ×7,3 $\times$ I,I cm; außen beige, innen rosa; grob gemagert; handgemacht; Zeitstellung: ältere Eisenzeit bis frühes Mittelalter.

2. Wandscherbe 5,6 × 4,0 × I,2 cm; orangerot; mittelgrob gemagert; eher handgemacht; Zeitstellung: ältere Eisenzeit bis frühes Mittelalter.

3. Wandscherbe 4,3 $\times 2,9 \times \mathrm{I}, 4 \mathrm{~cm}$; außen beige, innen rotorange; sehr fein gemagert; scheibengedreht; Zeitstellung: ältere Eisenzeit.

4. Wandscherbe 2,6 × I,7 × I,2 cm; orangerot; mittelgrob gemagert; eher handgemacht; Zeitstellung: ältere Eisenzeit bis frühes Mittelalter.

5. Wandscherbe 2,7 $\times$ I,9 $\times 0,8 \mathrm{~cm}$; rosabeige; sehr fein gemagert; Zeitstellung: ältere Eisenzeit.
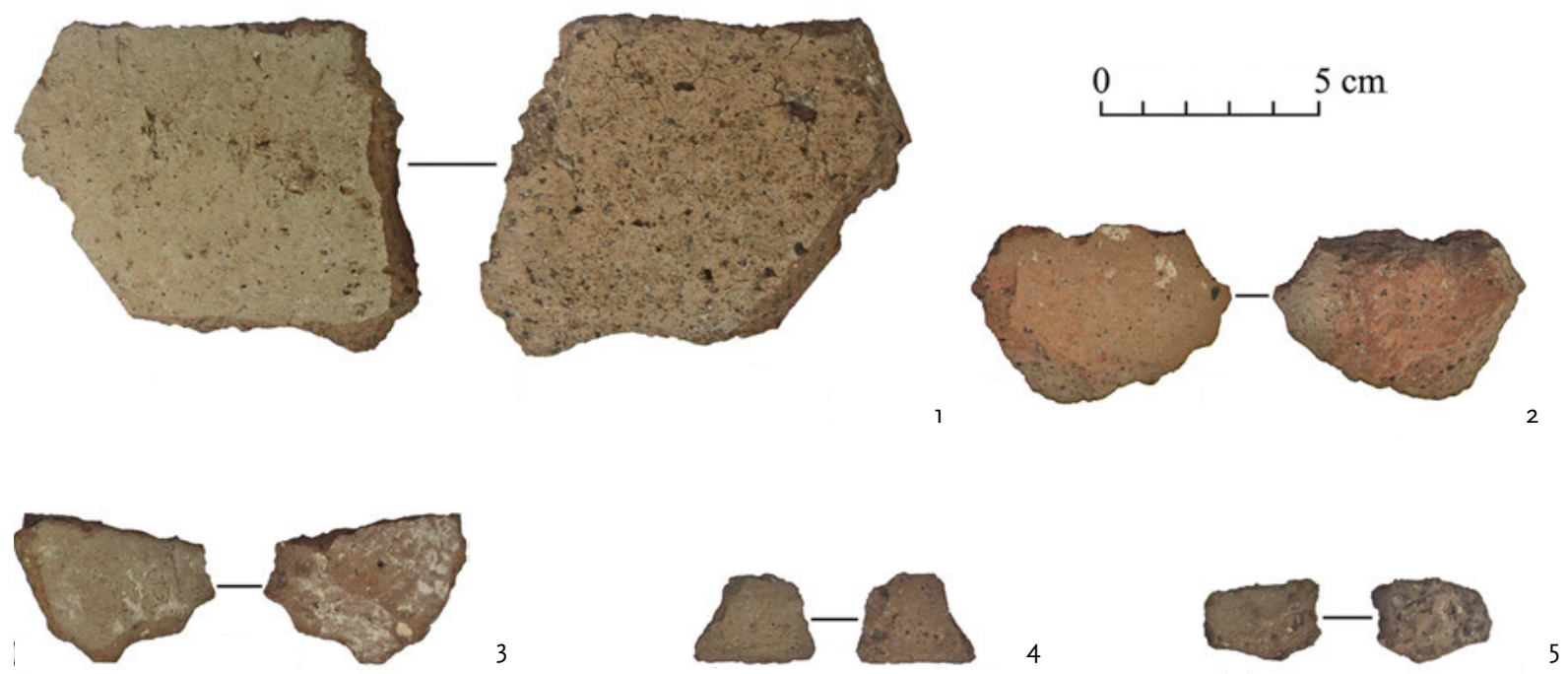

Abb. 235| Siedlung Bachtijar. Lesefunde 
Siedlung Cyganka 8 [FEZ] (Abb. 236-237; Karte 3 Nr. 7): ALT 7I4 m N43 22.325 E77 07.704; Gebiet Almaty (kasach. Алматы облысы), Talgarskij rajon (kasach. Талғар ауданы); Ausmaß N-S $50 \times$ O-W 33 m.

Die Siedlung Cyganka 8 befindet sich nördlich der Berge Kotyrbulak (kasach. Қотырбұлақ) und der Bergkette Transili-Alatau (kasach. Іле Алатауы), am rechten, östlichen Ufer des Flusses Cyganka (russ. Цыганка). Der Siedlungsplatz liegt $20 \mathrm{~km}$ ostnordöstlich der Stadt Almaty (kasach. Алматы), II km nordwestlich des Dorfes Talgar (kasach. Талғар), an der Südgrenze des Dorfes Imeni Panfilova (kasach. Панфилов атындағы).

Die von Norden nach Süden ausgedehnte Siedlungsstelle hat eine ovale Form und war an der Oberfläche als eine niedrige Erhebung (bis zu I,5 m) sichtbar. Cyganka 8 liegt direkt an der Uferböschung des Flusses. Dort, wo sich die

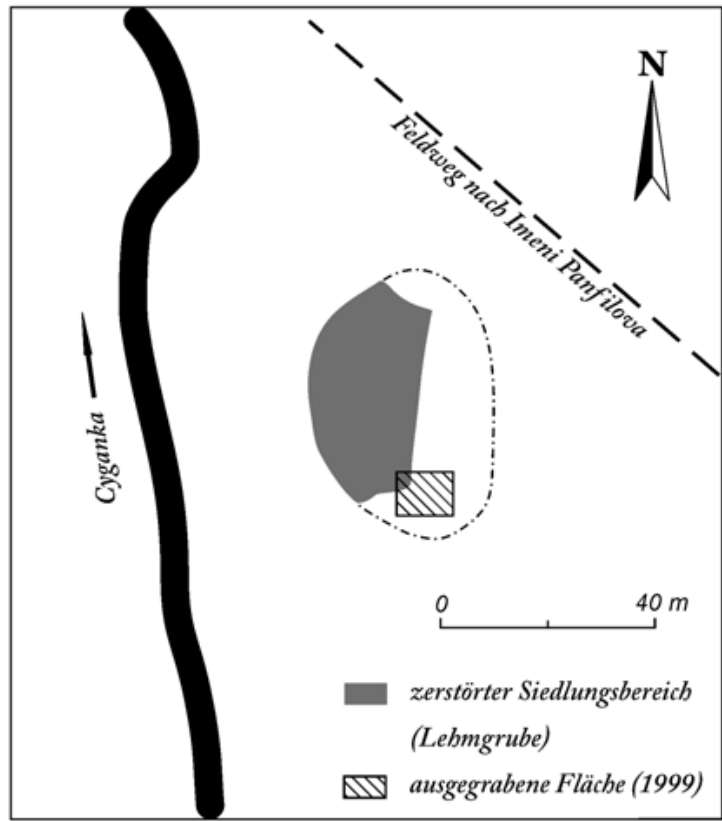

Abb. 236 | Lageskizze der Siedlung Cyganka 8 Westhälfte der Siedlung befand, ist heute eine Lehmgrube. Im südlichen Bereich wurde eine alte Grabungsfläche lokalisiert ${ }^{660}$. Auf diese Weise blieb nur ein schmaler, $33 \mathrm{~m}$ breiter Streifen in der Osthälfte der Siedlung unbeschädigt. In diesem Teil wurden jedoch weder Architektur noch Lesefunde festgestellt. Im Profil der Lehmgrube zeigten sich jedoch braungraue Verfärbungen, die man als Überreste von „Häusern“ deuten kann. Innerhalb der „Häuser“ finden sich noch zusätzlich unter Feuereinwirkung gebrannte Lehmschichten (russ. prokal).

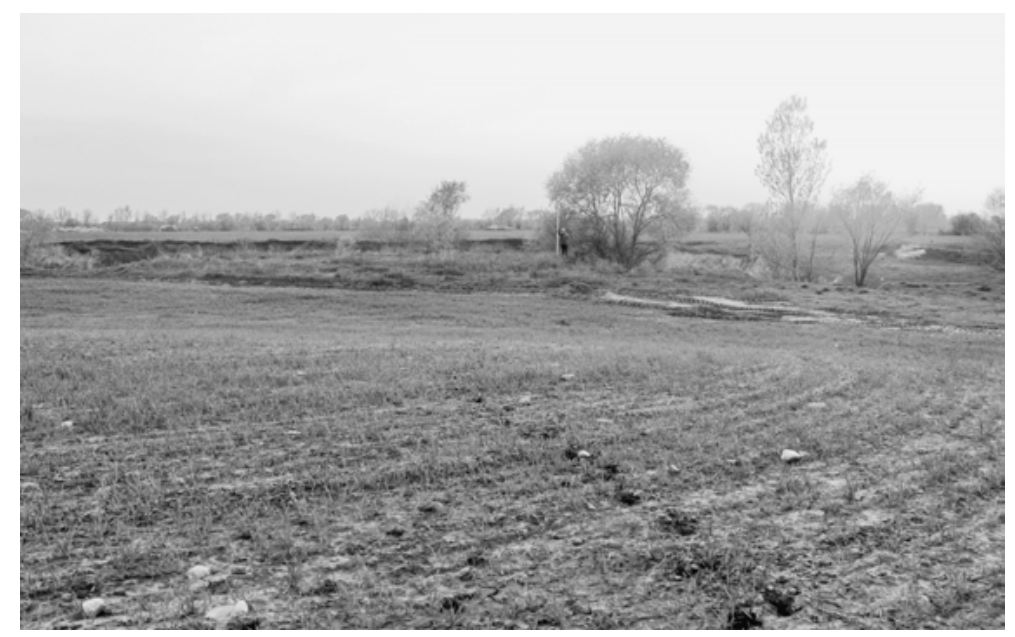

Abb. 237 | Siedlung Cyganka 8. Übersicht. Blick von O

660 Die Siedlung Cyganka 8 wurde im Jahre 2000 durch eine Kasachisch-Amerikanische Archäologische Expe- dition zum Teil ausgegraben (Baipakov 2008, 77-79; Chang u.a. 2003). 
Anhand der Grabungsergebnissen von 1998-2000 konnte Cyganka 8 der sakischen Periode der Früheisenzeit zugeordnet werden.

Forschungsgeschichte

Im Laufe der Untersuchung der archäologischen Hinterlassenschaften in der Talgar-Mikroregion wurde im Jahre I996 von der Kasachisch-Amerikanischen Archäologischen Expedition während eines geomorphologischen Surveys die Siedlung Cyganka 8 entdeckt (Chang u.a. 2003, 302).

Der Fundort wurde I998-2000 zum Teil ausgegraben. Es handelte sich um eine Nord-Süd ausgerichtete, $8 \times 22 \mathrm{~m}$ große Grabungsfläche (Chang u.a. 2003, 302). Man fand fünf ungestörte Grubenhäuser und mehrere dazugehörige Speichergruben (Baipakov 2008, 78).

Charakteristik der Bauten (Baipakov 2008, 78-79)

Grubenhaus 1 wurde sehr stark durch den Fluss beschädigt. Unversehrt blieb lediglich eine I,32 $\times$ 2,2 $\mathrm{m}$ großer Befund, der $0,35 \mathrm{~m}$ tief war. An das Grubenhaus I schloss eine runde $(\varnothing \circ, 7 \mathrm{~m}$; Tiefe $0,6 \mathrm{~m})$ Speichergrube an.

Grubenhaus 2 wies eine runde Form $\left(\varnothing_{4,2} \mathrm{~m}\right)$ auf. Der mit Lehm verstrichene Boden fand sich ०,7-I,O $\mathrm{m}$ unter der modernen Oberfläche. Ein zweiter Boden konnte in I,I m Tiefe von der modernen Oberfläche dokumentiert werden. Eine Probe aus diesem Befund ergab folgendes AMS-Datum: B-1336r3, 2130 +/- 40 BP (20-Bereich, 95\% - Cal BC 385-100) (Chang u.a. 2003, 303, Table I).

Grubenhaus 3 hatte eine rechteckige Form und war Nord-Süd ausgerichtet. Das Haus wies drei Böden auf, die sich in unterschiedlichen Tiefen (von o,6 bis I,9 m) zeigten. Auf dem Niveau des ersten, obersten Bodens (Tiefe O,6-I,O m) maß das Grubenhaus 6,0 × 2,8-3,7 m. Auf dem Boden kamen zwei Pfostengruben zum Vorschein, die durch mittelgroße Kieselsteine verkeilt worden waren (auf dem Hausboden- und auf dem Pfostengrubenboden). Der Durchmesser der Pfostengruben betrug 0,3-0,4 $\mathrm{m}$ und die Tiefe 0,7-0,88 $\mathrm{m}$. Der zweite und der dritte Boden fanden sich in der Tiefe I,4-I, $9 \mathrm{~m}$. Das Ausmaß des Hauses betrug hier 6,6 ×3,2 m. Unter dem zweiten Boden fanden sich einzelne Phytolithen von Gerste und die Überreste von Hirsehülsen. In einer Tiefe von I,35 m, von der modernen Oberfläche gemessen, wurden die Überreste einer organischen Riedmatte geborgen.

Im Norden schloss sich an das Haus ein Nord-Süd ausgerichteter, o, $86 \times 0,6 \times 0,6-0,7 \mathrm{~m}$ großer Flur an. Auf den untersten Böden des zweigeteilten Grubenhauses kamen zwei weitere Pfostengruben zum Vorschein, die auf dem Hausboden- und dem Pfostengrubenboden durch mittelgroße Kieselsteine verstärkt worden waren. Der Durchmesser der Pfostengruben betrug hier $0,35^{-}-4 \mathrm{~m}$ und die Tiefe 0,5-0,6 m.

Zwischen den Böden za und 3b, in einer Tiefe von I,I m, von der modernen Oberfläche gemessen, wurden Ascheschichten dokumentiert (Mächtigkeit - nicht angegeben). Die Beprobung der Asche ergab folgendes Datum: B-I336ı2, 2390 +/- 70 BP (20-Bereich, 95\% - Cal BC 775-370) (Chang u.a. 2003, 303, Table I).

Grubenhaus 4 wies eine ovale Form mit einem Durchmesser von 3,0-3,6 $\mathrm{m}$ auf. Die Tiefe des Hauses betrug $0,28-0,32 \mathrm{~m}$. In der Mitte des Befundes befand sich eine $0,3-0,35 \mathrm{~m}$ tiefe Pfostengrube mit einem Durchmesser von $0,4 \mathrm{~m}$.

Aus den Speichergruben wurden weitere ${ }^{\mathrm{I}} \mathrm{C}$ - und AMS-Daten gewonnen. Die Daten zeigten einen zeitliche Streuung von 740-7IO v. Chr. bis 210-40 v. Chr. (Chang u.a. 2003, 303, Table I), so dass die Siedlung der Früheisenzeit der sakischen Periode zuzuordnen ist ${ }^{66}$.

In der Speichergrube 13 fanden sich Pollenreste von Blütenpflanzen, was als ein Indiz für die Nutzung der Siedlung in den Sommermonaten gelten kann.

66I Nachweise zu den Proben im Einzelnen finden sich im

Appendix I Nr. 25-30. 
Von der Siedlungsfläche wurden die Scherben von 200 Gefäßen und mehrere Tierknochen geborgen. Die Analyse der Tierknochen ergab folgendes Bild: 46\% KWK, I6\% GWK, 3\% Pferd, ferner zwei Kamelknochen, zwei Eselsknochen und sechs Hundeknochen. Wild wurde durch die Knochen von Hirschen und Hasen repräsentiert (Baipakov 2008, 79).

Die Erforschung der Siedlungsfläche zeigte, dass die Siedlung Cyganka 8 ganzjährig benutzt wurde (Baipakov 2008, 79).

Lit.: Baipakov 2008, 77-79, Abb. 28-29; Bajpakov/Chang 2000, 266-268; Bajpakov u.a. 2000, i9; Chang u.a. 2003, 30I-309; Samašev u.a. 2005a, 52-53, I28-I29.

Siedlungsstelle bei der Stadt Issyk [?] (Abb. 238; Karte 3 Nr. I7): ALT IIO5 m N43 21.025 E77 26.803; Gebiet Almaty (kasach. Алматы облысы), Enbekšikazachskij rajon (kasach. Еңбекшіқазақ ауданы); Ausmaß N-S $90 \times$ O-W 88 m.

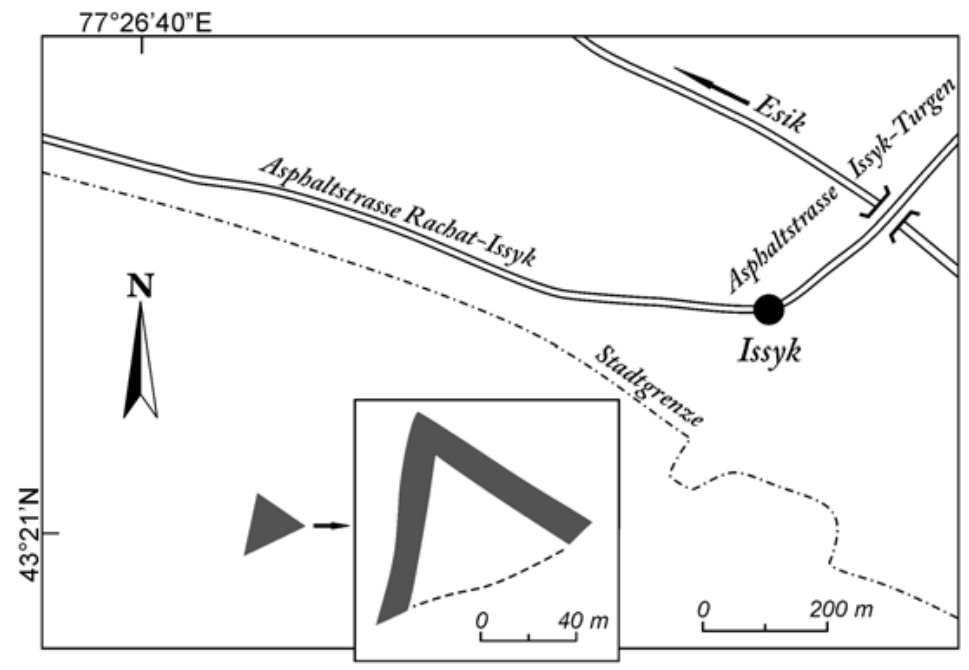

Abb. 238 | Lageskizze der Siedlungsstelle bei der Stadt Issyk

Die Siedlungsstelle befindet sich an der Nordseite der Bergkette Transili-Alatau (kasach. Іле Алатауы), auf dem Lösshügel des Berges Köksengir (kasach. Көксенгир), am linken, westlichen Ufer des Flusses Esik (kasach. Eciк). Der Siedlungsplatz liegt 44,5 km östlich der Stadt Almaty (kasach. Алматы) sowie an der Südgrenze der Stadt Issyk (kasach. Ecik). Die Siedlungsstelle nimmt die gesamte Kuppe des Lösshügels ein. Die From der Grundfläche orientiert sich an den natürlichen Grenzen der Kuppe, so dass sich im Planum eine dreieckige Form ergibt. Die äußeren Ecken der Siedlung sind nach Norden, Süden und Osten ausgerichtet. Die äußere Grenze wurde durch einen 2,7 $\mathrm{m}$ hohen (im inneren Bereich) und II,5 $\mathrm{m}$ breiten Schutzwall markiert. Da die äußeren Abhänge des Walls in die Lösshügelabhänge übergehen, konnte die genaue äußere Grenze vom Schutzwall nicht festgestellt werden. Dieser beginnt an einem Berghang und folgt dem Verlauf der Kuppe, so dass er zuerst von Osten nach Westen verläuft, dann unter einem Winkel von $45^{\circ}-50^{\circ}$ nach Süden abbiegt und an der anderen Seite des Berghanges endet. Sowohl im inneren Bereich der Siedlung als auch auf dem Schutzwall wurden keine Funde bzw. Befunde gemacht, daher ist die chronologische Einordnung des Bodendenkmals nicht möglich (Gass (im Druck)).

Lit.: Gass 20Iıb, 2ı8; Gass (im Druck). 
Siedlungsstelle Issyk „Tagebaustätte beim Geburtshaus" [FEZ bis MA] (Abb. 239; Karte 3 Nr. I8): ALT I203 m N43 20.043 E77 29.9I5; Gebiet Almaty (kasach. Алматы облысы), Enbekšikazachskij rajon (kasach. Еңбекшіқазақ ауданы); Ausmaß N-S I77 × O-W I4I m.

Die Siedlungsstelle befindet sich an der Nordseite der Bergkette Transili-Alatau (kasach. Іле Алатауы), an den nördlichen Ausläufern des Lösshügellandes, beim Ausgang der IssykSchlucht (kasach. Ecik) ins Tal, am rechten, östlichen Ufer eines namenlosen Baches, der ein rechter, östlicher Nebenfluss des Flusses Esik (kasach. Ecik) ist. Der Siedlungsplatz liegt $48 \mathrm{~km}$ östlich der Stadt Almaty (kasach. Алматы), an der Ostsüdostgrenze der Stadt Issyk (kasach. Есік).

Heute ist die Westhälfte der Siedlung durch die Lehmgrube der sog. „Tagebaustätte beim Geburtshaus-Issyk“ komplett abgetragen. Ursprünglich wies die Siedlungsstelle eine N-S ausgerichtete ovale Grundfläche auf. Auf der ungestörten Osthälfte, die sich auf der zweiten Flussuferterrasse befindet, wurden vier rundliche $\left(\varnothing_{4-8} \mathrm{~m}\right.$, Tiefe o,I-O,3 m) Gruben festgestellt, die möglicherweise zu Gruben- bzw. Halbgrubenhäusern gehören könnten. Auf dem gesamten Siedlungsareal lagen Scherben, Knochensplitter von Tierknochen (?) und mittelgroße Steine (ab $30 \times 20 \times 15 \mathrm{~cm})$ an der Oberfläche.

Die Aufschlüsse die durch den Tagebau entstanden waren, weisen eine Kulturschicht (Abb. 240) von bis zu o,4 m Mächtigkeit auf. Es handelt sich hier um dunkelbeige, lehmsandige Verfärbungen, Ascheschichten und Schichten von durchgebranntem Lehm (russ. prokal), mit Einsprengseln von Hüttenlehm, Keramik und Tierknochen.

Die aufgenommenen keramischen Streufunde (Abb. 24I) von der Siedlungsoberfläche lassen vermuten, dass dieser Siedlungsplatz schon in der Früheisenzeit existierte. Die Scherben verweisen auf eine breite chronologisch Streuung, die sowohl die sakischen als auch die wusunischen Perioden der Früheisenzeit und die frühtürkische Periode des Mittelalters umfasst.
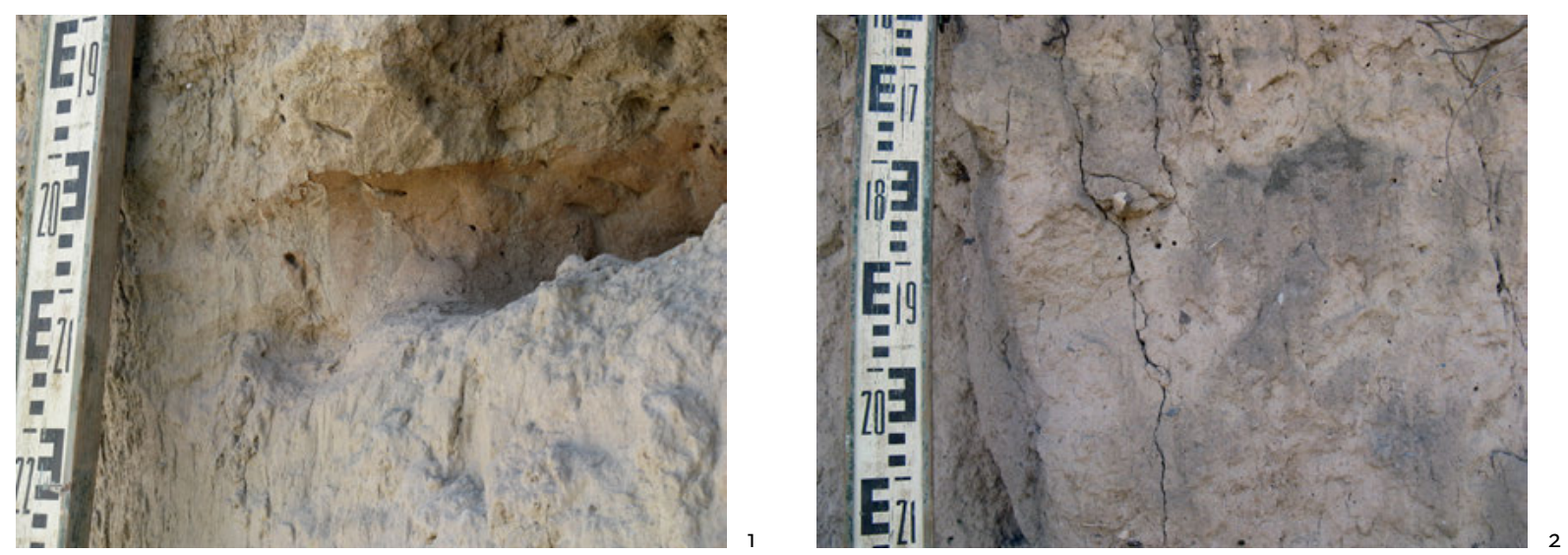

Abb. 240 | Issyk „Tagebaustätte beim Geburtshaus“. Aufschluss; I. Durchgebrannte Lehmschicht; 2. Ascheschicht, Feuerstelle (?) 

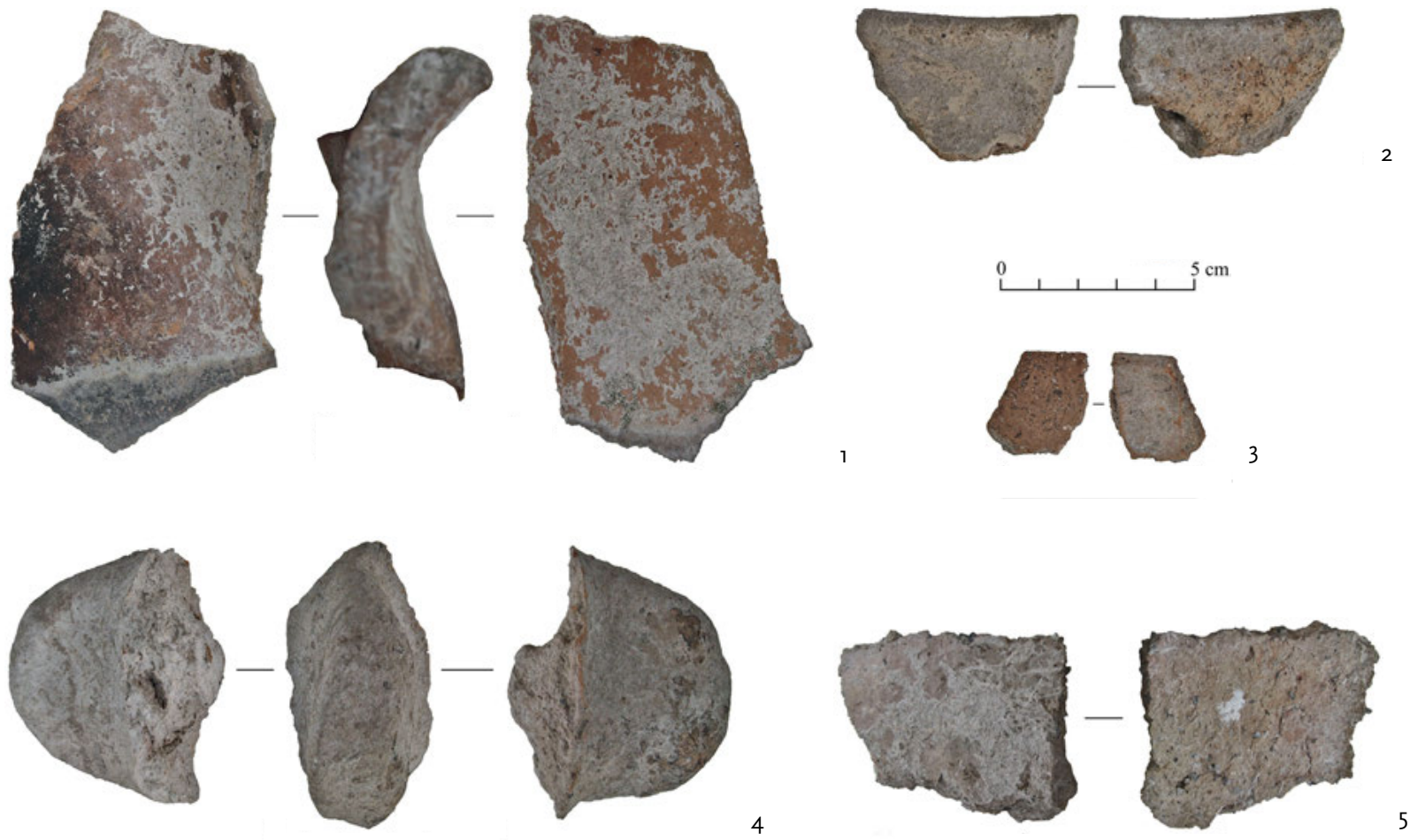

Abb. 241 | Siedlungstelle Issyk „Tagebaustätte beim Geburtshaus“. Lesefunde

\section{Charakteristik der Lesefunde}

I. Randscherbe II, $0 \times 6,5 \times 9,0 \mathrm{~cm}$; hellbraun bis orange; mittelgrob gemagert; scheibengedreht; Zeitstellung: sakische Periode der Früheisenzeit.

2. Randscherbe 5,4 × 3,3 × I,5 cm; außen beige, innen hellgrau; dickwandig; grob gemagert; scheibengedreht; Zeitstellung: ältere Eisenzeit bis frühes Mittelalter.

3. Randscherbe $2,4 \times 2,6 \times 0,9 \mathrm{~cm}$; rotorange; mittelgrob gemagert; scheibengedreht; Zeitstellung: sakische Periode der Füheisenzeit.

4. Griff (vom Ke-Kessel?) 6,3 × 4,7 × I,5-3,2 cm; beige; mittelgrob gemagert; handgemacht; Zeitstellung: jüngere Eisenzeit (Wusun-Periode) bis zum frühen Mittelalter.

5. Wandscherbe 6,5 $\times 4,6 \times 0,8 \mathrm{~cm}$; beige; grob gemagert; handgemacht; Zeitstellung: jüngere Eisenzeit (Wusun-Periode) bis zum frühen Mittelalter.

Lit.: Gass 20IIb, 218. 
Siedlung Issyk "Zentraler Friedhof" [FEZ bis MA] (Abb. 242; Karte 3 Nr. I6): ALT Io68 m N43 21.4I8 E77 28.440; Gebiet Almaty (kasach. Алматы облысы), Enbekšikazachskij rajon (kasach. Еңбекшіқазақ ауданы); Ausmaß $\mathrm{N}-\mathrm{S} 673 \times \mathrm{O}-\mathrm{W} 279 \mathrm{~m}$.

Die Niederlassung befindet sich nördlich der Bergkette Transili-Alatau (kasach. Іле Алатауы), im Flachland, auf einem Schwemmfächer, zwischen zwei namenlosen Bächen, die von Süden nach Norden fließen. Der Siedlungsplatz liegt $47 \mathrm{~km}$ östlich der Stadt Almaty (kasach. Алматы), am östlichen Stadtrand von Issyk (kasach. Еcik).

Die Siedlungsfläche ist dicht bebaut. Westlich, direkt an die Siedlung angrenzend, liegt ein Wohnbezirk der Stadt Issyk. Nördlich, östlich und südlich der Siedlungsstelle befinden sich Ackerflächen. Auf dem gesamten Siedlungsareal findet sich der „alte zentrale orthodoxe Friedhof“. Dadurch konnte über die innere Struktur der Siedlung kaum etwas gesagt werden.

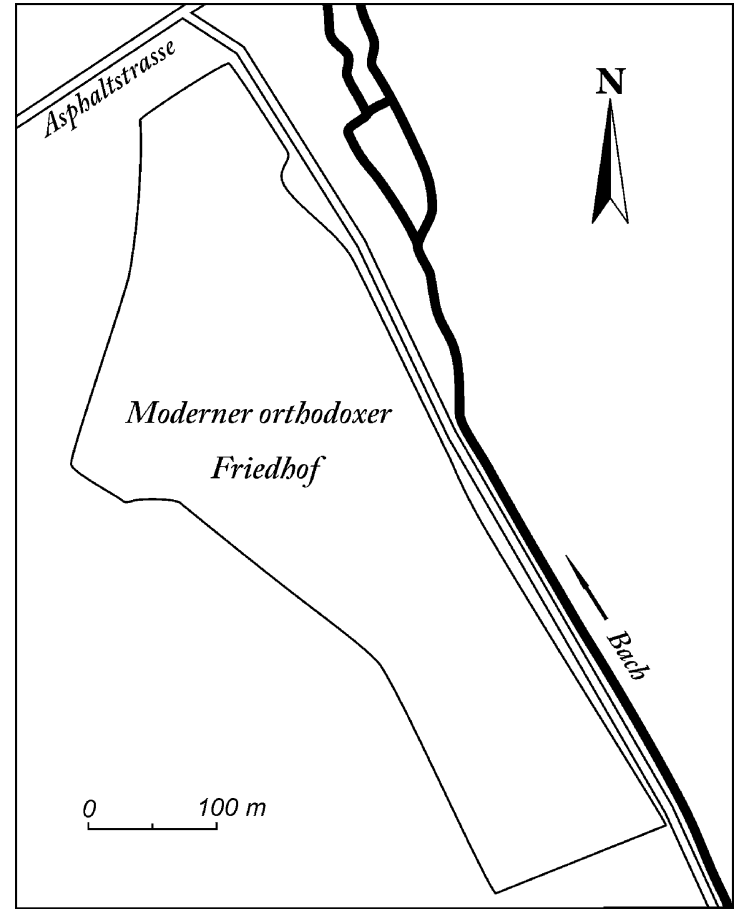

Abb. 242 | Lageskizze der Siedlung Issyk „Zentraler Friedhof“

Die Siedlungsstelle ist durch eine I,O-I, $5 \mathrm{~m}$ hohe Erhebung markiert. Ursprünglich hatte die Siedlung möglicherweise eine rechteckige Grundform, die sich von NW nach SO ausdehnte, so dass die Siedlungsecken an den vier Haupthimmelsrichtungen ausgerichtet worden waren. Für diese Annahme spricht die Lage der Nordecke, die noch erhalten war. Entlang der gesamten Ostseite und im Norden, im rechten Winkel Richtung Westen anschließend, ist ein Abschnitt des Schutzwalles (Abb. 243) erhalten geblieben. Die Höhe des Walls misst I-3 $\mathrm{m}$ und die Breite beträgt 3-5 $\mathrm{m}$. An einigen

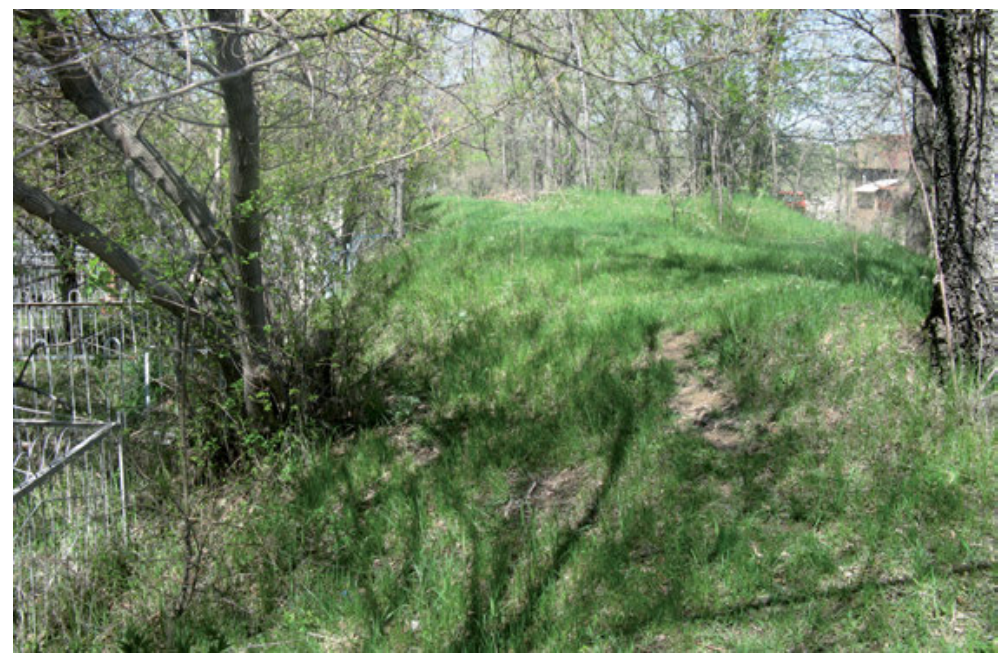

Abb. 243 | Siedlung Issyk „Zentraler Friedhof“. Ostseite, Schutzwall. Blick von SO 

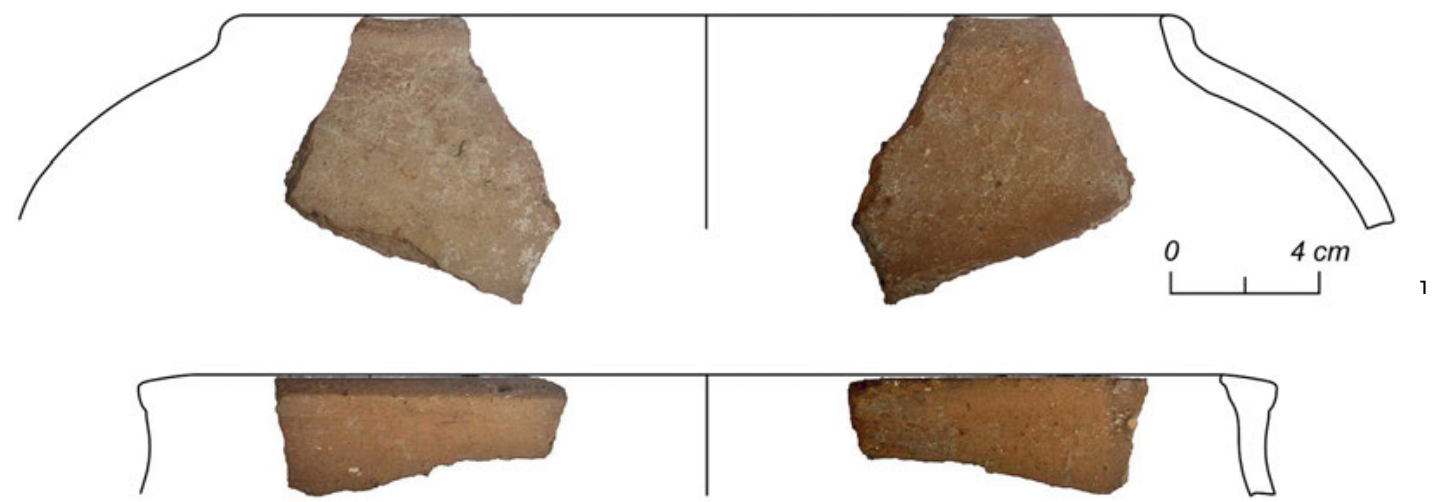

2
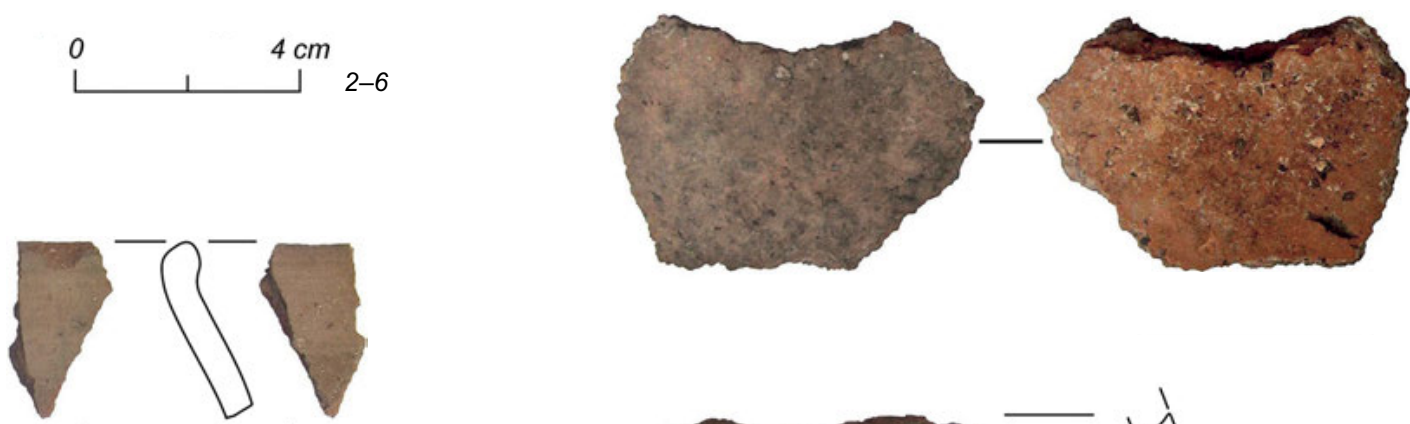

4
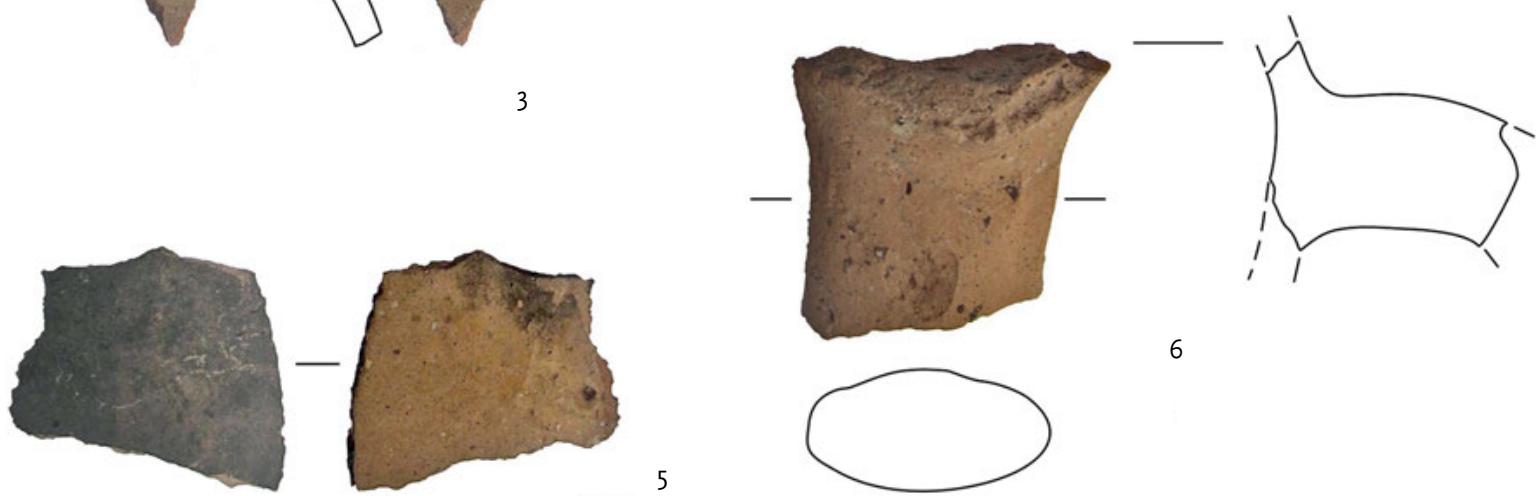

Abb. 244 | Siedlung Issyk „Zentraler Friedhof“. Nordwestlicher Bereich der Siedlung. Lesefunde (Zeichnung M.-R. Boroffka)

Stellen kamen an der Oberfläche des Walls Steinsetzungen zum Vorschein, die als Fundamentsreste der Verteidigungsmauer (?) interpretiert werden konnten. Im nordwestlichen Bereich der Siedlung traten an der Oberfläche unterschiedliche Scherben zutage.

Die keramischen Streufunde (Abb. 244) von der Siedlungsoberfläche lassen vermuten, dass dieser Siedlungsplatz schon in der Früheisenzeit existierte. Die Scherben zeigen eine breite chronologische Streuung auf, die eine Zeitspanne von der sakischen Periode der Früheisenzeit bis zur frühtürkischen Periode des Mittelalters abdeckt.

Charakteristik der Lesefunde

I. Randscherbe 7,6 $\times 8, \mathrm{I} \times 0,7 \mathrm{~cm}$; RDm $33 \mathrm{~cm}$; beige bis rot-beige; grob gemagert; von innen und von außen geglättet; handgemacht; Zeitstellung: frühes Mittelalter. Neuzeit.

2. Randscherbe 5,I × 2,0 ×0,6 cm; RDm $20 \mathrm{~cm}$; rot; fein gemagert; scheibengedreht; Zeitstellung: 
3. Randscherbe $\mathrm{I}, 6 \times 3,0 \times 0,7 \mathrm{~cm}$; rot-beige; fein gemagert; scheibengedreht; Zeitstellung: Neuzeit.

4. Wandscherbe $6,3 \times 4,3 \times 1,0 \mathrm{~cm}$; außen hellbraun, innen rot; grob gemagert mit kleinen Steinpartikeln; von innen und von außen geglättet; handgemacht; Zeitstellung: jüngere Eisenzeit (WusunPeriode) bis frühes Mittelalter.

5. Wandscherbe 4,9 $\times 3,4 \times 0,7 \mathrm{~cm}$; außen schwarzbraun, innen rot; fein gemagert; Zeitstellung: eher sakische Periode der Früheisenzeit.

6. Griff (vom Krug oder von einer Amphore) 4,3 × 4,I × 2,I cm; rot; mittelgrob gemagert; Zeitstellung: Früheisenzeit bis frühes Mittelalter.

Lit.: Gass 20IIb, 2I8.

Siedlung Junki-I [FEZ bis MA] (Abb. 245-246; Karte 3 Nr. 25): ALT 934 m N43 27.45I E77 53.857; Gebiet Almaty (kasach. Алматы облысы), Enbekšikazachskij rajon (kasach. Еңбекшіқазақ ауданы); Ausmaß N-S 76 × O-W $40 \mathrm{~m}$.

Die Siedlung Junki-I befindet sich an der Nordseite der Bergkette Transili-Alatau (kasach. Іле Алатауы), in den nördlichen Ausläufern des Lösshügellandes vom Berg Abdratekše (kasach. Абдратекше), am rechten, östlichen Ufer des Flusses Junki (kasach. Юнки), I,2 km tief in der Junki-Schlucht vor dem Ausgang der Schlucht ins Flachland. Direkt an den östlichen Siedlungsrand angrenzend fließt ein kleiner Bach. Der Siedlungsplatz liegt $83 \mathrm{~km}$ nordöstlich der Stadt Almaty (kasach. Алматы) und ıо km südsüdöstlich des Dorfes Teskensu (kasach. Тескенсу).

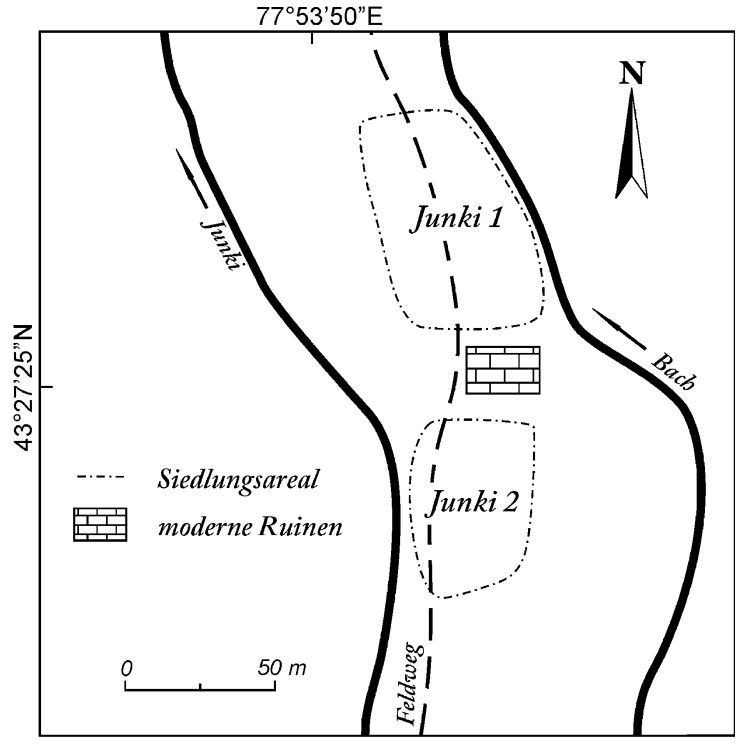

Abb. 245 | Lageskizze der Siedlung Junki-I

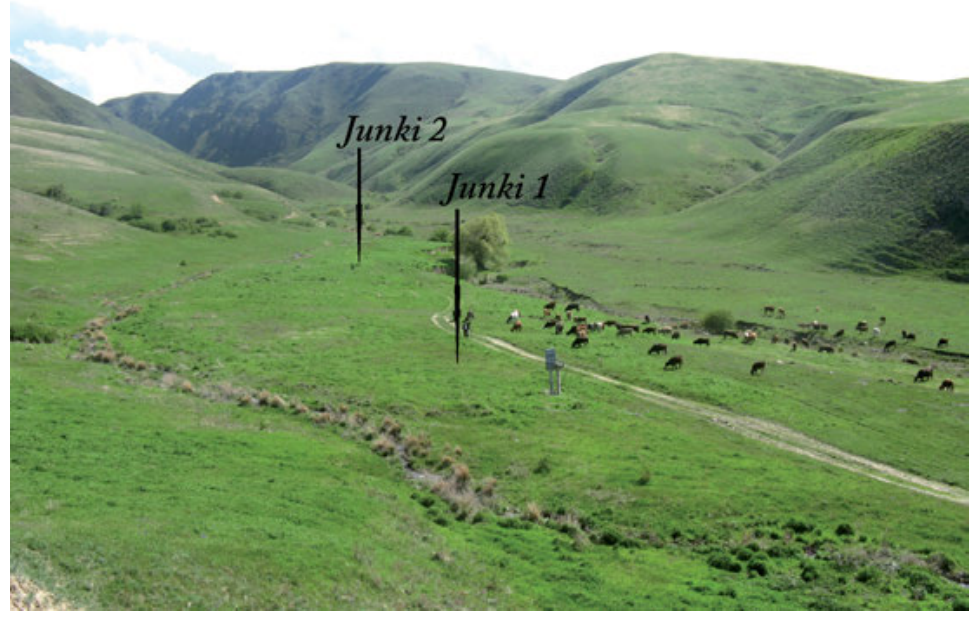

Abb. 246 | Junki-I und Junki-2. Blick von NNO 


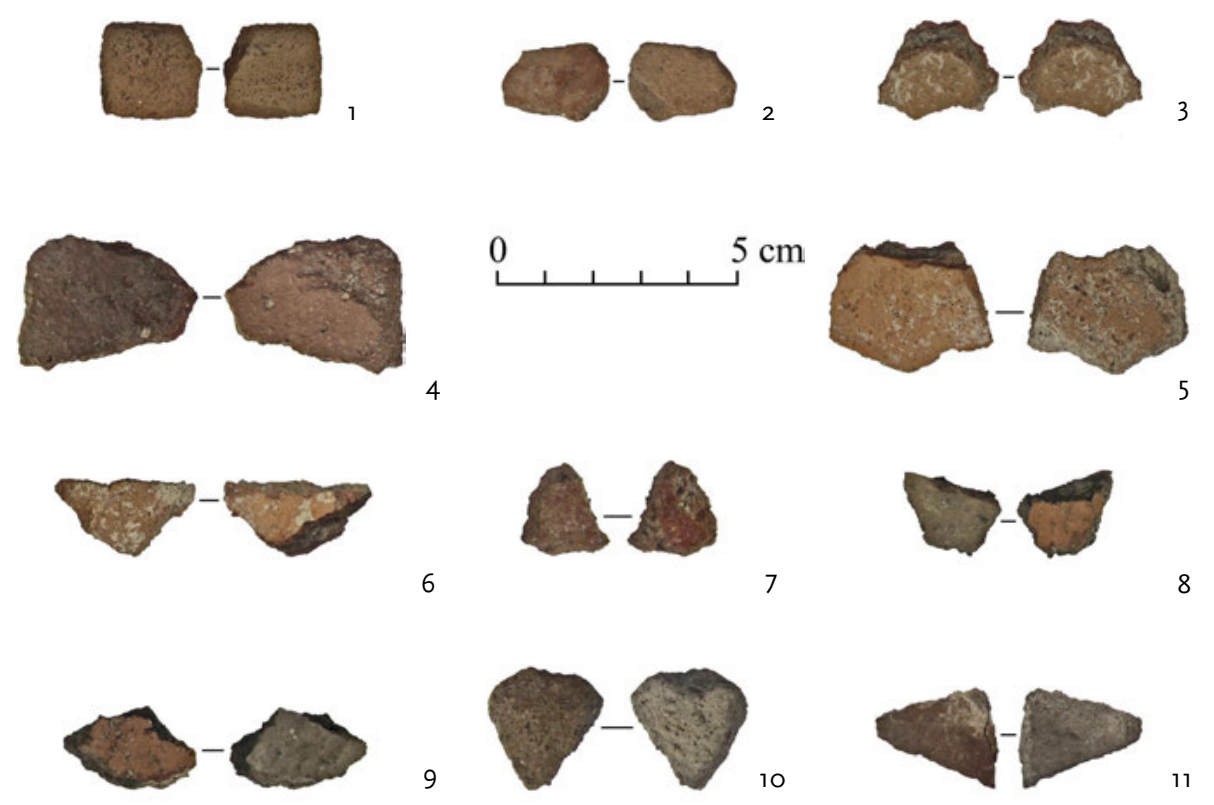

Abb. 247 | Siedlung Junki-I. Lesefunde

Die Siedlungsfläche stellt eine $0,5 \mathrm{~m}$ hohe, rechteckige Erhebung dar, die N-S ausgedehnt war. Direkt auf der Siedlungsfläche verläuft ein moderner Feldweg. Entlang der südlichen und östlichen Seiten dieser Erhebung zeigen sich an der Oberfläche Steinsetzungen, die als Fundamentsreste der Verteidigungsanlagen (?) interpretiert werden können. Zudem liegen an der Oberfläche auch Scherben und Knochensplitter. Das keramische Fundmaterial (Abb. 247) weist eine chronologische Streuung von der älteren Eisenzeit (sakische Periode) bis zur jüngeren Eisenzeit (Wusun-Periode) bzw. frühtürkischen Periode des frühen Mittelalters auf.

Im inneren Bereich der Siedlung sind keine Befunde festzustellen.

$35 \mathrm{~m}$ südlich der Fundstelle fand sich eine weitere, von N nach S ausgerichtete, im Plan eher ovale, 0,5 $\mathrm{m}$ hohe Erhebung, die als eine weitere Siedlung - Junki-2 (Karte 3 Nr. 26; ALT $940 \mathrm{~m} \mathrm{~N} 4327.392$ E77 53.86I; Ausmaß N-S $50 \times \mathrm{O}-\mathrm{W} 32 \mathrm{~m}$ ) - interpretiert werden kann. Allerding wurde hier an der Oberfläche nur bronzezeitliche Keramik (Abb. 248), die dem Andronovo-Kulturkreis zuzuschreiben ist, aufgelesen.

Zwischen beiden Siedlungsflächen liegen Betonruinen moderner Bauten.

Charakteristik der Lesefunde der Siedlung Junki-I

I. Randscherbe 2,O × I, $8 \times 0,6 \mathrm{~cm}$; rot; fein gemagert; von innen und von außen geglättet; Zeitstellung: ältere Eisenzeit, sakische Periode.

2. Wandscherbe $2,2 \times \mathrm{I}, 5 \times 0,4 \mathrm{~cm}$; rot; sehr fein gemagert; von außen geglättet; Zeitstellung: ältere Eisenzeit, sakische Periode.

3. Wandscherbe $2,3 \times \mathrm{I}, 5 \times 0,8 \mathrm{~cm}$; rot; mittelfein gemagert; handgemacht; Zeitstellung: jüngere Eisenzeit, Wusun-Periode bis frühes Mittelalter.

4. Wandscherbe 3,5 ×2,6 × I,I cm; rot bis rot-beige; mittelfein bis fein gemagert; von außen geglättet; Zeitstellung: ältere Eisenzeit, sakische Periode.

5. Wandscherbe 3,4 × 2,2 $\times 0,9 \mathrm{~cm}$; rot; mittelfein gemagert; handgemacht; Zeitstellung: jüngere Eisenzeit, Wusun-Periode bis frühes Mittelalter. 
6. Wandscherbe $2,2 \times 1,7 \times 0,7 \mathrm{~cm}$; rot bis rot-beige; mittelfein bis fein gemagert; von außen geglättet; Zeitstellung: ältere Eisenzeit, sakische Periode.

7. Wandscherbe 2,0 $\times$ I, $2 \times 0,8 \mathrm{~cm}$; dunkelrot; sehr grob gemagert; handgemacht; Zeitstellung: jüngere Eisenzeit, Wusun-Periode bis frühes Mittelalter.

8. Wandscherbe $2, \mathrm{I} \times \mathrm{I}, 5 \times 0,8 \mathrm{~cm}$; rot; sehr grob gemagert; handgemacht; Zeitstellung: jüngere Eisenzeit, Wusun-Periode bis zum früheren Mittelalter.

9. Wandscherbe 2,7 $\times$ I,7 $\times 0,7 \mathrm{~cm}$; rot; mittelfein gemagert; handgemacht; Zeitstellung: jüngere Eisenzeit, Wusun-Periode bis frühes Mittelalter.

IO. Wandscherbe $2, \mathrm{I} \times 2,6 \times 0,8 \mathrm{~cm}$; braun; grob gemagert; handgemacht; Zeitstellung: jüngere Eisenzeit, Wusun-Periode bis frühes Mittelalter.

II. Wandscherbe 2,5 × I,6 × 0,9 cm; rot; sehr grob gemagert; handgemacht; Zeitstellung: jüngere Eisenzeit, Wusun-Periode bis frühes Mittelalter.
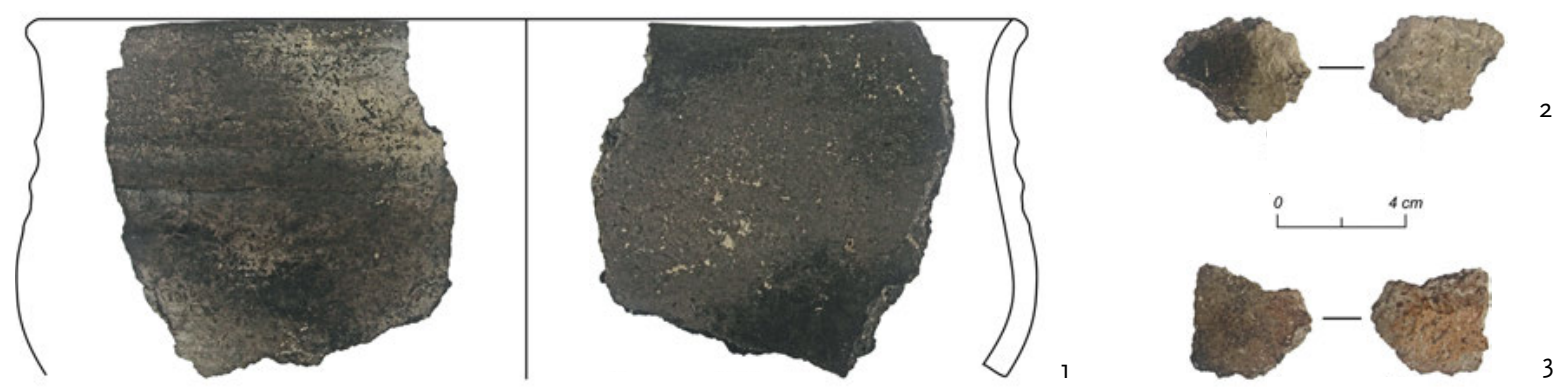

Abb. 248 | Siedlung Junki-2. Lesefunde (Zeichnung M.-R. Boroffka)

Charakteristik der Lesefunde der Siedlung Junki-2

I. Randscherbe II,3 × I0,4 × 0,7 cm; RDm $32 \mathrm{~cm}$; schwarz mit grauen Flecken; mittelgrob mit etwas Sand und Häcksel gemagert; innen verstrichen; außen geglättet; mit drei horizontalen Kanneluren an der Schulter verziert; handgemacht; Zeitstellung: Bronzezeit, Andronovo-Fedorovka-Etappe.

2. Wandscherbe 3,3 $\times 3,7 \times 0,7 \mathrm{~cm}$; grau-beige; grob gemagert; innen verstrichen; außen geglättet; handgemacht; Zeitstellung: Bronzezeit, Andronovo-Fedorovka-Etappe.

3. Wandscherbe 3,7 × 3,O × I,I cm; rosa-beige; grob gemagert; innen verstrichen; außen geglättet; handgemacht; Zeitstellung: Bronzezeit, Andronovo-Fedorovka-Etappe.

Siedlungsstelle Kajnazar [FEZ bis MA] (Karte 3 Nr. II): ALT 725 m N43 22.766 E77 I7.4I8; Gebiet Almaty (kasach. Алматы облысы), Enbekšikazachskij rajon (kasach. Еңбекшіқазақ ауданы); geschätztes Ausmaß N-S ca. 200-300 × O-W ca. 300-400 m.

Die Niederlassung Kajnazar befindet sich im Flachland, nördlich der Bergkette Transili-Alatau (kasach. Іле Алатауы), am linken, westlichen Ufer des Flusses Kajnazar (kasach. Қайназар). Der Siedlungsplatz liegt 33,5 km ostnordöstlich der Stadt Almaty (kasach. Алматы), 8 km nordöstlich der Stadt Talgar (kasach. Талғар), 2 km nordwestlich des Dorfes Kajnazar (kasach. Қайназар) und 370 m nördlich der Asphaltstraße Talgar - Issyk (kasach. Ecik).

Die Siedlungsfläche ist komplett überpflügt, so dass an der Oberfläche keine Spuren von Bauten erhalten sind. Überall auf dem Acker liegen jedoch Scherben von unterschiedlichen Gefäßen, Kno- 
chensplitter und fragmentarisch erhaltene Steingeräte verstreut herum. Weder die tatsächliche Form der Siedlung noch ihre Größe können festgestellt werden.

Das keramische Fundmaterial (Abb. 249,I-7) und ein Fragment eines Reibsteines (Abb. 249,8), die auf dem Acker aufgelesen wurden, deuten eine chronologische Streuung von der Früheisenzeit bis zum Mittelalter an.
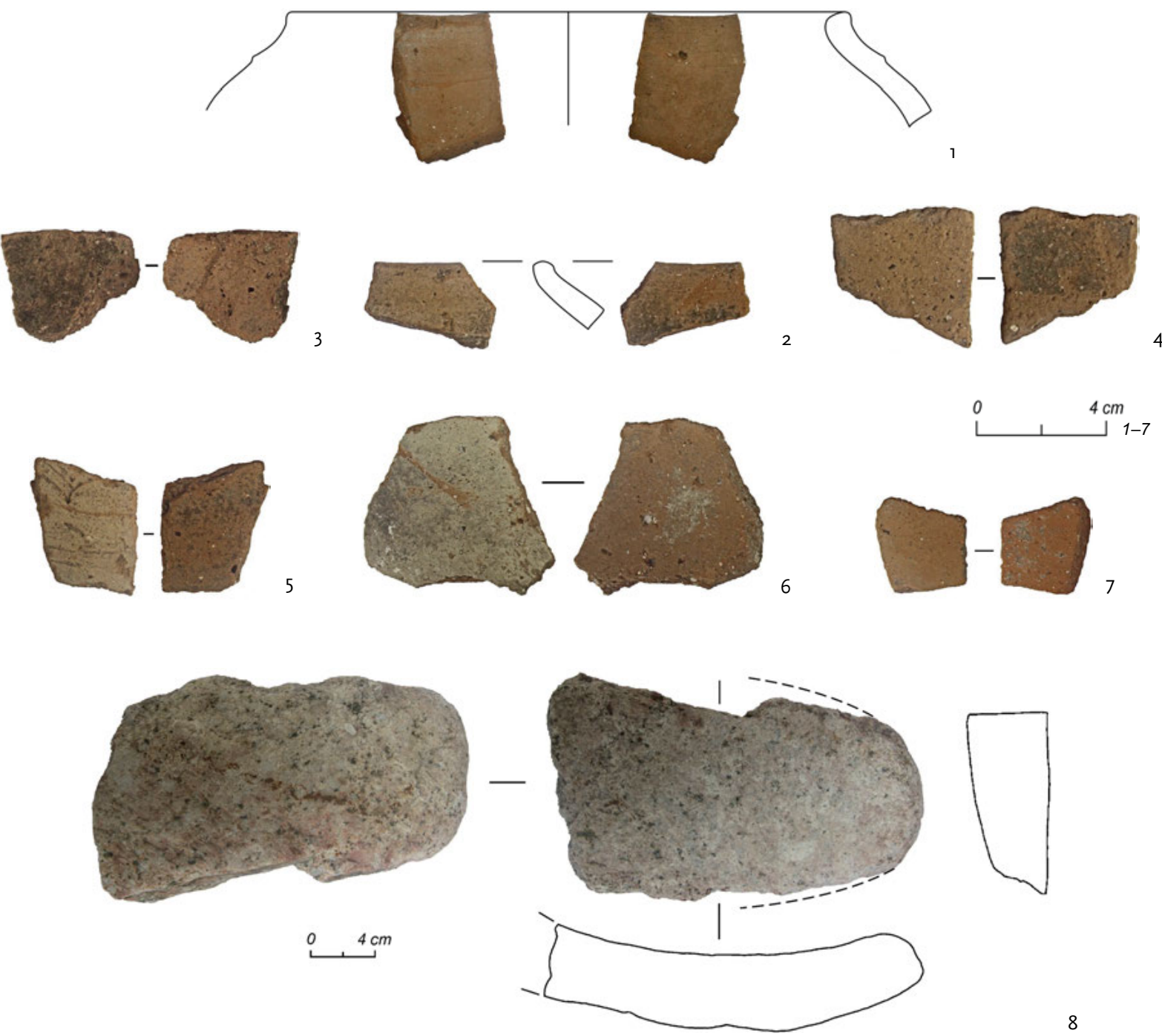

Abb. 249 | Siedlungsstelle Kajnazar. Lesefunde; I-7 Keramik, 8 Reibstein (Zeichnung M.-R. Boroffka)

Charakteristik der Lesefunde

I. Randscherbe mit einem Wulst nach außen 3,0 × 4,2 × 0,9 cm; RDm ca. I9 cm; rotorange; mittelfein gemagert; kompakter Ton mit feinem Sand; verstrichen; mit horizontalen Kanneluren am Hals verziert; scheibengedreht; Zeitstellung: ältere Eisenzeit, sakische Periode.

2. Randscherbe mit einem Wulst nach außen 3,9 $\times 2, \mathrm{I} \times 0,7 \mathrm{~cm}$; rotorange; mittelfein gemagert; verstrichen; scheibengedreht; Zeitstellung: ältere Eisenzeit, sakische Periode. 
3. Wandscherbe 4,O $\times 4,2 \times 1,0 \mathrm{~cm}$; beige bis orangerot; mittel bis grob gemagert; von außen geglättet; handgemacht; Zeitstellung: Früheisenzeit bis frühes Mittelalter.

4. Wandscherbe $3,8 \times 3,5 \times 0,9 \mathrm{~cm}$; beige bis orangerot; mittel bis grob gemagert; von außen geglättet; handgemacht; Zeitstellung: Früheisenzeit bis zum früheren Mittelalter.

5. Wandscherbe 3,3 $\times 2,9 \times \mathrm{I}, 2 \mathrm{~cm}$; beige bis orangerot; mittel bis grob gemagert; von außen geglättet; handgemacht; Zeitstellung: Früheisenzeit bis zum frühes Mittelalter.

6 . Wandscherbe $2,8 \times 2,9 \times 0,5 \mathrm{~cm}$; orangerot; fein gemagert; innen verstrichen, außen geglättet; scheibengedreht; Zeitstellung: jüngere Eisenzeit.

7. Wandscherbe 5,7 ×5,2 $\times 0,9 \mathrm{~cm}$; beige bis orangerot; mittel bis grob gemagert; von außen geglättet; handgemacht; Zeitstellung: Früheisenzeit bis frühes Mittelalter.

8. Reibstein I9,5 $\times$ II,I $\times 4,2 \mathrm{~cm}$; grobkörniger, rosa-grauer Granit; eine Hälfte ist erhalten; eine Seite geschliffen und abgenutzt; Zeitstellung: ältere Eisenzeit bis Mittelalter.

Forschungsgeschichte

Im Rahmen der archäologischen Betsandsaufnahme der archäologischen Bodendenkmäler im Gebiet Almaty untersuchte die archäologische Almaty-Expedition im Jahre 1987 unter der Leitung von T. V. Savel'eva den Siedlungsplatz Kajnazar (Nurmuchanbetov/Savel'eva I988, II-I3). Der Fundort wurde als unbefestigte Siedlung deklariert. Bereits I987 war die Siedlungsfläche komplett überackert. Die Ausdehnung der Siedlung wurde nach Angaben von Savel'eva auf $200 \mathrm{~m}$ von Norden nach Süden und 250-300 m von Osten nach Westen geschätzt. Es wurde festgestellt, dass ca. $0,3-0,5 \mathrm{~m}$ der Humusschicht durch den Pflug gestört worden ist (Savel'eva I994, 34). Nach den Angaben von Savel'eva (Savel'eva I994, 34-35) und später von Bajpakov u.a. (Bajpakov u.a. 2002, 28-29) wurden auf der Oberfläche Scherben von unterschiedlichen Gefäßen (Abb. 250), hauptsächlich von einfacher Keramik, aufgelesen. Es handelte sich um Fragmente eines Kessels aus Ton mit dazugehörigen Griffen, um Fragmente von Töpfen, Krügen oder Vorratsgefäßen. Zudem wurde ein fragmentarisch erhaltenes Gefäß
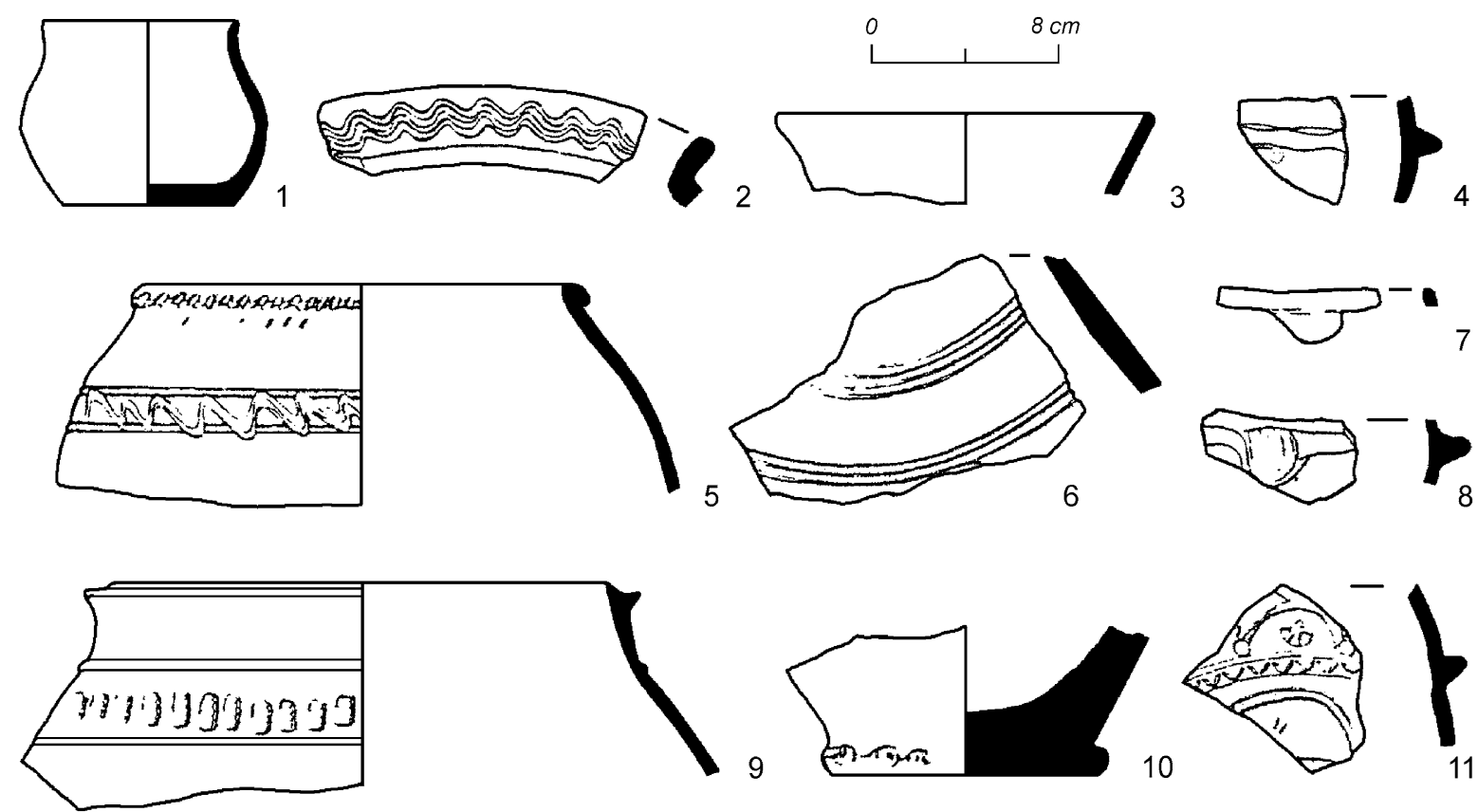

Abb. 250 | Unbefestigte Siedlung Kajnazar. Lesefunde (Savel'eva I994, Abb. II; graphische Nachbearbeitung von M.-R. Boroffka) 
gefunden, das durch Wellenlinien und Stempelabdrücke verziert worden war. Man fand auch Keramik mit grüner Aufgußglasur, außerdem Tonschlacke und Ziegelfragmente. Die Fragmente von Schüsseln, die eine durchsichtige Aufgußglasur aufwiesen, gaben der Ausgräberin ein Indiz, die Siedlungsstelle ins I0.-I2. Jh. n. Chr. zu datieren (Savel'eva I994, 35).

Lit.: Bajpakov u.a. 2002, 28-29; Nurmuchanbetov/Savel'eva I988, II-I3; Savel'eva I994, 34-35, 89-90, 93-II5, I26, Abb. II.

Siedlung (bzw. Turtkul) Karakemer [FEZ - frühtürkische Periode] (Abb. 25I; Karte 3 Nr. 20): ALT 953 m N43 24.457 E77 36.709; Gebiet Almaty (kasach. Алматы облысы), Enbekšikazachskij rajon (kasach. Еңбекшіқазақ ауданы); Ausmaß N-S $49 \mathrm{~m} \times \mathrm{O}-\mathrm{W}$ ? (teilweise zerstört).

Die Siedlung/Turtkul Karakemer befindet sich an der Nordseite der Bergkette Transili-Alatau (kasach. Іле Алатауы), am rechten, östlichen Ufer des Flusses Turgen (kasach. Турген), an der Stelle, wo der Fluss aus der TurgenSchlucht austritt, auf einem Schwemmfächer. Der Fundort liegt $59 \mathrm{~km}$ ostnordöstlich der Stadt Almaty (kasach. Алматы), I,8 km nordöstlich des Dorfes Turgen (kasach. Түрген) bzw. 0,5 km

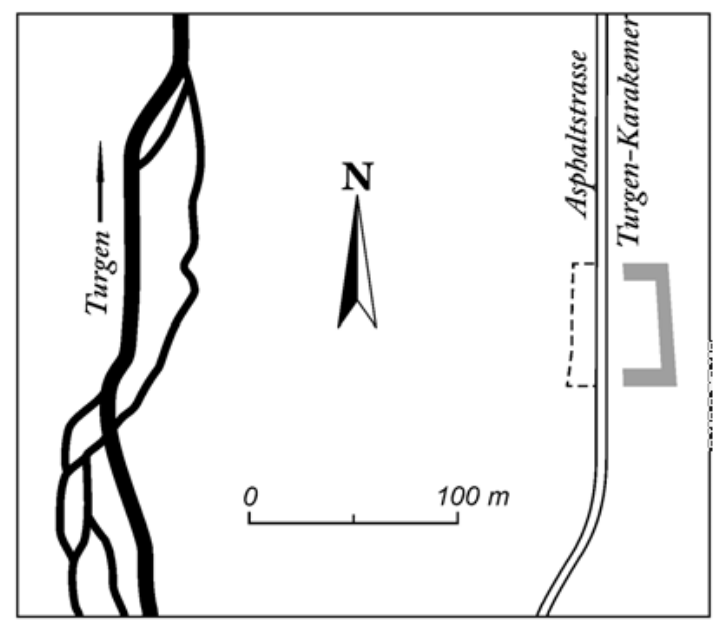

Abb. 251 | Lageskizze der Siedlung/Turtkul Karakemer östlich der Dorfgrenze von Turgen und I,9 km nordnordöstlich des Dorfes Karakemir (kasach. Қаракемір).

Die gesamte Siedlungsfläche ist durch einen Turtkul repräsentiert, das zu zwei Dritteln durch die Asphaltstraße zwischen Turgen und Karakemir zerstört wurde (Abb. 252). Der ungestörte, östliche Teil stellt eine quadratische bzw. viereckige Befestigung dar, deren Seiten an den vier Haupthimmelsrich-

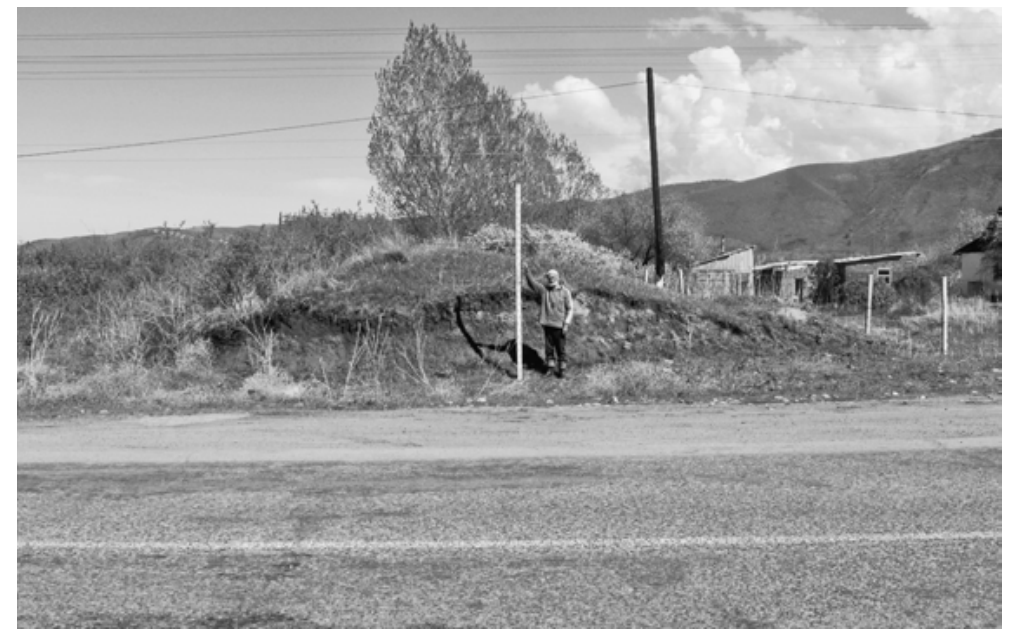

Abb. 252 | Siedlung/Turtkul Karakemer. Zerstörte Südseite. Schnittstelle von W 
tungen ausgerichtet wurden. Das Turtkul ist von einem Wall begrenzt. Vom Wall, der ursprünglich die gesamte Siedlungsfläche umschloss, sind nur die Ostseite (49 m lang), Teile von Nord- (I5 $\mathrm{m}$ lang) und Südseite (I2 m lang), die je im rechten Winkel zur Ostseite nach Westen anschließen, übrig geblieben. Die Breite des Schutzwalls beträgt I4 m, die Höhe 2 m. Im inneren Bereich der Siedlungsfläche wurden keine Spuren von Bauten festgestellt. Auf der Südostecke des Walls befinden sich einige moderne, muslimische Gräber.

Sowohl im „Innenraum“ des Turtkuls als auch auf dem Schutzwall wurden Scherben (Abb. 253) aufgelesen. Es handelt sich um Keramik von unterschiedlichen Gefäßen, die der Früheisenzeit bis zum frühen Mittelalter zugeordnet werden können.
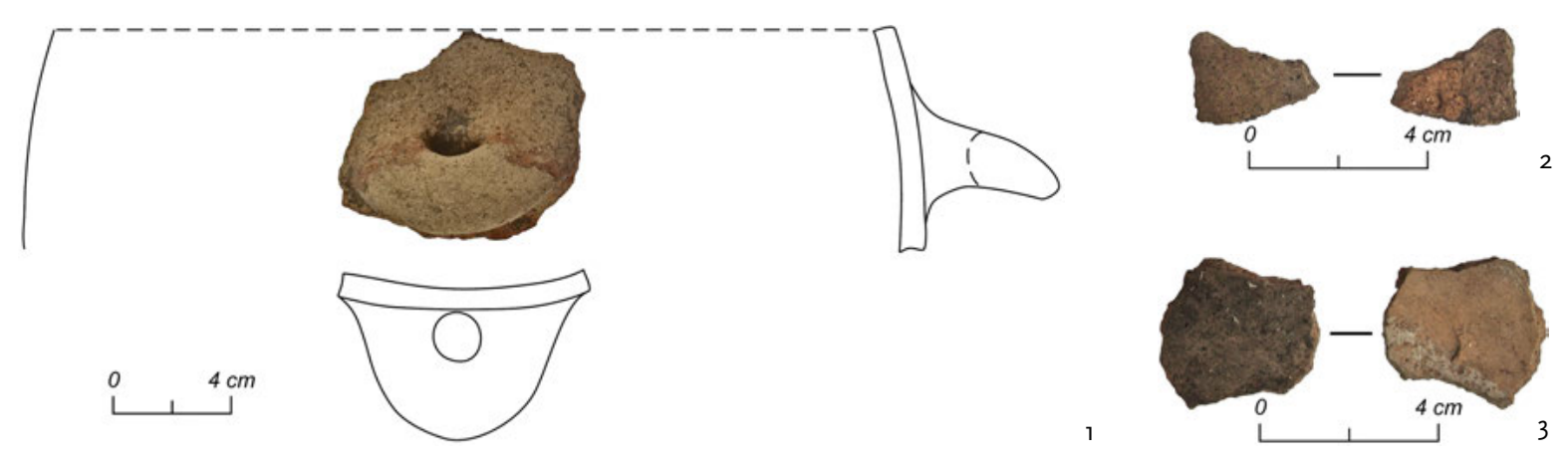

Abb. 253 | Siedlung/Turtkul Karakemer. Lesefunde (Zeichnung M.-R. Boroffka)

Charakteristik der Lesefunde

I. Henkel 9,0 ×6,5 ×6,5 cm; RDm ca. $28 \mathrm{~cm}$; außen gelb-beige, innen rotorange; mittelgrob gemagert mit viel Sand; verstrichen; handgemacht; Zeitstellung: ältere Eisenzeit bis frühes Mittelalter.

2. Wandscherbe $2, \mathrm{I} \times \mathrm{I}, 9 \times 0,6 \mathrm{~cm}$; rot bis hellbraun; mittelfein gemagert mit großen Sandpartikeln; scheibengedreht; Zeitstellung: ältere Eisenzeit.

3. Wandscherbe 3,3 $\times 3, \mathrm{I} \times 0,8 \mathrm{~cm}$; außen grau-braun, innen rot; mittelfein gemagert mit großen Sandpartikeln; scheibengedreht; Zeitstellung: ältere Eisenzeit.

Forschungsgeschichte

Die Siedlung/Turtkul Karakemer wurde erstmals im Bericht von B. N. Dublickij im Jahre I939 erwähnt (Dublickij I939a, 2). Bei der Beschreibung des Gräberfeldes Turgen vermerkte er, dass 0,5 km nordöstlich des Dorfes Turgen, nahe am Flussufer die Überreste einer Befestigung gestanden hätten. Die viereckige Fläche sei mit einem Erdwall umgeben, in dessen Mitte sich drei kleine Erhebungen befänden. Im Sommer 1939 begutachtete A. N. Bernštam die Fundstelle erneut (Bernštam I94Ib, 6). Er vermerkte, dass die Befestigung durch die neugebaute Asphaltstraße zum Teil zerstört worden sei und dass während der Straßenbauarbeiten sehr viel Keramik an die Oberfläche gekommen sei. Die aufgelesenen Funde ähnelten den Funden aus der mittelalterlichen Siedlung Talgar. Anhand der äußeren Übereinstimmungen datierte Bernštam die Siedlungsstelle in das II.-I2. Jh. n. Chr. E. I. Ageeva erwähnte I960 die Siedlung Karakemer nur und bezeichnete sie als „Siedlung Kara-kemir“ (Ageeva I96ob, 6). Eine weitere Erwähnung der Fundstelle erfolgte im Jahre I994. T. V. Savel'eva nennt den Fundort „Siedlung Turgen“ (Savel'eva I994, 48). Sie wiederholte weitgehend die Beschreibung von Bernštam und datierte sie ebenso in das II.-I2. Jh. n. Chr. Bajpakov u. a. beschreiben ebenso die „Siedlung Turgen“, jedoch datierten sie die Fundstelle in das I0.-I2. Jh. n. Chr (Bajpakov u.a. 2002, 30). 
Der Verfasser schlägt nach der chronologischen Analyse aufgelesener Keramik eine längere Nutzung der Siedlungsstelle vor, und zwar von der älteren Eisenzeit bis zum frühen Mittelalter (Gass 2oırb, 2I7-2I8).

Lit.: Ageeva I96ob, 2; Bajpakov u.a. 2002, 30; Bernštam I94Ib, 6; Dublickij I939a, 2; Gass 20IIb, 2I7-2I8, Abb. 22; Savel'eva I994, 48.

Siedlung Kotlovandy [FEZ] (Abb. 254-255; Karte 3 Nr. 30): ALT 2446 m N43 I4.735 E77 50.127; Gebiet Almaty (kasach. Алматы облысы), Enbekšikazachskij rajon (kasach. Еңбекшіқазақ ауданы); Ausmaß N-S I40 × O-W 2I7 m.

Die Siedlung Kotlovandy befindet sich direkt in den Bergen des TransiliAlatau (kasach. Іле Алатауы), in der Westhälfte des Hochbergtals Asy (kasach. Асы), im Bereich der alpinen Wiesen, oberhalb der Bergwaldgrenze. Die Siedlungsstelle liegt auf einer südlichen Terrasse des Berghanges und ist von drei Seiten durch die Berge geschützt. Unmittelbar südlich davon befindet sich eine Wasserquelle. Der Siedlungsplatz ist $74 \mathrm{~km}$ östlich von der Stadt Almaty (kasach. Алматы), 25,6 km südöstlich vom Dorf Turgen (kasach. Түрген) und I,2 $\mathrm{km}$ nördlich vom Zusammenfluss der Bäche Oj-Džajljau (kasach. Ой-Жайлау) und Kyzylbulak (kasach. Қызылбұлақ) entfernt.

Die im Plan eher ovale, von Westen nach Osten ausgedehnte Siedlungsstelle zeigte an der heutigen Oberfläche ca. I4

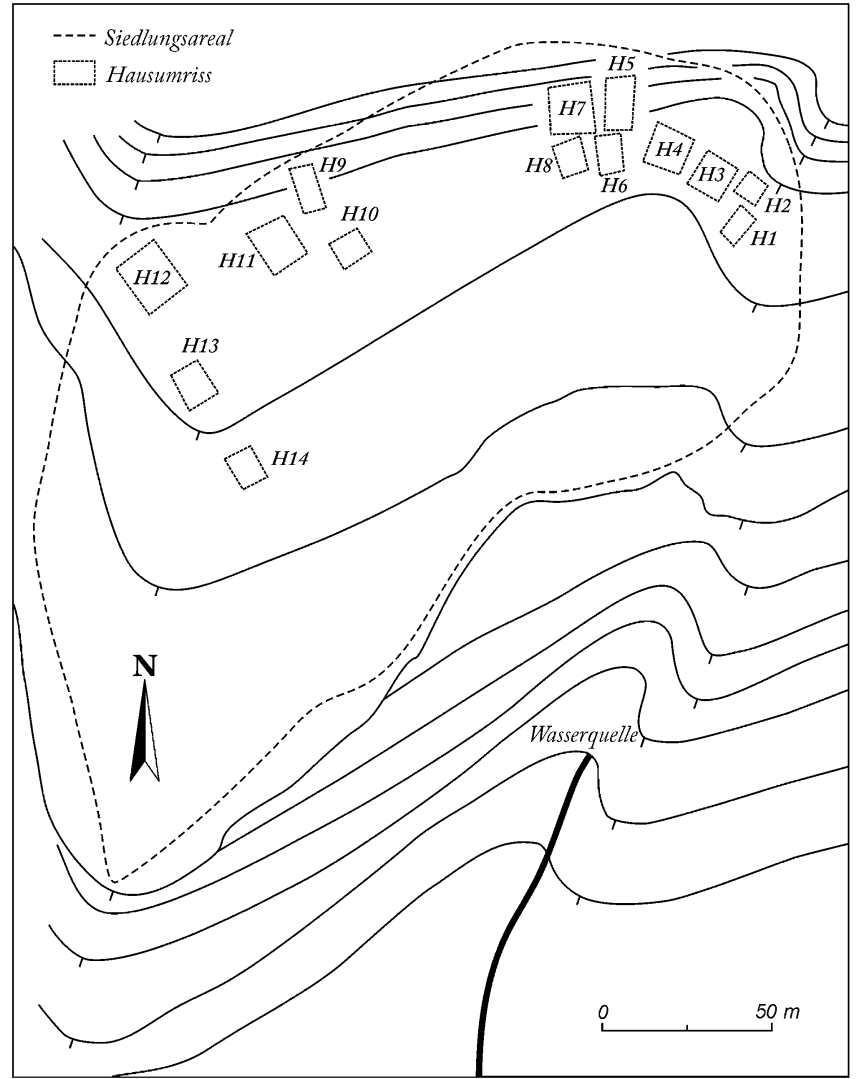

Abb. 254 | Lageskizze der Siedlung Kotlovandy (z.T. nach Bajpakov u.a. 2005a, 224) rechteckige Gruben oder in den Berghang eingegrabene, planierte, rechteckige Flächen. Sowohl die Gruben als auch die planierten Flächen wurden zusätzlich entlang ihrer äußeren Grenze durch einzelne Steinreihen markiert. Diese Steinreihen gehören möglicherweise zu den Fundamentresten der Bauten. Wahrscheinlich handelt es sich hier um Halbgrubenhäuser (russ. poluzemljanki). Sie bilden zwei Konzentrationen (eine westliche und eine östliche), die wiederum aus zwei oder drei Häuserreihen bestehen, die dem Verlauf der Bergterrasse folgen. Dementsprechend ist die Ausrichtung der Baukonstruktionen in der West- und Osthälfte unterschiedlich. Die Bauten der Westhälfte sind überwiegend NNW-SSO ausgerichtet und die Konstruktionen der Osthälfte N-S bis NO-SW.

Die genaue Zahl der Bauten und der Hausreihen kann erst durch eine Ausgrabung der Siedlung geklärt werden. 


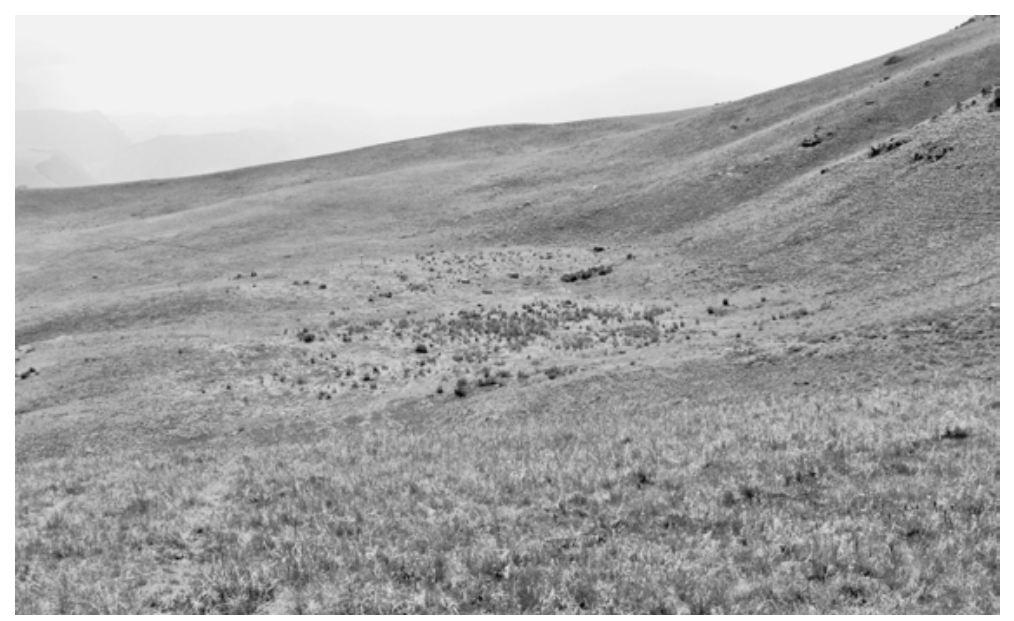

Abb. 255 | Siedlung Kotlovandy. Übersicht. Blick von O

Charakteristik der „Häuser“:

Östliche Gruppe

\section{Haus I}

Lage: N43 I4.737 E77 50.214; SO Haus der Gruppe Maße: $10,4 \times 6,3 \mathrm{~m}$

Form: rechteckige, ca. o,2 $\mathrm{m}$ tiefe Grube

Ausrichtung: NO-SW

Sonstiges: Hausgrube von einzelnen, mittelgroßen Steinen des Hausfundamentes (?) umrandet

Deutung: Halbgrubenhaus (russ. poluzemljanka)

\section{Haus 2}

Lage: N43 I4.742 E77 50.218; N des Hauses I, in unmittelbarer Nähe

Maße: $8 \times 6,3 \mathrm{~m}$

Form: rechteckige, ca. $\circ, 2 \mathrm{~m}$ tiefe Grube

Ausrichtung: NO-SW

Sonstiges: Hausgrube von einzelnen, mittelgroßen Steinen des Hausfundamentes (?) umrandet

Deutung: Halbgrubenhaus (russ. poluzemljanka)

\section{Haus 3}

Lage: N43 I4.743 E77 50.208; W von Haus 2, in unmittelbarer Nähe

Maße: I2 $\times$ IO m

Form: rechteckige, ca. o,2 $\mathrm{m}$ tiefe Grube

Ausrichtung: NO-SW

Sonstiges: Hausgrube von einzelnen, mittelgroßen Steinen des Hausfundamentes (?) umrandet

Deutung: Halbgrubenhaus (russ. poluzemljanka)

\section{Haus 4}

Lage: N43 I4.747 E77 50.200; W von Haus 3, in unmittelbarer Nähe

Maße: $\mathrm{I} 2,5 \times 10,4 \mathrm{~m}$
Form: rechteckige, ca. 0,2 $\mathrm{m}$ tiefe Grube auf einer planierten, in den Berghang eingegrabenen Fläche Ausrichtung: NO-SW

Deutung: Halbgrubenhaus (russ. poluzemljanka)

Haus 5

Lage: N43 I4.754 E77 50.I92; NW von Haus 4

Maße: $16,6 \times 8 \mathrm{~m}$

Form: rechteckige, ca. $0,2 \mathrm{~m}$ tiefe Grube auf einer planierten, in den Berghang eingegrabenen Fläche

Ausrichtung: N-S

Sonstiges: Hausgrube von einzelnen, mittelgroßen Steinen des Hausfundamentes (?) umrandet

Deutung: Halbgrubenhaus (russ. poluzemljanka)

Haus 6

Lage: N43 I4.748 E77 50.I88; S von Haus 5, in unmittelbarer Nähe

Maße: 10,4 × 6,3 m

Form: rechteckige, ca. $0,3 \mathrm{~m}$ tiefe Grube

Ausrichtung: N-S

Sonstiges: Hausgrube von einzelnen mittelgroßen Steinen des Hausfundamentes (?) umrandet

Deutung: Halbgrubenhaus (russ. poluzemljanka)

\section{Haus 7}

Lage: N43 I4.755 E77 50.I80; W von Haus 5, in unmittelbarer Nähe

Maße: $14,6 \times \mathrm{I} 2,5 \mathrm{~m}$

Form: rechteckige, ca. $0,3 \mathrm{~m}$ tiefe Grube auf einer planierten, in den Berghang eingegrabenen Fläche

Ausrichtung: N-S

Sonstiges: Hausgrube von einzelnen mittelgroßen Steinen des Hausfundamentes (?) umrandet Deutung: Halbgrubenhaus (russ poluzemljanka) 
Haus 8

Lage: N43 I4.748 E77 50.I80; W von Haus 6 und S von

Haus 7 , in unmittelbarer Nähe

Maße: $\mathrm{IO}, 4 \times 8 \mathrm{~m}$

Form: rechteckige, ca. $0,2 \mathrm{~m}$ tiefe Grube

Ausrichtung: N-S

Sonstiges: Hausgrube ist von einzelnen mittelgroßen Steinen des Hausfundamentes (?) umrandet

Deutung: Halbgrubenhaus (russ. poluzemljanka)

Westliche Gruppe

\section{Haus 9}

Lage: N43 I4.744 E77 50.I2I; nördlichster Bau der Gruppe

Maße: $12,5 \times 6,3 \mathrm{~m}$

Form: rechteckige, ca. $\bigcirc, 4 \mathrm{~m}$ tiefe Grube auf einer planierten, in den Berghang eingegrabenen Fläche

Ausrichtung: NNW-SSO

Sonstiges: Hausgrube von einzelnen mittelgroßen und großen Steinen des Hausfundamentes (?) umrandet Deutung: Halbgrubenhaus (russ. poluzemljanka)

Haus Io

Lage: N43 I4.735 E77 50.I27; östlichster Bau der Gruppe

Maße: $10,4 \times 8 \mathrm{~m}$

Form: rechteckige, ca. $০, 2 \mathrm{~m}$ tiefe Grube

Ausrichtung: NW-SO

Sonstiges: Hausgrube von einzelnen mittelgroßen Steinen des Hausfundamentes (?) umrandet

Deutung: Halbgrubenhaus (russ. poluzemljanka)
Haus II

Lage: N43 I4.737 E77 50.II4

Maße: $15 \times 12,5 \mathrm{~m}$

Form: rechteckige, ca. $\circ, 2 \mathrm{~m}$ tiefe Grube

Ausrichtung: NW-SO

Sonstiges: Hausgrube von einzelnen großen und mittelgroßen Steinen des Hausfundamentes (?) umrandet Deutung: Halbgrubenhaus (russ. pluzemljanka)

Haus 12

Lage: N43 I4.73I E77 50.084; westlichster Bau der Gruppe

Maße: I7 × I5 m

Form: rechteckige, ca. $0,2 \mathrm{~m}$ tiefe Grube auf einer planierten, in den Berghang eingegrabenen Fläche

Ausrichtung: NW-SO

Deutung: Halbgrubenhaus (russ. poluzemljanka)

Haus 13

Lage: N43 I4.7I4 E77 50.096

Maße: $\mathrm{I} 2,5 \times 8 \mathrm{~m}$

Form: rechteckige, ca. $0,2 \mathrm{~m}$ tiefe Grube

Ausrichtung: NW-SO

Sonstiges: Hausgrube von einzelnen großen und mittelgroßen Steinen des Hausfundamentes (?) umrandet Deutung: Halbgrubenhaus (russ. poluzemljanka)

Haus 14

Lage: N43 I4.70I E77 50.Io6; südlichster Bau der Gruppe

Maße: $10,5 \times 8 \mathrm{~m}$

Form: rechteckige, ca. $\circ, 2 \mathrm{~m}$ tiefe Grube

Ausrichtung: NW-SO

Sonstiges: Hausgrube von einzelnen großen und mittelgroßen Steinen des Hausfundamentes (?) umrandet

Deutung: Halbgrubenhaus (russ. poluzemljanka)

Die Grundrisse der Bauten der Osthälfte der Siedlungsfläche befinden sich wesentlich näher beieinander als die Häuser der Westhälfte. Dies kann durch den besseren Erhaltungszustand dieses Bereiches erklärt werden.

Zudem kann es auch sein, dass die Gruben der Häuser und die rechteckigen, planierten Flächen der Bauten zu einer größeren Konstruktion gehören, so dass es sich hier um einen komplexeren Bautyp handelt. Dies kann erst nach einer Ausgrabung geklärt werden.

Obwohl keine datierenden Lesefunde an der Oberfläche der Siedlung gefunden wurden, kann anhand ähnlicher Siedlungen mit identischer Bauweise und Hausorientierung innerhalb der Siedlungsfläche vermutet werden, dass dieser Wohnplatz zum sakischen Kulturkreis gehört.

Forschungsgeschichte und Bemerkungen

Die Siedlung Kotlovandy wurde im Laufe einer Revision der archäologischen Bodendenkmäler im Rajymbekskij rajon des Gebietes Almaty im Jahre 2004 vom Turgen-Forschungsteam der Almaty SurveyExpedition (APAЭ) unter der Leitung von A. Gorjačev entdeckt (Bajpakov u.a. 2005a, 223-224). Es wurden eine Beschreibung und ein topographischer Plan der Siedlungsfläche hergestellt. Jedoch wurden die Hausgrundrisse nicht dokumentiert. Man beschrieb sie lediglich und zählte 25-27 Hausgru- 
ben ${ }^{662}$. Ferner fand man an der Oberfläche einige Knochensplitter und fragmentarisch erhaltene Keramik, die für die ältere Eisenzeit des südöstlichen Siebenstromlandes typisch ist ${ }^{663}$.

Lit.: Bajpakov u.a. 2005a, 223-224; Mar'jašev/Gorjačev 2009b, Foto 7.

Siedlung Krasnyj Vostok [FEZ bis frühes Mittelalter] (Abb. 256; Karte 3 Nr. I3): ALT 903 m N43 22.095 E77 22.996; Gebiet Almaty (kasach. Алматы облысы), Enbekšikazachskij rajon (kasach. Еңбекшіқазақ ауданы); Ausmaß N-S $274 \times$ O-W $205 \mathrm{~m}$.

Die Siedlungsstelle befindet sich in den nördlichen Ausläufern des Lösshügellandes der Nordseite der Bergkette Transili-Alatau (kasach. Іле Алатауы) und wird sowohl von Westen als auch von Osten durch zwei kleine Bäche begrenzt. Der Siedlungsplatz Krasnyj Vostok liegt $40 \mathrm{~km}$ ostnordöstlich der Stadt Almaty (kasach. Алматы), 6,6 km westlich der Stadt Issyk (kasach. Ecik), am südwestlichen Rand des namengebenden Dorfes (russ. Красный Восток). Die Siedlung ist I,I km östlich der ähnlichen Siedlung Rachat und 2,6 km südlich des Gräberfel-

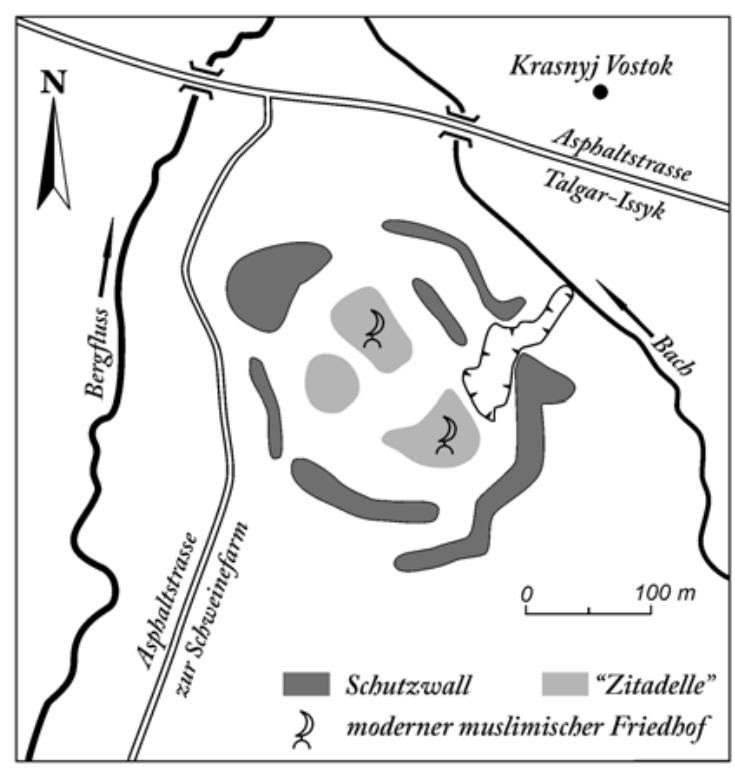

Abb. 256 | Siedlung Krasnyj Vostok. Lageskizze des Issyk platziert.

Die Siedlungsstelle weist eine eher ovale Form mit einem Durchmesser zwischen $205 \times 274 \mathrm{~m}$ auf und dehnt sich von Norden nach Süden aus. „Im mittleren Bereich befinden sich drei zitadellenartige Erhebungen, die ein Dreieck bilden. Alle haben eine abgeflachte Kuppe“ (Gass 20Irb, 2I9). Die „nördliche Zitadelle" hat ein Ausmaß von $69 \times 39$ m und eine eher rechteckige Form, die Nordwest-Südost ausgerichtet ist. Darauf befindet sich heute ein moderner muslimischer Friedhof. Die „südwestliche Zitadelle" ist die kleinste. Sie hat eine rundliche Form mit einem Durchmesser von $45 \mathrm{~m}$. Auf ihrer Kuppe befinden sich drei bis zu einem Meter hohe, rundliche Erhebungen (Abb. 257), die einen Durchmesser von 5-6 m aufweisen. Sie können als Überreste von Bauten gedeutet werden. Die „südöstliche Zitadelle" besitzt die Form eines Halbkreises und hat ein Ausmaß von 53 m (NW-SO) × 64 m (NO-SW). Auf der Kuppe dieses Hügels befindet sich der Rest des modernen muslimischen Friedhofes. Alle drei „Zitadellen“ haben die gleiche Höhe von ca. 20 m. Sie waren von einer Mauer oder einem Schutzwall umgeben. Diese Anlagen sind durch die Nachbearbeitung des Systems von Erosionsschluchten entstanden, in dem die Seiten des Walls begradigt und erhöht wurden. „Auf den Verteidigungsmauern befinden sich einige Erhebungen, welche eventuell als Wachtürme angesprochen werden können“ (Gass 20IIb, 2I9). Die östlich und westlich vom Siedlungsplatz fließenden Bäche boten der Siedlung einen natürlichen Schutz. Die südliche Seite war durch Berge geschützt. Nur an der nördlichen Seite wurde zusätzlich eine 5-7 $\mathrm{m}$ hohe Verteidigungsmauer angelegt, da hier keine natürliche Barriere vorhanden war.

662 Während des Topoi Surveys im Sommer 2009 wurden auf der Fundstelle mehrere Gruben festgestellt, jedoch nur bei I4 von ihnen kann man mit gewisser Überzeugung von Hausgruben sprechen.
663 Es gibt keine Abbildungen oder weiteren Beschreibungen von der erwähnten Keramik. Während des Topoi Surveys im Sommer 2009 wurde keine Keramik an der Oberfläche gefunden. 


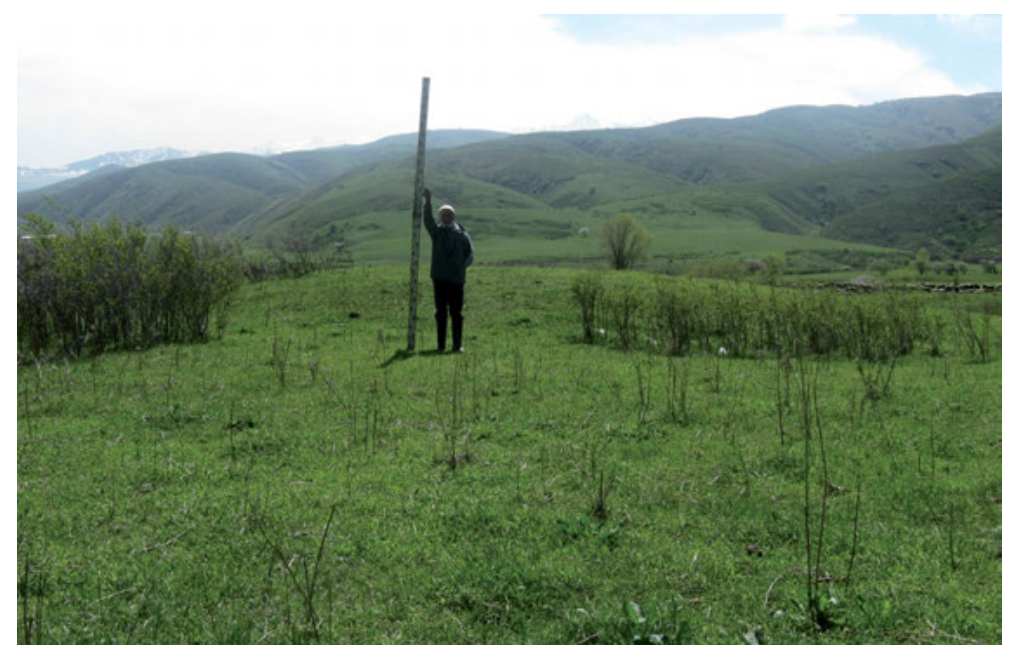

Abb. 257 | Siedlung Krasnyj Vostok. Rundliche Erhebung auf der südwestlichen Kuppe. Blick von W

Die Breite der Schutzwälle beträgt im oberen Bereich, also auf der südlichen Seite, Io bis I5 $\mathrm{m}$ und 3-5 Meter im Westen und Norden. Alle Schutzmauern verjüngen sich nach oben. Der östliche Bereich der Siedlungsstelle knüpft an die Erosionsschluchten an. Die genaue Grenze der Siedlung kann nicht exakt festgestellt werden.

Auf der Oberfläche des Siedlungsareals wurden Scherben aufgelesen. Das Fundmaterial (Abb. 258) weist eine chronologische Streuung von der älteren Eisenzeit bis zum frühen Mittelalter auf.

Charakteristik der Lesefunde

I. Wandscherbe 6,0 ×3,8 $\times 0,9 \mathrm{~cm}$; rot bis orange, innere Schicht hellgrau; mittelgrob gemagert; scheibengedreht; Zeitstellung: ältere Eisenzeit bis frühes Mittelalter.

2. Wandscherbe 4,6 ×3,5 ×0,9 cm; rot bis orange, innere Schicht hellgrau; mittelgrob gemagert; scheibengedreht; Zeitstellung: ältere Eisenzeit bis frühes Mittelalter.

3. Wandscherbe 3,2 $\times 3,4 \times 0,8 \mathrm{~cm}$; rot bis orange, innere Schicht hellgrau; mittelgrob gemagert mit einzelnen großen Sandpartikeln; scheibengedreht; Zeitstellung: ältere Eisenzeit bis frühes Mittelalter.
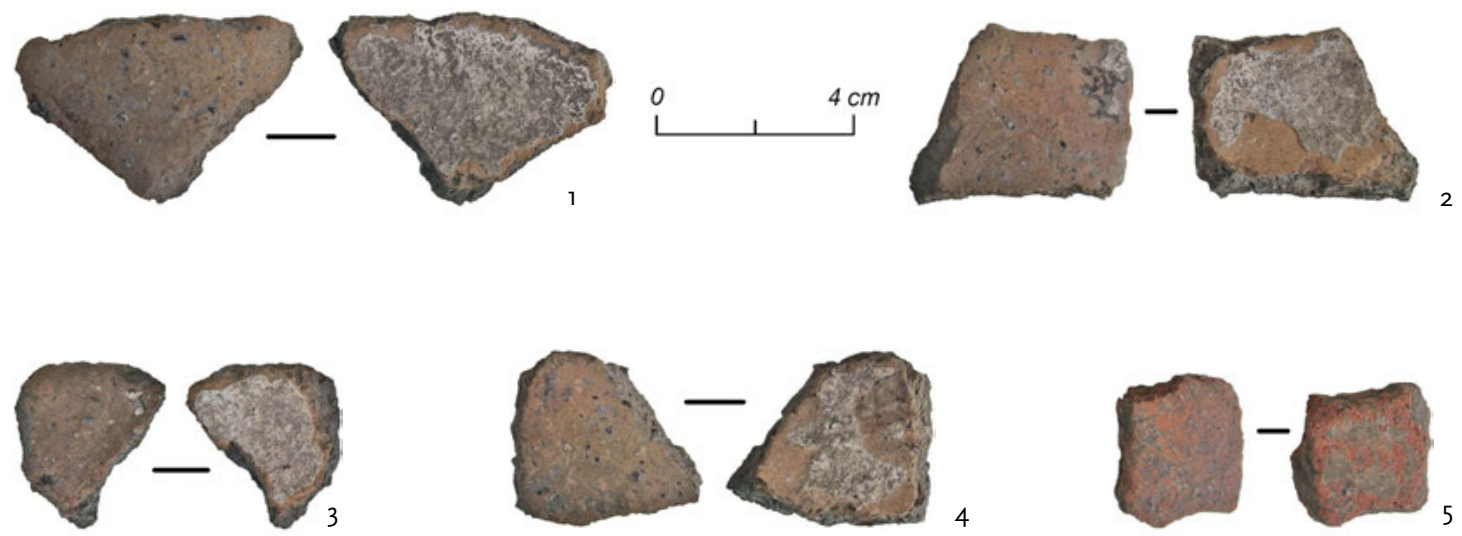

Abb. 258 | Siedlung Krasnyj Vostok. Lesefunde. 
4. Wandscherbe 4,I × 3,8 $\times$ I,O cm; rot bis orange, innere Schicht hellgrau; mittelgrob gemagert mit einzelnen großen Sandpartikeln; scheibengedreht; Zeitstellung: ältereEisenzeit bis frühes Mittelalter.

5. Wandscherbe 2,6 $\times 2,9 \times 0,6 \mathrm{~cm}$; rot bis dunkelrot, innere Schicht dunkelgrau; grob gemagert; scheibengedreht (?); Zeitstellung: frühes Mittelalter.

Forschungsgeschichte

T. V. Savel'eva erwähnte die Siedlung Krasnyj Vostok zuerst (Savel'eva I994, 47-48) als I25 × I25 m große Siedlung Issyk. Anhand der Lesefunde, die durch Fragmente von Vorratsgefäßen, einem keramischen Kessel, Krüge und Schüsseln mit durchsichtiger Aufgußglasur, die auf einer weißen Engobe aufgetragen worden ist, repräsentiert werden, ordnete sie die Siedlungsstelle dem Io.-I2. Jh. n Chr. zu.

K. M. Bajpakov und B. N. Nurmuchanbetov untersuchten im Jahr 1999 die Fundstelle erneut und schlugen anhand neuer keramischer Lesefunde eine Datierung von der älteren Eisenzeit bis zum Mittelalter vor (Bajpakov/Nurmuchanbetov 2000, I5) ${ }^{664}$. Ihrer Meinung nach, sei die erste Etappe der Siedlung mit den Trägern der sakischen Kultur verbunden (Bajpakov/Nurmuchanbetov 2000, I5-16). Sie spiele zu dieser Zeit die Rolle eines Zufluchtsortes und eines politischen Zentrums. Diese Rolle übernähme sie auch in der darauf folgenden jüngeren Periode der Eisenzeit, der Wusun-Periode und im Mittelalter.

Lit.: Bajpakov/Nurmuchanbetov 2000, I4; Gass 20IIb, 219, Abb. 25-27; Gass (im Druck); Savel'eva I994, 47-48.

Siedlung Kyzylbulak-2 [FEZ] (Abb. 259-260; Karte 3 Nr. 34): ALT 2475 m N43 I2.990 E77 51.942; Gebiet Almaty (kasach. Алматы облысы), Enbekšikazachskij rajon (kasach. Еңбекшіқазақ ауданы); Ausmaß NW-SO II3 $\times$ NO-SW $40 \mathrm{~m}$.

Die Siedlung Kyzylbulak-2 befindet sich direkt in den Bergen des Transili-Alatau (kasach. Іле Алатауы), im Bereich der alpinen Wiesen, oberhalb der Bergwaldgrenze, auf einer südlichen Terrasse des Hanges einer Bergkuppe, die ins Tal des Baches Kyzylbulak (kasach. Қызылбұлақ) abfällt. Allein durch die naturräumlichen Bedingungen ist die Siedlungsstelle von drei Seiten durch die Berge geschützt. Unmittelbar süd-südwestlich davon verläuft der Bach. Der Siedlungsplatz liegt $77 \mathrm{~km}$ östlich der Stadt Almaty (kasach. Алматы) und 29,6 km südöstlich vom Dorf Turgen (kasach. Түрген).

Die im Plan von NW nach SO ausgedehnte Siedlungsstelle weist ca. acht rechteckige Gruben auf, die an der heutigen Oberfläche noch sichtbar sind. Sie stellen in den Berghang eingelassene, planierte, rechteckige Flächen dar, die man als Überreste von Halbgrubenhäusern (russ. poluzemljanki)

664 Dieselbe Meinung vertritt auch der Verfasser (Gass 20IIb, 2I9; Gass, im Druck).

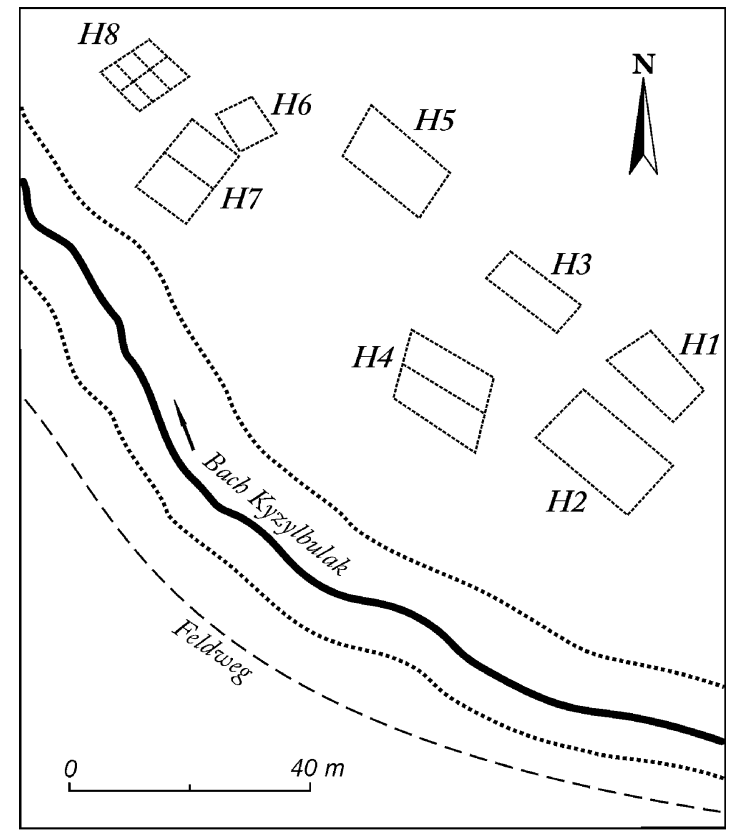

Abb. 259 | Lageskizze der Siedlung Kyzylbulak-2 
deuten kann. Die Baukonstruktionen bilden zwei Hausreihen, die dem Verlauf der Bergterrasse von Nordwesten nach Südosten folgen. Die Ausrichtung der Konstruktionen ist unterschiedlich. Die einfachen, rechteckigen Gruben in der Osthälfte sind NW-SO ausgerichtet. In der Westhälfte sind solche Hausgruben von Nordosten nach Südwesten ausgerichtet. Zudem verläuft durch die Mitte des Hauses 4 und quer durch die Mitte des Hauses 7 eine Erdwand (Breite ca. 0,5 m), so dass diese Bauten aus zwei Parzellen bestehen. Bei Haus 8 handelt es sich um sechs fast quadratische kleine Kammern, die in Zweierreihen nebeneinander angeordnet sind und die durch ähnliche Erdwände voneinander getrennt sind.

Die genaue Zahl der Bauten kann nur durch die Ausgrabung der Siedlung geklärt werden.

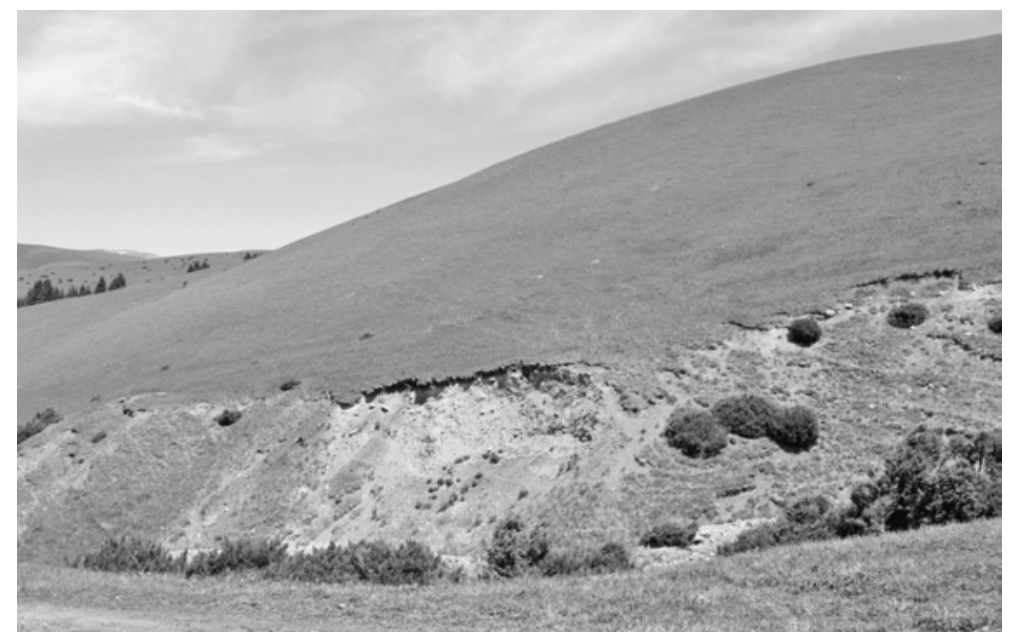

Abb. 260 | Siedlung Kyzylbulak-2. Übersicht. Blick von SO

Charakteristik der „Häuser“:

\section{Haus I}

Lage: N43 I2.97I E77 51.970

Maße: $16 \times 9 \mathrm{~m}$

Form: rechteckige, ca. $0,5 \mathrm{~m}$ tiefe Grube

Ausrichtung: NW-SO

Deutung: Halbgrubenhaus (russ. poluzemljanka)

\section{Haus 2}

Lage: N43 12.966 E77 51.964

Maße: $\mathrm{I} 7 \times \mathrm{I} 3 \mathrm{~m}$

Form: rechteckige, ca. $0,3 \mathrm{~m}$ tiefe Grube

Ausrichtung: NW-SO

Deutung: Halbgrubenhaus (russ poluzemljanka)

Haus 3

Lage: N43 I2.980 E77 51.954

Maße: $15 \times 5 \mathrm{~m}$

Form: rechteckige, ca. $0,3 \mathrm{~m}$ tiefe Grube

Ausrichtung: NW-SO

Deutung: Halbgrubenhaus (russ. poluzemljanka)

\section{Haus 4}

Lage: N43 I2.973 E77 51.947

Maße: I3 × II m
Form: rechteckige, fast quadratische $0,5 \mathrm{~m}$ tiefe Grube Ausrichtung: NW-SO

Sonstiges: Durch die Mitte der Konstruktion verläuft eine Erdwand (B ca. O,5 m), die ebenso NW-SO ausgerichtet ist; es kann hier um die Reste einer Trennwand handeln.

Deutung: zweiteiliges Halbgrubenhaus (russ. poluzemljanka)

\section{Haus 5}

Lage: N43 I2.990 E77 51.942

Maße: $16 \times 8 \mathrm{~m}$

Form: rechteckige, ca. $0,3 \mathrm{~m}$ tiefe Grube

Ausrichtung: NW-SO

Deutung: Halbgrubenhaus (russ. poluzemljanka)

Haus 6

Lage: N43 I2.995 E77 51.923

Maße: $7 \times 5 \mathrm{~m}$

Form: rechteckige, fast quadratische, o,4 $\mathrm{m}$ tiefe Grube einer planierten, in den Berghang eingegrabene Fläche Ausrichtung: NW-SO

Deutung: Halbgrubenhaus (russ. poluzemljanka) 
Haus 7

Lage: N43 I2.99I E77 51.9I4

Maße: I5,5 × IO $\mathrm{m}$

Form: rechteckige, ca. $0,5 \mathrm{~m}$ tiefe Grube

Ausrichtung: NO-SW

Sonstiges: Quer durch die Mitte der Konstruktion ver-

läuft eine Erdwand (B ca. $0,5 \mathrm{~m}$ ); es kann sich hier um

die Reste einer Trennwand handeln.

Deutung: zweiteiliges Halbgrubenhaus (russ. Poluzemljanka)

\author{
Haus 8 \\ Lage: N43 I2.999 E77 51.909 \\ Maße: $10 \times 7 \mathrm{~m}$ \\ Form: rechteckige, ca. $0,5 \mathrm{~m}$ tiefe Grube einer planier- \\ ten, in den Berghang eingegrabenen Fläche \\ Ausrichtung: NO-SW \\ Sonstiges: Die Hausgrube ist durch SW-NO und zwei \\ NW-SO verlaufende Erdwände in sechs fast quadrati- \\ sche (I,O-I,2 × I,O-I,2 m) Parzellen unterteilt. \\ Deutung: sechsteilige Baukonstruktion (?) [russ. Polu- \\ zemljanka]
}

Es kann jedoch auch sein, dass die Gruben der Häuser zu einer größeren Konstruktion gehören, so dass es sich hier um einen komplexeren Bautyp handelt. Diese Frage kann nur die Ausgrabung der Befunde klären.

Obwohl keine datierenden Lesefunde an der Oberfläche der Siedlung gemacht wurden, kann die Siedlung aufgrund analoger Fundstellen mit ähnlicher Befundlage der älteren Periode der Eisenzeit zugeordnet werden.

Forschungsgeschichte

Die Siedlung Kyzylbulak-2 wurde im Jahre 1996 im Laufe eines Surveys der archäologischen Siebenstromland-Expedition (CAЭ) unter der Leitung von A. Mar'jašev und A. Gorjačev entdeckt (Mar'jašev/ Gorjačev 2008, 6) und in einen archäologischen Komplex bronzezeitlicher Bodendenkmäler eingegliedert665. Eine weitere Untersuchung der Siedlung erfolgte im Jahre 2004 im Zuge einer Revision der archäologischen Bodendenkmäler im Rajymbekskij rajon des Gebietes Almaty durch das Turgen-Forschungsteam der Almaty Survey-Expedition (APAЭ) unter der Leitung von A. Gorjačev (Bajpakov u.a. 2005a, 202-203). Es wurden eine Beschreibung und skizzenhaft die topographische Ausdehnung der Siedlungsfläche aufgenommen. Anhand von Vergleichen zu topographischer Lage und innerer Struktur der Fundstelle mit anderen Siedlungen des südöstlichen Siebenstromlandes wurde dieser Wohnplatz der älteren Periode der Eisenzeit zugeordnet (Bajpakov u.a. 2005a, 202).

Lit.: Bajpakov u.a. 2005a, 202-203; Gorjačev 2004, 20; Mar’jašev/Gorjačev 2008, 6.

Siedlung Kyzyl-Gajrat [FEZ - frühtürkische Periode] (Abb. 26r; Karte 3 Nr. 8): ALT 947 m N43 I8.339 E77 Iо.o66; Gebiet Almaty (kasach. Алматы облысы), Talgarskij rajon (kasach. Талғар ауданы); Ausmaß N-S I73 $\times$ O-W $79 \mathrm{~m}$.

Die Siedlung Kyzyl-Gajrat befindet sich im Flachland, nördlich der nordöstlichen Ausläufer der Berge Kotyrbulak (kasach. Қотырбұлақ), die zur Bergkette Transili-Alatau (kasach. Іле Алатауы) gehören. Die Fundstelle liegt auf einem niedrigen Hügel, der durch einen sanften Anstieg der Ebene gen Norden wesentlich höher als im Süden erscheint. Diese Erhebung ist im Osten von einem Bach umgeben, westlich liegt ein ausgetrocknetes Flussbett. Diese Lage verschaffte der Siedlung einen natürlichen Schutz und somit einen strategischen Vorteil. Der Fundort liegt 2I km östlich der Stadt Almaty (kasach. Алматы), I,2 km westlich des Dorfes Kyzyl-Kajrat (kasach. Қызыл Қайрат), bzw. 0,5 km westlich von dessen Dorfgrenze, und an der Ostgrenze des Dorfes Taldybulak (kasach. Талдыбұлақ). Unmittelbar südlich der Siedlung (25 m entfernt) verläuft die Asphaltstraße Almaty-Talgar (kasach. Талғар).

$665 \mathrm{Zu}$ diesem Komplex gehören nach der Meinung der Forscher auch die Siedlungen - Turgen 2 und Kyzylbulak I, sowie die Gräberfelder - Kyzylbulak I, Kyzylbulak 2 und Kyzylbulak 4 (Mar'jašev/Gorjačev 2008, 6). 
Die Siedlungsstelle nimmt die gesamte Hügelkuppe ein und ist komplett durch einen modernen muslimischen Friedhof überbaut. Die Form der Siedlungsfläche Kyzyl-Gajrat orientiert sich an der dreieckigen Form des Hügels und ist von Süden nach Norden ausgedehnt. In der Mitte der Siedlungsfläche zeigt sich eine Befestigungsanlage (sog. Turtkul). Die Anlage ist fast quadratisch $(34 \times 29 \mathrm{~m})$, die Ecken sind an den vier Haupthimmelsrichtungen orientiert. Die viereckige Befestigung wird von einem ca. I,O-I,5 $\mathrm{m}$ hohen und 5,O-5,5 $\mathrm{m}$ breiten Schutzwall umgeben.

Sowohl im inneren Bereich der Befestigung als auch auf der übrigen Siedlungsfläche wurden keine Überreste von weiteren Bauten festgestellt.

Auf dem ganzen Siedlungsareal kamen Lesefunde (Abb. 262) zum Vorschein. Es handelt sich um Keramik, die eine chronologische Streuung von der Früheisenzeit bis zum frühen Mittelalter aufzeigt.

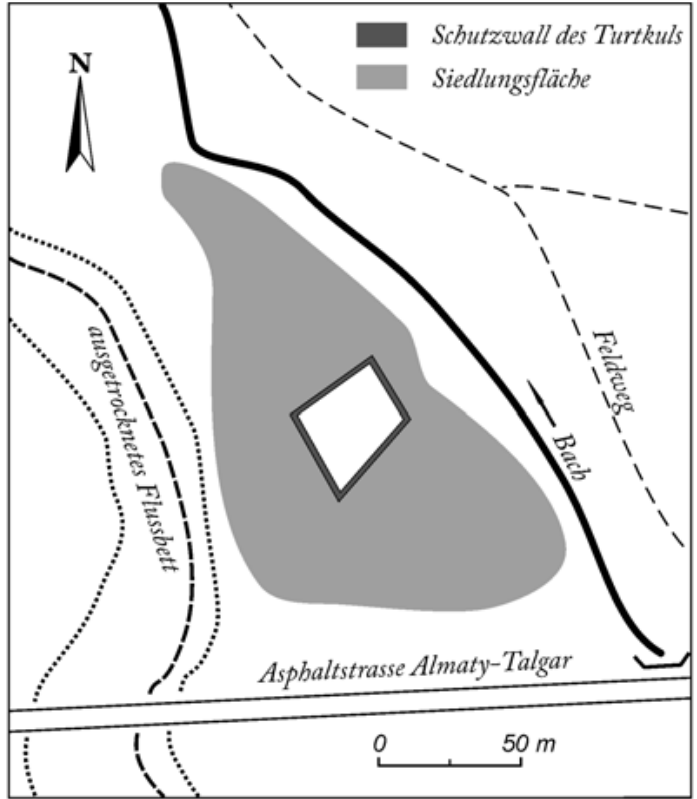

Abb. 261 | Lageskizze der Siedlung Kyzyl-Gajrat
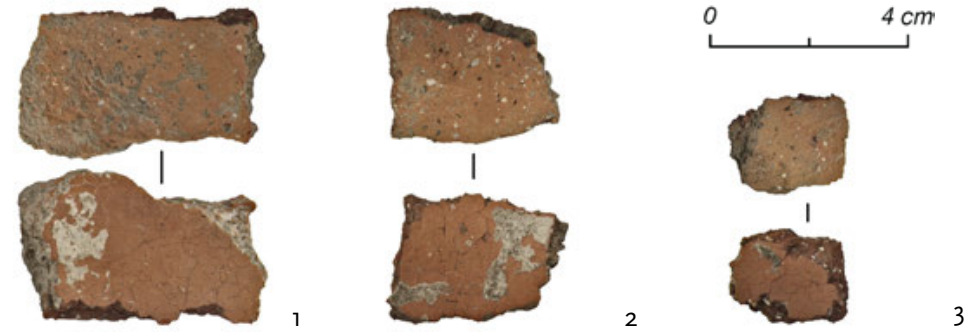

Abb. 262 | Kyzyl-Gajrat. Lesefunde

\section{Charakteristik der Lesefunde}

I. Wandscherbe $4,8 \times 3,0 \times 0,7 \mathrm{~cm}$; orange bis rotorange; mittelgrob gemagert mit viel Sand; verstrichen; handgemacht; Zeitstellung: ältere Eisenzeit bis frühes Mittelalter.

2. Wandscherbe $3,2 \times 2,3 \times 0,8 \mathrm{~cm}$; orange bis rotorange; mittelgrob gemagert mit viel Sand; verstrichen; handgemacht; Zeitstellung: ältere Eisenzeit bis frühes Mittelalter.

3. Wandscherbe $\mathrm{I}, 8 \times 2,0 \times 0,7 \mathrm{~cm}$; orange bis rotorange; mittelgrob gemagert mit viel Sand; verstrichen; handgemacht; Zeitstellung: ältere Eisenzeit bis frühes Mittelalter.

Forschungsgeschichte

T. V. Savel'eva beschrieb die Fundstelle im Jahre I994 (Savel'eva I994, 35). Sie erwähnte, dass das Turtkul an den Ecken noch sichtbare Erhebungen aufwies, die als Überreste der Wachtürme verstanden werden können, und dass sich in der Mitte des nordöstlichen Walls ein Eingangsbereich be- 
fand ${ }^{666}$. Die aufgesammelten Lesefunde stammten von keramischen Kesseln, von Krügen und von Vorratsgefäßen. Das Fundmaterial verglich sie mit den Funden aus den mittelalterlichen Schichten der Siedlung Talgar und datierte die Fundstelle Kyzyl-Gajrat in das II.-I2. Jh. n. Chr.

Lit.: Bajpakov u.a. 2002, 29; Savel'eva I994, 35 .

Siedlung Rachat [FEZ bis frühes Mittelalter] (Abb. 263-264; Karte 3 Nr. I2): ALT 905 m N43 22.033 E77 22.I57; Gebiet Almaty (kasach. Алматы облысы), Enbekšikazachskij rajon (kasach. Еңбекшіқазақ ауданы); Ausmaß N-S $297 \times$ O-W $353 \mathrm{~m}$.

Die Siedlungsstelle befindet sich auf den nördlichen Ausläufern des Lösshügellandes an der Nordseite der Bergkette Transili-Alatau (kasach. Іле Алатауы), am linken, westlichen Ufer des Rachat (kasach. Рахат), am Südostrand des gleichnamigen Dorfes. Der Siedlungsplatz liegt $39 \mathrm{~km}$ ostnordöstlich der Stadt Almaty (kasach. Алматы) und 7,7 km westlich der Stadt Issyk (kasach. Eciк). Die Siedlungsstelle ist I,I km westlich von einer ähnlichen Siedlung namens Krasnyj Vostok und 3,3 km südsüdwestlich vom

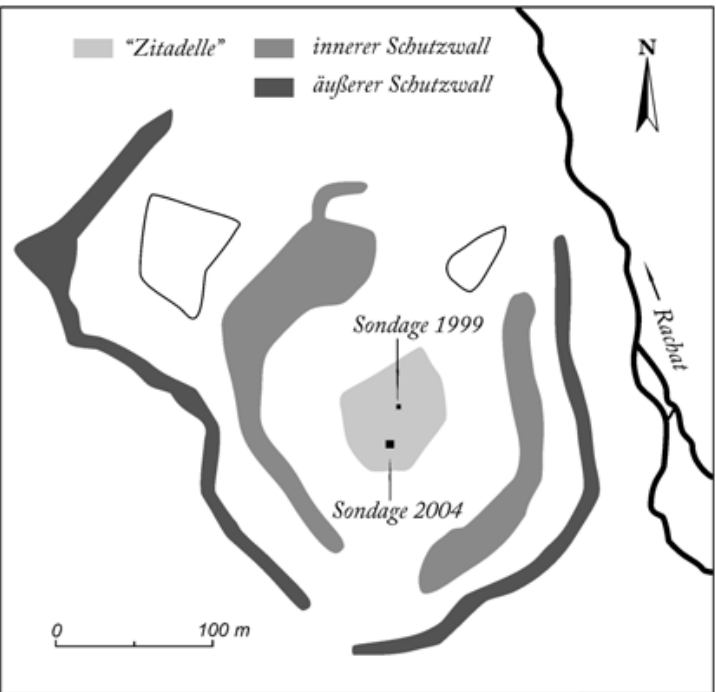

Abb. 263 | Siedlung Rachat. Plan Gräberfeld Issyk platziert.

Sie hat eine ovale, $353 \times 297 \mathrm{~m}$ große Form mit einer O-W Ausdehnung. In ihrer Mitte ist ein trapezförmiger Hügel („Zitadelle“?) zu erkennen, der im Süden io m über die erste Terrasse des Vorgebirges und im Norden $50 \mathrm{~m}$ über die Ebene emporragt. Der Hügel misst an der Basis $100 \times$ I20 m, die Kuppe ist kreisförmig und planiert mit einem Durchmesser von 6I m (Gass 20IIb, 2I8). Die Anlage ist von allen Seiten mit Erosionsschluchten umgeben. Diese Schluchten wurden begradigt und zusätzlich künstlich tiefer gelegt, so dass eine doppelte Wallanlage um die „Zitadelle“ bzw. ein Verteidigungssystem geschaffen wurde (Abb. 263-264).

Die innere Wallanlage um den mittleren Hügel hat einen Durchmesser von ${ }^{6} 65 \mathrm{~m}$ und eine Höhe von ca. $25 \mathrm{~m}$. Sie weist sieben kegelförmige Erhebungen auf, die den Wall um zwei bis drei Meter überragen, möglicherweise Überreste von Wachtürmen der inneren Verteidigungsmauer.

Am Außenrand der Siedlung existierte ein weiterer Wall von $353 \times 297 \mathrm{~m}$ und einer Höhe von IO-I2 m. Es könnte sich hier um die äußere Verteidigungsmauer handeln. Auch hier wurden ca. I4 kegelförmige Erhebungen beobachtet. Eine genaue Zahl konnte wegen der natürlichen Erosion nicht festgestellt werden (Gass 20IIb, 2I8). Die Breite der Schutzwälle beträgt im oberen Bereich 9 bis $20 \mathrm{~m}$. Alle Schutzmauern verjüngen sich nach oben. Die Nordhälfte des westlichen inneren Schutzwalls erweitert sich im oberen Bereich um bis zu $40 \mathrm{~m}$. Es könnte sein, dass das Erosionsschluchtensystem an dieser Stelle eine Art von Riedel hatte, der außer der Verteidigungsfunktion noch Platz für weitere Bauten bot. Der westliche Bereich der Siedlungsstelle knüpft an die Erosionsschluchten an. Nordöstlich der „Zita-

666 Während des Topoi Surveys im Frühling 2009 wurden solche Bauelemente des Turtkuls nicht mehr gesichtet. 


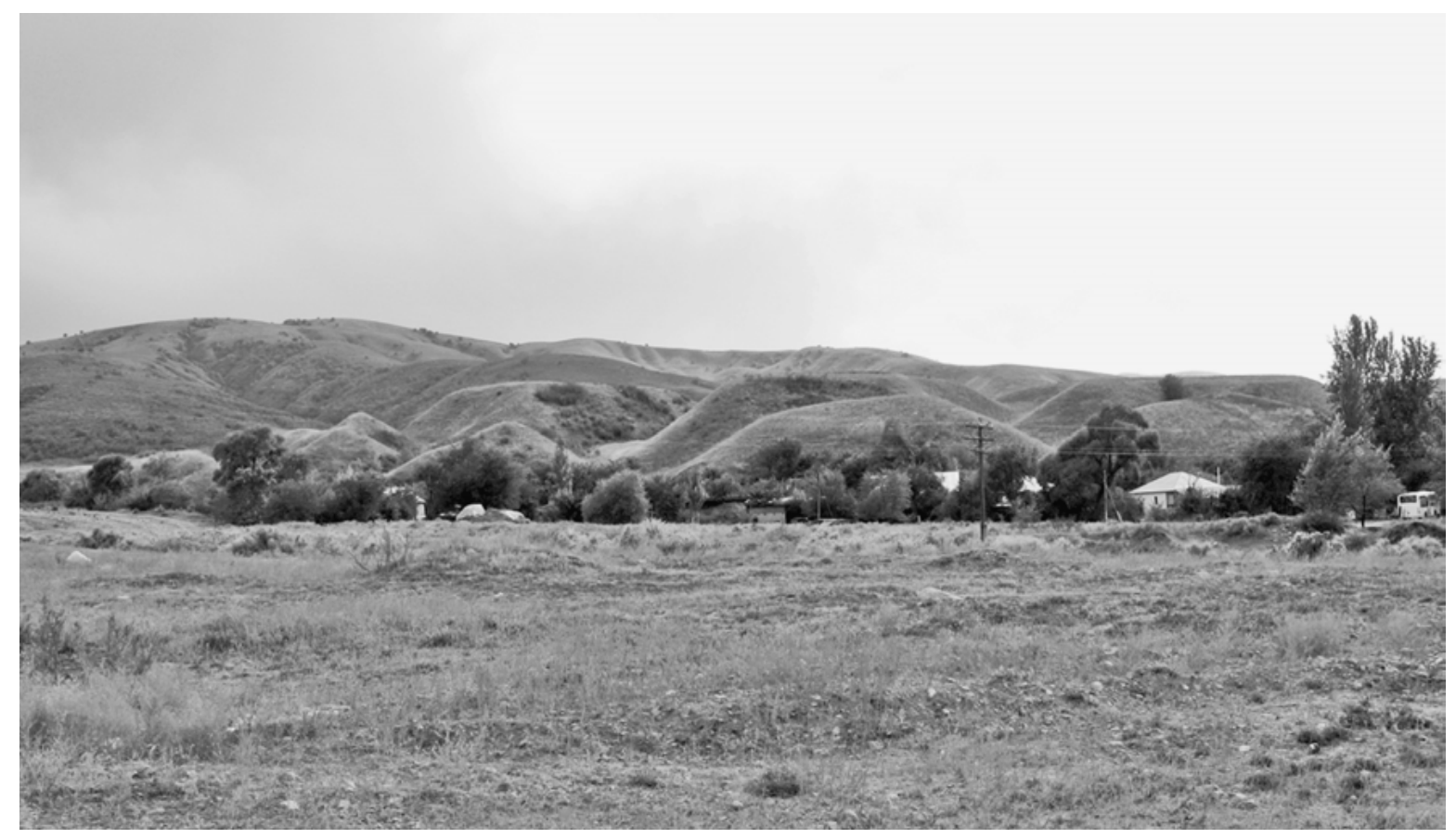

Abb. 264 | Siedlung Rachat. Blick von N

delle" und in der Westhälfte zwischen innerem und äußerem Schutzwall befinden sich weitere Erhebungen mit abgeflachten Kuppen, welche man ohne Ausgrabung nicht interpretieren kann.

Sowohl auf der Oberfläche der bereits erwähnten Erhebungen als auch auf der „Zitadelle“ wurden keine Spuren von weiteren Baukonstruktionen festgestellt.

Die in den Jahren 1999 und 2004 von Mitarbeitern des Archäologischen Institutes „A. Ch. Margulan“ (Almaty) angelegten Suchschnitte (zuerst $2 \times 2 \times 0,7 \mathrm{~m}$, im mittleren Bereich und fünf Jahre später $4 \times 4 \times 2,95 \mathrm{~m}$ in der südöstlichen Ecke) auf der "Zitadelle“ ergaben Asche, Knochen und Keramikscherben, welche sowohl aus dem Mittelalter als auch aus der älteren Früheisenzeit stammen (Bajpakov/Nurmuchanbetov 2000, I5-I6; Bajpakov u.a. 2005c, 4-5 Foto 4, 5, 9 Abb. I, 2, 6). Die Lesefunde von der Oberfläche des Siedlungsplatzes und von den Ufern des Flusses Rachat in der Nähe der Siedlung gehören überwiegend der sakischen Periode an (Baipakov 2008, I46-I47). So zum Beispiel wurde 2008 während des Baus eines Hauses ein Bronzekessel geborgen (Abb. 265) - GPS: N43 22.697 E77 22.078, ALT 8I8 m. Der Fundort befindet sich am rechten, östlichen Ufer des Rachat, I,I km nördlich der Siedlung Rachat. Der Kessel (Dm Mündung 24,0 cm, Dm Schulter 25,2 cm, Dm Hohlfuß I3,6 cm, H 24,5 cm) weist eine gerundete Wandung auf, die ab dem Schulterbereich nach innen ausläuft. Die Mündung ist abgerundet und endet mit einer leicht nach außen versetzten, verdickten Randlippe. Um die Schulter des Kessels läuft eine durchgehende Gußnaht. Einander gegenüber wurden an der Schulter von unten diagonal zwei ovale Henkel mit rundem Querschnitt aufgegossen. Im unteren Viertel befinden sich zwei große Brüche. Am Boden des Kesselskörpers ist ein stark beschädigter Hohlfuß angegossen worden. Offensichtlich wurde der konische Hohlfuß getrennt gefertigt und anschließend mit dem Kessel verbunden. Innen ist der Kessel mit grüner Patina bedeckt667.

667 Nach mündlicher Mitteilung von Dr. Sergej Demidenko (Moskau) kann dieser Kessel in das 2.-I. Jh. v. Chr. da- tiert werden. Für diese Information bedanke ich mich beim Herrn Demidenko herzlich. 
Es ist also anzunehmen, dass die Siedlungsstelle Rachat schon seit der älteren Eisenzeit existierte und wahrscheinlich mit einigen Unterbrechungen bis zum Mittelalter weiter genutzt wurde (Gass 20IIb, 2I9).
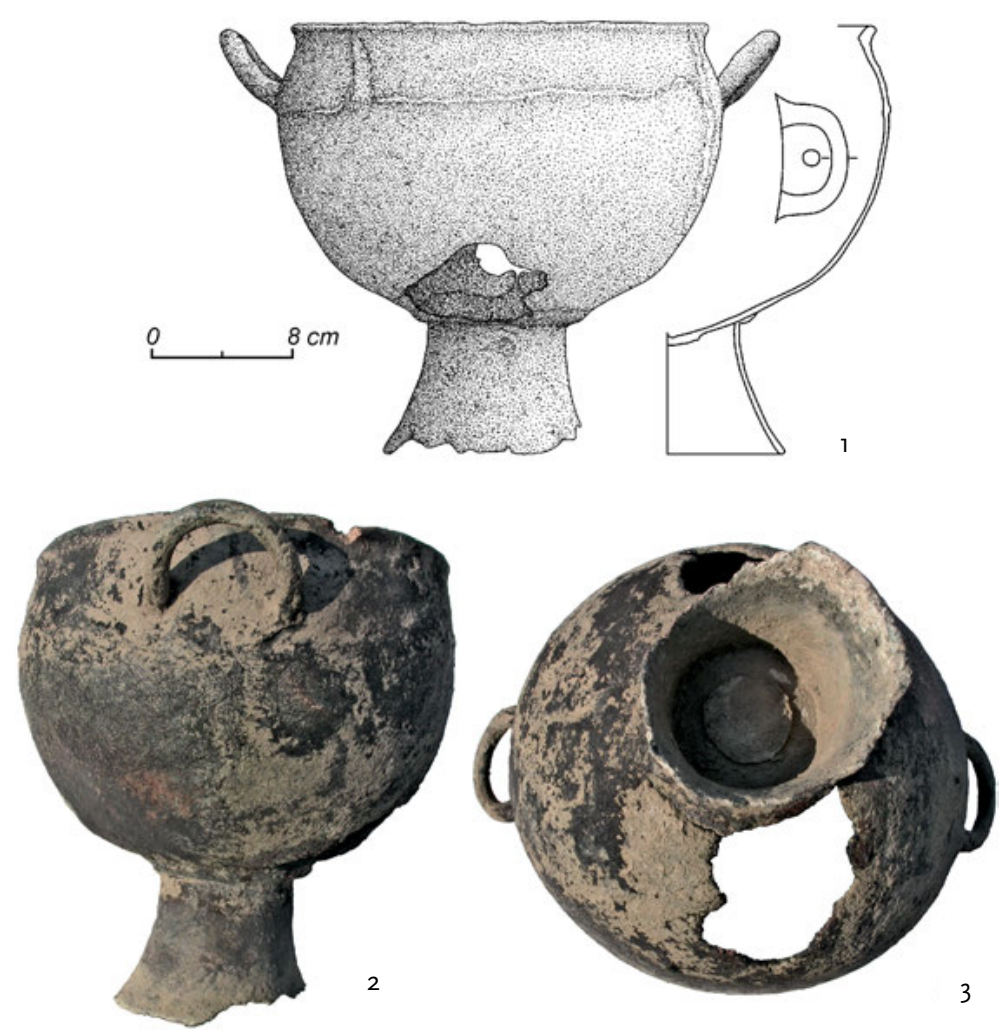

Abb. 265 | Kessel aus Bronze. Einzelfund in der Nähe der Siedlung Rachat (Fund 2008); Foto und Zeichnung: M.-R. Boroffka

\section{Forschungsgeschichte}

Im Jahre I999 wurden während der ersten Untersuchung der Siedlungsstelle auf der Kuppe der „Zitadelle“ einige ovale und viereckige Gruben, die man als Überreste von Bauten interpretierte, festgestellt (Bajpakov/Nurmuchanbetov 2000, I5) ${ }^{668}$. Sowohl K. M. Bajpakov als auch B. N. Nurmuchanbetov vertreten die Meinung, dass die erste Etappe der Siedlung mit den Trägern der sakischen Kultur verbunden wäre. Sie spiele zu dieser Zeit die Rolle eines Zufluchtsortes und eines politischen Zentrums. Diese Rolle übernähme sie auch in der folgenden Wusun-Periode der jüngeren Eisenzeit und im frühen Mittelalter mit dazukommender Funktion als Produktionsstätte (Bajpakov/Nurmuchanbetov 2000, 15-16). Jedoch schrieb Bajpakov im Jahr 2008, dass sich im Mittelalter die Funktion der Siedlung Rachat verändert habe. Die Siedlung spielte nur noch die Rolle eines Zufluchtsortes (Baipakov 2008, 72).

Lit.: Baipakov 2008, 7I-72, Abb. I6-I8; Bajpakov/Nurmuchanbetov 2000, I4-I6, Abb. 2; Bajpakov u.a. 2005c, 4-5, I2-2I; Gass 20IIb, 2I8-2I9, Abb. 23-24; Gass (im Druck).

668 Während des Topoi Surveys im Herbst 2008 und im Frühling 2009 wurden solche Bauelemente auf der „Zitadelle" nicht gesichtet. 
Siedlung Sarytau [FEZ] (Abb. 266-267; Karte 3 Nr. 7I): ALT I872 m N42 59.7I0 E79 I9.068; Gebiet Almaty (kasach. Алматы облысы), Rajymbekskij rajon (kasach. Райымбек ауданы); Ausmaß N-S $56 \times$ O-W $53 \mathrm{~m}$.

Die Siedlung Sarytau befindet sich am Ostrand des Hochplateaus Kegen (kasach. Keген), am Ausgang eines Längstals zum Plateau hin, an der Südwestseite der Temirlik-Berge (kasach. Темирлик), südlich vom Berg Sarytau (kasach. Сарытау), am Fuße der Bergkuppe, am rechten, östlichen Ufer des Flusses Kegen (kasach. Кеген). Der Fundort liegt 197 km ostsüdöstlich der Stadt Almaty (kasach. Алматы), $9 \mathrm{~km}$ ostsüdöstlich des Dorfes Kegen (kasach. Кеген) und $7 \mathrm{~km}$ westsüdwestlich des Dorfes Aktasty (kasach. Ақтасты).

Die Siedlungsstelle hat in der Aufsicht eine eher rundliche Form, die eine leichte N-S Ausdehnung aufweist. Im inneren Siedlungsbereich wurden elf Hausgrundrisse festgestellt. Sie bestehen aus rechteckigen Gruben, umgeben von großen Steinen, die evtl. zu den Fundamentresten gehören. Es kann sich hier um Halbgrubenhäuser (russ. poluzemljanki) handeln. Die Wohnbauten bilden zwei bis drei Hausreihen, die in einer N-S Achse ausgerichtet sind. Ihre genaue Zahl kann nur durch eine vollständige Ausgrabung der Siedlungsfläche festgestellt werden. Mit Ausnahme der Häuser 2, 3 und 5

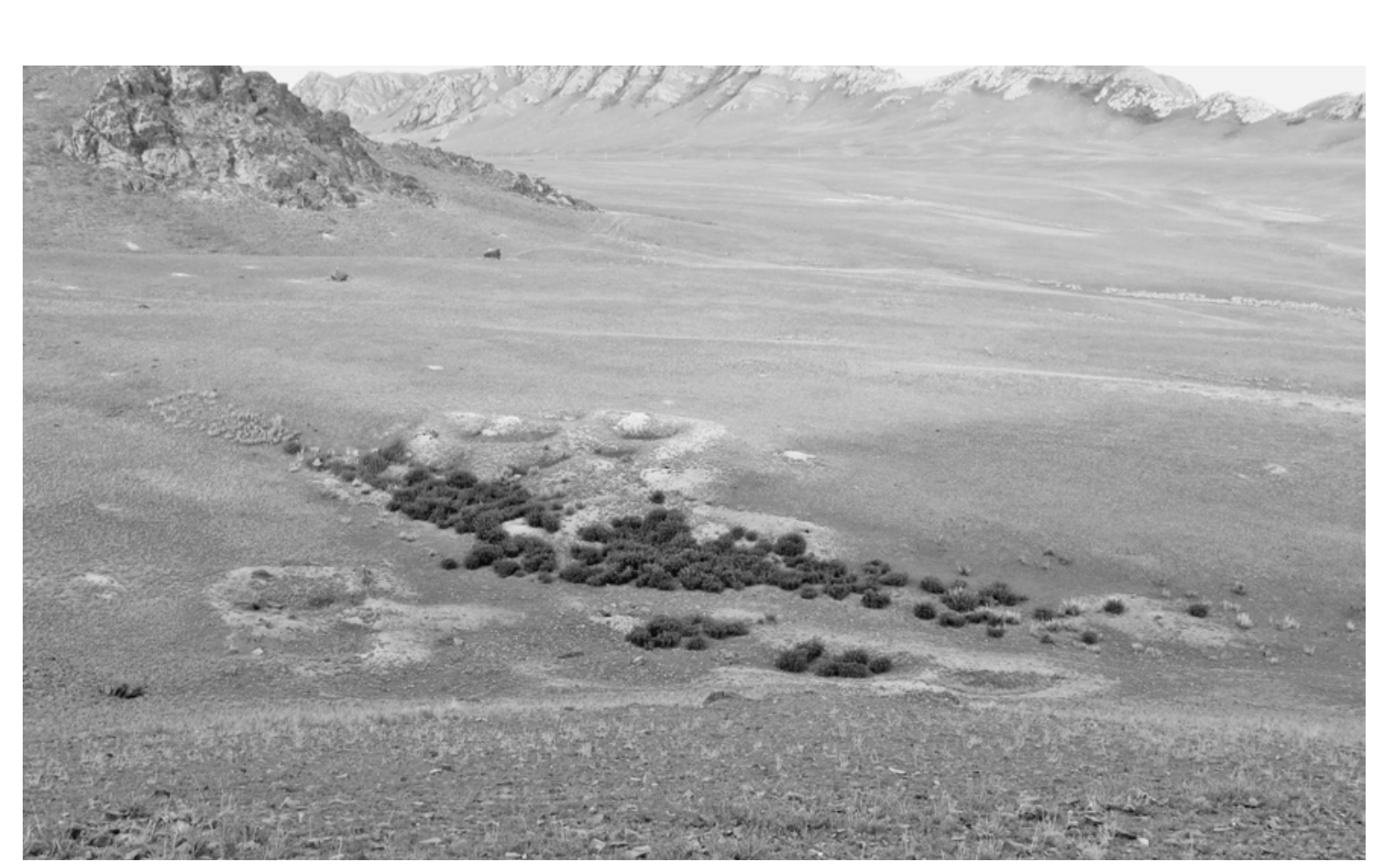

Abb. 267 | Siedlung Sarytau. Blick von W

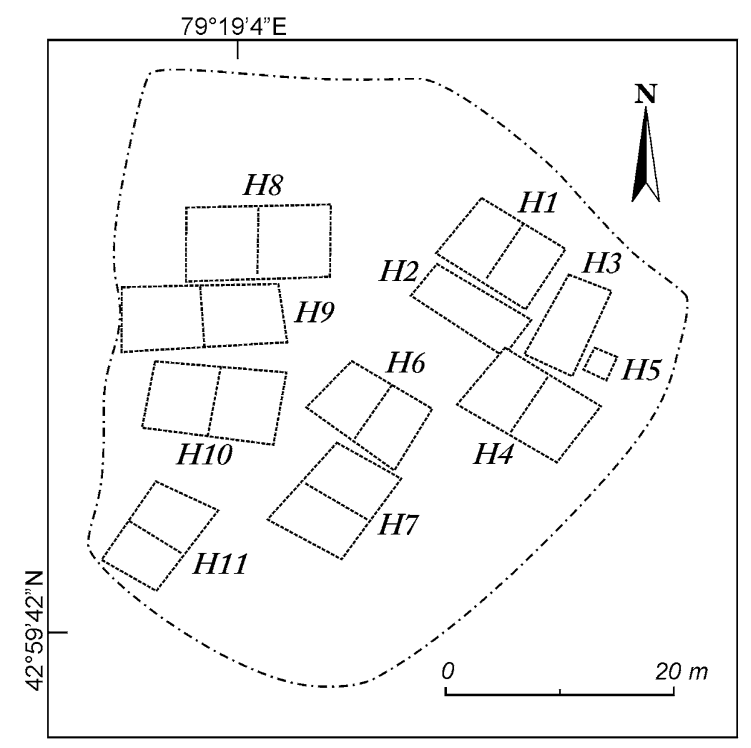

Abb. 266 | Skizze von der Siedlung Sarytau 
(nach der Arbeitsnummerierung) wurden die Hausgruben in der Mitte durch eine weitere Steinreihe bzw. eine Erdwand unterteilt, so dass sich je zwei Räume ergaben (Gass 20IIb, 22I). Die Ausrichtung der einzelnen Häuser ist eher unsystematisch.

Die Grundrisse der Häuser 8 bis in bilden die westlichste Hausreihe. Diese westliche Häuserzeile liegt direkt unterhalb des Berges Sarytau.

Charakteristik der Häuser:

Östliche Hausreihe

Haus I

Lage: N42 59.7I6 E79 I9.077; nordöstlichstes Haus der Siedlung

Maße: 9,3 × 6,7 m

Form: rechteckige, ca. $0,5 \mathrm{~m}$ tiefe Grube

Ausrichtung: NW-SO

Sonstiges: Hausgrube von großen Steinen des Hausfundamentes (?) umrandet; in der Mitte durch eine schmale (ca. $0,5 \mathrm{~m}$ Breite) Erdwand geteilt

Deutung: zweigeteiltes Halbgrubenhaus (russ. poluzemljanka)

Bemerkung: Es wäre möglich, dass die Gruben der Häuser I bis $5 \mathrm{zu}$ einem größeren Ensemble gehören.

\section{Haus 2}

Lage: N42 59.7I4 E79 I9.073; SW des Hauses I, in unmittelbarer Nähe

Maße: $10 \times 4 \mathrm{~m}$

Form: rechteckige, ca. $0,3 \mathrm{~m}$ tiefe Grube

Ausrichtung: NW-SO

Sonstiges: Hausgrube von mittelgroßen Steinen des Hausfundamentes (?) umrandet

Deutung: Halbgrubenhaus (russ. pluzemljanka)

Haus 3

Lage: N42 59.7I3 E79 I9.080; östlich der Häuser I und 2, in unmittelbarer Nähe

Maße: $8,3 \times 5 \mathrm{~m}$

Form: rechteckige, ca. $0,5 \mathrm{~m}$ tiefe Grube

Ausrichtung: NO-SW

Deutung: Halbgrubenhaus (russ. pluzemljanka)

Haus 4

Lage: N42 59.709 E79 I9.078; S der Häuser 2 und 3, in unmittelbarer Nähe

Maße: $10,7 \times 6,7 \mathrm{~m}$

Form: rechteckige, ca. $0,3 \mathrm{~m}$ tiefe Grube

Ausrichtung: NW-SO

Sonstiges: Hausgrube von mittelgroßen Steinen des Hausfundamentes (?) umrandet; in der Mitte durch eine quer verlaufende Steinreihe geteilt

Deutung: zweigeteiltes Halbgrubenhaus (russ. poluzemljanka)

\section{Haus 5}

Lage: N42 59.7II E79 I9.083; östlich des Hauses 3, in unmittelbaren Nähe

Maße: $2,3 \times 2,3 \mathrm{~m}$

Form: quadratische Grube

Ausrichtung: Ecken an vier Haupthimmelsrichtungen orientiert

Sonstiges: kleinste Baukonstruktion auf der Siedlungsfläche

Deutung: Wirtschaftsgebäude oder eine einfache Grube (Abfallgrube o.ä.)

Haus 6

Lage: N42 59.7I0 E79 I9.068

Maße: $10 \times 6 \mathrm{~m}$

Form: rechteckige, ca. $0,3 \mathrm{~m}$ tiefe Grube

Ausrichtung: NW-SO

Sonstiges: Hausgrube von großen Steinen des Hausfundamentes (?) umrandet; in der Mitte durch eine quer verlaufende Steinreihe geteilt

Deutung: zweigeteiltes Halbgrubenhaus (russ. poluzemljanka)

\section{Haus 7}

Lage: N42 59.705 E79 I9.064; S des Hauses 6, in unmittelbarer Nähe

Maße: 9,0 × 7,7 m

Form: rechteckige, ca. $0,3 \mathrm{~m}$ tiefe Grube

Ausrichtung: NO-SW

Sonstiges: Hausgrube von großen Steinen des Hausfundamentes (?) umrandet; in der Mitte durch eine quer verlaufende Steinreihe geteilt

Deutung: zweigeteiltes Halbgrubenhaus (russ. poluzemljanka)

Westliche Hausreihe

Haus 8

Lage: N42 59.7I6 E79 I9.06I; nördlichstes Haus der Reihe

Maße: $13,3 \times 6,7 \mathrm{~m}$

Form: rechteckige, ca. $0,3 \mathrm{~m}$ tiefe Grube

Ausrichtung: W-O

Sonstiges: Hausgrube von großen Steinen des Hausfundamentes (?) umrandet; in der Mitte durch eine quer verlaufende Steinreihe geteilt

Deutung: zweigeteiltes Halbgrubenhaus (russ. poluzemljanka) 


\section{Haus 9}

Lage: N42 59.7I5 E79 I9.057; direkt S des Hauses 8

Maße: $15,0 \times 5,7 \mathrm{~m}$

Form: rechteckige, ca. o,2 $\mathrm{m}$ tiefe Grube

Ausrichtung: W-O

Sonstiges: Hausgrube von mittelgroßen Steinen des Hausfundamentes (?) umrandet; in der Mitte durch eine quer verlaufende Steinreihe geteilt

Deutung: zweigeteiltes Halbgrubenhaus (russ. poluzemljanka)

\section{Haus Io}

Lage: N42 59.709 E79 19.057; S des Hauses 9, in unmittelbarer Nähe

Maße: $10,7 \times 6,0 \mathrm{~m}$

Form: rechteckige, ca. $0,3 \mathrm{~m}$ tiefe Grube

\section{Ausrichtung: W-O}

Sonstiges: Hausgrube von großen Steinen des Hausfundamentes (?) umrandet; in der Mitte durch eine quer verlaufende Steinreihe geteilt

Deutung: zweigeteiltes Halbgrubenhaus (russ. poluzemljanka)

\section{Haus II}

Lage: N42 59.704 E79 I9.054; südlichstes Haus der Reihe, liegt abseits der übrigen Häuser

Maße: 9,3 × 6,3 m

Form: rechteckige, ca. $0,3 \mathrm{~m}$ tiefe Grube

Ausrichtung: NO-SW

Sonstiges: in der Mitte durch eine Erdwand geteilt

Deutung: zweigeteiltes Halbgrubenhaus (russ. poluzemljanka)

Obwohl keine datierenden Lesefunde an der Oberfläche der Siedlung gefunden wurden, kann anhand von ähnlich angelegten Siedlungen mit identischer Bauweise und Hausorientierung vermutet werden, dass dieser Wohnplatz zum sakischen Kulturkreis gehört.

Lit.: Gass 20IIb, 22I-222, Abb. 30-3I.

Siedlung Talgar [FEZ - Mittelalter] (Abb. 268; Karte 3 Nr. 9): ALT ıo8I m N43 I6.775 E77 13.338; Gebiet Almaty (kasach. Алматы облысы), Talgarskij rajon (kasach. Талғар ауданы); Ausmaß N-S 3І2 × O-W 3IO $\mathrm{m}$.

Die Siedlung Talgar befindet sich im Flachland, auf dem Schwemmfächer, direkt nördlich des Lösshügellandes (30-250 m entfernt) der Berge Talgar (kasach. Талғар) der Bergkette Transili-Alatau

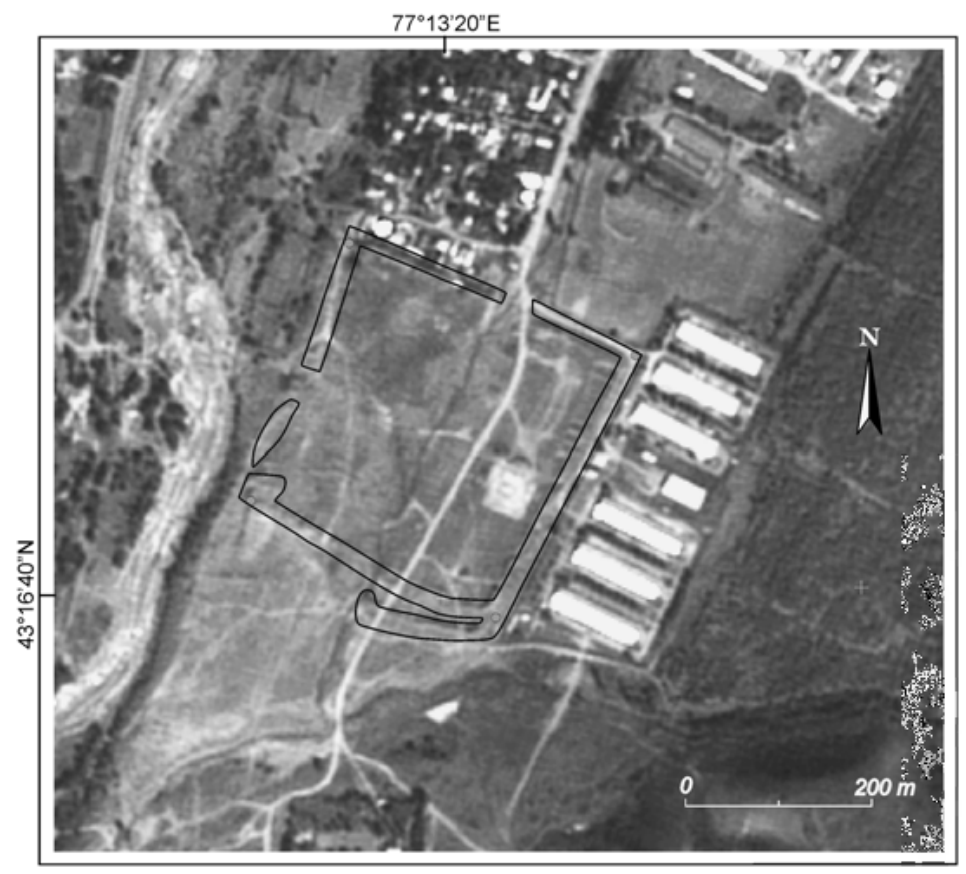

Abb. 268 | Siedlung Talgar (SPOT) 


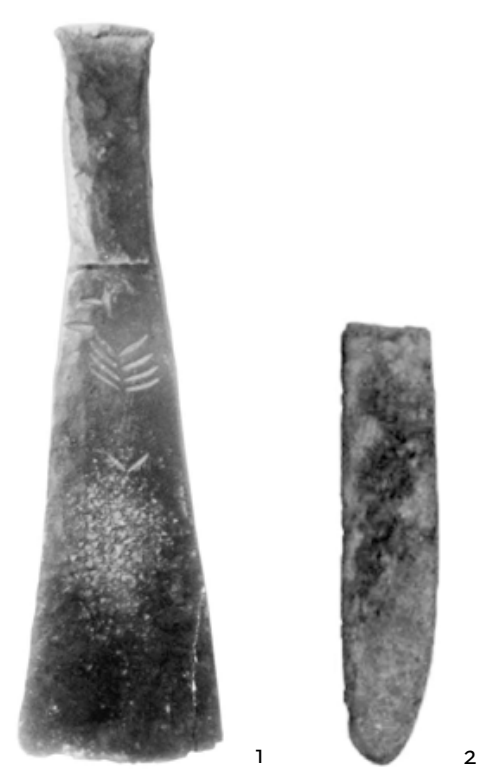

Abb. 269 | Siedlung Talgar; I. Lesefund von der Siedlungsfläche, Meißel, Bronze (Kopylov I956, Taf. I4,7); 2. Grabungsschnitt I8a, Klinge des Bronzemessers

(Kopylov I986, Taf. 29,I9); Ohne Maßstab (kasach. Іле Алатауы), auf dem rechten, östlichen Ufer des Flusses Talgar (kasach. Талғар), an der Stelle, wo der Fluss aus der Talgar-Bergschlucht herausströmt. Durch diese spezifische Landschaftslage ist die Siedlungsstelle von Süden und Südosten durch die Berge und von Westen her durch den Fluss natürlich geschützt. Ungeschützt blieb praktisch nur die Nordseite, die zum Flachland bzw. zur Steppe führte. Der Fundort liegt $25 \mathrm{~km}$ östlich der Stadt Almaty (kasach. Алматы), am Südrand der Stadt Talgar (kasach. Талғар).

Die Siedlung weist eine viereckige, fast quadratische Fläche auf, deren Ecken an den vier Haupthimmelsrichtungen orientiert sind. Das Ausmaß des Wohnplatzes beträgt 312 $\times 3$ Iо m, was einer Fläche von ca. 9 ha entspricht.

Die gesamte Siedlungsfläche ist von einem Schutzwall, welcher zum Teil stark beschädigt ist, umgeben. Die Höhe des Walls schwankt zwischen $7 \mathrm{~m}$ und $3 \mathrm{~m}$, mit einer Io-I2 $\mathrm{m}$ bis $\mathrm{zu}$ I5-I7 $\mathrm{m}$ breiten Basis. Die Wallecken sind noch zusätzlich durch die Verteidigungstürme verstärkt, die heute als rundliche Erhebungen sichtbar sind. Von Südosten ist die Siedlung durch eine zweite Wallanlage, die nur bis zur Siedlungsmitte verläuft, verstärkt. Die Befestigungsanlage der Siedlung hat zwei Eingangsbereiche - einen im Nordosten und der zweite im Südwesten - die durch eine gerade verlaufende Straße miteinander verbunden waren und die den Innenraum der Siedlung in zwei gleiche Hälften teilten. Diese Straße wird bis zum heutigen Tag als Feldweg genutzt. Parallel zum Weg fließt ein kleiner Bach. Im Siedlungsbereich hinter dem Schutzwall befinden sich an der Oberfläche gut erkennbare gerade Straßenbereiche und die Überreste von Bauten, die durch viereckige oder rundliche Gruben repräsentiert werden. Diese Gruben sind durch mittelgroße und große Steine der Hausfundamente (?) umrandet. Das heutige Aussehen der Siedlungsstelle entspricht dem mittelalterlichen (Kopylov I956; Ageeva I96ob; Savel'eva I993; Savel'eva I994, 2I-33; Bajpakov u.a. 2002, 8-28, 60-I49). Laut Grabungsberichten von I. I. Kopylov (Gorodeckij I924, II8-II9, Nr. 20; Kopylov I956, 32, Taf. I4,7; Kopylov I962, 26-27) wurden allerdings auf der Siedlungsfläche und in den untersten Siedlungsschichten ein bronzener Meißel (Abb. 269,I), ein sakischer Bronzekessel, eine Lanzenspitze aus Bronze und sakische Keramik gefunden. Es ist daher anzunehmen, dass die mittelalterliche Stadt Talchir (Kopylov I978, 6I-65; Savel'eva I994, I37; Bajpakov u.a. 2002, II, 20) an der Stelle einer früheisenzeitlichen Siedlung der sakischen Periode erbaut wurde (Kopylov I956, 32; Kopylov I962, 47-48; Kopylov i965, 56-57; Kopylov i982, 22-23).

\section{Forschungsgeschichte}

Der kasachische Allgemeingelehrte Čokan Valichanov besichtigte als erster die Siedlung Talgar in den I850-6oer Jahren und vermerkte, dass der Fundplatz von der einheimischen Bevölkerung als „Rustemovskij Kurgan" bezeichnet wurde (Bajpakov u.a. 2002, 2I).

Über die quadratische Befestigung Talgar am rechten Ufer des Talgar schrieb V. D. Gorodeckij im Jahre I924 (Gorodeckij I924, II8-II9, Nr. 20). Neben den mittelalterlichen Lesefunden der Siedlungs- 
stelle erwähnte er zudem noch einen sakischen Bronzekessel und eine Lanzenspitze aus Bronze (Gorodeckij I924, II8).

In den Jahren I936-I940 wurde die Siedlungsstelle von der archäologischen Siebenstromland-Expedition unter der Leitung von A. N. Bernštam untersucht (Bernštam I946, IIO). Allerdings handelte es sich hier nur um eine kleinflächige Ausgrabung, die die mittelalterlichen Schichten erfasste.

I956 begann die systematische Erforschung des Siedlungsplatzes zuerst unter der Leitung von I. I. Kopylov. Außer den bereits erwähnten Lesefunden, die den Anstoß zu der Vermutung gegeben hatten, dass die mittelalterliche Stadt an der Stelle einer früheisenzeitlichen Siedlung gegründet wurde, kamen im Jahre I962 in der Grube 3 in Quadrat 2 einige Scherben der „archaischen Periode“ (Kopylov I962, 48) sowie drei Fragmente eines keramischen Kessels zum Vorschein (Kopylov I962, 26-27). Nach Kopylov besaß dieser handgemachte Kessel statt eines Henkels einen Buckel, der im Profil einen pyramidenförmigen Kurgan „der Königsskythen“ darstellte. Aufgrund einer Analogie mit einem ähnlichen Gefäß aus dem Gräberfeld Kensaj (Süd-Kasachstan) wurde der Kessel aus der Siedlung Talgar ins 3.-I. Jh. v. Chr. datiert (Kopylov I962, 27). Während der Geländearbeit im Jahre I985 fand sich im mittelalterlichen Grabungsschnitt i8a eine Klinge eines Bronzemessers (Abb. 269,2), dessen Parallelen zu den bronzezeitlichen Funden des Ču-Tals und zu den tagarzeitlichen Funden des südwestlichen Sibiriens führen (Kopylov I986, 39, 52). Nach Meinung des Ausgräbers könnte es sein, dass dieses Messer an der Stelle eines zerstörten sakischen Kurgans von den Einwohnern der mittelalterlichen Stadt gefunden und weiter benutzt wurde (Kopylov i986, 39).

Im Jahre I98I fand die Untersuchung der mittelalterlichen Vorstadt und der näheren Umgebung der Stadt Talchir statt. Laut Kopylov (Kopylov I982, 2-3) fand man in der Südhälfte der östlichen Vorstadt ein komplett zerstörtes, überpflügtes Gräberfeld der älteren Eisenzeit, das aus Kleinkurganen bestand ${ }^{669}$. In der nördlichen Vorstadt standen mittelgroße Kurgane der „sakisch-wusunisch-frühtürkischen Periode“ (Kopylov I982, 2-3). Ebenso wurde eine fast zerstörte, aus kleinen Kurganen bestehende Nekropole der „sakisch-wusunisch-frühtürkischen Periode“ in der westlichen Vorstadt festgestellt. In der Westhälfte der südlichen Vorstadt kam ein Steinkreis zum Vorschein, der ein früheisenzeitliches Grab umgab (Kopylov I982, 22-23).

In den Jahren I98I bis I98 $5^{670}$ wurden in der Westhälfte der südlichen Vorstadt zehn Gräber ausgegraben (hier und im Weiteren folgen Angaben nach Kopylov I983, 4-5, 26-28; Kopylov I984, 23-33; Kopylov I985, 25-29; Kopylov i986, 2-7). Da eines davon drei frühmittelalterliche Bestattungen enthielt und eines gar kein Grab war, wurden diese Bestattungen hier nicht weiter betrachtet. Sechs Gräber waren von Steinkreisen mit einem Durchmesser von $4 \mathrm{~m}$ bis $8 \mathrm{~m}$ umgeben, ein weiteres Grab war durch eine doppelte Steinreihe gekennzeichnet. Drei Gräber mit Steinkreisen waren an der Oberfläche durch dunkle Verfärbungen markiert. Über drei weiteren Gräbern mit Steinkreisen waren rechteckige oder ovale Steinkonstruktionen aus mittelgroßen Steinen gebaut. Diese Steinkonstruktionen waren W-O, WSW-ONO oder NO-SW ausgerichtet und I,6-3,0 × 0,6-2,4 m groß. Mehr als die Hälfte der erforschten Gräber wies eine rechteckige Grabgrube mit einer Nische an der Nordwand (fünf Gräber) auf. Eines der Gräber hatte abgerundete Ecken. In der Regel handelte es sich um einfache rechteckige (ein Grab) oder ovale (zwei Gräber) Grabgruben. Die Hälfte aller Grabgruben befand sich in der Mitte der Anlage. Die restlichen zeigten sich in der Süd- oder Westhälfte sowie im Nordost- oder Südostbereich. Die meisten Gräber waren W-O (vier Gräber) ausgerichtet, einige auch WNW-OSO, NW-SO oder SW-NO, so dass die Ausrichtung in einer W-O Achse mit leichten Abweichungen eindeutig domi-

669 Relativchronologisch kann das Gräberfeld sowohl zur sakischen als auch zur Wusun-Periode der Eisenzeit, oder zur frühtürkischen Periode des Mittelalters gehören (Kopylov I982, 2).
670 I986 wurden zwei früheisenzeitliche Kurgane weiter südöstlich von der Siedlung Talgar in der Schlucht „Glubokaja ščel“ ausgegraben (Kopylov I987, 2-7) - ca. N43 I6.490 E77 I3.868. 

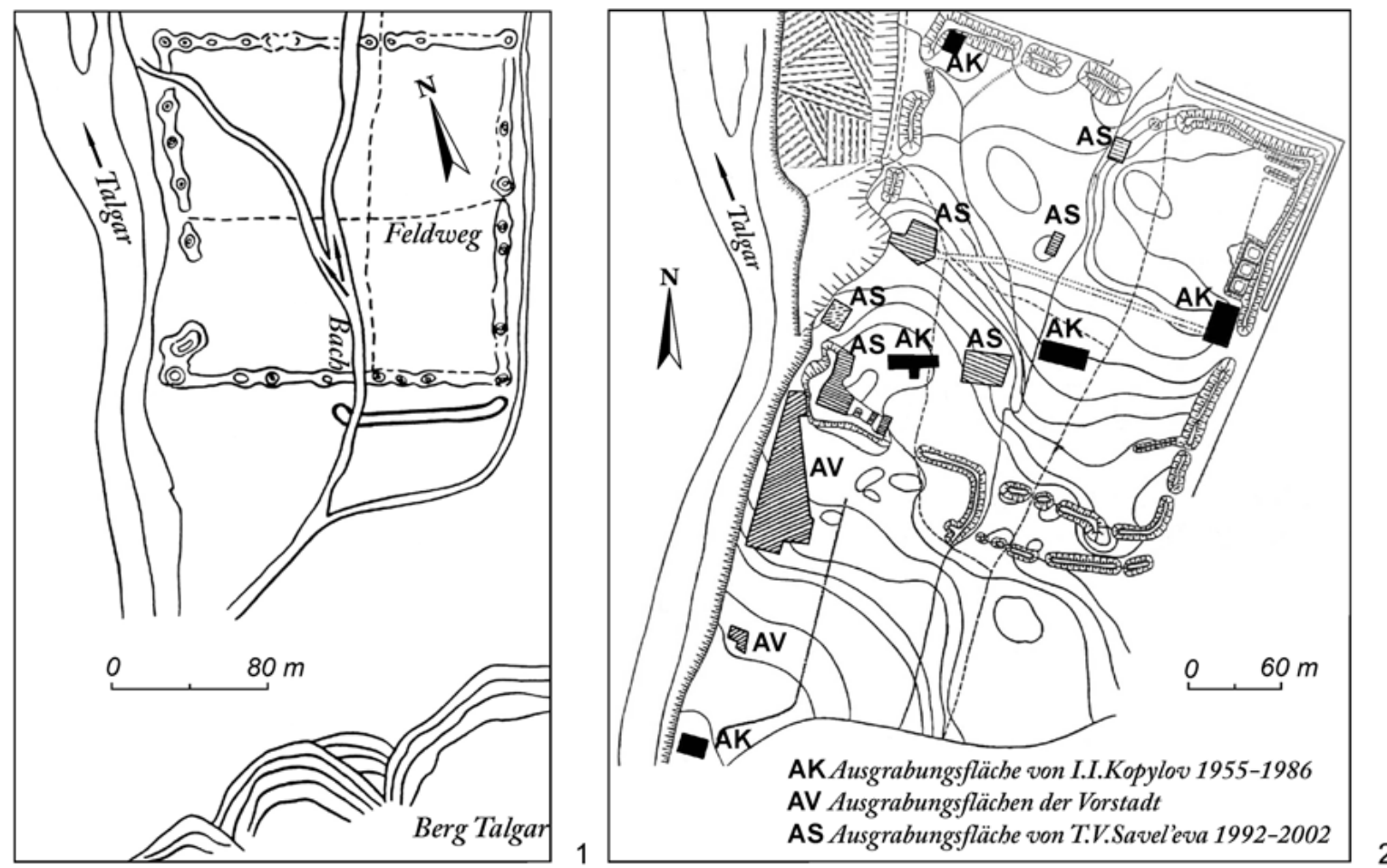

Abb. 270 | Plan der Siedlung Talgar (I nach Savel'eva I994, Abb. 2; 2 nach Bajpakov u.a. 2002, Abb. 2)

nierte. Die Maße der Gräber betrugen I,O-2,4 × 0,8-I,2 × I,45-2,2 m. Dies bedeutet, dass alle Gräber erst wesentlich tiefer angelegt worden waren. In überwiegender Zahl wurden in den Gräbern erwachsene Personen (fünf Männer und zwei Frauen ${ }^{67 \text { I }}$ ) einzeln bestattet. In einem Grab kam eine Doppelbestattung einer erwachsenen Frau und eines Kindes zum Vorschein. In einem weiteren Grab ruhte der bestattete Mann auf dem Grabboden. Einen Meter oberhalb davon war ein Hund beigelegt. Das bestattete Individuum in diesem Grab wurde vor der Beisetzung zerstückelt, linker Arm und untere Extremitäten wurden abgetrennt und lagen an den Seiten. Zwei Gräber beinhalteten Kinderskelette. Zudem waren zwei Gräber zerstört. In einem beraubten Grab fehlten jegliche Knochen. In einem weiteren Grab, das durch eine mittelalterliche Opferstelle zum Teil zerstört worden war, waren nur die unteren Extremitäten in situ erhalten. Alle Bestatteten lagen in Rückenstrecker Position mit dem Kopf nach Westen mit leichten Abweichungen, sowohl nach Nordwesten (zwei Bestattete) als auch nach Südwesten (ein Skelett). Zum Beigabenrepertoire gehörten ein Ohrring aus Bronzedraht (Kopylov I983, Taf. 3,3), sechs Töpfe mit flachem Boden (Kopylov I983, Taf. 3,2, Taf. 5,3, Taf. 6,4; Kopylov I985, 26, 28; Kopylov ig86, 3), 29 Fragmente von unterschiedlichen Gefäßen (Kopylov I983, 4), ein Topf (Kopylov I984 Taf.8,3) und eine Tasse mit einem Henkel mit rundem Boden (Kopylov I984, Taf. I2,3), ein Ockerwürfel (Kopylov I983, 5), ein Silexabschlag bzw. ein Feuersteinschaber (Kopylov I983, Taf. 3,4), ein Eisenmesser (Kopylov I984, Taf. I2,4), Holzfragmente (von einer Trage?) (Kopylov I983, 27) und Tierknochen von KWK (Kopylov I983, 5; Kopylov I985, 26). Die gesamte Keramik war handgemacht. Die Kurgane wurden in das 6.-4. Jh. v. Chr. - 5. Jh. n. Chr. datiert (Kopylov I983, 28; Kopylov I984, 24, 28; Kopylov I985, 27-28; Kopylov i986, 3).

67I Die anthropologischen Angaben richten sich nach dem Ausgräber. 
Seit I987 lag der Schwerpunkt der Untersuchungen ausschließlich auf den mittelalterlichen Nutzungsperioden der Siedlung. Es fanden regelmäßig Grabungskampagnen statt. Vorberichte zu diesen Grabungskampagnen wurden regelmäßig veröffentlicht (Savel'eva I989, 432-438; Kopylov/Kerekeša I993, I22-I36; Savel'eva/Vojakin I999, 68-75; Chang/ Tourtellotte 2000, 83-88; Savel'eva/Vojakin 2002, I46-I55).

In der Monographie von 1994 widmeten sich T. V. Savel'eva (Savel'eva I994) und K. M. Bajpakov, T. V. Savel'eva und C. Chang in einem Gemeinschaftswerk von 2002 (Bajpakov u. a. 2002) der Siedlung Talgar (Abb. 270). In einem wesentlichen Teil der Arbeit befassten sie sich sowohl mit der detaillierten Beschreibung der Befunde als auch der Funde der mittelalterlichen Schichten.

Lit.: Ageeva I957, 9-II, 55/64-57/66; Ageeva I96ob, 2, 9; Bajpakov u.a. 2000, I9; Bajpakov u.a. 2002, 8-28, 60-I49, I88-209; Bajpakov u.a. 2005d, 2-3; Bernštam I938, i9; Bernštam I94Ib, 3-5, 24-25, 30; Bernštam I946, IIo; Chang/ Tourtellotte 2000, 83-85; Dublickij I946b, I4; Gorodeckij I924, 68/II8/, Nr. 20; Kopylov I956, I9-33, Taf. 8-I5; Kopylov I962; Kopylov i963; Kopylov i965; Kopylov 1966; Kopylov 1978, 6I-65; Kopylov i982; Kopylov I983; Kopylov i984; Kopylov I985; Kopylov 1986; Kopylov I987; Kopylov/Kerekeša I993, I22-136; Korženkov u. a. 200I, IOI-IO2; Otčety otdelov i ekspedicij I979, 30-32; Otčety o rabote I98I, 35; Savel'eva I989, 432-438; Savel'eva I993; Savel'eva I994, 2I-33, 62-8I, 88-II5, I25, I28-I30, Abb. 2-IO, 35.I-2, 39; Savel'eva/Vojakin I999, 68-75; Savel'eva/Vojakin 2002, I46-I55.

Siedlung Tuzusaj [FEZ] (Abb. 27I-272; Karte 3 Nr. 6): ALT 723 m N43 2I.736 E77 07.000; Gebiet Almaty (kasach. Алматы облысы), Talgarskij rajon (kasach. Талғар ауданы); Ausmaß (са.) NW-SO I35 $\times$ SW-NO $63 \mathrm{~m}$.

Die Siedlung Tuzusaj befindet sich nördlich der Berge Kotyrbulak (kasach. Қотырбұлақ), die zur Bergkette Transili-Alatau gehören (kasach. Іле Алатауы), am linken, westlichen Ufer des ausgetrockneten Flusses Tuzusaj (kasach. Түзусай). Der Siedlungsplatz liegt $20 \mathrm{~km}$ nordöstlich der Stadt Almaty (kasach. Алматы), $600 \mathrm{~m}$ westlich des Dorfes Tuzusaj (kasach. Түзусай) und $270 \mathrm{~m}$ nordwestlich vom "Großen Almaty-Kanal“ (БАK ${ }^{672}$ ).

Die Siedlungsstelle weist keine Befunde an der Oberfläche auf. Es sind keine Spuren von Bauten oder Verteidigungsanlagen zu sehen. Daher kann nichts über die Siedlungsform bzw. über die Siedlungsausrichtung gesagt werden. Jedoch kann anhand der Lesefunde (Abb. 273) an der Oberfläche eine ungefähre Ausdehnung von ca. Io० × $60 \mathrm{~m}$ angenommen werden. Das rechte, östliche Ufer des ausgetrockneten Flusses ist komplett überackert. Dasselbe gilt für das linke, westliche Ufer. Allerdings teilte F. P. Grigor'ev ${ }^{673}$ mit, dass eine am linken Ufer errichtete Betonrinne einen Teil der Siedlung vom Acker abschirmte. Zudem verlaufen über die Siedlungsfläche parallel zur Uferkante zwei Erosionsrinnen, deren Breite 2-5 $\mathrm{m}$ und deren Tiefe I,5-2 m maß. Im mittleren Bereich der verbliebenen Siedlungsfläche zeigte sich eine alte Grabungsfläche ${ }^{674}$.

Anhand der Grabungsergebnisse von 1992-I996 konnte Tuzusaj der spätsakischen Periode der älteren Eisenzeit und der Wusun-Periode der jüngeren Eisenzeit zugeordnet werden.

672 Большой Алматинский Канал.

673 Für die Mitteilungen bezüglich der Forschungsgeschichte der Siedlungsstelle Tuzusaj möchte ich Fedor P. Grigor'ev herzlich danken.

674 Die Siedlung Tuzusaj wurde erstmals in den Jahren I992-1993 durch ein archäologisches Forschungsteam aus Almaty vom Projektentwicklungsinstitut für Konservierung und Restaurierung der Kulturdenkmäler „Kazproektrestavracija“ und in Jahren I994-1996 von der Kasachisch-Amerikanischen archäologischen Expedition zum Teil ausgegraben (Tujakbaeva u.a. I994; Chang/Grigoriev I999, 392-393). 


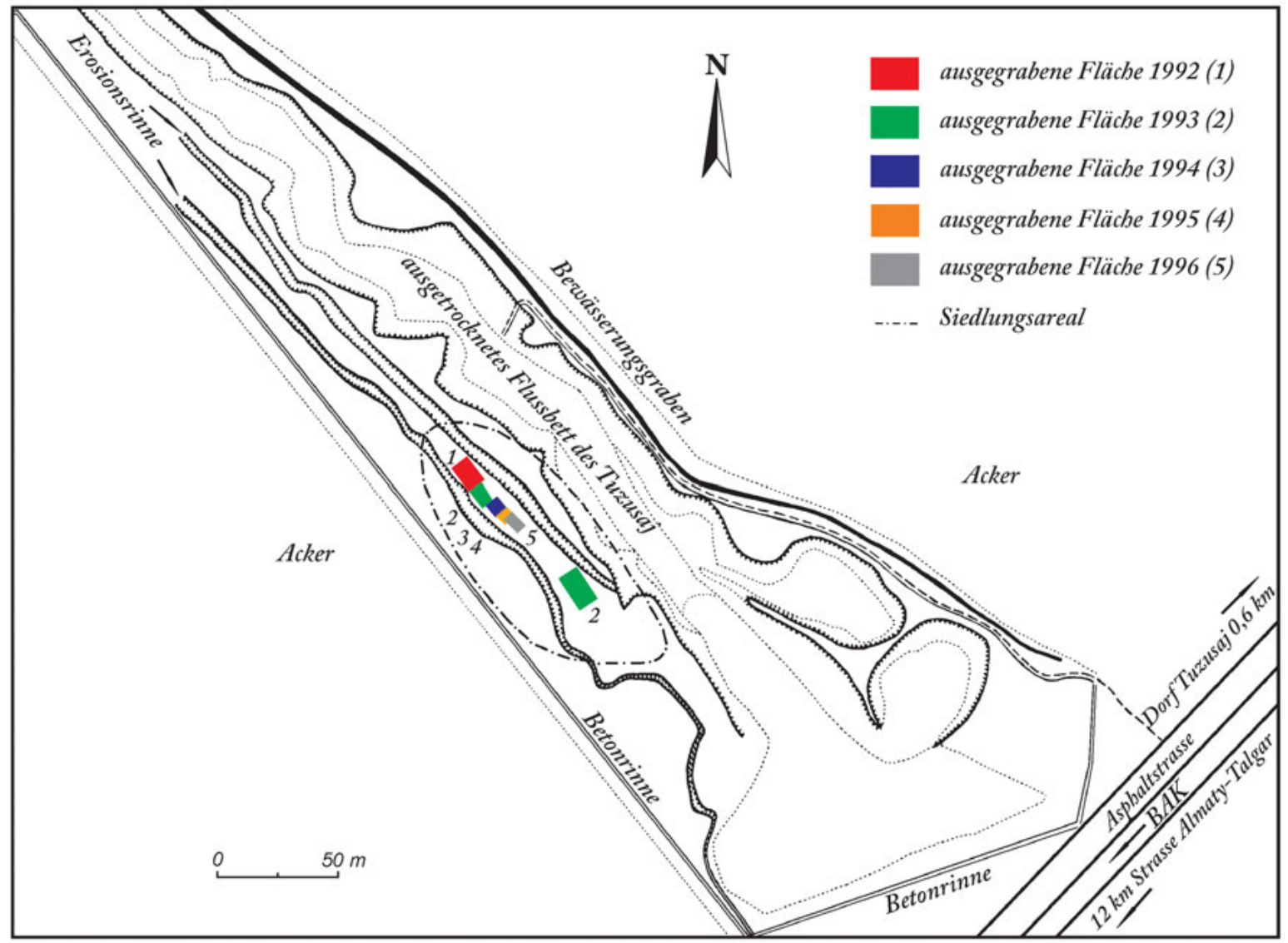

Abb. 27 | Lageskizze der Siedlung Tuzusaj (z.T. nach Tujakbaeva u.a. I994, Abb. I und nach Chang/Grigor'ev I999, Fig. I)

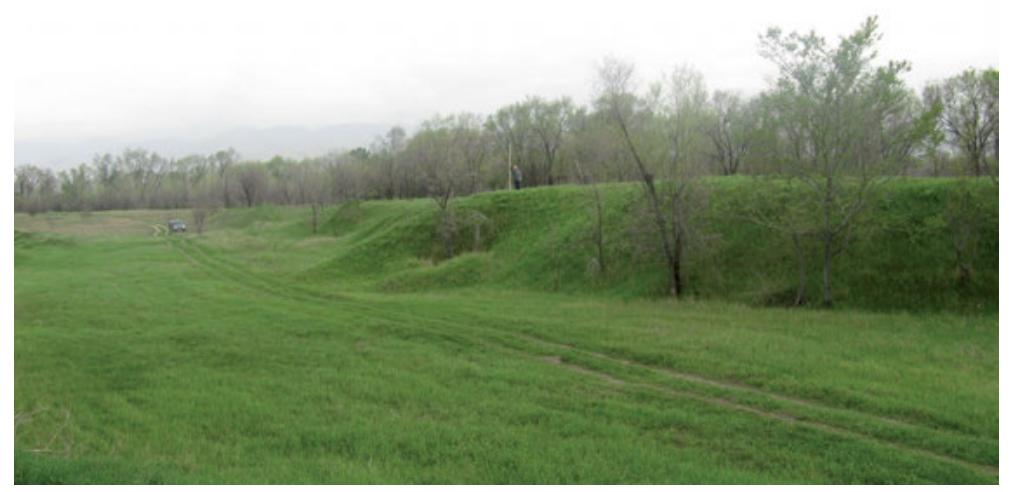

Abb. 272 | Siedlung Tuzusaj. Überblick vom ausgetrockneten Tuzusaj-Flussbett, von N

Charakteristik der Lesefunde

I. Randscherbe 4,6×3,0 ×0,9 cm; RDm ca. I $8 \mathrm{~cm}$; innen rot, außen schwarz; mittelfein gemagert mit viel Sand; verstrichen; handgemacht; Zeitstellung: ältere Eisenzeit, sakische Periode.

2. Randscherbe $6,8 \times 6,4 \times 0,5 \mathrm{~cm}$; RDm ca. $\mathrm{I} 6 \mathrm{~cm}$; rot-rotorange; mittelgrob gemagert mit feinen weißen Sandkörnern; innen geglättet; außen verstrichen; handgemacht; Zeitstellung: ältere Eisenzeit, sakische Periode. 
3. Wandscherbe $6,4 \times 4,9 \times 0,8 \mathrm{~cm}$; rot-rotbeige; grob gemagert; innen geglättet; außen verstrichen; handgemacht; Zeitstellung: ältere Eisenzeit, sakische Periode.

4. Wandscherbe 7,6 × 5,4 × 0,7 cm; rot-rotorange; fein gemagert; innen geglättet; außen verstrichen; handgemacht; gehört möglicherweise zusammen mit Randscherbe Nr. 2 zu einem Gefäß; Zeitstellung: ältere Eisenzeit, sakische Periode.

5. Wandscherbe $\mathrm{I} 2,0 \times 8,0 \times 0,6 \mathrm{~cm}$; rot; grob gemagert; innen geglättet; außen verstrichen; handgemacht; Zeitstellung: ältere Eisenzeit, sakische Periode.

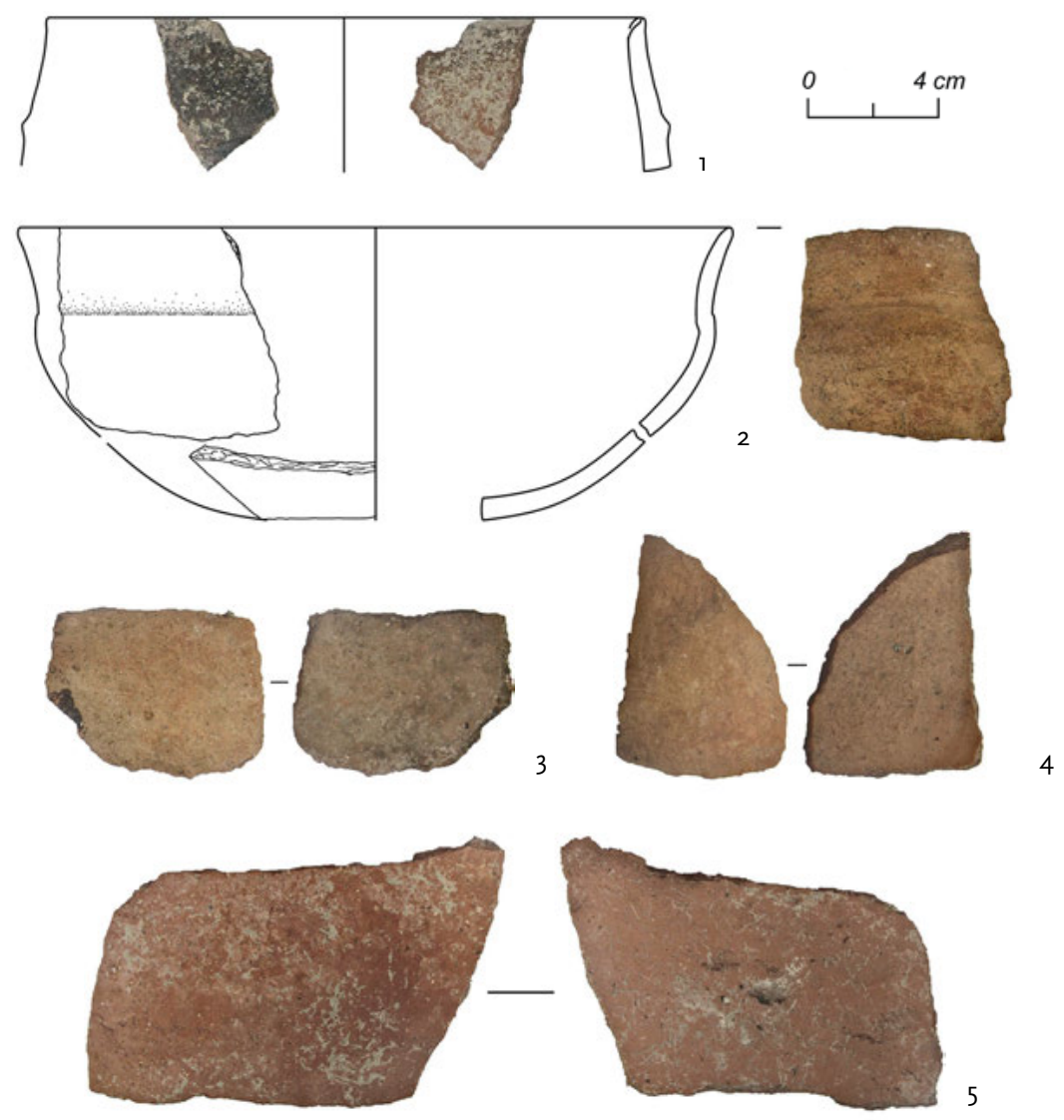

Abb. 273 | Siedlung Tuzusaj. Lesefunde

Forschungsgeschichte

Die Siedlung Tuzusaj wurde im Jahre 1979 entdeckt (hier und im Folgenden nach Tujakbaeva u.a. I993, 3). In den Jahren I984 und I986 wurde die Fundstelle zuerst durch ein archäologisches Forschungsteam des Institutes „Kazproektrestavracija“ untersucht. Sie wurde vermessen, fotografiert, beschrieben und die ersten Lesefunde wurden gemacht. Seit 1986 wird die Siedlung im Kataster als ein früheisenzeitliches archäologisches Bodendenkmal geführt. Nach Mitteilung von F. P. Grigor'ev (Baipakov 2008, 74), dem Entdecker der Siedlung, befand sich an der Südgrenze der Siedlungsfläche eine Kurgankette, die eine SO-NW Achse bildete. Weiterhin erklärte er, dass alle elf Kurgane an der Oberfläche eine Steinabdeckung aufwiesen und die Kurgane von Steinkreisen umgeben waren. Die Maße der Kurgane betrugen I2-40 $\mathrm{m}$ im Durchmesser und I-4 $\mathrm{m}$ in der Höhe. I980-I98I wurden sie jedoch durch eine Erweiterung der Agrarflächen zerstört. B. N. Nurmuchanbetov untersuchte zwei stark beschädigte Kurgane, die die Überreste der Kette darstellten. In großen rechteckigen Grabgruben, deren 
Wände durch Fichtenstangen verstärkt worden waren, kamen kleine zylindrische Knochenperlen und kleine goldene Plättchen zum Vorschein, die man in das 4.-3. Jh. v. Chr. datierte (Baipakov 2008, 74).

In der Zeit zwischen I984 und I99I veränderte sich das äußere Bild der Siedlungsfläche. Durch die Baumaßnahmen am „Großen Almaty-Kanal“ wurde der südliche Bereich des Wohnplatzes völlig zerstört. Das westliche und östliche Tuzusaj-Ufer wurde überackert. Am westlichen Ufer baute man eine Betonrinne, die die Uferzone, auf der sich ein Teil der Siedlung befand, vom Acker abschirmte. Diese Uferzone mit der Siedlungsfläche plante man als Gemüsegärten an die Einwohner des Dorfes Imeni Panfilova (kasach. Панфилов атындағы) zu verteilen (Tujakbaeva u.a. I993, 3). Aufgrund dieser Tatsachen führte ein archäologisches Forschungsteam aus Almaty vom Projektentwicklungsinstitut für Konservierung und Restaurierung der Kulturdenkmäler „Kazproektrestavracija“ in den Jahren I992-I993 auf der Siedlung Tuzusaj eine Ausgrabung durch (Tujakbaeva u.a. I993; Tujakbaeva u.a. I994; Baipakov 2008, 74). In diesen zwei Jahren wurden zwei Grabungsflächen von insgesamt $216 \mathrm{~m}^{2}$ geöffnet. Beide ausgegrabenen Flächen wiesen eine $0,5-\mathrm{I}, \mathrm{I} \mathrm{m}$ mächtige Kulturschicht auf. Man fand dort mehrere Scherben, Tierknochen und Holzkohlefragmente. Innerhalb der Kulturschicht wurden vier stratigraphische Horizonte nachgewiesen. Auf den Grabungsflächen wurden jedoch keine Spuren von Bau- oder Verteidigungsanlagen festgestellt. Die Siedlung wurde in das 4.-3. Jh. v. Chr. datiert (Baipakov 2008, 74).

Von 1994 bis I996 wurde die Siedlung von der Kasachisch-Amerikanischen archäologischen Expedition weiter erforscht. Es wurden drei Grabungsflächen von insgesamt $\mathrm{I} 20 \mathrm{~m}^{2}$ freigelegt (Chang/ Grigoriev 1999, 394-399). Hier wies man vier weitere Straten nach (Baipakov 2008, 75). Insgesamt wurden auf der erforschten Siedlungsfläche sieben Wirtschaftsgruben und zehn rechteckige Gruben von Gruben- und Halbgrubenhäuser sowie die Überreste von weiteren Baukonstruktionen festgestellt (Baipakov 2008, 75-76; Chang/Grigoriev I999; Parzinger 2006, 793). Zudem erfasste man eine repräsentative Auswahl an Keramik und eine große Zahl von Steingeräten (unterschiedliche Reibsteine und Mörser) sowie Phytolithen und Tierknochen (Baipakov 2008, 75-76).

Die Ergebnisse der paläobotanischen Untersuchungen ergaben Hinweise zur Getreide- und Pflanzennutzung: 69\% Weizen, 35\% Gerste, 8\% Weintraube, 8\% Nussschalen (Chang/Grigoriev I999, 405) ${ }^{675}$ und „möglicherweise sogar Reis“ (Parzinger 2006, 793; vgl. Baipakov 2008, 76-77).

Das Verhältnis der Tierknochen sah wie folgt aus: 49\% KWK, 3I \% GWK, I3 \% Pferd und 2 \% Hund (Baipakov 2008, 77). Man fand auch Knochen von domestizierten Eseln (Tujakbaeva u.a. I993, 43), von Vögeln (Baipakov 2008, 77) sowie von verschiedenen Wildtieren, wie Rothirsch, Reh, Wildschwein und Fuchs (Chang u.a. 2003, 305; Parzinger 2006, 793).

Die Erforschung der Siedlungsfläche zeigte, dass die Siedlung ganzjährig benutzt wurde. Die Bewohner der Tuzusaj-Siedlung nutzten sowohl den Trockenfeldbau als auch die Bewässerungsfeldwirtschaft einerseits und andererseits erfolgte Transhumanz (Baipakov 2008, 76, 79).

Absolutchronologisch wurde die Siedlung einer Zeitspanne vom 4. Jh. v. Chr. bis zum I. Jh. n. Chr. zugeordnet ${ }^{67} 6$ (vgl. Chang/Grigoriev I999, 395-400; Chang u.a. 2003, 303; Parzinger 2006, 793; Baipakov 2008, 76), was der sakischen Periode der älteren Eisenzeit und der Wusun-Periode der jüngeren Eisenzeit entspricht.

Lit.: Baipakov 2008, 74-77, Abb. 22-23; Bajpakov I995, 40-65, Abb. I-II; Bajpakov I997, 3, 47-56, 58-67; Bajpakov/ Nurmuchanbetov 2000, 6-II; Bajpakov u.a. 2000, I9; Bajpakov u.a. 2002, 9; Chang/Grigoriev I999, 39I-4I0; Chang/Tourtellotte 2000, 83-85; Chang u.a. 2003, 30I-309; Grigor'ev/Ismagil I999, 87; Grigor'ev u.a. 2007, I29-I39; Kuznecova I995, 58-65; Parzinger 2006, 793; Rosen u.a. 2000, 6II-623; Samašev u.a. 2005a, 52-53, I26-I27; Tujakbaeva u.a. ı993; Tujakbaeva u.a. I994.

675 K. M. Bajpakov schrieb, dass an der Siedlung Tuzusaj noch zusätzlich 44\% Hirse vorkam (Baipakov 2008, 76). Die paläobotanischen Ergebnisse sind zweifelhaft, da im ersten Fall (Chang/Grigoriev I999, 405) der Ge- samtanteil von Getreide- und Pflanzenresten I20\% ist und im zweiten Fall (Baipakov 2008, 76) sogar $164 \%$.

676 Nachweise zu den Proben im Einzelnen finden sich im Appendix I Nr. 3I-37. 